\title{
Functional Process Descriptions for the Program to Develop the Nuclear Waste Management System
}

Prepared for the U.S. Department of Energy

Office of Civilian Radioastive Waste Management

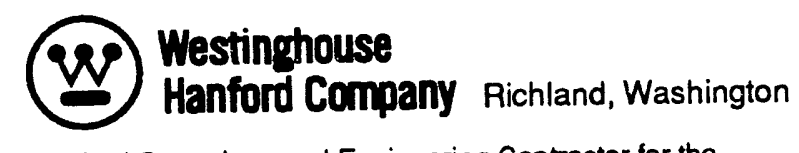

Hanford Operations and Engineering Contractor for the

U.S. Department of Energy under Contract DE-AC06-87RL10930 


\section{Functional Process Descriptions for the Program to Develop the Nuclear Waste Management System}

T. W. Woods

Date Published

September 1991

Prepared for the U.S. Department of Energy

Office of Civilian Radioactive Waste Management

\section{(2) Hestinghouse P.O. Box 1970 \\ Hanlord Compeny Richland, Washington 99352}

Hainford Operations and Engineering Contractor for the

U.S. Department of Energy under Contract DE-AC06-87RL-10930

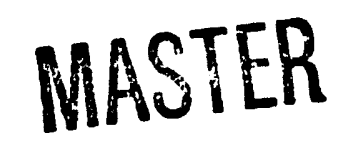

DISTRIBUTION OF THIS DOCUMENT IS UNLIMITED 


\section{LEGAL DISCLAIMER}

This report was prepared as an account of work sponsored by an agency of the United States Government. Neither the United States Government nor any agency thereot, nor any of their employees, nor any of their contractors, subcontractors or their employees, makes any warranty, express or implied, or assumes any legal liability or responsibility for the accuracy, completeness, or any third panty's use or the results of such use of any information, apparatus, product, or process disclosed, or represents that its use would not infringe privately owned rights. Relerence herein to any specific commercial product, process, or service by trade name, trademark, manufacturer, or otherwise, does not necessarily constitute or imply its endorsement, recommendation, or favoring by the United Stales Government or any agency thereof or its contractors or subcontractors. The views and opinions of authors expressed herein do not necessarily state or reflect those of the United States Government or any agency thereof.

This report has been reproduced from the best available copy. Available in paper copy and microfiche.

Available to the U.S. Department of Energy and its contractors from

Office of Scientific and Technical Information P.0. Box 62

Oak Ridge, in 37 ' 31

(615) $576-8401$

Available to the public from the U.S. Department of Commerce National Technical Information Service

5285 Port Royal Road

Springfield, VA 22161

(703) $487-4650$

Prinied in the United States of Ameriea

DISCLM-1.CHP $(1-91)$ 
Document Title:

Approved by:
Functional Process Descriptions for the Program to Develop The Nuclear Waste Management System

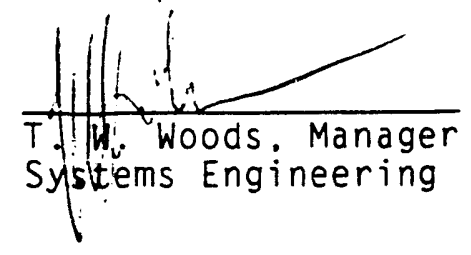

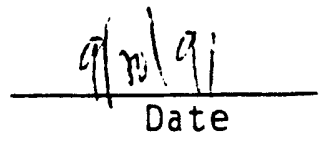


WHC-EP-0482

This page intentionally left blank. 
CONTENTS

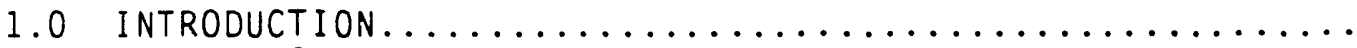

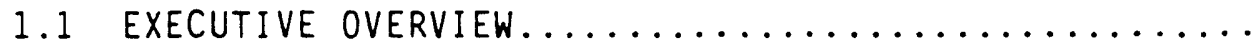

$1-1$

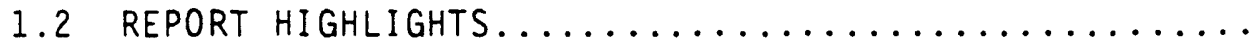

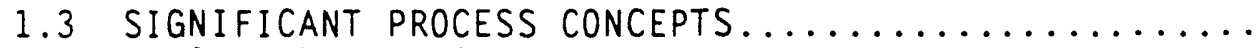

1.4 USES OF THE REPORT.

2.0 OVERVIEW OF INTEGRATED FUNCTIONAL PROCESSES ...........

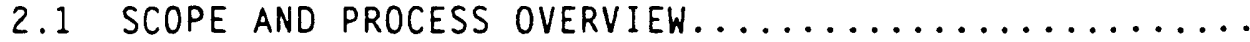

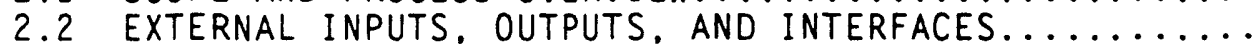

2.3 PROCESS EXECUTION AND MAJOR INFORMATION FLOWS.......

3.0 PERFORM SYSTEMS ENGINEERING PROCESS DESCRIPTION ......... $3-1$

3.1 PERFORM SYSTEMS ENGINEERING MISSION AND PROCESS

OVERVIEW............................... $3-1$

3.2 PERFORM SYSTEMS ENGINEERING EXTERNAL INTERFACES..... $3-7$

3.3 PERFORM SYSTEMS ENGINEERING PROCESS EXECUTION

DETAILS $\ldots \ldots \ldots \ldots \ldots \ldots \ldots \ldots \ldots \ldots \ldots \ldots \ldots \ldots \ldots \ldots \ldots \ldots \ldots \ldots \ldots \ldots \ldots \ldots \ldots \ldots \ldots \ldots$
3.4

4.0 DESIGN ENGINEERED SYSTEMS PROCESS DESCRIPTION.......... $4-1$

4.1 DESIGN ENGINEERED SYSTEMS MISSION AND PROCESS

4.2 DESIGN ENGINEERED SYSTEMS EXTERNAL INTERFACES ........

4.3 DESIGN ENGINEERED SYSTEMS PROCESS EXECUTION

DETAILS ........................... 4 . 16

4.4 DESIGN ENGINEERED SYSTEMS INTERNAL INTERFACES ...... 4 . 40

5.0 IDENTIFY AND CHARACTERIZE SITES ................. 5 -

5.1 MISSION AND PROCESS OVERVIEW................ $5-1$

5.2 EXTERNAL INTERFACES ...................... $5-5$

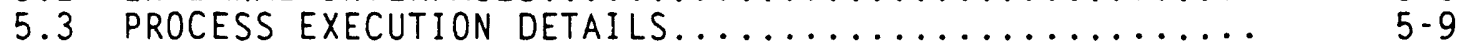

5.4 INTERNAL FEEDBACKS ................... $5-16$

6.0 EVALUATE INTEGRATED SYSTEM PROCESS DESCRIPTION ........... $6-1$

6.1 EVALUATE INTEGRATED SYSTEM MISSION AND PROCESS

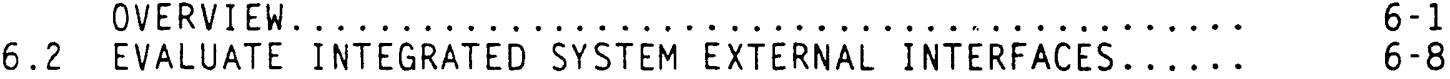

6.3 EVALUATE INTEGRATED SYSTEM PROCESS EXECUTION

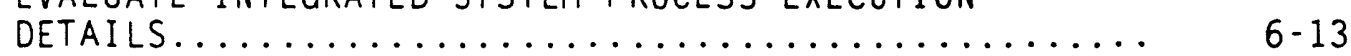

7.0 PERFORM CONFIRMATION/OPERATIONAL TESTING PROCESS

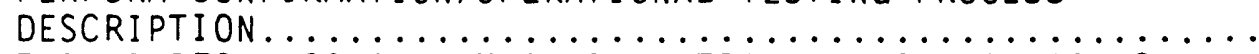

7.1 PERFORM CONFIRMATION/OPERATIONAL TESTING MISSION

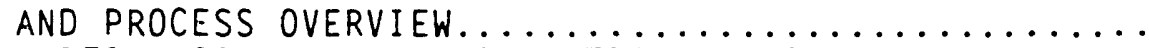

7.2 PERFORM CONFIRMATION/OPERATIONAL TESTING EXTERNAL

7.3 PERFORM CONFIRMATION/OPERATIONAL TESTING PROCESS

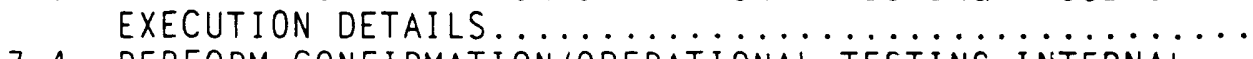

7.4 PERFORM CONFIRMATION/OPERATIONAL TESTING INTERNAL INTERFACE 
CONTENTS (cont.)

8.0 ENSURE REGULATORY COMPLIANCE PROCESS DESCRIPTION........ $8-1$

8.1 ENSURE REGULATORY COMPLIANCE MISSION AND PROCESS

OVERVIEW . .

8.2 ENSURE REGULATORY COMPLIANCE EXTERNAL INTERFACES....

8.3 ENSURE REGULATORY COMPLIANCE PROCESS EXECUTION

8.4 ENSURE REGULATORY COMPLIANCE INTERNAL INTERFACES ...

9.0 PROVIDE PROGRAM CONTROL PROCESS DESCRIPTION............ 9 -1

9.1 PROVIDE PROGRAM CONTROL MISSION AND PROCESS

OVERVIEW............................ 9-1

9.2 PROVIDE PROGRAM CONTROL EXTERNAL INTERFACES ......... 9.8

9.3 PROVIDE PROGRAM CONTROL EXECUTION DETAILS.......... $9-15$

10.0 SPECIAL TOPICS ............................ 10.

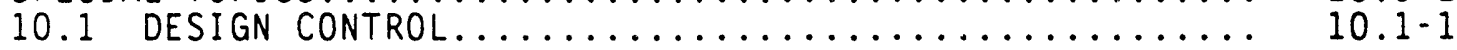

10.2 SYSTEM TEST, EVALUATION, AND VERIFICATION....... $10.2-1$

10.3 SCIENTIFIC RISK AND UNCERTAINTY ............ 10.3-1

10.4 PARALLEL DESIGN EFFORTS .................... 10.4-1

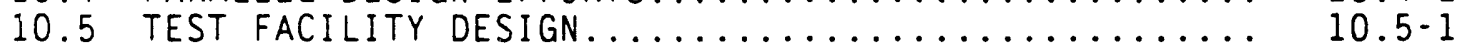

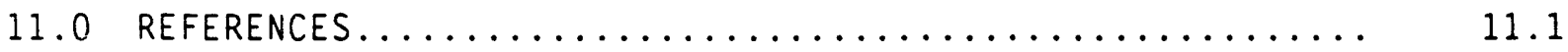

GLOSSARY $\ldots \ldots \ldots \ldots \ldots \ldots \ldots \ldots \ldots \ldots \ldots \ldots \ldots \ldots \ldots \ldots \ldots \ldots \ldots$ 


\section{LIST OF FIGURES}

2-1 Hierarchy of MSIS Programmatic Functions........... 2-2

$2-2$ Process Overview.............................. $2-5$

2-3 Information Flow in Performance Requirements

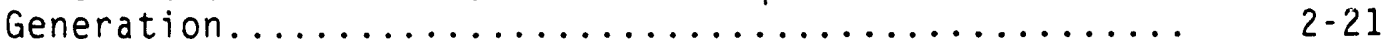

2-4 Information Flow in Program Direction Generation..... 2-25

2-5 Technical Information Flow and Management Direction................................. 2-29

2-6 Requirements Flow During System Definition......... 2-33

2-7 Technical Information Flow During System Definition............................ 2-37

2-3 Key Feedback Loops that Correct and Optimize System

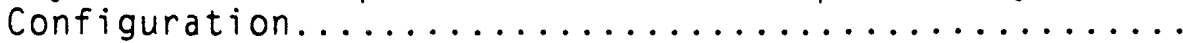

3-1 Perform Systems Engineering Function Hierarchy....... 3-4

3-2 Process Overview - Perform Systems Engineering....... 3-5

3-3 Process Overview - Define Mission Requirements....... 3-17

3-4 Process Overview - Define System Functional Structure................................. 3-19

3-5 Process Overview - Verify System Structure Definition.............................. 3-23

3-6 Process Overview - Identify System Performance Measures............................... 3-26

3-7 Process Overview - Control System Description........ 3-29

3-8 Perform Systems Engineering - Major Feedback Loops.... 3-34

4-1 Hierarchical Overview of Design Engineered Systems.... 4-3

4-2 Process Overview - Design Engineered Systems........ 4-5

4-3 Process Overview - Develop Engineered Systems Conceptual Design..................... 4-19

4-4 Process Overview - Develop Engineered
Systems Preliminary Design................... 4-25

4-5 Process Overview - Develop Engineered
Systems Final Design....................... 4 .31

4-6 Process Overview - Develop Engineered
Systems As-Built Design................... 4-37 
FIGURES (cont.)

4-7 Design Engineered Systems - Major Feedback Loops..... 4-41

5-1 Identify and Characterize Sites - Function

Hierarchy............................. $5-3$

5-2 Process Overview - Identify and Characterize Sites.... 5-4

5-3 Process Overview - Nominate Sites for

Characterization......................... 5-11

5-4 Process Overview - Characterize Sites............. 5-13

5-5 Identify and Characterize Sites - Major Feedback $5-18$

6-1 Evaluate Integrated System Function Hierarchy........ $6-2$

6-2 Process Overview - Evaluate Integrated System........ 6-5

6-3 Process Execution Details - Develop Evaluation

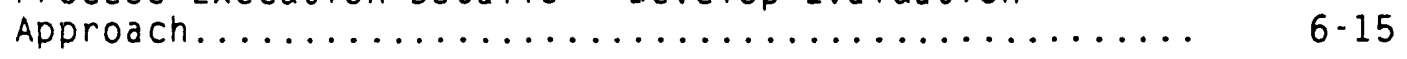

6-4 Process Execution Details - Develop Evaluation Tools.. 6-19

6-5 Process Execution Details - Access Evaluation Data... 6-22

6-6 Process Execution Details - Implement Evaluation

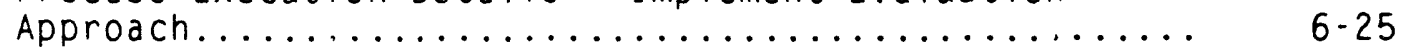

6-7 Process Execution Details - Assess System........... 6-28

6-8 Evaluate Integrated System - Major Feedback Loops.... 6-29

7-1 Hierarchical Overview of Perform Confirmation/ operational Testing....................... $7-2$

7-2 Process Overview - Perform Confirmation/ operation Testing....................... $7-5$

7-3 Process Overview - Develop Test Approach........... 7-17

7-4 Process Overview - Prepare for Test.............. 7-21

7-5 Process Overview - Execute Test................ 7-25

7-6 Perform Confirmation/Operational Testing - $7-29$

8-1 Ensure Regulatory Compliance Function Hierarchy...... 8-3

8-2 Process Overview - Ensure Regulatory Compliance...... 8-5

8-3 Process Overview - Identify Applicable Regulatory Requirements........................ $8-23$ 


\section{FIGURES (cont.)}

8-4 Process Overview - Develop Compitance Criteria...... 8-27

8-5 Process Overview - Develop Compliance Approach...... 8-31

8-6 Process Overview - Obtain Regulatory Approvals...... 8-35

8-7 Process Overview - Confirm Compliance Status......... 8-39

8-8 Ensure Regulatory Compliance - Major

Feedback Loops.............................. 8-42

9-1 Provide Program Control Function................ 9-2

9-2 Process Overview - Provide Program Control........... 9-5

9-3 Process Overview - Organize Program.............. 9-18

9-4 Program Direction Information Path Sample Contents.... 9-21

9-5 Process Overview - Organize Work.............. 9-22

9-6 Process Overview - Plan Work.................. 9-24

9-7 Process Overview - Authorize Work............. 9-27

9-8 Process Overview - Evaluate Program Performance...... 9-29

9-9 Process Overview - Manage Changes............... 9-33

9-10 Provide Program Control - Major Feedback........... 9-37

10.1-1 Information Flow in Controlling Design Process...... 10.1-3

10.1-2 Design Input Control..................... 10.1-5

10.1-3a Design Verification - Functional Sequence.......... 10.1-8

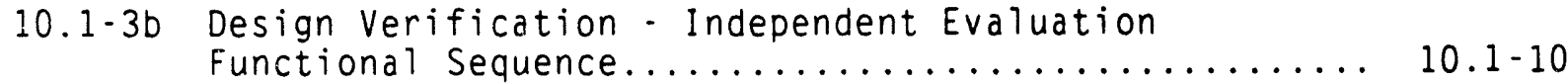

10.1-4 Technical Change Control................... 10.1-13

10.1-5 Technical Information Management and Control........ 10.1-16

10.2-1 Test, Evaluation. and Verification Function

flow Sequence................................ 10.2

10.2-2a Test, Evaluation, and Verification Control Paths..... 10.2-5

10.2-2b Test, Evaluation and Verification Feedback Paths..... 10.2-6

10.4-1 How Parallel Design Efforts Could Arise in the

OCRWM Program........................... 10.4-2 
FIGURES (cont.)

10.4-2 Information Flow in Establishing Parallel Design

Efforts................................. 10.4

10.4-3 Data Flow Between Parallel Design Efforts........... 10.4-7

10.4-4 Testing and Integrated System Evaluation for

Parallel Design Development Effort............... 10.4-9

10.5-1 MSIS Functions Where Test Facilities are Identified... 10.5-2

10.5-2 Process Flow to Identify Test Facility Needs for Management Review and Program Planning.............. 10.5-4

10.5-3 Test Facility Needs Generated During Engineering Design................................. 10.5-5

10.5-4 Process Flow Establishing Test Facility Development Program........................ 10.5-6 


\section{LIST OF TABLES}

2-1 External Inputs to the Eight MSIS Functions

Analyzed to Date.......................... 2-8

2-2 External Controls to the Eight MSIS Functions

Analyzed to Date........................... 2-12

2-3 External Outputs from the Eight MSIS Functions

Analyzed to Date.......................... 2-14

3-1 Perform Systems Engineering External Inputs......... 3-9

3-2 Perform Systems Engineering External Controls....... 3-13

3-3 Perform Systems Engineering External Outputs........ 3-14

4-1 Inputs to Design Engineered System.............. 4-8

4-2 Controls for Design Engineered System............ 4-11

4-3 Outputs from besign Engineered System............. 4-14

5-1 Summary of Inputs for Identify and Characterize

Sites............................... 5-6

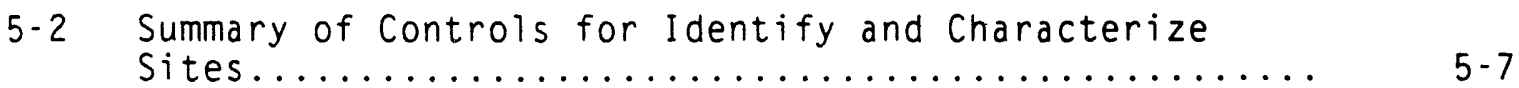

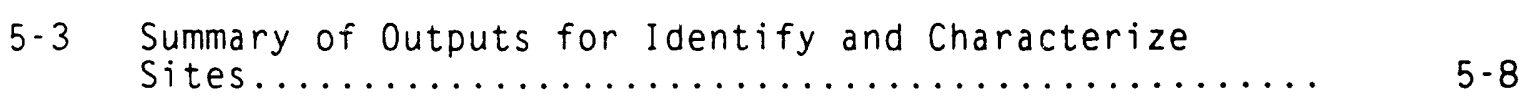

6-1 Evaluate Integrated System External Inputs.......... 6-9

6-2 Evaluate Integrated System External Controls......... 6-11

6-3 Evaluate Integrated System External Outputs......... 6-12

7-1 External Inputs to Perform Confirmation/ $7-8$

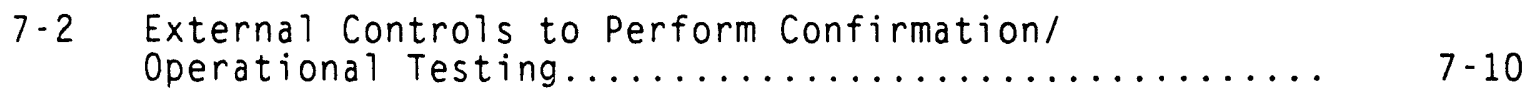

7-3 External Outputs from Perform Confirmation/
Operational Testing................................. 73

8-1 Ensure Regulatory Compliance Inputs............. 8-8

8-2 Ensure Regulatory Compliance Controls............. 8-14

8-3 Ensure Regulatory Compliance Outputs............. 8-18

9-1 Provide Program Control External Inputs............ $9-9$

9-2 Provide Program Control External Inputs............ 9-10 
WHC-EP-0482

\section{TABLES (cont.)}

9-3 Provide Program Control External Inputs........... 9-11

9-4 Provide Program Control External Controls........... 9-14

9-5 Provide Program Control External Outputs........... 9-16

10.2-1 Major Products from Test. Evaluate, and Verify

Process Flow................................. 10.2-8

10.3-1 Generalized Process Flow for Incorporating Risk...... 10.3-3

10.3-2 Generalized Process Flow for Incorporating

Uncertainty........................... 10.3-6 
WHC-EP-0482

\subsection{INTRODUCTION}

\subsection{EXECUTIVE OVERVIEW}

The Office of Civilian Radioactive Waste Management (OCRWM) is executing a plan for improvement of the systems implemented to carry out its responsibilities under the Nuclear Waste Policy Act of 1982 (NWPA). As part of the plan. OCRWM is performing a systems engineering analysis of both the physical system, i.e.. the Nuclear Waste Management System (NWMS), and the programmatic functions that must be accomplished to bring the physical system into being. The functional analysis effort is being performed by two separate teams working in parallel. One team is addressing the physical system functions, and the other is addressing the programmatic functions.

This report is produced by the team that is conducting the analysis of the programmatic functions. This report is one of a family of reports that addresses the programmatic functions analysis and provides descriptions of the major functional processes analyzed to date.

\subsubsection{Purpose and Overview}

The purpose of the program analysis is to provide a systematic identification and definition of all program functions, functional process flows, and function products necessary and sufficient to provide the physical system. The analysis resulting from this approach provides a basis for development of a comprehensive and integrated set of policies. standard practices, and procedures for the effective and efficient execution of the program. Thus, this analysis will form a basis for revising current OCRWM policies and procedures, or developing new ones as necessary.

The primary purposes of this report are as follows: (1) summarize the major functional processes and process flows that have been developed as a part of the program analysis and. (2) provide an introduction and assistance in understanding the detailed analysis information contained in the three volume report titled The Analysis of the Program to Develop the Nuclear Waste Management System (Woods 1991a).

\section{1 .2 Scope}

The current program functional analysis addresses seven of the 16 programmatic functions derived from the OCRWM Management Systems Improvement Strategy (MSIS) (DOE 1990). The seven functions are those that have the greatest significance to characterizing the site and development of the physical system design, and obtaining a license for operation of the ohysical system. The functions addressed thus far are Perform Systems Engineering (PSE). Design Engineered Systems (DES). Identify and Characterize Sites (ICS). Evaluate Integrated System (EIS). Perform Confirmation/Operational Testing (PCOT). Ensure Regulatory Compliance (ERC). and Provide Program Control (PPC).

In addition, the Provide Quality Assurance (POA) function has been analyzed sufficiently to determine its interfaces and impact on the other seven functions. While this function is not the subject of its own process 
WHC-EP-0482

processes discussion in Section 2.0. The remaining functions identified in the MSIS will be analyzed later.

This report addresses the process descriptions for the seven programmatic functions referenced above. The process descriptions have been developed to summarize the detailed analysis results for each of the functions and to communicate major concepts in how the functions are linked to form processes.

\subsubsection{Report Organization}

This report provides the following: (1) a complete set of process descriptions for the programmatic functions analyzed to date, (2) an overview of the integrated functional processes, and (3) a discussion of special topics that cut across functional boundaries and are vital to successful program implementation. The report is presented in 10 sections.

Section 1.0. "Introduction". provides an overview and introduces the report. It presents the purpose and scope of the report, describes the report organization, and identifies the relationship of this report to other reports produced as a result of the functional analysis.

Section 2.0. "Overview of Integrated Functional Processes", addresses the integrated set of MSIS functions analyzed to date, including the partial analysis of the Provide Quality Assurance function. It describes the interfaces and relationships among the functions and provides the information flows that address critical elements of the NWMS program that are larger in scope than any single function.

Sections 3.0 through 9.0 provide the process descriptions for each of the MSIS functions analyzed thus far. Each section provides a function mission description and process overview; identifies the function external interfaces: provides the execution details of the major subelements of the function; and discusses the internal interfaces within the function.

Section 10.0, "Special Topics", introduces topics that are important to understand with regard to NWMS program implementation and whose implementation transcends functional boundaries. These topics are discussed such that their end-to-end implementation is highlighted and the interfunctional boundaries are identified.

Sections 2.0 through 10.0 of this report present the process description and special topic information in a combination of outline and narrative forms. This manner of presentation was specifically selected to convey the process description information in the most concise, yet informative, manner.

In addition to the mechanics of how the functions operate and interface to form processes, each section in this report also attempts to address why the process is important to the success of the NWMS program. It is important to understand the rationale and reasoning behind each process, and its contribution to the overall program implementation. so that future modifications to program functional processes or interfaces are made with full knowledge of potential consequences to program success. 


\subsubsection{Relationship to Other Reports}

This report is one of four reports generated to document the results of the functional analysis efforts to date. The information within this report is intended to augment that contained in the other reports to provide the reader with a complete understanding of the analysis results. The contents of other related reports are summarized below.

- The Analysis of the Program to Develop the Nuclear Waste Management System (Woods 1991a). This is the three volume detailed report of the program functional analyses completed to date. The process descriptions and special topic discussions of Sections 2.0 through 10.0 are intended to provide a summary and introduction to the detailed information within this report.

- Program Information ArchitecturelDocument Hierarchy (Woods 1991b). This report defines the hierarchy of information and products produced by the MSIS programmatic functions analyzed thus far. It is a companion report to the detailed analysis report referenced above.

- Office of Civilian Radioactive Waste Management Decision

Methodology (Hoessel 1991). This report describes the recommended standard decision methodology deveioped for OCRWM.

\subsection{REPORT HIGHLIGHTS}

There are several areas of discussion that are highlights of this report. The first two of these. "Principles of Analysis" (Section 1.2.1) and "Functional Analysis Approach" (Section 1.2.2). are provided here to form a basis of understanding the principles or basic assumptions that guided the functional analysis effort and the approach taken to accomplish the analysis. An understanding of these principles and the approach taken is a prerequisite to understanding the process description information contained in this report.

The final two discussion areas. "Conclusions and Recommendations" (Section 1.2.3) and "Observations" (Section 1.2.4), present the key results and observations, drawn from the program functional analysis effort. presented in such a way that they relate to the process descriptions that follow.

\subsubsection{Principles of Analysis}

In performing the functional analysis, a set of first principles was devised to define the characteristics that should be intrinsic to the program. These principles are that the program and physical system must always encompass the following:

- Be mission-driven. Each function must contribute directly to the achievement of the program or system mission and be performed in accordance with the specified mission requirements. Every function identified within the program must contribute to providing the physical system. In turn, each function within the physical system must be directed toward disposing of the waste. Thus, no action should be taken. nor any function or physical system item exist, that does not contribute to the achievement of the program or system mission. 
- Be completely defined. The program must be defined at any point in time and changes to that program definition must be controlled. Similarly, the program must ensure that the physical system is defined at all times.

- Be integrated. The functional analysis must ensure the integration of the physical system elements, the technical development activities for the physical system, and the program processes for producing the system. The individual MSIS functional processes must also be integrated so that information is exchanged in a timely manner.

- Be controlled at all times. The definition and configuration of the physical system (i.e.. its functions, products, components, and processes) as well as the programmatic processes that produce the system must be under control at all times. No system or program change should be evaluated without consideration of the impacts of the change on other program or system areas, or assessment of the risks involved in implementing the proposed change.

- Incorporate performance assessment. There must be a continual and systematic assessment of physical system and program performance with respect to specified requirements throughout the system and program life cycles.

\subsubsection{Functional Analysis Approach}

The program functions identified in the MSIS plan (DOE 1990) provided the basis for development of the analysis. These principal functions were decomposed into sets of function hierarchies. The mission and scope of each function were defined and the functional interrelationships were established. Based on these definitions, process diagrams were developed that combined the functional process flows into a map of the integrated process necessary to produce the system. These functional process flow definitions identify how the functions convert an input information package to a desired output product within the constraints of the imposed controls.

All externally imposed program requirements were identified and each requirement was allocated to its appropriate functions. Where necessary. new functions were identified to address those external requirements. The requirements were maintained in a specially developed relational database that links each requirement to appropriate functions.

The analysis of each function was performed by a team of U.S. Department of Energy (DOE) and contractor personnel who were selected based on their areas of technical expertise. The analysis was facilitated by a systems analyst. The source documents, and the requirements within those documents. were identified by a Requirements Research Team. consisting of program licensing and technical personnel.

The individual functions were integrated into a single set of program functional processes by the Program Function Analysis Team systems analysts. The executability of the integrated processes was verified using a dynamic simulation computer model based on advanced colored Petri net simulation techniques. 
WHC -EP- 0482

The Integrated "Functional Processes Overview" (Section 2.0) and "Special Topics" (Section 10.0) discussions of this report were created to convey vital information that was not considered to be self-evident within the individual functional analyses. Several key activities that transcend function boundaries were identified and these became the subjects of the special topics section of the report. An integrated overview of the interfaces and relationships among the MSIS functions was created to provide the reader with a total system context within which the analyzed functions and processes operate.

\subsubsection{Conclusions and Recommendations}

Based on the functional analysis performed to date, as represented in this report by the process description and special topic discussions, several conclusions and recommendations have been developed that are believed to provide significant benefits to the program. These conclusions are included in the detailed functional analysis report and are repeated here for consideration.

Conclusion 1

The functional analysis method is a valid and effective approach to identify and define the functions, functional interfaces, processes, and products that are necessary and sufficient to execute the program. The results provide the basis for a program in which each activity and each item produced are directed toward the achievement of the mission within the constraints of the specified requirements. This has been verified by construction and operation of a working process model of the functional analysis rosults.

The functions can be used to identify the type of skills necessary to conduct the program. The functional interfaces and process descriptions can be used as the basis for arranging those skills into an effective and efficient organizational structure for performing the functions. The functional processes defined can be used as the basis for developing the program policies, standard practices, and procedures for executing the program.

Recommendation: Use the functional analysis to achieve the following general objectives:

- Validate or improve existing engineering management processes.

- Deveiop new engineering management processes.

- Develop program policies, standard practices, and procedures.

- Defire organizational adjustments and support contract consolidation areas.

- Develop program-wide information architectures and document hierarchies 
To achieve these objectives completely. the following actions should be taken:

- Complete the functional analysis of the remaining MSIS functions. Based on the experience gained, refine the current functional analyses and integrate them with the remaining functions. Expand the depth of analysis in those areas especially critical to program processes.

- Compare the current program policies and procedures with the functional analysis results and initiate revisions where necessary. Use the analysis as the basis for revising documents such as the Systems Engineering Management Plan. the Program Management System Manual, and the Quílity Assurance Management Plan.

- Maintain the functional analysis model and use it as the basis for evaluating future proposed changes to prograni policies and procedures.

Conclusion 2

The interrelationships of the program functional processes are extremely complex. To avoid serious and costly errors. their executability can best be determined through computer simulation.

A simulation of the functional processes was developed based on the functional flow diagrams and process descriptions presented in this report. Each of the MSIS functions wa.s analyzed on an individual basis, and subsequently integrated into a complete flow representation of the program and program processes. This model was used in integrating the individual functions and processes to ensure thejr executability. In working with this model, it appears that it can also be used to evaluate the dynamic characteristics of the program functional processes.

Recommendation: Include the additional functions not yet analyzed in the model. Use the model to gain insight into the dynamic characteristics of the programmatic functions and determine how robust and efficient the functional processes are. Use the results to refine and optimize the program processes.

Conclusion 3

Execution of the processes defined in tiris analysis results in development of a hierarchical structure of the physical system architecture. processes, and procedures. This physical system architecture is described in specifications, drawings, and procedures that represent a complete description of the site and engineered systems.

The physical system architecture hierarchy and the program functions resulting from the program functional analysis can be used as the basis for developing the work breakdown structure for the program. This structure forms the basis for work planning. scheduling, and cost control systems for the program.

Recommendation: Develop integrated work planning, scheduling, and cost control systems based on the integration of the physical system architecture items and the program functions. 
WHC-EP-048?

\section{Conclusion 4}

The NWMS program requirements imposed from external sources are extensive and complex. The most effective and efficient way to relate them to the appropriate function and control their disposition and changes is through a computerized relational database.

A prototype relational database was developed and used in performing this functional analysis. The analysis could not have been accomplished within the time and resources expended without the use of this prototype program. As the internal program requirements are defined and the physical system developed, the quantity and complexity of these requirements will increase. In addition, the complexity of controlling the requirements wiil increase because of anticipated changes in external requirements.

Recommendation: Continue to develop the production relational database for the program. The goal of this effort is to capture, control, and maintain all program requirements.

\subsubsection{Observations}

Several significant observations have reen derived as a result of performing the functional analysis and process description development. These observations have been included in the detailed functional anaiysis report and are included here for completeness.

1.2.4.1 Information Hierarchies. The information hierarchies developed as an inherent part of the functional analysis process can be combined in various ways to form the basis of programmatic documents necessary for the performance of the program, such as the Program Management Plan. Systems Engineering Management Plan. Quality Assurance Plan. Program Procedures Manual, or other similar plans.

As the program functions are decomposed and analyzed, not only are the subfunctions identified, but the products generated by each subfunction are defined. This means that a product hierarchy is produced as an inherent part of the functional analysis process. This product hierarchy identifies the products that must be generated, and the evolutionary stages through which these products must pass to provide the final product. The products of the analyzed MSIS functions are information packages. Thus, the functional analysis process has identified an information hierarchy for these seven functions. The top-down functional analysis and requirements methods ensure that the information developed is complete and integrated.

1.2.4.2 Change Control. Through the functional analysis process, the control of both program and physical system changes can be centralized and the concept of baseline change management can be applied.

The technical, cost, schedule, and work scope baselines define the program and physical system at any time. The technical baseline, and approved changes to that baseline. define the configuration of the physical system and the requirements that must be met by the system, at any point in time. Proposed changes to any of the baselines are evaluated and considered within the context of impacts on all program baselines. The processes of change management and evaluation including the management of the physical system configuration, reside within the Provide Program Control function. The appropriate technical expertise supports evaluation of proposed technical 
WHC-EP-0482

changes. The change management process addresses the integration and planning of cost. schedule and performance processes of the program, as well as the management of technical and program risks.

1.2.4.3 Decision Making. The functional analysis identifies points throughout the processes at which decisions must be made and identifies the information necessary for making those decisions.

The analysis does not address the processes of decision-making as a specific function. However, as a part of the overall analys is effort requested by OCRWM. a standard decision methodology was developed. This methodology is fully explained in a separate report entitled. Office of Civilian Radioactive Waste Management Decision Methodology (Hoessel 1991). The methodology consists of two parts. The first part provides guidance for the formulation of a decision problem in a series of basic steps common to all types of decisions. The second part is a logical procedure that selects the best decision alternative from a set of candidate solutions.

1.2.4.4 Risk. The program functional processes provide a basis for the systematic identification, quantification, evaluation of risk, and the development and application of risk management alternatives.

1.2.4.5 Technical Performance Measures. The program processes use the identification and application of technical performance measures in development of the physical system. The technical performance concept can also be used as a basis for development of a total quality program.

1.2.4.6 Program Definition. Complete identification of program functions and physical system functions defines the NWMS program. At the lowest leveis of decomposition and analysis, individual program functions can be grouped in various ways to form organizational structures for implementing the program. In the same manner, the lowest level of physical system functions can be combined in logical groupings to define physical system products and enditems. The intersections of program function and physical system function groupings can then be defined so that physical system products can be assigned to program organizations, and program and component work breakdown structures can be developed. The analysis completed thus far supports the establishment of function, information. and control hierarchies and the grouping of program and physical system functions to form working level elements for program implementation.

\subsection{SIGNIFICANT PROCESS CONCEPTS}

The following are significant concepts related to the process descriptions that should be explained and understood before reading Sections 2.0 through 10.0 . These concepts are presented below.

\subsubsection{Functional Analysis Concepts}

The program functional analysis that has produced the process descriptions contained in this report has been conducted using a structured systems engineering methodology applied across all of the functions analyzed. An understanding of the methods used is a prerequisite for evaluating and implementing the results of this analysis. 
WiHC-EP-0482

A function specifies what must be done to perform a mission. Functional analysis consists of functional decomposition, allocation of requirements to the resultant functions, and linking of the subfunctions to form processes required to accomplish the mission. Functional decomposition segments a single mission function into its subordinate functions, each with its own defined mission. so that the combined actions of the subordinates achieve the parent function exactly. That is, the complete compilation of subordinate functions is both necessary and sufficient to accomplish the parent function.

Controls or constraints that are imposed on parent functions are segmented and allocated to the subfunctions at each level of decomposition. By continuing the decomposition of each of the parent subfunctions to increasingly greater levels of detail. the elementary functions necessary to achieve the mission can be identified. It is the elementary functions, both program and physical system, that ultimately are linked and executed to implement the program. In performing the analysis, the functional decomposition identifies, defines, and scopes the specific functions in a function hierarchy. It defines functional interfaces and interdependericies. produces a logical flow of functions to accomplish the overall mission, and identifies the products produced by each function.

Thus, by beginning with the overall program mission. the necessary and sufficient functions to execute the mission, and the relationships among the functions, can be identified. When coupled with experience, this information clearly defines what must be done and the process by which it may be accomplished.

\subsubsection{Centralized Functions}

Some functions within a large program like the NWMS are identical. The functions have the same types of objectives, but operate on different information types or different levels of information detail. Two important occurrences of this functional commonality in the NWMS program are evident in the functions of program planning and program strategy development. In these two areas, the identical functional approach is used in dispersed parts of the program hierarchy.

The performance of these two functions has been centralized within the Dounds of the Provide Program Control function. Centralization of these functions was considered to be efficient and effective in eliminating redundant occurrences of functions that were essentially identical. The appearance of these functions within Provide Program Control can be viewed from two aspects. First, the common functions within Provide Program Control serve to create a template for use by other MSIS functions. Second, the Provide Program Control usage of the common template can be viewed as an integration of the more detailed or specific results from other MSIS functions. Either viewpoint fits the criteria for use of centralized functions.

Centralization of functions within Provide Program Control does not imply that the technical expertise to implement the functions lies within the program control organizational structure. The appropriate expertise required to perform program planning and strategy development for the specific NWMS programmatic functions resides within the organization tasked with performing each function. However, when the people with this expertise are performing planning or strategy development tasks, they are, in essence, performing a program control function. 
As additional MSIS functions are included within the functional analysis effort. it can be expected that new centralized functions will be identified and included within the analysis. A detailed discussion of the concept of Centralized Functions is presented in Section 2.3.2 of this report.

\subsubsection{Integrated Function Presentation}

A section has been included in this report to provide a description of the integrated program functional process (Section 2.0). This description includes all seven functions thus far analyzed. This description identifies the interfaces and relationships required among these functions to accomplish the critical program processes.

This integrated viewpoint is essential in establishing the framework and context within which each of the MSIS functions operates to accomplish its mission. It serves as an introduction to the details provided in each of the sections that address the individual functions and ties all of the functions together in performing top-level program processes.

Note that the current set of MSIS functions, and the corresponding integrated functional piocess overview. do not form a complete or selfcontained set of functions or processes. As arialyses of the remaining MSIS functions are completed. the current descripti ns will be modified and expanded to include the new functions. Only after all MSIS functions have been analyzed and incorporated into the process descriptions will a complete program set of functions be defined.

\subsubsection{Special Topics}

This report includes a section titled "Special Topics" (Section 10.0). These are specific topics of interest that transcend the boundaries of the individual MSIS functions and whose implementation requires the coordinated operation of multiple functions. They are presented here as an aid to the reader in understanding how topics that are wide-ranging and critical to the success of program implementation are able to be addressed within the context of the program functional analysis. The special topics identified thus far are as follows:

- Design Control (Section 10.1)

- System Test. Evaluation. and Verification (Section 10.2)

- Scientific Risk and Uncertainty (Section 10.3)

- Parallel Design Efforts (Section 10.4)

- Test Facility Design (Section 10.5).

Each of these topics has been selected because of its far-reaching implications and importance to the success of the overall NWMS program. As additional functional analyses are completed, new topics such as these will be identified and will be addressed in a similar fashion. 
WHC-EP-0482

\subsubsection{Information Inputs, Controls, and Outputs}

In the process description and special topics discussiors of this report, information flows and information processing are prestinted as inputs. controls, and outputs. These terms are defined as follows:

Inputs are the information that a function or process transforms into outputs. They may come from other functions or processes or from external sources.

- Controls bound the acceptable characteristics of the output or constrain the transformation of inputs by the function or process. They may be applied from other functions or processes or from external sources.

- Outputs are the products produced by the functions or processes. They may be inputs or controls to other functions or processes. or may go to an external destination.

\subsection{USES OF THE REPORT}

This report provides the fundamental information for understanding the concepts and approaches taken in performing the program functional analysis and summarizes the detailed results of the analysis in a series of process descriptions for each of the MSIS functions analyzed, as well as an integrated functional process overview. While this section is not intended to define a complete set of possible uses for the information within this report. two suggestions are offered for consideration.

\subsubsection{Introduction/Prerequisite to Functional Analysis Report}

The information contained within this redort should be used as a bridge to understanding the detailed functional analyses. The process descriptions focus on the higher levels of the hierarchies for each MSIS function, as well as on the integrated flow of information among individual functions.

In addition, the descriptions present quick references to the numerical identifiers for specific functions within the functional hierarchy as developed fully in the detailed discussions.

\subsubsection{Communication of Major Processes and Information Flows}

The integrated functional processes description and the discussion of special topics in this report are intended to communicate some of the significant processes that must be implemented within the program and the information flows that must exist to implement these prozesses. An understanding of these processes provides the fundamental information for development of the policies, standard practices, and procedures necessary to execute the program.

These process descriptions also serve to define the products and information packages that must be developed to execute the program and the interfaces that must exist between the MSIS functions to ensure that the proper products are generated and are translated into an operational physical system. 
WHC-EP-0482

This page intentionally left blank. 
WHC-EP- 0482

\subsection{OVERVIEW OF INTEGRATED FUNCTIONAL PROCESSES}

This section provides a summary description of how the Management System Improvement Strategy (MSIS) (DOE 1990) functions act as an integrated unit to convert the Nuclear Waste Management System (NWMS) mission and its associated requirements into a set of cirawings, specifications, procedures, and technical information necessary to characterize the site, produce the physical system. and provide information for obtaining licenses and permits.

This section addresses an integrated assembly of program functions analyzed to date. It describes the interfaces, relationships, and information flows that pass among them. It provides an overview of the integrated processes, identifies the external inputs, outputs, and controls: describes the overail integrated functional processes and major information flows: and discusses the information feedbacks and process iterations. Information flows are emphasized because these are the key to integrating the functions and represent the interfacing mechanism between them.

Details of the separate MSIS functions are addressed in subsequent sections. Therefore, this section neither defines nor discusses all the products of the individual functions. The internal workings of the individual functions are explained only as they apply to understanding the integrated process and the overall information flows.

\subsection{SCOPE AND PROCESS OVERVIEW}

\subsubsection{Scope}

2.1.1.1 Functions Addressed. The program functions that have been analyzed and are addressed in this section are identified in Figure 2-1 within the context of the complete set of sixteen MSIS functions. This set of MSIS functions, although integrated, does not form a complete or self-contained set. The complete assembly of MSIS functions is necessary to fully describe the program. The integrated set covers those aspects of the program necessary to define the engineered system configuration, characterize the site, and provide licensing information. It also includes the program/technical functions necessary to control the performance of these functions. The functions analyzed were selected because they are the most significant to the current program activities. The remaining MSIS functions will be analyzed and a report submitted at a later date.

The Provide Quality Assurance function was included because of its importance to the functions analyzed. The quality assurance (QA) function provides important input to forming the program requirements in these areas. A complete picture of the seven analyzed functions could not be developed without considering the impact of quality assurance requirements. Therefore. a partial analysis of OA was performed to determine the interfaces and iriterrelationships between $Q A$ and the functions of interest, and to identify and consider the associated OA requirements. This was done so that the OA functional analysis. once completed. would not significantly impact the work done to date. 
Figure 2-1. Hierarchy of MSIS Programmatic Functions.

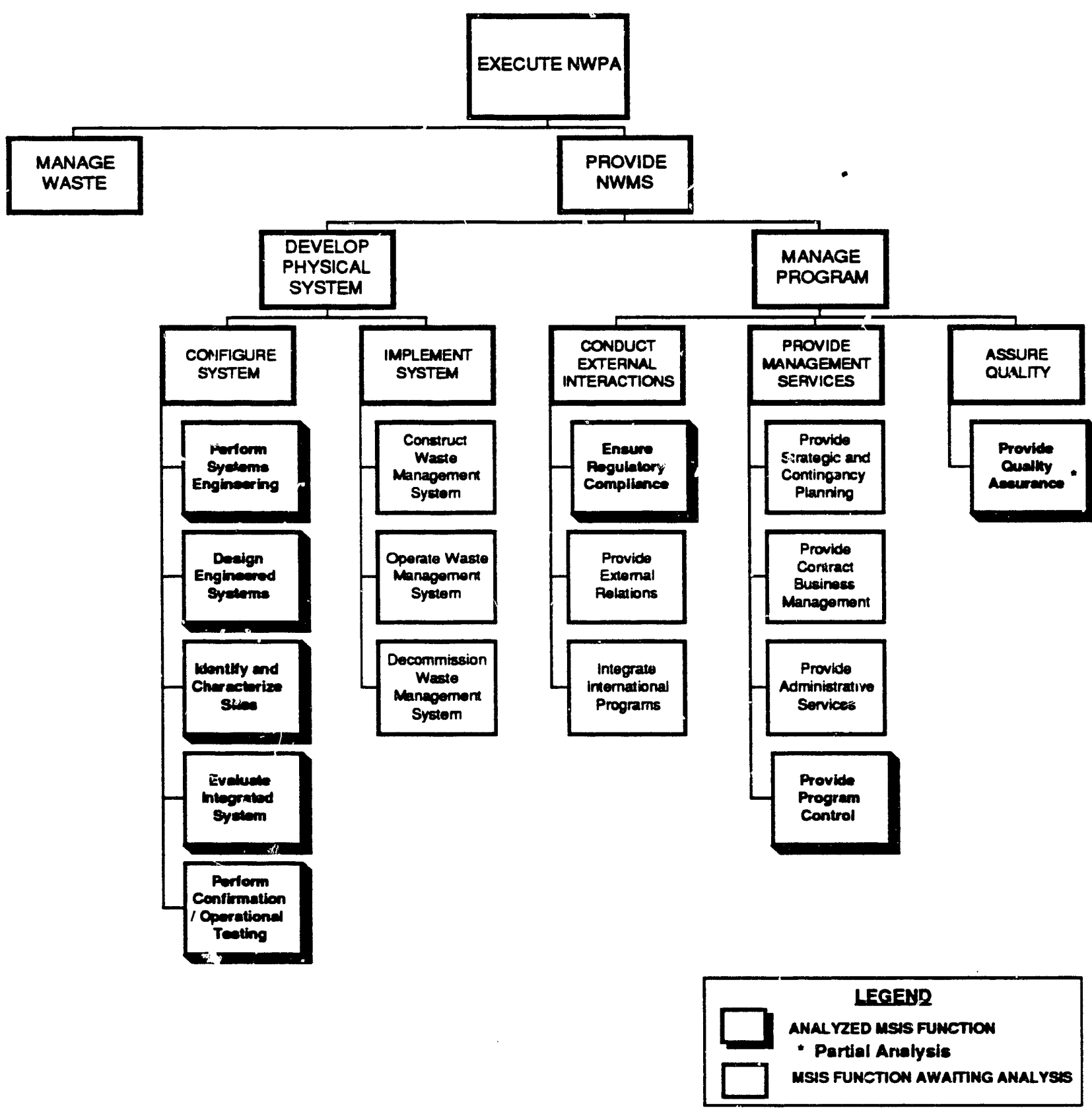


2.1.1.2 Scope of Functions Addressed. The complete set of MSIS functions, including those analyzed to date, are shown in Figure 2-1. The set of functions discussed herein encompasses developing the configuration for the NWMS, characterizing the sites, supporting system development and site characterization and verifying their acceptability. preparing the licensing applications and supporting information, and controlling the programmatic and technical functions necessary to achieve this.

Temporally, these functions begin with the first program functions of defining the program mission. They address all functions. with the exception of procurement and construction. until the system is operational. Some of the functions described continue throughout the total program life cycle, e.g.. Provide Program Control. Provide Quality Assurance, and Ensure Regulatory Compliance continue throughout system operations and decommissioning. Specific actions of these functions during operations and decommissioning are not shown because the technical functions they control are not yet analyzed. However the types and contents of their outputs, and the nature of their interfaces during operations and decommissioning will be similar to the outputs and interfaces during development.

The scope of activities of these functions is summarized below.

- Controlling the Program. Within the Provide Program Control function are all the functions necessary to define the program organization, plan work, evaluate program status and respond to the results of the evaluations. Also included are the functions that generate cost and schedule direction and exercise change control of information necessary to control the program. The Ensure Regulatory Compliance function provides regulatory compliance requirements that the program must meet and determines that these requirements have been met. The Provide Quality Assurance function provides the requirements for assuring the quality of program execution and of the product produced.

- Defining the System Configuration. The Perform Systems Engineering. Design Engineered Systems, and Identify and Characterize Sites functions include a 11 functions required for defining the system configuration. These functions include all required analyses, assessments, evaluations, and testing required to convert a mission description (including regulatory requirements) into the technical information necessary to buy. fabricate, assemble, instal1, test, operate and decommission the NWMS, to characterize the site, and to provide information necessary for licensing.

- Verifying Compliance to Requirements. Evaluate Integrated System and Perform Confirmation/Operational Testing functions include all activities necessary to define how to verify compliance of the system to specified requirements and to perform the tests. measurements, and observations to demonstrate compliance. The Evaluate Integrated System function supports development of engineered systems as well as characterization of the site. These functions continue in support of confirmation and operational testing following submittal of the license application. The Ensure Regulatory Compliance function ensures a consistent interpretation of the regulatory requirements throughout the program, interfaces with the regulatory agencies, and determines the acceptability of the submittal to the regulatory agency. 
- Assuring Quality of the Product and Processes. The Provide Quality Assurance function interprets the quality assurance requirements, provides quality assurance requirements, and assures the program is executed in accordance with those requirements and verifies that the quality of the product is acceptable.

\subsubsection{Overview of the Integrated Assembly Process Flow.}

The sequence of execution of the eight MSIS functions can be characterized as information flows. These flows are shown schematically in Figure 2-2. The process starts with receipt of the mission. the statutory requirements, and DOE direction from external sources in Provide Program Control. Based on these, an initial program strategy, organization, and plan. are generated by Provide Program Controls. Using this as initial program direction. Ensure Regulatory Compliance identifies all applicable laws. regulations and other externally imposed requirements and develops an approach toward meeting these requirements. Provide Quality Assurance defines the quality program and its requirements. Provide Program Control receives the compliance requirements, the compliance approach. a quality program definition and quality requirements, and then updates the program, strategy. organization, and plans to meet them.

System regulatory requirements and Program Direction (including programmatic requirements) are issued by Provide Program Control and initiate the engineering system configuration development and site characterization. The mission and Requirements are received by Perform System Engineering and used as the basis for the NWMS mission analysis. The mission and system functional analyses are the basis for allocating the system performance requirements. The requirements are allocated by NWMS hardware function and by the MSIS program function that addresses each portion of the NWMS configuration. The allocated technical requirements along with the associated Program Direction initiate Design Engineered Systems. Identify and Characterize Sites. Evaluate Integrated System, and Perform Confirmation/Operational Testing. These functions develop the system configuration, verify the physical system architecture acceptability, and provide the results to the technical information control process in perform Systems Engineering. The perform System Engineering function monitors. coordinates, and integrates the program technical development functions and the physical system attributes.

The system definition process is monitored for effectiveness and redirected based on changes to the program environment. The Provide Program Control function monitors the program status and evaluates program performance. The Provide Quality Assurance function audits program processes and products and assures conformance to quality assurance requirements. The Ensure Regulatory Compliance function confirms compliance of program processes and products to the regulatory requirements. In the evolution of the program. changes in program strategy, plans. schedules, budgets, and work packages occur in the Provide Program Control function based on: (1) discovery of new program needs as the program is defined. (2) change requests issued from within the program. (3) evaluation of the program or product performance, or (4) external events (e.g.. changes to regulations and laws) that change system or program requirements. 


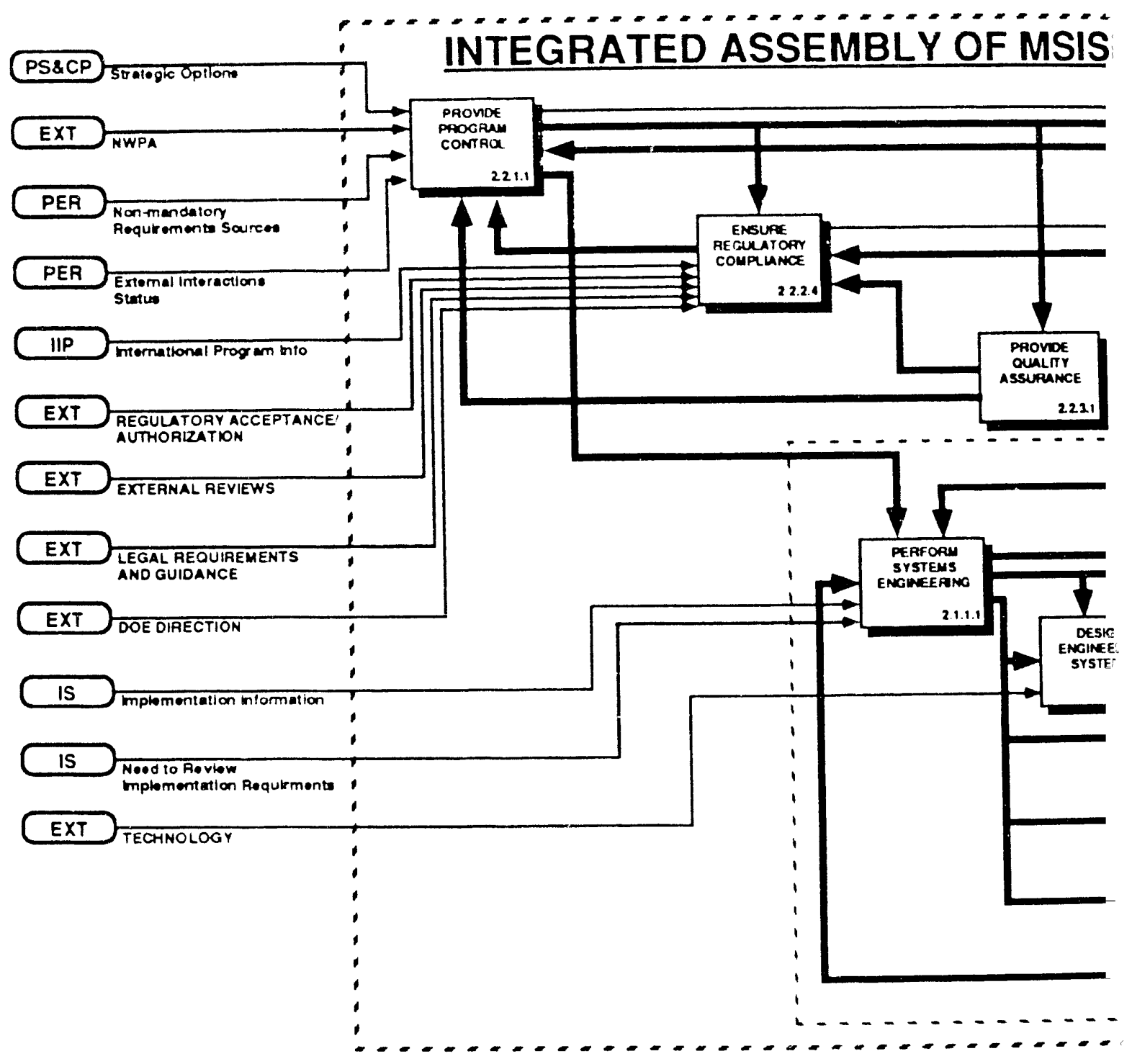




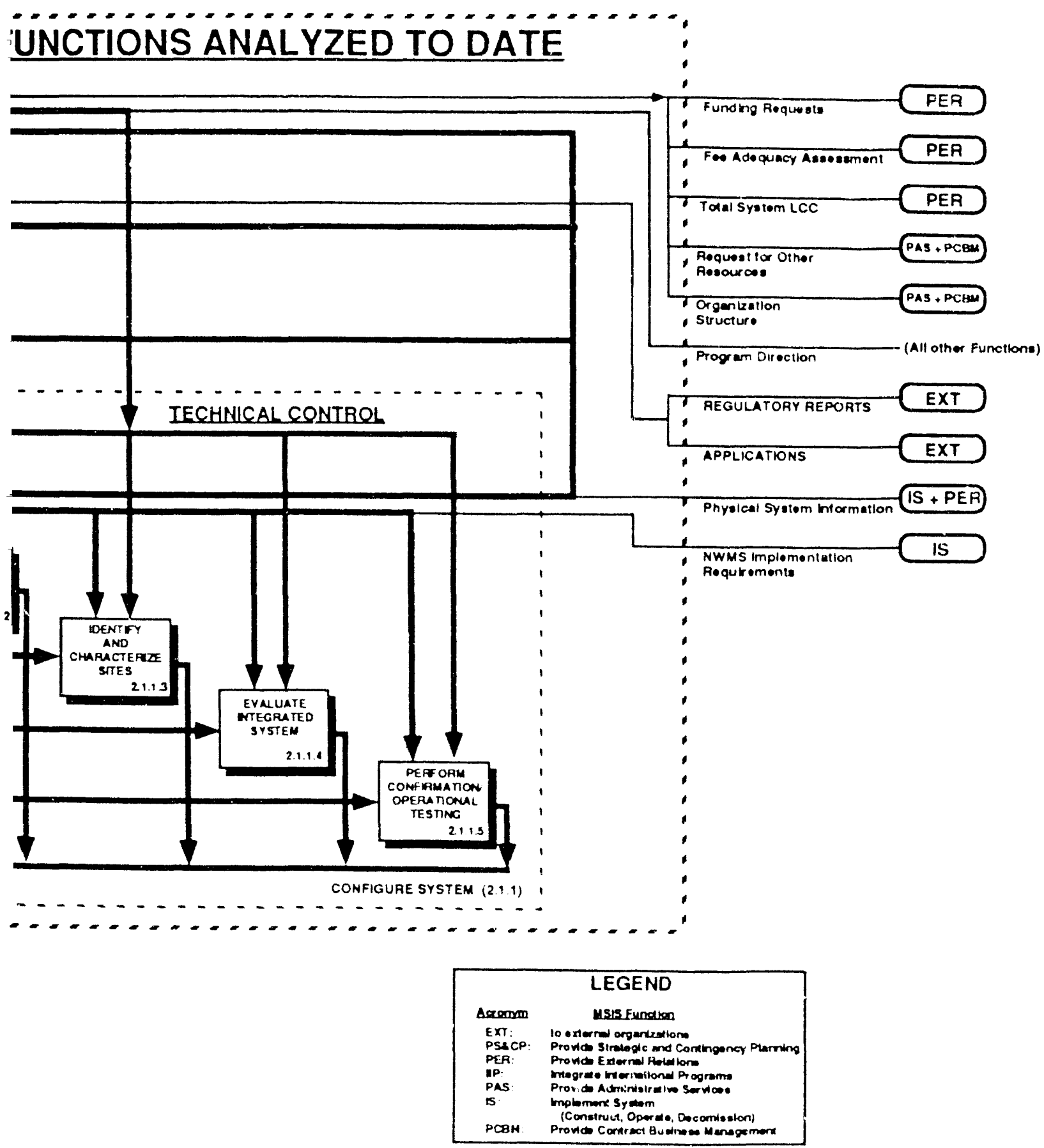


WHC-EP- 0482

\subsection{EXTERNAL INPUTS, OUTPUTS. AND INTERFACES}

\subsubsection{Scope of Discussion}

This subsection examines the inputs, outputs, and controls that interface with sources external to the integrated MSIS functions. These interfaces could be with entities outside the program, or with other MSIS functions not yet analyzed. There are controls within the integrated assembly that flow from one of the analyzed functions to another, but which are formed from external information. This latter case of controls is discussed in the section on control information flows. In some cases the external nature of the inputs, outputs, and controls reflects only that the analys is is not complete: the remaining MSIS functions must be analyzed to understand the complete program.

\subsubsection{External Inputs to Overall Process}

In this set of MSIS functions, external inputs primarily influence the execution of the program control processes. The exception is the input for technology to Design Engineered Systems. The external inputs, as named and defined in the functional analysis, are summarized in Table 2-1. program:

The following are the four categories of inputs from outside the

- Legal Requirements and Guidance/NWPA. These are statutory and regulatory information, including the NWPA. They originate from Federal. state, and local government bodies and are received by Ensure Regulatory Compliance to develop a comprehensive set of external requirements applicable to the program and the system.

- Regulatory Acceptance and Authorization/External Reviews. These consist of external reviews and responses to technical and program information. They originate from regulatory agencies (e.g.. NRC) and are received by Ensure Regulatory Compliance. Their purpose is to provide the program with results of reviews and authorization (e.g.. licenses and permits) to act. They are used in updating the compliance approach and in verifying compliance status.

- U.S. Department of Energy (DOE) Direction. These consist of direction and commitments that originate. from DOE management and the executive branch of government. They provide the program with a set of policies, directives, and system requirements to be considered for applicability to OCRWM and the NWMS.

- Technology. Technology represents the enginearing and scientific data from which an engineering design can be developed. It iricludes any technical information available to the program. It may originate from any government and civilian research. development, and engineering source and is utilized by all phases of design. The technology of interest changes with design phases (e.g.. from technology concepts in conceptual design to vendor 
Table 2-1. External Inputs to the Eight MSIS Functions Analyzed to Date. (sheet 1 of 3 )

\begin{tabular}{|c|c|c|}
\hline Input Name & Input Definition & Destination Function \\
\hline $\begin{array}{l}\text { International } \\
\text { Program } \\
\text { Information }\end{array}$ & $\begin{array}{l}\text { A description of waste management } \\
\text { technologies, evaluation methods, } \\
\text { acceptability standards or other } \\
\text { aspects of a waste management } \\
\text { system that have been developed or } \\
\text { adopted outside the United States } \\
\text { and may be applicable to the OCRWM } \\
\text { program }\end{array}$ & $\begin{array}{l}\text { ERC: } \\
\text { 2.2.1.1.3.2.3 Evaluate } \\
\text { Significance of } \\
\text { Issues and } \\
\text { Requirements } \\
\text { 2.2.1.1.3.3.1 Define } \\
\text { Strategic } \\
\text { Constraints } \\
2.2 .1 .1 .3 .2 \text {. Identify } \\
\text { Possible } \\
\text { Approaches }\end{array}$ \\
\hline $\begin{array}{l}\text { Regulatory } \\
\text { Acceptance } \\
\text { and } \\
\text { Authorization }\end{array}$ & $\begin{array}{l}\text { Documented approval received in } \\
\text { response to applications for } \\
\text { construction, operation, or } \\
\text { decommissioning of NWMS elements }\end{array}$ & $\begin{array}{l}\text { ERC: } \\
\text { 2.2.1.1.4.3.1 Analyze } \\
\text { Significance of } \\
\text { Approval } \\
\text { Conditions } \\
\text { 2.2.1.1.4.3.2 } \\
\text { Determine Impacts } \\
\text { on Requirements } \\
\text { and Activities } \\
\text { 2.2.1.1.4.3.3 Transmit } \\
\text { Regulatory } \\
\text { Approvals }\end{array}$ \\
\hline $\begin{array}{l}\text { External } \\
\text { Reviews }\end{array}$ & $\begin{array}{l}\text { Results of test, analyses, audits, or } \\
\text { other modes of confirmation } \\
\text { conducted by external entities to } \\
\text { assess compliance with programmatic } \\
\text { or physical system regulatory } \\
\text { requirements }\end{array}$ & $\begin{array}{l}\text { ERC: } \\
\text { 2.2.1.1.5.2 Compare } \\
\text { Review Results } \\
\text { Against } \\
\text { Requirements }\end{array}$ \\
\hline $\begin{array}{l}\text { Legal } \\
\text { Requirements } \\
\text { and Guidance }\end{array}$ & $\begin{array}{l}\text { All Federal and State statutory, } \\
\text { regulatory, and Executive Department } \\
\text { directives which OCRWM must meet, } \\
\text { exclusive of all DOE direction. Does } \\
\text { not include requirements imposed by } \\
\text { regulatory agencies as conditions for } \\
\text { approvals }\end{array}$ & $\begin{array}{l}\text { ERC: } \\
\text { 2.2.1.1.1.2 Compile } \\
\text { and Maintain } \\
\text { Candidate } \\
\text { Requirements } \\
\text { Sources }\end{array}$ \\
\hline DOE Direction & $\begin{array}{l}\text { All DOE Orders, Directives, } \\
\text { Secretarial notices, and Secretarial } \\
\text { memos which OCRWM must meet. } \\
\text { Also includes interdepartmental } \\
\text { agreements }\end{array}$ & $\begin{array}{l}\text { ERC: } \\
\text { 2.2.1.1.1.2 Compile } \\
\text { and Maintain } \\
\text { Candidate } \\
\text { Requirements } \\
\text { Sources } \\
\end{array}$ \\
\hline
\end{tabular}


Table 2-1. External Inputs to the Eight MSIS Functions Analyzed to Date. (sheet 2 of 3 )

\begin{tabular}{|c|c|c|}
\hline $\begin{array}{l}\text { Strategic } \\
\text { Options }\end{array}$ & $\begin{array}{l}\text { Options, strategies, and associated } \\
\text { risks that should be considered in } \\
\text { development of the overall NWMS } \\
\text { program strategy. These options and } \\
\text { strategies reflect current and } \\
\text { forecasted socio-political } \\
\text { considerations in planning for the } \\
\text { disposal of hi-level nuclear waste }\end{array}$ & $\begin{array}{l}\text { PPC: } \\
\text { 2.2.2.4.1.2 Develop } \\
\text { Program Strategy }\end{array}$ \\
\hline $\begin{array}{l}\text { Non-mandatory } \\
\text { Requirements } \\
\text { Sources }\end{array}$ & $\begin{array}{l}\text { Sources of program requirements } \\
\text { exclusive of the regulatory compliance } \\
\text { requirement. (e.g. DOE orders, } \\
\text { oversight authorities, other applicable } \\
\text { agencies, or national standards) }\end{array}$ & $\begin{array}{l}\text { PPC: } \\
\text { 2.2.2.4.1.3.1 Define } \\
\text { Internal Program } \\
\text { Requirements }\end{array}$ \\
\hline NWPA & $\begin{array}{l}\text { The Nuclear Waste Policy Act and its } \\
\text { amendments }\end{array}$ & $\begin{array}{l}\text { PPC: } \\
\text { 2.2.2.4.1.1 Develop } \\
\text { Program Mission }\end{array}$ \\
\hline $\begin{array}{l}\text { External } \\
\text { Interaction } \\
\text { Status }\end{array}$ & $\begin{array}{l}\text { Status of program interactions where } \\
\text { such interactions may influence } \\
\text { program cost, schedule, or technical } \\
\text { progress }\end{array}$ & $\begin{array}{l}\text { PPC: } \\
\text { 2.2.2.4.5.3.1 Identify } \\
\text { Variances Subject } \\
\text { to Analysis }\end{array}$ \\
\hline $\begin{array}{l}\text { Implementation } \\
\text { Information }\end{array}$ & $\begin{array}{l}\text { Information passed to systems } \\
\text { engineering from the Implement } \\
\text { System function to include the } \\
\text { following: System configuration or } \\
\text { description information incorporated } \\
\text { into the technical baseline or system } \\
\text { technical information; and Information } \\
\text { provided for evaluation/analysis } \\
\text { against established baseline and } \\
\text { system description or configuration } \\
\text { information to assess consistency with } \\
\text { approved requirements }\end{array}$ & $\begin{array}{l}\text { PSE: } \\
\text { 2.1.1.1.5.2 Provide } \\
\text { System } \\
\text { Description } \\
\text { Accounting }\end{array}$ \\
\hline \begin{tabular}{l|} 
Need for \\
Review of \\
NWMS \\
Implementation \\
Requirements
\end{tabular} & $\begin{array}{l}\text { A need for review of the NWMS } \\
\text { implementation requirements } \\
\text { because of potential problems with } \\
\text { meeting the requirements }\end{array}$ & $\begin{array}{l}\text { PSE: } \\
\text { 2.1.1.1.2.2.1 Define } \\
\text { System } \\
\text { Performance } \\
\text { Requirements } \\
\text { 2.1.1.1.2.2.2 Identify } \\
\text { Interface } \\
\text { Requirements } \\
\end{array}$ \\
\hline
\end{tabular}


Table 2-1. External Inputs to the Eight MSIS Functions Analyzed to Date. (sheet 3 of 3 )

\begin{tabular}{|l|l|c|}
\hline Technology & Descriptions of the engineering parts, & DES: \\
& materials, principles, practices, & 2.1 .1 .2 .2 .3 .1 Assess \\
concepts, and ideas that 1) that have & Accessible \\
been generated by the world-wide & Technology \\
engineering community, and 2) that & 2.1 .1 .2 .3 .1 .2 Assess \\
will be used to form the system & Common \\
configuration of the NWMS. Includes & Technologies \\
data from all US engineering and a & 2.1 .1 .2 .3 .2 .2 Assess \\
selected part of data from international & Accessible \\
sources. This information channel & Implementation \\
represents the total body of technical & Techniques \\
resource information used by the & 2.1 .1 .2 .4 .1 .2 \\
engineering process to develop the & Determine \\
NWMS engineered system. It & Accessible End- \\
includes subparts that address the & Items \\
needs of the various phases of & 2.1 .1 .2 .5 .2 Evaluate \\
engineering design: technology & Vendor \\
concepts (conceptual design), & Engineering Data \\
techniques to implement concepts & \\
(preliminary design), end-item & \\
descriptions (final design), and vendor & \\
descriptions of supplied parts (as-built & \\
design). & \\
\hline
\end{tabular}


parts data in as-built design). The functional analysis uses this input to show the relationship of engineering design to the engineering community and the screening of available technology solutions based on program strategy. program direction. and programmatic requirements.

The following are inputs from other MSIS functions:

- System Implementation Information. These data consist of information describing activities, status, and issues in the Construction/ Operations/Decommissioning process. They originate from the system implementation functions (Construct NWMS, Operate NWMS, and Decommission NWMS) and are received by Perform Systems Engineering. Their purpose is to provide data by which hardware is verified and hardware configuration is controlled, and to identify issues in meeting requirements hardware.

- External Interactions Status. This is programmatic and technical information resulting from interactions with Congress. public interest organizations, and advisory groups within DOE. It originates in the Provide External Relations function and is received by Provide Program Control. The purpose is to provide outside inputs for evaluating program progress and efficacy of program approaches.

- Strategic Options and Nonmandatory Requirements Sources. These describe possible programmatic requirements. They are generated by the Strategic and Contingency Planning and the Provide External Relations functions and are received by Provide Program Control. Their purpose is to provide a complete set of considerations from which to develop the program strategy.

- International Program Information. This is technical information on waste management technology originating from international sources. It is identified by Integrate International Programs function and received by Ensure Regulatory Compliance. Its purpose is to provide the program with the benefit of technical insights and program strategies generated in other countries.

\subsubsection{Overall Process Controls and External Information}

2.2.3.1 Origin and Destination of External Controls. All external controls to the area of developing the program requirements. The external controls as named and defined in the functional analysis, are summarized in Table 2-2. There are two sources of external controls. The first is Legal Requirements and Guidance. These are statutory and regulatory information. including the NWPA. They originate from Federal, state, and local government bodies and are receiver by Ensure Regulatory Compliance. These regulatory descriptions. which were used as inputs to the development of the compliance approach, are used as controls in the evaluation of the program approach. 
Table 2-2. External Controls to the Eight MSIS Functions Analyzed to Date.

\begin{tabular}{|l|l|c|}
\hline Control Name & \multicolumn{1}{|c|}{ Control Definition } & Destination Function \\
\hline Legal & All Federal and State statutory, & ERC: \\
Requirements & regulatory, and Executive Department & 2.2 .1 .1 .1 .1 Define \\
and Guidance & directives which OCRWM must meet, & Bounds of \\
& exclusive of all DOE direction. Does & Regulatory \\
& not include requirements imposed by & Sources \\
& regulatory agencies as conditions for & \\
& approvals & \\
\hline DOE Direction & All DOE Orders, Directives, & ERC: \\
& Secretarial notices, and Secretarial & 2.2 .1 .1 .1 .1 Define \\
& memos which OCRWM must meet. & Bounds of \\
& Also includes interdepartmental & Regulatory \\
& agreements & Sources \\
& & 2.2 .1 .1 .5 .1 Review \\
& & Status of \\
& & Verification \\
& & 2.2 .1 .1 .5 .2 Compare \\
& & Review Results \\
& & Against \\
& & Requirements \\
\hline
\end{tabular}


The second is DOE Direction. This consists of DOE internal documents defining how to do business. They originate from DOE management and the executive branch of government and are received by the Ensure Regulatory Compliance function ensures a single source and interpretation of external requirements for the program. As controls, these are used, along with the compliance approach, to evaluate system and program performance to ensure compliance.

2.2.3.2 External Information Used to Form Integral Controls. A variety of external information is used to form internal controls on the execution of the program functions described in this report. Details of the information flows that form these controls from external inputs are discussed in section 1.3. However, it is important to mention briefly two of these control sources to understand the nature of constraints on the integrated MSIS functions.

- System Regulatory Requirements. These originate with the review of Legal Requirements and Guidance in the Ensure Regulatory Compliance function. The result of the review is combined with DOE Directives which impact the physical system to form a comprehensive set of regulatory requirements on the NWMS. The regulatory requirements set is then input to Perform Systems Engineering where they are analyzed to form system performance requirements issued to the development activities. Thus, the entire NWMS development process and products are constrained to meet the legal and other externally imposed requirements.

- Elements of Program Direction. Program Strategy. Programmatic Requirements. These are formed from inputs and controls that originate with Legal Requirements and Guidance. DOE Direction (including $Q A$ and fiscal policies), program plans, and OCRWM commitments to Congress and other external bodies. In Provide Program Control. these become Program Direction that is applied to a 11 program functions. Subsequent sections of this document show this in detail. Thus, execution of all system configuration development functions is constrained to meet all externally imposed requirements and internally generated policies and procedures.

\subsubsection{External Outputs From Overall Process}

In this set of MSIS functions, external outputs consist of information prepared in response to regulatory requirements, programmatic status information and assessments, and physical system development information. The external outputs, as named and defined in the functional analysis, are summarized in Table 2-3.

The Applications output is the only output going outside the NWMS program. This output consists regulatory license and permit applications and supporting information submitted to regulatory agencies. They are generated in Ensure Regulatory Compliance and are received by the appropriate regulatory body. Their purpose is to demonstrate compliance by documenting system qualities. 
Table 2-3. External Outputs from the Eight MSIS Functions Analyzed to Date. (sheet 1 of 2)

\begin{tabular}{|c|c|c|}
\hline Output Name & Output Definition & Originating Function \\
\hline $\begin{array}{l}\text { Regulatory } \\
\text { Reports }\end{array}$ & $\begin{array}{l}\text { Progress reports, topical reports, } \\
\text { statements of findings, notices of } \\
\text { issuance, and other documents } \\
\text { containing information requested by } \\
\text { or required by concerned parties or by } \\
\text { regulatory requirements }\end{array}$ & $\begin{array}{l}\text { ERC: } \\
\text { 2.2.1.1.4.2.4 } \\
\text { Complete } \\
\text { Submittal }\end{array}$ \\
\hline Applications & $\begin{array}{l}\text { Requests for permits, licenses, or } \\
\text { other authorizations to test, construct, } \\
\text { operate, or decommission any part of } \\
\text { the NWMS }\end{array}$ & $\begin{array}{l}\text { ERC: } \\
\text { 2.2.1.1.4.2.4 } \\
\text { Complete } \\
\text { Submittal } \\
\end{array}$ \\
\hline $\begin{array}{l}\text { Funding } \\
\text { Requests }\end{array}$ & $\begin{array}{l}\text { Requests for funds to execute planned } \\
\text { work }\end{array}$ & $\begin{array}{l}\text { PPC: } \\
\text { 2.2.2.4.3.3.3 } \\
\text { Formulate Funding } \\
\text { and Resource } \\
\text { Requests }\end{array}$ \\
\hline $\begin{array}{l}\text { Fee Adequacy } \\
\text { Assessment }\end{array}$ & $\begin{array}{l}\text { The assessment whether the Nuclear } \\
\text { Waste Fund contains, and will contain, } \\
\text { adequate funds to pay for the NWMS }\end{array}$ & $\begin{array}{l}\text { PPC: } \\
\text { 2.2.2.4.3.4 Develop } \\
\text { TSLCC and Fee } \\
\text { Adequacy } \\
\end{array}$ \\
\hline $\begin{array}{l}\text { Total System } \\
\text { Life Cycle Cost }\end{array}$ & $\begin{array}{l}\text { The total of the direct, indirect, } \\
\text { recurring, nonrecurring and other } \\
\text { related costs incurred or estimated to } \\
\text { be incurred in the design, } \\
\text { development, production, operation, } \\
\text { maintenance, support, and final } \\
\text { disposition of the NWMS over its } \\
\text { anticipated useful life span }\end{array}$ & $\begin{array}{l}\text { PPC: } \\
\text { 2.2.2.4.3.4 Develop } \\
\text { TSLCC and Fee } \\
\text { Adequacy }\end{array}$ \\
\hline $\begin{array}{l}\text { Program } \\
\text { Direction }\end{array}$ & $\begin{array}{l}\text { Technical, management, and } \\
\text { administrative direction, policy, plans, } \\
\text { procedures, assumptions, and } \\
\text { constraints that specify and guide } \\
\text { program implementation }\end{array}$ & $\begin{array}{l}\text { PPC: } \\
\text { 2.2.2.4.1.3.5 } \\
\text { Formulate } \\
\text { Program Direction }\end{array}$ \\
\hline $\begin{array}{l}\text { Request for } \\
\text { Other } \\
\text { Resources }\end{array}$ & $\begin{array}{l}\text { Request for resources other than } \\
\text { funding (services, equipment, } \\
\text { material, facilities, personnel) to } \\
\text { execute planned work }\end{array}$ & \begin{tabular}{|l} 
PPC: \\
2.2.2.4.3.3.3 \\
Formulate Funding \\
and Resource \\
Requests
\end{tabular} \\
\hline $\begin{array}{l}\text { Organization } \\
\text { Structure }\end{array}$ & $\begin{array}{l}\text { An organizational hierarchy that } \\
\text { identifies functions, relationships, } \\
\text { roles, and authorities }\end{array}$ & $\begin{array}{l}\text { PPC: } \\
\text { 2.2.2.4.2.2 Develop } \\
\text { Organizational } \\
\text { Structure }\end{array}$ \\
\hline
\end{tabular}


Table 2-3. External Outputs from the Eight MSIS Functions Analyzed to Date. (sheet 2 of 2 )

\begin{tabular}{|c|c|c|}
\hline $\begin{array}{l}\text { Program } \\
\text { Information }\end{array}$ & $\begin{array}{l}\text { An information compendium } \\
\text { describing resources, schedules, and } \\
\text { other programmatic data that may be } \\
\text { relevant to OCRWM design and } \\
\text { development functions }\end{array}$ & $\begin{array}{l}\text { PPC: } \\
\text { 2.2.2.4.3.3.2 Establish } \\
\text { Cost and } \\
\text { Schedule Baseline } \\
\text { 2.2.2.4.5.3.4 Review } \\
\text { Program }\end{array}$ \\
\hline $\begin{array}{l}\text { Physical } \\
\text { System } \\
\text { Information }\end{array}$ & $\begin{array}{l}\text { Information passed from Systems } \\
\text { Engineering to other NWMS functions. } \\
\text { Includes current and approved NWMS } \\
\text { physical system technical baseline } \\
\text { (system configuration) information; } \\
\text { information/data controlled by systems } \\
\text { engineering but not considered part of } \\
\text { the technical baseline; } \\
\text { information/requests provided to } \\
\text { NWMS program management } \\
\text { functions indentifying the need for } \\
\text { relief from, or review of, direction or } \\
\text { constraints imposed upon the physical } \\
\text { system to meet NWMS mission } \\
\text { requirements. }\end{array}$ & $\begin{array}{l}\text { PSE } \\
\text { 2.1.1.1.5.2 Provide } \\
\text { System } \\
\text { Description } \\
\text { Accounting } \\
\text { 2.1.1.5.3.1.3 Distribute } \\
\text { Review Packages } \\
\text { 2.1.1.5.3.3.4 Distribute } \\
\text { Documentation } \\
\text { Packages }\end{array}$ \\
\hline $\begin{array}{l}\text { NWMS } \\
\text { Implementation } \\
\text { Requirements }\end{array}$ & $\begin{array}{l}\text { Technical requirements applicable to } \\
\text { constructing and decommissioning } \\
\text { the NWMS physical system (e.g., } \\
\text { construction specifications) }\end{array}$ & $\begin{array}{l}\text { PSE: } \\
\text { 2.1.1.1.5.2 Provide } \\
\text { System } \\
\text { Description } \\
\text { Accounting }\end{array}$ \\
\hline
\end{tabular}


There are several outputs that are used by the MSIS functions analyzed but are also provided to other MSIS functions outside of the functions analyzed. These include the following:

- Physica? System Information. The requirements and design developed for the NWMS physical system are provided by Perform Systems Engineering and received by system implementation functions and by Provide External Relations and Integrate International Programs. System implementation functions (Construct. Operate. Decommission) use it as instruction for building and operating the NWMS: Provide External Relations uses it as the basis of interactions with Congress and public affairs (becomes part of external output External Information from Provide External Relations): Integrate International Programs uses it to guide reviews and assessments of international technical activities.

- Program Information. This program information, e.g.. fiscal. schedule, and planning status, is provided by Provide Program Control and received by Provide External Relations and Integrate International Programs. Provide External Relations uses this information as a basis for interactions with Congress, other government agencies. and the public (becomes part of external output External Information from Provide External Relations): Integrate International Programs uses it to guide assessments and provide information in international waste management efforts.

- Program Direction and Strategy. This information consists of programmatic requirements and the caneral approach to meeting those requirements. It also includes the physical system externally imposed requirements. It is developed by Provide Prograil Control and provided to a 11 functions. Its purpose is to ensure consistency in interpretation and understanding of the requirements and to ensure that they are executed in an integrated manner.

The following are unique outputs provided only to single MSIS functions outside of the integrated set of MSIS functions:

- Total System Life Cycle Cost and Fce Adequacy Assessments. These are contractual status outputs provided by Perform Program Control and received by Provide External Relations and used as the basis for interactions with Congress and public organizations (becomes part of the external output External Information from Provide External Relations).

- Requests for Resources/Organization Structure. These outputs define the funding and other resources needed to execute the OCRWM program. The originate in Perform Program Control and received by Perform Contract Business Management and Provide Adminisirative services. They are used as the basis for obtaining resources from Congress and other agencies and for organizing the responses to requests for resources. 
WHC-EP- 0482

\subsection{PROCESS EXECUTION AND MAJOR INFORMATION FLOWS}

\subsubsection{Scope of Discussion}

This subsection describes the key information flows that integrate the MSIS functions analyzed thus far. These flows show how the functions interface and work as a group to accomplish NWMS configuration development. The information flows described here are those that link several functions and tie the missions of several functions together to accomplish a larger whole. They are the most significant in defining the overall process for developing the system configuration. The specific information flows discussed in this section are those for forming technical requirements from regulatory sources, for forming program direction and strategy. for evaluating program performance using controlled technical data, for controlling system performance requirements during configuration development, and for controlling system configuration description during configuration development. This section begins with a discussion of centralized functional processes in order to locate critical elements of these processes in the list of analyzed MSIS functions. This section emphasizes the success-oriented path in the information flows: feedbacks caused by failure of a product to accomplish its mission are discussed. where appropriate to show the integration.

Details of individual functions are addressed only to the extent necessary to understand the flow of information: details of individual functions generally are deferred to Sections 3.0 to 9.0. Section 10.0. Special Topics, covers several additional information fiows that cross multiple MSIS functions. This apart of the discussion also includes the interfaces and information flows for the Provide Quality Assurance function even though that function has not been completely analyzed.

\subsubsection{Centralized Functions}

2.3.2.1 Concept. Some programmatic functions occur in many places in a large program. For example, planning is performed by all organizations and is part of all programmatic processes. It is important that a large program have a standard process for planning, reviewing, and authorizing work tasks.

The programmatic analysis could have developed a standard analysis for these processes and placed the resulting process in all of the programmatic functions. The associated advantages and disadvantages are as follows:

- Advantage: Explicitly shows that all functions and processes use the same procedure.

- Disadvantage: The process may be distributed so broadly that the program-wide implications are not evident: the functional analysis result may not be suitable for developing a common standard practice for the program.

- Disadvantage: This approach requires inserting into the functional analysis a somewhat arbitrary integration function that may imply a new organization or organizational chains not intended by analysis. 
- Disadvantage: This approach complicates the analysis because it requires many information flows for exchange of data among the duplicative functions and between the duplicative functions and the integrating function.

This analysis chose to show these common processes only once in a Centralized Function as part of the programmatic process whose mission most fully encompassed the common process. The associated advantages and disadvantages are as follows:

- Advantage: The centralized approach results in a detailed description that is consolidated and can be easily referenced by all functions within the program.

- Advantage: Analysis and analytical results are greatly simplified and the basic structure of the information flow and process interactions are more easily elucidated.

- Disadvantage: The multidisciplinary nature of the processes (i.e., that they require participation by all organizations) is sometimes not evident.

2.3.2.2 Application. The programmatic functional analysis used centralized functions to represent the common processes that apply to multiple organizations and multiple program processes. A centralized functional process is defined as one that is intrensic to all functions and consequentiy has been consolidated into a single subfunction of one of the MSIS functions. The process spans organizational and functional boundaries in that many organizations and processes require the same process to be performed to execute their mission. The process also spans organizational and functional boundaries in that it requires participation by all organizations to accomplish the program-wide execution of the centralized process.

The analysis recognizes that in the process of performing his OCRWM assignment, one person will execute parts of several programmatic functions. When an engineer performs component design, he is executing part of the Design Engineered Systems function. However, when planning his work, he is executing part of the Provide Program Control function: when participating in configuration management, he is performing part of the Perform systems Engineering function. Thus, an engineering organization will implement the Design Engineered Systems function to accomplish design work, and part of the Provide Program Control function when it develops plans, schedules, tasking. etc. A program-wide plan requires input from design engineers. site/geoscientists, test engineers, program analysts, management, and others.

2.3.2.3 Process and Information $\mathrm{Flow}$. The programmatic functional analysis used the centralized function approach for five key processes in the control of system definition development.

Program Strategy and Programmatic Direction Development. All functional processes require a strategy or fundamental approach to meet the requirements of the program and the program standard practices and procedures. An integrated approach must be developed for the entire program, and the individual strategy are elements (e.g.. design strategy) are derived from the program strategy. Therefore all strategy and program direction development is concentrated in Provide program Control. These subfunctions of Provide Program Control represents the process 
used by each OCRWM organization regardless of its technical assignment. Thus, the program-wide strategy will be developed with participation from all functions and disciplines. This overall program strategy will then be used as the basis to develop the specific strategies of the individual MSIS functions.

- Work and Task Planning, Budgeting, and Scheduling. All work performed in the execution of functions, will be performed in accordance with defined and approved work plans. Individual task plans will be reviewed based on the program plans. schedules, and budgets and approved only if the task is consistent with them. Work planning and work authorization functions have been centralized in the Provide Program Control function. These functions plan both the complete program and the individual tasks within the program. Program-wide planning is a multidisciplinary task and as such requires participation of engineers. geoscientists, test engineers, regulatory experts, and others in order for the plan to accurately reflect the needs of the program. All OCRWM participating functions will use the same planning approach for executing the individual functions. This approach is described in the Provide Program Control function.

- Change Control. To control changes, each proposed change must be evaluated to determine the technicai. cost, and schedule impacts and disposition the change. It is then necessary to develop and issue the technical and program direction modifications to execute the change. This process is clearly multidisciplinary. If a proposed change is to the physical system definition, technical as well as fiscal. planning and other programmatic inputs are needed to assess program impact. This change control process, is centralized in the Provide Program Control function.

- Program Evaluation/Status Analysis. The program, as a whole, and the subelements of the program executing specific tasks, must assess their status and evaluate their performance and their product. The results of these evaluations are the basis for replanning or redirecting tasks to improve performance, correct problems, and enhance products. Program evaluation and status assessment processes are consolidated as a subfunction of Provide Program Control function. All functions will implement this same process. Thus, the design, site, test, etc. functions will all assess and evaluate their performance. Thus, the same technical staff will execute both their technical functions as well as this assessment and evaluation subfunction of the Provide Program Control process. The provide Program Control function will assess and evaluate the overa 17 program performance.

- Procurement and Acquisition of Resources. Every functional process requires support in acquisition of equipment. materials,and services. This acquisition support process is centralized in the Provide Contract Business Management function. This MSIS function is not yet analyzed and no details on the process are available.

2.3.2.4 Significant Considerations. The concept of centralized functions provides an facile approach to performing program-wide functions which require the technical expertise of multiple disciplines. Having one concise centralized description of the function to be used by all disciplines 
WHC - EP- 0482

performing that function. ensures that a standard practice can be developed that will simplify intraprogram interactions and facilitate integration across the program.

Understanding centralization is critical to understanding the functional analysis results. The analysis has defined functions. but not organizations. One organization will perform several functions to execute its OCRWM assignment. The interfaces between function processes assume that each organization executes the centralized function and thus, the functional processes need not exchange information when staff perform their several functions (i.e.. the flow diagrams do not indicate data transfer because the staff have the information when they execute the other function). Divergence from this approach has a significant effect on the analysis. To change from centralized functions requires adding many new subelements to the MSIS functional analysis results. Such a change would have a major impact on the way in which the functional analysis results are presented.

\subsubsection{Physical System Mission and External Requirements Identification Flow}

2.3.3.1 Concept. The NWMS is a mission driven system where each system characteristic is incorporated based on the need to fulfill a required capability. A complete and integrated set of regulatory requirements must be prepared for the engineered and natural systems. The set of mission and external requirements must be integrated so that all conflicts within the set can be identified and resolved. so that a single and complete interpretation of legal compliance can be developed for the entire program, and so that a compliance approach that is fully responsive can be deveioped. Furthermore. the requirements set must be validated so that the end product of configuration development can be verified. licensed, and approved. Thus, a single. controlled. set of regulatory requirements is required to ensure all functional processes are solving the same problem and will yieid an integrated result.

The MSIS functional analysis shows that the program systematically develops a single. integrated set of mission and external requirements. Furthermore, it shows how this integrated requirements set is supplied through a single control point to form the basis for program execution and system configuration development.

2.3.3.2 Analysis Approach. The generation of an integrated, validated. controlied set of mission and external requirements requires interaction between the regulatory analysis process and the program controls functions before initiating technical work. The requirements set is formed in the MSIS program functions of Ensure Regulatory Compliance and Provide Pregram Control. Executing the regulatory analys is process requires legal and technical disciplines. Developing. controlling, and evaluating progress toward achieving all regulatory requirements is a centralized Program Control function requiring participation by all technical functions. Converting the regulatory requirements into specific technical requirements and allocating them to physical system functions is part of the Perform Systems Engineering function.

2.3.3.3 Process and Information Flow. Developing the mission and external requirements set begins in the Ensure Regulatory Compliance function. passes through the Provide Program Control function, and culminates in the delivery of the requirements set to the Perform Systems Engineering Function. This process is outlined in Figure 2-3. 
Figure 2-3. Information Flow in Performance Requirements Generation.

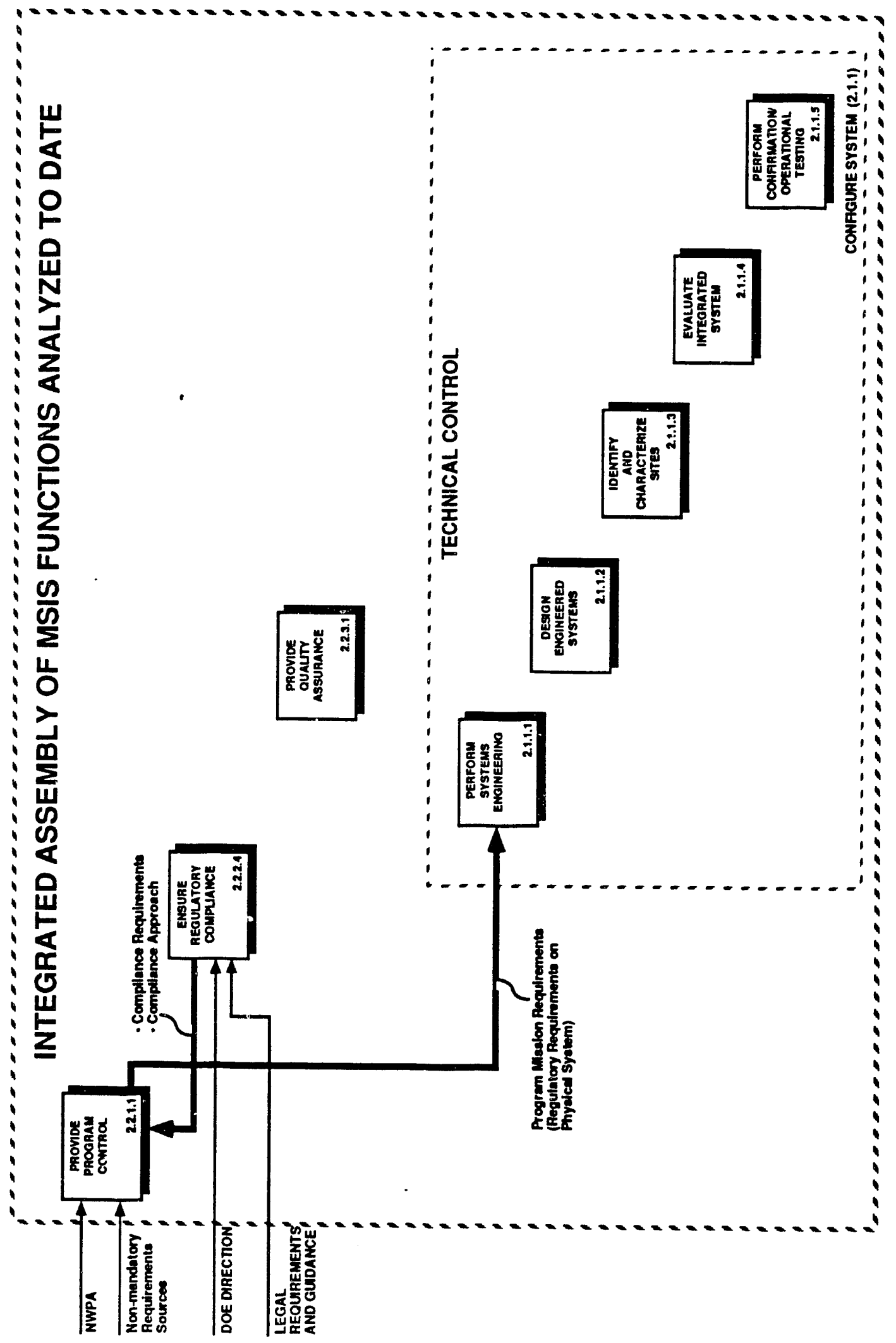


WHC -EP-0482

The process begins with the gathering of regulatory requirements in the Ensure Regulatory Requirements process. The inputs are from all regulatory and statutory sources including Federal. state, and local sources. All sources are evaluated for applicability. precedence, and scope. A library of sources and source documents is maintained. Ensure Regulatory Compliance function identifies the appropriate requirements within these source documents, resolves conflicts among them. and develops a compliance approach which will be satisfactory to the regulatory agency. The compliance requirements and compliance approach are then output to Provide Program Control.

The results of regulatory requirements evaluation is combined with OCRWM program obligations in the Provide Program Control process. Nonregulatory source documents, program commitments (to Congress, public interest groups, DOE policies and directives, etc.) are evaluated. The compliance approach and program needs are then integrated to complete the mission and external requirements set. The requirements set is analyzed to identify items that must be controlled. These are marked appropriately in the information system.

The integrated program requirements set is then distributed to other functional processes as part of the program direction described in the Provide Program Control function Requirements are partitioned as system performance requirements and programmatic requirements. System performance requirements i.e.. system mission and system technical requirements, are provided to the Perform Systems Engineering process which, in turn, controls the development of the technical characteristics of the system that responds to those requirements. Programmatic requirements are provided as controls to each function.

2.3.3.4 Feedbacks and Control Points in the Process. Constraining program execution within the bounds defined by the requirements set requires monitoring and controlling program execution and a feedback mechanism so that conflicts, contradictions, and problems can be resolved. Monitoring and controliing the program is accomplished through three MSIS functions. The Provide Program Control function includes evaluation of program status in terms of accomplishing milestones and meeting program commitments for physical system capabilities. The Ensure Regulatory Compliance function includes evaluation of the physical system and the program with respect to its acceptabi?ity to the regulatory agency. The Perform Systems Engineering function includes technical reviews and evaluations of the physical system and its performance characteristics. The results of these evaluations are combined in the Provide Program Control function where they are used to determine if program replanning or redirection is required. The results of the assessment causes updates to be provided to each MSIS functional process.

Feedback between functional processes is accomplished through change requests. Change requests are generated by system development functions when conflicts, contradictions, and problems in meeting requirements are identified. These requests are input to the change control process in provide Program Control. Change requests are then evaluated and the disposition of requests relating to technical performance is fed back to the technical information control process in Perform System Engineering. The change request can result in redirection of development functions or in reinterpretation of the compliance approach.

2.3.3.5 Specific Products in the Flow of Information. The two key products of this process are the compliance approach and the system mission requirements. The compliance approach defines the manner in which each 
WHC - EP- 0482

regulation will be addressed by the physical system. It may not define a performance value, but associates a development approach by which an area of the physical system will be developed to meet the regulation.

The system mission requirements are contained as a subelement of the total program requirements and are part of the direction that the program control process provides to the development functions. The mission performance requirements may address isolation effectiveness. throughput. safety, reliability, availability, supportability. logistics, cost, and schedule. The verification requirements are also included and define the degree of verification required and the allowable uncertainty and confidence levels.

2.3.3.6 Significant Considerations. It is essential that the requirements integration process ensures completeness and control of the requirements set. An incomplete requirements set will yield an unlicensable system and will yield a development process whose efficacy can easily be questioned. In this analysis. completeness of requirements identification is ensured by means of the regulatory source evaluation and databasing process in Ensure Regulatory Compliance and the assessment of nonregulatory sources in Provide Program Control. Also in this analysis, completeness of the total requirements set is further ensured by the integration if the requirements set and the identification of controlled items in Provide Program Control.

Similarly. if the requirements set and its use are not controlled, then the resulting system is not likely to meet all requirements (i.e.. not receive regulatory approval) and is not likely to integrate smoothly (i.e.. pieces developed to differing constraints will not fit together). In our analysis. control is exerted through the change control and program evaluation processes in Provide Program Control function.

\subsubsection{Program Strategy and Program Direction Generation.}

2.3.4.1 Concept. There are many different ways to implement a program to accomplish a given set of development work. Not all of these ways are available to the OCRWM program because of the regulatory, external review, and political group and public interest group evaluations of the program and its products. The constraints to the legal and politically accessible methods of program execution are embodied in the OCRWM Programmatic Requirements, a subset of the total program requirements described above. Furthermore, only a limited number of programmatic approaches is effective in accomplishing the OCRWM mission. Thus, the implementation of the OCRWM program must be doubly constrained by a set of programmatic requirements traceable to the external programmatic constraints and by a strategy that identifies an effective method for accomplishing the NWMS mission within these constraints.

Program Direction is the flowdown of these external requirements and the program strategy to the specific processes described in the individual MSIS functions. Program direction constrains the functions to execute their steps according to legal requirements, government policies, and standard practices and procedures. Program strategy defines an approach for each function to meet these requirements in an efficient manner that will produce products in the most convenientiy used form. It also defines an approach to meeting system performance requirements given the program requirements and direction. In addition, it defines a method to integrate the MSIS functional processes into a coherent whole that interfaces smoothly and efficientiy. 
$W H C \cdot E P \cdot 0482$

These highly important programmatic controls are incorporated into the functional analysis process. Their method of generation is well defined and controlled and they form the basis for assessments of program execution.

2.3.4.2 Analysis Approach The functional analysis consolidates the development of program requirements, and development direction, and strategy into a single subfunction in the Provide Program Control process. Because these items are key inputs to organizing the program. planning and approving tasks, and evaluating program performance, they are iogically centralized within Provide Program Control. the function responsible for planning work and evaluating programmatic performance. The Program Direction product includes program strategy, standard practices and procedures for the program. and the external requirements for execution of a government program.

The program strategy part of this product defines the program's approach to accomplishing its mission. The program-wide strategy is a multidisciplinary product. It is produced through efforts by senior experts in all program technical and mariagement disciplines. The resulting programwide strategy flows down to form the basis for lower level strategies for each MSIS function. Flowdown tailors the program-wide strategy to specific needs of each functional process (e.g.. formation of design strategy to address particular issues in constraining the design process). Flowdown also tailors the program-wide strategy to specific needs of the organizations responsible for implementing each functional processes.

2.3.4.3 Process and Information Flow. The process of generating and applying programmatic requirements, direction, and strategy has three steps: the initial strategy, the initial direction, and the application of direction. The information flow process is summarized in Figure 2-4 and can be described as follows.

- Develop Initial Program Strategy. The initial program direction consisting of only a strategy is developed at the beginning of the program before any technical work or any assessment of legal requirements begins. The generating function is contained in Provide Program Control and uses as inputs the NWPA and program commitments, the results of program mission objectives analysis. and the strategic options (provided by the Perform Strategic and Contingency Planning MSIS function). Development of the initial strategy requires participation by representatives of key program disciplines and organizations. This initial strategy is the basis for developing the regulatory requirements source list and compliance requirements and approach in the Ensure Regulatory Compliance MSIS function. Ensure Regulatory Compliance provides these outputs to Provide Program Control in response to the initial strategy.

- Develop Initial Program Direction. Program Direction is essentially the application of the program strategy and program requirements to other MSIS functional processes. Program Direction is developed by a separate function in Provide Program Control that incorporates a multidisciplinary approach using expertise from each technical element. and requiring participation of each function. The inputs to this initial direction development are the initial program strategy. the program commitments, the 
Figure 2-4. Information Flow in Program Direction Generation.

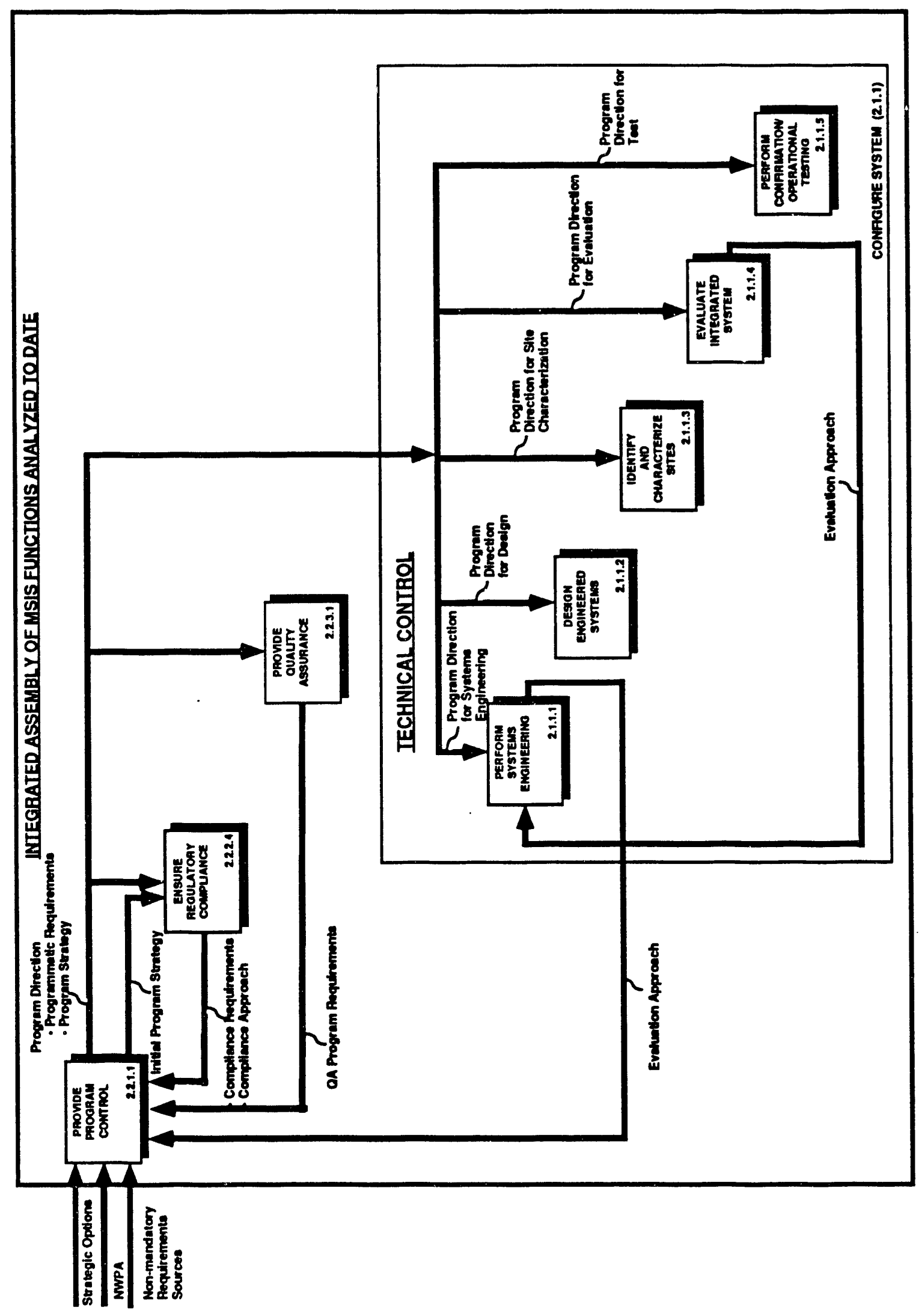


compliance requirements, the compliance approach, and the $O A$ program requirements. These are integrated to form Program Direction and the program strategy is updated.

- Flowdown of Program Direction to All Other Functions. Program Direction is a control placed on all MSIS functional processes. especially those responsible for system definition. In the functional analysis report, the Program Direction information flow incorporates a 11 strategy elements. all compliance requirements and approach. and all standard practices for doing business. As illustrated in the figure, and defined in detail in the functional analysis report. Program Direction is applied as a control to each of the MSIS functions. Thus, development of the NWMS is constrained to follow the approach. policies, and standard practices issued as Program Direction.

2.3.4.4 Feedbacks and Control Points in Process. In developing and applying Program Direction, feedbacks are necessary because system development is an iterative process and because evolution of the program may require evolution of the Program Direction. The feedbacks and constraints in applying Program Direction can be described as follows:

- Feedbacks in Iterative Refinement of Program Direction. The compliance approach and the system evaluation approach are formed as products of the initial program direction. The compliance approach is developed as result of the initial strategy and includes evaluating the effects of each regulatory requirement within program approach. This evaluation shows the suitability of the strategy for accomplishing compliance. The evaluation approach is developed in the Evaluate Integrated System function as a result of initial program direction and includes determining methods to quantify how wel1 system performance meets requirements. Development of a complete and executable evaluation approach shows feasibility of implementing hardware that meets the strategy. Each of these evaluations may identify issues in implementing the strategy. Such issues are fed back to Provide Program Control for revision of program direction.

- Constraining Program Execution to Program Strategy. Program Direction is a control on the planning of tasks. Tasks are not authorized unless they meet strategy and programmatic requirements and no work is performed uniess the task is authorized. Thus. program execution is constrained to the bounds defined by the program direction and. in particular, the program strategy.

- Monitoring of Program Execution. Program Direction is an input that forms a reference against which program performance is evaluated. Deviations from program direction become focal points for corrective action.

- Feedback on Issues in Implementing Program Strategy. Each functiona 1 process must meet system performance requirements and program strategy simultaneously. If program strategy is inadequate, then it will not allow system performance requirements to be met within the allowable program constraints. An inability to meet a system performance requirement generates a Need for Requirements Review which in turn initiates the change request and 
change evaluation processes. Thus, there is a real time control feedback on the effectiveness of the program strategy.

2.3.4.5 Specific Products in the Flow of Information. Key subelements of the overall Program Direction information flow include the following:

- Program Direction/Strategy for Perform Systems Engineering (PSE):

Programmatic requirements, guidance and constraints for implementing systems engineering program: addresses structuring of physical systems, structuring the review process, developing Technical Performance Measures (TPM), and organizing and controlling technical information.

- Program Direction/Strategy for Design Engineering Systems (DES): Programmatic requirements and overall philosophy for structuring design effort: addresses review process. accessible technologies. design validation testing philosophy. cost/schedule guidelines. There are separate strategy elements for each phase of design.

- Program Direction/Strategy for Identify and Characterize Sites (ICS): Programmatic requirements and programmatic approach to site identification and characterization: addresses directed evaluations, top-level site screening techniques, methods for resolving data need conflicts, guidance for forming data acquisition strategies.

- Program Direction/Strategy for Evaluate Integrated systems (EIS): A set of directed evaluations resulting from regulatory analys is and an approach to developing evaluition methods and criteria that ensures consistency with compliance approach and that ensures acceptability of evaluations to regulatory agencies.

- Program Direction/Strategy for Perform Confirmation/Operational Testing ( $P C O T$ ). Programmatic requirements and constraints on the execution of test activities: addresses resource availability, authorizations to proceed after readiness reviews, documentation approvals, and resolution of schedule and resource requirements conflicts.

2.3.4.6 Significant Considerations. Program Direction and Program strategy are critical to ensuring program effectiveness. They form the standard practices and procedures by which program activities are constrained. Furthermore, the strategy defines a top-level technical approach to addressing the multiple technical constraints that the regulators place on each physical system item. In forming and applying Program Direction and strategy, several considerations are especially important:

- Program Direction/Strategy must be formed as early as possible because it influences all technical activities. Without control by Program Direction/Strategy, technical activities will be difficult to coordinate and integrate and technical products from the separate organizations will likely not be comparable.

- Program Direction/Strategy development is iterative. The effectiveness of direction and strategy can be judged by the products derived from them. As the direction and strategy are applied to individual processes, issues may be identified that necessitate updates to the direction/strategy. 
- Program Direction/Strategy forms the basis for programmatic evaluations. Once direction and strategy are formed. all tasks and task performance must be evaluated to determine how well they are implementing direction/strategy. Appropriate corrective action must be taken if deviations are outside established acceptance criteria.

\subsubsection{Technical Information Flow and Program Direction.}

2.3.5.1 Concept. A large program such as OCRWM's will evolve with time as a result of the normal development of the physical system. changes to the regulatory environment, and technical investigations indicating unforeseen NWMS characteristics. Technical decisions must be made that will determine how the program will respond to these changes in terms of both technical process (e.g.. priorities of tasks) and technical content (e.g.. values of performance requirements) and will consider cost. schedule, risk, and technical ramifications. The decisions must be based on the best information available including an understanding of the NWMS configuration and the options available for evolving this configuration. Thus, there is an interface and an interaction required between the management decision process and the technical development process. The functional analysis shows how this interface and iteration occurs and how decisions are made to control the technical developments within the program.

2.3.5.2 Analysis Approach. The approach taken in the functional analysis is to have a single centralized function that performs assessment of program effectiveness. program status, and changes. In this approach, there is a single input point for technical data into the program decision process: this is the same point at which cost and schedule information is input. This single input point represents the fact that all data must be integrated in order for it to be sufficiently complete for program decisions. This single input point also represents the fact that all data must be controlled in order for its validity and veracity to be sufficient for program decisions.

The functional analysis shows dual paths for disseminating the results of program decisions. There is a single, integrated input point (Perform Systems Engineering) for all technical requirements changes and evolutions to be input to the technical process; this represents the continuing control and integration of system performance requirements. There are distributed inputs (one per MSIS function) for input of changes to program direction and program strategy: this represents the centralized flowdown of program direction to the needs of each MSIS functional process.

2.3.5.3 Process and Information Flow. Figure 2-5 illustrates the process by which program technical information is generated and evaluated and program replanning and redirection is performed. All system definition development functional processes begin work under the constraints of Program Direction. Technical information is audited and integrated in Perform systems Engineering.

Technical information forms half of the iterative loop and is produced by the configuration develupment functions and then audited and integrated in the technical information control process found in the Perform systems

Engineering function. Controlled and audited technical information originates from this process and is then passed to the program evaluation process in Provide Program Control. If a system requirement cannot be met, the 
Figure 2-5. Technical Information Flow and Management Direction.

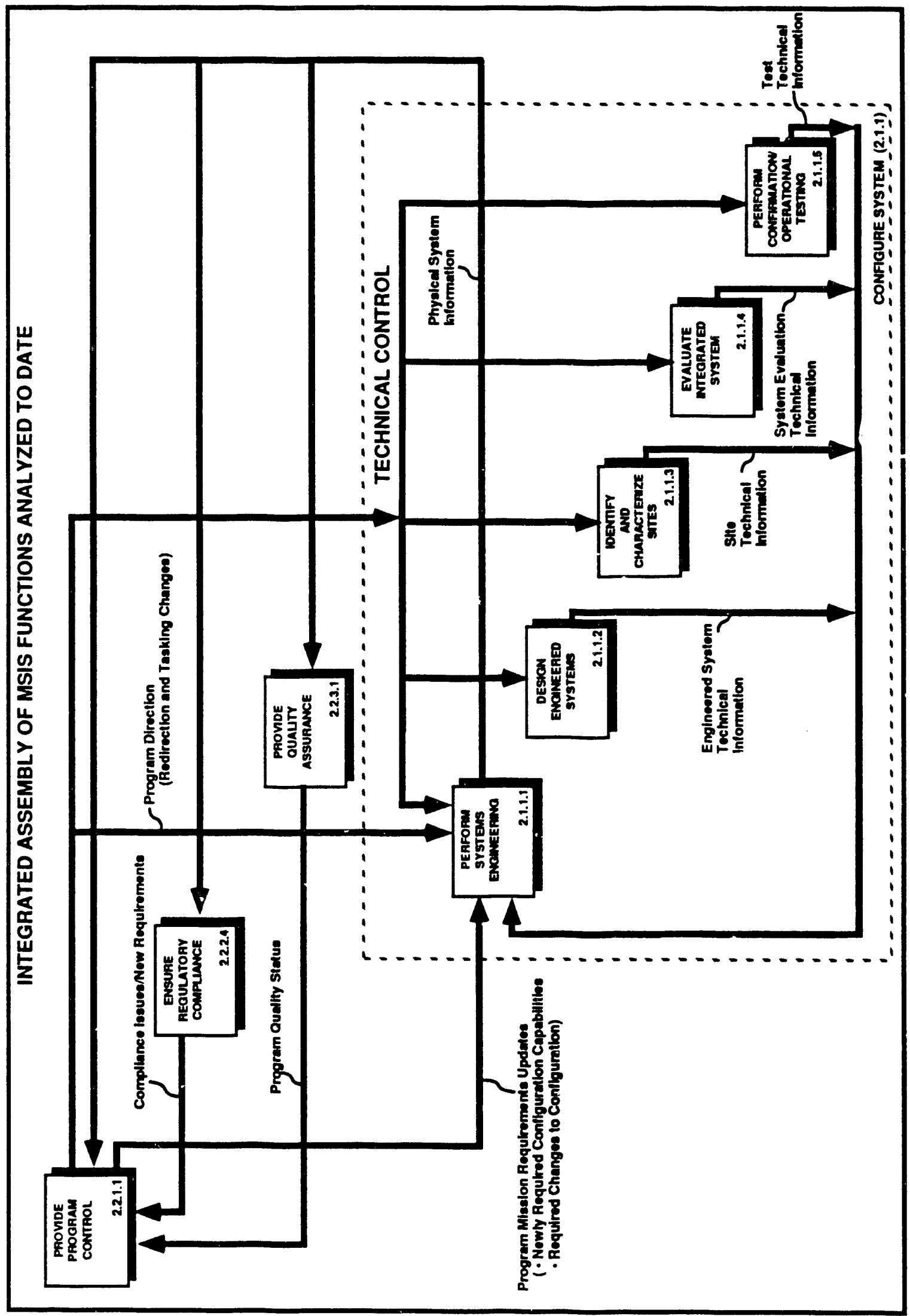


configuration development functions generate a Need for Requirements Review that is received by Perform Systems Engineering where it is placed under control and irtegrated with the relevant technical material. This Need for Requirements Review generates Change Requests to the change control process in Provide Program Control.

The program decisions are the other half of the iterative loop. Change requests and program technical data are evaluated as part of the program performance evaluation found in the Provide Program Control function. This is a multidisciplinary evaluation involving management, planners, and technical staff. During this time the technical data is combined with the cost/schedule data developed within the Provide Program Control function. Approved and disapproved change requests are returned to Perform Systems Engineering and performance requirements reallocation occurs based on this response. Updates to Program Direction and Strategy are provided to individual MSIS functions to redirect their activities to conform to the results of the evaluations.

In the program response to external changes, external changes are input - o the program through the Ensure Regulatory Compliance function (changes to laws and regulatory processes or changes to DOE directives and policies) and the Provide External Relations function (changes to program resources and commitments). Statutary and regulatory changes can result in change requests to requirements or to direction, including the compliance approach and the strategy. Provide Program Control evaluates program performance and status on such change requests and information from external interactions. Evaluation can generate a need for remedial action which initiates a revision to programmatic requirements, direction, and/or strategy. Revised requirements. direction, and/or strategy are inputs tc system configuration development functions. Revisions define how to restructure work as well as how to make technical accommodations.

2.3.5.4 Feedbacks and Control Points in Process. The above process is an interactive, feedback process: the critical control points are in Provide Program Control. Ensure Regulatory Compliance, and Perform Systems Engineering functions. Control for program evaluation occurs in Provide Program Control and checks fiscal/schedule status but also reviews technical progress relative to task plans. Control for compliance status confirmation occurs in Ensure Regulatory Compliance and ensures that program direction and strategy will accomplish compliance with a 17 laws. Monitoring of system description is controlled in Perform Systems Engineering and ensures a? 1 requirements have been addressed and that predicted characteristics are traceable to requirements.

2.3.5.5 Specific Products in the Flow of Information. The key products of this process are represented by the arrows in the previous figure. The technical contents of these arrows can be described as follows:

- Physical System Information. This information describes the system configuration and its characteristics and the results from the technical information auditing review and control process in Perform Systems Engineering.

- Need for Requirements Review and Change Requests. These define where there are issues in meeting all requirements and direction simultaneously. The former is passed from development functions to Perform Systems Engineering and cause the latter to be issued from Perform Systems Engineering to Provide Program Control. 
WHC - EP- 0482

- Approved/Disapproved Change Requests. These define the technical response to change requests in terms of changes to the system configuration. They result from the change control and evaluation process in Provide Program Control.

- Program Direction/Strategy Updates. These define the programmatic response to change requests and external changes and are passed to a 11 MSIS functions from Provide Program Control.

2.3.5.6 Significant Consiaerations. Control of a broad scope technical program periodically requires decisions to revise the program structure and content based on changes in the program environment and newly identified technicai information. Such decisions must be based on technical datalevaluation as well as on programmatic information. The functional analysis has identified elements to an effective decision process:

- Use of controlled, integrated technical data. Data control and auditing ensures that decisions are based on the best available information: data integration ensures that a complete technical evaluation of potential changes is formed.

- A centralized evaluation of proposed changes. Whether externally imposed or internally identified, a need for technical or programmatic revision to program requirements can have a broad range of effects. Maintaining a program-wide strategy, with all subtier strategies as derivations, and a centralized planning process provides for identifying all functional processes and technical products that may be affected by the proposed change. Thus, a program-wide response can be developed and program integration can be maintained

\subsubsection{System Technical Performance Requirements} Development Flow Functions.

2.3.6.1 Concept. System acceptability is measured in terms of meeting the mission within the constraints imposed by laws and regulations. The system mission and its associated external requirements define what the system must do and determine its acceptance criteria. However, they often are not stated in the form of technical specifications that can be applied in a straight forward manner. Some requirements are stated only in qualitative terms, not in engineering and scientific form. These qualicative requirements must be converted into quantitative values and descriptions that can be used to develop the system configuration. Additional technical performance requirements are defined as the configuration is defined. These requirements are derived from the initial set as the system functions are decomposed and architected into the design solution. Thus, they are both mission-dependent performance requirements and derived performance requirements. Further reauirements are developed to define the evaluations and testing required to meet regulations for verification. Therefore, there are four classes of technical performance requirements constraining configuration development: mission dependent, derived, evaluation, and testing requirements.

To maintain an integrated system configuration, especially in the case of parallel design efforts such as MRS design and MGDS design. the system technical performance requirements for all configurations development must be constrained to a common and controlled requirements source that is traceable to the program-wide requirements set originating (see Section 2.3.3) from the 
regulatory analyses process. The functional analysis explicitly addresses conversion of requirements to engineering and scientific form, derivation of quantative requirements from qualitative requirements, control of these requirements, resolution of conflicting requirements, and allocation of requirements to appropriate system elements.

2.3.6.2 Analysis Approach. The functional analysis addresses this issue by placing all system definition development functions under the control of a single requirements interpretation, allocation, auditing, and review process within the Provide System Engineering function. This one function develops a system mission and functional analysis, analyzes the statutory requirements. converts the requirement from qualitative to quantative values where necessary, and allocates them to subfunctions within the system. The Provide System Engineering function performs these functions for the entire system to ensure uniformity of interpretation and application of requirements across all elements. This same function performs technical reviews and audits to ensure the system is technically acceptable and integrated. Including these two functional processes within the scope of one MSIS function provides the required consistency in the approach to review and submittal of all technical information regardless of origin. It also provides the integration of the review and auditing process to ensure completeness and consistency of the reviews.

2.3.6.3 Process and Information Flow. The control of system requirements is implemented via an interactive process within the functions for configuring the system. The information flow in this process is illustrated in Figure 2-6. The analysis and allocation of regulatory requirements occurs in the Perform Systems Engineering function. A mission analysis and requirements allocation are performed by means of functional analysis and requirements flowdown. This results in a definition of the physical system functions in the NWMS and a specification of the requirements that apply to each.

The progressive decomposition of physical system functions, and the flowdown of requirements to the newly defined subfunctions occurs as the system configuration is defined by the system development MSIS functions (Design. Site. Evaluate, and Test). Each MSIS function addresses those requirements appropriate to its mission. Allocation of requirements responsibilities among the MSIS functions is a prerequisite to execution of technical activities in these functions.

The results of addressing requirements are delivered to the technical review and auditing process in the Perform Systems Engineering function. Technical data are reviewed and used as a basis for expanding the system requirements set using the derived requirements formed by the expanded system configuration description. Reallocation and change requests can be generated during the review process.

Transfer of requirements and information occurs during the technical review, auditing, and reallocation processes. For example, in Evaluate Integrated System, the evaluation approach may generate requirements for data collection by Design Engineered Systems. Identify and Characterize Site, and Perform Confirmation/ Operational Testing. These data collection requirements are passed to the appropriate MSIS functional process. The delivery of requirements to Perform System Engineering represents the fact that these requirements also need control and traceability audits. As a further example. 
Figure 2-6. Requirements Flow During System Definition.

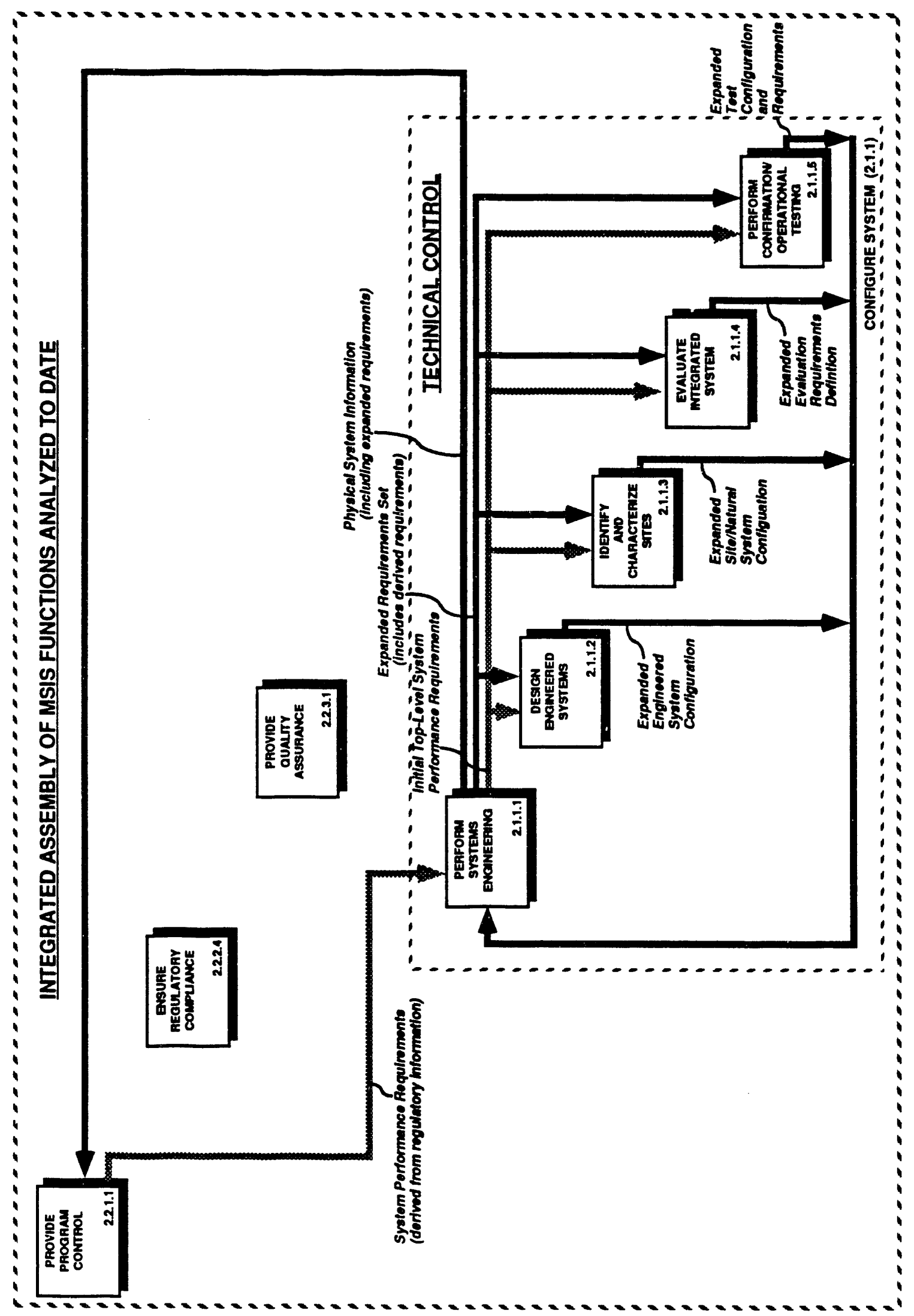


in Identify and Characterize Sites, the site characterization results may generate requirements for operating conditions and the environment of engineered systems. These also are placed under control and provided to the appropriate MSIS functional process.

2.3.6.4 Feedbacks and Control Points in Process. Control of this iterative process is exercised at two key points:

- System Technical Reviews: These reviews ensure completeness of data and traceability of characteristics to requirements: inciuded are external and independent reviews. Technical review results can cause the Provide Program Control process to generate redirection of other MSIS functions if technical products are not adequate.

- Integrated System Evaluations: These are analytical evaluations of the system configuration and its ability to meet requirements and comply with statutes. These evaluations are critical inputs to system technical reviews.

2.3.6.5 Specific Products in the Flow of Information. There are three key MSIS function products that formalize the iterative reallocation of requirements:

- The Technical Baseline provides progressive expansion of the performance requirements for engineered items and are formalizations of the derivation of component requirements during configuration development. Issuance of these requirements initiates the following:

The Functional Requirements Baseline, resulting from the mission and functional analysis and requirements allocation, initiates conceptual design:

- The Conceptual Design Requirements, resulting from the approved conceptual design, initiate the preliminary design:

- The Design Requirements Baseline, resulting from approved engineered system preliminary design. initiates final design:

- The Product Configuration Baseline, resulting from approved engineered system final design, initiates construction;

- Site Characterization Planning Documents define the characteristics of sites that must be measured and includes analysis to determine values required to meet site requirements. These documents, in order of precedence, are as follows:

Data Acquisition Strategies plan the processes by which site programmatic requirements will be met and allorate site requirements into a set of measures that can be quantified. 
- Test and analysis plans define the process of making measurements and determine the specific data items based on the quantified site measures.

- Investigation plans are derived form the Test and Analysis Plans and specify the detailed procedures for measurements and analysis.

- Suitability Measures and Attributes, determined from the system verification requirements, determine a set of quantifiable parameters that will be evaluated and used to measure integrated system suitability.

2.3.6.6 Significant Considerations. The system performance requirements flow process is necessarily iterative and can be controlled only if the requirements set is fully integrated. There are three important elements to the requirements flowdown and control process. The first element is the progressive reallocation of requirements to successively lower levels. Statutory requirements will be converted into scientific and technical requirements so that characteristics of technical products can be defined. These requirements must be further decomposed and allocated as the technical solution to the NWMS mission is developed.

The second element is the integrated review and auditing process. This process serves three purposes. It provides the:

- The Independent technical review that is essential to ensure technical acceptability.

- The Integrated technical review that is necessary to ensure all technical products are subjected to the same level of review, the same review standards, and the same auditing process

- The Integrated auditing that is necessary to maintain completeness of the requirements set at all times.

The final element is integrated requirements allocation. Integrated allocation occurs by physical system function and MSIS function. The integrated allocation by physical system function is the only way to ensure that total system performance is maintained during element. subsystem. assembly development. Also, integrated allocation by physical system function is necessary to maintain compatibility of technical effort and provides the ability to integrate technical products. Integrated allocation by MSIS function is necessary to maintain coordination and unification among the parallel efforts for engineered systems. site, evaluation, and test.

\subsubsection{System Configuration Development Flow}

2.3.7.1 Concept. Development of the definition of the system configuration is performed by the five MSIS functions grouped under the title of Configure System. Performance of these functions and their products must be integrated. Developing the system configuration requires performing several interrelated but relatively independent functions,e.g.. design and site characterization. Each functional process addresses a distinct aspect of the system configuration development and performs its actions relatively independentiy of the others. 
Each individual system definition development process lilust provide information needed by the other individual functional processes. No one function can complete its mission without having the detailed results of the other interfacing functional processes. Compatibility of products can be ensured only if the assumptions, approaches, and requirements are shared in common. This information exchange process also must be controlled to ensure timeliness of data availability and to ensure accuracy of the data exchanged. The functional analysis address each of these concerns.

2.3.7.2 Analysis Approach. The approach to controlling technical information exchange among the system definition development MSIS functions is similar to that used for controlling system requirements. A centralized functional process is used to perform these actions for all technical data. This means that the same process is applied to all data and the data is integrated to form a unified whole. Databasing, auditing, and control mechanics may be distributed geographically. The essential aspects are a single process, integration of data, and control of entries and updates.

This single process exerts control over the technical data. No data are entered into the technical information system without review, audit. integration. This process is formalized in a technical information change control process. Auditing and review ensure completeness and identify conflicts in information. The integration process includes distribution and notification to all relevant organizations.

2.3.7.3 Process and Information Flow. The technical information flow iterates through the technical review, auditing, integration, and control processes within the Perform Systems Engineering function. The information flow in this process is illustrated in Figure 2-7. As each function develops additional configuration definition information, the results are passed to the Perform Systems Engineering function. Within Perform Systems Engineering. there are subfunctions that perform technical review, auditing, integration. and control. A Controlled NWMS Description is then formed and is passed back to each of the other MSIS functions. This description contains the approved version of the information each function passed to the technical review. auditing, integration, and control processes. It allows each MSIs function access to data generated in parallel processes. The controlled description is integrated to show how the data from all functional processes fit together.

This controlled description is the basis for the technical information required by the program functions of Provide Program Control. Ensure Regulatory Compliance. Provide Quality Assurance.

2.3.7.4 Feedbacks and Control Points in Process. Control and feedback are accomplished by the information management process in Perform Systems

Engineering. This process integrates the information and requirements flows and connects the technical information to the change control process. There are three control points in the information flow. The first is the technical information control process. The Perform Systems Engineering subfunction for controlling system description provides the technical review, auditing. integration process. and the Evaluate Integrated System function plays a key role in analyzing the integrated technical product to ensure acceptability and compliance.

The second control point is for feedback between functional processes. An MSIS functional process can identify information needs that can only be fulfilled by the processes incorporated in a parallel MSIS function. As such 
Figure 2-7. Technical Information Flow During System Definition.

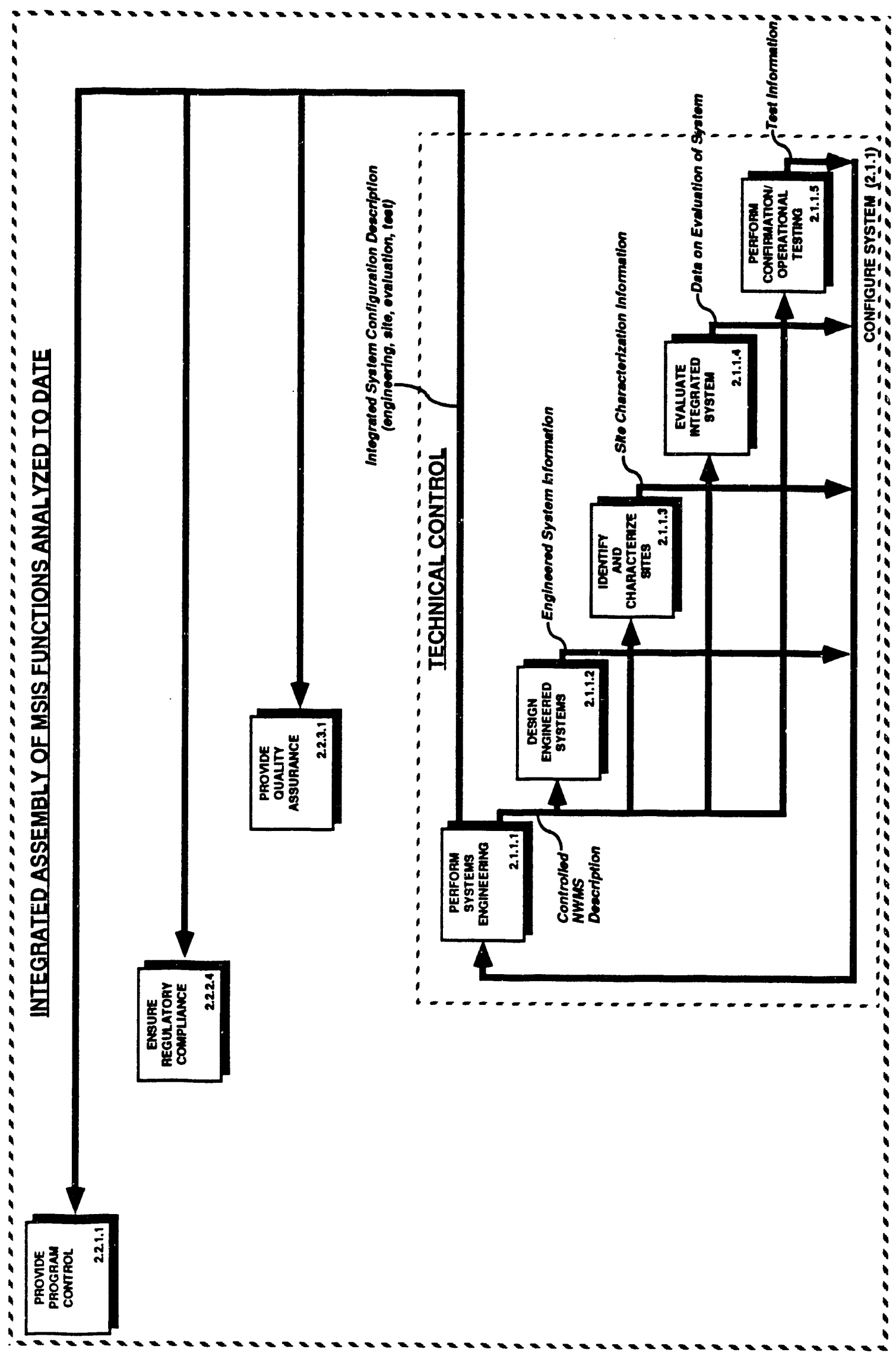


needs are identified, requests are generated that are passed to the appropriate parallel process. These requests link the technical information management loop to the requirements control and allocation loop. The requests pass into the technical review and auditing process via the technical loop and are transferred to the requirements loop to become requirements for information generation on the appropriate MSIS functional process.

The third control point is for conflict resolution and the change control. One functional process may find that it cannot meet its system performance requirements given the results from another functional process. This condition causes a Need for Requirements Review to be generated that initiates the change request process. The change eva?uation process (in Provide Program Control) then provides conflict resolution.

2.3.7.5 Specific Products in the Flow of Information. The important products in the technical information control loops are the outputs of the individual

MSIS functions to Perform Systems Engineering and the return information flow from the technical review, auditing, integration, and control subfunction of Perform Systems Engineering. These are described below:

- The Controlled NWMS Description contains the integrated description of the entire NWMS configuration in its current form. It is updated as new technical information is reviewed, audited. integrated and is always available to any functional process via the information management system.

- The Engineered System Information contains the design description and design characterization for engineered systems. It includes successive outputs for conceptual, preliminary, final design phases, and contains separate flows for each engineered system that is defined as a separate design effort.

- The Site Characterization Information contains the planning information and the characterization data from site evaluations and contains a continuous feed of data to the information management system.

- The System Evaluation Data contains the planning information, data requests, and evaluation results from integrated system evaluations.

- The Test Information contains the planning information and the test results from testing of items specified in testing requirements. It includes new test data provided based on the test requirements, the test plan schedule, and the program schedule.

2.3.7.6 Significant Considerations. The system technical information flow process is necessarily iterative and can be controlled only if the configuration description is fully integrated. The three important characteristics of the process are iterative data exchange, integrated review and audit, and the linkage to change control. For iteration and feedback between MSIS functions, each function needs to exchange data with other functions to complete its mission; data exchange may include requests for specific evaluations of needed quantities. The integrated review and auditing ensures that information is complete, that a 11 information is fully reviewed. 
WHC-EP- 0482

and that information is made available only after review. The link to the change control process is how conflicts are resolved. It requires change control technical evaluation, program decisions, and possible redirection of MSIS functions.

\subsubsection{Major Feedback Loops in Overall Functional Process.}

2.3.8.1 Concept. Development of the physical system configuration is a technically complex problem and will require an iterative approach to provide solutions. The previous discussion described the success-oriented pathways through the integrated assembly of MSIS functions. However, the process must al so accommodate the condition where the initial outputs of MSIS functions may not fully meet specified requirements. A function product may fail to meet either technical or programmatic requirements or may no longer be acceptable because the program needs or requirements have changed.

Earlier parts of this section have shown there are iterative processes embedded within the successful system configuration definition processes. e.g.. design development, site characterization, the change control processes. This same concept of iteration is applied to address failure of any function's product to meet its specified requirements. Once a failure is identified, the determination is made to modify the system configuration or if that is not feasible within the technical and programmatic constraints imposed in the program. to request a revision of the specified requirement. Feedback loops are provided among the MSIS functions to permit such corrective actions. The discussion below recasts the feedback and iteration issues in the light of methods for correcting the potential failures of function products.

2.3.8.2 Background on Functional Analysis Principles. Understanding how the functional analysis results define processes to identify and remediate failures requires understanding the role of centralized and distributed processes in the MSIS functions and how these functions interface during program execution.

For centralized functions and processes, an entire multi-disciplinary. inter-organizational process is contained in a single MSIS subfunction. The process is explicitly defined as requiring participation by all affected organizations and all relevant technical and programmatic expertise areas. All iterations on such processes are contained within the centralized subfunction. Gathering of information is generally implicit in the function (i.e.. a result of executing the elements of the function and not produced by any other MSIS process).

For distributed functions and processes, accomplishing a particular program goal requires pieces of several MSIS functional processes. The information exchange is shown explicitly for such cases: information dependencies propagate as far down the functional decomposition as is necessary to show the process. The information from several MSIS functions is flowed to an integration function which makes the appropriate decision or selection. This function is located in the MSIS function that had the most appropriate mission and scope.

There are several assumptions about the interfacing between MSIS functional processes. When the information exchange is shown explicitly, it is assumed that the exchange is provided in a timely manner. The critical issue is that the function description shows what information is needed to perform the function. Unless shown explicitly. there is no method specified 
in the analysis. to overcome late data arrival via guessing the required input. Any function can be restarted based on instructions in Program Direction and the availability of an appropriate copy of its input.

These assumptions were used throughout the analysis and are common to al1 MSIS functional processes.

2.3.8.3 Process and Information Flow. The key feedback loops for reevaluating and revising program products are shown in Figure 2-8. Each feedback loop is numbered in the figure and described below.

- Feedback from Ensure Regulatory Compliance (arrow 1 in Figure 2-8). The Ensure Regulatory Compliance function evaluates the system suitability evaluation approach and the system technical data to verify that compliance requirements are being met. When shortfalls

or issues in the system technical data are identified, a requirement for corrective action to meet compliance is provided to the Program Direction process in Provide Program Control. The Program Direction process can then redirect the system definition development functions.

- Feedback from Provide Quality Assurance (arrow 2). The Provide Quality Assurance function reviews specifications for system hardware to ensure proper quality standards have been applied to the specifications and that proper quality procedures are part of the specifications. When shortfalls or issues in the specifications are found, they are identified in the program quality status data provided to the program evaluation in provide Program Control. The program evaluation process can then determine the needed remedial action. which is transformed into a redirect to the system definition development functions.

- Feedback from Provide Program Control (arrow 3). The Provide Program Control function evaluates program performance. especially with respect to the application of programmatic requirements. When shortfalls or issues are found in meeting programmatic requirements or in accomplishing technical requirements. they are used to determine the needed remedial action. which is transformed into a redirect to the system definition development functions.

- Feedback from Perform Systems Engineering (arrow 4). The Perform Systems Engineering function audits the technical information provided by the other system definition development functions and performs the system technical reviews. When shortfalls or issues are found in the technical data. they are used to define technical requirements for new analyses, evaluations, etc.. that are passed to the other system definition development functions.

2.3.8.4 Significant Considerations in Multifunction Feedbacks. To maintain order within the program. the feedback loops must be well defined and must have integrating focal points to resolve potential conflicts. These two characteristics are critical for the following reasons:

- Defined Areas of Review Responsibility and of Control. Defined responsibilities for review and control are important to fully define the nature of the evaluation and the type of feedback loop. 
Figure 2-8. Key Feedback Loops that Correct and Optimize System Configuration.

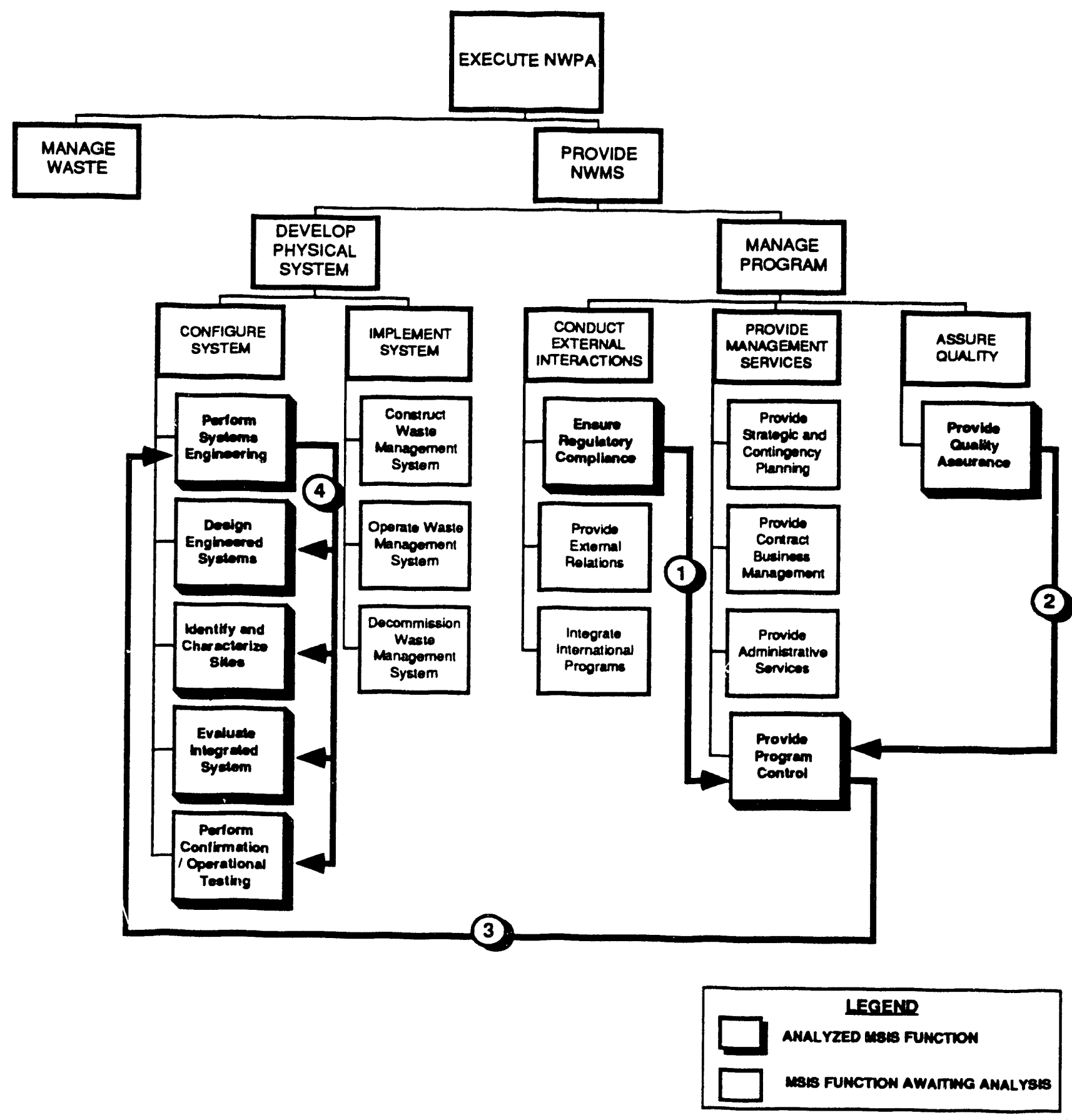


Each of the MSIS functions has a defined mission and scope. The technical and programmatic evaluations for which they are responsible are defined to be within the scope of the function.

- Single Points of Integration of all Feedbacks. An integrating point for feedbacks and remedial action requests is important to maintain program organization and to eliminate conflicts in required actions. Provide Program Control consolidates all changes and remediation requests that have program, tasking. budgeting ramifications. Perform Systems Engineering consolidates all changes and change requests that affect the system performance requirements and the system technical configuration. 
WHC-EP-0482

\subsection{PERFORM SYSTEMS ENGINEERING PROCESS DESCRIPTION}

This section of the report presents the process descriptions for the Perform System Engineering (PSE) (2.1.1.1) function. Included among the discussions of this section are the following:

- The PSE function mission identification and statement of scope. and overview of the entire process, including function structure. primary subfunction descriptions, and discussion of the process flows required to accomplish the function mission.

- PSE external interfaces to include breakouts of information inputs to PSE functions, control information provided, and output information generated.

- Discussion of the major subfunctions of PSE, including process flows. mission and scope identification. irternal processing flow interfaces, outputs generated, and considerations that are important to the successful execution of each subfunction.

- Identification and discussion of significant internal feedback loops and processes within the PSE function that are required for successful process execution or are required to correct problems or address issues that must be resolved before successful completion of the function process.

- This process description addresses the mechanics of functional processes and interfaces in accordance with the results of the Office of Civilian Radioactive Waste Management (OCRWM). The Ana?ysis of the Program to Develop the Nuclear Waste Management System (Woods 1991a). More importantly, the report also addresses the rationale for the processes and process sequences. as well as the importance that the process outputs and products have in ensuring the success of the OCRWM program and the successful development and operation of the Nuclear Waste Management System (NWMS) physical system.

\subsection{PERFORM SYSTEMS ENGINEERING MISSION AND PROCESS OVERVIEW}

This section of the report identifies the mission and scope of the PSE function. presents the function hierarchical structure, and provides an overview of the overall process flow.

\subsubsection{Mission/Objective}

The mission and objective of the PSE function are as follows:

- Define the mission and mission requirements of the NWMS physical system.

- Translate input program mission requirements and constraints into a set of system functions, functional relationships, and requirements allocated to the functions to describe the NWMS physical system completely. 
Translate qualitative requirements and constraints into quantitative values.

Incorporate all directed physical system requirements and constraints in the system functional structure and allocated requirements.

- Identify system technical performance measures and acceftance criteria by which the progress and performance of critical system elements can be evaluated as the system evolves.

- Provide formal control of the physical system configuration and associated system description information.

- Perform technical reviews of physical system development status and technical products to do the following:

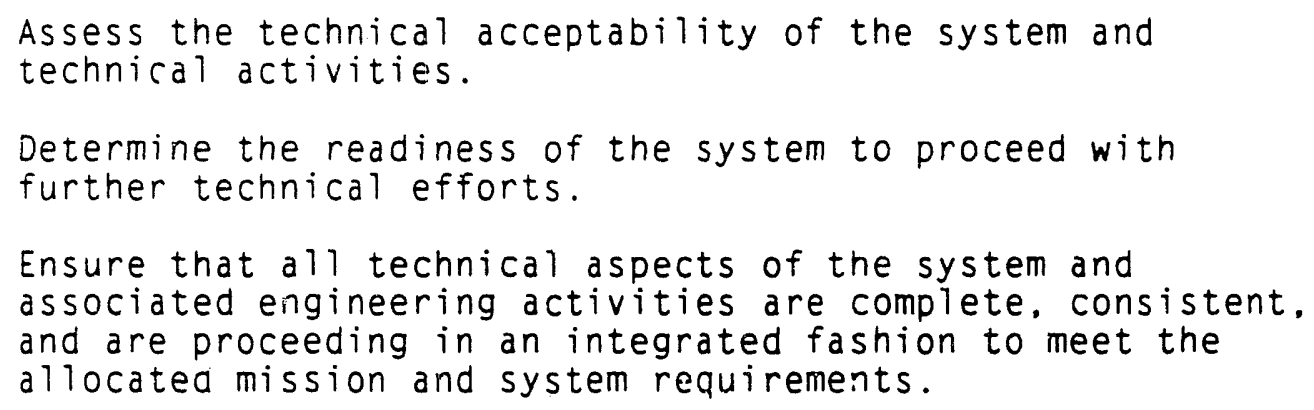

\subsubsection{Scope}

PSE operates entirely within the scope of the NWMS physical system and its associated technical requirements and attributes. The function interacts with the Provide Program Control (PPC) function to perform change control and information and requirements identification and management for the entire program. Within the context of its overall function scope. PSE performs as follows:

- Performs analyses and decompositions of program mission requirements into a physical system functional architecture.

- Decomposes directed system requirements into technical performance requirements and a? iocates them to functions within the architecture.

- Performs reviews and evaluations of physical system technical products and engineering activities to integrate all technical aspects of the physical system development. testing. and operation.

- Provides control and management of system configuration and other techrical items to ensure that a consistent and correct technica? baseline exists at all times and that all programmatic functions are provided with the same set of controlled information. 
WHC-EP- 0482

- The hierarchical structure of the PSE function is shown in Figure 3-1. This structure addresses subfunctions down to the third level of indenture. There are even lower-level subfunctions within PSE that are not illustrated in this figure. A complete description of the PSE function hierarchy is contained in The Analysis of the Program to Develop the Nuclear Waste Management System (Woods 1991a). The hierarchical organization of the PSE function parallels the function mission and scope statements. Feedbacks. control mechanisms, and interactions among PSE subfunctions that are required to continually evaluate and verify the correctness of the current technical baseline and the technical progress made by other physical system programmatic functions are detailed in subsequent discussions within this report section.

\subsubsection{Process Overview}

The overall PSE process flow is illustrated in Figure 3-2. This flow illustrates the major inputs to the systems engineering process from other programmatic functions, the interfaces between the PSE top-level functions. and the outputs provided to other programmatic functions.

The flow of information and processing shown in Figure 3-2 is that which is required to achieve the PSE mission objectives, assuming no errors or problems exist within the functional process. Information and process flow to handle the most likely error or problem conditions are shown in Section 3.4 of this report.

The numbers associated with each major subfunction of PSE correspond to the function numbers within The Analysis of the Program to Develop the Nuclear Waste Management System (Woods 1991a). They are shown in this figure, and throughout this report, to provide rapid indexing and cross-referencing to more detailed discussions and information.

There are two internal feedback processes within PSE that are important to the successful identification and management of system requirements and to the integration of the technical aspects of the physical system. System performance measures are identified and refined by the Identify system Performance Measures subfunction through interaction with Evaluate Integrated System and are then fed back into the Verify System Structure Definition subfunction to complete the system requirement verification process. This feedback 10op is executed each time that modifications or additions to performance measures are required. The Control System Description subfunction provides current system configuration information to the Define System Functional Structure subfunction for assessment and evaluation when program mission requirements change or when a request to review existing requirements is received from other programmatic functions.

\subsubsection{Significant Messages}

The role that PSE $p$ ?ays in the identification and management of system requirements, and the integration and control of system technical information and technical activities, is illustrated in the process shown in figure 3-2. 
Figure 3-1. Perform Systems Engineering Function Hierarchy.

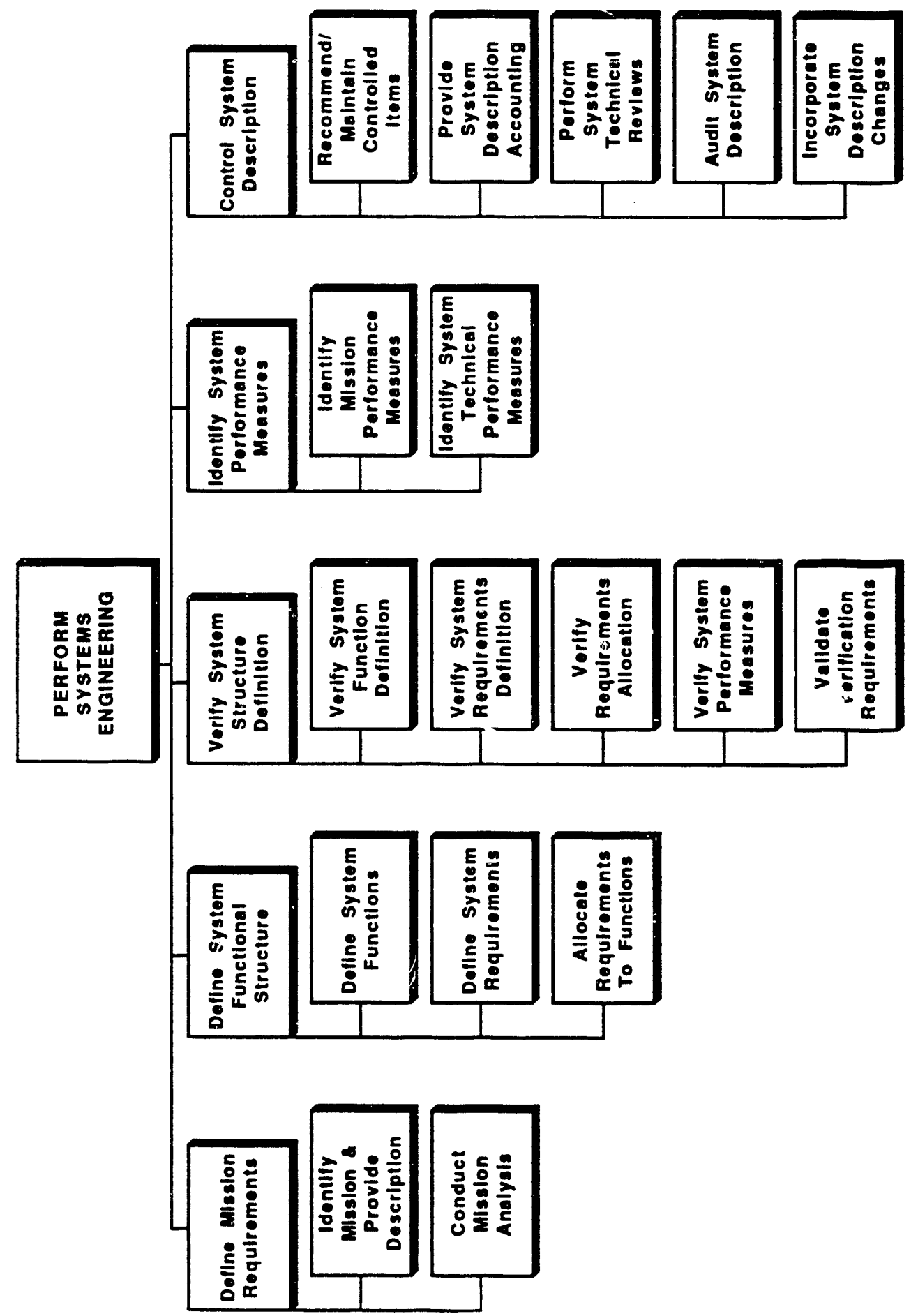




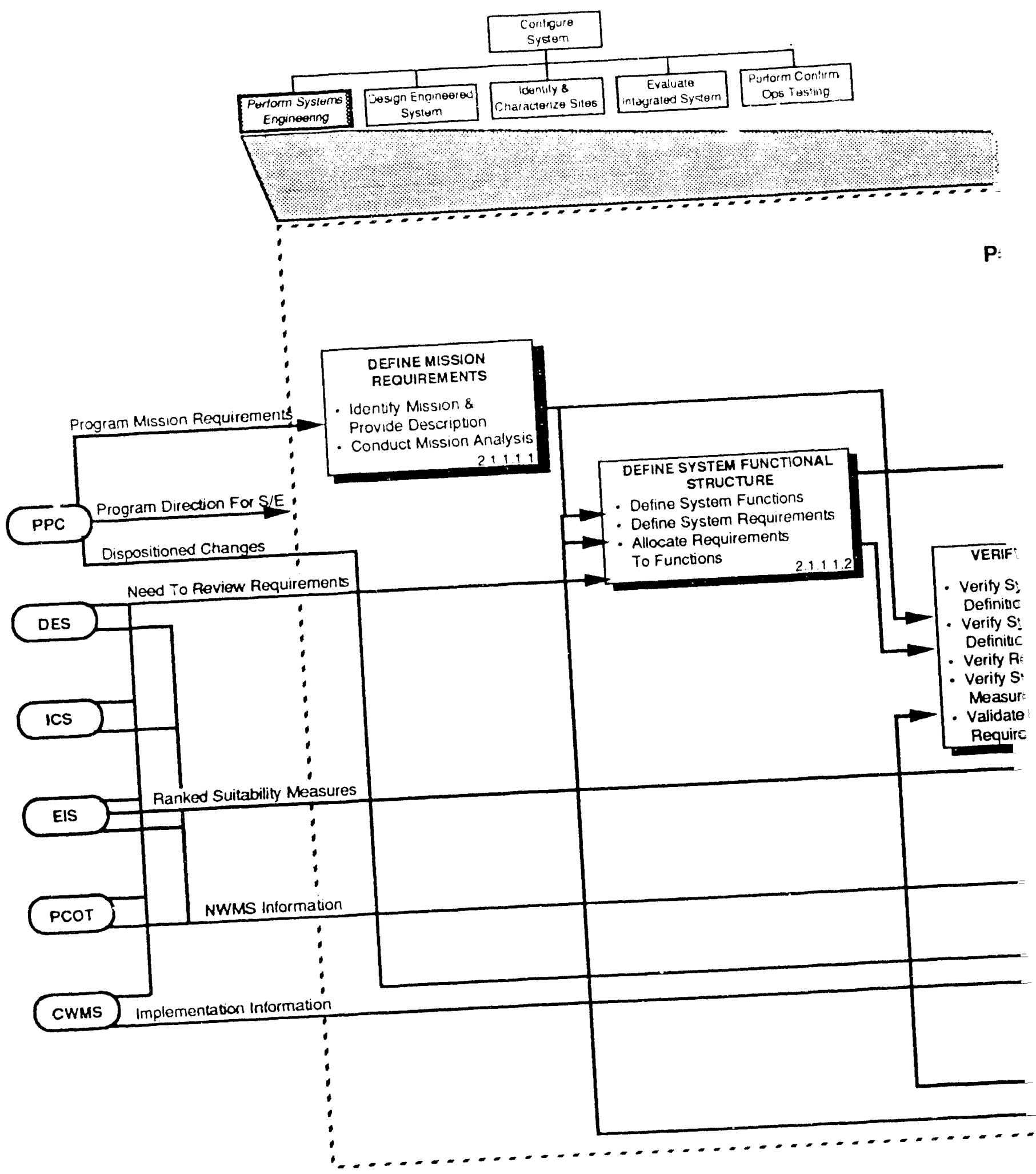




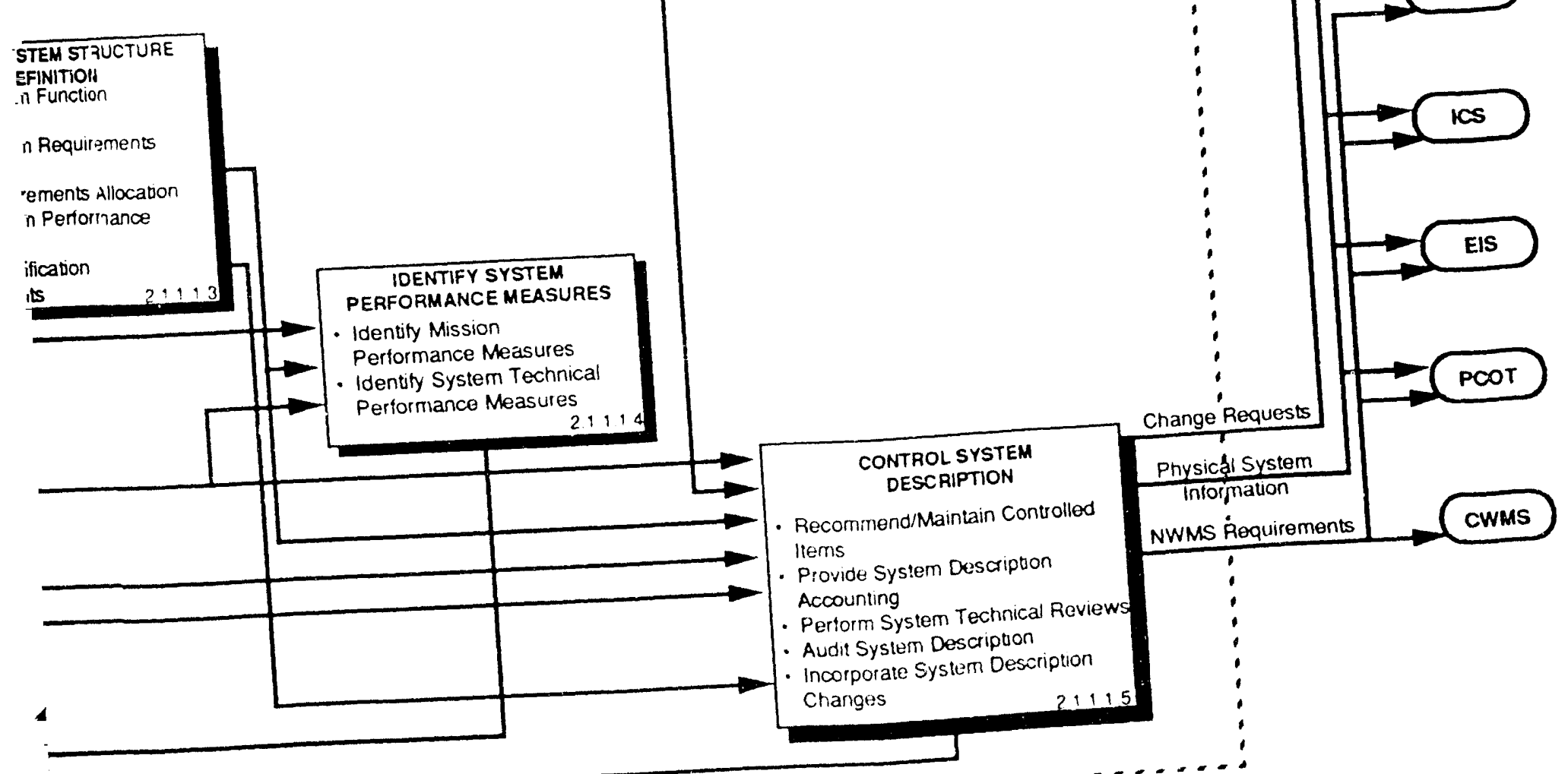


WHC -EP-0482

A11 PSE functions are performed within the context of program direction developed by PPC. Program Direction establishes the framework. strategies. and management policies and directives within which all programmatic functions operate. as well as the authorization to proceed with further activities.

The impetus for identification of system requirements is the input of program mission requirements from PPC. Progran mission requirements are translated into a system functional hierarchy and performance, interface, and verification requirements allocated to the system functions. System performance measures are identified, consistent with program mission requirements and program direction, and are refined with the Evaluate Integrated System (EIS) function to provide a complete set of performance measures and data requirements. Following a system technical review and authorization from $P P C$. system requirements are issued to the other physical system programmatic functions and form the functional requirements baseline for the system. This baseline is assessed and managed continuously in response to changes in program mission requirements or to change requests generated by PSE and evaluated by PPC.

PSE interfaces with each of the other Configure System programmatic functions, and the construct NWMS function, to receive information regarding the physical system and system items and the status of technical engineering or development activities. PSE enters received information and items into accountability, performs reviews, evaluations, and audits to ensure that system requirements and functional structure are complied with. and that technical efforts are proceeding in a consistent and integrated fashion toward implementation and operation of the system. Information maintained by the Control System Description subfunction is provided to the Define System Functional Structure subfunction for review and analys is when new mission requirements are received. Requests from other functions to review existing system requirements are received by PSE and transiated into systems Engineering Change Requests for action by PPC.

After review and evaluation of the input system technical information. PSE provides recommendations and a determination of system technical acceptability to PPC for authorization to proceed with further work. When authorization is received from PPC, along with Program Direction and new requirements, the system configuration or associated technical information is formally updated and distributed to the appropriate programmatic functions for implementation.

PSE provides centralized control, management, and distribution of system configuration and associated technical information to all programmatic functions requiring the data.

\subsection{PERFORM SYSTEMS ENGINEERING EXTERNAL INTERFACES}

PSE operates within the context of an integrated set of programmatic functions to accomplish its mission. support the other functions in accomplishment of their missions, and contribute to overall system and program success. Correct and timely implementation of interfaces between programmatic functions is required to ensure that each function is provided with the necessary information to perform its job, and that each function provides required information to the proper destination. Information is passed between functions in the forms of inputs, controls, and outputs, as defined in the introduction to this report. 
The major input, control, and output information interfaces between PSE and other programmatic functions are highlighted in the following sections.

\subsubsection{External Inputs}

Table 3-1 highlights the major external information inputs provided to PSE. Inputs are presented in terms of information name, a summary description of the input information. and the lowest level PSE subfunction making use of the information.

For this discussion, each information input is described only to the extent that it exists. without decomposition. within the functional descriptions for PSE. For example. NWMS Information is composed of many unique information units and these are processed by different subfunctions. In this discussion, the input NWMS Information is traced only as far as it remains undecomposed by a subfunction. Tracing of the component information units within PSE is discussed in detail in The Analysis of the Program to Develop the Nuclear Waste Management System (Woods 1991a).

Program mission requirements, applicable to the physical system, are provided to PSE by PPC. The inputs are processed by the subfunctions of Identify Mission and Provide Description and Conduct Mission Analysis, which are components of Define Mission Requirements, to provide a complete set of system mission requirements before performing a functional analysis and requirements allocation. They are the basis for the mission and functional analyses conducted by PSE and for the identification and allocation of requirements to establish the functional requirements baseline for the physical system. These input requirements will most likely include qualitative and quantitative statements of system mission performance and PSE will translate the qualitative statements into quantitative values. or ranges of values, and system performance acceptance criteria.

Program mission requirements will include those system requirements that are directed from outside of OCRWM, as well as externally directed functions. PSE responds to changes or modifications to these input requirements by updating existing mission and operations analyses to determine the impact on system mission requirements. Changes in system mission requirements are provided to other subfunctions for additional processing and development of functional requirements. The current set of program mission requirements is included within the physical system configuration information set. The initial processing and continuing review and evaluation of input program mission requirements against the evolving design, construction, test, and operation of the physical system is a vital aspect of the PSE role in requirements ma"agement and technical integration of the physical system.

Ranked suitability measures are inputs from the EIS function that contain a prioritized list of the measures required to evaluate the physical system to determine to what level or degree the system performance requirements are met. These inputs are assessed and transformed into physical system requirements by the Identify Mission Performance Measures component of the Identify System Performance Measures subfunction. 
Table 3-1. Perform Systems Engineering External Inputs. (sheet 1 of 2).

\begin{tabular}{|c|c|c|}
\hline Input Name & Input Definition & Destination Function \\
\hline $\begin{array}{l}\text { Program } \\
\text { mission } \\
\text { requirements }\end{array}$ & $\begin{array}{l}\text { Inputs received from Provide Program } \\
\text { Control program mission } \\
\text { requirements that have been } \\
\text { allocated to the physical } \\
\text { system. Includes qualitative and } \\
\text { quantitative statements the Systems } \\
\text { Engineering translates into system } \\
\text { functions, requirements, and } \\
\text { acceptance criteria. }\end{array}$ & \begin{tabular}{|} 
2.1.1.1.1.1 - Identify \\
Mission \& Provide \\
Description \\
2.1 .1.1.1.2 - Conduct \\
Mission Analysis
\end{tabular} \\
\hline $\begin{array}{l}\text { Implementation } \\
\text { information }\end{array}$ & $\begin{array}{l}\text { Inputs received from Construct NWMS } \\
\text { identifying the specific configuration of } \\
\text { the components of the physical } \\
\text { system that have been installed, } \\
\text { assembled, and integrated into an } \\
\text { operational configuration. }\end{array}$ & $\begin{array}{l}\text { 2.1.1.1.5.2 - Provide } \\
\text { System Description } \\
\text { Accounting }\end{array}$ \\
\hline $\begin{array}{l}\text { Dispositioned } \\
\text { changes }\end{array}$ & $\begin{array}{l}\text { Information input from Provide } \\
\text { Program Control identifying the } \\
\text { disposition of requested changes to } \\
\text { the physical system configuration or } \\
\text { supporting system description } \\
\text { information. Used by Systems } \\
\text { Engineering to initiate update to } \\
\text { system configuration or description } \\
\text { information. }\end{array}$ & $\begin{array}{l}\text { 2.1.1.1.5.2 - Provide } \\
\text { System Description } \\
\text { Accounting }\end{array}$ \\
\hline $\begin{array}{l}\text { Ranked } \\
\text { suitability } \\
\text { nieasures }\end{array}$ & $\begin{array}{l}\text { Ranked suitability measures for the } \\
\text { physical system provided by Evaluate } \\
\text { Integrated System. Systems } \\
\text { Engineering compares the information } \\
\text { with available prioritizing criteria and } \\
\text { develops data gathering requirements } \\
\text { for other programmatic functions. }\end{array}$ & $\begin{array}{l}2.1 .1 .1 .4 .1 \text { - Identify } \\
\text { Mission } \\
\text { Performance } \\
\text { Measures }\end{array}$ \\
\hline $\begin{array}{l}\text { Nuclear Waste } \\
\text { Management } \\
\text { System } \\
\text { (NWMS) } \\
\text { information }\end{array}$ & $\begin{array}{l}\text { Information provided to Systems } \\
\text { Engineering by other programmatic } \\
\text { functions defining the current physical } \\
\text { system configuration or state of } \\
\text { function processes and including } \\
\text { support information to be placed } \\
\text { under formal control. } \\
\text { Provided information is reviewed and } \\
\text { assessed to determine system } \\
\text { technical acceptability and readiness } \\
\text { to proceed with further development. }\end{array}$ & $\begin{array}{l}\text { 2.1.1.1.4.1 - Identify } \\
\text { Mission } \\
\text { Performance } \\
\text { Measures } \\
\text { 2.1.1.1.5.2 - Provide } \\
\text { System Description } \\
\text { Accounting }\end{array}$ \\
\hline
\end{tabular}


Table 3-1. Perform Systems Engineering External Inputs. (sheet 2 of 2 ).

\begin{tabular}{|l|l|c|}
\hline Need for review & Information provided to Systems & 2.1 .1 .1 .2 .2 .1 - Define \\
of NWMS & Engineering by other programmatic \\
requirements & Sunctions indicating a need to review & Performance \\
& the current configuration of physical & Requirements \\
& system requirements because current & 2.1.1.1.2.2.2 - Identify \\
& $\begin{array}{l}\text { requirements cannot be met, or a } \\
\text { more effective and efficient system } \\
\text { can be produced if requirements are } \\
\text { changed. }\end{array}$ & Requirements \\
\end{tabular}


The prioritization allows decisions to be made concerning the appropriate level of effort to be expended to evaluate the individual performance measures. PSE assesses the input suitability measures and associated rankings for consistency with prioritization information that is furnished as a part of program direction and also to determine if additional system performance or verification requirements must be identified to satisfy the suitability measures as input.

Need for review of NWMS requirements are inputs from each of the other Configure system programmatic functions expressing a request to review or change a current NWMS physical system requirement to allow other requirements to be met. to permit the programmatic function to proceed with its assigned task. or to provide for more effective or efficient system performance. This information is processed by the Define System Performance Requirements and Identify Interface Requirements subfunctions of PSE where the input request is evaluated and, if appropriate from a technical perspective, transformed into a change request for evaluation and processing by PPC. This information includes an identification of the requirements to be changed, suggested changes or alternatives to the existing requirement, and engineering or technical data to support the suggested requirement change.

Implementation information is input to PSE by the Construct NWMS programmatic function describing the configuration of the physical system as it is installed, assembled, and integrated into increasingly more capable elements of the operational configuration. The information provided by the Construct NWMS function is evaluated as part of system technical reviews to ensure that the final design of the physical system is being correctly implemented by the Construct function. The data are cataloged by the Provide System Description Accounting element of the Control System Description subfunction and are disseminated by the same element. The information provides a description, at any point in time, of the physical system as it is actually implemented. This becomes part of the physical system configuration information. controlled by PSE. and is furnished to other programmatic functions as requested.

Dispositioned changes are inputs provided by PPC containing the disposition status (i.e.. approved, disapproved, etc.) of all change requests that affect the physical system. Dispositioned changes inputs are processed by the Provide System Description Accounting subfunction for cataloging and routing. Approved changes to system configuration information are provided to the Define system Functional Structure subfunction for incorporation into functional analyses and requirements allocation before updating the system configuration information. No functional analysis or change incorporation occurs without receipt of Program Direction and/or new requirements from PPC. Approved changes to system description information (not part of the system configuration) are incorporated within the Control System Description subfunction. Disapproved changes are cataloged and the information distributed to the appropriate physical system programmatic function. For the most part. these dispositioned changes will be received in response to change requests that were generated by PSE, after review and evaluation by the PPC function. However, it is possible to receive a dispositioned change response to a change request that was generated by other programmatic functions. such as Ensure Regulatory Compliance (ERC).

NWMS information is the physical system information provided from the other Configure System programmatic functions for control and management as part of the system configuration or system description. This information is processed by the Identify Mission Performance Measures subfunction (for data 
requests from EIS) or by the Provide System Description Accounting subfunction (a) others) within PSE. This includes design specifications, site characterization information. interface control documentation. test and evaluation plans and procedures, test results, performance models, requests for data from EIS. and other information that will be subject of review and/or control by PSE in determining the technical acceptability or readiness of the physical system or its technical efforts and in ensuring that all technical efforts on the program are completely integrated and consistent with one another and with program objectives and priorities.

\subsubsection{External Controls}

Control information is provided to PSE by the PPC function in the form of program direction. The breakout and routing of program direction within the PSE function is shown in Table 3-2. Reference numbers are provided for each PSE subfunction that receives program direction to provide easy crossreference to The Analysis of the Program to Develop the Nuclear Waste Management System (Woods 1991a).

Program direction is received from PPC. This control information is pervasive across almost all PSE subfunctions, including all of the primary level subfunctions, and establishes the programmatic environment within which systems engineering activities are conducted. Program direction contains such information as the OCRWM Systems Engineering Management Plan (SEMP) (DOE 1991). which describes the processes, programmatic procedures, and management controls and interfaces that must be in place to perform the physical system programmatic functions (i.e.. Systems Engineering, Design. Site. Evaluation, and Test functions). Program direction includes the programmatic requirements for accomplishing specialty engineering and the integration of specialty engineering processes. The program direction control information is passed to the lowest appropriate PSE subfunction for implementation.

\subsubsection{External Outputs}

Table 3-3 depicts the external outputs produced by PSE and identifies the subfunctions that produces the output. Each node, or subfunction. within PSE that generates the output information is identified in the table. Reference numbers of the subfunctions are provided so that the reader may more easily relate the information of these process descriptions to the detailed contents of The Analysis of the Program to Develop the Nuclear Waste Management System (Woods 1991a).

For this discussion, each information output is described only to the extent that it exists. after composition by its component elements. within the functional descriptions for PSE. For example. Physical System Information is composed of many unique information units and within PSE the units are generated by different subfunctions. In this discussion. the output Physical System Information is traced only as far as it remains composed. Further detailed tracing and descriptions are provided within The Arialysis of the Program to Develop the Nuclear Waste Management System (Woods 1991a). 
Table 3-2. Perform Systems Engineering External Controls.

\begin{tabular}{|c|c|c|}
\hline Control Name & Control Definition & Destination Function \\
\hline $\begin{array}{l}\text { Program } \\
\text { direction for } \\
\text { Systems } \\
\text { Engineering }\end{array}$ & $\begin{array}{l}\text { Control information } \\
\text { provided to Systems } \\
\text { Engineering by } \\
\text { Provide Program } \\
\text { Control to include the } \\
\text { established strategies, } \\
\text { programmatic } \\
\text { management policies } \\
\text { and practices to be } \\
\text { implemented for } \\
\text { Systems Engineering, } \\
\text { and authorization to } \\
\text { proceed with } \\
\text { engineering } \\
\text { work. Used to set the } \\
\text { programmatic and } \\
\text { management context } \\
\text { within which systems } \\
\text { engineering functions } \\
\text { are performed. }\end{array}$ & 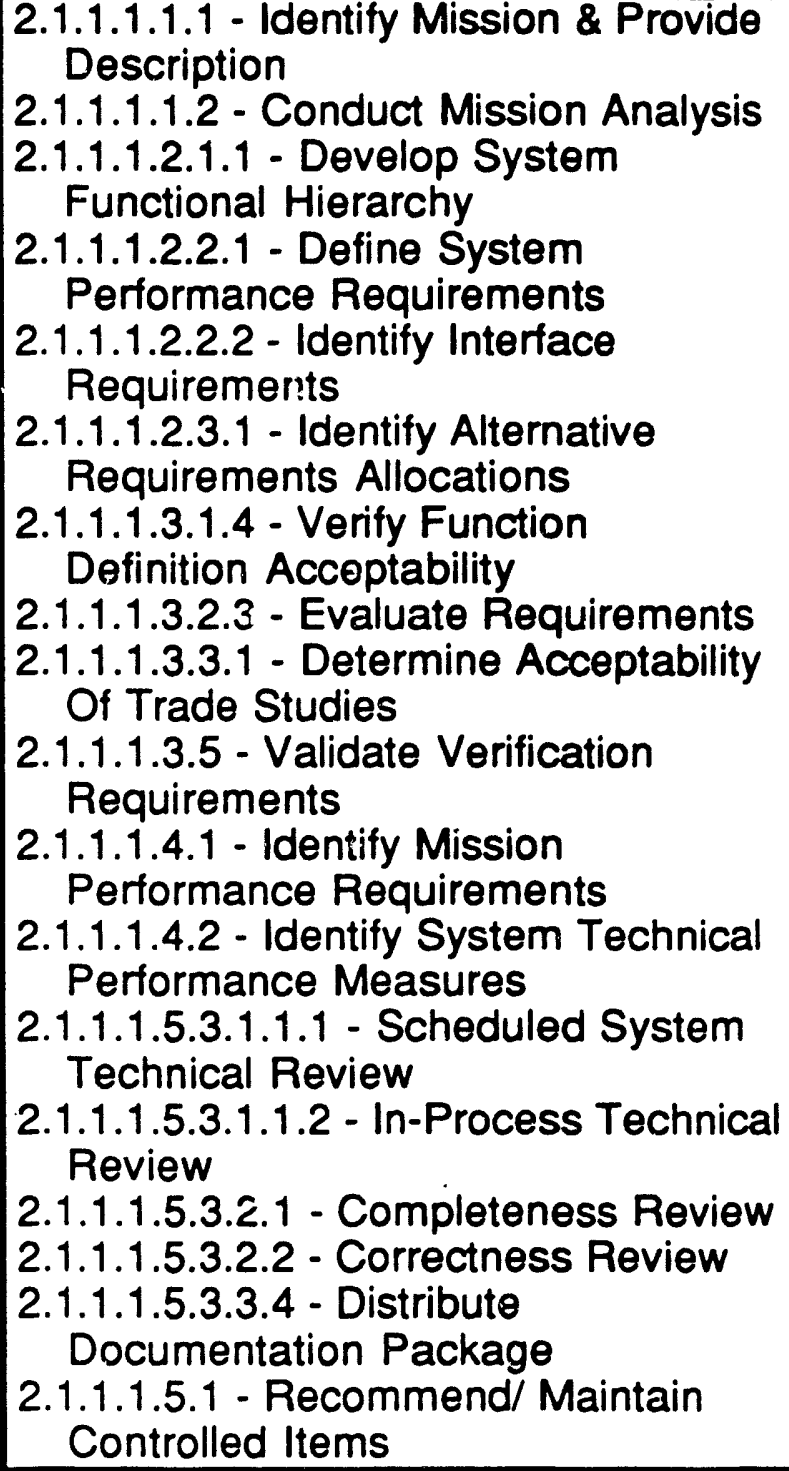 \\
\hline
\end{tabular}


Table 3-3. Perform Systems Engineering External Outputs.

\begin{tabular}{|c|c|c|}
\hline Output Name & Output Definition & Originating Function \\
\hline $\begin{array}{l}\text { Cnange } \\
\text { requests }\end{array}$ & $\begin{array}{l}\text { Information provided by Systems } \\
\text { Engineering to Provide Program } \\
\text { Control requesting a change to the } \\
\text { current physical system configuration } \\
\text { or to system description information } \\
\text { that is controlled by Systems } \\
\text { Engineering (eg, system performance } \\
\text { models). }\end{array}$ & $\begin{array}{l}\text { 2.1.1.1.2.2.1 - Define } \\
\text { System } \\
\text { Performance } \\
\text { Requirements } \\
\text { 2.1.1.1.2.2.2 - Identify } \\
\text { Interface } \\
\text { Requirements } \\
2.1 .1 .1 .5 .2 \text { - Provide } \\
\text { System Description } \\
\text { Accounting }\end{array}$ \\
\hline $\begin{array}{l}\text { Physical } \\
\text { system } \\
\text { information }\end{array}$ & $\begin{array}{l}\text { Information provided by Systems } \\
\text { Engineering to other programmatic } \\
\text { functions regarding the current } \\
\text { configuration of the physical system or } \\
\text { system description information } \\
\text { controlled by Systems } \\
\text { Engineering. This output is used by } \\
\text { Systems Engineering to provide all } \\
\text { necessary system configuration or } \\
\text { description information to appropriate } \\
\text { programmatic function recipients. }\end{array}$ & $\begin{array}{l}\text { 2.1.1.1.5.2 - Provide } \\
\text { System Description } \\
\text { Accounting } \\
2.1 .1 .1 .5 .3 \text { - Perform } \\
\text { System Technical } \\
\text { Reviews }\end{array}$ \\
\hline $\begin{array}{l}\text { NWMS } \\
\text { requirements }\end{array}$ & $\begin{array}{l}\text { Physical system requirements } \\
\text { provided by Systems Engineering to } \\
\text { other Configure System programmatic } \\
\text { functions and to the Construct NWMS } \\
\text { function. This information contains the } \\
\text { appropriate functional, performance, } \\
\text { interface, verification, and support } \\
\text { requirements to completely define and } \\
\text { implement the NWMS physical } \\
\text { system. }\end{array}$ & $\begin{array}{l}\text { 2.1.1.1.5.2 - Provide } \\
\text { System Description } \\
\text { Accounting }\end{array}$ \\
\hline
\end{tabular}


NWMS requirements are the set of performance, interface, and support requirements developed by PSE to describe the NWMS physical system completely. This set is compiled by the Provide System Description Accounting subfunction for cataloging and dissemination. These requirements form the basis for the design. development, and operation of the NWMS physical system and for the assessment, evaluation, and integration of all technical aspects of the system. The set includes design. siting. evaluation. test. and implementation requirements to be met by other programmatic functions. The set is composed of many components developed within PSE, including the approved system description, the verified system performance measures, and the approved system requirements. The set is subject to system technical reviews for approval before dissemination.

Physical system information is the main output stream for all physical system configuration and system description information provided to other programmatic functions by PSE. It is compiled by Provide System Description Accounting and Perform System Technical Review subfunctions for dissemination and distribution. Physical system information is provided by PSE to any other programmatic function desiring technical information about the NWMS physical system. It includes all physical system information that is placed under control and management by PSE. It includes system configuration information such as specifications, interface control documents, requirements documentation. performance information. actual physical system construction/configuration data, etc. Other technical items that are controlled include executable code and performance data of system models or simulators. It also includes data gathered by one programmatic function (e.g.. Test) to be analyzed or evaluated by other functions (e.g.. Design. Evaluate Integrated System) for performance confirmation or assessment.

Systems engineering change requests are requests for changes to system configuration or system description information that is currently under contrcl and management by PSE. The set is compiled by Provide system Description Accounting for output to PPC for evaluation and decision upon action to be taken. The set consists of two types of change requests. The system configuration change request is generated by Define System Performance Requirements or Identify Interface Requirements subfunction for requested changes to the physical system configuration. Changes may be requested by PSE or by other Configure system functions. Technical data change requests are generated by Provide System Description Accounting subfunction for requested changes to physical system information that is controlled by PSE but is not a part of the system configuration.

\subsection{PERFORM SYSTEMS ENGINEERING PROCESS EXECUTION DETAILS}

The previous sections of the PSE process description have addressed the overall function mission. scope, processes flow and external interfaces. This section of the report provides a more detailed discussion of the primary PSE subfunctions, iriternal interfaces and information flows. and feedback 10ops and processes that are executed within the function.

Feedback loops are covered for success-oriented paths through the process and for those cases in which reexecution of subfunctions is required to complete the process.

The following are the major messages to be conveyed in this section: (1) the primary PSE subfunctions are directed specifically at satisfying the function mission. (2) the mechanics of the process sequences and interrelationships are well defined and integrated with the processes of other 
programmatic functions and. (3) PSE fulfills a key role in the identification and management of system requirements and in the technical integration of the physical system and the technical engineering activities for the system. The technical integration aspect of PSE is vital to the success of the physical system and of the overait program.

\subsubsection{Define Mission Requirements}

The Define Mission Requirements Process (2.1.1.1.1) is illustrated in Figure 3-3.

3.3.1.1 Mission/Objective. The mission/objective of the Define Mission Requirements process is as follows:

- Determine system functions that must be performed.

- Translate program mission requirements into system requirements and acceptance criteria.

- Translate qualitative physical system requirements and constraints into quantitative values and acceptance criteria.

- Identify critical external system functional interfaces.

- Perform a complete set of mission and operations analyses to identify quantitative mission requirements.

3.3.1.2 Process Flow. The program mission requirements input from PPC serve as the initiator for this process. The process is restarted each time that program mission requirements change to ensure that systems Engineering analyses. evaluations, and requirements definition and allocation activities are conducted using the latest available program requirements information.

To accomplish its missicn, the process is composed of two primary subfunctions. The Identify Mission and Provide Description subfunction describes the system mission and describes the overall system in qualitative terms, based on input program mission requirements. It includes general functions to be performed by the physical system and their scope required to meet system mission requirements. The Conduct Mission Analys is subfunction translates qualitative system descriptive data and directed quantitative requirements or constraints into a complete set of quantitative physical system mission requirements to be used as inputs to functional analyses and requirements allocations. This subfunction performs both operations and mission analyses to create the complete and correct set :f system requirements.

Qualitative, or nondirectly measurable, requirements or constraints levied upon the physical system are categorized, described, and then translated into quantitative performance values. or acceptable ranges of values, with associated acceptance criteria.

Ouantitative directed requirements, including system performance and external interface requirements, are transiated into system mission requirements and combined with the translated qualitative requirements to comoose the conrinete set of system mission requirements. 
Figure 3-3, Process Overview - Define Mission Paguirements.

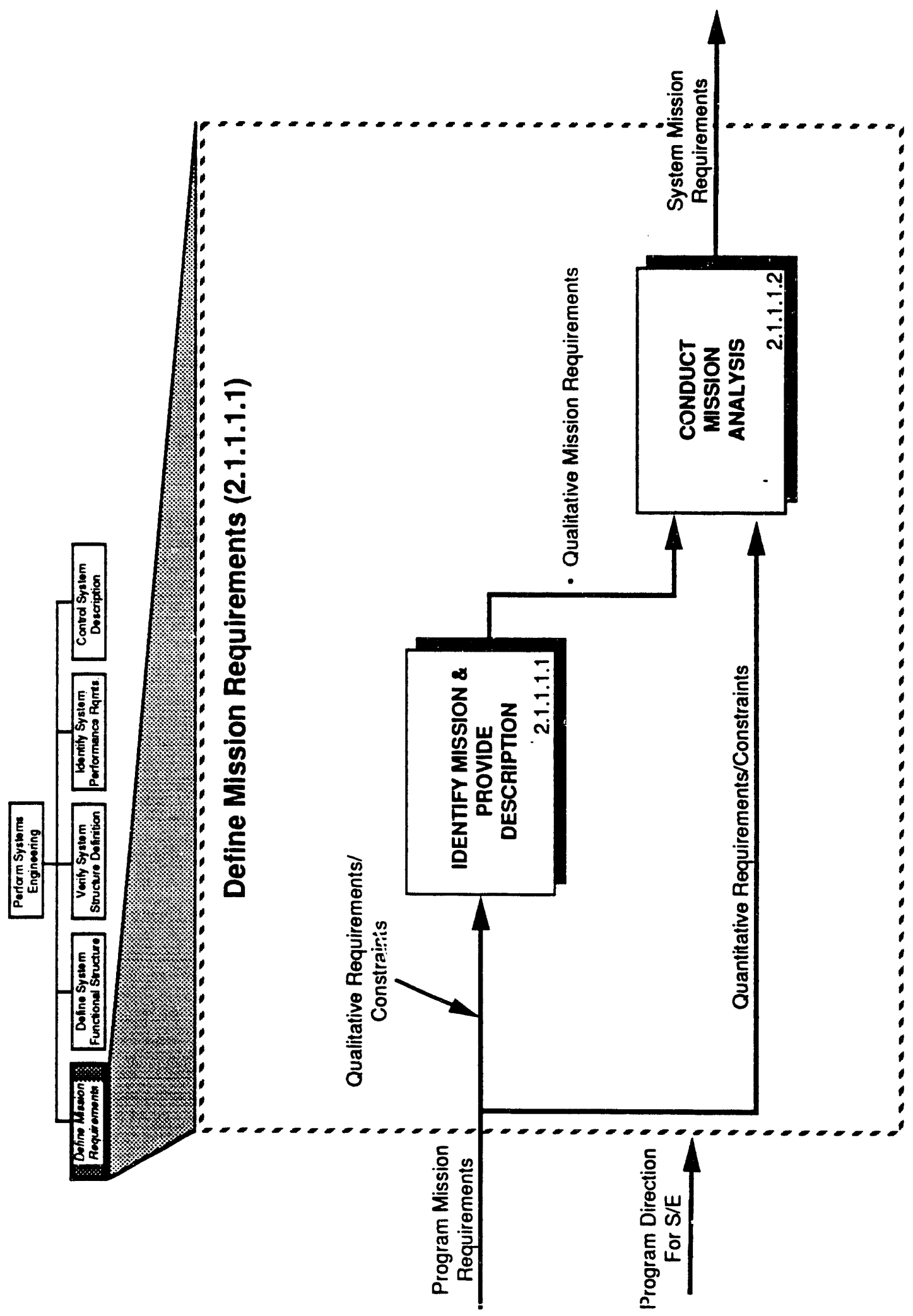


3.3.1.3 Outputs. The system mission requirements output from this process serve as the primary inputs to the processes of functional decomposition and analysis and requirements definition and allocation. These requirements will also form the initial component of the physical system confiçuration.

3.3.1.4 Significant Considerations. There are several aspects of the significant considerations process that should be considered within the overall context of contribution to the success of the program. These are as follows:

- This process forms the initial technical activity for the program and, through analyses, interpretations, and translations of program mission requirements, ensures that all physical system technical activities are driven by, and directly traceable to, the program and system missions and system requirements.

- This process combines with the processes of PPC to form clear and concise definitions of the overall program and the physical system that supports it.

- The process is not completed until each program mission requirement or constraint. whether qualitative or quantitative. has been translated into a system mission requirement and associated acceptance criteria.

- All directed system functions must be accounted for in the system mission requirements.

- System mission requirements must address the requirements for all interfaces external to the physical system.

- The process is reinitiated each time that program mission requirements change. The output is a complete updated set of system mission requirements. This reexecution and reevaluation of program mission requirements against existing system configuration ensures that system development will always remain requirements driven and will be responsive to mission goals and objectives.

\subsubsection{Define System Functional Structure}

The Define System Functional Structure (2.1.1.1.2) process is illustrated in Figure 3-4.

3.3.2.1 Mission/Objective. The mission/objective of the Define System Functional Structure process is to accomplish these three things:

(1) Translate physical system mission requirements and directed functional configuration constraints into a functional description of the physical system, to include functional hierarchy, functional interfaces, functional flows, and functional time dependencies: (2) Allocate system requirements to the identified system functions; ensure that all system requirements are completely allocated and that each identified function has at least one associated requirement and acceptance criterion; and (3) Evaluate new system information and requirements throughout the system development cycle to ensure consistency with current functional structure and identify required changes to the structure. 


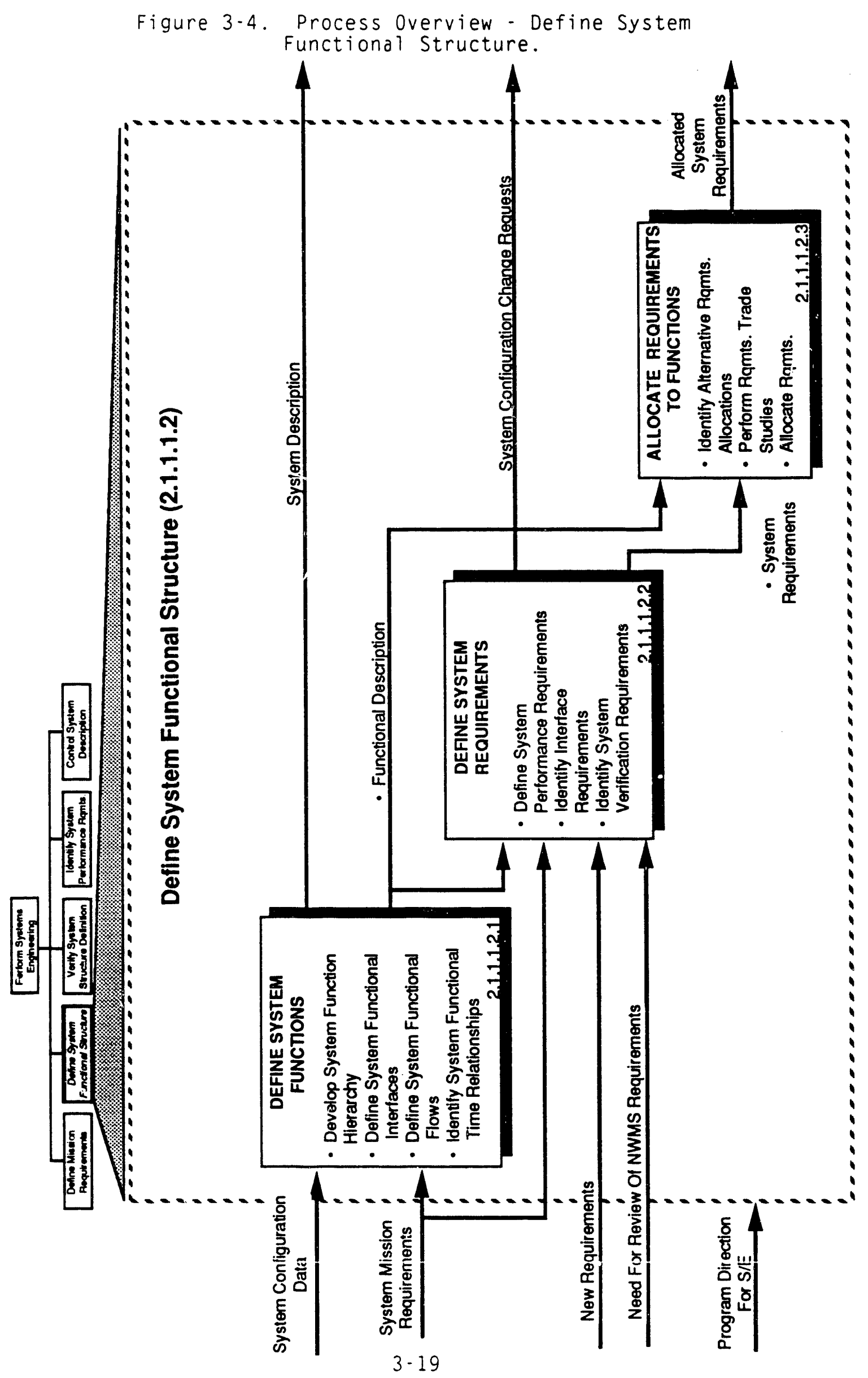


3.3.2.2 Process Flow. System mission requirements from the Define Mission Requirements process serve as the initial trigger for this process. The process is restarted each time that system mission requirements change, a need for a new requirement is identified, or a request to review existing requirements is received.

To accomplish its mission, the process is composed of the following three primary subfunctions: (1) Define System Functions. This subfunction operates on the input system mission requirements to produce an initial functional description of the system, including functional hierarchy. interfaces, flows, and time relationships. Subsequent operation is triggered by a change in system mission requirements or a request for review of existing requirements. System configuration data are provided to the function for comparison with input requestey changes or new mission requirements and to initiate the process of updating controlled corifiguration information: (2) Define System Requirements. This subfunction operates on input system mission requireinents and system functional description to define physical system requirements including performance, interface, and sysiem verification requirements. Subseouent subfunction operation is triggered by a change in system mission requirements or a request to review existing requirements: and (3) Allocate Requirements To Functions. This subfunction operates on the input provided by the previous two subfunctions to allocate all physical system requirements and accestance criteria to system functions. Each time that either of the two inputs changes, this subfunction is triggered again to perform its allocation.

3.3.2.3 Outputs. The following three outputs are produced by this process: (i) Allocated System Requirements. This is the complete set of physical system performance, interface, and verification requirements allocated to system functions: (2) System Description. This is the current functional description of the NWMS physical system; and (3) System Configuration Change Requests. These are requested changes to the current system configuration provided to Provide Program Control. The changes are generated by internal Systems Engineering processing or in response to a request to review existing requirements received from other Configure system programmatic functions.

3.3.2.4 Significant Considerations. Important aspects of this process within the context of overall program success are as follows:

- This process ensures that all physical system mission requirements are transformed into performance, interface, or verification requirements and are appropriately decomposed and allocated to elements of the system functional hierarchy.

- The process is not initiated until system mission requirements are received from Define Mission Requirements.

- The process is not completed until all system requirements have been allocated to system functions. Each requirement must be allocated to a function, or set of functions, and each system function must have allocated to it at least one system requirement.

- Each system requirement must have an associated acceptance criteria and verification requirement.

- The process is reinitiated each time that system mission requirements change, a need for a new requirement is identified. 
or a request to review existing physical system requirements is received. The reexecution of this process ensures that the physical system configuration is responsive to the current set of system mission requirements and that each physical system programinatic function operates on the same set of requirements as a) other functions.

\subsubsection{Verify System Structure}

The Verify System Structure process (2.1.1.1.3) is illustrated in Figure $3-5$.

3.3.3.1 Mission/Objective. The mission/objective of the Verify System Structure process is to assure that the functional analyses, allocation of requirements, and definition of acceptance criteria and system verification requirements are correct and complete.

3.3.3.2 Process Flow. System mission requirements, system description, allocated system requirements, and system performance measures are the primary inputs to the verification and validation activities performed within this process.

To accomplish its mission. the process is composed of the following five major subfunctions:

- Verify System Function Definition. This subfunction performs analyses, reviews, and evaluations to ensure that the functional description for the physical system is correct and complete. The subfunction is triggered by the initial presence of system mission requirements, system description, and allocated system requirements inputs, and is reinitiated each time that any of the inputs changes.

- Verify System Requirements Definition. This subfunction performs analyses, reviews, and evaluations to ensure that the set of physical system requirements is correct and complete. The subfunction is triggered when the verified system functions and allocated requirements inputs are both present. The subfunction is subsequently reexecuted when either of inose two inputs changes or validated system verification requirements are received.

- Verify Requirements Allocation. This subfunction verifies that the allocation of system requirements, including performance. interface, and verification requirements, to system functions is correct and complete. The subfunction is triggered when the verified system requirements input is present and is executed again whenever that input changes.

- Verify System Performance Measures. This subfunction verifies. through independent review and analysis. that sound techinical performance measures have been established for those physical system performance and operational parameters upon which the success of the mission depends. The subfunction is initially executed when the verified system requirements and system performance measures inputs are available and is reexecuted whenever with input changes. 
WHC-EP-0482

This page intentionally left blank. 


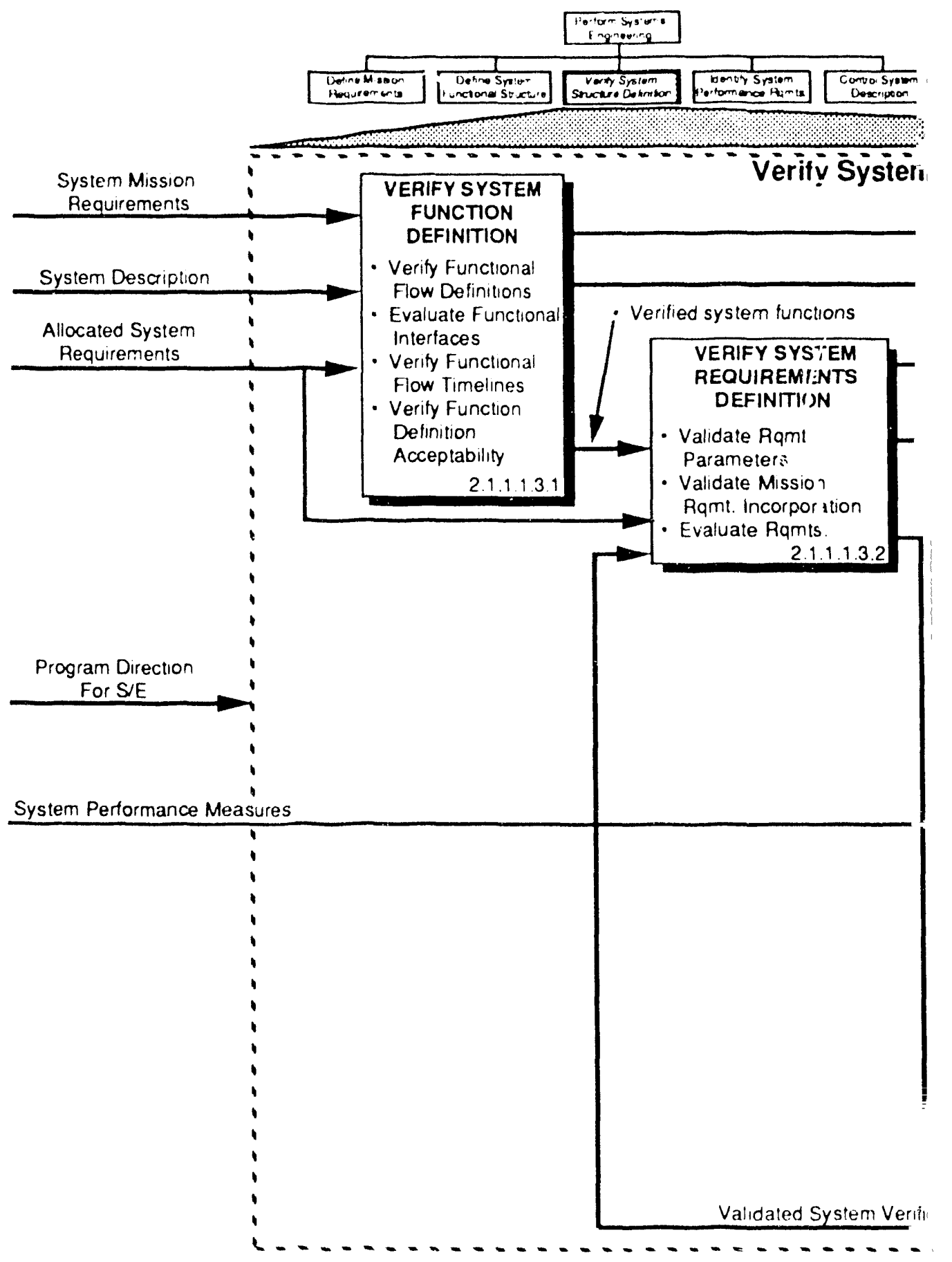


Figare 35 . Process overview Verify system structure Definition.

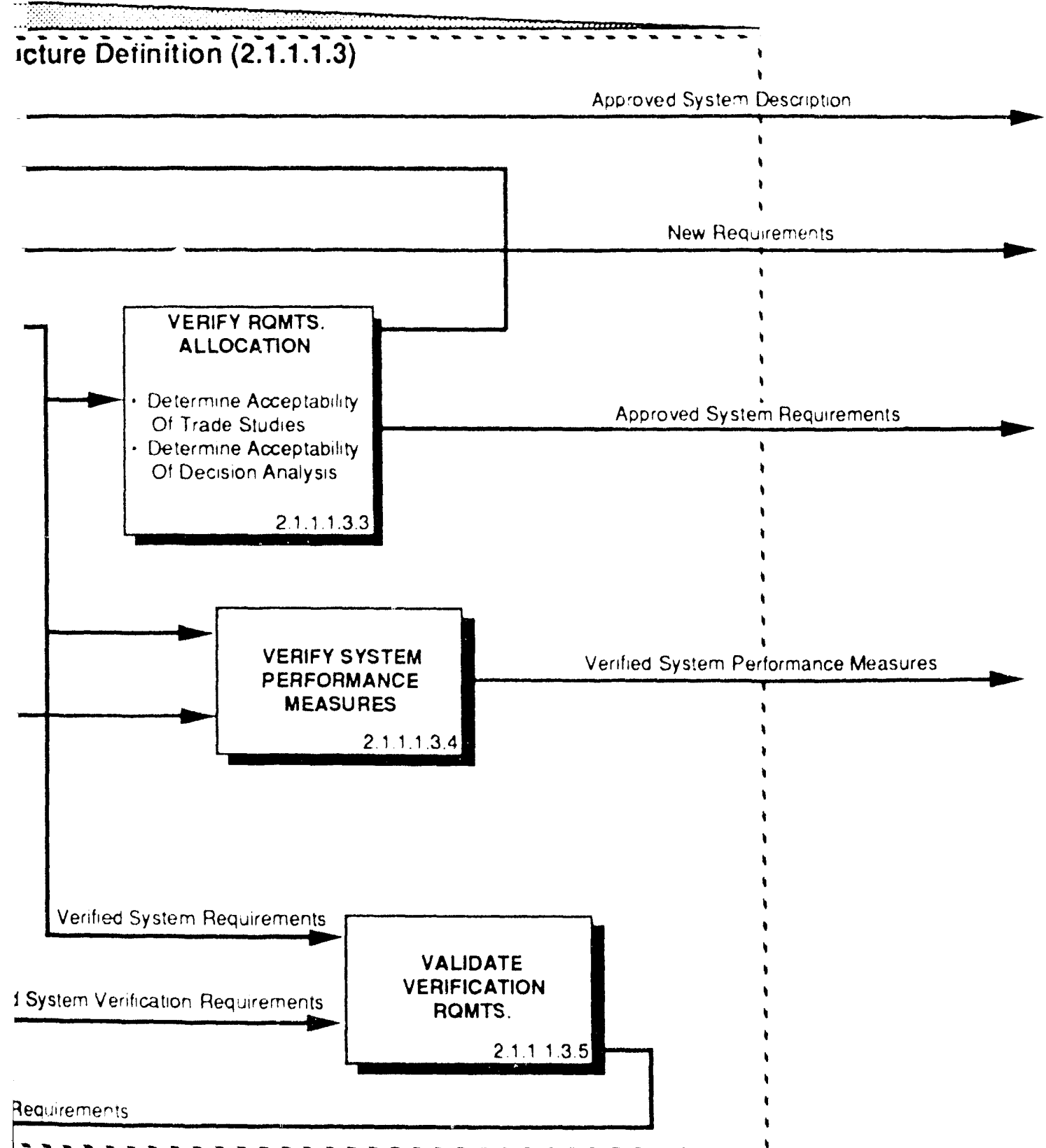


- Validate Verification Requirements. This subfunction validates the system verification requirements to ensure that a complete and correct set of requirements has been identified and that these requirements are consistent with the system functional description and allocated system requirements. The subfunction is initially triggered when the verified system requirements and verified system verification requirements are input and is subsequently reexecuted whenever either of the inputs changes.

3.3.3.3 Outputs. This process outputs an approved system description. approved system requirements, and verified system performance measures to other PSE functions for accountability and for dissemination to the other Configure system programmatic functions for implementation as the physical system function requirements baseline. This process also outputs a need for new requirements if the current set of physical system requirements is incomplete or cannot be completely allocated to system functions. This output is provided to the Define system Functional Structure process for evaluation and analysis.

3.3.3.4 Significant Considerations. The following aspects of this process are important for consideration and evaluation of their coritribution to success of the program:

- This process cannot be initiated until the system mission requirements, sysiem description, and allocated system requirements inputs are all available.

- This process cannot be completed until the system performance measures input is made available.

- This process cannot be completed until any need for a new requirements has been addressed and resolved by the Define System Functional structure process.

- The outputs of this process provide the basis for the physical system functional requirements baseline that is critical to the further development of the system.

- This process is reinitiated each time that any one of the inputs changes.

\subsubsection{Identify System Performance Measures}

The Identify System Performance Measures (2.1.1.1.4) process is illustrated in Figure 3-6.

3.3.4.1 Mission/Objective. The three mission/objectives of the Identify System Performance Measures Process are as follows:

- Identify critical mission and system performance measures that may directly affect the ability of the physical system to meet mission and system level requirements.

- Ensure that system evaluation requirements are consistent with directed inputs and that requisite data needs are translated into requirements for physical system programmatic functions. 
Figure 3-6. Process Overview - Identify System Performance Measures.

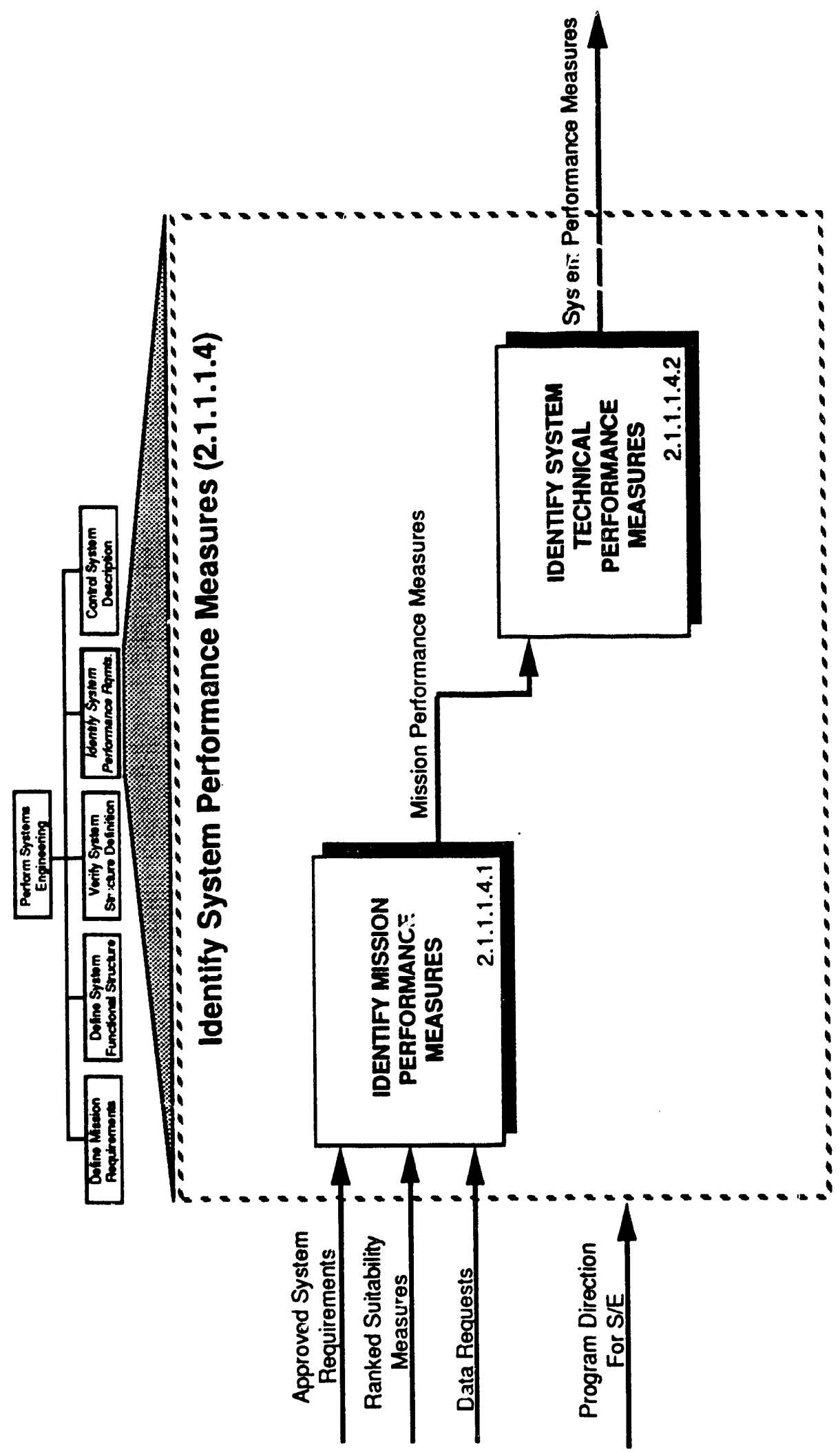


WHC-EP- 0482

- Derive system verification requirements for each performance requirement.

3.3.4.2 Process Flow. Approved system requirements and ranked suitability measures serve as the initial inputs to this process. The process also executes when either of these two inputs is changed or when data requests are received from EIS.

To accomplish its mission, this process is composed of two primary subfunctions. The Identify Mission Performance Measures subfuncticn operates on input approved system requirements and ranked suitability measures to develop and confirm specific mission performance measures and to compare ranked system suitability measures with prioritization criteria provided by PPC. The subfunction also processes data requests from EIS to derive additional physical system requirements for the appropriate programmatic function to implement.

The Identify System Technical Performance Measures subfunction operates on the mission performance measures input to develop and confirm specific system technical performance measures. The function operates when mission performance measures are initially available and is reexecuted each time that the input changes state. The output of this product is system performance measures that are input to the Verify System Structure Definition process for verification and validation.

3.3.4.3 Outputs. System performance measures are output from this process and are forwarded to the Verify system Structure Definition process for verification and for incorporation into a complete and correct set of physical system allocated requirements.

3.3.4.4 Significant Considerations. The following are four important items to consider within the context of this process execution:

- The process is not completed until the ranked suitability measures are available from EIS and can be compared with control prioritization data from PPC.

- The process is reinitiated whenever data requests are received or when the inputs of approved system requirements or ranked suitability measures change.

- Output system performance measures are furnished to the Verify Structure Definition process for incorporation into the complete set of physical system requirements.

- This process interfaces with the EIS function to ensure that critical system evaluation and performance criteria are identified and that the responsibility for performing data gathering and performance measurements and evaluation is clearly identified.

\subsubsection{Control System Mescription}

The Control System Description (2.1.1.1.5) process is illustrated in Figure $3-7$. 
WHC-EP-0482

This page intentionally left blank. 


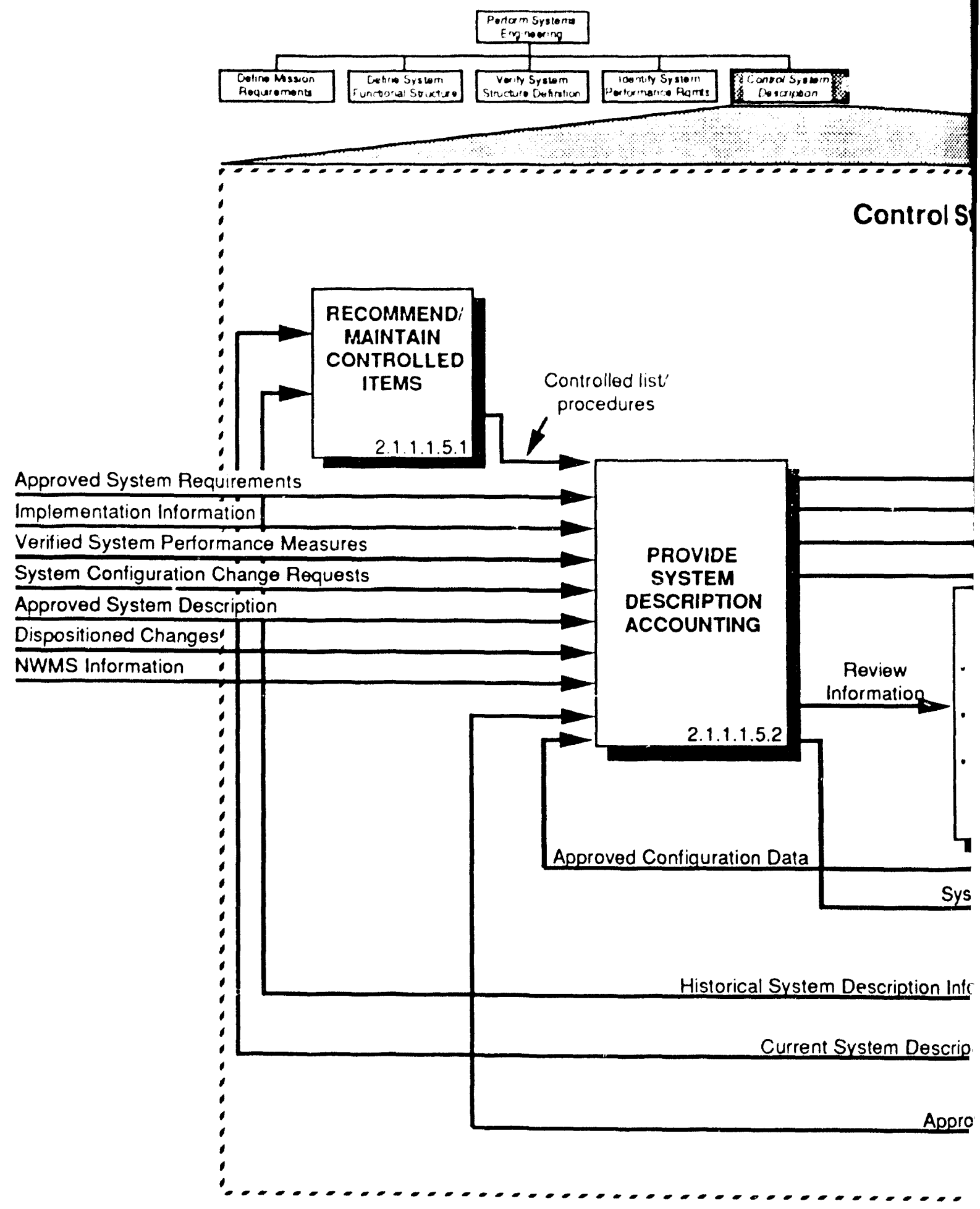




\section{ERFORM SYSTEM} :CHNICAL REVIEWS

epare For Sustem rchnical Reviews nouct System Technical zviews

cument System chnical Reviews

\subsection{3} I Data
Review Packages

Review Documentation \& Recommendations

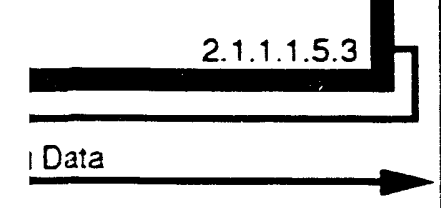

\section{AUDIT SYSTEM} DESCRIPTION

2.1 .1 .1 .5 .4

aticn

Information

System Description Change Status 
3.3.5.1 Mission/Objective. The following are the four mission/objectives of the Control System Description process:

- Identify the information to be placed under control by Systems Engineering and the internal function processes for control and dissemination of the information.

- Maintain current and historical descriptions of the physical system configuration and disseminate updated information in accordance with approved procedures.

- Provide an accountability and control system that ensures a complete and correct set of information is maintained for the system configuration.

- Perform technical reviews of physical system status, development products, and technical activities to determine technical acceptability. readiness to proceed, and complete integration of all technical products and efforts for the physical system.

3.3.5.2 Process Flow. This process operates upon a wide variety of input information to accomplish its mission.

Approved system description, verified system performance measures, and approved system requirements are combined for review, evaluation, and distribution as the physical system functional requirements baseiine. This activity is performed each time that any of the inputs change.

System configuration change requests are entered into accountability and forwarded to PPC for evaluation and processing.

- NWMS information is received from other Configure System programmatic functions. is entered into accountability. and then processed in accordance with the type of information received.

- Dispositioned changes are received from PPC. are entered into accountability and matched with generated change requests. where possible, and forwarded to the appropriate Systems Engineering function for processing.

- Implementation information is received from the Construct NWMS function. is entered into accountability as a part of the system configuration. and is forwarded to appropriate programmatic functions for evaluation or analysis.

- To accomplish its mission, the process is composed of the following five primary subfunctions:

Recommend and Maintain Controlled Items. This subfunction operates on input program direction to construct an initial list of information to be maintained as a part of the physical system configuration or as a part of additional technical items for control. This list, and a set of internal systems Engineering control and information distribution procedures. is provided to Provide System Description Accounting for implementation. This subfunction also operates to maintain the current and 


\section{nistorical system configuration description for retrieval and referral. \\ Provide System Description Accounting. This subfunction operates on input data to compile. enter into accountability, and distribute the formally controlled set of information that makes up the physical system configuration or additional technical items for control. The subfunction interfaces with Perform System Technical Reviews to provide the proper documentation or information for review and to receive approval to distribute updated technical documentation after the system technical review is completed. \\ - Perform System Technical Reviews. This subfunction performs reviews and evaluations of physical system technical documentation, and information regarding the status and progress of system technical efforts to determine the technical acceptability of the system or its technical efforts and establish the readiness of the physical system to proceed with further technical efforts. This subfunction performs the service of integrating the physical system technical information as well as integrating the technical system development and engineering efforts. \\ - Audit System Description. This subfunction operates on input system configuration information to establish a technical audit procedure and perform audits on all input information. Audits are performed to ensure that the system configuration is in functional and physical conformance with established requirements and that all information and correct and complete in accordance with the latest compliance requirements. \\ - Incorporate System Description Changes. This subfunction operates on approved changes to the system configuration or additional controlled technical items to incorporate updates and modifications prior to distribution of the information to the appropriate users.}

3.3.5.3 Outputs. The outputs produced by this process include Physical System Requirements. NWMS Requirements, and Systems Engineering Change Requests.

Physical System Information is the primary output source for Systems Engineering to convey the current system configuration information and additional controlled technical information to other NWMS programmatic processes.

NWMS Requirements outputs are the physical system performance. interface, and verification requirements. that have been allocated to each of the Configure System programmatic functional areas, as well as the construct NWMS function.

Systems Engineering Change Requests are requested changes to system configuration or other controlled technical information. 
3.3.5.4 Significant Considerations. The following are three aspects of this process that warrant consideration within the context of overall program success and function execution:

- This process is never actually completed. It is performed throughout the life cycle of the physical system and is tasked with tho responsibility for ensuring that the current system configuration meets allocated system requirements, and that the physical system technical activities are completely integrated and consistent with each other.

- The Perform System Technical Review subfunction is tasked with performing system technical reviews at major milestone points (e.g.: functional requirements baseline. preliminary design baseline. product baseline, etc.). In addition, the function will establish the technical adequacy of any information packages consolidated to support licensing. site identifilation and nomination, and environmental impact statements. It will perform reviews of multiple system technical development efforts. as needed to ensure that the system technical efforts are integrated and consistent with each other.

- This process ensures that there is a central focal point within the program for the control. integration. and distribution of system technical information and that ali technical development efforts are responsive to. and in agreement with. physical system functional descriptions and requirements allocations.

\subsection{INTERNAL FEEDBACKS}

The primary feedback loops for the PSE function are iliustrated in Figure 3-8. This process description feedback loop discussion addresses only the top two subfunction levels of breakout. This provides an overview of the feedback loops that are most important to the successful execution of PSE functions and to the reexecution of subfunctions to resolve open issues or problems in identification and management of system requirements or technical system integration. Discussions of feedback loops at the lowest functional breakout level are contained within The Analysis of the Program to Develop the Nuclear Waste Management System (Woods 199la).

The six feedback loops are as follows:

- Verify System Structure Definition Functions - Define System Requirements (Loop 1) - A feedback mechanism by which the structure verification function ensures that the system functional structure definition and requirements are complete and correct and. if not. notifies the requirements definition function of the need for additional requirements. new al location of requirements. or addition of system functions. This feedback loop occurs only if the system functional structure definition or requirements definition/allocation is incomplete or incorrect. 
Figure 3-8. Perform Systems Engineering Major Feedback Loops.

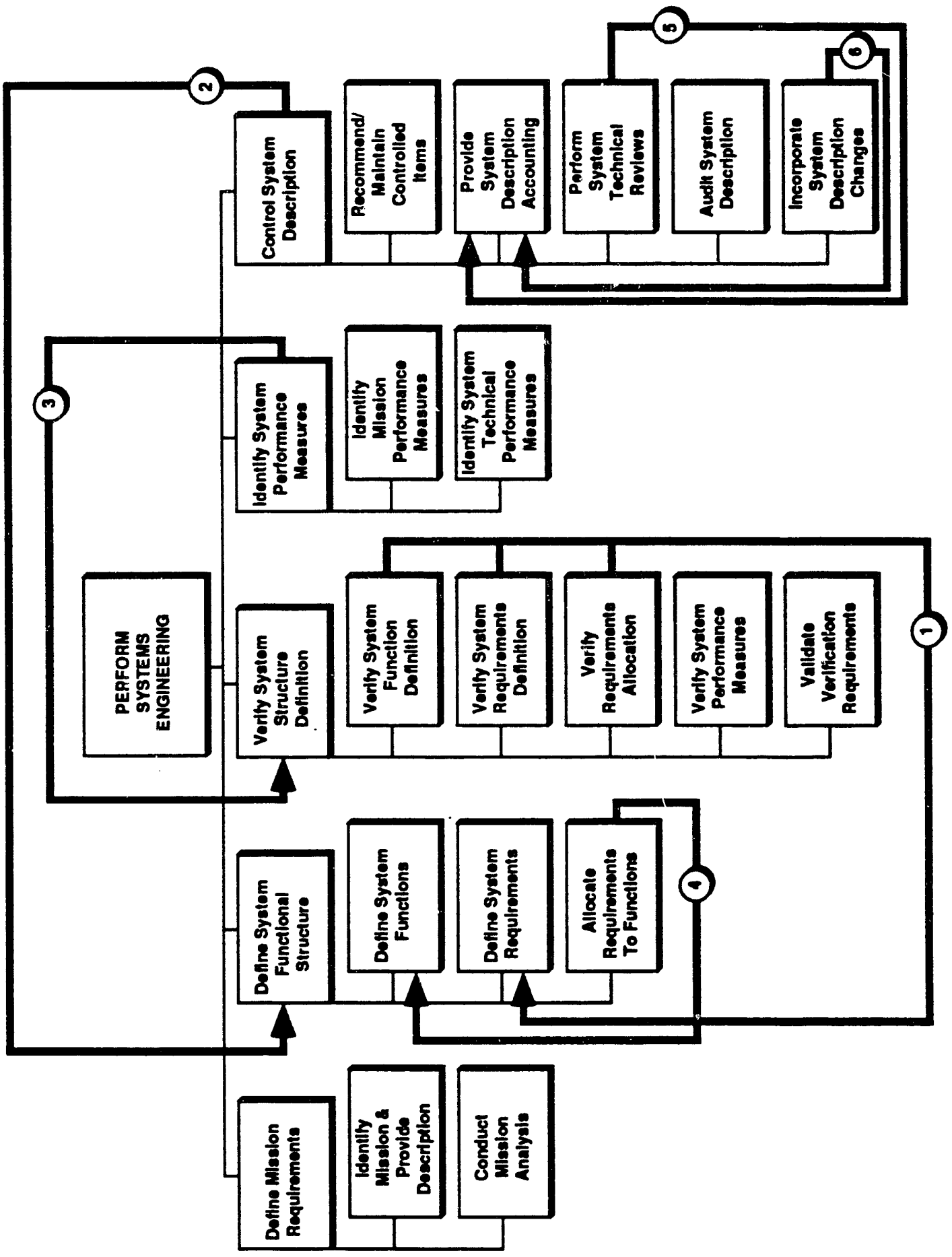


WHC - EP- 0482

- Control System Description - Define System Functional Structure (Loop 2) - The feedback loop by which current system configuration information is provided to the functional structure definition process to evaluate changes in system mission requirements or requested reviews or changes to NWMS physical system requirements. and to begin the process of incorporating approved changes into the system functional description, requirements allocation, or performance measures. This feedback loop occurs as a standard part of Systems Engineering processing.

- Identify System Performance Measures - Verify System Structure Definition (Loop 3) - The feedback loop by which system technical performance measures and verification requirements are verified to be consistent with system functional structure definition and requirements allocation. This feedback loop occurs as a standard part of Systems Engineering processing.

- Allocate Requirements To Functions - Define System Functions (Loop 4) - The major Systems Engineering feedback loop to ensure that the complete set of system requirements is appropriately allocated to system functions. This identifies the need for a new system function to which requirements must be allocated. This feedback loop occurs only if new system functions are required to complete the allocation of performance, interface, or verification requirements.

- Perform System Technical Reviews - Provide System Description Accounting (Loop 5) - The primary feedback mechanism by which the approval for update and release of system configuration or system description information is relayed to the function responsible for information dissemination. This feedback loop occurs as a standard part of Systems Engineering processing.

- Incorporate System Description Changes - Provide System Description Accounting (Loop 6) - The feedback mechanism by which updated system configuration or system description information is provided for dissemiriation. This feedback loop occurs as a standard part of Systems Engineering processing. 
WHC-EP- 0482

This page intentionally left blank. 
WHC-EP-0482

\subsection{DESIGN ENGINEERED SYSTEMS PROCESS DESCRIPTION}

This section provides a description of the Design Engineered Systems (DES) (2.1.1.2) process as tailored to meet the Nuclear Waste Management System (NWMS) program goals within the regulatory environment of the Nuclear Waste Policy ACt of 1982 (NRC 1982). The discussion to follow will show the following four aspects as they relate to the engineering design process:

- The process should begin by focusing on system drivers, solving these first and then adjusting a 11 elements of the engineered system to the selected solutions.

- The process is mission-driven and has a close relationship to the mission/requirements analysis of the Perform Systems Engineering (PSE) prccess and the system suitability analyses of the Evaluate Integrated System (EIS) process.

- The process includes testing and experimentation throughout all phases to ensure design credibility.

- The process addresses the specialty engineering topics of safety. reliability, and maintainability throughout the effort beginning with the conceptual design.

The discussion to follow begins with an overview of the engineering design process. This is followed by a detailed explanation of the inputs and outputs of the process and the origins and nature of the system and program requirements that control the design. Next. a detailed description of the phases of engineering design is given: this description concludes with a discussion of the feedback loops by which the design process iterates on engineering solutions to ensure their adequacy.

\subsection{DESIGN ENGINEERED SYSTEMS MISSION AND PROCESS OVERVIEW}

\subsubsection{Mission/Objective}

The engineering design process performs the analyses, development work, and testing activities necessary to convert the physical system requirements into an instruction and data package sufficient to provide or fabricate or construct, to license, to test, to operate, to maintain, and to support the engineered items and systems in the NWMS. Engineering design is a missiondriven process responding exclusively to Design requirements. Physical system requirements control the design process by forming characteristics that any proposed design must achieve to be considered for acceptance. Design engineering program requirements control the design process by defining actions that must be pertarmed during design development and selection to have an acceptable design description. Engineering design sequentially adds more detail to the configuration that meets these requirements. The additional detail yields design parameters that form derived requirements for the next layer of detail. 
WHC-EP-0482

Requirements originate in the following ways:

- Direct regulatory requirements are specified in laws and applied to physical system design.

- Mission analysis derived requirements are identified during mission and functional analysis: the NWMS mission defined by law and, therefore, the performances required to accomplish the mission are derived requirements.

- Design development derived requirements result from a particular architectural solution to meet mission requirements: thus. the specifications for these solutions are derived requirements.

- Requirements to support evaluation processes are tasks incorporated in the design process so that required evaluations can be made.

\subsubsection{Scope}

The engineering design process addresses a 11 man-made items and the interfaces between man-made items and natural systems. The functional decomposition of this process is summarized in Figure 4-1.

The engineering design process will develop specifications for all items in the NWMS requiring fabrication. construction. or installation. For example, the Design Engineered Systems function addresses the following:

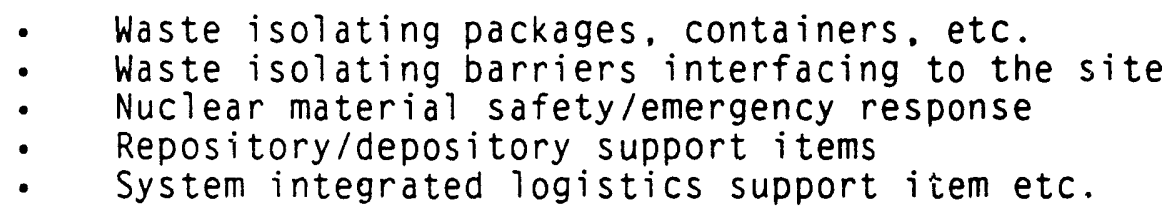

The engineering design process may be programmatically organized into multiple parallel efforts each of which execute all the subfunctions described within the DES MSIS function. For example, all elements of the DES function would be applied to each of the following:

- Systems: acceptance, transport, store, and dispose

- Major test facilities

- Developmental items as part of systems.

The engineering design process includes all activities necessary to identify. characterize, select among. and document technologies and technology implementations that, when procured and assembled. will meet the physical system requirements. The Design Engineered System function includes the following:

- Identification Activities: Determining available and accessible technologies. surveys of technology/previous designs, functional analyses, design conceptualization, design screening, etc. 
Figure 4-1. Hierarchical Overview of Design Engineered Systems.

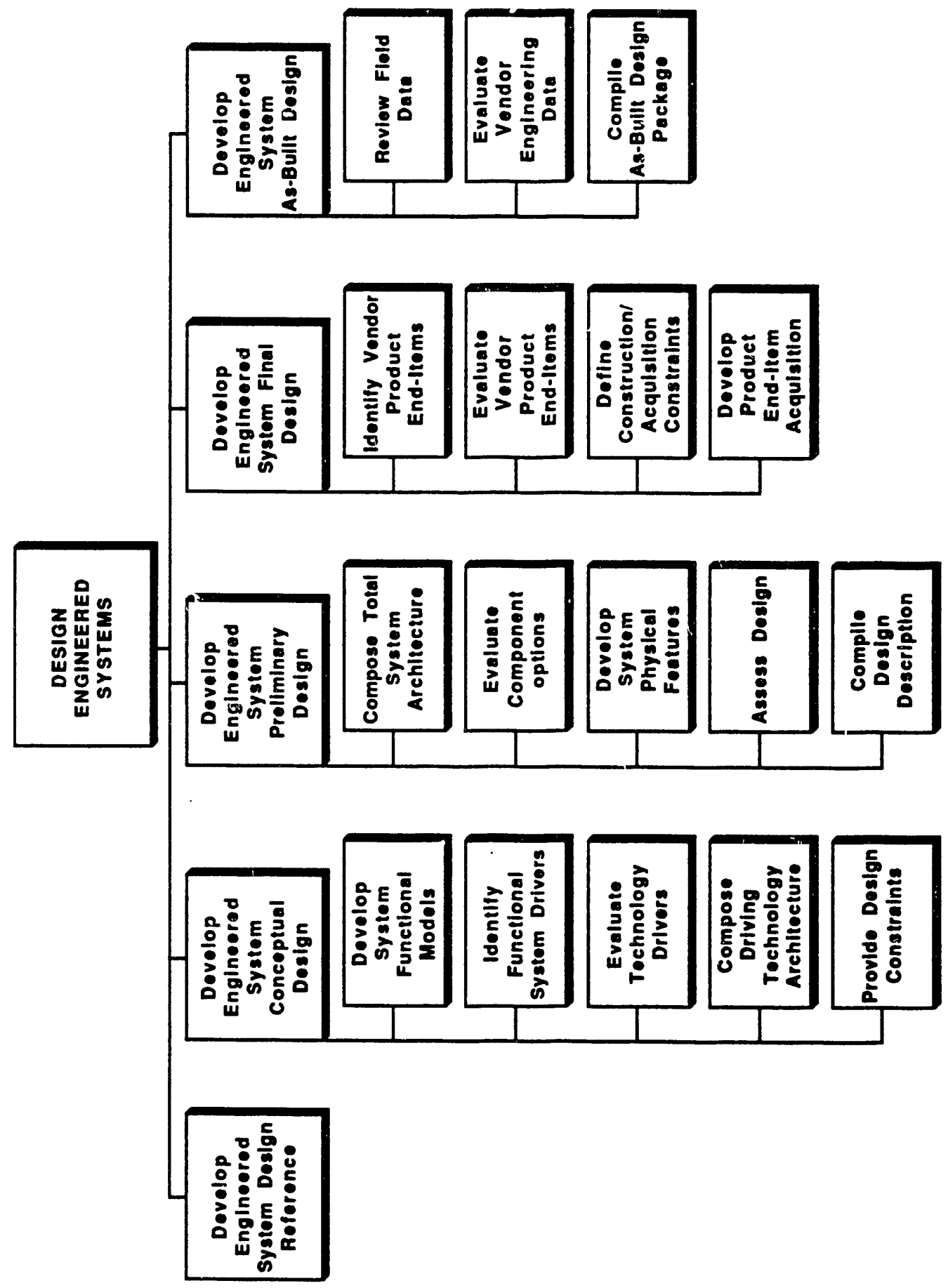


WHC-EP-0482

- Characterization Activities: Design parameter analyses, paramietric calculations, sensitivity studies, trade studies. concept verification testing. prototype hardware testing and evaluation, etc.

- Selection Activities: Application of system Technical Performance Measures, application of design measures of merit, evaluation of regulatory suitability measures. decision analysis of measures and criteria. application of decision analys is algorithms. technical/peer reviews and assessments, etc.

- Documentation Activities: Specification document generation, design description drawings and documents. technical reports from characterization analyses, test reports and hardware evaluation reports, etc.

\subsubsection{Process Overviaw}

The basic engineering design process flow consists of the input of a partially developed engineered system/item configuration. the augmentation of that configuration via design activities, and the return of the augmented configuration for baselining, review, evaluation, and approval. The flow of activities in this process is summarized in Figure 4-2 and proceeds as follows:

- The input configuration is the current, approved description of the system that meets all requirements: it increases in detail with each design phase.

- The augmentation adds the next level of design detail by identifying and characterizing options and selecting the one that best meets requirements.

- The output configuration is a recommended new configuration and additional layer of derived requirements.

- External events may occur such as regulatory requirements changes or program scope changes: these can cause a phase of the design process to be restarted or repeated.

External controls apply at all iterations through the steps of DES function. All the design products are sent to the technical information control and audit process in Perform Systems Engineering (PSE) function. The response to a design product can be to continue, to repeat a portion of the current design phase. or to restart an earlier phase. Such redirection arrives from Provide Program Control (PPC) process via the requirements allocation process in the PSE function.

\section{1 .4 Role}

The role of the engineering design process in the office of Civilian Radioactive Waste Management (OCRWM) program changes significantly during the course of system development, implementation, and operation. Early in the process, during system configuration development, the role of DES is to convert requirements into instructions for construction and operation. DES is the lead function for determining what configuration will be given to the 


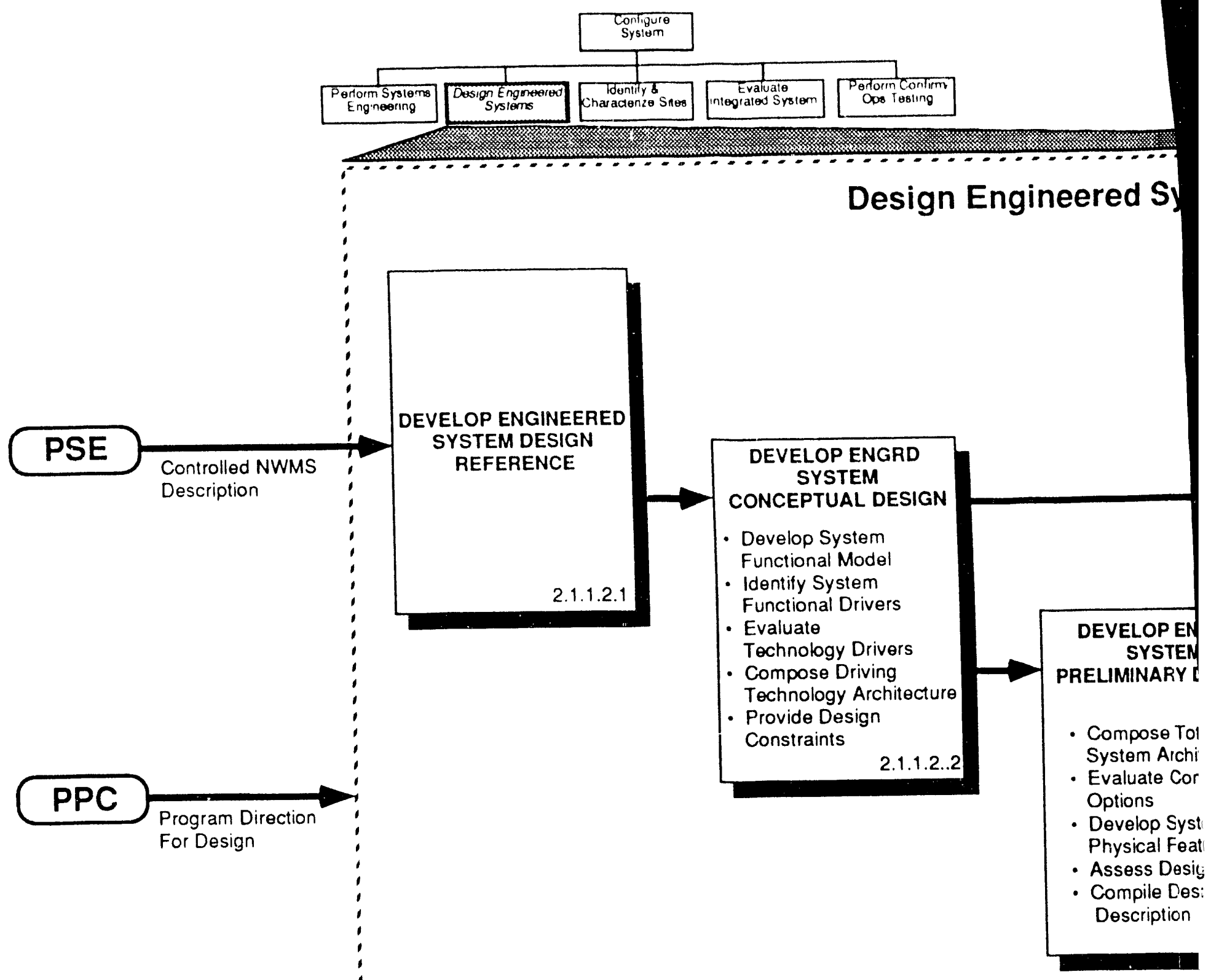

NWMS Design

Fiequirements 

ES cture ponent $m$ res i $n$

DEVELOP ENGRD SYSTEM FINAL DESIGN

- IGentify $v e n d o r$

Product End-liems

- Eváluate Vendor Produc: End-liems

- Define Construntion/ Acquisition Constraints

- Develop Product End-hems Acouisition Parkages

\section{PSE}

- Need For Reviews

of NWMS Design

- Requirements

,

,

;

- Engirieered System

- Conceptual Design Info

PSE

PSE

- Engineered System

- Preliminary Design Into

PSE

\section{' Engineered System}

¿Final Design Into

EVELOP ENGRD

SYSTEM

AS-BUILT DESIGN

- Review Field Data

- Evaluate Vendor

Engineering Data

- Compile As-Buitt

Uesign Package
PSE
'Engineered System

- As-Buit Design Info 
engineered systems and the engineered-to-natural systems interfaces. Late in the process. during system implementation and operation, the role of DES is to resolve technical problems identified by the construction and operations engineers. DES is a support function; construction and operations engineers lead the implementation process.

This change in roles is reflected in the overall structure of the DES function. Conceptual. Preliminary. Final Design functions are called out separately, consistent with DOE Order 4700.1. and the distinctions in issues addressed in each phase. DES leads system configuration definition during these design stages. The As-Built Design function executes during the system implementation and operation priase when engineering design plays a support role. The As-Built Design has been structured to match the needs of supporting construction and operations.

\subsection{DESIGN ENGINEERED SYSTEMS EXTERNAL INTERFACES}

The DES programmatic function is a requirements-driven process that develops a detailed system configuration in response to the defined physica? systern functions and their allocated requirements. The process is initiated by the receipt of requirements and an initial system functional configuration which includes a mission environment definition. Physical system requirements and program direction and strategy control the process by stating the properties the configuration must have and the characteristics the development process must maintain. The output cinfiguration, if approved, becomes a set of derived requirements controlling the next phase of design. The following section describes these inputs. controls, and outputs in more detail.

\subsubsection{External Inputs}

The engineering design process operates exclusively on controlled. baselined, configuration descriptions and performs its augmentation of this configuration using engineering and technology description and definition data. These inputs are defined in Table 4-1.

The Controlled NWMS Description originates in the PSE technical information auditing and control process. The description contains information from design, site characterization, test, and construction processes. It is received at the beginning of each phase of design. passes through the design reference formation process, and then to the initial activity of each phase. It defines the approved starting point for the design analyses in terms of engineered item definitions. site and mission environment, and results of related efforts. It describes all aspects of the current configuration, system functions/their characteristics, function implementations selected to date. mission operating environment, and site characterization results. It also describes all relevant program technical data. the results from integrated system evaluations, testing reports on hardware systems, and field data from hardware construction.

The description evolves with time in the following ways:

- To Conceptual Design: Functional Requirements Baseline description of functions. mission analysis results, initial site data, mission environment description 


\section{Table 4-1. Inputs to Design Engineered System.}

\begin{tabular}{|c|c|c|}
\hline Input Name & Input Definition & Destination Function \\
\hline $\begin{array}{l}\text { Controlled NWMS } \\
\text { Description }\end{array}$ & $\begin{array}{l}\text { A complete technical description of the NWMS } \\
\text { in its current state of development. Includes all } \\
\text { definition, descriptive, characterization } \\
\text { information on the system (engineered and } \\
\text { natural elements) configuration (design and } \\
\text { physical), the bases, models, } \\
\text { plans/procedures on which the configuration is } \\
\text { based, and system characteristics based on } \\
\text { hardware tests and observations. This } \\
\text { information addresses both the engineered } \\
\text { system and the site. It includes information on } \\
\text { all parallel design efforts. It also includes all } \\
\text { information generated in response to data } \\
\text { needs issues from the Evaluate Integrated } \\
\text { System process. }\end{array}$ & $\begin{array}{l}\text { 2.1.1.2.1 Develop } \\
\text { Engineered System } \\
\text { Reference }\end{array}$ \\
\hline Technology & $\begin{array}{l}\text { Descriptions of the engineering parts, } \\
\text { materials, principles, practices, concepts, and } \\
\text { ideas that } 1 \text { ) that have been generated by the } \\
\text { world:wide engineering community, and } 2 \text { ) that } \\
\text { will be used to form the system configuration of } \\
\text { the NWMS. Inctudes data from all US } \\
\text { engineering and a selected part of data from } \\
\text { international sources. This information channel } \\
\text { represents the total body of technical resource } \\
\text { information used by the engineering process } \\
\text { to develop the NWMS engineered system. It } \\
\text { includes sub-parts that address the needs of } \\
\text { the various phases of engineering design: } \\
\text { technology concepts (conceptual design), } \\
\text { techniques to implement concepts (preliminary } \\
\text { design), end-item descriptions (final design), } \\
\text { and vendor descriptions of supplied parts (as- } \\
\text { built design). }\end{array}$ & $\begin{array}{l}\text { 2.1.1.2.2.3.1 Assess } \\
\text { Accessible Technology } \\
\text { 2.1.1.2.3.1.2 Assess } \\
\text { Common Technologies } \\
\text { 2.1.1.2.3.2.2 Assess } \\
\text { Accessible Implementation } \\
\text { Techniques } \\
\text { 2.1.1.2.4.1.2 Determine } \\
\text { Accessible End-ltems } \\
\text { 2.1.1.2.5.2 Evaluate Vendor } \\
\text { Engineering Data }\end{array}$ \\
\hline
\end{tabular}


- To Preliminary Design: Approved concept descriptions for function implementation. additional site data. results of information and data need requests made during conceptual design. and results of integrated system evaluations using Conceptual Design resuits

- To Final Design: Approved Design Requirements Baseline description of components/techniques selected. final site data. and results of integrated system evaluations using Preliminary Design Results

- To As-Built Design: Approved Product Configuration Baseline description of acquirable end-items selected, field engineering and inspection data, test results on acquired hardware, and results of integrated system evaluations and hardware quality examinations.

The Technology input originates with the research and development community, technology developers, and component suppliers. Different aspects of these data are received by each phase of design (e.g.. technology/concept data in Conceptual Design and component designs in Final Design). This information initiates the definition of design options for candidate design formation and defines the range of available design options for candidate design formation and evaluation. It ties the design to engineering experience, standard practice, research and development results, and available hardware. It provides the definition of the technologies, technology implementing techniques and components, and the acquirable end-items that can be tailored to meet requirements. It defines the feasible engineering options including technology/technique/component descriptions, research and development and scientific information. conventional engineering designs. previous (non-OCRWM) systems information, ard engineering reference/background data.

The information which this input represents evolves with time in the following manner:

- To Conceptual Design: Concepts and available technology descriptions; technology survey/forecast information

- To Preliminary Design: Techniques for implementing technology/concepts in components: classes/categories of existing components: definitions of component types that are under development

- To Final Design: Component/end-item descriptions currently in vendor production: vendor definitions of components to meet specifications; component development/research and development results

- To As-Built Design: Design and characterization data on procured components including vendor testing and analysis results.

\subsubsection{External Controls}

The engineering design process responds to two types of controls: reference controls to which it must make its products conform (i.e.. the physical system requirements for the engineered system) and programmatic 
controls that constrain the process of identifying and selecting among the product options ( $i . e .$. program direction and strategy). These controls are defined in Table 4-2.

NWMS Design Requirements are the physical system requirements that originate from the mission and functional analysis and requirements allocation process in PSE. They are traceable to the Ensure Regulatory Compliance (ERC) analysis of regulations and PPC assessment of engineering standards. An updated requirements baseline is received by the initial step in each phase of design. It is passed on to all subsequent steps in each phase. The requirements update between design phases is the result of the review and approval of derived requirements included in the design produced by the preceding phase. The requirements may also have updates because of changes resulting from requests for requirements reviews. Changes could also result from external events: for example, the regulatory environment could change yielding new requirements.

NWMS Design Requirements define the characteristics that the design products must possess to be acceptable. The types of Design requirements include the following:

- Performance Requirements. These are numerical yalues specifying a propertv the design must have or quantifying a behavior it must display. They address topics such as isolation capability. throughput, environmental effects, safety, reliability. cost. logistics and support, etc.

- Functional Requirements. These define a specific behavior that the design must incorporate: mission analysis or design analysis may, but need not, derive a numerical performance value corresponding to the functional requirement. For example, mission analyses may show that the system must integrate with the local power grid and there will be a requirement for a system function to perform that integration.

- Requirements to Support System Evaluation. These requirements consist of defined evaluations, analyses, and calculations that must be performed during the design process to supply data to be used in the integrated system evaluation of regulatory compliance.

- Requirements to Support other Program Functions. These define other actions that must be performed during the design process to supply data used in another functional process $(e . g$. to support site characterization).

Program Direction for Design originates from the program organization and task planning processes in the PPC function and is received during each phase of the engineering design process. The purpose of program direction is to define the constraints and overall approach to structuring program activities to ensure that national policies. legislative preferences, and regulatory agency concerns will be met. Program direction includes requirements to generate specific design data for regulatory submittals. Different elements of direction and strategy are received by the various subfunctions of DES based on the type of direction and strategy needed to accomplish the subfunction's mission. The evolution of direction and strategy between design phases is an expansion/update based on the maturation of design 
Table 4-2. Controls for Design Engineered System. (sheet 1 of 2 )

\begin{tabular}{|c|c|c|}
\hline Control Name & Control Definition & Destination Function \\
\hline $\begin{array}{l}\text { NWMS } \\
\text { Design } \\
\text { Requirements }\end{array}$ & $\begin{array}{l}\text { The compilation of all physical } \\
\text { system pertormance requirements } \\
\text { that apply to engineered items; } \\
\text { includes those directly specified in } \\
\text { regulations, those developed } \\
\text { during the mission analysis in } \\
\text { Periorm Systems Engineering, } \\
\text { and those developed to satisfy } \\
\text { information needs of other } \\
\text { functional processes. The } \\
\text { content of this arrow evolves with } \\
\text { time. The evolution occurs as } \\
\text { recommended configuration } \\
\text { descriptions, generated by the } \\
\text { design process, are accepted and } \\
\text { approved as derived requirements } \\
\text { during the technical review } \\
\text { process. Through out design } \\
\text { development, other physical } \\
\text { system requirements may be } \\
\text { generated that relate to } \\
\text { test/analytical chaiacteristics that } \\
\text { must be supplied to support } \\
\text { processes such as site } \\
\text { characterization and integrated } \\
\text { system evaluation. }\end{array}$ & $\begin{array}{l}\text { 2.1.1.2.2.1.1 Determine Function Behavior } \\
\text { Trends } \\
\text { 2.1.1.2.2.3.4 Perform Concept Assessment } \\
\text { Testing } \\
\text { 2.1.1.2.3.1.1 Characterize Non-Driver } \\
\text { Functions } \\
\text { 2.1.1.2.3.3.3 Perform Implementation } \\
\text { Technique Evaluation Testing } \\
\text { 2.1.1.2.3.3.5 Expand Design Characterization } \\
\text { 2.1.1.2.4.1.1 Identify End-Item Acceptability } \\
\text { Drivers } \\
\text { 2.1.1.2.4.2.s Test End-Item Suitability }\end{array}$ \\
\hline
\end{tabular}


Table 4-2. Controls for Design Engineered System. (sheet 2 of 2 )

\begin{tabular}{|c|c|c|}
\hline Control Name & Control Definition & Destination Function \\
\hline $\begin{array}{l}\text { Program } \\
\text { Direction For } \\
\text { Design }\end{array}$ & $\begin{array}{l}\text { An overall approach and } \\
\text { guidelines set for structuring the } \\
\text { design iffort so that all design } \\
\text { require nents are met and the } \\
\text { design is responsive to the } \\
\text { programmatic direction from other } \\
\text { functions and the evolution of the } \\
\text { site characterization process and } \\
\text { data. The direction includes a } \\
\text { detailed application of program } \\
\text { directives to form a management } \\
\text { plan for the design effort. It } \\
\text { describes any constraints to the } \\
\text { technology to be considered and } \\
\text { the design trade space to be } \\
\text { accessed that are not required by } \\
\text { law, and which do not result from } \\
\text { requirements allocation, but have } \\
\text { been accepted as desirable by } \\
\text { program management (e.g., } \\
\text { limitations to international } \\
\text { technology availability as a result of } \\
\text { political considerations). It also } \\
\text { may include any schedule and } \\
\text { cost guidelines that are not } \\
\text { included in design requirements. }\end{array}$ & 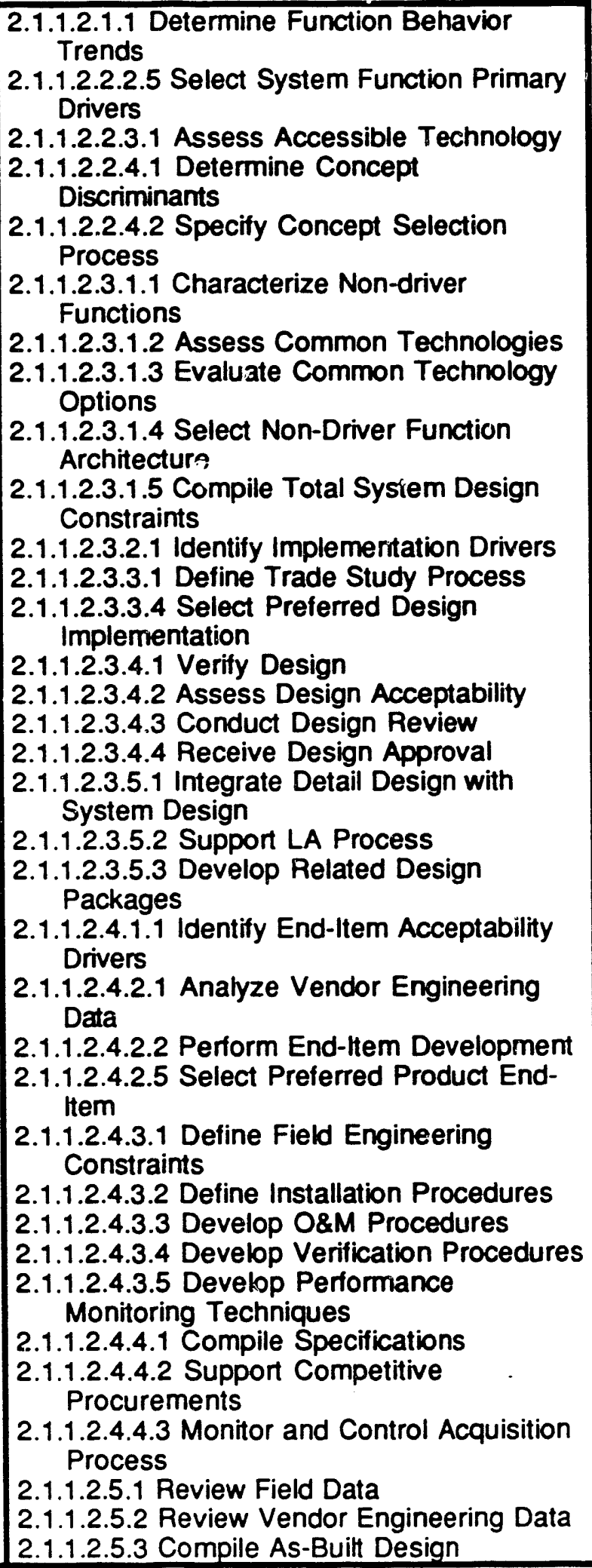 \\
\hline
\end{tabular}


WHC-EP-0482

information. The design strategy also includes a programmatic approach to adjusting to external changes and to accommodate internal program changes. The strategy for responding to program changes defines the general response approach for changes technical items and requirements, the new program program actions needed to incorporate those technical changes, and the portions of the configuration to be revised/left alone.

The contents of Program Direction include program practices, policies. and structure/organization interfaces. The direction input to the design process tailors the overall program approach/strategy to design activities as follows:

- Conceptual Design Direction/Strategy. This control includes guidelines for models (substantiation requirements, regulatory preferences, and model commonality to other processes). technology constraints/preferences, concept selection criteria/processes, and documentation needs and requirements.

- Preliminary Design Direction/Strategy. For this phase of design. the program direction defines total architecture constraints. accessible/approved component sources, mandatory design evaluations/criteria, and external review/assessment procedure.

- Final Design Direction/Strategy. For Final Design the direction addresses constraints on vendor types/sources, vendor selection criteria/processes, standard construction practices, standard specification practices, and programmatic interface to procurement.

- As-Built Design Direction/Strategy. This element of program direction specifies programmatic interfaces to field engineers. programmatic interfaces to suppliers. field/supplier data review approach, and archive documentation approach.

\subsubsection{External Outputs}

The engineering design process produces technical data in the Engineered Systems Information output and issues for examination by engineering management in the Need for Review of Design Requirements output. These products are outilined in Table 4-3.

Engineered System Information consists of configuration specifications. the technical descriptions substantiating this configuration. and records of the tools, techniques, and reference data used to develop the configuration. Inputs to Engineered System Information originate at five points in the design effort: at the end of Conceptual Design, at the completion of the total system architecture. at the end of Preliminary Design. at the end of Final Design, and at the end of As-Built Design. The information is received by the technical information database maintenance and auditing function in PSE and is made available to all organizations ( $i$.e... information is then accessible to all other functional processes). The specification portion of Engineered System Information describes the requirements, specifications, and selected engineered item implementations for the current stage of design. A system technical description accompanies each design specification and describes the nature, properties, characteristics, behaviors, and behavior trends for the selected system design specification. It also records the results of all 
Table 4-3. Outputs From Design Engineered System. (sheet 1 of 2 )

\begin{tabular}{|c|c|c|}
\hline Output Name & Output Definition & Originating Function \\
\hline $\begin{array}{l}\text { Engineered } \\
\text { System } \\
\text { Information }\end{array}$ & $\begin{array}{l}\text { The sum of all information produced by } \\
\text { the engineering design effort } \\
\text { including design definitions (i.e., } \\
\text { design descriptions, design } \\
\text { characteristics, design analyses, test } \\
\text { results, design bases, models), design } \\
\text { related plans and needs statements } \\
\text { (e.g., test plans, test facility resource } \\
\text { needs, info/data needs), and technical } \\
\text { information in support of other } \\
\text { programmatic functional processes } \\
\text { (e.g., technical information for } \\
\text { procurements and license application) } \\
\text { This information output is the pattway } \\
\text { for all design produced technical } \\
\text { information to be incorporated into the } \\
\text { technical information databasing, } \\
\text { auditing, control processes of the } \\
\text { Perform Systems Engineering } \\
\text { process. This is the pathway by which } \\
\text { design data enters the technical } \\
\text { review process and is made available } \\
\text { to site characterization and integrated } \\
\text { system evaluation processes. }\end{array}$ & 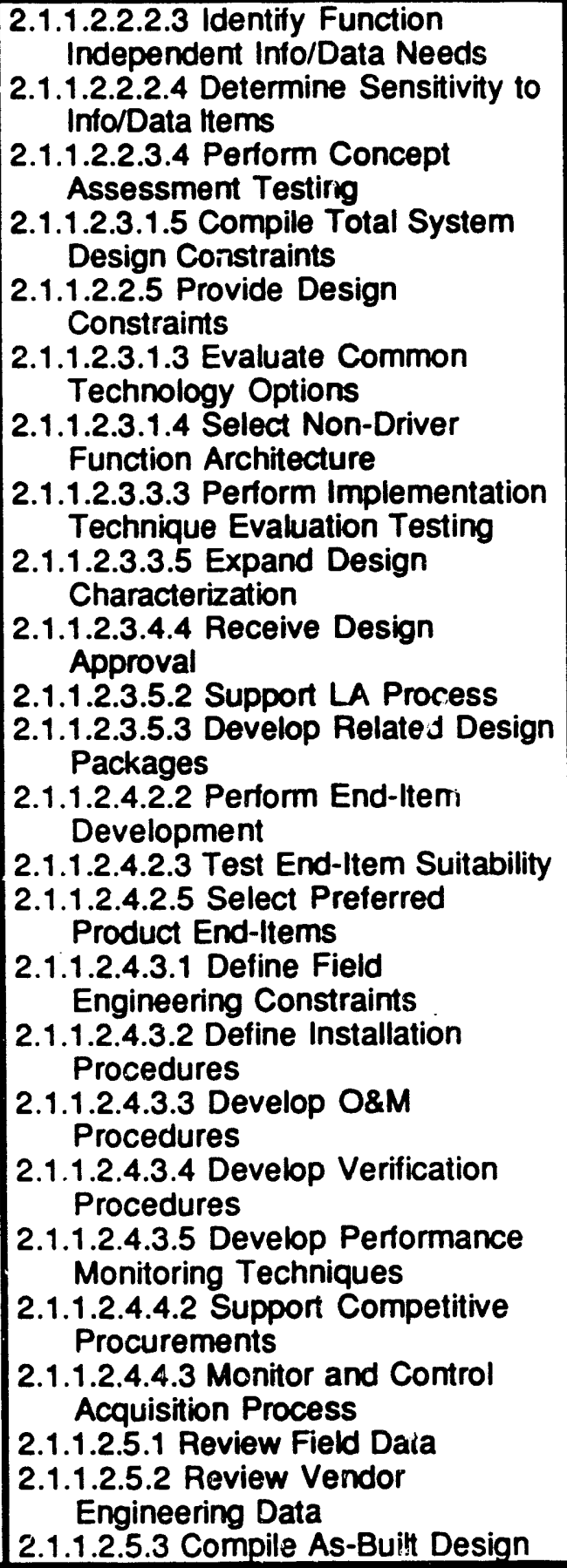 \\
\hline
\end{tabular}




\section{Table 4-3. Outputs From Design Engineered System. (sheet 2 of 2 )}

\begin{tabular}{|c|c|c|}
\hline Output Name & Output Definition & Originating Function \\
\hline $\begin{array}{l}\text { Need to Review } \\
\text { NWMS Design } \\
\text { Requirements }\end{array}$ & $\begin{array}{l}\text { A description of a problem that the } \\
\text { engineering design process has } \\
\text { encountered in meeting the system } \\
\text { performance process. Includes a } \\
\text { request for review/action by } \\
\text { management, a description of the } \\
\text { problem and design attempts to } \\
\text { resolve it, and any design generated } \\
\text { recommendations for solutions. This } \\
\text { message is generated when the } \\
\text { design process reaches an impasse in } \\
\text { identifying and selecting 1) a design } \\
\text { solution that meets all engineered } \\
\text { system performance requirements, } \\
\text { and 2) performing the identification } \\
\text { and selection within the bounds of the } \\
\text { program strategy and program } \\
\text { direction. Note that this arrow does } \\
\text { not directly address program strategy } \\
\text { OR program direction. The design } \\
\text { process, BY DEFINITION OF } \\
\text { PROGRAM DIRECTION AS A } \\
\text { CONTROL, always conforms to the } \\
\text {-rnaram direction. In conforming to } \\
\text { the program direction, it may not be } \\
\text { possible to meet performance } \\
\text { requirements; if this Occurs, then a } \\
\text { Need to Review NWMS Design } \\
\text { Requirements message is generated } \\
\text { describing the system performance } \\
\text { requirement that cannot be met. } \\
\text { Management may respond by } \\
\text { changing the program direction (see } \\
\text { Provide Program Control functional } \\
\text { process) }\end{array}$ & 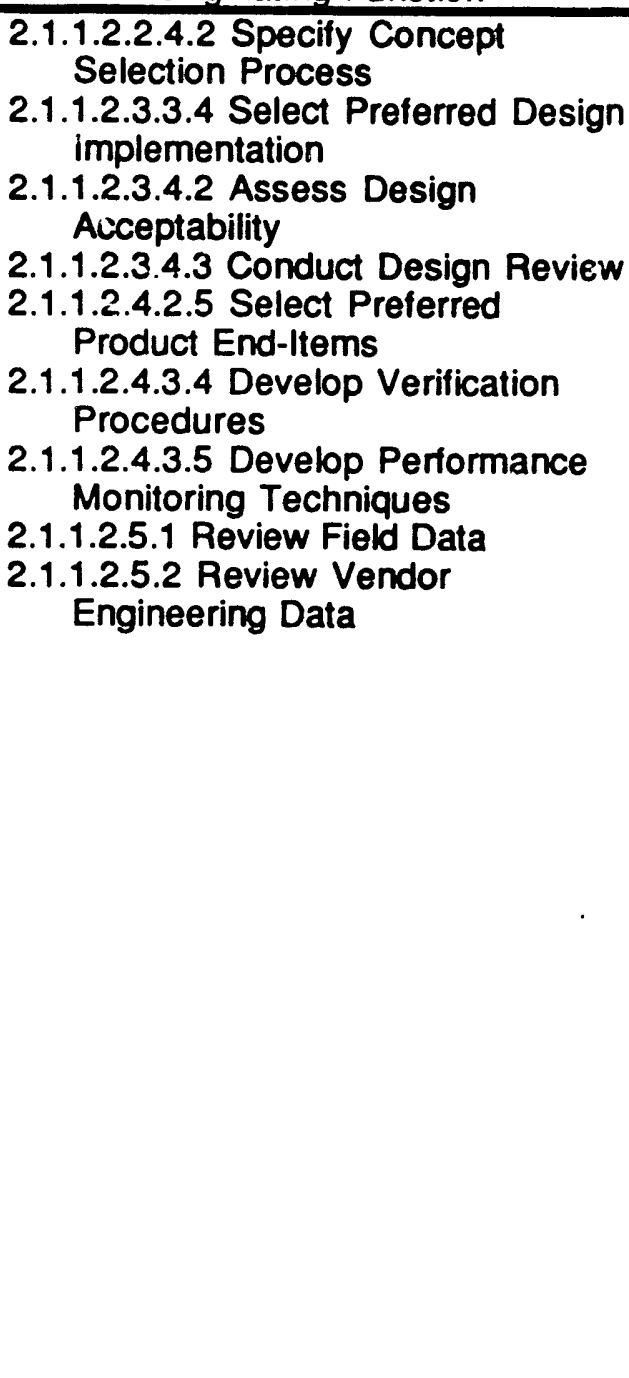 \\
\hline
\end{tabular}


analyses used to select the specification. Referen a data and technical bases are included with the system technical description and originate from each technical analysis function. Their purpose is to provide a historical record of how the design was developed and an archive of tools for use in later erigineering efforts. The design bases include standard technical data/background data, design process/procedure descriptions, and technical reports. The models include executables and descriptions, results from calculations, and technical plans/planning documents.

The four major components of Engineered System Information are the products of the four major phases of design. The contents of Engineered System Information at the conclusion of these design phases are as follows:

- Conceptual Design Products include the driving technology architecture. parametric technology analyses, technology evaluation test data, the System Functional Model and the Hybrid System Model. and technology concept assessments (design bases).

- Preliminary Design Products consist of the Total System Architecture, parametric technology analyses, the Enhanced System Model (and its design bases), the Recommended Design Requirements Baseline, trade study results. implementation technique test data. design performance characterizatior, design analysis tools/models (and their design bases), and technology implementation data (design bases).

- Final Design Products include the recommended Product Configuration Baseline. componert/end-item analyses. developmental end-item analyses. component/end-item test data. developmental end-item test data, integrated design performance analyses, system procedures (including those for field engineering. installation. operations and maintenance, verification. and performance monitoring, and acquisition technical packages.

- As-Built Design consists of the expanded Product Configuration Baseline resulting from the incorporation of field and vendor data, and the as-built hardware characterization analysis results.

The output Need for Design Requirements Review can originate during the design assessment. review. and evaluation step in each design phase and is received by the technical information auditing function in PSE. The result causes formation of a change request to the change control process in PPC. This output occurs if design requirements contain an inconsistency or cannot be satisfied given programmatic requirements. constraints. and strategy. The content of this output identifies the requirements that must be reviewed to determine how to proceed given the identified problem in satisfying the existing set of requirements.

\subsection{DESIGN ENGINEERED SYSTEMS PROCESS EXECUTION DETAILS}

This section provides descriptions of the steps in executing each phase of engineering design. The following discussions are success oriented; they show the flows of activities and information as if each design step accomplishes its goal on the first attempt. The success oriented approach provides the simplest and clearest explanation of the required steps in engineering design. The relationship between design activities and data flows is most easily seen if the feedbacks to earlier steps are not shown. 
A discussion of feedbacks is given in a later subsection and shows where feedbacks can occur when a function product is not perfect/acceptable on the first try.

\subsubsection{Conceptual Design}

4.3.1.1 Mission/Objective. The purpose of Conceptual Design (2.1.1.2.2) is to identify the drivers to system performance and acceptability and to determine the most effective technology concepts and approaches for implementing solutions to those drivers. Defining and solving system drivers is the only topic addressed in Conceptual Design.

System drivers can originate from any performance requirement including isolation capability, nuclear safety, system/component reliability. and ability to verify performance. There are two types of system drivers:

- Performance Dominating Function: System level performance is highly sensitive to the individual performance of a performance dominating furiction.

- System Risk Dominating Function: The required level of performance for a function exceeds the demonstrated capabilities of all technology concepts identified to perform the function.

Only system drivers are addressed during Conceptual Design because these determine system success in terms of meeting performance requirements and regulatory compliance requirements. Therefore, they are the highest priority items and should be addressed first when the design is most flexible. All other functions/technologies have a lesser effect on system success and can be made to adjust to accommodate drivers with little impact.

4.3.1.2 Process Flow. The conceptual design process identifies drivers by means of sensitivity studies and finds solutions to the drivers using parametric calculations of performance and behavior. The Conceptual Design process is summarized in Figure 4-3. The first tier of subfunctions in the Conceptual Design Process is shown in the figure and can be described as follows:

- The Develop System Functional Model function begins with the Functional Requirements Baseline from the mission and functional analysis and requirements allocation processes (see PSE function) and then develops algorithms to model performance trends and behavior characteristics using theory, engineering practice. experience with related systems, etc.

- The Identify System Functional Drivers function identifies the performance dominating functions by means of sensitivity analyses using the System Functional Model and includes additional functional decomposition of performance dominating functions to isolate the functional characteristic that is causing the performance dominating behavior.

- The Evaluate Technology Drivers function identifies candidate technologies for each performance dominating function and also identifies all risk dominating functions based on results of techrology assessments. This part of the process includes both 
WHC-EP-0482

This page intentionally left blank. 


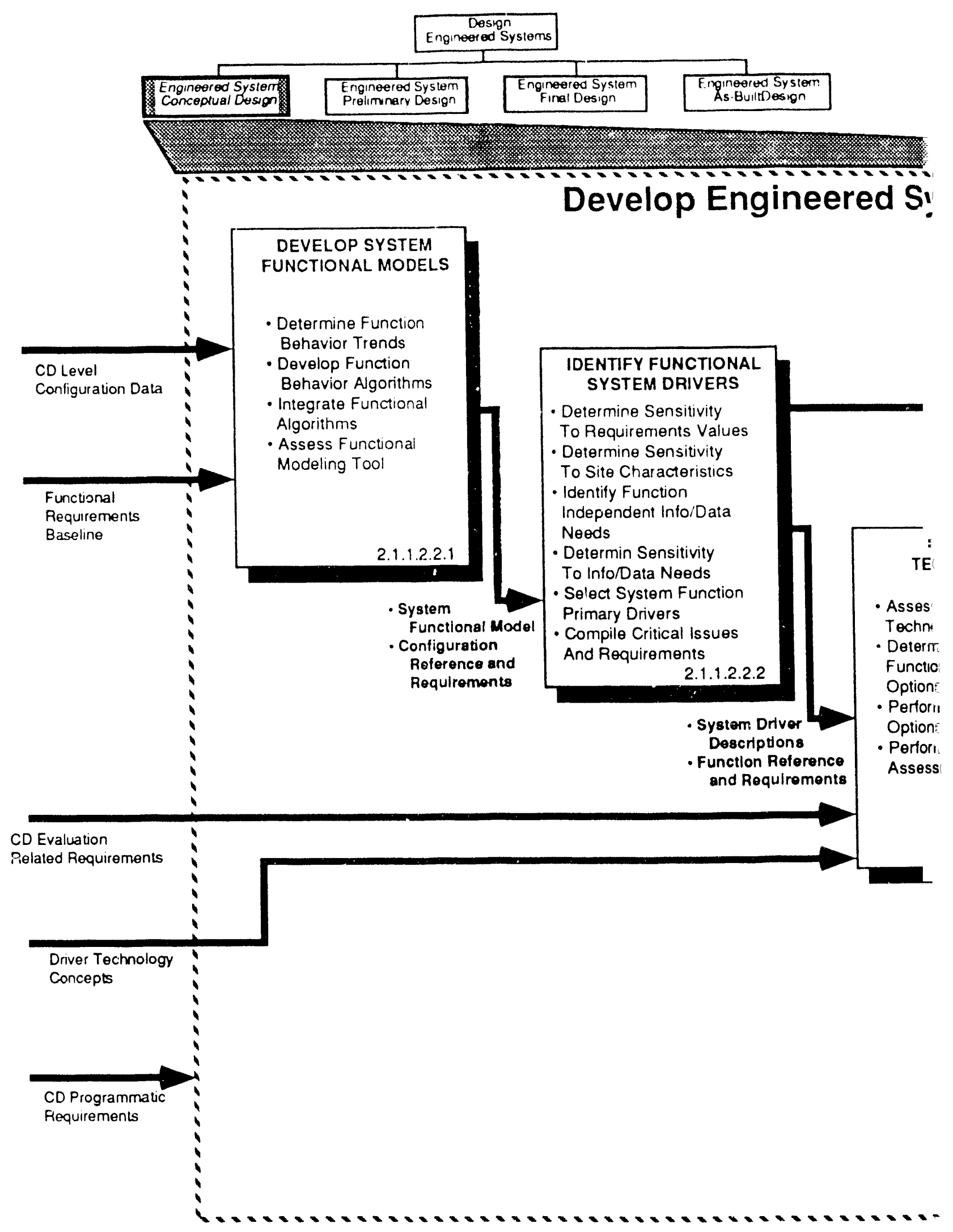




\section{Figure 4.3. Process overview Cevilo Englnered Systems concetual Design.}

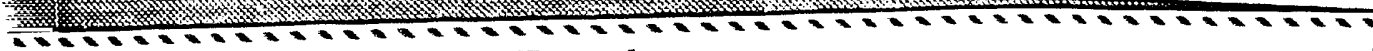 stems Conceptual Design}

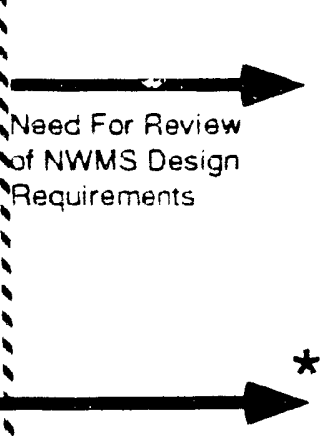

ico Intojoata

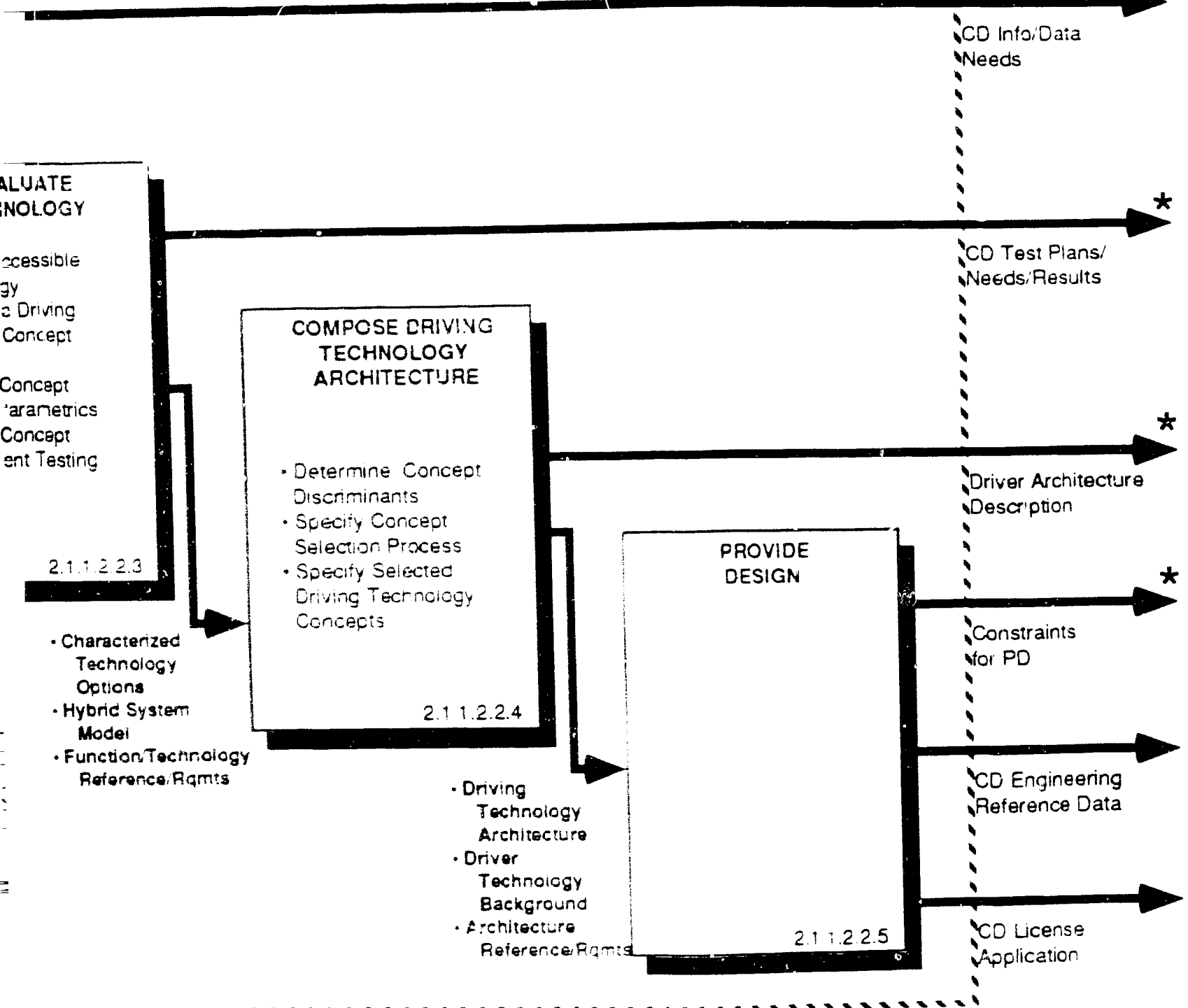

- Combined torm "Engreered System Cu 
parametric analyses and concept evaluation testing to characterize technology concepts. The Hybrid Functional Model is formed by substituting technology models for the driver functions (performance and risk dominating) into the System Functional Mode 1 .

- The Compose Driving Technology Architecture function performs the evaluation of all candidate technology concepts based on the previously generated characterization data and makes the selection of technology for each driving function. It includes decision analyses to develop the selection process from the technical performance measures and other technology measures of merit.

- The Provide Design Constraints function produces the final documentation package for the conceptual design phase and defines the process/constraints by which technologies for nondrivers will interface/integrate with the selected driving technologies.

Iterations within Conceptual design can be caused by the driver solution assessment, by changes in the mission conditions or requirements, or by the results of external reviews as follows:

- Conceptual Design Assessment: The Compose Driving Technology Architecture function can identify shortfalls in the candidate concepts or in the available data and can cause iterations back to earlier functions in the Conceptual Design process to provide additional candidates or data.

- Changes in Externally Imposed Requirements/Conditions: This can cause an unsuccessful design assessment in the Compose Driving Technology Architecture function and can yield iterations within Conceptual Design. A requirements change may come with a program direction update that directs a restart at any point in the Conceptual Design process.

- External Reviews: If the selected design is not approved, the review process causes the program evaluation process (see PPC function) to redirect the design process to repeat part or all of the Conceptual Design process.

4.3.1.3 Outputs. The primary product of Conceptual Design is the Driving Technology Architecture. The contents of the driving technology architecture are the following:

- Descriptions of a 11 system functions including derived functions formed in decomposing performance dominating functions and in making all driving functions specific to selected technologies

- Descriptions of selected technology concepts for each driving function including design approach. design parameters. and specifications of design parameters

- Characterization data generated during parametric analyses and show that selected conceots can meet requirements and that selected concepts are more effective than alternatives. 
The output from the Conceptual Design process also documents the tools and methods for achieving that architecture. The system model documentation contains the executable code for System Functional and Hybrid System Models. the theoretical development of algorithms, the algorithms

implementation/integration description. procedures for use and sample data, and the model validation/assessment results and data. The engineering reference data documentation contains a 11 technology survey/assessment data. all standard engineering data used and its origins. and all standard design tools used and their origins. The design selection documentation contains the criteria used to make the selection, the procedure used to apply criteria, the comparison of all candidates evaluated, and the traceability of the selected candidate to requirements.

4.3.1.4 Significant Considerations. Significant considerations in performing conceptual Design include the following:

- Conceptual Design is complete only when all drivers have been identified and technology concepts have been selected that have the potential to meet requirements once additional design details have been developed.

- At the Conceptual Design stage, specialty engineering issues (reliability, productibility. logistics, and maintainability) are assessment and evaluation characteristics during technology survey and concept evaluation. They form criteria in the driving technology architecture selection process. Programs to perform detailed specialty engineering evaluations are initiated so that they can provide necessary information during Preliminary Design.

- Items critical to nuclear safety are given strong consideration as system drivers. ATl items assessed for safety issues form criteria in the driving technology architecture selection process.

Significant considerations in planning a conceptual design include the following:

- Maintaining focus exclusively on drivers: all other issues are outside the scope of Conceptual Design and examining them consumes critical resources needed for Conceptuál Design

- Providing adequate resources and control mechanisms on software development (Functional System Model and Hybrid System Model): software efforts are notoriously difficult to control.

- Specifying technology assessment criteria: these must be consistent with program strategy and performance requirements but also must clearly distinguish between the characteristics of alternatives.

- Completeness of technology concept survey/assessment/ identification: it is important to capture all important/useful concepts: however. this process must not consume too many resources gathering data of an inappropriate level of detail. 


\subsubsection{Preliminary Design}

4.3.2.1 Mission/Objective. Preliminary Design (2.1.1.2.3) determines the engineered system components so that detailed performance characterization and acceptability evaluation can be performed. The nature and specifications for a 11 system components are determined and shown to meet requirements. The system design is essentially complete and design data can be used to build a license application. At this stage of design development. all system performances can be evaluated based on detailed knowledge (i.e... specifications and nature) of each of the parts. System performance under a 11 excursion conditions, emergency situations. failure modes, throughputs, etc.. can be calculated and system cost (capital. construction, operating. logistics costs) and schedule characteristics can be defined.

\subsubsection{Process Flow. The Preliminary Design process begins by completing} the engineered system architecture. It then characterizes the candidate items in the architecture and performs trade studies to determine the most effective set of items. Next, it selects the most effective design and completes all details required for license application. The Preliminary Design process is summarized in Figure 4-4. The first tier of subfunctions to Preliminary Design are identified in the figure and can be described as follows:

- The Compose Total System Architecture function completes the engineered system architecture by selecting technology concepts for nondriver system functions and integrating these with the driving technology architecture. It produces another layer of derived requirements (for the non-driver system functions) that constrain the remainder of Preliminary Design.

- The Evaluate Component Options function identifies and screens all methods/techniques for implementing the technologies in the architecture. It develops detailed characteristics for the methods/techniques including constraints on their interfaces. It composes design alternatives by forming compatible assemblies of the methods/techniques.

- The Develop System Physical Features function performs trade studies that characterize each design aiternative and provides data to compare their relative performance and behavior. It assesses requirements, technical performance measures and suitability measures to determine a proper set of trade studies. It also includes testing of example hardware to validate calculations, demonstrate levels of capability. and examine phenomena not readily calculated. It concludes by selecting the most effective design aiternative.

- The Assess Design function verifies the selected design with respect to ali requirements. technical performance measures. and suitability measures. It assesses acceptability with respect to program strategy, compliance approach. and requirements for icense application. It then conducts design reviews to obtain independent evaluations of acceptability. 
WHC-EP-0482

This page intentionaily left blank. 


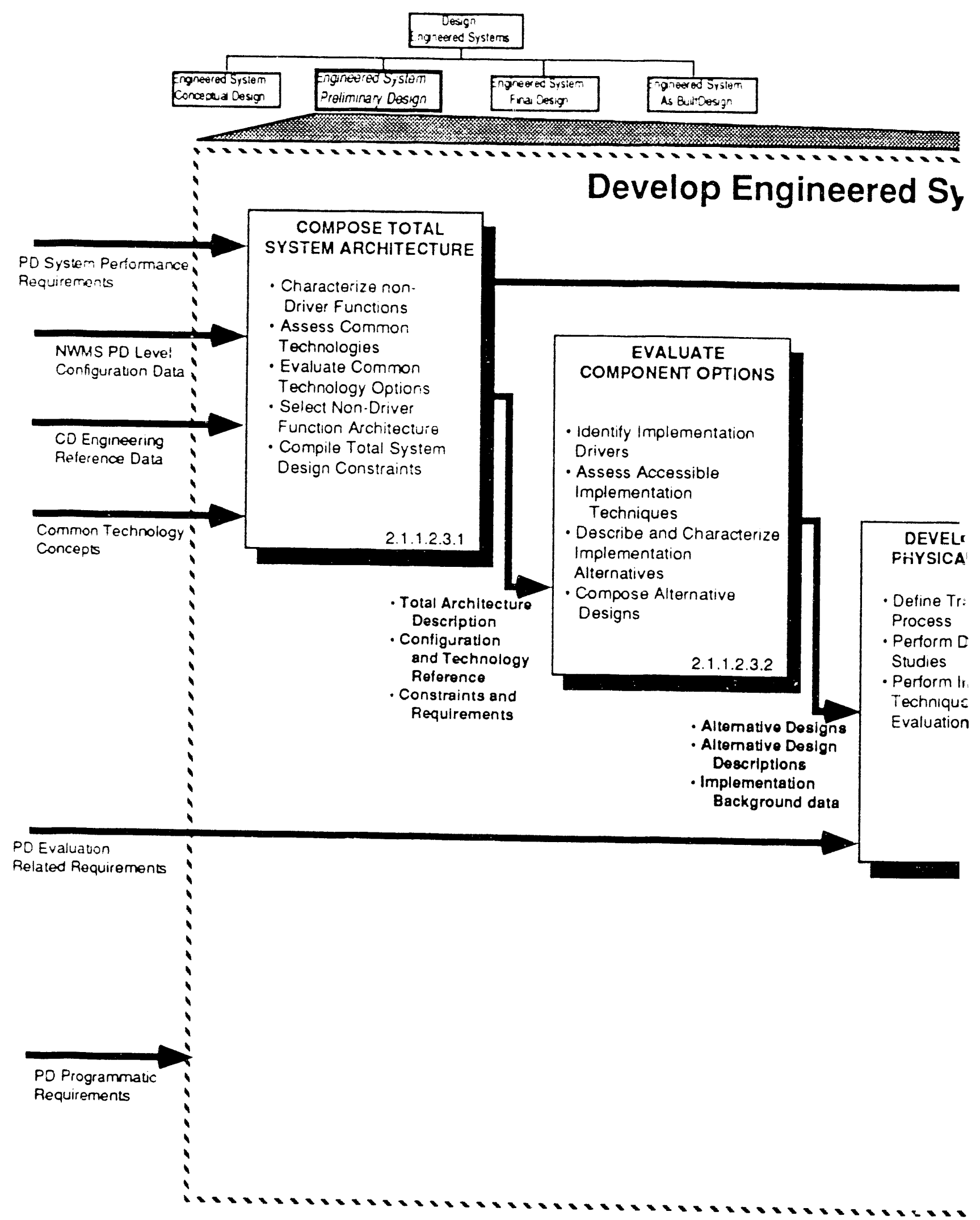


:PD Engineoring

Reference Data

1

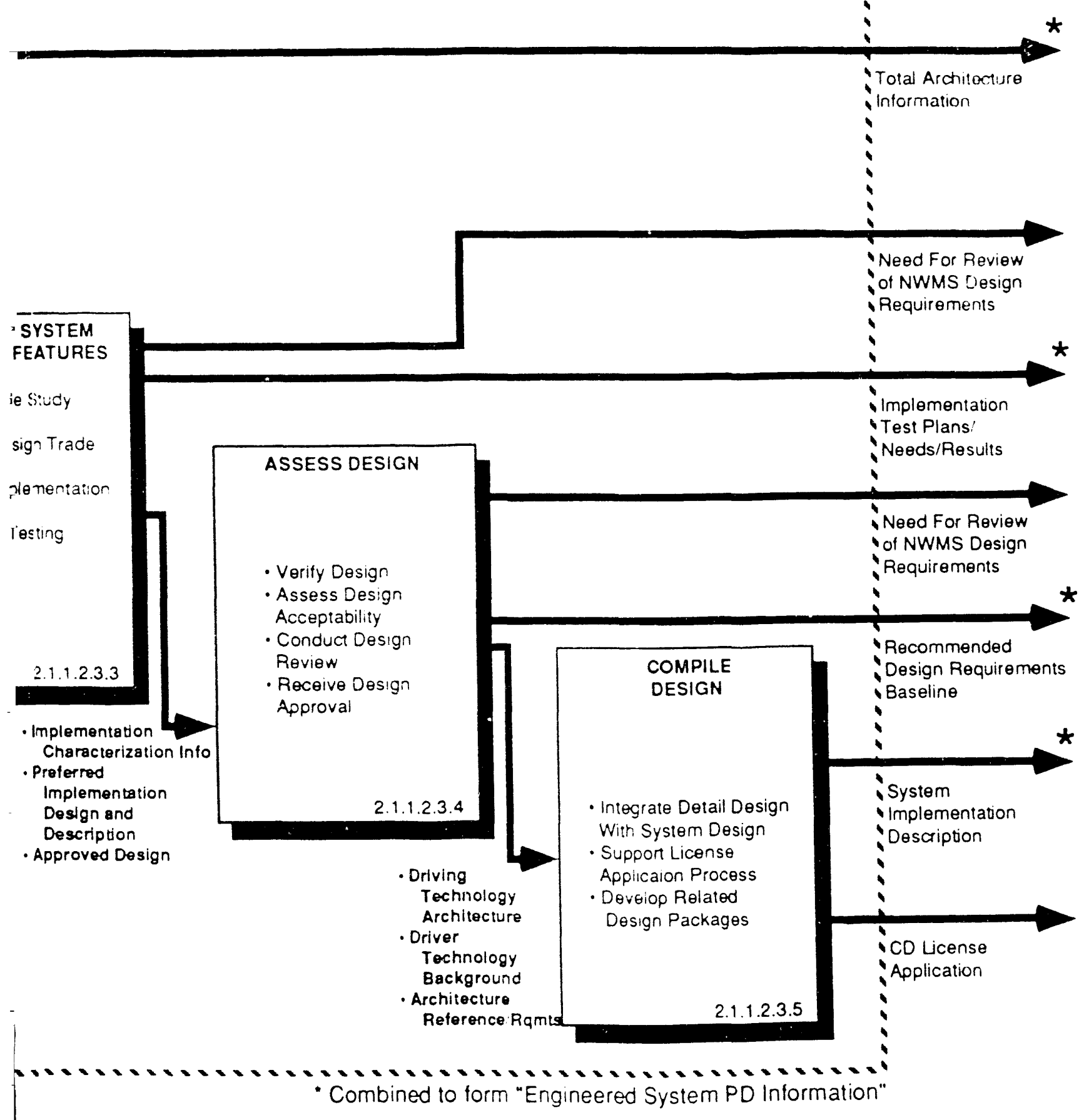


- The Compile Design Description function compiles a complete design package for use in final design and archives all relevant data/results from the Preliminary Design phase. It includes technical support to the license application process and produces the necessary application documents from the integrated design description.

The design assessment process is the focal point for both iterations and feedback in the Pieliminary Design Process. Iterations in Preliminary Design can occur in the following ways:

- Iterations on Implementation Techniques and Trade Studies: The design assessment process can identify a need for additional data or for additional design alternatives; this causes feedback to earlier steps in Preliminary Design produce the needed data or alternatives

- Interface to External Review and Evaluation Iterations: Preliminary Design is used as a basis for external regulatory review and license applications: these can also identify needs for more data or additional alternatives. These needs can result in redirection of the design process (see PPC function) to repeat parts of Preliminary Design on some/all system items.

\subsubsection{Outputs. The primary product of Preliminary Design is the} Recommended Design Requirements Baseline. The sum of a 11 Preliminary Design outputs addresses all needs for Final Design. The Recommended Design Requirements Baseline encompasses the following:

- Definition, description. specification for all components in the engineered system including all components to isolate wastes and a 17 support systems required for their operation

- Detailed evaluation of all system characteristics and behaviors related to system requirements focussing on isolation performance but including detailed analyses for safety. reliability. logistics, maintainability. fabrication

- Analytical evaluations and test reports from prototype hardware testing.

The Preliminary Design process produces several other outputs. An early output of Preliminary Design is the Total System Architecture. This product is a complete architecture of technology concepts for all (driver and nondriver) system functions and contains specifications. constraints, and derived requirements. Preliminary Design also provides support to the License Application. This support consists of producing the technical package for applications, providing technical assistance during application reviews, and performing analyses to address review action items. Preliminary Design also generates developmental end-items information (consisting of end item specifications and descriptions, development approaches, and development resource requirements) and data to support integrated system evaluation (e.g. the results of directed testing and analyses).

4.3.2.4 Significant Considerations. To accomplish Preliminary Design effectively, analyses and trade studies must address details to the component level. The full scope of engineered system characteristics must be examined. 
The Preliminary Design is done when two criteria have been met: all components have been specified and characterized. and the design has been shown to meet requirements via the technical review/external review process.

Significant considerations for specialty engineering efforts during Preliminary Design include the following:

- Reliability: detailed reliability calculations at component. integrated assembly. system levels are performed: fault tree/failure mode analyses are performed: mean time between failures and mean time to repair specifications are produced for a) 11 components

- Maintainability/Maintenance/Logistics: design approach to achieve maintainability is defined and specifications for components to implement the approach are developed: maintenance approaches are defined for all components; logistics support requirements for all components are defined and characterized and support facilities/apparatus are defined

- Manufacturability/fabrication: preferred approach for producing a 11 components is developed and specified: cost/schedule characteristics are quantified.

- Safety: issues addressed include hazard analyses, accident analyses. safety systems design. operations control/emergency responses procedures, and critical nuclear safety components selection including part numbers/vendors/experience history and test results for those not previously used.

Significant considerations in planning a preliminary design include the

- Cost-Effective Trade Study Methodology: methodology should emphasize defining specific, controllable analysis tasks, ensuring analysis tasks address, the most important characteristics, and determining when enough data are available to select a design

- Plarning the Design Assessment/Review Process: schedule and milestones should be identified early for planning analyses: technical issues to be addressed should be specified early: a formal assessment mechanism should be defined to ensure adequate treatment of all action items

- Methodology to Respond to Updates: many design input updates are expected including site characteristics, program plans, interface designs, and external requirements updates: a process is necessary to ensure that updates are accommodated in a consistent manner and that updates do not prevent progress. 


\subsubsection{Final Design}

4.3.3.1 Mission/Objective. Final Design (2.1.1.2.4) develops all specifications, instructions, constraints, and descriptions necessary to control implementation (i.e.. construction. fabrication, installation, and assembly) and acquisition of the selected engineered system design. The Final Design produces the following:

- Specification of all parts. items, processes, fabrications. constructions necessary for implementing the system: specifications are sufficient to purchase each of the above from a qualified vendor

- Instructions for performing all processes, fabrications. constructions, installations during system implementation: includes procedures for verification

- Technical support to acquisition via technical documentation to be used in acquiring all parts, items, processes, fabrications, constructions from vendors.

4.3.3.2 Process Flow. The Final Design process selects the end-items that correspond to the components defined in the Design Requirements Baseline. The acquirable end-items that Final Design selects can be defined as pieces of physical hardware, physical fabrications. or physical processes that can be acquired as a unit. To implement the Final Design, an end-item must be specified for all engineered items in the system. The Final Design process is summarized in Figure 4-5. The first tier of subfunctions to Final Design is shown in the figure and can be described as follows:

- The Identify End-Items function is first step of the Final Design process and establishes a database of end-items that are accessible to the program and compiles all technical materials describing them. The accessibility of end-items affected by program strategy (e.g.. national policy such as buying American products). program direction (e.g.. to meet regulatory agency preferences such as using hardware previously used in a given role), and program constraints (e.g., cost, availability, or schedule). Developmental end-items are considered if they are consistent with program strategy, direction, and constraints. Accessibility criteria for end-items are developed as are the criteria used in the next step of the process to select the design.

- The Evaluate End-Items function selects and qualifies both vendor acquirable and developmental end-items. Vendor acquirable enditems are end-items that can be readily purchased from vendors such as existing parts or fabrications/constructions using standard processes. These parts and processes are evaluated against the specifications from Preliminary Design: analyses for the evaluations include structural/mechanical analyses. thermal/mechanical analyses, flow/throughput analyses. electrical/electronic circuit analyses. radiation transport/safety analyses, and reliability analyses. Developmental end-items are those items not readily available from suppliers and development contracts are required. Some end-items may be of sufficient scope 
WHC-EP-0482

This page intentionally left blank. 


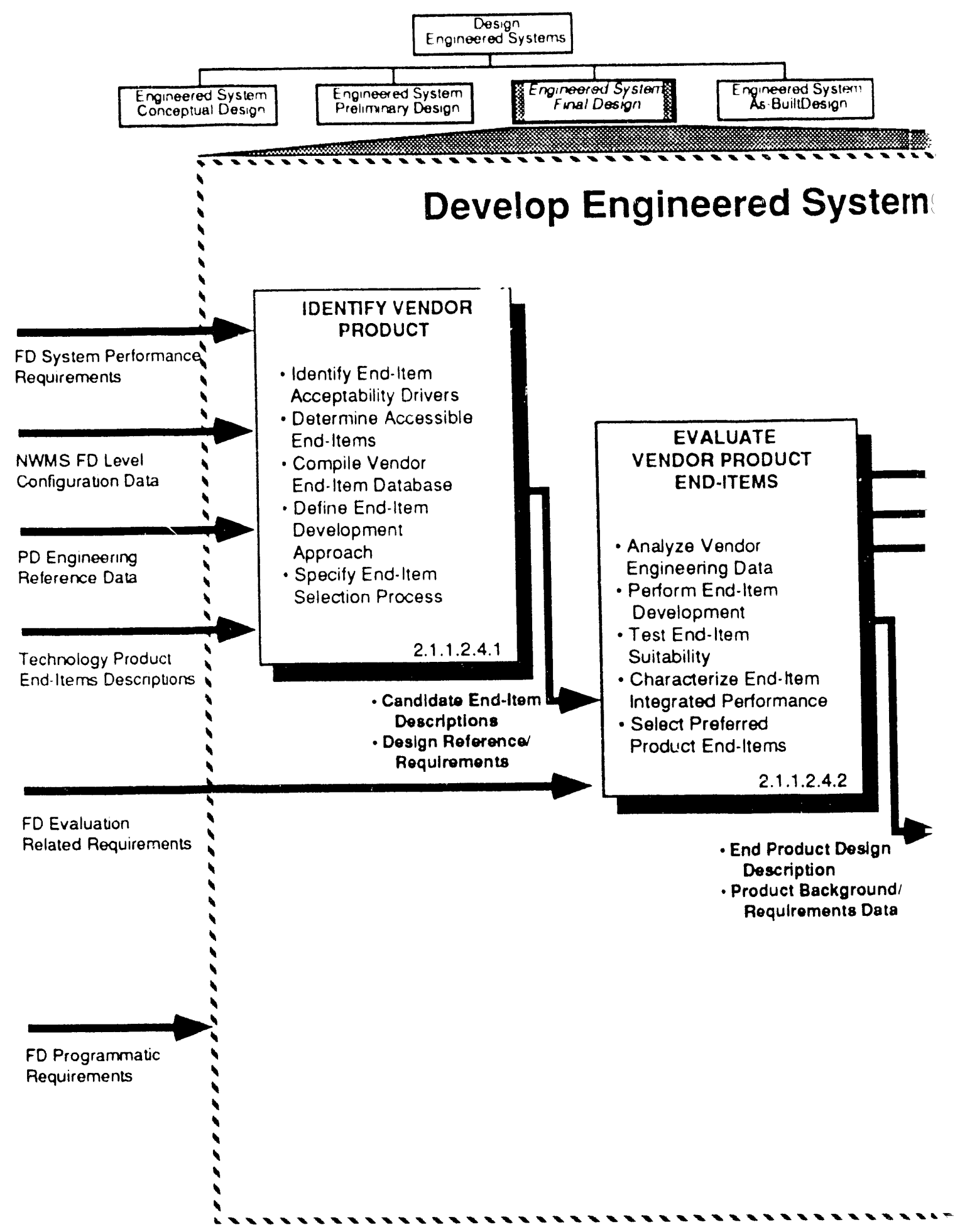


loupe a s frocess overview

develos rnameered syotems

ind Desian.
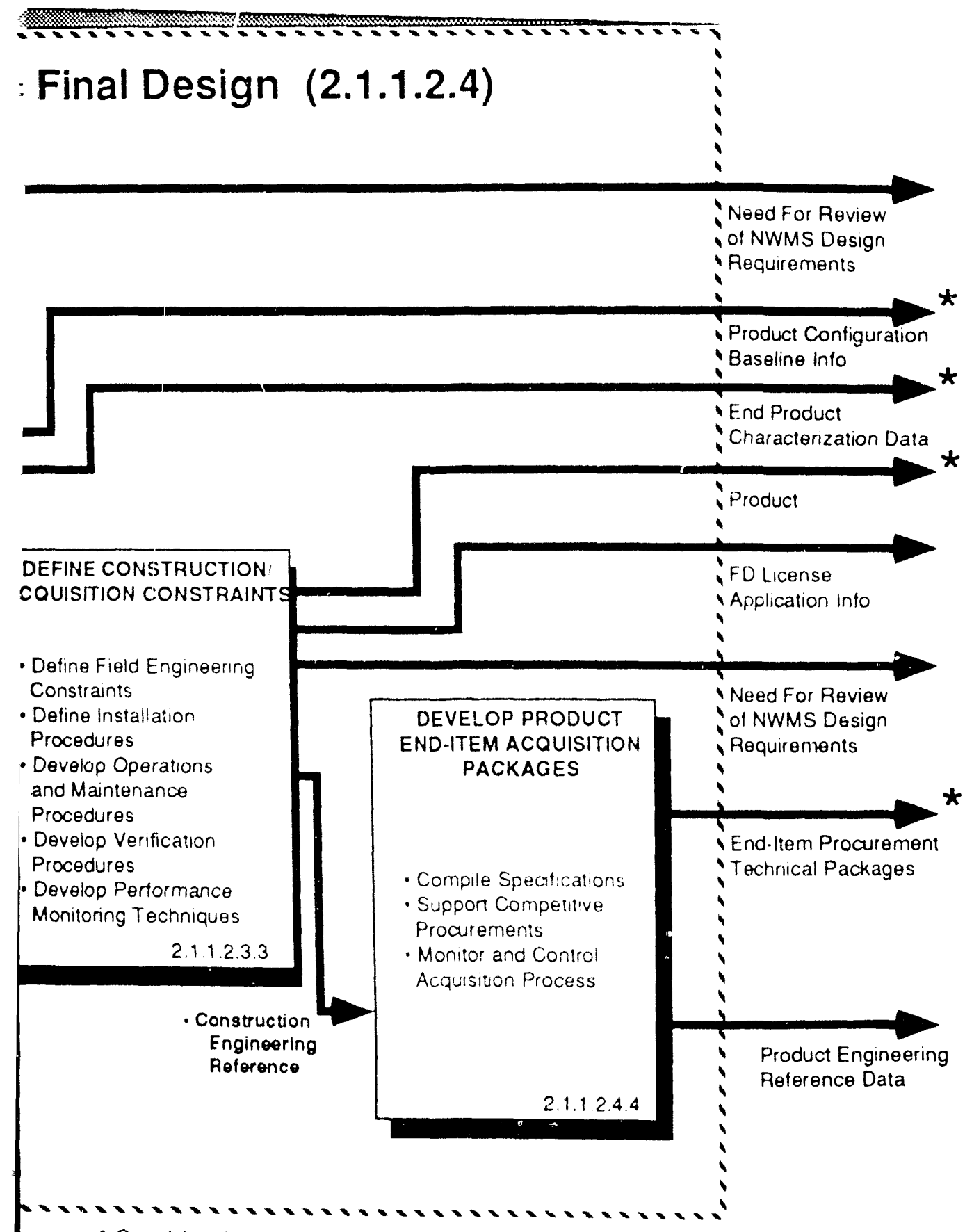

"Combined to form "Engineered System FD Information" 
that the development process is a microcosm of the complete engineering design process. The development process requires interfacing with business management functional processes and includes the define development technical approach. acquisition of research and development support (internal/externai). release/monitor or development contracts, and assessment of developed item suitability. The Evaluate End-Items function also includes all testing necessary to perform end-item evaluation and qualification for use. Integrated system performance analys is and behavior modeling is performed based on the details of the enditems. Analyses address parametric performance and performance under excursion conditions. Based on the results of analyzing individual end-items and the integrated assembly of end-items, the Final Design is selected. The selection of end-items defines the final design. The selection is based on performance requirements and criteria developed from program strategy. direction. constraints.

- The Define Construction/Acquisition Constraints function defines the procedures, processes, instructions, and constraints for deploying the acquired end-items to implement the system. It defines how to build and operate the system built from the selected end-items.

- The Develop Product End-Item Acquisition Packages function defines all the technical materials that will be used in the business management processes for purchase/contracting/acquisition of the selected erid-items.

The Final Design Process completes the specification of the system configuration. From a program flow perspective, Final Design forms the interface between configuration specification and configuration implementation. The information flow from Final Design forms an interface to the MSIS functions in the Implement systems area. Key issues in this process are the following:

- Interfacing via Controlled Information: All products from final Design (like those from earlier design phases) are delivered to the technical information auditing/control and technical review processes (see PSE). The ultimate destination for Final Design data is generally outside of the Configure System process:

Interfacing to Engineered System Construction: Field engineering and installation procedures define how construction will be performed.

- Interfacing to Engineered System Operations: System operations and maintenance procedures and performance monitoring procedures are key inputs to system operations processes.

- Interfacing to Business/Contract Management: End-item acquisition technical packages are produced solely to support the business management process of acquiring the selected end-items.

Interfacing to EIS and Perform Confirmation/ Operational Test (PCOT): System verification procedures are in 
response to levels of verification required to support integrated system evaluation and are a key input to the system testing process.

- Internai Iterations: Because of the detail in analysis and review/approval in Preliminary Design. it is expected that minimal iterations will occur among Final Design steps. Iteration loops included in the functional analys is are those from the procedure and technical package development back into the analysis of enditems.

4.3.3.3 Outputs. The Final Design products consist of the Recommended Product Configuration Baseline, the set of procedures to constrain system acquisition and implementation, and the technical information packages for use in the business/contract managemerit process of engineered item acquisition. These products can be described as follows:

- Recommended Product Configuration Baseline. This consists of specifications defining each part to be purchased. fabricated. constructed and includes definitions of the fabrications ario constructions and the methods by which they will be implemented and controlled to meet requirements. Performance characterizations are included with the baseline and address all levels of system integration from individual end-items. through assembiies of end-items and subsystems, to complete system. Al1 performance characteristics addressed in Preliminary Design (isolation performance and waste throughput and detailed analyses for safety, reliability. logistics, maintainability, fabrication. etc.) are examined using parameters specific to the selected enditems. Characterization data inciudes analytical evaluations and test reports from prototype/example handware testing.

- Engineered System Procedures. These procedures define how to assemble the system from the acquired end-items, how to verify that it meets requirements, and how to operate it once it is assembled and verified. These procedures include field engineering procedures defining the bounds on construction engineer implementation of site specific hardware. installation procedures defining all critical integration steps required to ensure end-item integrity, operations and maintenance procedures defining how each item. assembly, and subsystem will be operated and maintained, verification procedures defining test. measurement, and analysis procedures to verify hardware is as designed, and performance monitoring procedures defining test. measurement, and surveillance techniques for continuing evaluation of system performance throughout its life cycle.

- End-Item Acquisition Packages convert the system configuration/design into technical documents that are used in the procurement process.

The following additional information is produced during Final Design: End-item description database: Archive of technical material on end-items examined 
- Developmental Item Information: Technical support to business management for research and development contracts to implement development approaches

- Support to Integrated System Evaluation: Results of testing and analyses in response to requirements to support integrated system evaluation

- Need for Requirements Review: Identification of issues in obtaining or developing end-items to meet specifications from Preliminary Design given program strategy. direction. constraints: causes a technical review (see PSE process) that may generate input to the change control and program evaluation processes (see PPC process).

4.3.3.4 Significant Considerations. Significant considerations in performing Final Design include the following:

- The Final Design is complete when a 11 parts are defined to the point that procurement contracts be let for all items and all field engineering. construction. and installation processes are available to build the system from the acquired parts.

- All safety and specialty engineering analyses performed in Preliminary Design must be repeated during the final design using the data on the parts to be acquired. Alt input values for reliability, maintainability. logistics. manufacturability, etc., are verified with tests or vendor experience data.

Significant considerations in planning a Final Design effort include the following:

- Integration of Testing: Test data are critical to design credibitity. The planning of the Final Design effort must establish clear criteria for what must be tested. must incorporate sufficient consideration for testing into the program schedule. and must allocate sufficient resources for performing the testing.

- Structuring the Interface to Business Management: The interface between the engineering and business management processes must be structured to identify information and product needs for timely response. to balance cost and technical needs, and to provide schedule control for both engineering products and acquisition milestones.

- Developmental End-Item Planning: The development of some enditems may be of sufficient scope that it can be modeled by the same steps used to model the overall design process (i.e.. a conceptual design, a preliminary design, and a final design): thus, the Final Design process can be divided into many parailel efforts that must be closely integrated to ensure compatibility of the final products.

\subsubsection{As-buitt Design}

4.3.4.1 Mission/Objective. As-Built Design (2.1.1.2.5) develops a system documentation package that will support the system life cycle from 
construction through decommissioning. The As-Built Design package must support all system operation and evolution activities from the completion of system construction through decommissioning (including system initiation. system waste storage operations, system decommissioning operations, and postdecommissioning isolation monitoring and surveillance). The documentation to support the remainder of the system life cycle must be complete and detailed. It must incorporate all details from construction and field engineering, from vendor parts, and from testing that establishes performance. It must also include a complete system characterization to serve as a baseline for comparison to current system capability once operations commence. It must include substantiation that this baseline is acceptable, given the design from which the system was constructed.

4.3.4.2 Process Flow. The As-Built Design process reviews all information generated during system implementation and compiles that information into a complete description of the nature and characteristics of the system actually obtained. The As-Built Design process is summarized in Figure 4-6. The first tier of subfunctions in As-Built Design is shown in the figure and can be described as follows:

- The Review field Data function reviews, evaluates, and analyzes field data from system implementation to determine if the implemented system conforms acceptably to the design. Field data consists of values for field selectable items. measurements on size/shape/form factors. field inspection and installation integrity examinations. quality assurance data. verification test data, etc. The evaluation of field data examines all aspects of system fidelity to design including operating characteristics. reliability, safety, etc.: it includes examining subsystems and integrated assemblies of end-items.

- The Evaluate Vendor Engineering Data function reviews, analyzes, and evaluates the characteristics and engineering descriptions of vendor supplied end-items. Vendor engineering data is information provided by end-item suppliers defining the end-item design (including drawings). performance (including qualification and quality assurance measurements), operation, reliability, and safety: all data generated by the supplier at his location. These data. when integrated with the field data, are used to evaluate both end-item performance and system performance. The evaluation use analysis tools and models from Final Design

- The Compile As-Built Design Package function generates a complete package to document the system hardware. its characteristics, and its development history. It uses the design package from final Design and the field data and vendor engineering uata.

The As-Built Design process supports system operation and provides key inputs to the evaluation of the integrated system as follows:

Interfacing via Controlled Information: All output from the As-Built Design process (like that from earlier design phases) is delivered to the technical information auditing/control and technical review processes (see PSE) prior to dissemination to other MSIS Functional Processes. 


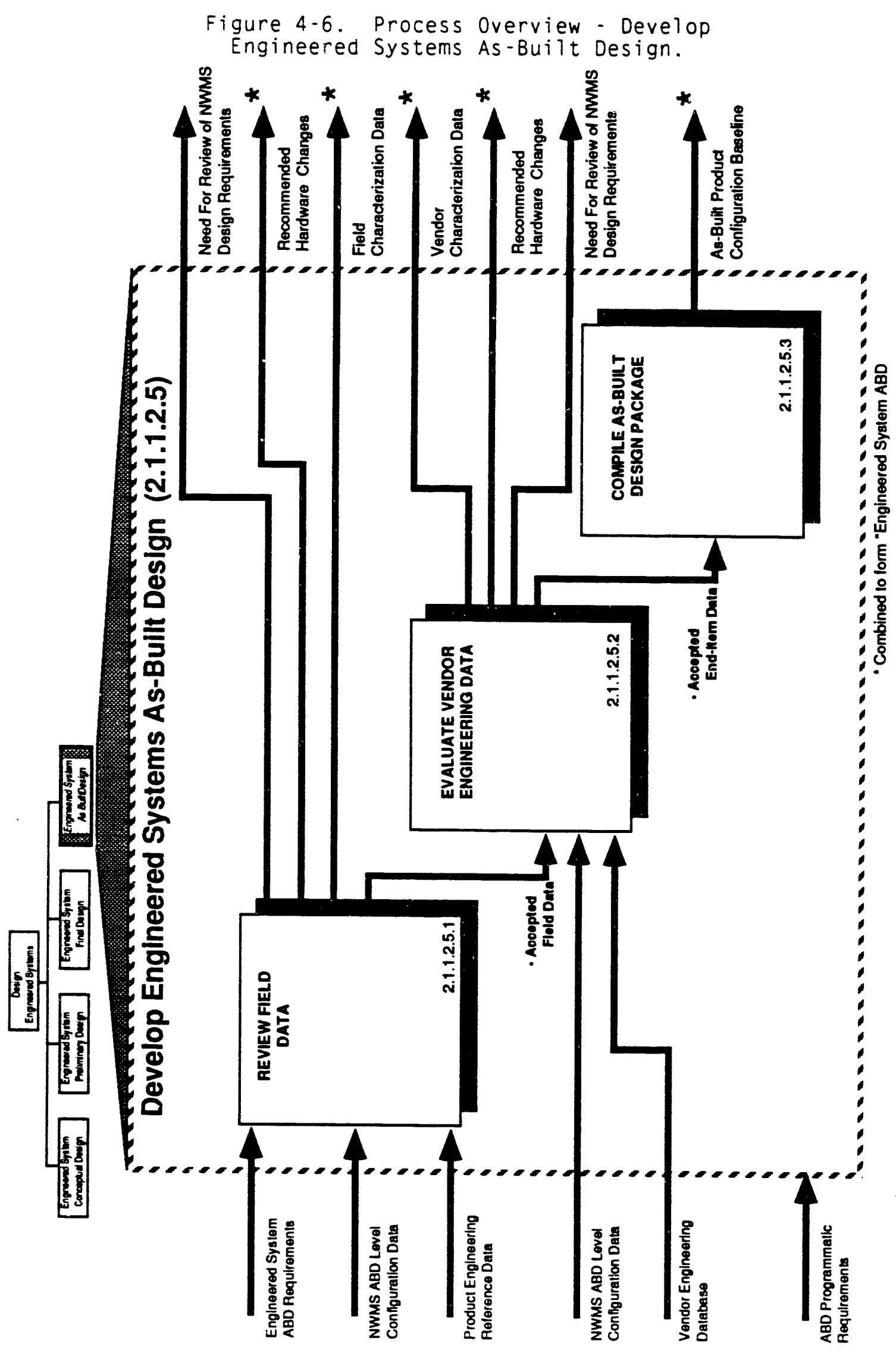


WHC-EP-0482

- Interfacing to Engineered System Operations: The As-Built Design package. combined with the operations and maintenance procedures. form the working document used to control system operations.

- Interfacing to Integrated System Evaluation: The characteristics of the as-built system are a key input to integrated system evaluation. The As-Built Design process essentially preprocesses the raw data from implementation into a form useful in the suitability evaluations (see EIS process).

4.3.4.3 Outputs. The As-Built Design output integrates the final design with field data, vendor design data, and hardware characterization analyses. As-Built Design products the following:

The As-Built Design Package: The As-Built Design package is formed from the Final Design by incorpcrating all implementation data. A complete Final Design is included in the As-Built Design. Field data/vendor data are added so the Final Design as an expansion in detail. All variances, substitutions, and discrepancies are noted and traced to their origin and to approval. Hardware performance characterization is included and compared to the corresponding Final Design information. A 11 variances, substitutions, and discrepancies are noted and traced to their origin and to approval.

- Recommendations on Variances: Review of field/vendor data may identify discrepancies between the Final Design and the hardware procured. Each is analyzed in detail. If acquired hardware is not acceptable. then a change is requested. If the recommendation is acceptable, then a notification of acceptance is issued and the change is noted in the package.

- Request for Requirements Review: Analyses of as-built performance may show that the design does not perform as predicted even though the acquired hardware matches design. A request for technical review is made. This may ultimately yield either a change in the requirements or in a repeat of a design step.

4.3.4.4 Significant Considerations. In performing the As-Built Design Function, the following considerations are significant:

The driving consideration in the As-Built Design process is the effective implementation of the interfaces between the the As Built Design process and the processes it supports.

- The As-Built Design process will increase the amount of technical information by at least an ordei of magnitude. This will severely strain the information databasing and control processes (see definitions in PSE process). The definition of the databasing and control methodologies and the as-built design analysis methodologies, and the integration between the two. must ensure completeness, thoroughness, and control during compilation of the As-Built Design Package.

- The results of the As-Built Design analysis and characterization constitute the bulk of the input to the integrated system evaluation (see EIS process). The two processes have distinct goals (As-Built design to verify the design has been implemented 
and EIS to verify compliance). The integration between the two processes must be such that both goals are accomplished.

\subsubsection{Develop Engineered Systems Design Reference}

4.3.5.1 Mission/Objective. Develop Engineered Systems Design Reference (2.i.i.2.1) provides a forma i integrating information link between a given design effort and the corresponding site characterization process. and between parallel engineering design efforts addressing different elements of the physical system.

Parallel and relatively independent functional processes [e.g.. DES and Identify and Characterize sites (ICS)] must have formal definitions for how each process will represent the physical items and processes shared in common. The design reference provides this formal definition of the physical system aspects that exceed the scope of any single functional process. Because there may be multiple design efforts, there will be a design reference for each engineering design program and its contents will be tailored to the needs of the design effort it supports.

4.3.5.2 Process Flow. The Engineered Systems Design Reference is developed from the information in the Controlled NWMS Information database that is produced in the PSE process. The process flow for forming the design reference is as follows:

- The first step is the assessment of mission and function analysis and mission environment. This assessment determines what factors from processes outside DES will influence the results of a given design effort. It assesses the level of detail required for design, assesses outside models for utility and defines terms. effects. and algorithms. This step applies to site characteristics in particular.

- The next step is the assessment of interfacing requirements and interface designs. This step assesses interfaces to engineered systems being addressed in parallel, independent engineering programs. It assesses the evolving interface design detail. determines the level of definition detail required, selects common models for interfaces, and defines terms, effects, and algorithms.

- The third step in producing the design reference is the incorporation of program direction. Program direction and program strategy are examined to determine how to resolve impasses among the needs of the parallel efforts. The examination prioritizes influences on interface nature, defines bounds for evolution of interfaces, and implements data exchange/coordination.

- Finally, the Design Reference is formalized by compiling the results of the above steps into an official document to describe how the interfaces (to other engineered system and to natural systems) will be represented in engineering analyses. It defines how interfaces will be treated in parametric analyses, excursion studies. and testing. and includes the interface reference description and algorithms. 
The Engineering Design Reference forms the primary information link between the engineering effort and the site effort and between parallel engineering efforts. It plays the following key roles:

- Site Characterization Interfacing: The design reference for site information is updated for each phase of the design effort. The key issues are to determine the latest, most appropriate, site characteristics and to assess all site data to determine characteristic trends for use in parametrics and excursion studies.

- Parallel Design Effort Interfacing: The design reference is updated at each phase of the design effort, and whenever the parallel design programs significantly evoive their half of the interface design.

4.3.5.3 Outputs. The Engineering Design Reference specifies the design bases with respect to mission environment. site, and interfaces to engineered elements outside the scope of the current design effort. The Design Reference has the following three elements:

- Mission environment definition that includes all variations in conditions defining how the engineered system must accomplish its mission. It defines throughput variations, feedstock variations. etc. It defines the bounds on the system included in program strategy and is closely connected to system performance requirements.

- Site characteristics reference that specifies the values to be used in the design calculations, the bounding values for parametrics and excursion studies. and site performance algorithms used to assess interactions between engineered and natural systems.

- Engineered systems interface reference that specifies the values to be used for parallel system parameters, the bounds on these values and their behavior trends for parametrics and excursion studies, and the performance algorithms used to assess interactions between the two engineered systems.

4.3.5.4 Significant Considerations. The two most important considerations in developing design references are coordination and formalization. Coordination is critical to ensure accuracy and timeliness of the reference: coordination prevents changes from passing unnoticed by the parallel effort. Formalization is critical to ensure that all design processes. staff. models. etc. use the same representation of the parallel system and thus achieve comparable results.

\subsection{DESIGN ENGINEERED SYSTEMS INTERNAL INTERFACES}

The engineering design process is an interative process in which requirements are analyzed. alternatives are characterized, a selection is made and assessed, and then revised based on the comparison with requirements and constraints. The most important iteration paths are shown in Figure 4-7. 
Figure 4-7. Design Engineered Systems -

Major Feedback Loops.

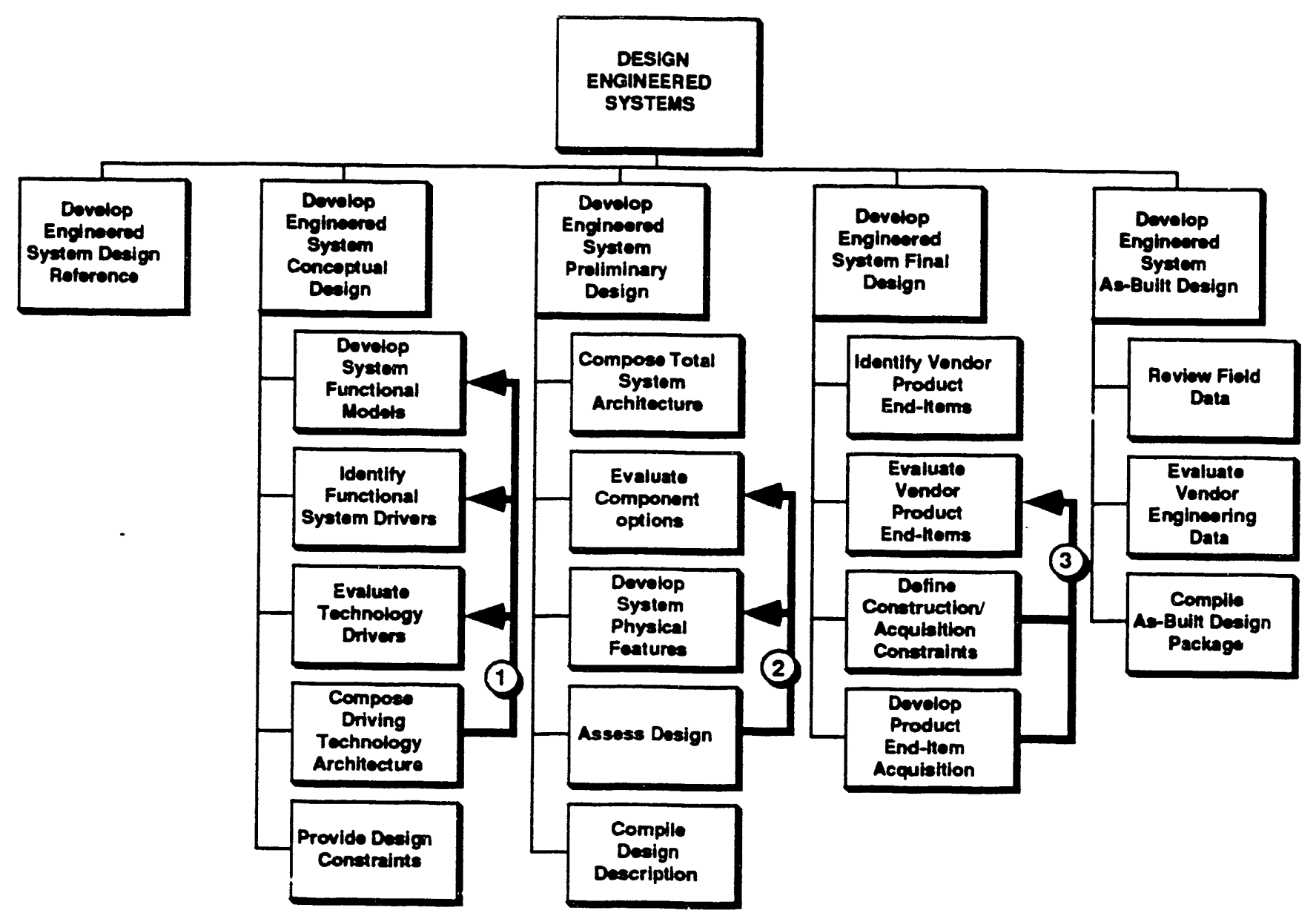


This figure shows that at the end of each design phase, there is a design evaluation and selection step that can cause internaliy controlled iterations within each design phase. This step can identify a need to repeat one or more of the earlier steps. The reasons to repeat earlier steps are as follows:

- Insufficient information to make a decision, more analyses are required.

- Insufficient information to complete the programmatic requirements for characterization and documentation.

- None of the candidates successfully meets all the criteria. additional candidate designs are required.

- Requirements have changed and the selected design is no longer completely satisfactory, part of the design needs revision.

The feedback loops in Conceptual Design (labeled 1 in Figure 4-7) can be initiated during the selection of the technology concepts for system drivers. Shortfalls in the existing technical material and analysis results may be found that prevent selection of any candidate for the Driving Technology Architecture. The shortfalls could be a need for a better model to quantify evaluation criteria or could be a need for better model validation to improve the veracity of selection criteria values. Both cases cause feedback to model development steps of Conceptual Design for model enhancements. Alternatively. the selection process could find that some driver function issues are not sufficiently addressed or that there are concerns with the particular characteristics obtained for a driver. This causes feedback to the sensitivity analyses in the system driver identification subfunction of Conceptual Design. Additionally, the selection process could find that the data on technology concepts is insufficient to prove the concepts can be made to meet requirements. This causes feedback to the parametric analyses in the technology evaluation function.

The feedback loops in Preliminary Design (labeled 2 in Figure 4-7) can be initiated during the design assessment. The assessment could find that characterizations of individual implementation techniques are insufficient to justify selection of any candidate technique. This causes feedback to the component technique characterization analyses and testing in the component options evaluation function. The assessment could also find that characterization of complete system design is insufficient. This causes feedback to trade studies and experiments in the system physical features analysis function. In these two cases earlier functions are reinitiated not because the candidates do not meet requirements but because the design data is not sufficient to prove or disprove that they meet requirements. If it is determined that no designs meet requirements, then there is feedback to the Evaluate component options function where candidate designs are formed. This is followed by a repeat of the trade studies in the Develop System Physical Features function. Note that there are also iterative loops within the Compose Total System Architecture function to select and optimize the technology concepts for nondriver functions; these are not shown because the figure does not show the fourth tier subfunction involved in the iterations.

The feedback loops in Final Design (labeled 3 in Figure $4-7$ ) originate in the development of system procedures and acquisition packages. It could be found that the characterization. evaluation, and qualification of end-items is insufficient to develop procedures for construction and operation. This causes feedback to the end-item analyses in Evaluate Vendor Product End-Items 
function for addition analyses and characterization. Alternatively, it could be found that the characterization, evaluation. and qualification of end-items is insufficient to develop procurement packages. This also causes feedback to the end-item analyses in the Evaluate Vendor Product End-Items function for additional end-item analysis. 
WHC-EP-0482

This page intentionally left blank. 
WHC - EP- 0482

\subsection{IDENTIFY AND CHARACTERIZE SITES}

This section describes the process by which sites will be identified and characterized for evaluation as potential hosts for the elements of the Nuclear Waste Management System (NWMS). The discussion includes the following elements:

- An overview of the Identify and Characterize Sites (ICS) function. to include function mission and scope descriptions, and a process overview

- Key interfaces with other functions in the Office of Civilian Radioactive Waste Management (OCRWM) program for development and application of the NWMS

- Identification and review of the major subfunctions of the ICS function

- Identification and description of the significant internal feedback loops and processes required for successful process execution or are needed to correct problems/address issues which must be addressed before the process can be successfully completed.

\subsection{MISSION AND PROCESS OVERVIEW}

\subsubsection{Mission/Objectives}

The mission of the ICS function is to identify sites that are potentially suitable to be hosts for elements of the NWMS and to acquire scientific and socioeconomic characterization data sufficient to meet requirements for evaluation of these sites (by the Evaluate Integrated System (EIS) function) relative to each other and relative to their ability to meet regulatory requirements imposed upon them. The mission encompasses the following three primary site types:

- Potentially acceptable transportation routes between sources of high-level radioactive waste and the processing facilities of the NWMS

- A suitable site for monitored retrievable storage before permanent disposal

- A geologic formation suitable for permanent disposal of tha highlevel waste.

This function plays a critical role in the early stages of system configuration development by identifying potentially acceptable geographical locations for the NWMS elements, and later nominating sites for characterization. The execution of these activities correspond to major program milestones, particularly for the Mined Geologic Disposal System (MGDS) where the need for these activities is already established by regulatory requirement. 


\section{1 .2 Scope}

The functions that must be performed to accomplish the mission defined for ICS function are shown in Figure 5-1. The functional structure for selecting potentially suitable sites and acquiring the data with which to evaluate compliance with requirements is viewed, within this analysis, in terms of the following three basic subfunctions:

- Identification of a comprehensive set of transportation routes. interim storage facility sites, and permanent disposal sites (combined in subsequent discussion into the single term. sites)

- Nomination of a limited number of sites within each of these categories for characterization

- Characterization of sites to acquire technical and socioeconomic data to augment existing data such that sufficient information is available to support evaluation and comparison of sites against all performance criteria.

The primary focus of this function is the generation of site data to support design development, system evaluation, and regulatory submittals. It generates these data in response to requirements identified by other functions, and imposed on this function by the Perform Systems Engineering (PSE) function. It is important to note that characterization data acquired during performance of this function are used primarily by the EIs function to assess site suitability: the scope of ICS function is limited to the acquisition of data to support technical and socioeconomic assessments and does not extend to the application of that data to site evaluation.

Characterization. though its main component is geologic and hydrologic testing of potential repository sites, also includes: analyses. literature searches. and any other data acquisition method that would provide technical or nontechnical information to support the EIS function for sites for any of the NWMS elements.

The decomposition of this function down to the third level is shown in Figure 5-1. This representation depicts a fundamental characteristic of the functional decomposition, namely, that the subfunctions shown at any level. obtained by decomposing the function immediately above. represent identically the same mission as the parent function from which they were derived (but with greater precision). In a complete function hierarchy. the set of lowest level functions (not shown in Figure 5-1) constitutes the most precise representation of the functions necessary to accomplish the NWMS mission.

\subsubsection{Process Overview}

The process relationship among the three second-level functions identified in Figure 5-1 is shown in Figure 5-2. If each function executes successfully, the process is serial. With the first function being essentially a coarse screening of potential sites, the second a more refined screening. and the third a data acquisition function from which a sound, defensible assessment of site suitability can be made. The first two functions in Figure 5-2 are relatively straightforward examples of formal decision making and. therefore, require little or no further decomposition to reach a level at 
Figure 5-1. Identify and Characterize Sites-Function Hierarchy.

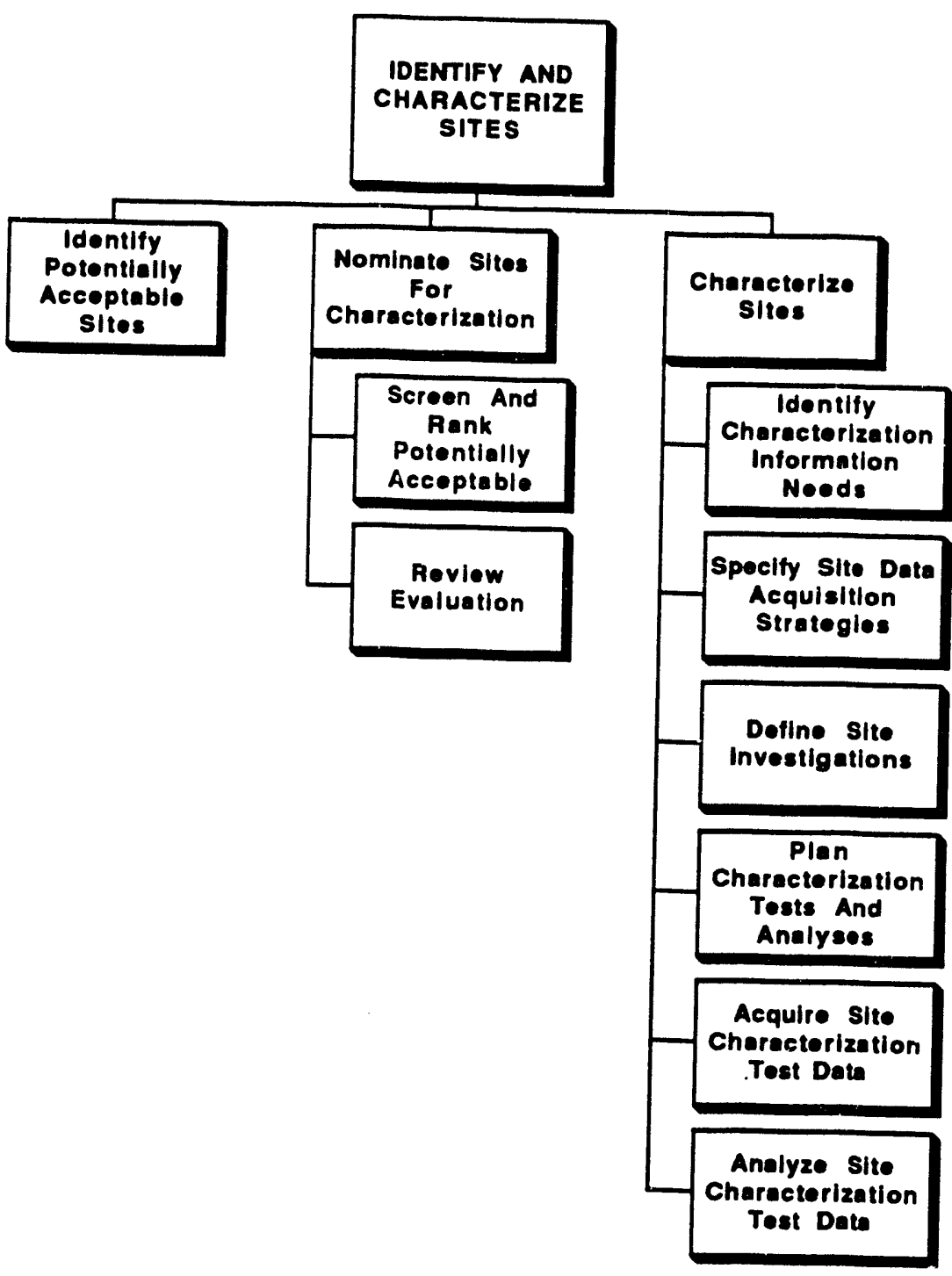


Figure 5-2. Process Overview--Identify and Characterize Sites.

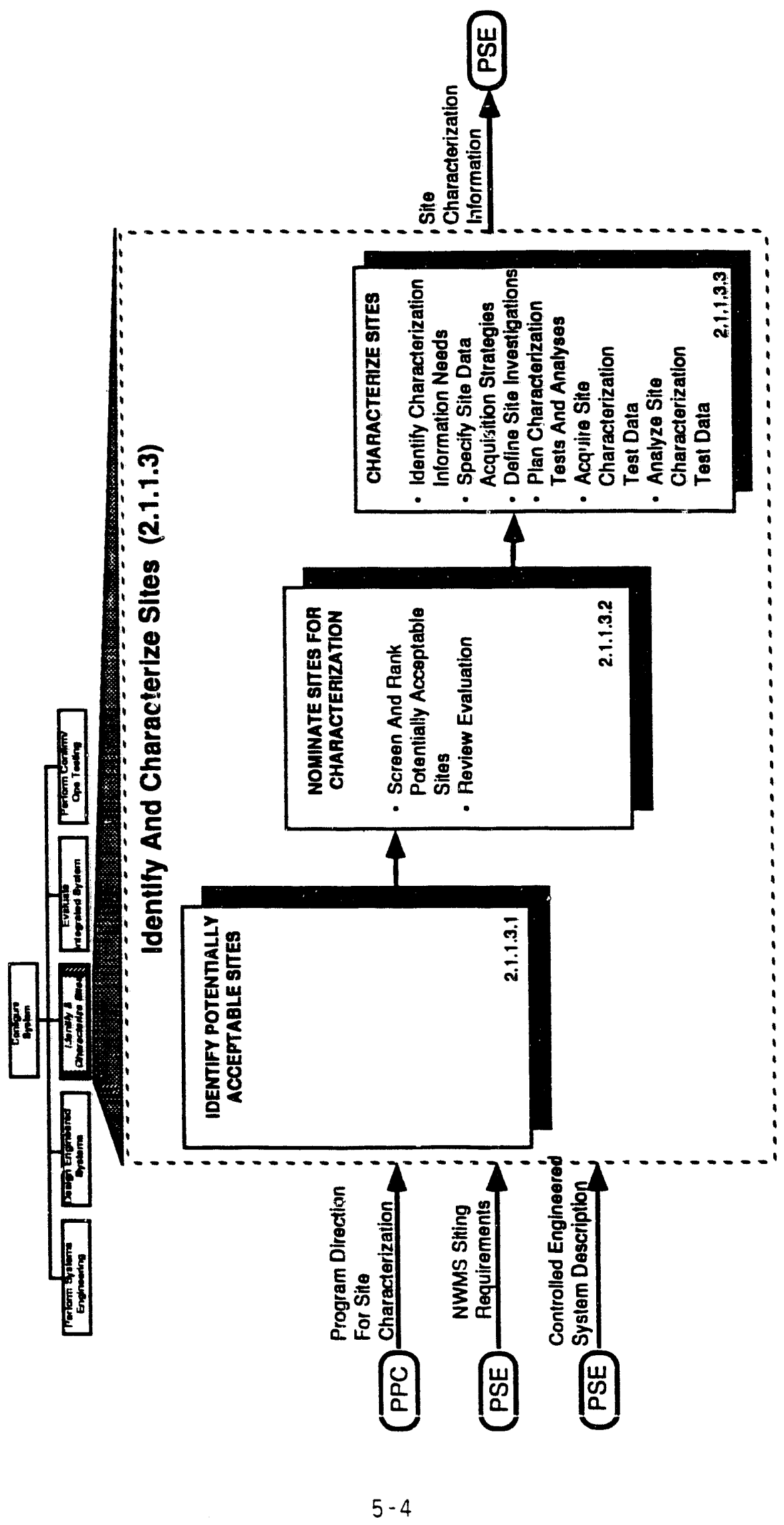


WHC-EP-0482

which performance of the functions can be defined in terms of standard practices and protocols. The third function. Characterize Sites. is decomposed into six subfunctions and entails determining:

- What information must be obtained

- How it will be obtained

- When it will be obtained and obtaining it

- Whether the quality and quantity of information acquired meets the requirements imposed on the function and is, therefore, suitable for the evaluation process to which it will be applied.

Figure 5-2 indicates the information flow paths for the ideal case in which each function produces a product that meets all of its requirements within the constraints of its initial inputs and controls. The information flows shown in Figure 5-2 can be termed the fully successful process. For simplicity, the specific products transported between functions are not labeled. and some are not shown: more detailed representations of the information flows are provided in function diagrams contained in The Analysis of the Program to Develop the Nuclear Waste Management System (Woods 1991a).

Although feedbacks between the three principal functions shown in Figure 5-2 are not depicted. the detailed functional process includes two information pathways from Nominate Sites fo: Characterization back to Identify Potentially Acceptable sites. but none froin Characterize Sites back to the identification and nomination functions. The premise of the functional structure with respect to these feedback paths is that the array of sites that will be characterized will meet at least one of the following criteria:

- Sufficiently extensive to ensure that at least one will meet requirements, or

- Sufficiently well-characterized before initiation of characterization testing to ensure that at least one of the candidates will meet requirements.

For this premise, the probability of needing additional candidate sites is judged to be sufficiently low that feedback loops from the characterization function to the site identification or nomination functions are not needed. Internal feedback loops are discussed more fully in Section 5.4. Internal Interfaces.

The EIS and Design Engineered Systems (DES) functions are the principal sources of requirements for, and principal users of, information generated by the site characterization function. The requirements and resulting data, however, are controlled and channeled to the information-generator and information-user functions, respectively. by the PSE function.

\subsection{EXTERNAL INTERFACES}

The interfaces between ICS function ind other functions in the NWMS program are expressed as inputs, controls, and outputs. Inputs are information that is transformed by the function into an output. Controls constrain the acceptable characteristics of the function output or the way in which the function is performed. An output is the product produced by the 
function. In this case, it is the body of information that supports evaluation of any site. The interface items, shown in Figure $5_{1}-2$ as three discrete items entering the function and one item leaving, are in fact diverse bodies of information. parts of which are used (or generated in the case of the output) in other functional processes. The product of an unsuccessful execution of the function. Need for Review of NWMS Siting Requirements, not showil in Figure 5-2. is discussed later in this section.

In the tables presented in this section. all of the functions that use or generate any part of an interface item are listed at the lowest applicable level included in the functional analysis: some of the indicated function names and numbers, therefore. do not correspond to functions discussed in this summary process description.

\subsubsection{External Inputs}

Inputs to the ICS function are summarized in Table 5-1.

Table 5-1. Summary of Inputs for Identify and Characterize Sites.

\begin{tabular}{|c|c|c|}
\hline $\begin{array}{l}\text { Input } \\
\text { Information } \\
\text { Name }\end{array}$ & Summary Description & $\begin{array}{c}\text { Functions Using Input } \\
\text { Information }\end{array}$ \\
\hline $\begin{array}{l}\text { Program Dir- } \\
\text { ection for } \\
\text { Site Charac- } \\
\text { terization }\end{array}$ & $\begin{array}{l}\text { An extensive array of potentially } \\
\text { suitable transportation routes and } \\
\text { processing facility sites is provided to } \\
\text { the Identify and Characterize sites } \\
\text { function via the Provide Program Control } \\
\text { function as the basis for selection of } \\
\text { potentially acceptable sites. }\end{array}$ & $\begin{array}{l}\text { 2.1.1.3.1. Identify } \\
\text { Potentiaily } \\
\text { Acceptable Sites }\end{array}$ \\
\hline $\begin{array}{l}\text { Controlled } \\
\text { Engineered } \\
\text { System } \\
\text { Description }\end{array}$ & $\begin{array}{l}\text { A description of the engineered system } \\
\text { that is controlled as part of the } \\
\text { technical baseline: used to evaluate } \\
\text { compatibility between a candidate site } \\
\text { and the engineered system that must } \\
\text { operate within that site. }\end{array}$ & $\begin{array}{l}\text { 2.1.1.3.2.1. Screen } \\
\text { and Rank Potentially } \\
\text { Acceptable Sites } \\
\text { 2.1.1.3.2.2. Review } \\
\text { Evaluation } \\
\text { 2.1.1.3.3.1.1.1. } \\
\text { Review Character- } \\
\text { istics of Site } \\
\text { 2.1.1.3.3.2.2. } \\
\text { Evaluate Impacts of } \\
\text { Data Acquisition } \\
\text { Strategies } \\
\text { 2.1.1.3.3.2.1.2. } \\
\text { Define Availability } \\
\text { Criteria } \\
\text { 2.1.1.3.3.2.1.3. } \\
\text { Select Feasible Data } \\
\text { Acquisition } \\
\text { Strategies }\end{array}$ \\
\hline
\end{tabular}




\subsubsection{Controls}

Controls that constrain performance of ICS are summarized in Table 5-2.

Table 5-2. Summary of Controls for Identify and Characterize Sites.

\begin{tabular}{|c|c|c|}
\hline $\begin{array}{l}\text { Control } \\
\text { Information } \\
\text { Name }\end{array}$ & Summary Description & $\begin{array}{l}\text { Functions Using } \\
\text { Control Information }\end{array}$ \\
\hline $\begin{array}{l}\text { Program Dir- } \\
\text { ection for } \\
\text { Site Charac- } \\
\text { terization }\end{array}$ & $\begin{array}{l}\text { The set of programmatic requirements } \\
\text { related to processes for conducting site } \\
\text { identification and characterization } \\
\text { functions. }\end{array}$ & $\begin{array}{l}\text { 2.1.1.3.1. Identify } \\
\text { Potentially } \\
\text { Acceptable Sites } \\
2.1 .1 .3 .2 .1 \text {. Screen } \\
\text { and Rank Potentially } \\
\text { Acceptable Sites } \\
2.1 .1 .3 .2 .2 \text {. Review } \\
\text { Evaluation } \\
2.1 .1 .3 .3 .1 .3 .3 \text {. } \\
\text { Reduce Redundancy of } \\
\text { Information Needs } \\
\text { 2.1.1.3.3.2.3.1. } \\
\text { Compare Strategies } \\
\text { with Screening } \\
\text { Criteria } \\
2.1 .1 .3 .3 .3 .1 .4 .3 \text {. } \\
\text { Reconcile Tests and } \\
\text { Analyses } \\
2.1 .1 .3 .3 .3 .1 .4 .4 . \\
\text { Select Tests and } \\
\text { Analyses }\end{array}$ \\
\hline $\begin{array}{l}\text { NWMS Siting } \\
\text { Requirements }\end{array}$ & $\begin{array}{l}\text { The subset of NWMS requirements derived } \\
\text { from interpretation of system } \\
\text { configuration direction and } \\
\text { implementation information which } \\
\text { constitutes requirements the site and } \\
\text { siting process must meet. The } \\
\text { requirements consist of site } \\
\text { identification. site screening and site } \\
\text { characterization requirements. Also } \\
\text { includes data requirements to support } \\
\text { the Evaluate Integrated System. Design } \\
\text { Engineered System and Construct Waste } \\
\text { Management System functions. }\end{array}$ & $\begin{array}{l}\text { 2.1.1.3.1. Identify } \\
\text { Potentially } \\
\text { Acceptable Sites } \\
\text { 2.1.1.3.2.1. Screen } \\
\text { and Rank Potentially } \\
\text { Acceptable Sites } \\
2.1 .1 .3 .2 .2 \text {. Review } \\
\text { Evaluation } \\
2.1 .1 .3 .3 .1 .1 .1 . \\
\text { Review Character- } \\
\text { istics of Site } \\
\text { 2.1.1.3.3.1.1.2. } \\
\text { Assemble Relevant } \\
\text { Conceptual Models } \\
\text { 2.1.1.3.3.1.3.1. } \\
\text { Standardize } \\
\text { Information Need } \\
\text { Descriptions }\end{array}$ \\
\hline
\end{tabular}


NWMS Siting

Requirements

(cont.)
2.1 .1 .3 .3 .2 .4 Reconcile Data Acquisition Strategies

2.1.1.3.3.3.1.1.2. Select Feasible Tests and Analyses

2.1.1.3.3.3.1.4.2. Rank Tests and Analyses

2.1.1.3.3.3.2.2. Reconcile and Select Facilities

2.1.1.3.3.6.2. Ident ify Parameters for Revised Models

\section{2 .3 Outputs}

The outputs for the ICS function are summarized in Table 5-3.

Table 5-3. Summary of Outputs for Identify and Characterize Sites.

\begin{tabular}{|c|c|c|}
\hline $\begin{array}{c}\text { Output } \\
\text { Information } \\
\text { Name }\end{array}$ & Summary Description & $\begin{array}{l}\text { Functions Receiving } \\
\text { Output Information }\end{array}$ \\
\hline $\begin{array}{l}\text { Site Charac- } \\
\text { terization } \\
\text { Information }\end{array}$ & $\begin{array}{l}\text { A compilation of site data at any phase } \\
\text { of the NWMS program: data include those } \\
\text { available prior to characterization } \\
\text { testirig in addition to test plans. } \\
\text { descriptions of test facilities and } \\
\text { prerequisites. well as processed) for } \\
\text { potentially suitable sites and for sites } \\
\text { disqualified at any point in the } \\
\text { screening or characterization processes: } \\
\text { also includes hypothesized conceptual } \\
\text { models of site features. processes and } \\
\text { predicted future changes. }\end{array}$ & $\begin{array}{l}\text { 2.1.1.3.2.2. Review } \\
\text { Evaluation } \\
2.1 .1 .3 .3 .1 .1 .2 \text {. } \\
\text { Assemble Relevant } \\
\text { Conceptual Models } \\
2.1 .1 .3 .3 .6 .1 \text {. Assess } \\
\text { Consistency of Site } \\
\text { Models and Data } \\
2.1 .1 .3 .3 .6 .2 \text {. } \\
\text { Identify Parameters } \\
\text { for Revised Models } \\
\text { 2.1.1.3.3.6.3. Revise } \\
\text { Parameter Attributes }\end{array}$ \\
\hline $\begin{array}{l}\text { Need for } \mathrm{Re}^{-} \\
\text {view of } \mathrm{NWMS} \\
\text { Siting } \mathrm{Re}- \\
\text { quirements }\end{array}$ & $\begin{array}{l}\text { Description of issues and problems in } \\
\text { complying with NWMS siting requirements } \\
\text { which. because they involve integrated } \\
\text { system decisions. must be resolved } \\
\text { within the Perform System Engineering } \\
\text { function; included are the need for } \\
\text { review of site identification, screening } \\
\text { and characterization requirements. }\end{array}$ & $\begin{array}{l}\text { 2.1.1.3.1. Identify } \\
\text { Potentially } \\
\text { Acceptable Sites } \\
2.1 .1 .3 .2 .1 \text {. Screen } \\
\text { and Rank Potentially } \\
\text { Acceptable Sites } \\
2.1 .1 .3 .3 .1 .1 .1 \text {. } \\
\text { Review } \\
\text { Characteristics of } \\
\text { Site }\end{array}$ \\
\hline
\end{tabular}


WHC -EP- 0482

\subsection{PROCESS EXECUTION DETAILS}

This section describes the major subfunctions for the ICS function. The functions are discussed initially only from the perspective of successful execution culminating in production of the desired product. Section 5.4 discusses feedbacks engendered by failure to execute the function successfully, either because of:

- Faulty or incomplete inputs, and/or

- An inability to perform within the constraints imposed by the controis.

\subsubsection{Identify Potentially Acceptable Sites}

This function provides an initial screening of the comprehensive set of sites that are potentially suitable locations for NWMS elements and includes transportation routes, interim storage locations, and geologic repositories.

5.3.1.1 Mission/Objective. The objective of this function is to identify and reject those sites that cannot meet requirements or that are clearly inferior to other candidates, and thereby to reduce the lists of candidates to sets that can be evaluated in greater detail.

5.3.1.2. Process Flow. To the extent possible within the constraint of available information, regulatory criteria for site selection are applied to this screening process, guided by policies and an initial, extensive list of candidate sites provided via the Provide Program Direction function. No decomposition below the primary function was judged to be needed, because the screening process was viewed as an application of standard. formal decisionmaking protocols.

5.3.1.3 Outputs. The product of successful execution of the function is a body of data that describes potentially acceptable sites that warrant more detailed consideration as candidates for characterization. These data are passed as a principal input to the succeeding function. Nominate sites for Characterization.

\subsubsection{Nominate Sites for Characterization}

5.3.2.1 Mission/Objective. The mission of this function is to evaluate potential acceptable sites to determine their acceptability and identify those which should be nominated for characterization.

Site nomination for characterization has a mission similar to that for the site identification process. However, the activity is conducted at a level of detail commensurate with the commitment of resources that will accompany selection of any site for characterization. There are several primary differences between the site identification and site nomination functions, these include:

- More detailed evaluation of the compatibility between sites and the conceptual designs for engineered systems 
- Greater focus on ranking sites in accordance with criteria weighted by importance. in contrast to sorting into acceptable or unacceptable categories in the site identification function

- More detailed review of the potential for compliance with regulatory and program direction requirements.

5.3.2.2 Process Flow. As shown in Figure 5-3, the site nomination function required decomposition into only two subfunctions to reduce it to the level of standard practices that needed no further decomposition.

5.3.2.3 Outputs. The function provides the following two categories of site data for use in evaluations that will ultimately lead to the selection of sites for characterization:

- Data for potentially suitable sites that can be evaluated without further characterization information

- Available data for potentially suitable sites that must be further characterized to establish a basis for suitability assessment.

\subsubsection{Characterize Sites}

5.3.3.1 Mission/Objective. The ICS function provides sufficient data for evaluation to determine the acceptability of a site as a host for an NWMS element.

5.3.3.2 Process Flows. The site characterization function is decomposed into the six functions shown in Figure 5-4. It is important to recognize that assessment of site suitability for its intended purpose is not the role of the the characterization function. The characterize Sites function provides the site data needed for site evaluation. But the excellence of a site can only be determined within the context of its capabilities as part of an overall system, i.e.. in conjunction with the engineered elements of the system. A direct result of this perspective is that most information needs. defined by the first of the six functions shown in Figure 5-4, are determined by the EIS function rather than by the site characterization function.

Once information needs have been defined, the means by which information will be acquired must be established. The next three Characterize Sites functions depict a process, evolving from the selection of broad data acquisition strategies, through the definition of detailed tests and analyses by which the strategies can be implemented, and finally into the organization of specific plans for conducting the tests and analyses.

The last two functions under Characterize Sites represent the implementation of the test and analysis plans, resulting in valid data that can be used by the PSE and EIS functions for the following two primary purposes:

- Evaluation of compliance with requirements

- Evaluation of the validity of conceptual models that were the basis for formulating numerical models and defining information needs. 
Figure 5-3. Process Overview--Nominate sites for Characterization.

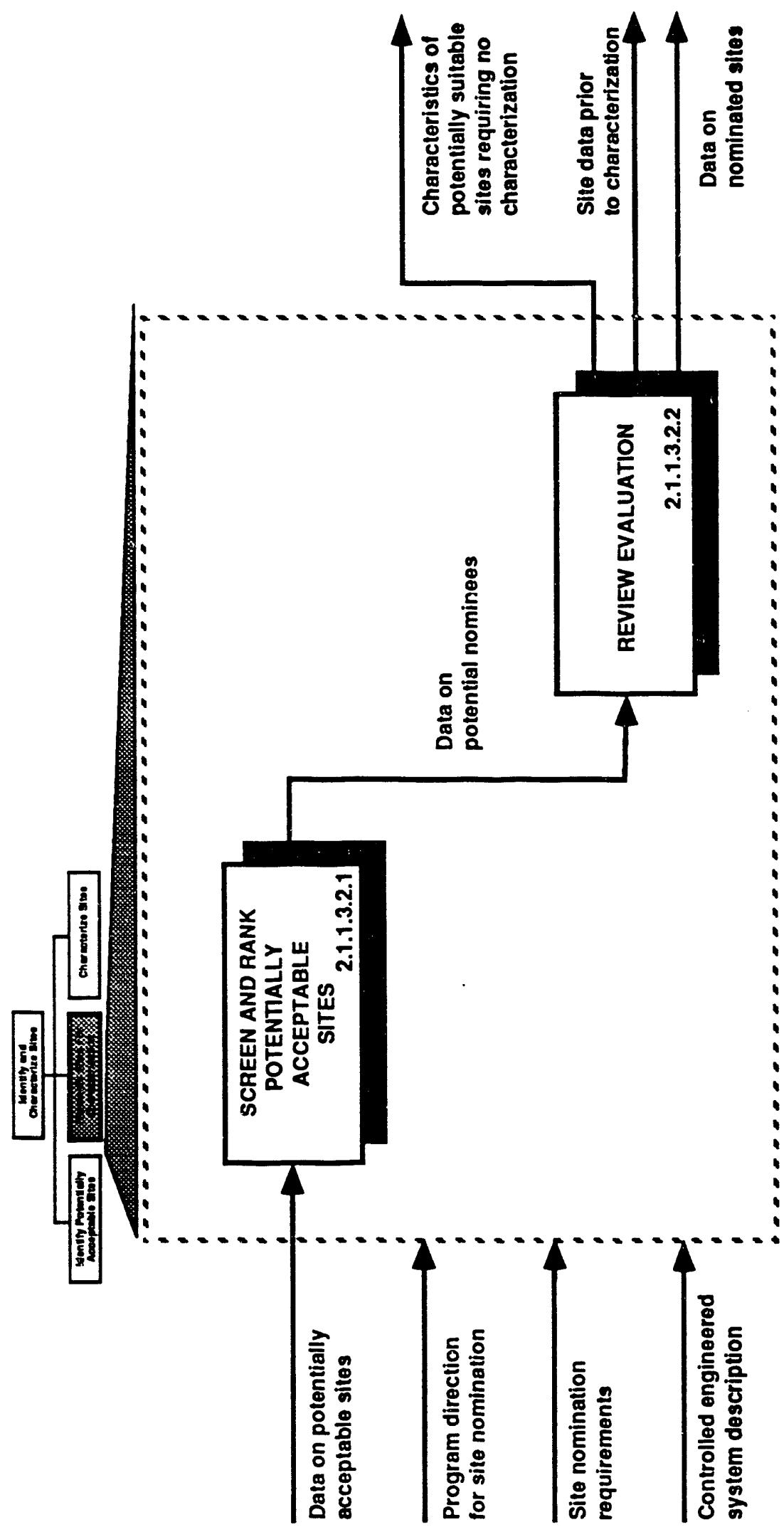


WHC-EP-0482

This page intentionally left blank 


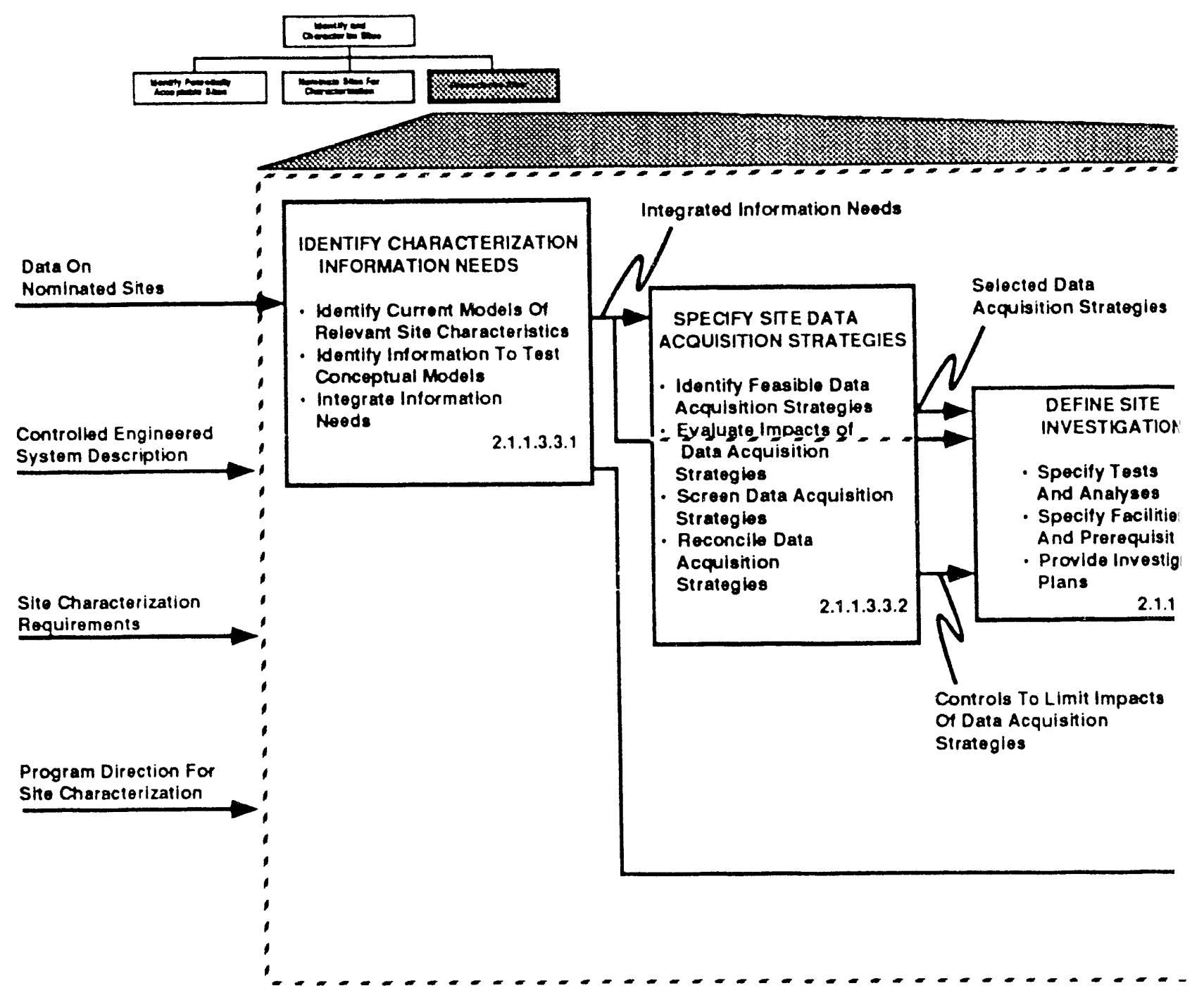




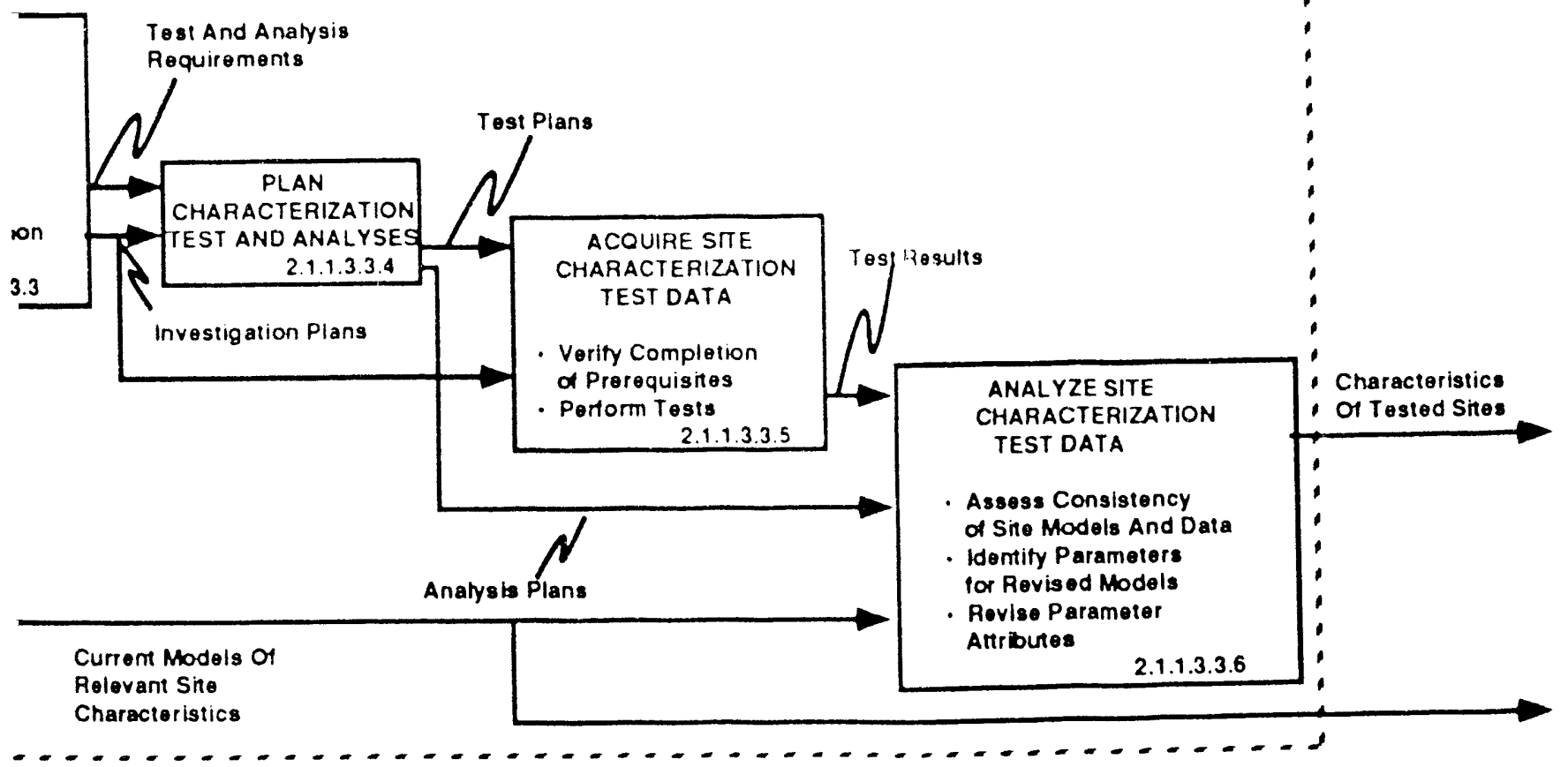


WHC-EP-0482

A brief description of the process associated with each of the subfunctions of Characterize sites is presented in the following paragraphs.

- Identify Characterization Information Needs. The first function under Characterize Sites is driven princidally by the need for four categories of site information: information in support of conceptual model validation: information to provide input values for numerical models utilized in system evaluation; directed information that must be acquired to comply with specific regulatory requirements and information necessary to support the design of engineered systems. The function first must formulate conceptual models which are then used concurrently to define information needs for conceptual model validation and numerical model development. The information needs defined by these two activities, in conjunction with directed information and design support needs, are then integrated to provide the basis for development of a complete, cost-effective, data acquisition program.

- Specify Site Data Acquisition Strategies. The next step in the site characterization process is the development of broad strategies for acquisition of the information defined by the preceding function. The principal objective in this function is to identify applicable categories of data acquisition. e.g.. literature search. laboratory analysis. analysis of natural analogues, nonintrusive in situ exploration. surface-based in situ exploration. subsurface-based in situ exploration, or other information-gathering methods that might be used for acquiring environmental or socioeconomic data, and to synthesize these categories into rational strategies. An important aspect of this function is impact assessment. i.e.. evaluation of trade-offs between data quality. potential compromises to system integrity caused by data acquisition (e.g.. number and location of boreholes) data acquisition schedules and costs, and interferences between concurrent activities. The product of this function is a description of the data acquisition framework upon which specific test and analysis methods can be defined.

- Define Site Investigations. The functional sequence next progresses to the selection of specific tests and facilities consistent with the framework of data acquisition strategies defined in the preceding function. A primary objective of this function is to optimize the use of resources (including time) and minimize the risk of failing to acquire all of the required data. The products of this function are as follows: (1) investigation plans that outline the tests to be conducted, description of the facilities in which the tests will be conducted, and delineation of the prerequisites that must be completed prior to, or during. data acquisition tests, and (2) detailed test requirements for individual tests and analyses.

- Plan Characterization Tests and Analyses. The test and analysis descriptions provided by successful completion of the preceding function provide the basis for preparation of detailed test and analysis procedures and plans for conducting the individual tests and analyses. This function constitutes a straightforward transformation of investigation plans and test/analysis 
requirements into test/analysis plans and, therefore, the function was not further decomposed.

- Acquire Site Characterization Test Data. Although the magnitude of the effort represented by this function is large with regard to resources, the function is clearly defined by the procedures. facilities and prerequisites established by prior functions. As a result. subsequent decomposition of this function yielded only two subfunctions: Verify Completion of Prerequisites, and Perform Tests. Failure to complete specified prerequisites can generate significant hold-points in terms of facilities or other prerequisites. but if no special problems are encountered, data acquisition proceeds within the framework of standard practices that require no further functional decomposition.

- Analyze Site Characterization Test Data. The test results from the Perform Confirmation/Operational Testing (PCOT) function either will verify the validity of conceptual models utilized for prefiminary system evaluations, in addition to providing refinements in the input data for those evaluations, or it will serve as a basis for modifying the conceptual models. The product of the Analyze Site Characterization Test Data function. characteristics of tested sites, will either be sufficient for the Evaluate Integrated System function to assess compliance with requirements and enable a judgment of acceptability to be made. or to define needs for additional data. If the product is insufficient to support evaluations for use in a license application. new requirements would be generated that would reinitiate the site identification and characterization function at a function location appropriate to the deficiency that caused the iteration in the functional process.

5.3.3.3 Outputs. The ICS function produces the following two principal outputs:

- Before testing begins, site conceptual models are hypothesized. from which the EIS function determines test data needs related to evaluation.

- The test activity yields characteristics of tested sites. a major component of site characterization information. which is the principal product of ICS.

\subsection{INTERNAL FEEDBACKS}

Successful execution of ICS is a straightforward process composed of subfunctions that occur serially or in parallel: i.e.. there are no programmed iterations in the functional process. However, a likely outcome of some functions within the site identification and characterization process. compared to the fully successful process emphasized in the preceding discussion, is an unsuccessful execution as a result of being unable to meet specified requirements. In these cases, an interim product identified as a Need for Review of (requirement) will be generated which requests reconsideration and relaxation of the requirement, if possible. Based on this request. one or more of the constraints imposed on the function may be modified and result in reinitiation of the function. and possibly other functions earlier in the functional sequence, with a new set of constraints. 
The most significant potential "Need for Review of..." feedbacks for ICS are shown in Figure 5-5: obviously, not all of the indicated feedbacks will be exercised, and the impact of any feedback on successful completion of the function will depend on the severity of the problem that engendered the "Need for Review of..." feedback. If a problem or issue cannot be resolved within the functions shown as feedback recipients in the figure, it will roll back until it is transferred to PSE as a Need for Review of NWMS Siting Requirements.

Six principal feedback paths are shown in Figure 5-5. In the comprehensive functional analysis, the problem/issue transported along the feedback path is labeled "Need for Review of" followed by a descriptor for the item whose constraints prevented successful execution of the function. The path numbers from the figure. lowest-level originating functions for the problems or issues, and descriptors for the items that fail to meet their constraints, are as follows:

Path 1 .

From: Screen and Rank Potentially Acceptable Sites. To: Identify Potentially Acceptable Sites.

Feedback: Potentially Acceptable Sites.

If none of the initial candidates, or an insufficient set of candidates, is a suitable nominee for characterization, additional candidate sites must be selected for evaluation in Nominate Sites for Characterization, or revisions must be made to the program direction or requirements for site nomination.

- Path 2.

From: Review Evaluation.

To: Screen and Rank Potentially Acceptable Sites.

Feedback: Potential Nominees.

If nominees for characterization are identified in an initial screening and ranking process, but subsequently rejected in a more stringent review within the nomination process, it may be necessary to expand the 1 ist of potential nominees or to revise the review direction or requirements.

- Path 3

From: Specify Site Data Acquisition Strategies. To: Identify Characterization Information Needs. Feedback: Information Needs.

If no suitable approach to obtaining specific data can be identified, it may be necessary to revise the analytical method by which a particular performance measure was to be assessed or to develop alternative models for which data can be obtained.

- Path 4

From: Define Site Investigations.

To: Specify Data Acquisition Strategies.

Feedback: Data Acquisition Strategies.

If the translation of a data acquisition strategy into detailed investigation plans reveals problems that compromise the effectiveness of the strategy, that information must be fed back to the function in which the strategy was originaliy selezted. 
Figure 5-5. Identify and Characterize Sites-Major Feedback Loops.

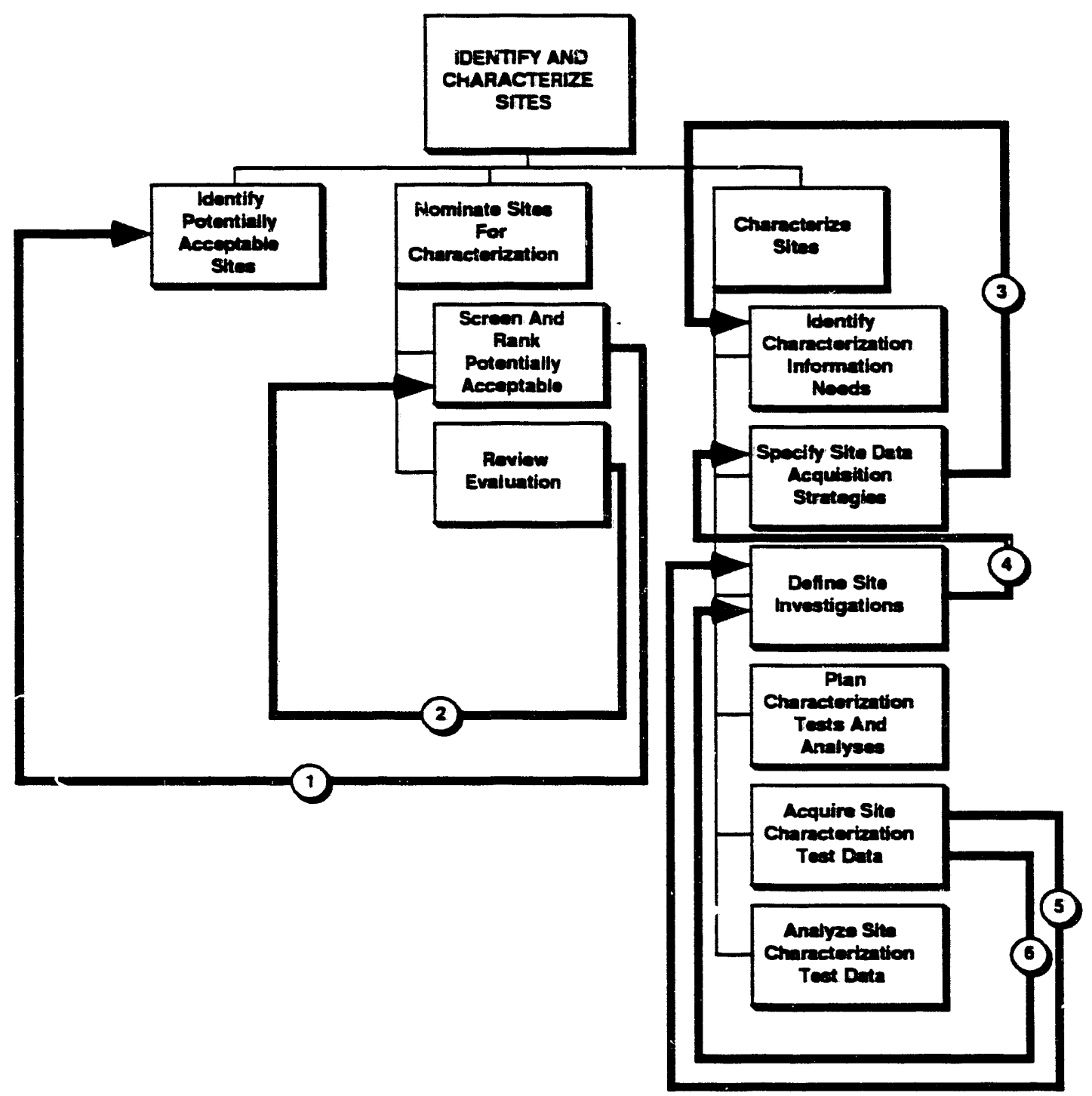




Path 5. From: Define Site Investigations, ana
To: Define Site Investigations.
Feedback: Facilities.
If the readiness review process indicates that facilities for
acquisition of data are incapable of obtaining data of sufficient
quality or unavaliabe for any reason, it may be necessary to
revise the investigation plans from which the need for that
facility was established.
Path 6. From: Acquire Site Characterization Test Data.
To: Define Site Investigations.
Feedback: Prerequisites (other than facilities)
If the readiness review process indicates that other prerequisites
for data acquisition for obtaining data of sufficient quality or
unavailable are unsatisfied for any reason, it may be necessary to
revise the investigation plans from which the need for that
prerequisite was established.


WHC-EP-0482

This page intentionally left blank. 
WHC-EP-0482

\subsection{EVALUATE INTEGRATED SYSTEM PROCESS DESCRIPTION}

\subsection{EVALUATE INTEGRATED SYSTEM MISSION AND PROCESS OVERVIEW}

\subsubsection{Mission/Objectives}

The following are the mission/objectives for the Evaluate Integrated System (EIS) (2.1.1.4) process:

- Reduce program technical performance risk through a continuing effort of review and analysis of the total system performance based on data provided by inspections. demonstrations, tests, and other analyses. Verify all NWMS te ...ical requirements. Recommend changes to the configuration based on evaluation results.

- The EIS function represents an analytic capability tightly coupled to the Perform Systems Engineering (PSE) activities. EIS functions are conducted with analytical models based on requirements and data passed from PSE with the results and recommeridation passed back $=0$ PSE.

\section{1 .2 Scope}

Figure 6-1 shows the hierarchical relationship for the first three levels of subfunctions that make up the EIS function. The extent of the

functional scope defined by the hierarchy is described by the following:

- Develop configuration and mission references to a establish traceable basis for a 11 activities related to evaluation including data collection, data analysis, assessments of analysis results. and recommendations for system configuration changes.

- Define specific physical configurations and interfaces to be used to evaluate specific requirements.

- Define specific mission scenarios and the associated environments to be used to define the conditions to be used for each evaluation.

- Define techniques appropriate to collecting data. Techniques can include inspection, demonstration, test, and analysis.

- Define the data needs for evaluations, coordinate activities throughout the program to collect the data in accordance with the configuration and mission references and defined data collection techniques. 
Figure 6-1. Evaluate Integrated System Function Hierarchy.

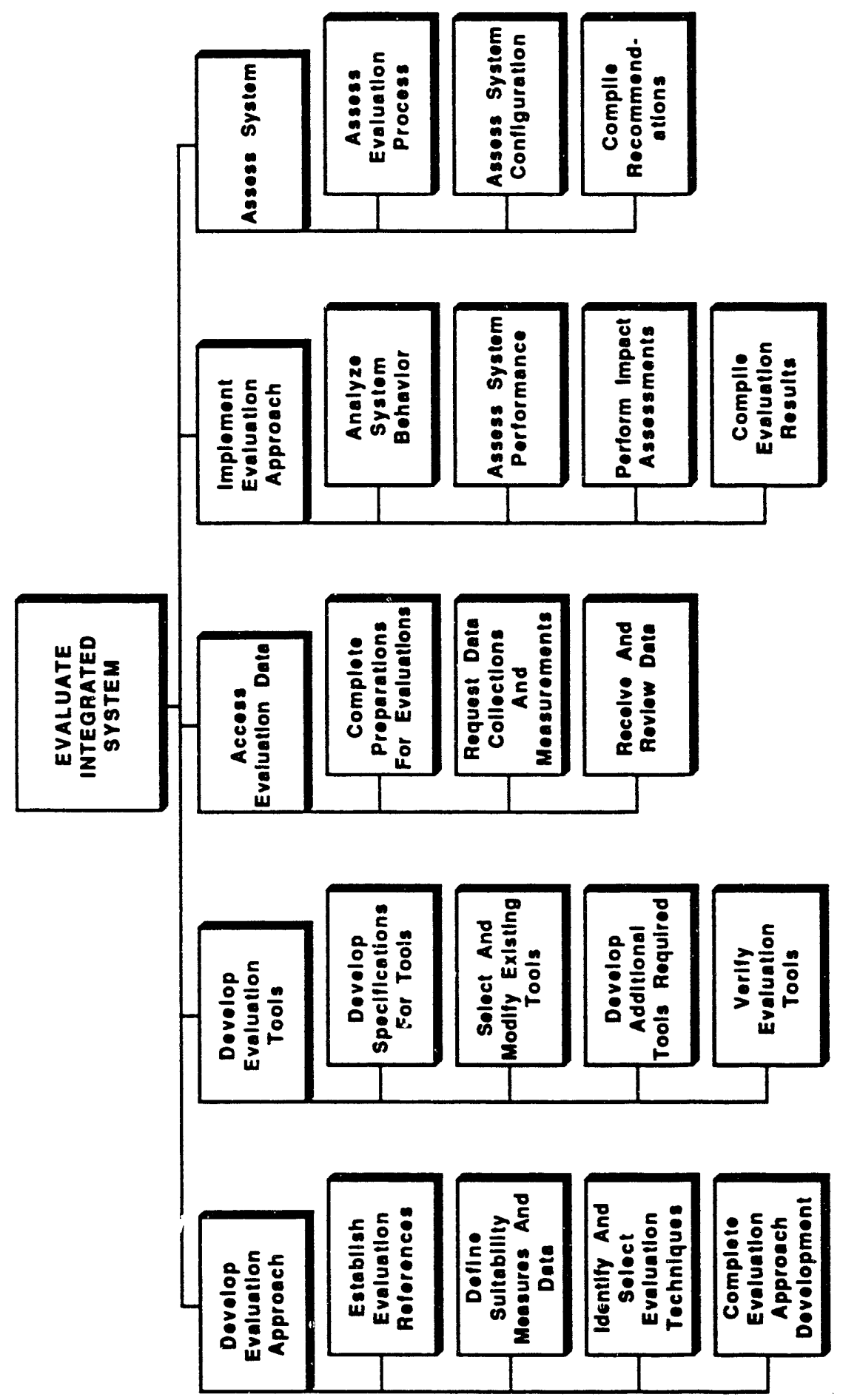


- Provide organizational integration of data needed for system evaluation by identifying the specific data needed: identifying the organizations responsible for obtaining the data: and coordinating the flows of data needs and the resulting obtained data.

- Review data received from other functions for completeness and consistency with established references.

- Conduct integration and evaluation of inspection. demonstration. test, and other analytical results conducted by Design Engineered Systems (DES). Identify and Characterize Sites (ICS). and Perform Conformation/Operational Testing (PCOT) functions.

- Evaluate physical system design capabilities and site characteristics relative to the total system performance.

- Conduct performance evaluations and environmental impact assessments.

- Evaluate results of assessments for each suitability measure for completeness. level of suitability. specific shortfalls, and make recommendations for correcting the shortfalls.

\subsubsection{Process Flow}

The EIS functional flow is shown in Figure 6-2. The small inset in the upper left corner of the figure shows the relationship of EIS to the other MSIS functions within the Configure System function. The large dashed box in the figure represents the EIS functional boundary between the other MSIS functions outside the box and the subfunctions that make up EIS inside. Inside each subfunction, shown as shadowed boxes, are the tities of the next level subfunction as identified by black dots. All inputs to and outputs from EIS are shown as labeled lines ending or passing through the dashed-line box. To focus on the primary EIS processes, the internal EIS paths shown inside the dashed-line box have been simplified. The simplification of the internal path includes omitting the feedback paths from Figure 6-2. The feedbacks are discussed separately in a subsequent subsection. The details of all the information paths are presented in the associated diagrams that correspond to the function [see volume 2 of The Analysis of the Program to Develop the Nuclear Waste System (Woods 1991a)].

The top-level view in Figure 6-2 shows the five EIS subfunctions which process an input from PSE and which are constrained by controls from PSE and Provide Drogram Control (PPC). The result of the EIS processes are outputs that return to PSE and PPC. Subsection 6.2 provides details on the contents of each information path including functional destinations for the inputs and controls and functional origins for the outputs.

The process flow through the EIS subfunctions can be described beginning with the inputs and controls. The input Controlled NWMS Description is operated on directly by the following three EIS functions:

- Develop Evaluation Approach uses the input to determine the items to be evaluated. 
WHC-EP-0482

This page intentionally left blank. 


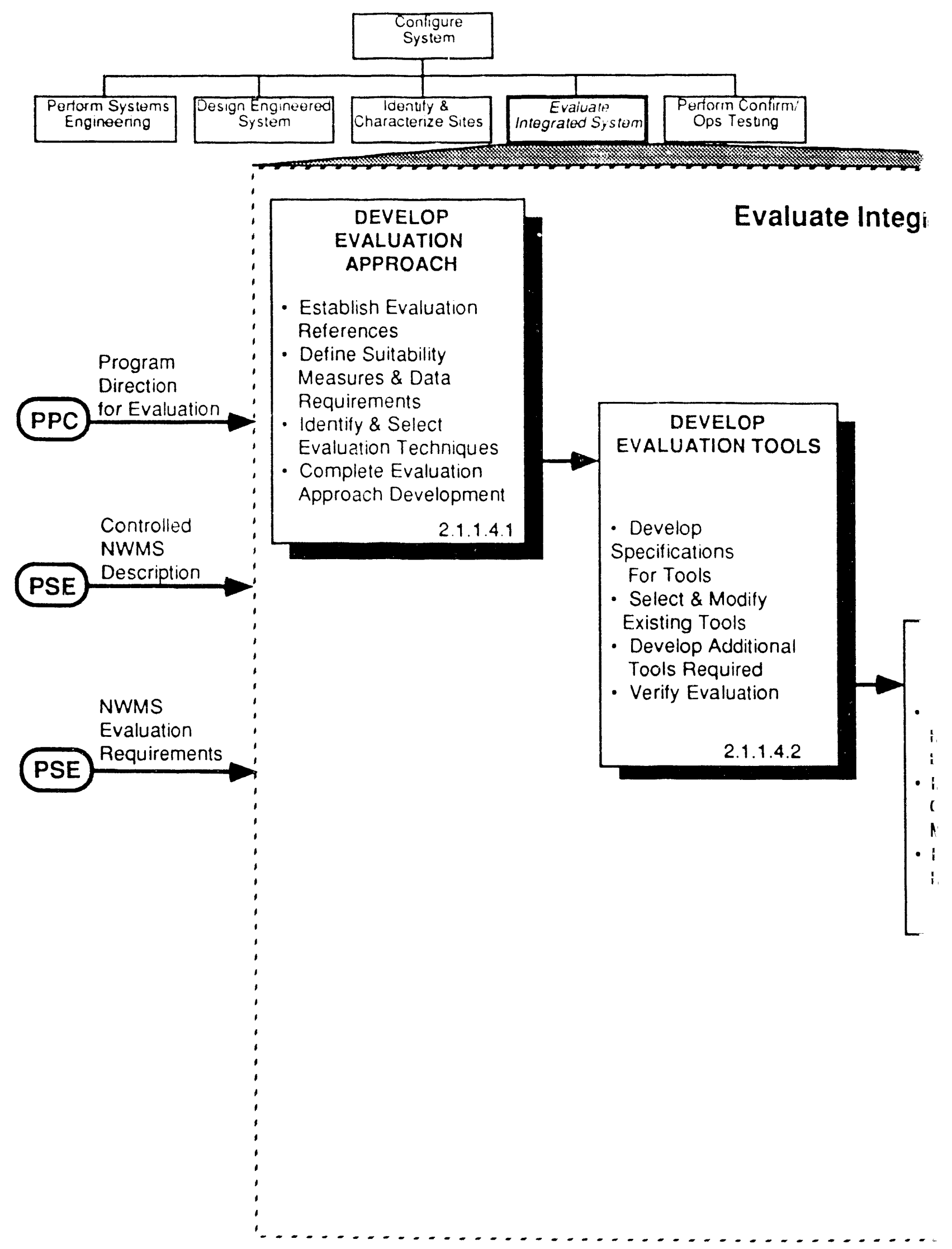




\section{ited System (2.1.1.4)}

ACCESS
VALUATION
DATA
omplete
reparations For
-valuations
equest Data
ollections \&
easurements
eceive \&
eview Data

2.1.1.4.3
IMPLEMENT

EVALUATION

APPFUACH

- Analyze System

Behavior

- Assess System

Performance

- Perform Impact

Assessments

- Compile

Evaluation
NRrw NWMS

Evaluation

Requirements

PSE

Ranked

Suitability

Measures

PSE

Data on

Evaluation

System

PSE

ASSESS

SYSTEM

- Assess Evaluation Process

- Assess System Configuration

- Compile 
- Develop Evaluation Tools uses the input to retrieve measured data for validating the evaluation tools.

- Access Evaluation Data accepts the data gathered by other NWMS functions (i.e.. DES, ICS, and PCOT) and determines if the data are acceptable for use by the evaluation tools.

The EIS processes are constrained and directed by a control input from PSE. NWMS Evaluation Requirements and a control input from PPC. Program Direction for Evaluations. These two controls provide the following:

- Specific mission. function. and performance measures to be evaluated

- Constraints and direction on suitability criteria levels

- Specifically directed evaluations and impact assessments

- Specific constraints and directed methods for conducting the evaluations

- Criteria for determining the relative importance of suitability measures.

The flow of the input through the EIS functions is a multipass process. Early passes develop a set of data needs that are passed to PSE for further dissemination. Later passes receive the needed data and process it with the evaluation tools.

The data needs in the earlier passes are developed by the first three functions Develop Evaluation Approach. Develop Evaluation Tools, and Access Evaluation Data. In parallel with the needs identification. the first two functions develop evaluation tools that are consistent with the data that will be returned. The later passes receive the measured data, evaluate it with the developed tools, identify the specifics of any shortfalls relative to the system requirements, and develop recommendations for correcting those shortfalls either with modified design or site characteristics or by modifying the performance requirements.

Associated with the earlier passes, is the development of configuration and mission references to establish a consistent basis for all the program evaluations. These references flow both to the Develop Evaluation Tools and back to PSE as part of the Ranked Suitability Measures to ensure consistency. traceability, and comparability among evaluations for both the data and the evaluation methods.

The primary result of the EIS function activities is the output Data on Evaluation System. The Data on Evaluation System has two major parts that, on the first pass, requests data from the PSE, and then on the second pass, tells PSE the results and recommendations of the evaluations. In addition, the Data on Evaluation System acts as a path for requesting data specifically for validating the evaluation tools and then for reporting on the results of those evaluations.

Other outputs from EIS provide information on the EIS function itself, rather than on the evaluation results. The Need for Review of NWMS Evaluation Requirements is a request to modify some aspect of the evaluation requirements. The Evaluation Approach is provicied to PPC so that it can be 
used in program strategy updates as the program proceeds. The Ranked Suitability Measures is provided to PSE so that it can update its information on performance measures.

The EIS integrated program assessment is tied to the total program requirements for meeting the regulatory requirements. The direction to EIS is provided from PSE (NWMS Evaluation Requirements) and PPC (Program Direction for Evaluation). The ultimate source of both the PSE technical direction and the PPC program direction is the PPC function. which combines the regulatory and nonregulatory requirements. The evaluation approach, tools, data. recommendations, and other documentation are provided to PSE for data archiving and control. The information is provided to the program on the path titled Physical System Information.

This Physical System Information is reviewed by Ensure Regulatory Control (ERC) to determine if the planned evaluation approach will meet the regulatory requirements, compliance criteria are adequately reflected in evaluation methods, or the evaluation tools selected and verified are acceptable and have been verified in accordance with the compliance requirement.

\subsection{EVALUATE INTEGRATED SYSTEM EXTERNAL INTERFACES}

This subsection provides details of the external EIS interfaces listed in Figure 6-2. The interface information is separated into three external interface categories: inputs, controls, and outputs. The distinction between inputs and controls is made in this subsection as an aid to the reader who will also read the associated functional analysis diagrams [see volume 2 of The Analysis of the Program to Develop the Nuclear Waste Management System (Woods 1991a)]. However, throughout the process descriptions, the figures that show interfaces to functions do not make this distinction between inputs and controls. The lack of this distinction is a simplification to help the reader focus on the processes.

The following subsections provide a figure listing and summarize the particular interfaces to EIS. Discussions briefly highlight specific aspects of the information in the figures.

\subsubsection{External Inputs}

Table 6-1 lists the single input to the EIS function. The input name is listed in the first column. The second column provides a summary description of the type of information that EIJ will be provided by the input. The third column lists the EIS subfunctions that directly process the input.

Controlled NWMS Description flows to four subfunctions, which obtain the following type of data from the path:

- Descriptions of the items to be evaluated, and the functional and physical interfaces for each

- Item definitions of sufficient detail to permit identification of critical phenomenology requirements and identification or performance variables most likely to dominate the performance measurements: fidelity sufficiency definitions: and accuracy. precision, and sensitivity requirements 
Table 6-1. Evaluate Integrated System External Inputs.

\begin{tabular}{|c|c|c|}
\hline Input Name & Input Definition & Destination Function \\
\hline $\begin{array}{l}\text { Controlled } \\
\text { NWMS } \\
\text { Description }\end{array}$ & $\begin{array}{l}\text { A complete technical description of } \\
\text { the NWMS in its current state of } \\
\text { development. Includes all definition, } \\
\text { descriptive,characterization } \\
\text { information on the system } \\
\text { (engineered and natural elements), } \\
\text { configuration (design and physical), } \\
\text { the bases, models, plans/procedures } \\
\text { on which the configuration is based, } \\
\text { and system characteristics based on } \\
\text { hardware tests and observations. This } \\
\text { information channel is a subset of } \\
\text { Physical System Information that } \\
\text { contains all possible technical } \\
\text { information on the NWMS. It } \\
\text { addresses both the engineered } \\
\text { system and the site. It includes } \\
\text { information on all parallel design } \\
\text { efforts.It also includes all information } \\
\text { generated in response to data needs } \\
\text { issued from the Evaluate Integrated } \\
\text { System process. Early in the } \\
\text { development cycle, it contains only } \\
\text { top-level configuration definition } \\
\text { information. As development } \\
\text { progresses, it includes results from } \\
\text { design and site characterization } \\
\text { efforts. Late in the development cycle, } \\
\text { it includes information about the } \\
\text { acquired hardware and the } \\
\text { inspections of implemented system } \\
\text { items. Updates are provided as they } \\
\text { are made available by the various } \\
\text { generating programmatic functional } \\
\text { processes. }\end{array}$ & $\begin{array}{l}\text { 2.1.1.4.2.4 - Verify } \\
\text { Evaluation Tools } \\
2.1 .1 .4 .3 \text { - Access } \\
\text { Evaluation Data } \\
\text { 2.1.1.4.3.3 - Receive } \\
\text { and Review Data }\end{array}$ \\
\hline
\end{tabular}


WHC-EP-0482

- Organizational technical interfaces including responsibilities of those organizations that will gather the data

- Data collected by other functions to be used by EIS to verify that the evaluation tools have been appropriately defined and developed

- Data collected by other functions to be used by EIS to perform the system evaluation.

\subsubsection{External Controls}

Table 6-2 lists the controls to the EIS function. The first column lists the names of the two controls. The second column provides a summary description of the type of information that EIS will be provide by the controls. The third column lists the EIS subfunctions that receive the controls.

These two controls constrain and direct the processes implementing the EIS functions.

NWMS Evaluation Requirements flows to seven subfunctions. Which obtain the following type of data from the path:

- System level mission, function, and performance requirements that must be incorporated in the suitability measures and the associated data needs that are developed by the EIS functions

- Constraints and direction on the criteria to be used to establish suitability levels

- Directed evaluations including impact assessments.

Program Direction for Evaluation flows into three subfunctions. which obtain the following type of data from the path:

- Requirements on which evaluation processes must be used and how they must be implemented

- Requirements on the selection of data collection techniques (i.e.. inspection, demonstration, test, or analysis) and analytical evaluation tools

- Criteria for establishing the relative importance among system mission. function, and performance requirements.

\subsubsection{External Outputs}

Table 6-3 has the same format as the input and control figures with three columns that provide the output name. a description, and the functions that provide the elements of the output. 
Table 6-2. Evaluate Integrated System External Controls.

\begin{tabular}{|c|c|c|}
\hline Control Name & Control Definition & Destination Function \\
\hline $\begin{array}{l}\text { NWMS } \\
\text { Evaluation } \\
\text { Requirements }\end{array}$ & $\begin{array}{l}\text { Requirements defining the integrated } \\
\text { system measures to be determined } \\
\text { and assessed for level of acceptability } \\
\text { and confidence. These requirements } \\
\text { also include the missions and } \\
\text { environments that define the } \\
\text { conditions for the measurements and } \\
\text { assessments. }\end{array}$ & \begin{tabular}{|l} 
2.1.1.4.1.1 - Establish \\
Evaluation \\
References \\
2.1.1.4.1.2.1 - Identify \\
Suitability \\
Measures and \\
Acceptable Criteria \\
2.1 .1 .4 .1 .2 .2 - \\
Determine Relative \\
Importance of \\
Measures \\
2.1.1.4.4.2 - Assess \\
System \\
Performance \\
2.1 .1 .4 .4 .3 - Perform \\
Impact Assessment \\
2.2 .1 .4 .5 .1 - Assess \\
Evaluation Process \\
2.1 .1 .4 .5 .2 - Assess \\
System \\
Configuration
\end{tabular} \\
\hline $\begin{array}{l}\text { Program } \\
\text { Direction for } \\
\text { Evaluation }\end{array}$ & $\begin{array}{l}\text { Directed evaluations (e.g., } \\
\text { environmental impact assessments } \\
\text { and socio-economic impact } \\
\text { assessments), specific requirements } \\
\text { on the evaluation methods to be used, } \\
\text { criteria for establishing the relative } \\
\text { importance between system perform- } \\
\text { ance measures and any other } \\
\text { constraints or directives on the } \\
\text { conduct of evaluations. }\end{array}$ & $\begin{array}{l}\text { 2.1.1.4.1.1 - Establish } \\
\text { Evaluation } \\
\text { References } \\
2.1 .1 .4 .1 .2 .2 \text { - } \\
\text { Determine Relative } \\
\text { Importance of } \\
\text { Measures } \\
\text { 2.1.1.4.1.3 - Identify \& } \\
\text { Select Evaluation } \\
\text { Techniques }\end{array}$ \\
\hline
\end{tabular}


Table 6-3. Evaluate Integrated System External Outputs.

\begin{tabular}{|c|c|c|}
\hline Output Name & Output Definition & Originating Function \\
\hline $\begin{array}{l}\text { Need to Review } \\
\text { NWMS } \\
\text { Evaluation } \\
\text { Requirements }\end{array}$ & $\begin{array}{l}\text { Request to change evaluation } \\
\text { requirements in order to allow } \\
\text { specified techniques, performance } \\
\text { requirements, or other evaluation } \\
\text { requirements to be met or to provide } \\
\text { for better system performance. }\end{array}$ & $\begin{array}{l}\text { 2.1.1.4.1.4 - Complete } \\
\text { Evaluation } \\
\text { Approach } \\
\text { Development }\end{array}$ \\
\hline $\begin{array}{l}\text { Ranked } \\
\text { Suitability } \\
\text { Measures }\end{array}$ & $\begin{array}{l}\text { Information passes from Evaluate } \\
\text { Integrated Systen to Systems } \\
\text { Engineering for the purpose of } \\
\text { development of more detailed } \\
\text { requirements to be levied against the } \\
\text { Design Engineered Systems, Identify } \\
\text { and Characterize Sites, and Perform } \\
\text { Confirmation/Operations Testing } \\
\text { functions. Evaluate Integrated } \\
\text { System analyzes the initial NWMS } \\
\text { evaluation requiremerits and } \\
\text { translates those requirements into } \\
\text { specific suitability measures and } \\
\text { associated attributes that are then } \\
\text { used by System Engineering to } \\
\text { develop detailed requirements for } \\
\text { design, siting, and testing fiunctions. }\end{array}$ & $\begin{array}{l}\text { 2.1.1.4.1.2 - Define } \\
\text { Suitability Measures } \\
\text { and Data } \\
\text { Requirements }\end{array}$ \\
\hline $\begin{array}{l}\text { Data on } \\
\text { Evaluated } \\
\text { Systems }\end{array}$ & $\begin{array}{l}\text { Information on the evaluation } \\
\text { process and the evaluation results } \\
\text { and recommendations. The } \\
\text { information includes:(1) technical } \\
\text { reports documenting: (a) the results } \\
\text { of integrated system performance } \\
\text { analyses, (b) integrated system } \\
\text { suitability assessment, (c) evaluation } \\
\text { data used in ihe assessnent, (d) the } \\
\text { evaluation approach and data plans } \\
\text { used to execute the assessments, } \\
\text { and (e) the required program impact } \\
\text { assessments; (2) technical } \\
\text { descriptions of the recommended } \\
\text { system configuration actions that will } \\
\text { overcome shortfalls in system } \\
\text { s'jitability and otherwise improve } \\
\text { overall integrated system suitability; } \\
\text { (3) an historical archive of the } \\
\text { evaluation tool; and (4) requests for } \\
\text { data to be collected or produced by a } \\
\text { ivivivis organization to sivippont the } \\
\text { evaluation process. }\end{array}$ & $\begin{array}{l}\text { 2.1.1.4.2.1 - Develop } \\
\text { Specifications for } \\
\text { Tools } \\
\text { 2.1.1.4.2.4 - Verify } \\
\text { Evaluation Tools } \\
\text { 2.1.1.4.2.4.2 - Conduct } \\
\text { Tool Verification } \\
\text { Testing } \\
\text { 2.1.1.4.3.1 - Complete } \\
\text { Preparation for } \\
\text { Evaluations } \\
\text { 2.1.4.3.2 - Request } \\
\text { Jata Collections } \\
\text { and Measurements } \\
\text { 2.1.1.4.4.1 - Analyze } \\
\text { System Behavior } \\
\text { 2.1.1.4.4.3 - Perform } \\
\text { Impact Assessments } \\
\text { 2.1.1.4.4.4 - Compile } \\
\text { Evaluation Results } \\
\text { 2.1.1.4.5.3 - Compile } \\
\text { Recoriniendations }\end{array}$ \\
\hline
\end{tabular}


Data on Evaluated System flows from nine subfunctio-s. Which provide the following type of data to the output path:

- The evaluation approach

- Requests for data to be collected by any other NWMS/OCRWM organization to support the evaluation of the NWMS integrated system item under evaluation

- Technical reports that document the results of integrated system performance analyses, integrated system suitability assessment. the evaluation approach and data plans used to execute the assessments, and the required program impact assessment information

- Technical descriptions of the recommended system configuration actions that will overcome shortfalls in system suitability and otherwise improve overall integrated system suitability

- An historical archive of the integrated system evaluation tool. its method or operation and use, and the verification of its output.

Evaliation Approach flows from one subfunction that provides the stepby-step plans for conducting evaluations including mission and configuration references, the suitability measures to be evaluated. the configurations to be evaluated. and the techniques to be used by non-EIs functions to collect the necessary data. The information in the plans is of sufficient detail that the following information can be developed by other functions:

- To allow organizational interfaces to be identified

- To allow the necessary evaluation tools to be identified. obtained, and verified

- To allow evaluations to be coriducted, results analyzed, and reports developed.

Ranked Suitability Measures flows from one subfunction. The output consists of a prioritized list of the suitability measures. The prioritization allows decisions to be made concerning the appropriate level of effort to be expended to evaluate tine measures and allows technical

integration of physical system data and starus.

Need for Review of NWMS Evaluation Requirements flows from the same subfunction that provides the Evaluation Approach. The output is a request to chançe evaluation requirements to illow either improvements in the evaluation process or to adjust for an inability of the EIS functions to meet the requirements.

\subsection{EVALUATE INTEGRATED SYSTEM PROCESS EXECUTION DETAILS}

This section expands the process flow discussion of Section 6.1. Each of the five subfunctions shown in Figure 6-2 are individually discussed in suosections 6.3.1 through 6.3.6. In each subsection, a figure similar to Figute $6-2$ is presented which expands one of the tis subtunctions into the next lower level of subfunctions. As in Figure 6-1. the function (a first- 
level subfunction of EIS) is shown as a dashed box with the next level of subfunctions shown as shadowed boxes. Within the shadowed buies are either another lower level of subfunctions indicated by black dots. or if no lower level of subfunctions was developed, a phrase in parentheses listing the major elements of the subfunction.

\subsubsection{Develop Evaluation Approach}

6.3.1.1 Mission/Objective. Figure 6-3 shows the five subfunctions that make up the function Develop Evaluation Approach (2.1.1.4.1). The combined mission of these subfunctions is to translate the measurable system requirements that must be evaluated into evaluation plans that enforce data collection and data content consistency throughout the program and also to define the steps necessary for evaluating the data.

These functions are analytical; the input information is analyzed and organized into reference configurations. reference missions. suitability measures, data needs, data collection techniques, and finaliy into evaluation plans.

6.3.1.2 Process Flows. The Develop Evaluation Approach function provides the Evaluation approach information to all the other EIS functions. Within the Develon Evaluation Approach function, the flow of information is similar to that of adding additional dimensions to a matrix of evaluation criteria (the word matrix is used here as a concept rather than an actual matrix chart). The Develop Evaluation Approach functions receive a detailed description of the system configuration from PSE. In addition. Develop Evaluation Approach receives constraints and direction on how to conduct the evaluations from the PSE and from PPC. These two sets of constraints differ in content. The PSE information tells Develop Evaluation Approach what system mission. function. and performance requirements must be evaluated and the acceptability criteria for each. The PSE information tells Develop Evaluation ADproach what. if any, imitations there are on the evaluation approach. It also may define specific evaluations such as environmental impact assessments that must be conducted.

The Establish Evaluation References subfunction develops evaluation criteria by identifying system item physical configurations (i.e.. individual items and combinations of items) and interfaces necessary to determine (through inspection, test, demonstration, or other analysis) the requiled performance values. The subfunction also develops additional evaluation criteria by establishing the environments that each configuration must be evaluated within and the conditions those environments place on the evaluations.

The evaluation matrix is expanded by the Define Suitability Measures and Data Requirements subfunction. The subfunction develops suitability measures and the data necessary to evaluate each one and associates these with the evaluation configurations and environments.

The final addition to the evaluation matrix is a dimension that associates the particular data collections technique to be used to collect the data. These techniques can be inspection, demonstration, test, or other dnalyses and are conducted by non-EIS functions (i.e.. DES. ICS. PCOT). The techniques are selected in the Identify and Select Evaluation Techniques subfunction. 


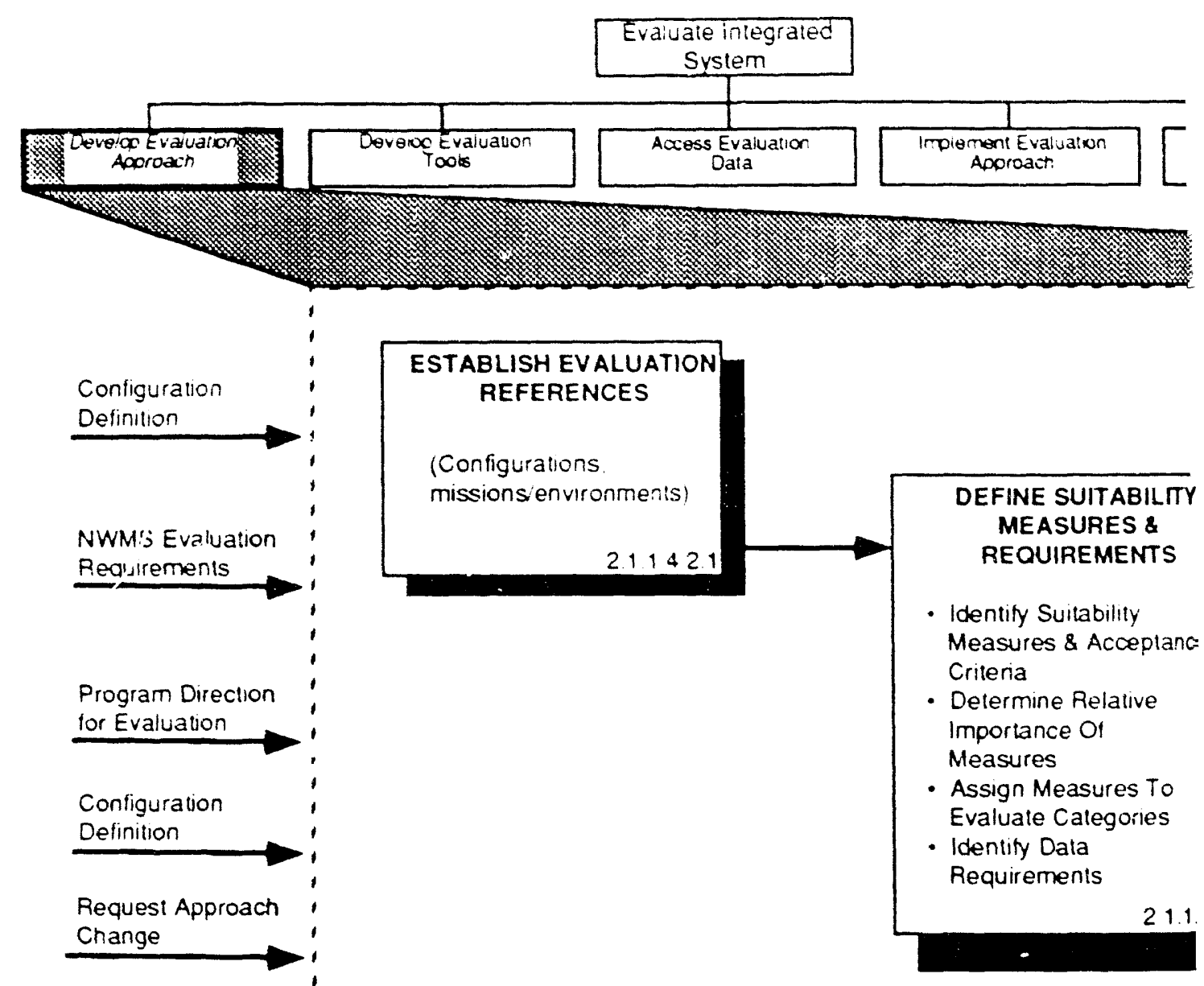




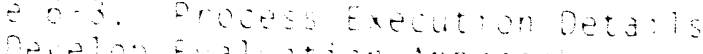

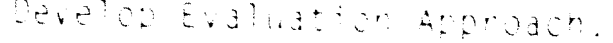

Assess Sisiem

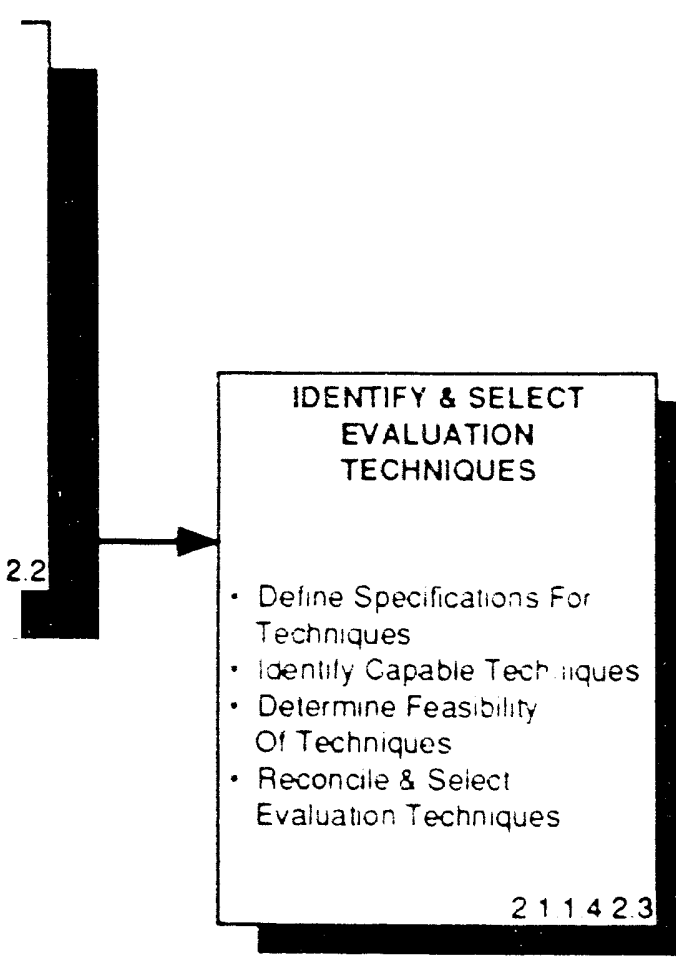

Configuration \&

Mission References

- Ranked Suitability

- Measures \& Data

'Requirements

- Evaluation Approach

'NRVW NWMS

'Evaluation

'Requirements

COMPLETE EVALUATION APPROACH DEVELOPMENT

(Step-by-slep plans)

2.1 .1 .4 .4 
WHC - EP- 0482

The references, measures, data riguirements, and techniques developed by the preceding functions are combined into a plan for each evaluation in the Complete Evaluation Approach Development subfunction.

6.3.1.3 Outputs. The references on the configurations to be evaluated and the environments to ce considered in the evaluations are provided with the evaluation approach to other Develop Evaluation Approach functions. In addition, the evaluation approach is provided to PPC. which uses it to update its program strategy formulation. Aiso provided is a feedback information path that requests PSE to consider making specific changes to the evaluation requirements. The other output from Develop Evaluation Approach provides PSE with suitability measures that have been ranked according to criteria established by the PPC constraints.

\subsubsection{Significant Considerations. The Develop Evaluation Approach}

functions serve as the NWMS center for maintaining consistency for all program data collection activities that will be used to assess the integrated system performance. Develop Evaluation Approach establishes the basis for consistency among data format, content, accuracy, precision, other data attributes, and the tools that will be used to conduct the evaluations.

The: Develop Evaluation Approach output Ranked Suitability Measures provides input to the program management process that determines the allositions of resources to the data collection activities. The decision information provided is the ranking of the suitadiity measures and associated data. The Ranked Suitability Measures information is provided to PSE where the priopitization is verified against the original NWMS Evaluation Requiremerts. PSE passes the ranked measures to PPC in the Physical system Information path.

$P P C$ uses the information in reviewing work plans and can make decisions on balancing resource requirements based on the measures rankings and the data collection activities associated with it. The specific activities required to collect the data are identified by another EIS function. Access Evaluation Data in conjunction with the specific planning functions that are associated with the DES. ICS, and PCOT data collecting functions. These planning functions are described within the Plan Program discussion in PPC Process section of this volume.

Tine Develop Evaluation Approach functions will identify techrical problems associated with verifying regulatory requirements, and will formulate the evaluation approach so that it addresses those problems.

Through the Evaluation Approach output from Develop Evaluation Approach to $P P C$. a feedback path is provided that is used to update the program strategy. This link between the EIS functions and the PPC functions helps ensure that the program assessments will be compliant with regulatory requirements associated with licensing, permits, and other compliance requirements, and that program strategy can be responsive to new insights gathered as the evaluation process is developed and updated.

\subsubsection{Develop Evaluation Tools}

6.3.2.1 Mission/Objective. Identify and obtain the analytical tools necessary to conduct the evaluations. 
6.3.2.2 Process Flows. Figure 6.4 shows a simplified view of the subfunctional relationships within the Develop Evaluation Tools (2.1.1.4.2) functions. The flow through the first three of the four Develop Evaluation Tools subfunctions each builds on the results of the preceding function. The fourth verifies that the tools can produce results that meet the evaluation requirements and passes the verified tools on to the Implement Evaluation Approach function.

The Develop Evaluation Tools functions obtain references and evaluation approaches from the preceding EIS function. Develop Evaluation Approach. In addition, the Develop Evaluation Tools functions receive information from the non-EIS function PSE. The data from PSE are the tool validation data developed within DES. ICS, and PCOT.

The initial subfunction. Develop Specifications for Tools, processes the input references and approaches to identify the necessary results from tools, define build-to requirements for the tools including the critical phenomenology that the tools must address. and develop a set of specifications.

The next two subfunctions either obtain existing tools that can meet, or be modified to meet. the specifications (Select and Modify Existing Tools) or to develop tools to meet the specifications (Develop Additional Tools Required).

The final step in the flow is to demonstrate that the obtained evaluation tools (Verify Evaluation Tools) address all critical phenomenology. reflect the NWMS item under evaluation with sufficient fidelity and, provide results of the required accuracy. precision, and sensitivity.

This validation step depends on test or otier observation data provided from non-EIS functions such as DES, ICS. PCOT.

6.3.2.3 Outputs. The initial output from Develop Evaluation Tools is a request through Perform Sy'stems Engineering for specific data items needed by Develop Evaluation Tools to verify the selected tools performance. The data will be collected by the same functions (DES. ICS, and PCOT) that collect the actual evaluation data.

The analytic tools information is provided to the Implement Evaluation Approach function. For the purpose of configuration control, the tool information is also provided to PSE. The tool information includes documentation of the tools selected and the verification of their performance.

6.3.?.4 Important Considerations. The selected tools are tied to the suitability measures and the data collection techniques identified in the Develop Evaluation Approach function through the evaluation approach. The selected tools are traceable to program requirements through the evaluation approach. They are reviewed for compliance by the ERC function and the information gets to that function from the EIS path. Data on Evaluation system. which is provided to PSE. PSE provides the tool information to ERC in the Physical System Information Path. 


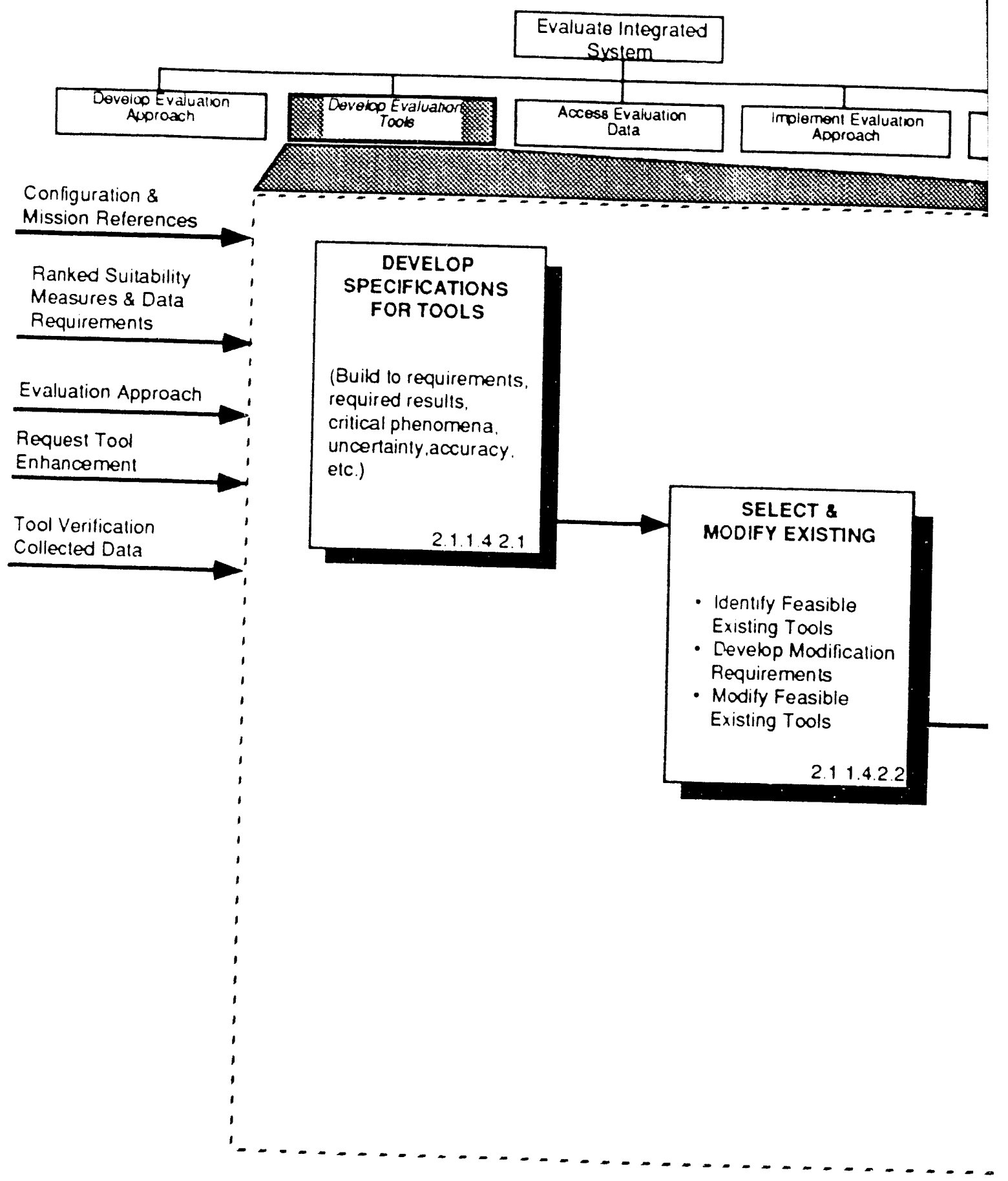




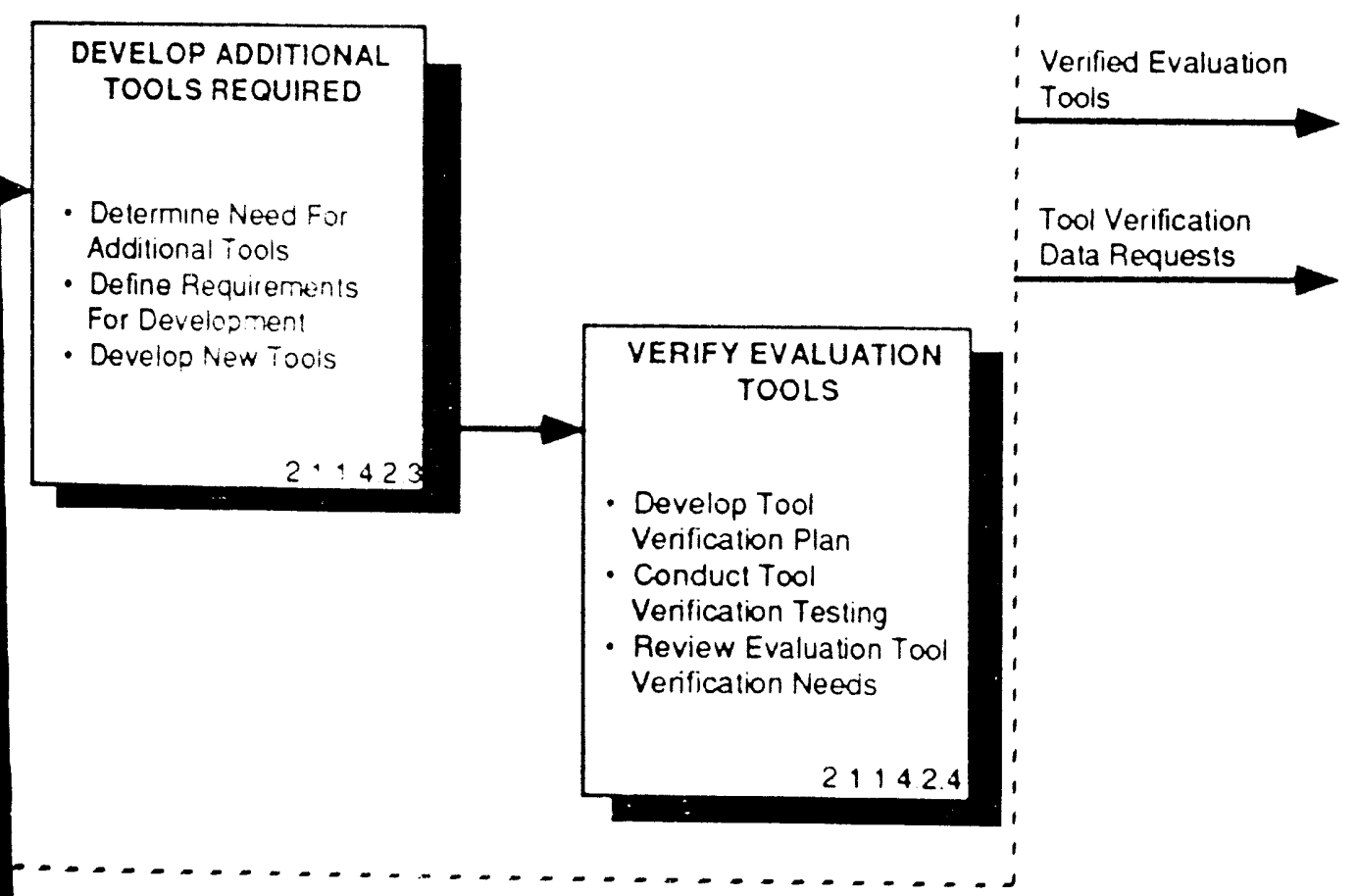


WHC-EP-0482

\subsubsection{Access Evaluation Data}

6.3.3.1 Mission/Objective. The Access Evaluation Data (2.1.1.4.3) function is a bridging or communicating set of activities to tie the data needs of the evaluating functions together with the data gathering functions of DES. ICS, and PCOT.

6.3.3.2 Process Flows. Figure 6.5 shows a simplified view of the subfunctional relationships within the Access Evaluation Data function. The three subfunctions that make up Access Evaluation Data flow out of two input data paths. The initial input to Access Evaluation Data is the evaluation approach, which is used to develop data requests. When the non-EIs functions develop the data in rejponse to the request. Access Evaluation Data receives and accepis the data.

The first Access Evaluation Data subfunction. Complete Preparations for Evaluations, develops plans for obtaining the data including identifying the prerequisites that must be fulfilled before the data collection effort and identifying the program organizations that will collect the data. This interface for technical information is maintained within the subfunction and is directly supported by the Request Data Collections subfunction. which provides descriptions, instructions, and related support to the data collecting organizations. The subfunction also provides support to test readiness reviews conducted by PSE functions.

The final subfunction, Receive and Review Data receives the data and transfers it to the appropriate evaluation personnel. This data path is the second input to the Access Evaluation Data subfunctions and occurs at a time later than the completion of the approach development in Develop Evaluation Approach. The subfunction also supports the data acceptability reviews and archiving of the data.

6.3.3.3 Outputs. The Access Evaluation Data subfunctions provide two outputs at two different times. A data request output is provided to PSE and at a later time, when the requested data are received. the accepted data are passed on to the Implement Evaluation Approach.

6.3.3.4 Significant Considerations. Access Evaluation Data identifies the evaluation prerequisites that span multiple organizations or that require external interactions and certifies completion of the evaluation

prerequisites. The process flows in Access Evaluation Data primarily provide support to the organizations that have responsibility for the DES, ICS, and PCOT data collection functions. Organizational interfaces are identified and maintained, and instructions for data collection are provided.

Support is also provided to the readiness review activities to ensure the prerequisites are identified and met.

\subsubsection{Implement Evaluation Approach}

6.3.4.1 Mission/Objective. The objective is to use the system evaluation data and evaluation tools to analyze the performance and suitability of the integrated system. This analytical function processes the received and approved evaluation data and compares them to the standards established by the first EIS subfunction. Develop Evaluation Approach, and to standards directed by $P P C$. 
Figure 6-5. Process Execution Details. Access Evaluation Data.

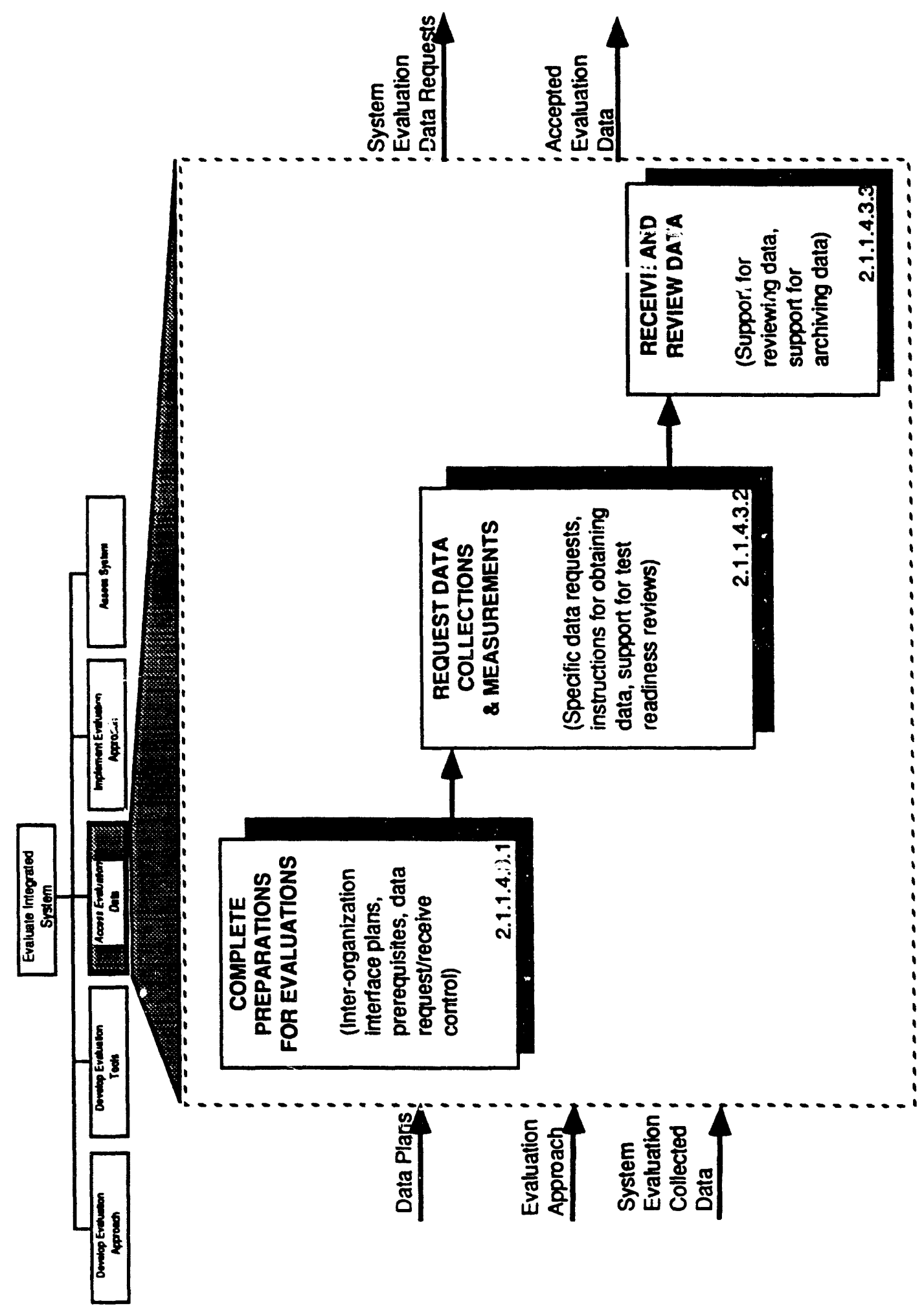


6.3.4.2 Process Flows. Figure 6.6 shows the first subfunction of Implement Evaluation Approach (2.1.1.4.4) creates the information necessary for the second subfunction. The third subfunction uses information from both of the first two to conduct its assessments. The fourth subfunction compiles the results of the first three.

The Analyze System Behavior subfunction does the actual evaluation calculations including conducting uncertainty analyses. Assess System Performance compares the results of the calculations to the suitability measures and to the system requirements. In addition. the subfunction also determines the system configuration item that cause any deviations from acceptable performance. Lastly, the subfunction evaluates the evaluation tool itself to determine if it can be improved or should be modified.

Perform Impact Assessments uses the results of the evaluation calculations and the system assessments to develop all legally required impact assessments including environmental impacts, socioeconomic impacts, and impacts related to transportation. This function does not prepare the impact statements, but rather provides the information to PSE. PSE assembles all technical information related to the impact statements and provides them to ERC where the formal statements are generated.

The Compile Evaluation Results subfunction documents the system assessment results and recommendations.

6.3.4.3 Outputs. Implement Evaluation Approach has three outputs. Two provide information on the analysis results and the third is a feedback information path requesting improvements to the evaluation tool.

Evaluation Recommendations provides information on specific shortfalls in the system configuration and recommends actions to overcome them. The recommendations consist of information on the evaluation results identifying specific configuration items and the characteristics of those items that preclude the system performance from reaching the defined suitability thresholds. Recommendations can also identify items and characteristics that would provide enhanced system performance beyond the required levels.

The Evaluation Analysis Resulcs output is a subset of the Evaluation Analysis Results and Information output. The former output provides the next EIS subfunction. Assess System. with the results to be used to develop recommendations for system changes. The later output is combined with other information on the EIS process and is provided to the PSE function. In addition to evaluation results, the output contains the evaluation approach. data plans, and data used in the evaluation.

The Request Tool Enhancement output is a feedback to the EIS subfunction. Develop Evaluation Tools, requesting the evaluation tools be modified to improve their ability to perform high-conficence analyses of system performance and suitability.

\subsubsection{Assess System}

6.3.5.1 Mission/Objective. The objective is to use the results of the integrated system perforinince and behavior analyses and suitability assessments to develop guidan'e for future system evaluations and further item development. This function fitends the previously developed assessment 
$W H C-E P \cdot 0482$

This page intentionally left blank. 


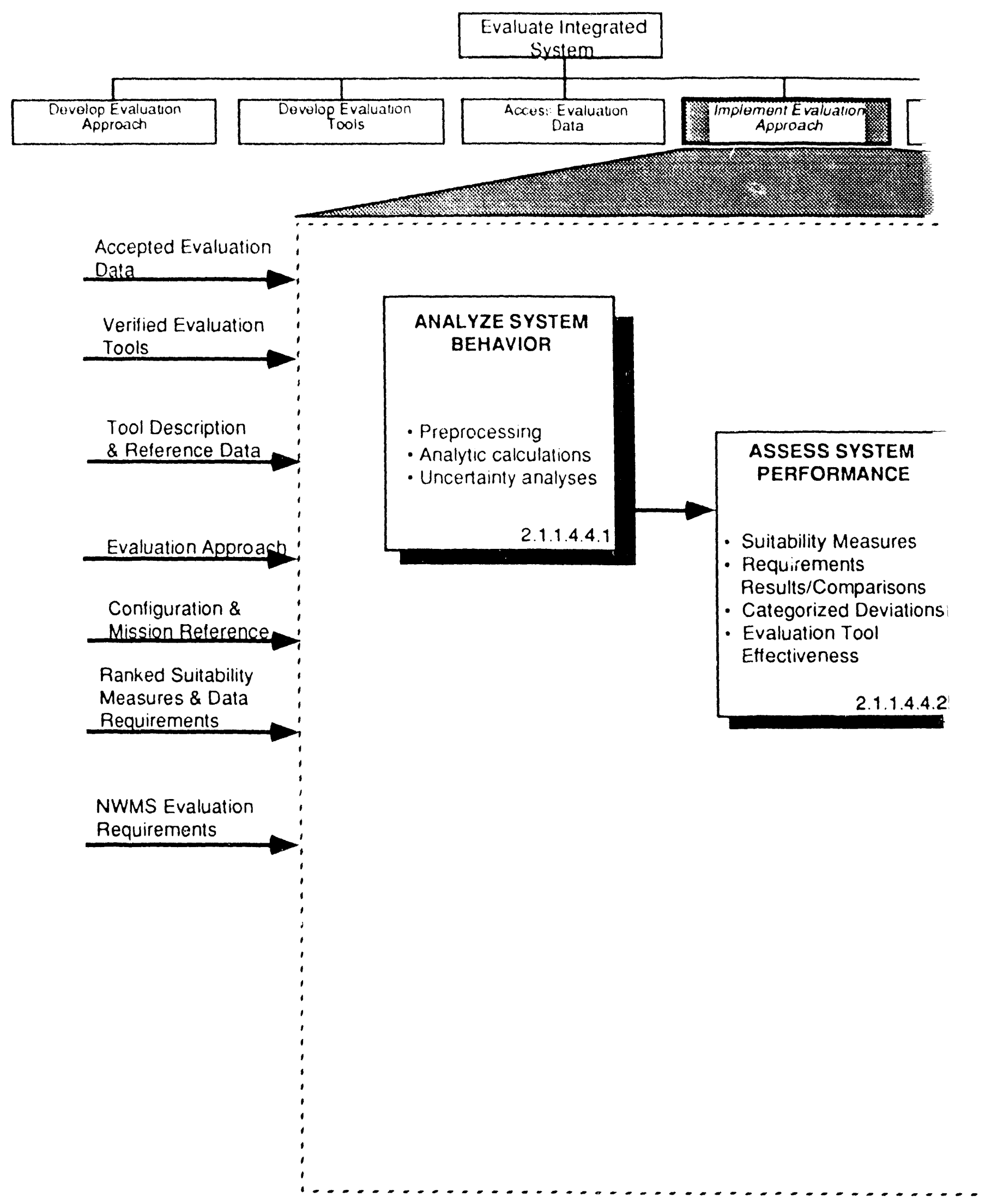


Figure 6-6. Process Execution Details Implement Evaluation Approach.
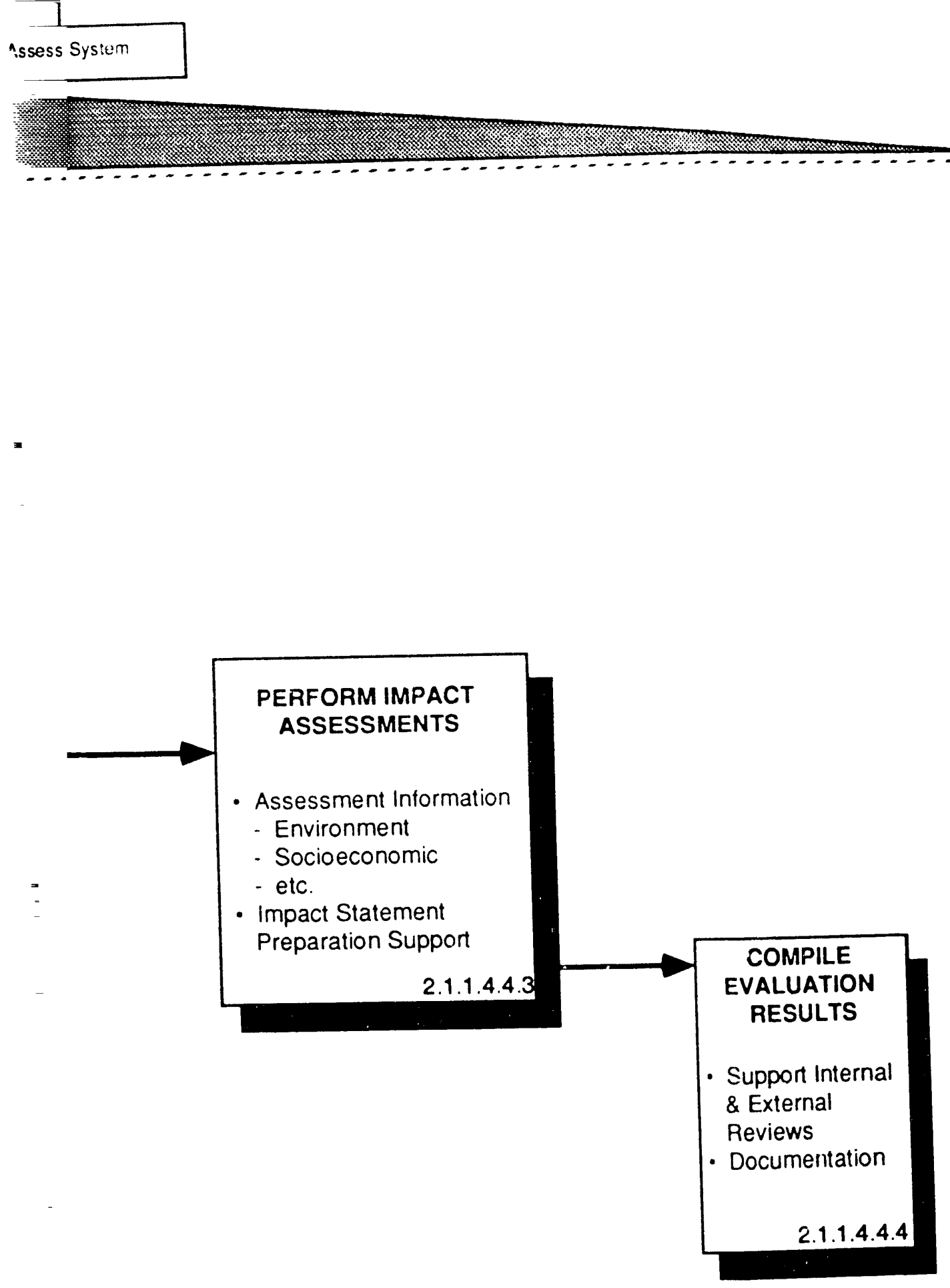
interpretations by determining what specific aspects of the system could be changed to improve the analysis results.

6.3.5.2 Process Flows. Figure 6-7 shows the first two Assess System (2.1.1.4.5) subfunctions perform different types of assessments on the evaluation results. One assesses the evaluation process, and the other assesses the system configuration. The results of those assessment types are compiled by the third subfunction.

The Assess Evaluation subfunction determines the confidence of tre results and assesses how this confidence level affects the utility of the evaluation process itself. Any undesirable levels of confidence are traced to their source (e.g. configuration description, evaluations tools, evaluation data. or evaluation approach) and recommendations for improving the confidence are developed.

The Assess System Configuration subfunction determines the detrimental behaviors of specific configuration items that negatively impact the integrated system performance.

The Compile Recommendations subfunction uses the results from both of the other subfunctions to develop specific instructions for improving the NWMS system and the evaluation approach.

6.3.5.3 Outputs. The results from the Assess System assessments are provided on two outputs. One, the Evaluation Recommendations, is provided to PSE. The other. Request Approach Change is a feedback requesting an improved, or otherwise modified, evaluation approach.

6.3.5.4 Significant Considerations. Recommendations from EIS can vary with the maturity of the program. During the early program phases, design and site selection recommendations can be for new analyses, or new design or site candidates. During the program construction phase, recommendations can include modification. replacement, or redesign of items or additional site analyses or surveys. During system operations, recommendations can include item modification, replacement, or redesign, the addition of new systems, and modifications to procedures and processes.

PSE makes determinations on the disposition of the data from EIS. Data requests for both tool validation and for the actual evaluations are distributed by PSE to the data collecting functions by generating new requirements for those functions. PSE returns the data to EIS as controlled items (Controlled NWMS description). Recommendations for changes to the configuration by EIS are processed by PSE and will result in Change Requests from PSE. PPC evaluates the requests and makes determinations of the disposition. PSE will either get the rejection change through Change Disposition or will get the change implementation through Program Direction. PSE will redirect, if appropriate, through NWMS Evaluation Requests. Also. PPC may redirect EIS through Program Direction for Evaluation.

The function includes a continual review and potential improvement of the evaluation process itself. 
Figure 6-7. Process Execution Details - Assess System.

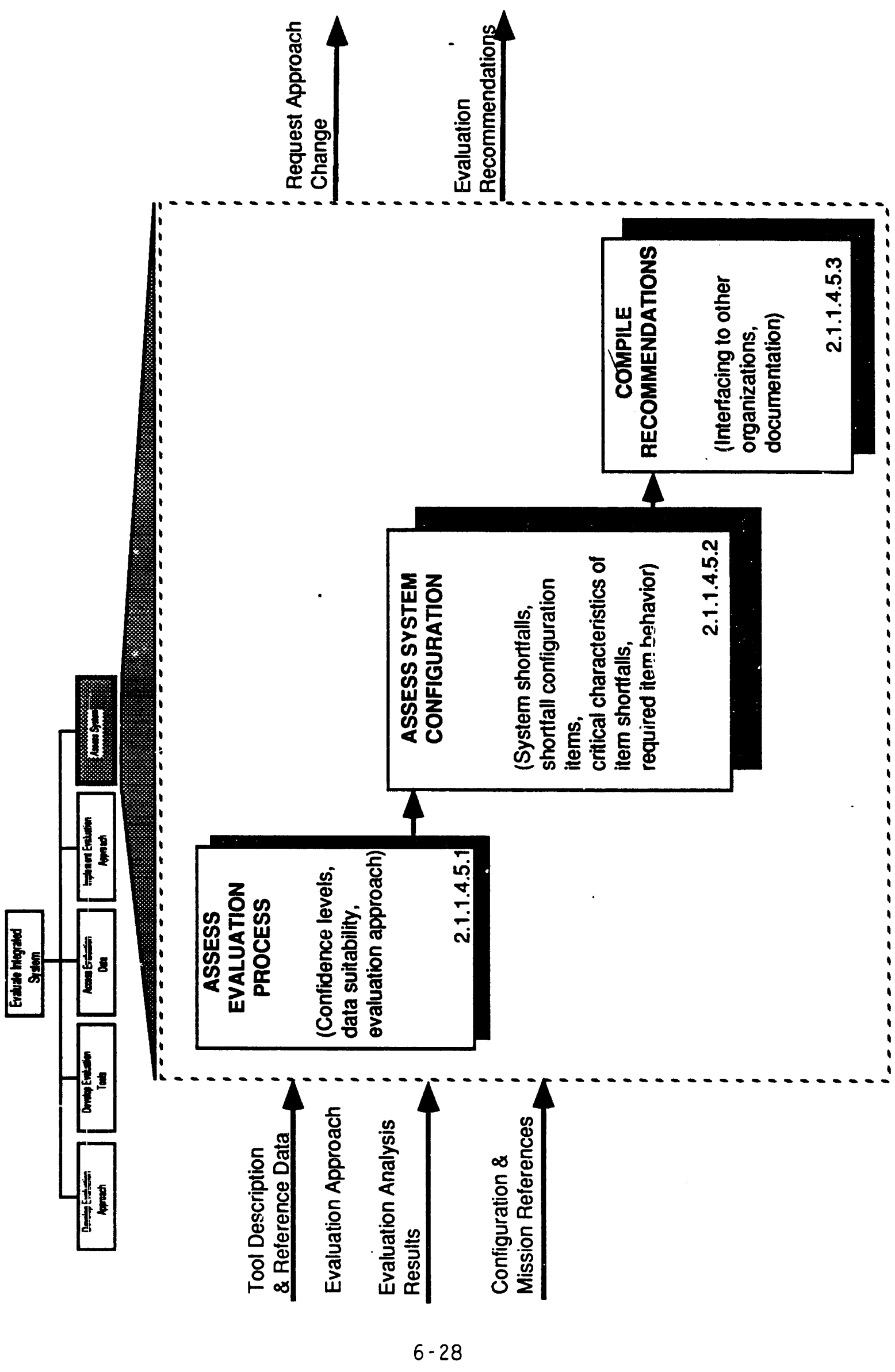


Figure 6-8. Evaluate Integrated System Major Feedback Loops.

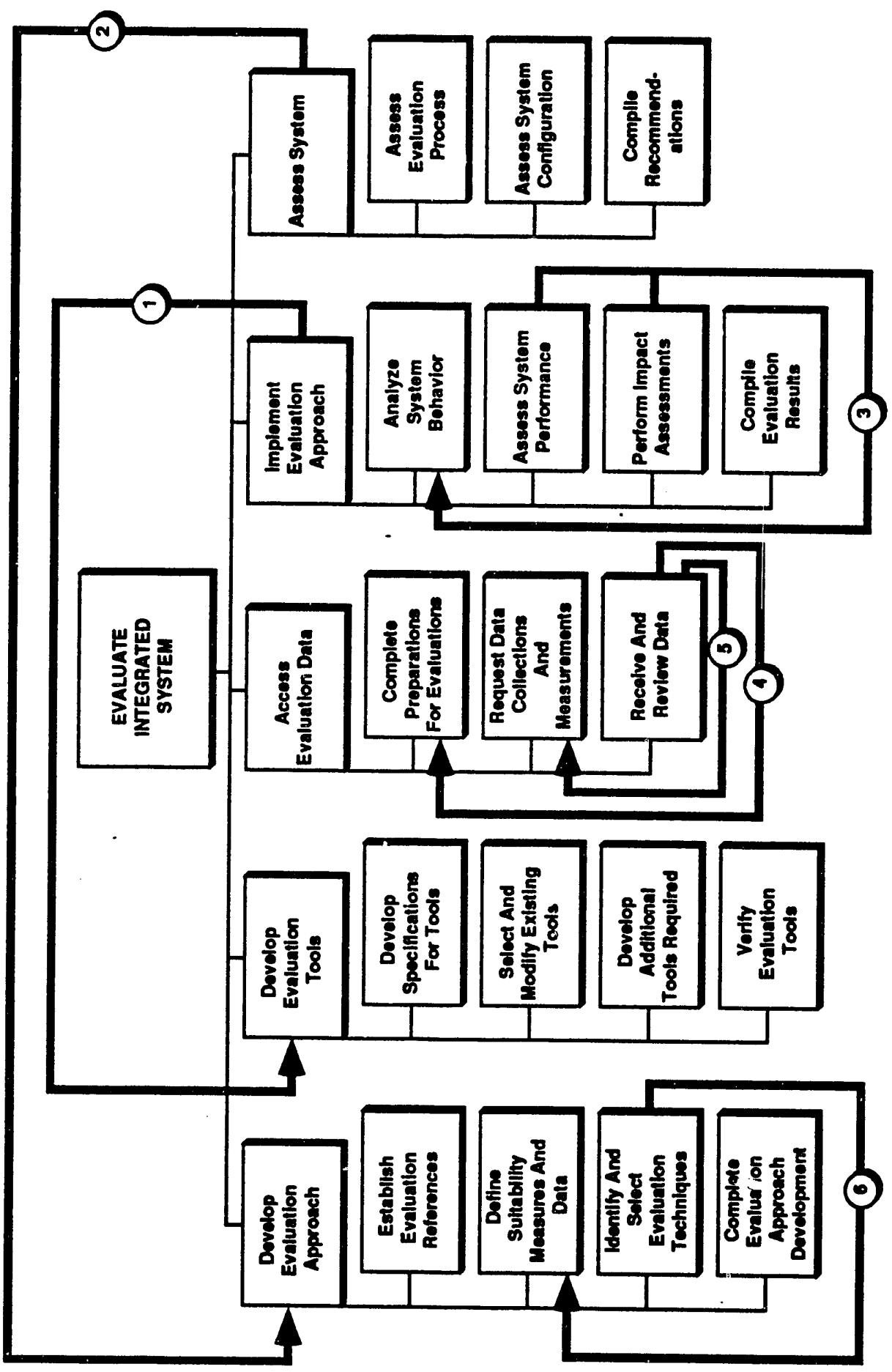


WHC - EP-0482

\subsubsection{Internal Feedbacks}

Figure $6-8$ is a hierarchical representation of the top three levels of functions that make up EIS. The normal flow of information in the chart is from left to right between the second-level subfunctions and from top to bottom for the third-level subfunctions. The dark. numbered arrows shown on the figure indicate where feedback of information occurs between functions.

The feedback arrows provide paths for functions occurring at one point in the process flow to communicate with preceding functions to obtain new or modified information. These feedback paths allow for iterations between functions so, as new knowledge is gained during subsequent function activities, it can be used to improve the approach developed in preceding functions.

The functional analysis provides feedback paths for the functions that are most likely to identify a needed modification of an earlier function output. For example. when the Implement Evaluation Approach is started. the results of accessing data may affect the requirements on the evaluation tools that were developed. The feedback path to Develop Evaluation Tools. path 1. provides a mechanism for the new requirements to lead to an improved evaluation tool.

Similarly. when the results of assessing the evaluations become available (Assess System) the determination may be made that the evaluation approach was inappropriate or could be improved so a feedback path. path 2 , is shown to Develop Evaluation Approach. The information fed back can request changes in any aspect of the evaluation approach such as new definitions of the configuration items, mission scenarios, environments, data collection techniques, and the other items that are defined in the approach.

The feedback loops in the third-level subfunctions shown in the figure also provide similar paths for adjusting or improving preceding function outputs. The loops in path 3 provide a means for the Assess system Performance and the Perform Impact Assessments functions to request more analysis so that the assessments can be adjust to unanticipated or incomplete analysis results.

Paths 4 and 5 both allow for the data collection process to be adjusted to accommodate received data either by adjusting the data plan (in the Complete Preparations for Evaluations function) or by sending out new requests for more data (from the Request Data Collection and Measurements function). Path 6 provides an iteration path allowing adjustments to the data requirements definitions as the assignments of data to data collection techniques are made. 
WHC-EP- 0482

\subsection{PERFORM CONFIRMATION/OPERATIONAL TESTING PROCESS DESCRIPTION}

This section provides a description of the Perform Confirmation/ Operational Testing (PCOT) (2.1.1.5) process. The discussion to follow will show that PCOT is a process driven by defined test requirements: responds to test requirements from several other programmatic functional processes: and includes both iterative processes to ensure requirements achievement and integrative processes to ensure program wide efficiency.

\subsection{PERFORM CONFIRMATION/OPERATIONAL TESTING MISSION AND PROCESS OVERVIEW}

\subsubsection{Mission/Objectives}

The confirmation/operational testing process plans, conducts, and documents tests that characterize the performance and behavior of the engineered and natural systems in the Nuclear Waste Management System (NWMS). The PCOT process responds to a defined testing requirement to demonstrate a performance characteristic or to satisfy a data need for another functional process. The process responds to testing requirements supporting the Evaluate Integrated System (EIS) function, hardware integration and checkout. initiation of operations, and continuing site characterization.

\section{1 .2 Scope}

The confirmation/operational testing process addresses all man-made items, natural systems and the interfaces between man-made items and natural systems. A functional decomposition of this process is shown in figure 7-1. Confirmation testing is a continuation of site characterization testing to ensure site performance is not affected by the implementation of the engineered system. It begins at License Application and continues through closure and decommissioning. The test function develops a site monitoring process based on site characterization techniques and performs the measurements and reporting consistent with the performance confirmation requirements of 10 CFR 60 . Subpart $F$. Operational testing is the testing of all assemblies of end-items once they have been installed at the site. and installation has been verified. Operational testing begins during system construction and continues through approval to operate and includes testing on redesigns or expansions of the system. The test function develops and implements test plans and procedures for specified performance characteristics, configurations, conditions.

The process includes all activities necessary to produce verified data that satisfies the testing requirements. To satisfy the testing requirements, the PCOT functional process performs the following:

- Identifies the testing approach options, characterizes them, and selects the most effective approach

- Integrates across the testing activities to optimize the number of measurements, the resources required for testing, the commonality of equipment and procedure, the influence on other schedules 
Figure 7-1. Hierarchical Overview of Perform Confirmation/Operational Testing.

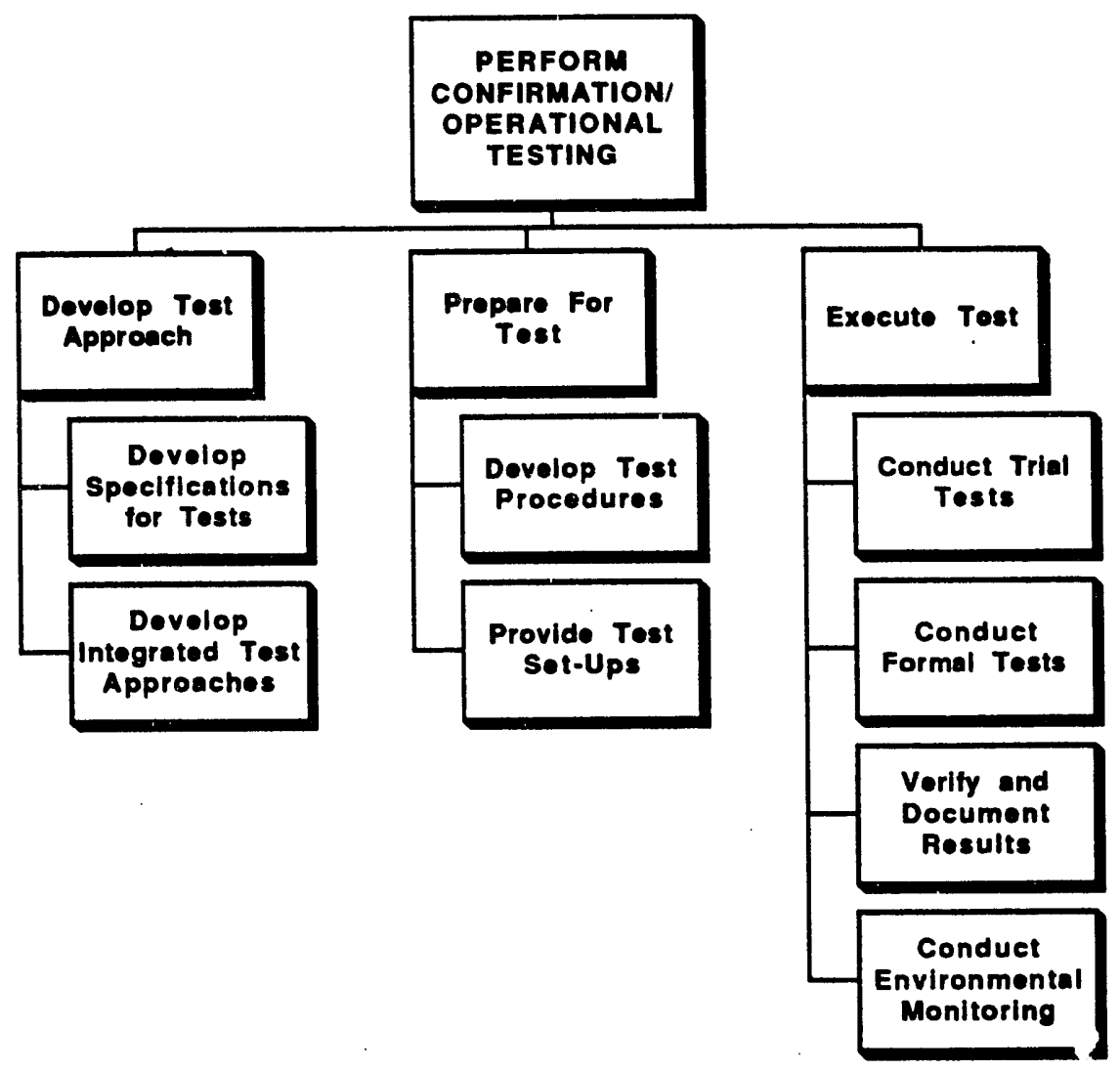


- Develops the detailed step-by-step procedures and develops and implements the test set-up

- Performs all procedure validation and pretest runs, collects all data, and implements all necessary quality methodologies during data collection

- Verifies quality, completeness, and appropriateness of data collected and develops all test and data documentation.

\subsubsection{Process Overview}

The PCOT process flow (see Figure 7-2) begins with a set of defined test data and performance measurements that must be obtained. Test data definitions originate in the processes that PCOT supports. The PCOT process then develops and executes methods to gather the data or measure the performance. The process outputs the documented and verified test data for analysis, review, and evaluation within the functional process that generated the need for the data.

- Inputs to PCOT define the system characteristics to be measured. the configuration and conditions for the measurement, and constraints on the data collection methodology. The PCOT process derives from these the procedure, the test set-up, the instrumentation, the data collection apparatus, etc.

- The PCOT process produces two types of outputs. The first type are plans and procedures that define the resources required and provide for technical review and evaluation. The second type of outputs are test reports that give complete documentation of the raw data, reduced data. conditions, methods, and limitations.

- Externally controlled iterations through the PCOT process can occur in two ways. In the first path, test plan reviews and Test Readiness Reviews can generate new test requirements. if the review finds need for changes in plan or procedure. These reviews are part of the technical process in the Perform Systems Engineering (PSE) function. A second iterative pathway is via a Need for Review of NWMS Testing Requirements. This need identifies an issue in meeting the test requirements and is input to the requirements control process in PSE. It can yield a change request which could, in turn, may cause a redirection of either the PCOT process or the functional process that produced the test requirement.

\section{1 .4 Role}

The role of PCOT is to support system evaluation, initiation, and operation through testing of acquired hardware after the system final design has been selected.

- Support to Integrated System Evaluation. Testing requirements are developed in EIS that define the quantities that must be measured to evaluate system suitability. PCOT receives these testing requirements, develops the plans for satisfying them, and then 
WHC-EP- 0482

This page intentionally left blank. 


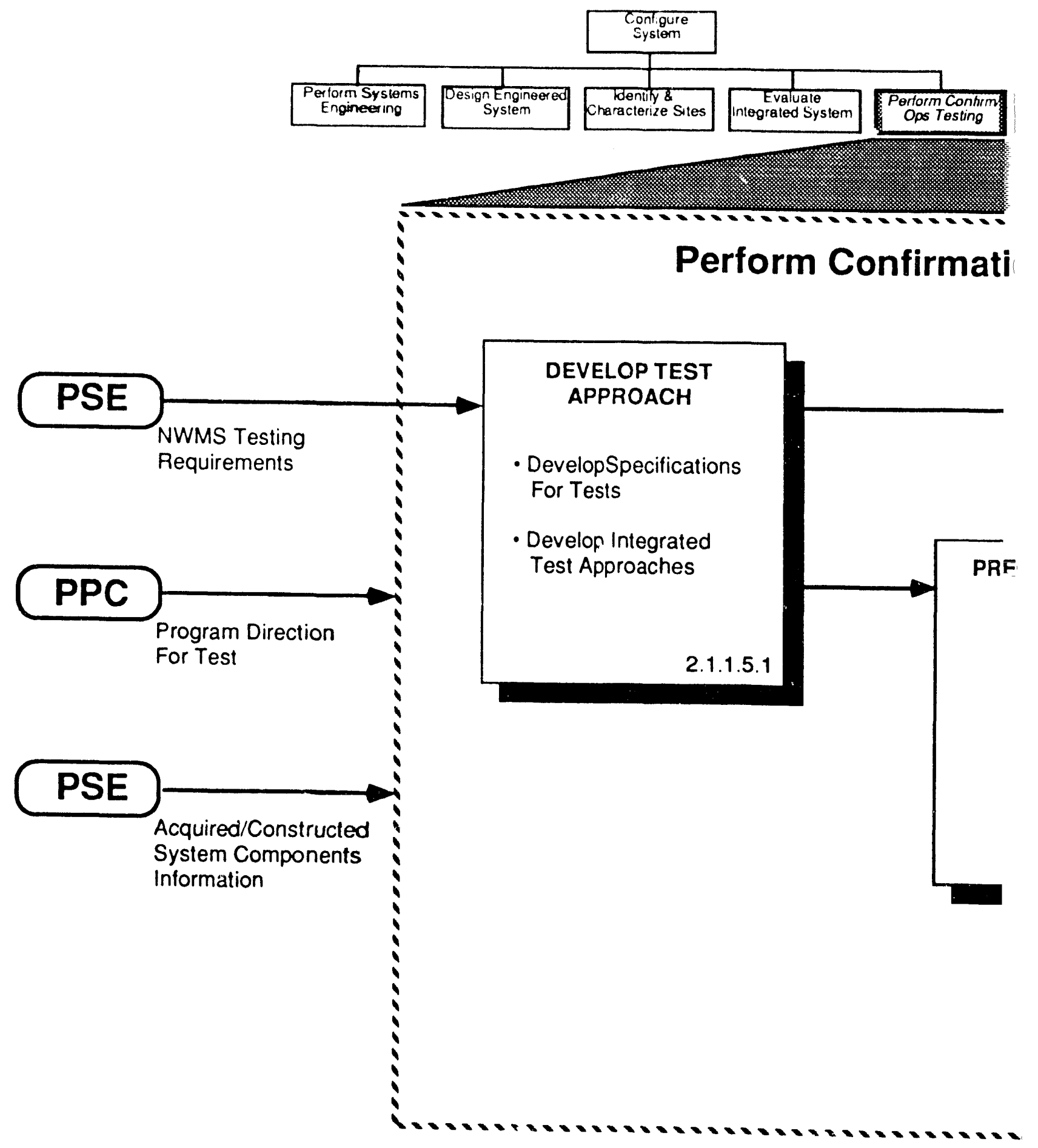


Figure 7-2. Process Overview Perform Confirmation/operational Testing.

\section{i/Operational Testing}

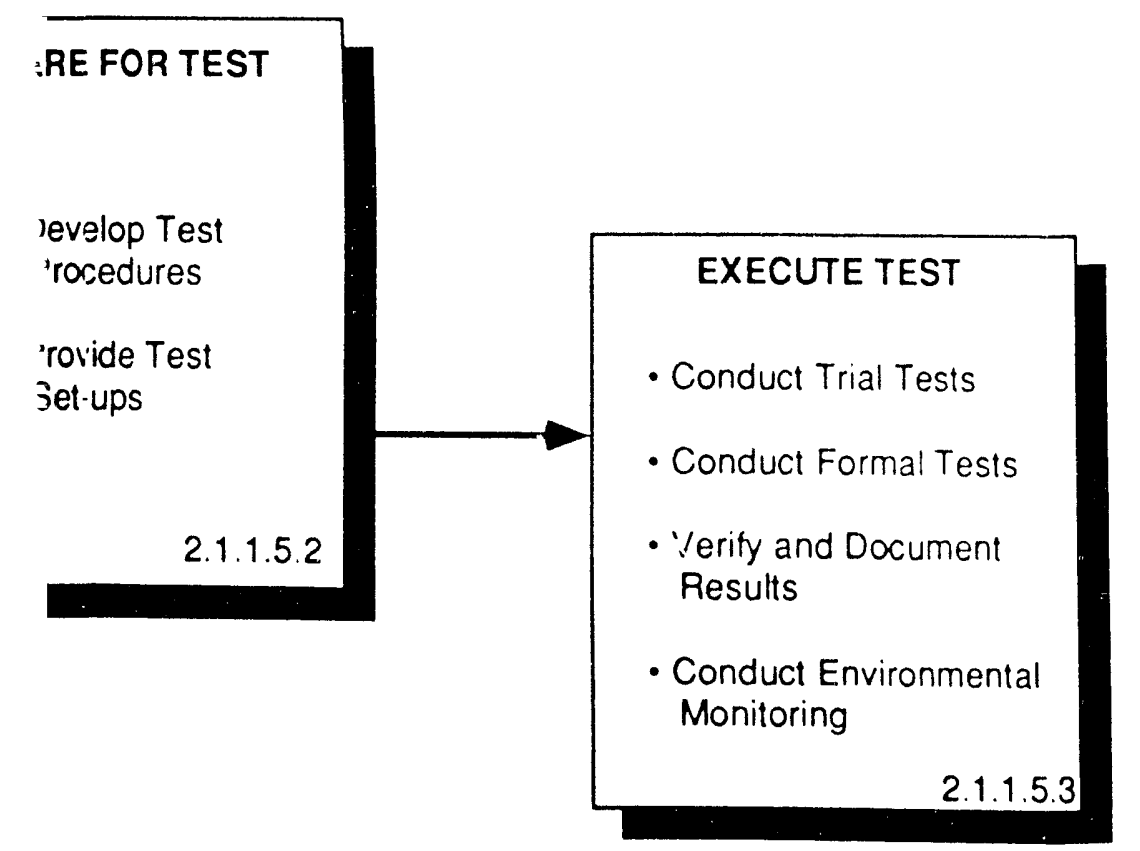

\section{PSE}


collects and validates the data. Data are then provided to EIS for analysis and for determining system suitability.

- Support to System Initiation. Requirements for verifying system operational procedures and operational processes are defined in Design Engineered System (DES) and EIS. PCOT receives these testing requirements, develops the plans and procedures for satisfying them, and then collects and validates the data. Data are then provided to DES for analysis and incorporation into the As-Built design archive and to EIS for analysis and for determining system suitability.

- Support to Systems Operations. Requirements and processes for performing site monitoring are developed in Identify and Characterize Sites (ICS) and EIS. PCOT receives these testing requirements and performs the needed monitoring.

\subsection{PERFORM CONFIRMATION/OPERATIONAL TESTING EXTERNAL INTERFACES}

The PCOT function is a requirements-driven process that produces test results in response to defined testing requirements. Testing requirements and system descriptions initiate test planning and procedure development. The process continues until the requirements have been satisfied by the collection of high quality data. The following section describes these inputs, controls. and outputs in more detail.

\subsubsection{External Inputs}

To define the detailed test procedures, the PCOT process uses the controlled descriptions of natural systems and engineered items as input. This input and its distribution are outlined in Table 7-1. The Acquired/Constructed System Components Information input originates from the controlled system configuration description (i.e.. Technical Baseline) maintained in PSE and constructed from DES and ICS data and data from system implementation. It is received by the Develop Test Approach and Prepare for Test subfunctions. It provides an understanding of the hardware to be tested so that test points, test limitations, typical performances, etc.. can be determined. The information is used in test planning to interpret test requirements and is used in procedure development to specify apparatus. instrumentation interfaces, etc.

The input information to the PCOT process defines the articles to be tested and the status and configuration of these articles when testing is to be performed. The test process extracts the definitions of natural systems and engineered items that must be tested. Other system configuration data extracted from the controlled database include the following:

- Design information including engineered item specifications, drawings, and operational modes/processes

- Implementation information consisting of inspection data and field data

- Background information such as previously collected data and previously used procedures from the DES and ICS functional processes 
Table 7-1. External Inputs to Perform Confirmation/Operational Testing.

\begin{tabular}{|c|c|c|}
\hline Input Name & Input Definition & Destination Function \\
\hline $\begin{array}{l}\text { Acquired/ } \\
\text { constructed } \\
\text { system } \\
\text { components } \\
\text { information }\end{array}$ & $\begin{array}{l}\text { All engineered and } \\
\text { natural system } \\
\text { component information } \\
\text { requireed for system } \\
\text { operation. The acquired } \\
\text { or constructed system } \\
\text { components become the } \\
\text { subjects for conduct of } \\
\text { confirmation or } \\
\text { operational testing. As } \\
\text { such, information about } \\
\text { them must be available } \\
\text { to the test preparation } \\
\text { and test executions } \\
\text { functions to permit test } \\
\text { function execution }\end{array}$ & $\begin{array}{l}\text { 2.1.1.5.1.1.2.1 Define Test } \\
\text { Scope and Purpose } \\
2.1 .1 .5 .1 .1 .2 .2 \text { Determine } \\
\text { Conditions, Modes and } \\
\text { Interfaces } \\
2.1 .1 .5 .1 .2 .1 \text { Identify } \\
\text { Commonalities } \\
2.1 .1 .5 .2 .2 .2 \text { Configure Test } \\
\text { Set-ups }\end{array}$ \\
\hline
\end{tabular}


WHC-EP-0482

- Verification procedures developed by the DES functions as part of Final Design.

\subsubsection{External Controls}

The confirmation/operational testing process responds to testing requirements that define the measurements to be made, and to programmatic requirements that define the standard practices for testing. These controlis are outlined in Table 7-2. The requirements provide all information necessary to define the nature of the measurement required, the conditions under which the measurements must be made, and the processes used to fulfill these requirements. NWMS Testing Requirements and Program Direction for Test can be described as follows:

- NWMS Testing Requirements define the system characteristic to be measured. the conditions of measurement, and (for integrated system evaluation testing requirements) the general approach to the measurement.

- All testing requirements arrive from the requirements allocation process in PSE: the technical content of these requirements originates in the EIS function, the DES function, the ICS function. the mission and functional analysis of the PSE function, and the ERC function.

- Requirements are received by the approach development part of the testing process and serve as reference controls on test approach development and test preparation defining what the plans and preparations must accomplish.

Modifications to the design and changes to regulatory requirements can cause changes to the testing requirements.

- The requirements include all constraints on how the test is performed including design description of the configuration of the unit under test, reference information on how the data will be used, and procedure information when results must be compatible with earlier measurements.

- The testing requirements consist of confirmation testing requirements (site performance oriented), operational testing requirements (verifies hardware performance and implementation relative to the design). Integrated system Evaluation testing requirements (generate data to feed calculate suitability measures) and directed testing requirements mandated by 1 aw or regulation.

- Program Direction for Test defines standard practices, defines the relationship of test and quality programs, defines fiscal and organizational constraints, and defines strategy for ensuring tests fit within compliance process.

- Program Direction originates from the program organization and task planning processes in Provide Program Control (PPC) function 
Table 7-2. External Controls to Perform

Confirmation/Operational Testing.

(sheet 1 of 2 )

\begin{tabular}{|c|c|c|}
\hline Control Name & Control Definition & Destination Function \\
\hline $\begin{array}{l}\text { NWMS Testing } \\
\text { Requirements }\end{array}$ & $\begin{array}{l}\text { All requirements } \\
\text { necessary and sufficient } \\
\text { to develop an NWMS } \\
\text { physical system } \\
\text { confirmation/operational } \\
\text { test program to include } \\
\text { test approach } \\
\text { development, } \\
\text { preparation for tests, test } \\
\text { conduct, and test data } \\
\text { verification. The Perform } \\
\text { Systems Engineering } \\
\text { function generates the } \\
\text { performance verification } \\
\text { requirements for the } \\
\text { NWMS physical system } \\
\text { that must be addressed } \\
\text { in } \\
\text { confirmation/operational } \\
\text { tests. For confirmation } \\
\text { testing, the requirements } \\
\text { are expressed in the } \\
\text { form of.suitability } \\
\text { measures and data } \\
\text { collection descriptions } \\
\text { (or attributes). The } \\
\text { specific requirements for } \\
\text { performance verification } \\
\text { testing include the } \\
\text { following: directed and } \\
\text { derived tests, directed } \\
\text { and derived test } \\
\text { methods, directed and } \\
\text { derived performance or } \\
\text { suitability measures, } \\
\text { directed and derived } \\
\text { acceptance criteria, and } \\
\text { directed and derived test } \\
\text { environment } \\
\text { requirements }\end{array}$ & $\begin{array}{l}\text { 2.1.1.5.1.1.1 Define Necessary } \\
\text { Documentation } \\
2.1 .1 .5 .1 .1 .2 .1 \text { Define Test } \\
\text { Scope and Purpose }\end{array}$ \\
\hline
\end{tabular}


Table 7-2. External Controls to Perform Confirmation/Operational Testing.

(sheet 2 of 2 )

Program Direction for Test
The control from the Provide Program Control function which authorizes the initiation of test activities and provides test resources and test program guidance. This control provides program direction, requirements, and constraints to the test function, including the following: work authorization, approvals of draft documents, TRR and other review inputs. Information on the availability and timing of the test resources (personnel, equipment, and facilities) requested to accomplish the test program is also provided via this test control path
2.1.1.5.1.1.2.1 Define Test Scope and Purpose

2.1.1.5.1.1.2.2 Determine Conditions, Modes and Interfaces

2.1.1.5.1.1.2.3 Define Measure Attributes

2.1.1.5.1.1.1 Define Necessary Documentation

2.1.1.5.2.1.1 Prepare Test Procedures

2.1.1.5.2.2.1 Design Test Setups

2.1.1.5.3.1.1 Conduct Critical Test Procedures

2.1.1.5.3.2.1 Conduct All Test Procedures 
- Program Direction is received by each stage of the testing process and defines how test development and execution will be implemented in a programmatic process. Program Direction evolves as the program plan and program strategy evolve and is responsive to changes in regulatory environment and compliance approach.
An important element of Program Direction is standard practices. Standard practices define a basic methodology for doing business and address standards applied to work execution. standards and standard forms applied to products, and standard procedures for programmatic activities (e.g.. reviews, task planning, reporting, etc.). In the PCOT function, standard practices address documentation. test procedures and Test Readiness Reviews. quality assurance practices during testing, and test data validation processes. Many standard practices may be required by law (e.g.. meet state construction and safety codes).

\subsubsection{External Outputs}

The PCOT process produces two classes of technical outputs: test planning documents and test reports. In addition, the testing process generates needs for review of NWMS requirements. These products are outlined in Table 7-3. The products provide all information necessary to control the program. to allocate resources and to form a traceable historical archive of the performance of the NWMS. Test Information and Need for Review of Test Requirements can be described as follows:

\section{The Test Information output consists of test planning and test reporting products.}

Test planning products originate from the Develop Test Approach subfunction (includes test plans with specifications for test and documentation specifications) and the Prepare for Test subfunction (includes detailed procedures and test set-up description)

- Test planning products become part of the controlled technical description database (see PSE function) and are available to PPC for updating program plans. Test planning products are used in technical reviews, in compliance reviews, and for updating program plans.

- Test planning products define the methodology to satisfy testing requirements and specify the support required to satisfy the requirements.

- Test planning products consist of test plans that specify the overall approach to meeting individual requirements as well as to integrating the overall testing program; document specifications that define the nature of the testing process product and which specifically address quality procedure implementation 
Table 7-3. External Outputs from Perform Confirmation/Operational Testing.

\begin{tabular}{|c|c|c|}
\hline Output Name & Output Definition & Originating Function \\
\hline Test Information & $\begin{array}{l}\text { The set of information } \\
\text { delivered to the Provide } \\
\text { System Engineering } \\
\text { function for formal review } \\
\text { and/or distribution. Test } \\
\text { Information includes the } \\
\text { following: (1) requests } \\
\text { for needed test } \\
\text { resources and } \\
\text { prerequisites, (2) test } \\
\text { plans, (3) test } \\
\text { procedures, (4) test set- } \\
\text { ups, and (5) test and } \\
\text { monitoring results. It } \\
\text { does not include internal } \\
\text { test documentation. }\end{array}$ & $\begin{array}{l}\text { 2.1.1.5.1.1.1 Define Necessary } \\
\text { Documentation } \\
\text { 2.1.1.5.1.2.2 Finalize Test } \\
\text { Specifications and } \\
\text { Techniques } \\
\text { 2.1.1.5.1.2.3 Develop Test } \\
\text { Plans } \\
\text { 2.1.1.5.2.1.2 Assemble Test } \\
\text { Procedures } \\
\text { 2.1.1.5.2.2.2 Configure Test } \\
\text { Sit-ups } \\
\text { 2.1.1.5.3.3 Verify and } \\
\text { Document Results } \\
\text { 2.1.1.5.3.4 Conduct } \\
\text { Environmental Monitoring }\end{array}$ \\
\hline $\begin{array}{l}\text { Need for Review } \\
\text { of NWMS Testing } \\
\text { Requirements }\end{array}$ & $\begin{array}{l}\text { Detailed explanation of a } \\
\text { need to review testing } \\
\text { requirements because } \\
\text { the defined requiremerts } \\
\text { cannot be successfully } \\
\text { incorporated into a } \\
\text { confirmation/operational } \\
\text { test approach. The } \\
\text { Develop Specifications } \\
\text { for Test function attempts } \\
\text { to allocate each testing } \\
\text { requirement to a specific } \\
\text { confirmation/operational } \\
\text { test or to a series of } \\
\text { connected tests. If this } \\
\text { attempt is unsuccessful, } \\
\text { the specific test } \\
\text { requirement must be } \\
\text { reviewed and evaluated } \\
\text { for modification by the } \\
\text { Perform Systems } \\
\text { Engineering Function. }\end{array}$ & $\begin{array}{l}\text { 2.1.1.5.1.1.2.3 Define Measure } \\
\text { Attributes }\end{array}$ \\
\hline
\end{tabular}


and reporting: test needs/prerequisites that address test process prerequisites and resource needs such as test facility development. scheduling requirements relative to construction. etc.: test procedures that detail a step-by-step listing of actions to collect data: and test set-ups that detail the configuration of the test including test points and test instrumentation.

- Test reporting products are produced during the Execute Test subfunction and result from verification and documentation of test data

- Test reporting products are delivered to the controlled technical description database (see PSE function) and serve as input data for analyses of system performance.

- - Test reporting products are analyzed by EIS (possibly by DES, if they apply to the As-Built design process) to determine if the system is suitable: they are used as substantiation of claims of suitability to regulatory agencies.

- The primary test reporting product is Verified Test Results comprised of raw data, reduced data, procedures, documentation of prerequisites (e.g.. calibrations, set-up verification, reference runs. etc.) results of quality procedure implementation. results of data verification. and results of analyses required to meet requirement.

- Need for Review of Test Requirements requests a technical (and possibly programmatic) review of a particular aspect of requirements and is produced when the requirements set (including program direction) has an incompatibility or an unfeasible requirement.

- This output originates from the test approach development process when no test approach or procedure can be developed to yield data that meets requirements. It usually occurs only after several iterations on the test approach. procedure, and data.

- This output is delivered directly to the technical baseline control process in PSE and eventually reaches the program evaluation and change control processes in PPC.

\subsection{PERFORM CONFIRMATION/OPERATIONAL TESTING PROCESS EXECUTION DETAILS}

This section provides descriptions of the steps in accomplishing the PCOT process. The following discussions are success-oriented and shc'y information and activity flows as if each test process step accomplishes its goal on the first pass. The success-oriented approach provides the simplest and clearest explanation of the flow of activities. The relationship between steps is more easily seen if feedbacks to earlier steps, to improve products. 
WHC-EP-0482

are not shown. Subsection 7.4 shows where feedbacks can occur when a function product is not perfect/acceptable on the first pass.

\subsubsection{Develop Test Approach}

7.3.1.1 Mission/Objective. The Develop Test Approach function (2.1.1.5.1) defines a testing program that will satisfy the NWMS testing requirements. Methodologies. techniques, and specifications are developed to meet testing requirements and an overali $n l a n$ is developed to ensure consistency between tests and effectiveness of resource use.

7.3.1.2 Process Flow. Test approach development begins by defining the methodology required to collect data for each testing requirement. It then integrates these methodologies into a complete testing program. The flow of activities in Develop Test Approach is illustrated in Figure 7-3. The first tier of subfunctions to Develop Test Approach is shown in the figure and can. be described as follows:

- The Develop Specifications for Tests function examines each testing requirement individually and determines what is required to satisfy it. It determines test documentation needs that define the data to be collected including those data needed to verify suitability of results and implement quality procedures. From the data collection/documentation requirements. specifications for the test are derived by defining the scope of each test series, the conditions and configuration for each test series, and the characteristics of the data (e.g.. uncertainty. confidence, statistical properties, etc.). Candidate data collection/testing techniques are then identified, characterized, and screened.

- The Develop Integrated Test Approaches function identifies commonalties in specifications and techniques. Where appropriate. additional commonalties are superimposed and the redundancy in test series is eliminated. The integrated organization of test series is defined. The final selection of techniques and specifications is then made based on the commonality assessment and a detailed review against testing requirements. Test plans are then developed to formalize the results of the approach development.

The development of the testing approach is the point at which the PCOT Process interacts with all external feedback loops. Test plans are input to the technical review process (see PSE function) where external review validates the technical approach. Problems in developing an effective approach are revealed in the technical review and can cause change requests or reinitiation of test planning. In adaition, test plans define the desired relationship between testing and other processes and any special support requirements. They are input to the program evaluation process (see Provide Program Control function) and can cause redirection of the PCOT function or another MSIS functional process.

7.3.1.3 Outputs. The Test Approach Development function produces all the planning information needed to execute and manage the test program. The test Approach Development function produces four outputs: Test Plans. Documentation Specifications. Test Needs and Prerequisites, and Need for NWMS Test Requirements Review. Test Plans are the final product of approach development. They embody all test specifications and test techniques that are 
WHC-EP-0482

This page intentionally left blank. 


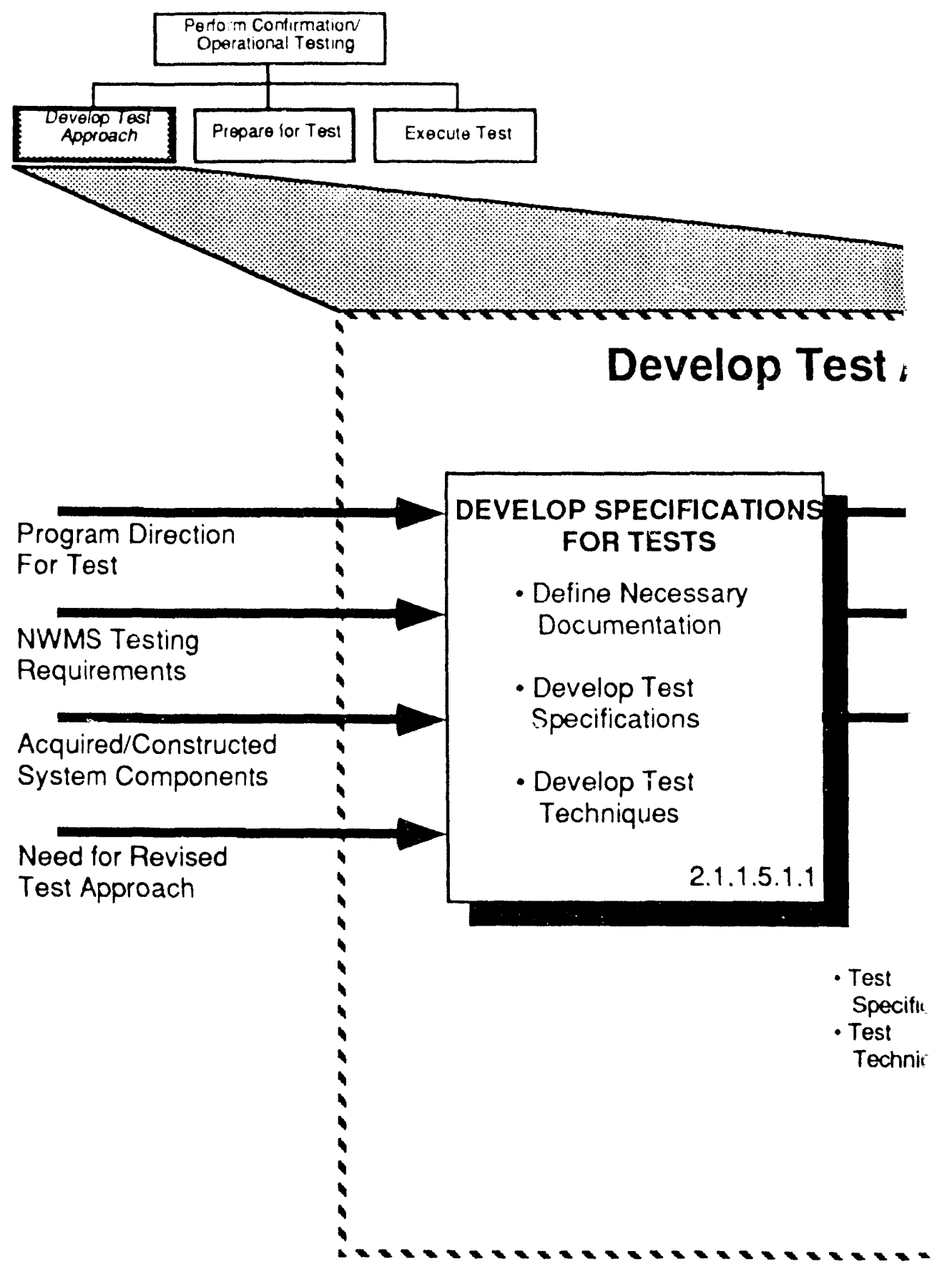


Fiqure 7-3. process Overview Develop Test Approach.
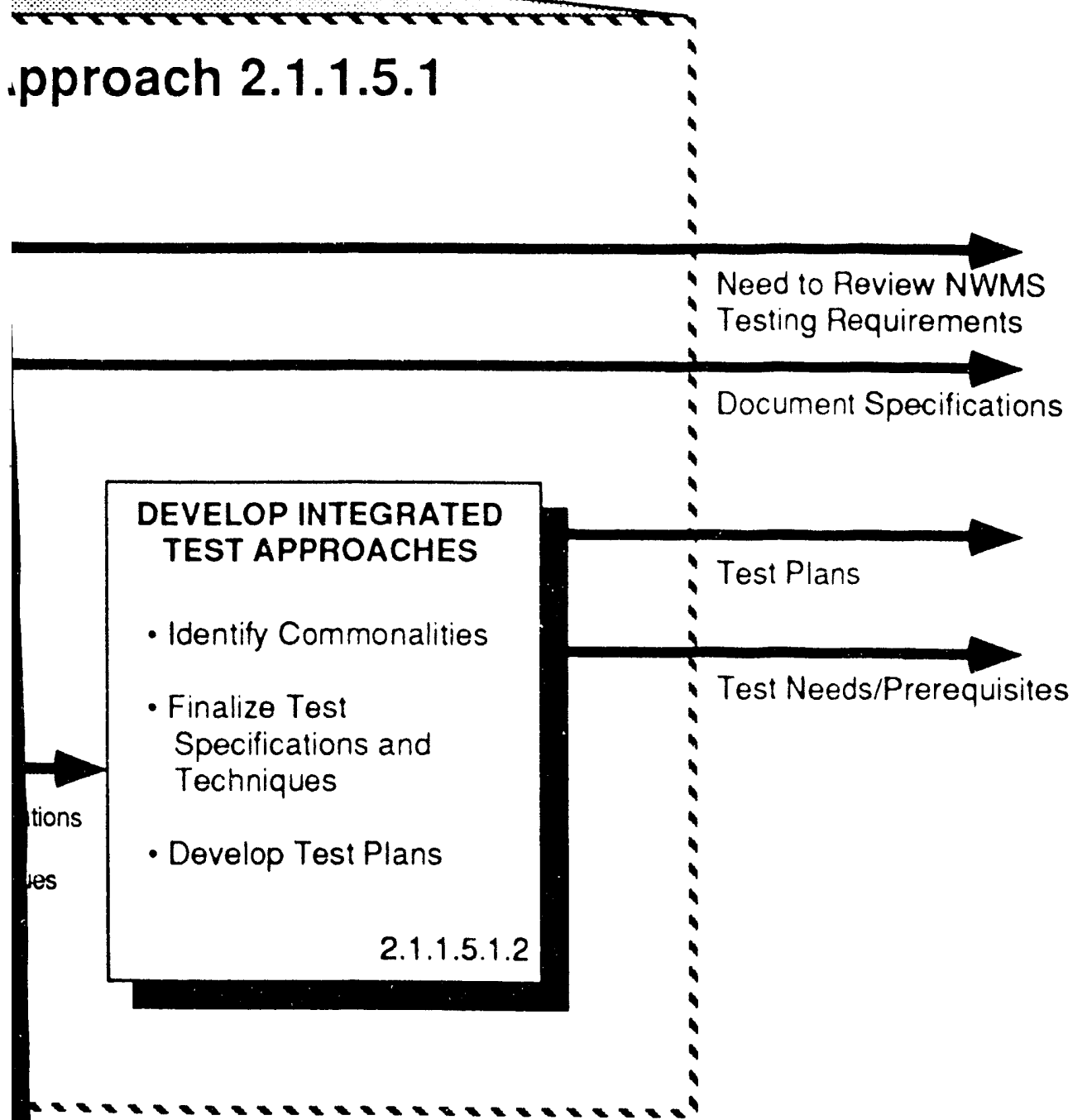
sufficient to meet requirements. Documentation Specifications define how the testing process will be documented to ensure verifiable results and a valid historical archive. They translate quality standards to test procedures. Test Needs and Prerequisites define resources that must be provided to perform testing. The Need for NWMS Test Requirements Review defines problems in developing an effective approach and transmits them to the program control functional processes via the PSE control and integration process.

7.3.1.4 Significant Considerations. To accomplish test approach development effectively, the Develop Approach function must perform the following:

- Identify, organize, and control the necessary and sufficient sets of tests and test related activities that satisfy the complete set of testing requirements.

- Formulate an approach to test conduct that establishes the intent and scope of the test program and that identifies the test methods to be employed.

- Develop an integrated set of scenario-diven test plans capable of addressing test requirements in a test environment that is fully responsive to the critical characteristics of the mission environment.

- Identify the complete set of preparations needed to complete each test successfully with regard to resources (hardware, software. staff, procedures. facilities and test environment) and prerequisite approvals (authority to proceed. safety review and approval, test plan review and approval, etc.).

\subsubsection{Prepare For Test}

7.3.2.1 Mission/Objective. The Prepare for Test function (2.1.1.5.2) develops the detailed procedures, prerequisites, and apparatus necessary for test execution. It produces the step-by-step procedure and the completed configuration of the test set-up. It also identifies feasibility problems in implementing the test plan in the procedure or set-up.

7.3.2.2 Process Flow. Preparations begin by developing the procedure and then continue by developing the test set-up corfiguration. Both processes are iterative to ensure specifications are met. The flow of activities in Prepare for Test is illustrated in Figure 7-4. The first tier of subfunctions to Prepare for Test is shown in the figure and can be described as follows:

- The Develop Test Procedures function begins deriving an overall list of test procedures from the specifications in the test plan. The needed procedures are then grouped based on commonalties of test type, test data, test goals, etc. From the grouped list, a reduced list of procedures is developed that emphasizes common procedures for related tests. Product requirements, derived from test plans and specifications and program direction, are then allocated to each procedure. Test specifications are then expanded and flowed down to form a step-by-step procedure that is based on the technique identified in the plan and that identifies outside support requirements and test hardware requirements. 
WHC-EP-0482

This page intentionally left blank. 


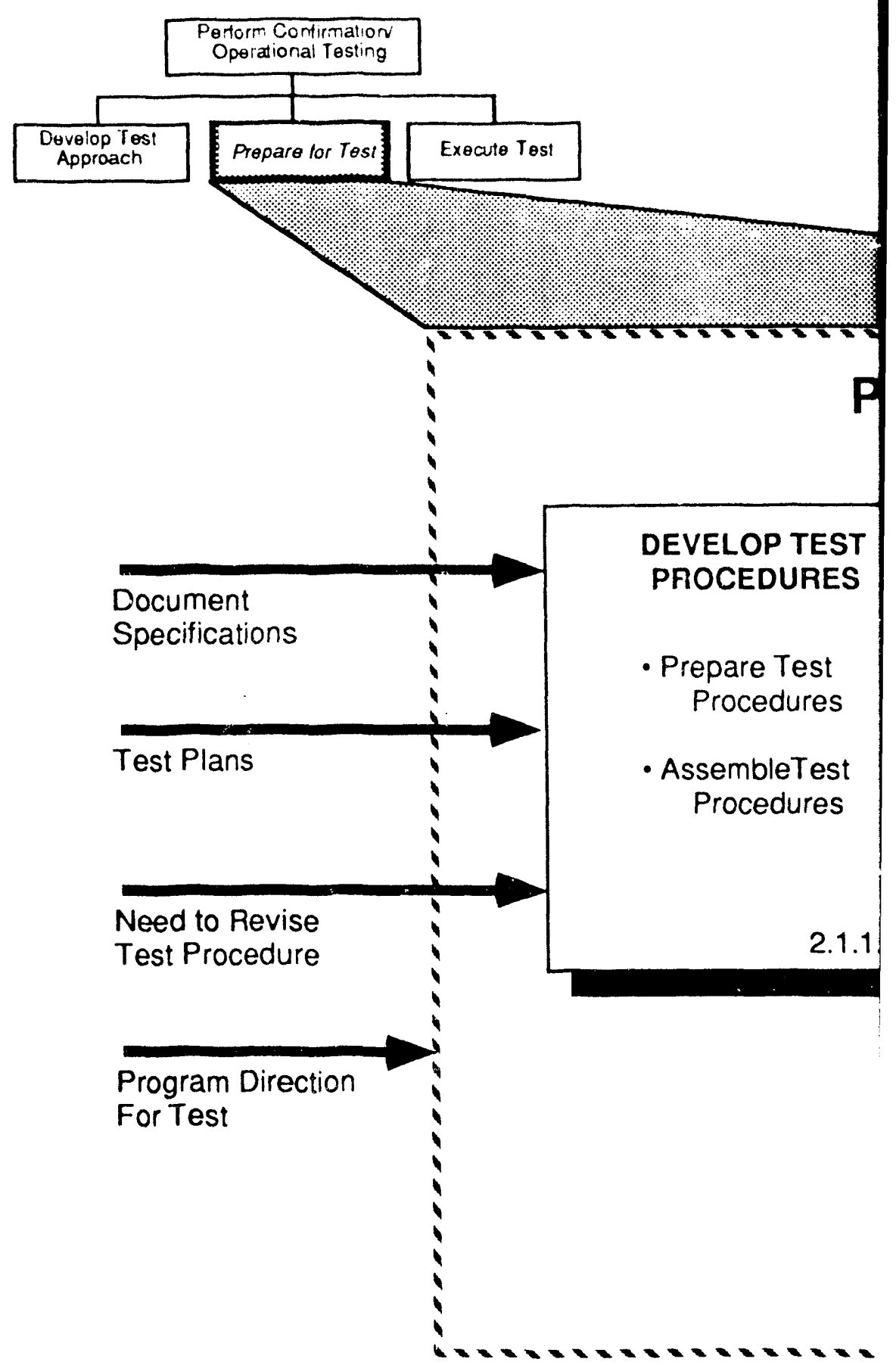


Figure 7-4. Process Overview Prepare for Test.

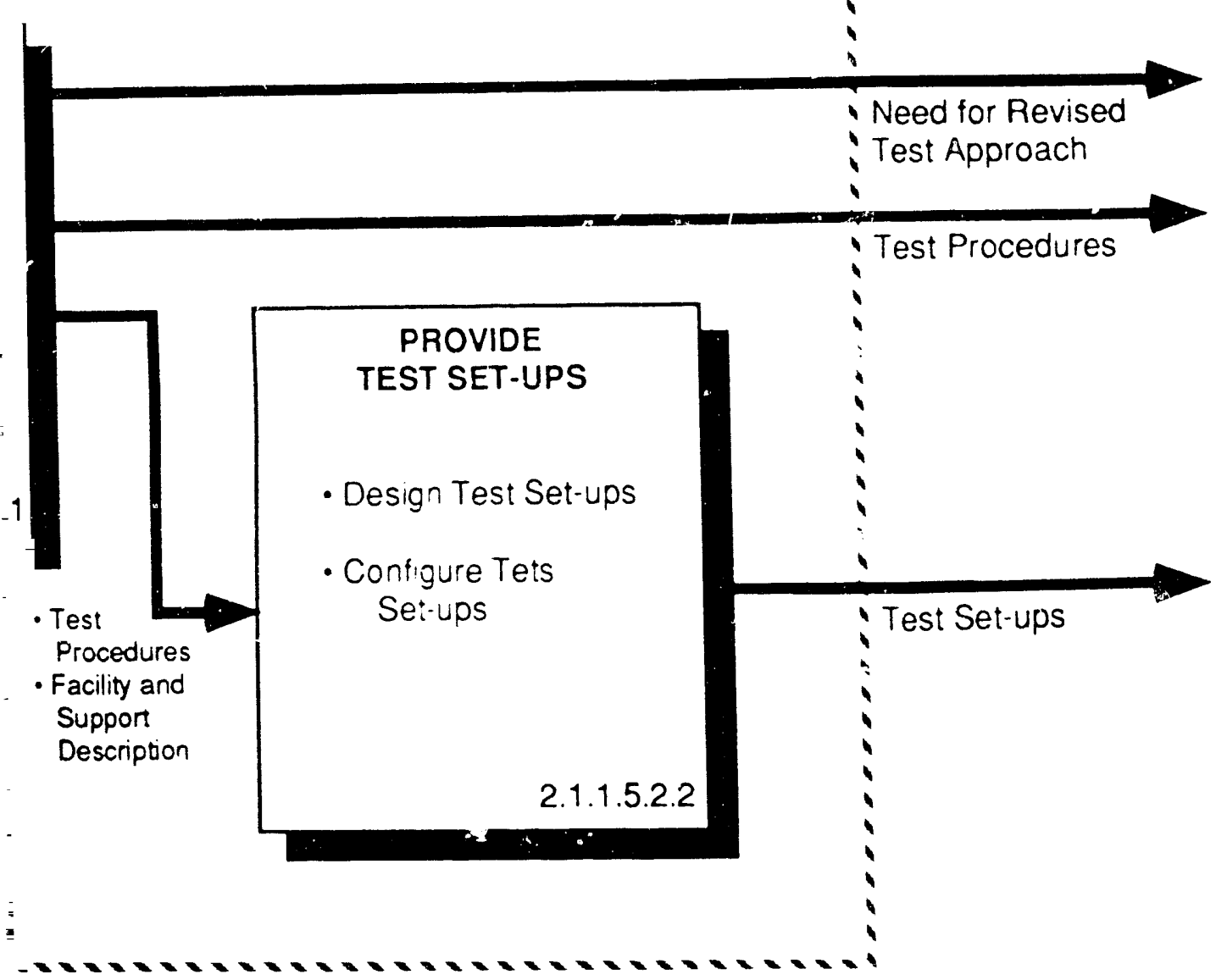


WHC - EP- 0482

- The Provide Test Set-ups function ensures that all apparatus. system configuration, trained personnel, etc.. are available at the proper time and location. It includes ali coordination between organizations necessary to accomplish test readiness. The first step in the process translates hardware/software requirements of the procedure into a test configuration specification. The configuration includes an appropriate response to program direction concerning availability, access, etc. The test configuration is then implemented via assignments for hardware/software assembly, personnel training, facilities scheduling, etc. This function produces a ready apparatus.

The test preparation process interacts with the external review process and includes internal iterations. Once the outputs from Prepare for Test are ready they are input to the technical review process (see PSE function) for Test Readiness Reviews. The review process can result in approval to proceed. requirements to repeat procedure or test set-up development, or redirection of the PCOT process. The latter two responses can occur when the Test Readiness Review results are input to the Program evaluation process in the PPC function. If the test procedure and set-up development show that the test plan cannot be implemented, problems in procedure and set-up development are fed back to revise the test plan. Furthermore, test set-up development may show it is not possible to implement the procedure. Problems with set-up development are first fed back to the procedure development to determine if alternative procedures are possible: if there are no alternatives then the problem is identified for test plan revision.

7.3.2.3 Outputs. The test preparation phase of PCOT produces the detailed procedures and the test configuration. These outputs can be described as follows:

- The Test Procedure includes instrumentation connections to the test item. pretest calibrations required and their procedure. pretest instrumentation checkout procedures, standard test conditions for each test run, verification procedures for conditions, modes, interfaces in the apparatus, test apparatus operating procedures, and procedures for documenting set-up. procedures, data.

- The Test Set-up specifies and describes all facilities, all instrumentation. the unit under test, all required support hardware, all required software (operating and data acquisition). and all interconnections among the above.

7.3.2.4 Significant Considerations. To prepare for testing effectively, the Prepare for Test function must accomplish the following:

- Develup a set of step-by-step procedures for each test that will allow the collection of the correct data to satisfy the test requirements and support the evaluation of system performance.

- Identify the physical set-up/support needs (schedules. configurations, environments, and units under test) for each test.

- Monitor the status of the prerequisite approvals to make certain that they will be available in a timely manner. 


\subsubsection{Execute Test}

7.3.3.1 Mission/Objective. The Execute Test function (2.1.1.5.3) of PCOT implements the test procedures by collecting the data, verifying the quality of the data, and documenting the entire test process as follows:

- For all tests in general: Dry-runs of procedures, execution of procedures, verification and reduction of data, and documentation of complete test process from procedure to data

- For Confirmation Testing: Results feed integrated system evaluation and are essential to deciding to proceed to next level of integration/next stage of system implementation

- For Operational Testing: Results showing successful system hardware are mandatory to initiate operation of that part of NWMS

- Special Case for Environmental Monitoring: Results produced routinely through out system implementation and operatior, as required by permits and regulatory documents.

7.3.3.2 Process Flow. The test execution process performs trial tests to verify efficacy of procedures, executes all required procedures and data collection, and verifies and documents the results of the test. The flow of activities in Execute Test is illustrated in Figure 7-5. The first tier of subfunctions to Execute Test is shown in the figure and can be described as follows:

The Conduct Trial Tests function determines that the procedures are effective and safe. Critical elements of procedures are executed in a dry-run mode. The critical elements are defined as those steps critical to the safety of test execution and critical to the ultimate use of data. Data from trial tests are reviewed and verified to determine if the procedures are adequate for implementation. Any resulting problems initiates upgrades to the procedures.

- The Conduct Formal Tests function collects the data necessary to meet the testing requirements. All the steps in a 17 procedures are executed and the data are reviewed for adequacy and archival purposes. The data review determines that all required data are present and formally archives the data for later use. It determines that all quality procedures were implemented and assures that any problems identified cause repeat testing.

- The Verify and Document Results function ensures that the test requirements rave been fully met and that the data have sufficient confidence to meet the needs of their ultimate application (e.g.. for high-confidence, integrated, system evaluation). The data verification reviews the quality procedure results, compares the results to pretest predictions, and analyzes the test configuration and process in light of observations during the test. The documentation ensures that the data are sufficient to meet legal requirements and legal challenges to NWMS regulatory compliance. It also provides historical archives for reference during system operation. 


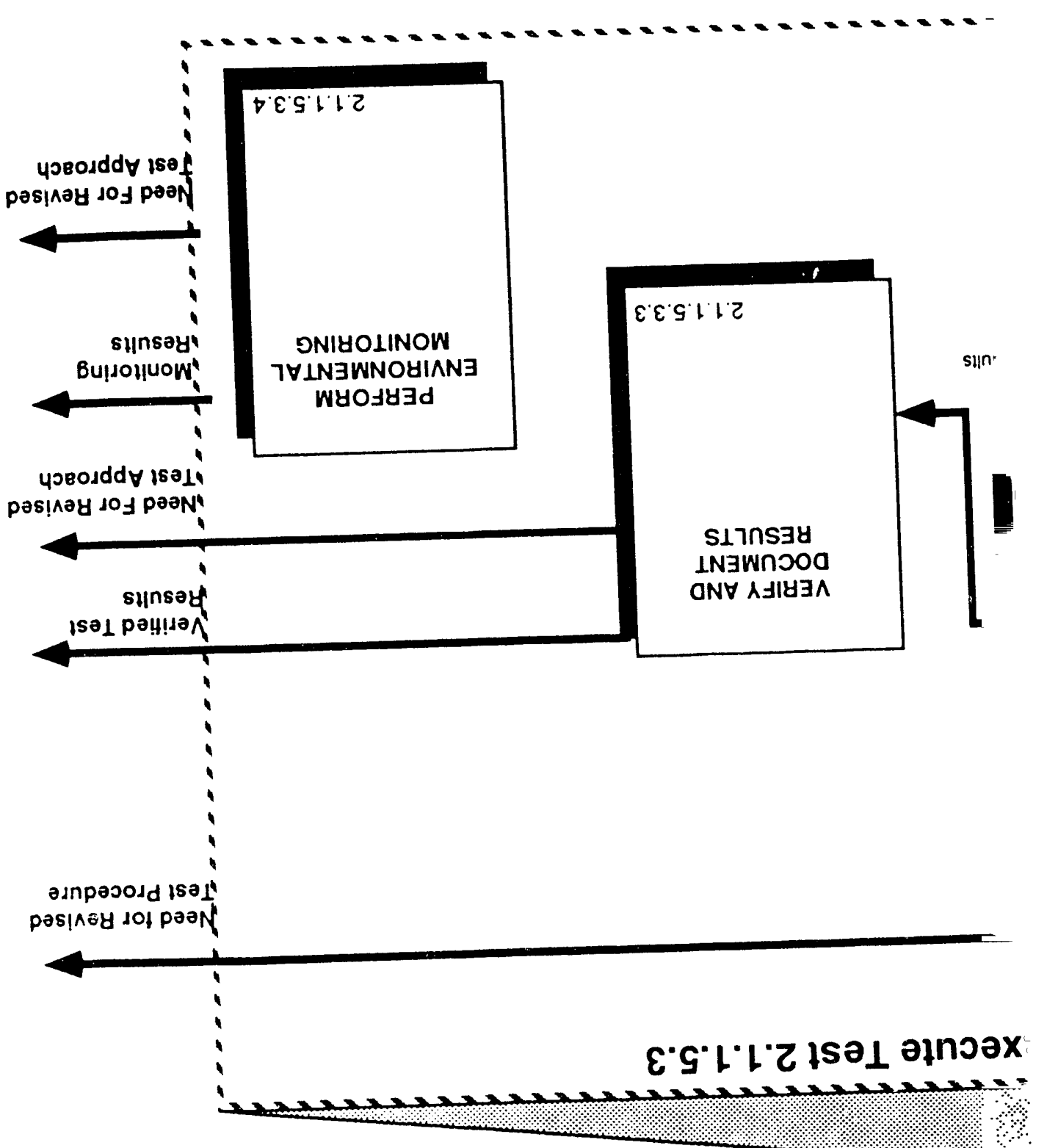




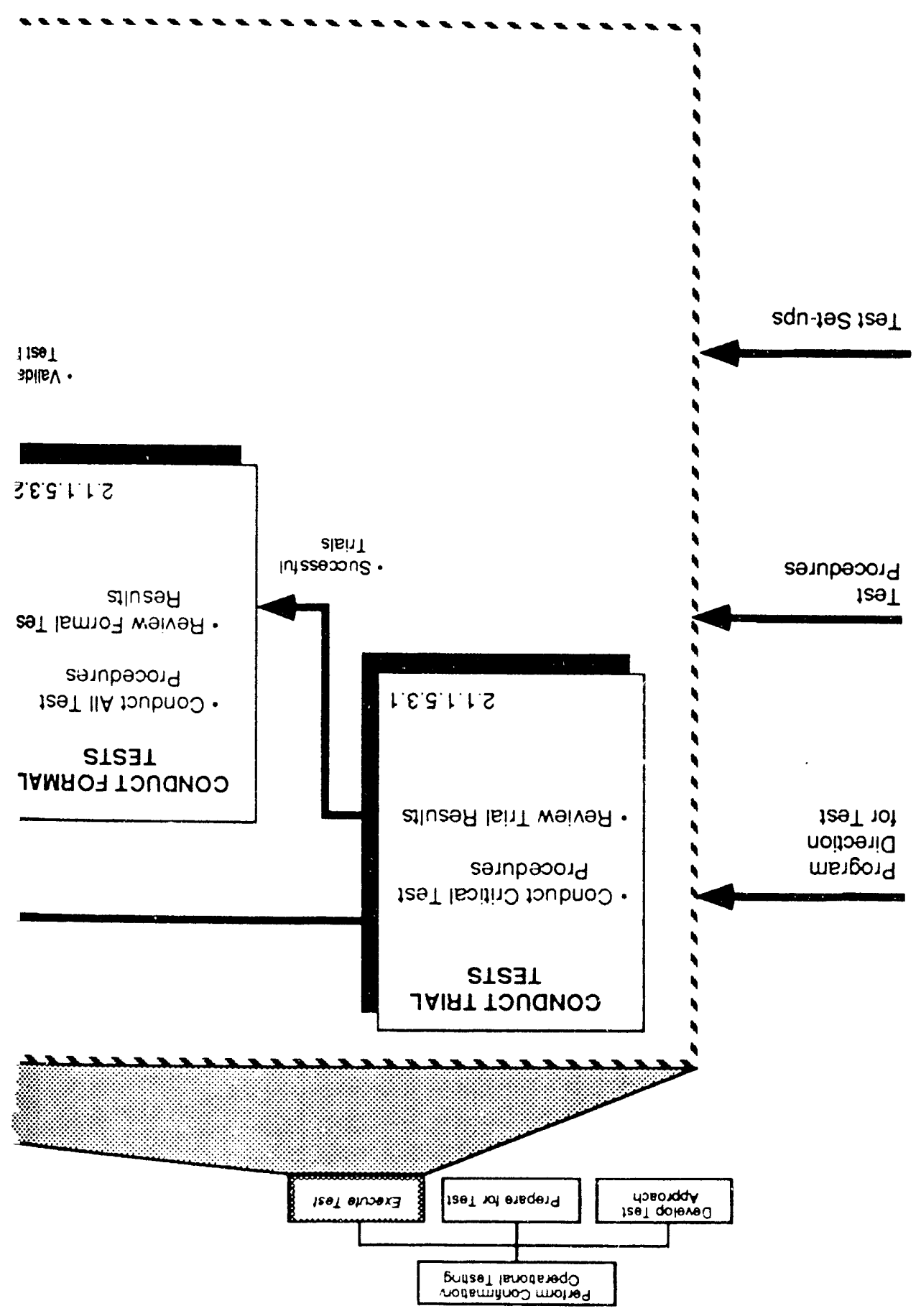


WHC-EP- 0482

- The Conduct Environmental Monitoring function ensures that system implementation and operation have no adverse environmental effects. This function implements specified monitoring apparatus (see Develop Performance Monitoring Techniques in DES) and includes calibration. operation. maintenance of the apparatus is well as recording of measurements. The resulting data are supplied to the EIS function to determine appropriate action.

The Execute Test function is the key point of feedback within the overall testing process and is the point of interface with the evolving Controlled NWMS Description. The feedback and interfacing processes can be described in terms of the following activities:

- Feedback within the Test Function

- Unsuccessful tests (i.e., data could not be physically collected. data could not be verified, data could not be collected that matched required characteristics for uncertainty, confidence, conditions, etc.) require revision of the testing plans and/or the testing procedures.

- Feedback on test plans occurs when the procedure can be executed but the data are not adequate to meet the original testing requirements (not verifiable, insufficient confidence, etc.). Therefore, a change in overall approach to a requirement is required.

- Feedback on Test Procedures occurs when a dry-run of a test procedure shows a problem in implementing the procedure (e.g.. cannot achieve proper conditions, the steps in procedure are insufficient to control configuration, etc.). Therefore.. requires a revision to the procedure and set-up is required.

- Interfacing to Controlled NWMS Description

The controlled NWMS technical description (Technical Baseline plus other controlled information) is the audited and approved description of the current state of the system; it is the official reference database whose use by all functions ensures coherence of all functional processes.

- Test data and reports produced by the Execute Test function are entered into the controlled NWMS technical description and are used by the DES functional process (formation of parts of the As-Built Design Package), the EIS functional process (input to the evaluation and suitability measure calculations), the Ensure Regulatory Compliance (ERC) functional process (to verify compliance), and other processes.

7.3.3.3 Outputs. The Execute Test function produces two test reporting products: Verified Test Reports and Performance Monitoring Test Reports. Verified Test Reports are provided for confirmation and operational tests and include procedures, configurations, hardware and software used, raw data. reduced data, quality procedure results, and verification results.

Environmental Monitoring Test Reports are provided on a scheduled basis as 
WHC-EP- 0482

part of system implementation and system operations routines. These reports provide data for producing environmental impact assessments (see EIS function) and meeting applicable environmental quality regulations (see ERC function).

7.3.3.4 Significant Considerations. To execute the testing effectively, the Execute Test function must do three things. It must ensure the faithful execution of the test procedures and test set-ups so that all test results can be validated. It must compare the test results to the test requirements to ensure that all required data were collected and the test results can be verified. And it must prepare the documentation in a form to facilitate comparison of system characteristics against the mission. functional. and performance requirements.

\subsection{PERFORM CONFIRMATION/OPERATIONAL TESTING INTERNAL INTERFACES}

Under normal conditions, the PCOT process is a sequential process in whicin requirements flow down to test plans and then to procedures and the procedures are executed. However, because of the complexity of the NWMS items, the test planning process includes feedbacks for iterating on the plans, procedures, and data. The most important iteration paths are shown in Figure 7-6. The important iterative loops are numbered in the figure and can be described as follows:

- From Test Execution to Test Preparation (labeled 2 in Figure 7-6): When conducting trial tests, it may be found that a procedure is not feasible or does not produce data of sufficient quality. This causes a repeat of the procedure development function.

- From Test Execution to Test Approach Development (labeled 1 in Figure 7-6): During data verification, it may be that test results will not satisfy the test requirement or cannot be verified. This causes a repeat of the test approach and test plan development function.

- From Test Preparation to Test Approach Development (1abeled 3 in Figure 7-6): When developing test procedures, it may be that a procedure yielding verifiable data cannot be formulated given the selected approach. This yields a request for a new testing approach. This feedback also occurs when test verifiable procedures can be formulated but all procedures are impractical due to cost. resources required. impact on system hardware or site, etc.

- Within Test Approach Development (labeled 4 in Figure 7-6): This feedback is produced during review of test techniques and specifications against testing requirements. It occurs when the review identifies shortfalls relative to requirements. inconsistencies in specifications. specification changes that improve commonality for test plan efficiency.

- Within Test Preparation Process (1abeled 5 in Figure 7-6): If a test set-up to meet procedures is not feasible (relative to cost. complexity, risk to hardware or schedule) then a procedure change is requested and feedback occurs. The procedure development is iterative to ensure a match to specifications and the test set-up development is iterative to ensure the design selected is 
Figure 7-6. Perform Confirmation/Operational Testing Major Feedback Loops.

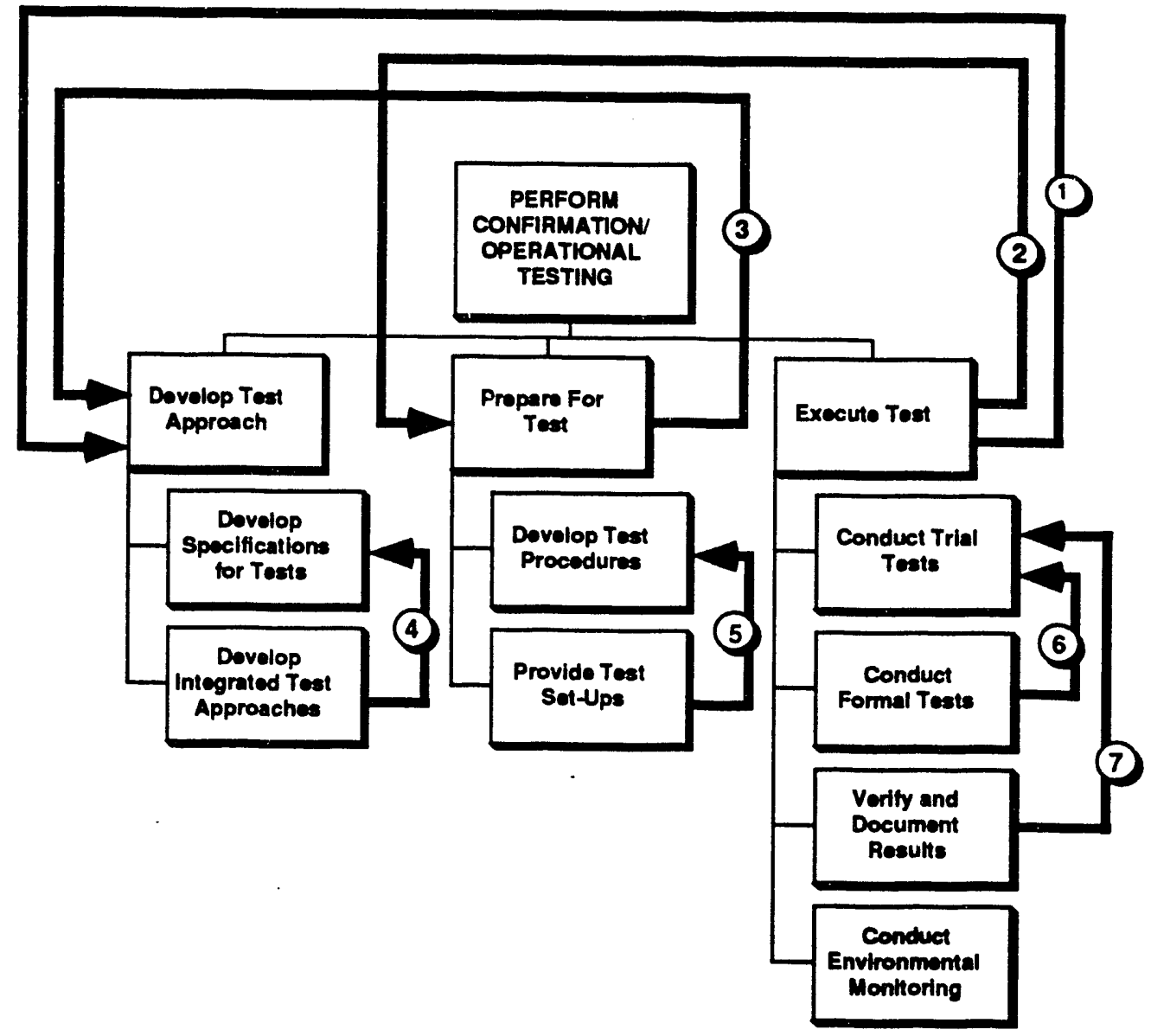


feasible. These last two iterations occur among the fourth tier subfunctions which are not shown in the figure. Hence, the last two iterative loops are not seen in the figure.

- Within Test Execution Process (1abeled 6 and 7 in Figure 7-6): When conducting formal tests, when verifying results. Or when conducting environmental monitoring tests, it may be found that additional data gathering is required to satisfy the requirement fully. For these cases the data gathering process is begun again. This feedback occurs when the approach and procedure are adequate and all that is needed is additional data collection. 
WHC-EP- 0482

\subsection{ENSURE REGULATORY COMPLIANCE FROCESS DESCRIPTION}

This section presents the process description for the Ensure Regulatory Compliance (ERC) function. The descriptions are as follows:

- The ERC mission and scope

- An overview of the ERC process, including descriptions of its primary subfunctions and major programmatic interfaces

- The identification of the inputs, controls, and outputs that occur at the overall function level

- Details on the ERC subfunctions and their operation

- Principal feedback mechanisms that allow the process to iterate and converge on final products.

ERC will be shown to be a function that assists the program in identifying the regulatory requirements that control program execution and strategies to respond to those requirements, acts in an advocacy role to obtain the necessary regulatory approvals, and monitors program execution over the life cycle of the program to confirm that regulatory compliance is achieved.

An important aspect of the approach selected in this functional analysis is that licensing and other regulatory applications will be treated in the same manner as a 11 other requirements. The production of the necessary information will be identified by ERC and subsequently integrated with all other information needs so that the most efficient approach to acquiring application design or consolidating that design with other licensing information appears in the functional analysis. This information will be generated and the license applications produced in accordance with requirements consistent with all other program requirements derived and integrated by systems engineering and program control functions.

\subsection{ENSURE REGULATORY COMPLIANCE MISSION AND PROCESS OVERVIEW}

\subsubsection{Mission/Objectives}

The mission and objectives are to ensure that the program meets all regulatory requirements and to accomplish this result by executing the following activities:

- Identify the regulations applicable to the program.

- Develop criteria and strategies for regulatory compliance.

- Obtain licenses, permits, approvals, and other prerequisites necessary to construct, operate, and decommission NWMS elements.

- Determine the acceptability of compliance activities with applicable regulations. 
In addition. this function will coordinate the preparation of all regulatory documents, and act as the sole program interface to external parties involved in establishing regulatory compliance.

\subsubsection{Scope}

This function is executed within the following bounds:

- This function provides compliance requirements to the program; other functions implement those requirements.

- This function does not verify the technical adequacy of information produced in response to program requirements. It does make the judgement whether that information and those requirements are sufficient to establish regulatory compliance.

- During the initial stages of the program. this function works with other functions to define and produce the necessary regulatory submittals, and acts in an advocacy role to obtain the approvals. Later as the program moves to implement those approvals, it provides an independent judgement on whether the program is in compliance with regulatory requirements.

- This function does not audit or monitor the performance of program activities. It does ensure that those reviews conducted by 1 ine functions are adequate to confirm regulatory compliance.

The ERC function does it not deal with.issues that involve discretionary judgements on the part of Office of Civilian Radioactive Waste Management (OCRWM), nor does it interact with concerned parties that act in advisory roles relative to OCRWM.

\subsubsection{Process Overview}

A structured look at this ERC mission and scope is provided in Figure 8-1. This hierarchy diagram shows the result of the ERC functional decomposition down three levels. Execution of the following five major subfunctions constitutes the execution of the ERC function:

- Identify Applicable Regulatory Requirements (2.2.1.1.1)

- Develop Compliance Criteria (2.2.1.1.2)

- Develop Compliance Approach (2.2.1.1.3)

- Obtain Regulatory Approvals (2.2.1.1.4)

- Confirm Compliance Status. (2.2.1.1.5)

The first three of these five functions provide an evolutionary development of inputs and outputs as follows:

- From legal requirements (identified from the external regulatory environment) 
Figure 8-1. Ensure Regulatory Compliance Function Hierarchy.

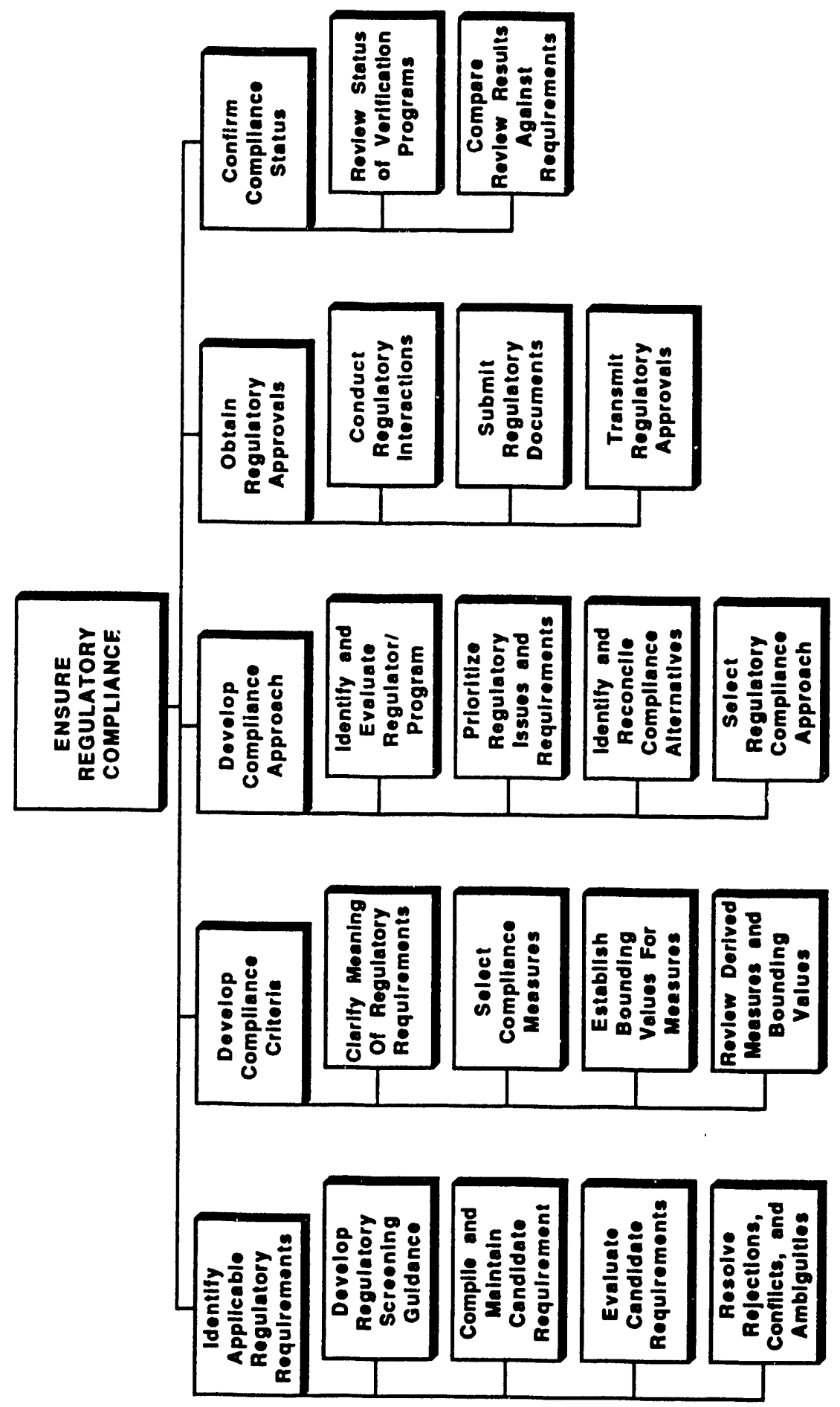


WHC-EP-0482

- To applicable regulatory requirements (produced by the first function)

- To compliance criteria (prodused by the second function)

- To compliance requirements and associated compliance approach (which are produced by the third function and delivered to program control functions for incorporation into the program).

The fourth function relies on compliance requirements and other program direction to produce regulatory submittals initially and then respond to the approvals; all interactions with external parties are accommodated within this function. The fifth function is an independent review activity that operates during ail stages of the program to assess the regulatory compliance status of the program.

A more comprehensive view of the ERC functional flow is provided in Figure 8-2. The five major subfunctions are arranged in a sequential fashion with major information flows identified by arrows. Inputs and outputs to the entire ERC function are shown on the boundary of the diagram along with the function that originates that input or output. One of the major subfunctions. Obtain Regulatory Approvals, has been decomposed further on the diagram to identify a major external interface that affects its internal operation.

\section{1 .4 Role}

Certain key product requirements drove the functional analysis for the ERC process to delineate its role relative to other OCRWM functions and the external environment as follows:

- The identification of applicable regulatory requirements and the nature and scope of compliance criteria, compliance requirements, and the compliance approach needed to be consistent with the planned activities of the Nuclear Waste Management System (NWMS) as found in program strategy. physical system information. international program information. and program information.

- Requirements derived by other functions on the basis of compliance requirements need to be reviewed for adequacy and consistency with the associated compliance criteria; where necessary, change requests (a need for review of performance measures and values) would have to be generated to address anomalies.

- The compliance approach and compliance requirements, once reconciled with the overall program strategy, must determine the scope of regulatory approvals to pursue and be used as a basis for confirming compliance status.

- Interactions with regulators and other concerned parties must be planned and executed to support the production of submittals required to establish regulatory compliance, and conform to the relevant compliance requirements and compliance approach, and current NWMS configuration. 


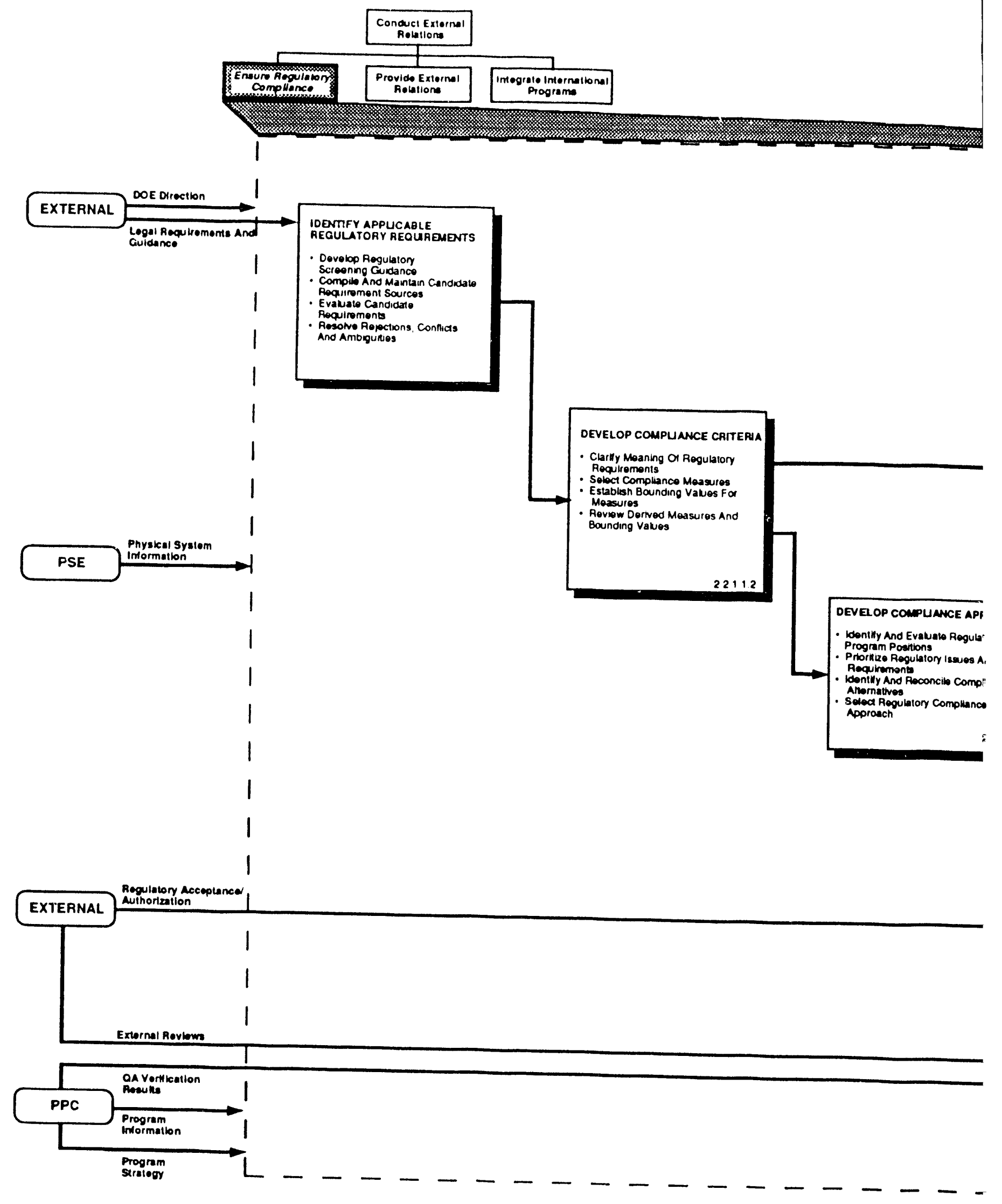


- Regulatory approvals must be screened against the existing compliance requirements and compliance approach for regulatory impacts before implementation by the program.

- Internal reviews by the Provide Quality Assurance (PQA) function and external reviews conducted by regulators must be analyzed with other program review data to confirm regulatory compliance.

- DOE direction can act both as a source of regulatory requirements for OCRWM and as the driver mandating the manner in which OCRWM determines compliance status.

- Compliance status and other compliance information must be provided to the Provide External Relations (PER) function to support public affairs, Congressional relations, and litigation functions.

In general, the role of the ERC function will continue over the life of the NWMS. It will be initiated upon the receipt of program strategy, with which some bounds on applicable regulatory requirements can be estabi ished. During the early stages of the program, a complete set of compliance requirements and the associated compliance approach will be produced and delivered to the program control functions for integration and reconciliation. Subsequent efforts will concentrate on obtaining the necessary regulatory approvals, analyzing approvals, and producing regulatory authorizations to proceed. Once construction begins. efforts will be devoted to confirming the compliance status of the program, and will continue through the operation and decommissioning of the NWMS.

\subsection{ENSURE REGULATORY COMPLIANCE EXTERNAL INTERFACES}

The ERC function is provided information in the form of inputs and controls which are used to produce information outputs used by other MSIS. level functions to fulfill the OCRWM mission. The identification of these inputs, controls and outputs assist in identifying the bounds of the ERC function and also provide a rationale for the underlying functions that must transform those inputs in accordance with the imposed controls to produce the requisite outputs.

\subsubsection{External Inputs}

Inputs to the ERC function are provided by the Provide Program Control ( $P P C$ ) function. Perform Systems Engineering (PSE) function. and by sources external to OCRWM. These inputs are identified in Table 8-1. Two of these inputs. Physical System Information and Program Information, allow ERC to monitor the full scope of program activities not only to build an adequate compliance approach, but also to execute the approach and finally confirm compliance. As such, these two inputs must be distributed to a large number of the functions internal to ERC to ensure that the appropriate information is captured at the proper points in the functional process. The other inputs noted in the table are captured by the specific functions which do the following:

- Capture externally imposed requirements in Identify Applicable Regulatory Requirements (2.2.1.1.1) 
Table 8-1. Ensure Regulatory Compliance Inputs. (sheet 1 of 3 )

\begin{tabular}{|c|c|c|}
\hline Input Name & Input Definition & Destination Function \\
\hline $\begin{array}{l}\text { Physical System } \\
\text { Information }\end{array}$ & $\begin{array}{l}\text { Information provided by the Perform } \\
\text { Systems Engineering function } \\
\text { regarding the current configuration } \\
\text { of the physical system, and system } \\
\text { description information controlled by } \\
\text { that function. }\end{array}$ & 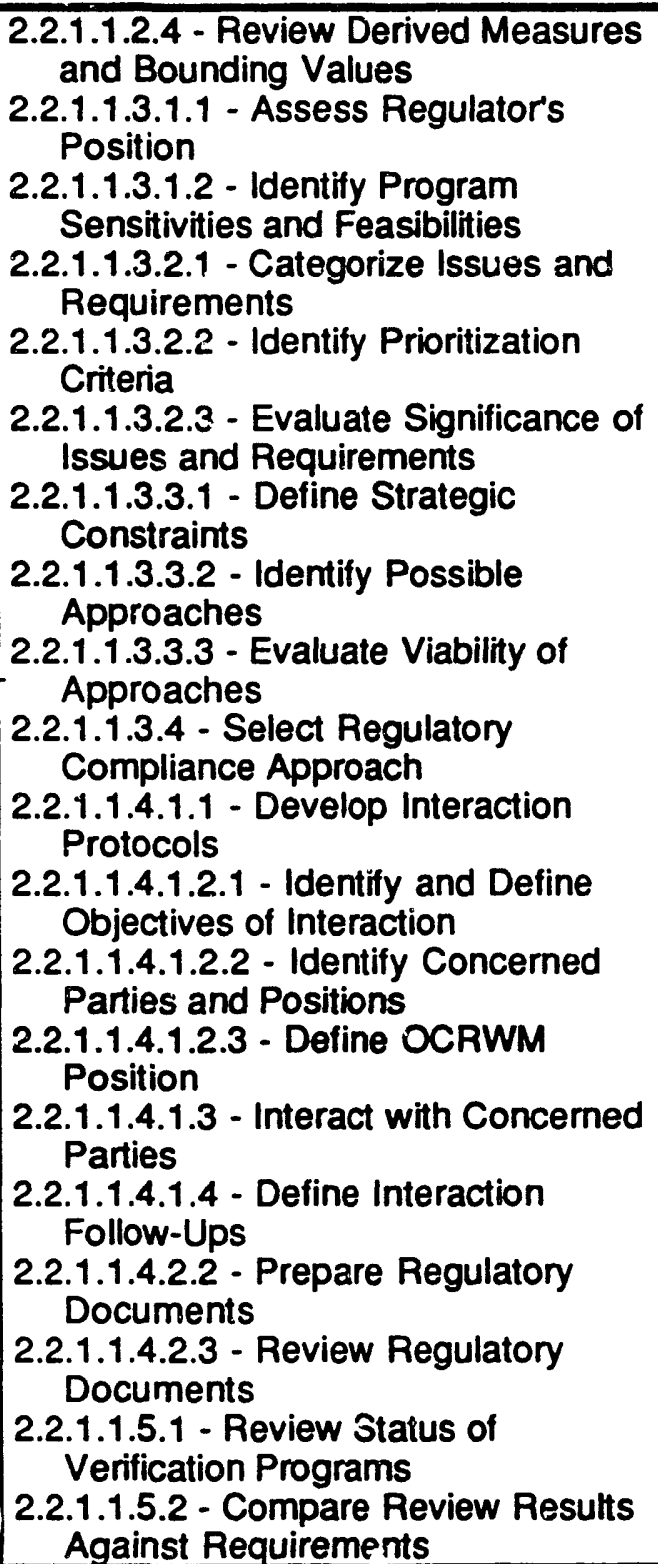 \\
\hline $\begin{array}{l}\text { International } \\
\text { Program } \\
\text { Information }\end{array}$ & $\begin{array}{l}\text { A n input provided by the Integrate } \\
\text { International Programs function } \\
\text { which includes a description of } \\
\text { waste management technologies, } \\
\text { evaluation methods, acceptability } \\
\text { standards or other aspects of a } \\
\text { waste management system that } \\
\text { have been developed or adopted } \\
\text { outside the United States and may } \\
\text { be applicable to the OCRWM } \\
\text { program. }\end{array}$ & $\begin{array}{l}\text { 2.2.1.1.3.2.3 - Evaluate Significance of } \\
\text { Issues and Requirements } \\
\text { 2.2.1.1.3.3.1 - Define Strategic } \\
\text { Constraints } \\
\text { 2.2.1.1.3.3.2 - Identify Possible } \\
\text { Approaches }\end{array}$ \\
\hline
\end{tabular}


Table 8-1. Ensure Regulatory Compliance Inputs. (sheet 2 of 3 )

\begin{tabular}{|c|c|c|}
\hline $\begin{array}{l}\text { Program } \\
\text { Information }\end{array}$ & $\begin{array}{l}\text { Program information provided by the } \\
\text { Provide Program Control function. it } \\
\text { includes resource, schedule, and } \\
\text { performance information on } \\
\text { historical, current, and planned } \\
\text { program activities. }\end{array}$ & 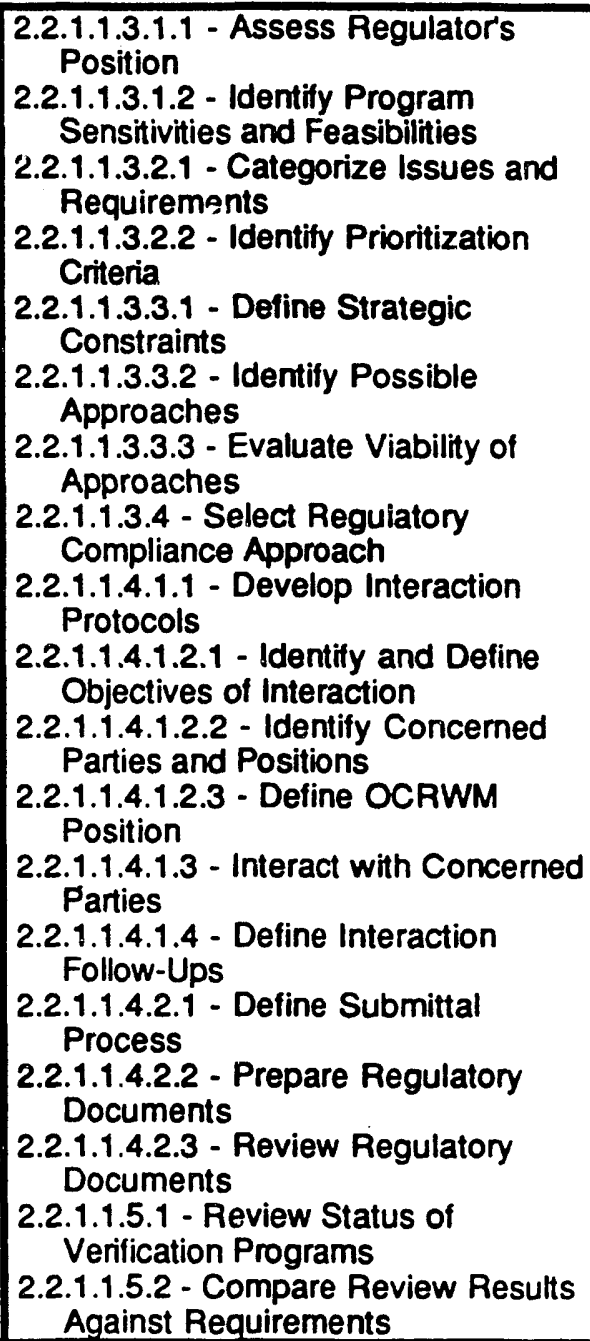 \\
\hline $\begin{array}{l}\text { Program } \\
\text { Strategy }\end{array}$ & $\begin{array}{l}\text { Programmatic direction provided by } \\
\text { the Provide Program Control } \\
\text { function, encompassing the } \\
\text { approach to achieving program } \\
\text { objectives. Includes direction and } \\
\text { constraints on the execution of } \\
\text { program functions, as well as } \\
\text { bounds on the desired outputs of } \\
\text { those functions. These directions } \\
\text { will also include factual or } \\
\text { methodological assumptions that } \\
\text { must be incorporated by all functions } \\
\text { in their execution. }\end{array}$ & $\begin{array}{l}\text { 2.2.1.1.1.3.2 - Establish Match-Ups } \\
\text { and Rejections }\end{array}$ \\
\hline $\begin{array}{l}\text { Regulatory } \\
\text { Acceptance/ } \\
\text { Authorization }\end{array}$ & $\begin{array}{l}\text { An input received from external } \\
\text { regulatory agencies.containing } \\
\text { documented approval received in } \\
\text { response to applications for } \\
\text { construction, operation, or } \\
\text { decommissioning of NWMS } \\
\text { elements. }\end{array}$ & $\begin{array}{l}\text { 2.2.1.1.4.3.1 - Analyze Significance of } \\
\text { Conditions } \\
\text { 2.2.1.1.4.3.2- Determine Impacts on } \\
\text { Requirements and Activities } \\
\text { 2.2.1.1.4.3.3 - Determine Actions To } \\
\text { Be Taken }\end{array}$ \\
\hline
\end{tabular}




\begin{tabular}{|c|c|c|}
\hline $\begin{array}{l}\text { Qi Verification } \\
\text { Results }\end{array}$ & $\begin{array}{l}\text { An input received from the Provide } \\
\text { Quality Assurance Function which } \\
\text { includes the results of independent } \\
\text { tests, analyses, audits, or other } \\
\text { modes of confirmation to assess } \\
\text { compliance with programmatic or } \\
\text { physical system regulatory } \\
\text { requirements. }\end{array}$ & $\begin{array}{l}\text { 2.2.1.1.5.2 - Compare Review Results } \\
\text { Against Requirements }\end{array}$ \\
\hline External Reviews & $\begin{array}{l}\text { An input provided by external parties } \\
\text { which includes the results of tests, } \\
\text { analyses, audits, or other modes of } \\
\text { confirmation to assess compliance } \\
\text { with programmatic or physical system } \\
\text { regulatory requirements. }\end{array}$ & $\begin{array}{l}\text { 2.2.1.1.5.2 - Compare Review Results } \\
\text { Against Requirements }\end{array}$ \\
\hline $\begin{array}{l}\text { Legal } \\
\text { Requirements } \\
\text { and Guidance }\end{array}$ & $\begin{array}{l}\text { All Federal and State statutory, } \\
\text { regulatory, and Executive } \\
\text { Department directives which } \\
\text { OCRWM must meet, exclusive of all } \\
\text { DOE direction. }\end{array}$ & $\begin{array}{l}\text { 2.2.1.1.1.2 - Compile and Maintain } \\
\text { Candidate Req' sirement Sources }\end{array}$ \\
\hline DOE Direction & $\begin{array}{l}\text { All DOE Orders, Directives, } \\
\text { Secretarial notices, Secretarial } \\
\text { memos which OCRWM must meet. } \\
\text { Also includes intradepartmental } \\
\text { agreements. }\end{array}$ & $\begin{array}{l}\text { 2.2.1.1.1.2 - Compile and Maintain } \\
\text { Candidate Requirement Sources }\end{array}$ \\
\hline
\end{tabular}




\section{WHC-EP-0482}

- Evaluate internally derived requirements in Develop Compliance Criteria (2.2.1.1.2)

- Integrate special international program objectives into the compliance approach in Develop Compliance Approach (2.2.1.1.3)

- Determine compliance impacts of conditions on regulatory approvals in Obtain Regulatory Approvals (2.2.1.1.4)

- Evaluate external review results as basis for determining compliance status in Confirm Compliance Status. (2.2.1.1.5).

Several of the inputs shown on the table have specific subsets of information that are captured by unique functions at lower levels of the functional analysis and thus do not appear on Figure 8-2 or in Table 8-1. Physical System Information separates into an input called other Performance Measures and Values that feeds Review Derived Measures and Bounding Values (2.2.1.1.2.4). Physical System Information also separates into another input called Functional Description that feeds Establish Match-Ups and Rejections (2.2.1.1.1.3.2). Similarly. Program Strategy separates into an input called Programmatic Functional Structure that feeds Establish Match-Ups and Rejections (2.2.1.1.1.3.2).

The subsets listed above represent specific instances of decomposing the information hierarchy for certain inputs that have bundled together large amounts of output information from other functions.

The principal external inputs are summarized below as follows:

- Physical System Information

- Provided by PSE

- Used by key functions that monitor the development of the configuration for consistency with the compliance approach. regulatory applications and supporting external interactions, and previous confirmations of regulatory compliance

- Used to ensure that ERC activities remain current with changes in the development of the NWMS requirements and designs

- Comprised of the sum of the technical baseline.

- International Program Information

- Provided by Integrate International Programs

- Used by functions that provide key constraints on the compliance approach

- Used to ensure that important international program objectives are captured in the compliance approach

- Comprised of a 17 strategies and activities designed to integrate the OCRWM program with similar international programs. 
- Program Information

- Provided by PPC

- Used by key functions that monitor current and planned program activities for consistency with the compliance approach, regulatory applications and supporting external interactions, and previous confirmations of regulatory compliance

- Used to ensure that ERC activities remain current with changes in the existing and planned program activities

- Comprised of the sum of the cost/schedule baseline and analysis of performance results against that baseline.

- Program Strategy

- Provided by PPC

- Used by the function that establishes preliminary allocations of potentially appicable regulatory requirements against functions

- Used to determine applicability of regulatory requirements to the program

- Comprised of the programmatic functional analysis conducted by the PPC function (partial component of Program Strategy).

- Regulatory Acceptance/Authorization

- Provided by external regulatory agencies

- Used by the function that analyze regulatory approvals and conditions on regulatory approvals

- Used to determine the regulatory impact of conditions on approvals and determine whether regulatory authorizations to proceed can be issued

- Comprised of the full text of responses to applications from external regulatory approval bodies.

- Quality Assurance Verification Results

- Provided by PQA

- Used by the function that compares review results against compliance requirements

- Used to confirm regulatory compliance, i.e. determine compliance status

- Comprised of the results and conclusions of Quality Assurance (OA) management audits. 
WHC-EP-0482

- External Reviews

- Provided by external regulatory agencies

- Used by the function that compares review results against compliance requirements

- Used to confirm regulatory compliance, i.e. determine compliance status

- Comprised of the results and conclusions of independent surveys and audits conducted by external regulatory agencies to determine regulatory compliance.

- Legar Requirements and Guidance

- Provided by all external bodies that produce requirements that the OCRWM program must meet

- Used by the function that compiles and maintains regulatory source documents from which all regulatory requirements applicable to OCRWM can be derived

- Used to compile and maintain current regulatory source documents to enable the extraction of all applicable regulatory requirements

- Comprised of the universe of regulatory sources that could potentially affect the OCRWM program.

- DOE Direction

- Provided by DOE officers and departments external to OCRWM

- Used by the function that compiles and maintains regulatory source documents from which all regulatory requirements applicable to OCRWM can be derived

- Used to compile and maintain current regulatory source documents to enable the extraction of all applicable regulatory requirements

- Comprised of the universe of U.S. Department of Energy (DOE) sources that could potentially affect the OCRWM program.

\subsubsection{External Controls}

Controls to the ERC function are provided by the PPC function. PSE function, and by sources external to OCRWM. These controls are identified in Table 8-2. Three of these controls. Physical System Information. Program Strategy, and Program Information, allow ERC to monitor the full scope of program activities and strategies primarily to identify the full range of regulatory requirements that the program will encounter, but al so io develop compliance criteria and approaches, and finally confirm compliance. As such, these three controls must be distributed to a large number of the functions internal to ERC to ensure that the 
Table 8-2. Ensure Regulatory Compliance Controls. (sheet 1 of 2 )

\begin{tabular}{|c|c|c|}
\hline Control Name & Control Definition & Destination Function \\
\hline $\begin{array}{l}\text { Physical System } \\
\text { Information }\end{array}$ & $\begin{array}{l}\text { Information provided by the Perform } \\
\text { Systems Engineering function } \\
\text { regarding the current configuration } \\
\text { of the physical system, and system } \\
\text { description information controlled by } \\
\text { that function. }\end{array}$ & $\begin{array}{l}\text { 2.2.1.1.1.1.1 - Define Bounds of } \\
\text { Regulatory Sources } \\
\text { 2.2.1.1.1.1.2 - Define Applicability } \\
\text { Criteria } \\
\text { 2.2.1.1.1.2 - Compile and Maintain } \\
\text { Candidate Requirement Sources } \\
\text { 2.2.1.1.1.3.1 - Identify Potentially } \\
\text { Applicable Regulatory } \\
\text { Requirements } \\
\text { 2.2.1.1.1.4.1 - Identify Alternative } \\
\text { Positions } \\
\text { 2.2.1.1.1.4.2 - Evaluate Program } \\
\text { Impacts } \\
\text { 2.2.1.1.1.4.3 - Develop Program } \\
\text { Position } \\
\text { 2.2.1.1.1.4.4 - Determine Resolution } \\
\text { Approach }\end{array}$ \\
\hline Program Strategy & $\begin{array}{l}\text { Programmatic direction provided by } \\
\text { the Provide Program Control } \\
\text { function, encompassing the } \\
\text { approach to achieving program } \\
\text { objectives. Includes direction and } \\
\text { constraints on the execution of } \\
\text { program functions, as well as } \\
\text { bounds on the desired outputs of } \\
\text { those functions. These directions } \\
\text { will also include factual or } \\
\text { methodological assumptions that } \\
\text { must be incorporated by all } \\
\text { functions in their execution. }\end{array}$ & $\begin{array}{l}\text { 2.2.1.1.1.1.1 - Define Bounds of } \\
\text { Regulatory Sources } \\
\text { 2.2.1.1.1.1.2 - Define Applicability } \\
\text { Criteria } \\
\text { 2.2.1.1.1.4.1- Identify Alternative } \\
\text { Positions } \\
\text { 2.2.1.1.1.4.4 - Determine Resolution } \\
\text { Approach } \\
\text { 2.2.1.1.1.4.5 - Implement Approach } \\
\text { 2.2.1.1.2.1 - Clarity Meaning of } \\
\text { Requirements } \\
\text { 2.2.1.1.2.2 - Select Compliance } \\
\text { Measures } \\
\text { 2.2.1.1.2.3 - Establish Bounding } \\
\text { Values for Measures } \\
\text { 2.2.1.1.2.4 - Review Derived Measures } \\
\text { and Bounding Values } \\
\text { 2.2.1.1.3.1.2 - Identify Program } \\
\text { Sensitivities and Feasibilities } \\
\text { 2.2.1.1.3.2.2 - Identify Prioritization } \\
\text { Criteria } \\
\text { 2.2.1.1.3.3.1 - Define Strategic } \\
\text { Constraints } \\
\text { 2.2.1.1.3.3.2 - Identify Possible } \\
\text { Approaches } \\
\text { 2.2.1.1.3.3.3 - Evaluate Viability of } \\
\text { Approaches } \\
\text { 2.2.1.1.3.4 - Select Regulatory } \\
\text { Compliance Approach }\end{array}$ \\
\hline $\begin{array}{l}\text { Legal } \\
\text { Requirements } \\
\text { and Guidance }\end{array}$ & $\begin{array}{l}\text { All Federal and State statutory, } \\
\text { regulatory, and Executive } \\
\text { Department directives which } \\
\text { OCRWM must meet, exclusive of all } \\
\text { DOE direction. }\end{array}$ & $\begin{array}{l}\text { 2.2.1.1.1.1.1 - Define Bounds of } \\
\text { Regulatory Sources }\end{array}$ \\
\hline
\end{tabular}




\section{Table 8-2. Ensure Regulatory Compliance. Controls. (sheet 2 of 2 )}

\begin{tabular}{|c|c|c|}
\hline DOE Direction & $\begin{array}{l}\text { All DOE Orders, Directives, } \\
\text { Secretarial notices, Secretarial } \\
\text { memos which OCRWM must meet. } \\
\text { Also includes intradepartmental } \\
\text { agreements. }\end{array}$ & $\begin{array}{l}\text { 2.2.1.1.1.1.1 - Define Bounds of } \\
\text { Regulatory Sources } \\
\text { 2.2.1.1.5.1 - Review Status of } \\
\text { Verification Programs } \\
\text { 2.2.1.1.5.2 - Compare Review Results } \\
\text { Against Requirements }\end{array}$ \\
\hline $\begin{array}{l}\text { Program } \\
\text { Information }\end{array}$ & $\begin{array}{l}\text { Program information provided by the } \\
\text { Provide Program Control function. It } \\
\text { includes resource, schedule, and } \\
\text { performance information on } \\
\text { historical, current, and planned } \\
\text { program activities. }\end{array}$ & $\begin{array}{l}\text { 2.2.1.1.1.1.1 - Define Bounds of } \\
\text { Regulatory Sources } \\
\text { 2.2.1.1.1.1.2 - Define Applicability } \\
\text { Criteria } \\
2.2 .1 .1 .1 .2 \text { - Compile and Maintain } \\
\text { Candidate Requirement Sources } \\
\text { 2.2.1.1.1.3.1 - Identify Potentially } \\
\text { Applicable Regulatory } \\
\text { Requirements } \\
\text { 2.2.1.1.1.4.1 - Identify Alternative } \\
\text { Positions } \\
\text { 2.2.1.1.1.4.2 - Evaluate Program } \\
\text { Impacts } \\
\text { 2.2.1.1.1.4.3 - Develop Program } \\
\text { Position } \\
\text { 2.2.1.1.1.4.4 - Determine Resolution } \\
\text { Approach }\end{array}$ \\
\hline
\end{tabular}


appropriate information is captured at the proper points in the functional process. The other controls noted in the table are captured by specific functions that accomplish the following:

- Utilize externally imposed requirements to establish regulatory applicability criteria in Identify Applicable Regulatory Requirements (2.2.1.1.1)

- Utilize externally imposed requirements to develop methodologies for determining compliance status in Confirm Compliance Status $(2.2 .1 .1 .5)$.

Certain of the controls also act as inputs when they are captured by other receiving functions as described previously. This characteristic of acting as a control in some instances and acting as an input in others can occur for these reasons: In some cases, the information is transformed by the function into some other information product (input): in other cases, the information is used to influence the manner in which other information is transformed by the function (control).

The principal external controls are summarized as follows:

- Physical System Information

- Provided by PSE

- Used by key functions that identify applicable regulatory requirements

- Used to ensure that the identification of applicable regulatory requirements remains current with changes in the development of the NWMS requirements and designs

- Comprised of the sum of the technical baseline.

- Program Information

- Provided by PPC

- Used by key functions that monitor current and planned program activities to establish the scope of applicable regulatory requirements

- Used to ensure that the identification of applicable regulatory requirements remains current with changes in the existing and planned program activities

- Comprised of the sum of the cost/schedule baseline and analysis of performance results against that baseline.

- Program Strategy

- Provided by PPC

- Used by key functions that identify applicable regulatory requirements, develop compliance criteria, and develop the compliance approach 
- Used to ensure that ERC activities remain consistent with changes in the overall program strategy

- Comprised of the rationales under which the program will execute its mission.

- Legar Requirements and Guidance

- Provided by all external bodies that produce requirements that the OCRWM program must meet

- Used by the function that defines the bounds of regulatory sources (jurisdictional considerations)

- Used to establish regulatory screening guidance for the identification of regulatory sources and requirements

- Comprised of all regulatory sources that potentially could affect the OCRWM program.

- DOE Direction

- Provided by DOE officers and departments external to OCRWM

- Used by the function that defines the bounds of regulatory sources (jurisdictional considerations) and by the functions that confirm compliance status

- Used to establish regulatory screening guidance for the identification of regulatory sources and requirements and to establish the methods and criteria for confirming regulatory compliance

- Comprised of all DOE sources that could potentially affect the OCRWM program.

\subsubsection{External Outputs}

Outputs from the ERC function are provided to the PPC function. PER function, and to sources external to OCRWM. These outputs are identified in Table 8-3. The outputs noted in the table are produced by specific functions that accomplish the following:

- Establish the rationale for resolving problems of regulatory applicability in Identify Applicable Regulatory Requirements $(2.2 .1 .1 .1)$

- Identify problems with internally derived requirements in Develop Compliance Criteria (2.2.1.1.2)

- Establish and document the rationale for the compliance approach and compliance requirements in Develop Compliance Approach $(2.2 .1 .1 .3)$ 
Table 8-3. Ensure Regulatory Compliance Outputs.

\begin{tabular}{|c|c|c|}
\hline Output Name & Output Definition & Originating Function \\
\hline $\begin{array}{l}\text { Compliance } \\
\text { Information }\end{array}$ & $\begin{array}{l}\text { Information describing both the } \\
\text { results and the process for } \\
\text { obtaining compliance } \\
\text { requirements and the compliance } \\
\text { approach. Also contains } \\
\text { resolution status information on } \\
\text { applicability of regulatory } \\
\text { requirements currently being } \\
\text { evaluated for incorporation into } \\
\text { the program. }\end{array}$ & $\begin{array}{l}\text { 2.2.1.1.1.4.3 - Develop Program } \\
\text { Position } \\
\text { 2.2.1.1.1.4.5 - Implement Approach } \\
\text { 2.2.1.1.3.4 - Select Regulatory } \\
\text { Compliance Approach }\end{array}$ \\
\hline $\begin{array}{l}\text { Need for Review of } \\
\text { Performance } \\
\text { Measures and } \\
\text { Values }\end{array}$ & $\begin{array}{l}\text { Descriptions of problems or issues } \\
\text { related to integration and } \\
\text { reconciliation of derived } \\
\text { pertormance measures and } \\
\text { bounding values with existing } \\
\text { compliance requirements. }\end{array}$ & $\begin{array}{l}\text { 2.2.1.1.2.4 - Review Derived Measures } \\
\text { and Bounding Values }\end{array}$ \\
\hline $\begin{array}{l}\text { Compliance } \\
\text { Approach }\end{array}$ & $\begin{array}{l}\text { The strategic principles, } \\
\text { consistent with program strategy, } \\
\text { by which compliance with } \\
\text { regulatory requirements will be } \\
\text { demonstrated. }\end{array}$ & $\begin{array}{l}\text { 2.2.1.1.3.4 - Select Regulatory } \\
\text { Compliance Approach }\end{array}$ \\
\hline $\begin{array}{l}\text { Compliance } \\
\text { Requirements }\end{array}$ & $\begin{array}{l}\text { The set of requirements derived } \\
\text { trom applicable regulatory } \\
\text { requirements and translated into } \\
\text { compliance criteria and } \\
\text { subsequently adopted, possibly } \\
\text { with additional translation, as } \\
\text { constraints within a compliance } \\
\text { approach. }\end{array}$ & $\begin{array}{l}\text { 2.2.1.1.3.4 - Select Regulatory } \\
\text { Compliance Approach }\end{array}$ \\
\hline Applications & $\begin{array}{l}\text { Requests for permits, licenses, or } \\
\text { other authorizations to test, } \\
\text { construct, operate, or } \\
\text { decommission any part of the } \\
\text { NWMS. }\end{array}$ & 2.2.1.1.4.2.4 - Complete Submittal \\
\hline $\begin{array}{l}\text { Regulatory } \\
\text { Reports }\end{array}$ & $\begin{array}{l}\text { Progress reports, topical reports, } \\
\text { statements of findings, notices of } \\
\text { issuance, and other documents } \\
\text { containing information required by } \\
\text { compliance requirements. }\end{array}$ & 2.2.1.1.4.2.4 - Complete Submittal \\
\hline $\begin{array}{l}\text { Regulatory } \\
\text { Authorization to } \\
\text { Proceed }\end{array}$ & $\begin{array}{l}\text { Notification to Provide Program } \\
\text { Control functions that regulatory } \\
\text { barriers to implementation of a } \\
\text { particular activity no longer exists. }\end{array}$ & $\begin{array}{l}\text { 2.2.1.1.4.3.3 - Determine Actions To } \\
\text { Be Taken }\end{array}$ \\
\hline Compliance Status & $\begin{array}{l}\text { The summation of findings } \\
\text { defining the degree of compliance } \\
\text { with proniammatic and physical } \\
\text { system requirements at any stage } \\
\text { of development, construction, } \\
\text { operation, or decommissioning of } \\
\text { NWMS elements. }\end{array}$ & $\begin{array}{l}\text { 2.2.1.1.5.2 - Compare Review Results } \\
\text { Against Requirements }\end{array}$ \\
\hline
\end{tabular}


- Produce the necessary regulatory applications and reports, or transmit regulatory authorizations. in Obtain Regulatory Approvals $(2.2 .1 .1 .4)$

- Determine compliance status in Confirm Compliance Status $(2.2 .1 .1 .5)$

One of the outputs shown on the table. Compliance Information, has specific subsets of information that are produced by unique functions at lower levels of the functional analysis and thus do not appear on Figure 8-2 or in Table 8-3.

Program Position. Resolution Status, and Confirmed Rejections are all produced in the function Identify Applicable Regulatory Requirements (2.2.1.1.1). Subsequently, they are bundied together as Regulatory Status Information to document the status of resolving rejections, conflicts, and ambiguities among potentially applicable regulatory requirements. Compliance Approach Information is produced in the function Develop Compliance Approach (2.2.1.1.3), which combines not only the established compliance approain and compliance requirements, but also the rationale used to develop those products.

The subsets described above represent the decomposition of the information hierarchy for Compliance Information. which has bundled together output information from several functions within the ERC function.

The principal external outputs are summarized as follows:

- Compliance Information

- Produced by the functions that resolve conflicts and ambiguities in the applicability of regulatory requirements, and by the function that selects the compliance approach

- Used by the PER function

- Used to support external interactions with Congress and the public, as well as to document the program's position on demonstrating regulatory compliance for litigation purposes

- Comprised of the program position on applicability, the documented results of applicability determinations, and the rationale behind the choice of a particular compliance approach together with the compliance approach and requirements.

- Need for Review of Performance Measures and Values

- Produced by the function that reviews derived performance measures and their bounding values

Used by the PPC function as a change request to the technical baseline

Used to identify inconsistencies between derived performance requirements and the upper level compliance criteria from which they were derived 
- Comprised of specific findings of inconsistencies or other problems in derived performance requirements.

- Conpliance Approach

- Produced by the function that selects the compliance approach

- Used by the PPC function

- Used to develop an integrated program strategy

- Comprised of a 11 the strategic elements of the approach chosen to demonstrate regulatory compliance.

- Compliance Requirements

- Produced by the function that selects the compliance approach

- Used by the PPC function

- Used to form the basis for program requirements

- Comprised of all applicable regulatory requirements that have been translated in compliance criteria and have had an adequate compliance approach developed such that compliance can be generated.

- Applications

- Produced by the function that completes regulatory submittals

- Used by external regulatory agencies

- Used to obtain regulatory approvals

- Comprised of all submittals to regulatory agencies to obtain approvals to proceed with the execution of the program mission.

- Regulatory Reports

Produced by the function that completes regulatory submittals

- Used by external regulatory agencies and other concerned parties

- Used to satisfy report production requirements

- Comprised of all submittals to external agencies or the public at large in which the publication itself allows OCRWM to proceed with the execution of the program mission. 
- Regulatory Authorization to Proceed

- Produced by the function that determines actions to be taken on the basis of regulatory approvals (and conditions on approvals) received by OCRWM

- Used by the PPC function

- Used to establish that no regulatory obstacles exist to the authorizazion of a particular program activity

- Comprised of specific statements by the ERC function that all necessary regulatory requirements have been satisfied for a particular activity.

- Compliance Status

- Produced by the function compares review results against compliance requirements to confirm compliance status

- Used by the PER function

- Used to support external interactions with Congress and the public, as well as to docuinent the program's assessment of regulatory compliance for litigation purposes

- Comprised of ERC judgements on the programs compliance with regulatory compliance.

\subsection{ENSURE REGULATORY COMPLIANCE PROCESS EXECUTION DETAILS}

This section provides detail on the five major subfunctions of ERC. The discussions focus on the nominal process flow omitting major feedback loops. These feedback loops are discussed separately at the end of this section.

\subsubsection{Identify Applicable Regulatory Requirements}

8.3.1.1 Mission/Objective. Identify all externally imposed requirements that the program must meet. Regulatory Requirements are defined as all those requirements that this function identifies as appiicable to the program. Mandatory demands on OCRWM are derived from Federal statutes, regulations. Executive Orders, other Executive Department directives, DOE orders and directives, Secretarial Notices, and Secretarial Memoranda, as well as relevant State and local ordinances.

The function includes all external, mandatory requirements. Certain recommendations may become mandatory by their adoption by the program and inclusion in program strategy as program commitments. Guidance is derived from legal precedent. legislative histories, agency interpretations; and other advisory opinions may be used to assist in the identification of applicable regulatory requirements, but cannot themselves constitute such requirements.

The function includes monitoring changes to OCRWM's regulatory environment through the life cycle of the program. and ensuring that the appropriate regulatory requirement changes are made to confirm compliance. 
WHC-EP-0482

8.3.1.2 Process Flows. This function is composed of the following four subfunctions:

- Develop Regulatory Screening Guidance: Develop procedures and criteria to identify regulatory sources and regulations that apply to the OCRWM program.

- Compile and Maintain Candidate Requirements Sources: Implement the regulatory screening guidance to identify a candidate requirement source lists. Collect all applicable regulatory sources. Maintain cognizance over these regulatory sources to include the periodic capture and review of these sources to identify and incorporate any new regulatory sources and identify and delete any obsolete regulatory sources. Identify sources that have uncertain OCRWM aPplicability and that need further analysis.

- Evaluate Candidate Requirements: Identify specific, discrete requirements within candidate sources and identify the OCRWM functions to which they apply. Identify requirements that are ambiguous, or that appear to conflict with each other. Provide rationales for requirements that have been rejected along with any reservations concerning the validity of the rejection (or anticipated challenges to the rejection).

- Resolve Rejections, Conflicts, and Ambiguities: Resolve questions concerning the appicability of requirement sources and requirements to the OCRWM program. Document the rationale for rejecting requirements because of conflicts among requirements.

This function occurs in sequential fashion (see Figure 8-3) as follows:

- Initially, regulatory screening guidance must be produced that will later control the identification of sources, the evaluation of individual requirements, and the resolution of rejections. conflicts. and ambiguities.

- The appropriate regulatory sources are identified, compiled, and maintained.

- Sources are analyzed to identify elemental requirements, and those requirements are evaluated for applicability to program functions. and inherent conflict or ambiguities.

- Requirements found to be inapplicable. or which contain conflicts or ambiguities, are resolved.

Internal feedback loops within this process will operate when uncertain source documents or rejected requirements are reinstated (as an outcome of the resolution process) for further consideration.

8.3.1.3 Outputs. The process will produce the following three types of outputs:

- Regulatory resolution information, which is produced on a periodic basis relating to the resolution of rejections, conflicts, and ambiguities 


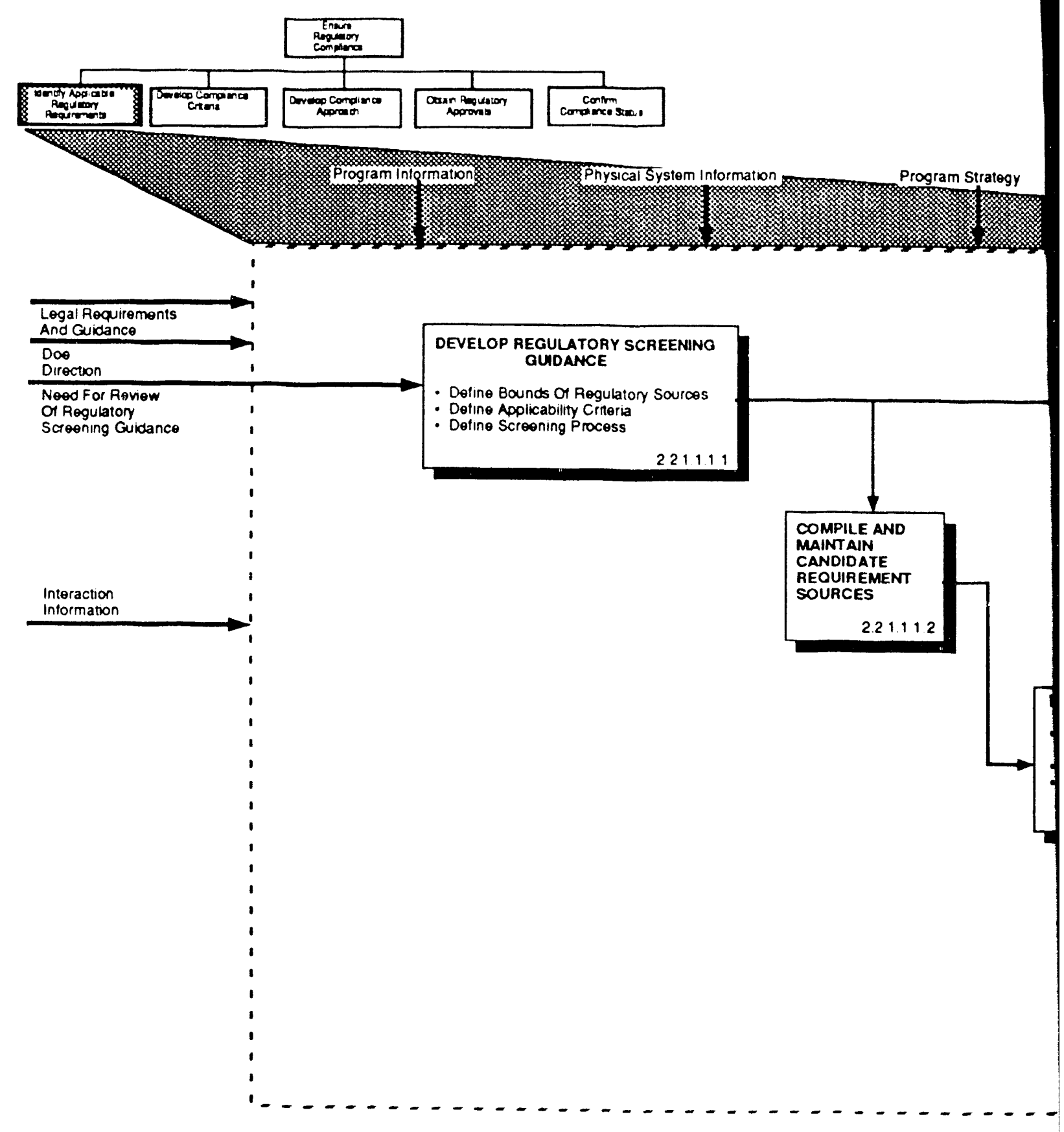


Figure 8-3. Process Overview - Identify Applicable Regulatory Requirements.

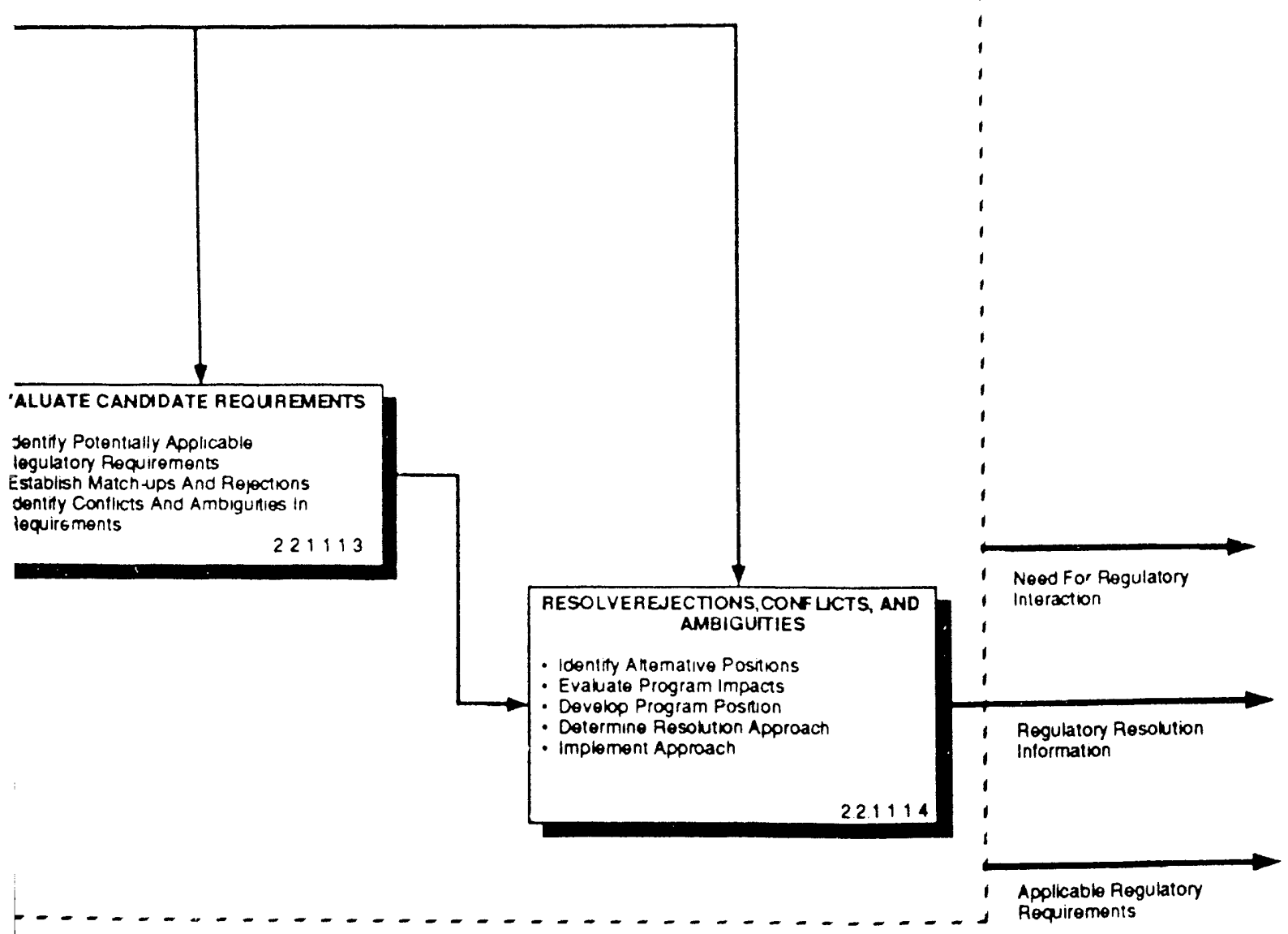


- A need for regulatory interaction, when the regulatory screening guidance cannot be produced based on available sources. Or in its application, the guidance is found to be unworkable

- Applicable regulatory requirements, which are free from any conflicts or ambiguities in applicability.

Only issues of applicability are decided in this process: clarifications of meaning in requirements with respect to implementation and verification are handled in other functions.

8.3.1.4 Significant Considerations. This process can begin when sufficient guidance in the form of program strategy is received to establish the bounds of the regulatory environment facing OCRWM. It continues to operate through the life of the program to determine whether the regulatory sources or the program have changed enough to cause a change in that regulatory environment. and will iterate as needed to capture changes and produce modifications to the applicable regulatory requirements.

\subsubsection{Develop Compliance Criteria}

8.3.2.1 Mission/Objective. The objective is to establish measures and values that can be used to determine when compliance with regulatory requirements has been achieved. Requirements are analyzed to produce unambiguous

interpretations of the requirements. Related requirements are grouped to allow for the development integrated compliance criteria, and compliance measures are established for each requirement. as well as acceptable bounding values.

Interpretations, measures, and bounding values are developed for those regulatory requirements identified as applicable to the OCRWM mission. Some regulatory requirements will be clear and will not require interpretation or further evaluation for compliance measures and bounding values.

8.3.2.2 Process Flows. This function is composed of the following four subfunctions:

- Clarify Meaning of Regulatory Requirements: Analyze regulatory requirementsts to determine, first. if alternative interpretations of the requirements are possible, or second, if the requirements are unclear, insufficiently quantitative, or otherwise difficult to interpret. If any such conditions exist, develop interpretations that would lead to consistent and uniform understanding by both OCRWM and the regulatory agencies.

- Select Compliance Measures: Identify and select performance measures that can be used to assess compliance with individual requirements that have been clarified and interpreted by the program.

- Establish Bounding Values for Measures: Establish limits (bounding values) for the performance measures so that compliance with those limits would constitute compliance with regulatory requirements.

- Review Derived Measures and Bounding Values: Perform an integrated review of the lower-tier performance measures and 
associated bounding values developed by other program functions to ensure that the regulatory intent is satisfied.

This function occurs in two modes (see figure 8-4): As applicable regulatory requirements are identified, this process will operate to produce the corresponding compliance criteria (measures and bounding values). As system requirements are generated and become part of the system configuration. this process will analyze that subset of those requirements that was derived from previously generated compliance criteria for consistency and integration with the existing compliance criteria.

In the first mode, the process will work sequentially to accomplish the following: (1) clarify the requirements, if necessary. (2) select the appropriate compliance measures, and (3) establish the quantitative bounding values for the measures that will be used to confirm compliance. In the second mode, the function will examine the derived measures and values against the existing compliance criteria, and make changes to compliance criteria or identify problems to be resolved. The process does not have internal feedback loops in either mode.

\subsubsection{Outputs. This process will produce the following three types of} outputs:

- A need for regulatory interaction, when clarification of regulatory requirements requires direct contact with a regulator. or when the selection of a compliance measure involves the need for advise or consent from the regulator

- Compliance criteria, which correspond to the applicable regulatory requirements

- A need for review of derived performance measures and values. which will be translated into a change request when these derived measures are found to be inconsistent with the intent of the underlying compliance criteria.

The compliance measures generated by this process subsequently may be adopted by other functions as system suitability measures, or they may be refined in greater detail for that purpose.

8.3.2.4 Significant Considerations. This process is activated by the generation of applicable regulatory requirements for which compliance criteria must be produced (Mode 1 ), or by the generation of derived measures and values which must be reviewed (Mode 2 ). This process will also iterate in its entirety when major changes in program strategy conflict with the existing compliance criteria. It will cease to operate when all such inputs have been processed. 


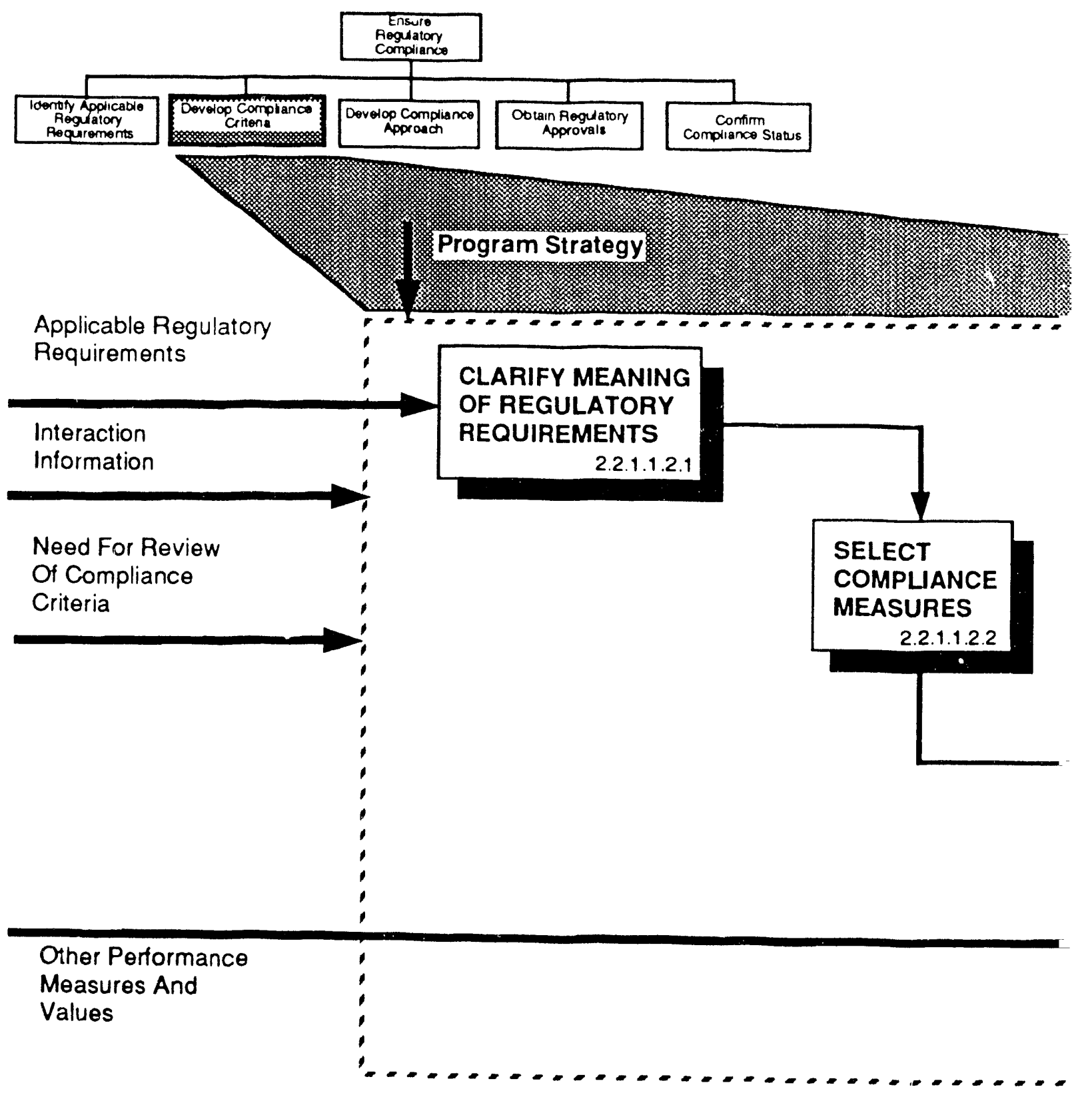


Figure 8.4. Process Overview Develop Compliance Criteria.

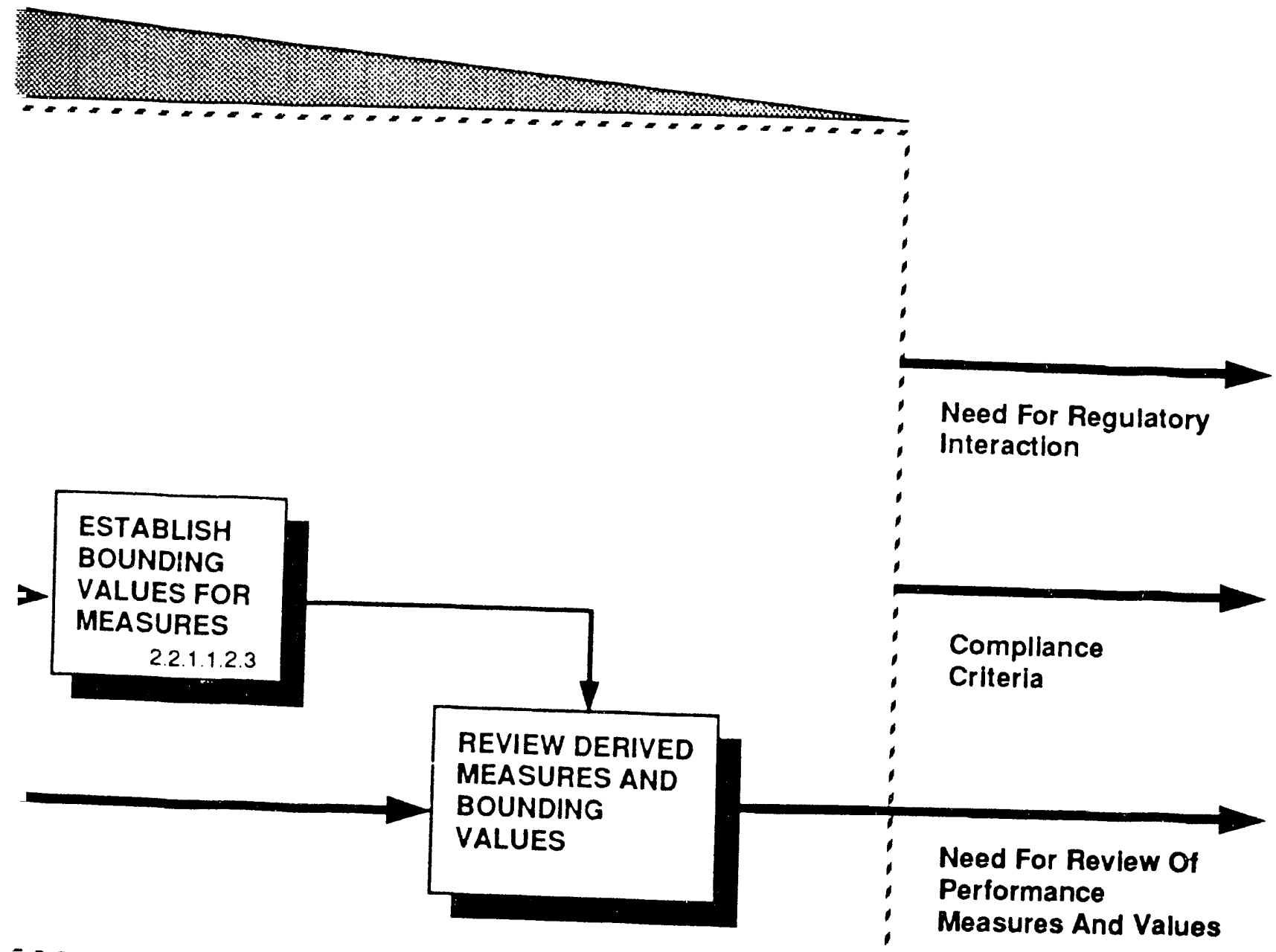




\subsubsection{Develop Compliance Approach}

8.3.3.1 Mission/Objective. The objective is to develop strategies that can be used to comply with regulatory requirements and to translate compliance criteria into compliance requirements that are consistent with the compliance approach. This process accomplishes the following:

- Analyzes the applicable regulatory requirements (as incorporated in the compliance criteria) to determine the need for considering alternative strategies, as well as the range of alternatives that should be considered.

- Develops alternative strategies for complying with requirements. or sets of requirements.

- Establishes and applies decision criteria to select compatible compliance approaches.

Compliance approaches will be delivered to the PPC function to establish consistency of the compliance approach with overall program strategy.

The compliance approach will be developed and will incorporate the scientific and engineering goals and objectives of the program. However, the need to meet regulatory requirements is a program mandate, and engineering and scientific strategies must work within this mandate to achieve the program objectives. This function cannot dictate program activities, but the compliance approach will always be formulated to ensure that regulatory compliance will be achieved.

\subsubsection{Process Flows. This function is composed of the following four} subfunctions:

- Identify and Evaluate Regulator/Program Positions: Identify the regulator's position with regard to specific compliance criteria. Assess compliance criteria to identify those that influence. dominate. or control programmatic risk (including cost. schedule. and technical performance risk). Compare regulator and program positions with regard to regulatory requirements (as contained in compliance criteria) based on dominant factors governing the ease or difficulty of developing compliance to approaches for compliance.

- Prioritize Regulatory Issues and Requirements: Evaluate the similarities and differences in the positions of OCRWM and the regulators to identify and prioritize areas to resolve.

- Identify and Reconcile Compliance Alternative: Define a set of viable compliance strategies for subsequent detailed evaluation and selection.

- Select Regulatory Compliance Approach: Select a preferred compliance approach from among the viable approaches formulated and evaluated that best meets the physical system and programmatic criteria established for the selection of a compliance approach. 
This function operates in the following sequential fashion (see Figure 8-5):

- Initially, the compliance criteria will be evaluated to identify differences in positions between OCRWM and the regulator on demonstrating compliance.

- Regulatory issues and requirements are then identified and prioritized as follows:

- Categories of issues and requirements are identified. relationships among categories are established, and the precedence hierarchy of the categories is defined.

- Prioritization criteria relating to demonstrating compliance are derived from program strategy.

- The categories are then evaluated against the differences in positions and the prioritization criteria to articulate and prioritize the concerns involved in demonstrating compliance for each category of issues and requirements.

- Compliance alternatives are formulated and refined on the basis of strategic constraints (derived from the prioritized concerns) and their viability for implementation.

- Compliance approaches are selected that conform best to program strategy.

The process outlined above starts with compliance criteria, groups criteria, and then builds around each group, the logical framework of strategic. information and arguments that become the compliance approach and associated compliance requirements. Internal feedback loops will operate in two cases: The first case is when the program position on compliance could not be implemented under any alternative compliance approach. The second case is when the prioritization criteria were found to lead to inconsistent treatment in the prioritization of categories of issues and requirements.

\subsubsection{Outputs. This process produces the following six types of outputs:}

- The compliance approach. which is delivered to the PPC function for integration into the overall program strategy

- The compliance requirements, which are sent to the PPC function for adoption as program requirements

- Compliance approach information, which is delivered to the PER function as the compendium of the compliance approach, compliance requirements, and the rationale behind the development of both

- A need for regulatory interaction, which occurs only if viable alternative compliance approaches cannot be found and assistance from the regulator in shaping an acceptable approach must be sought 


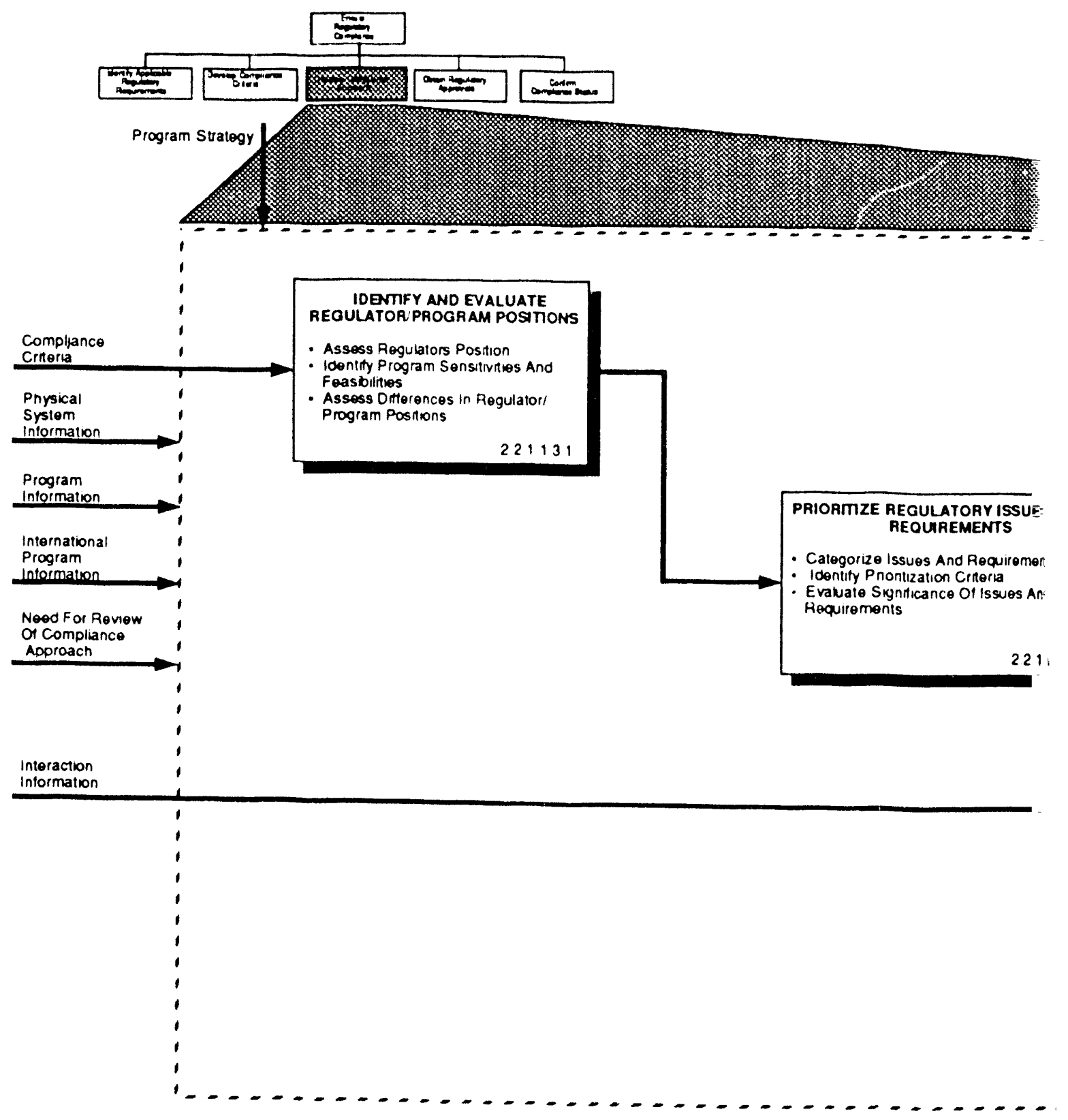


Siale 8.5. Process overview

Develop compl ance Aproroch.

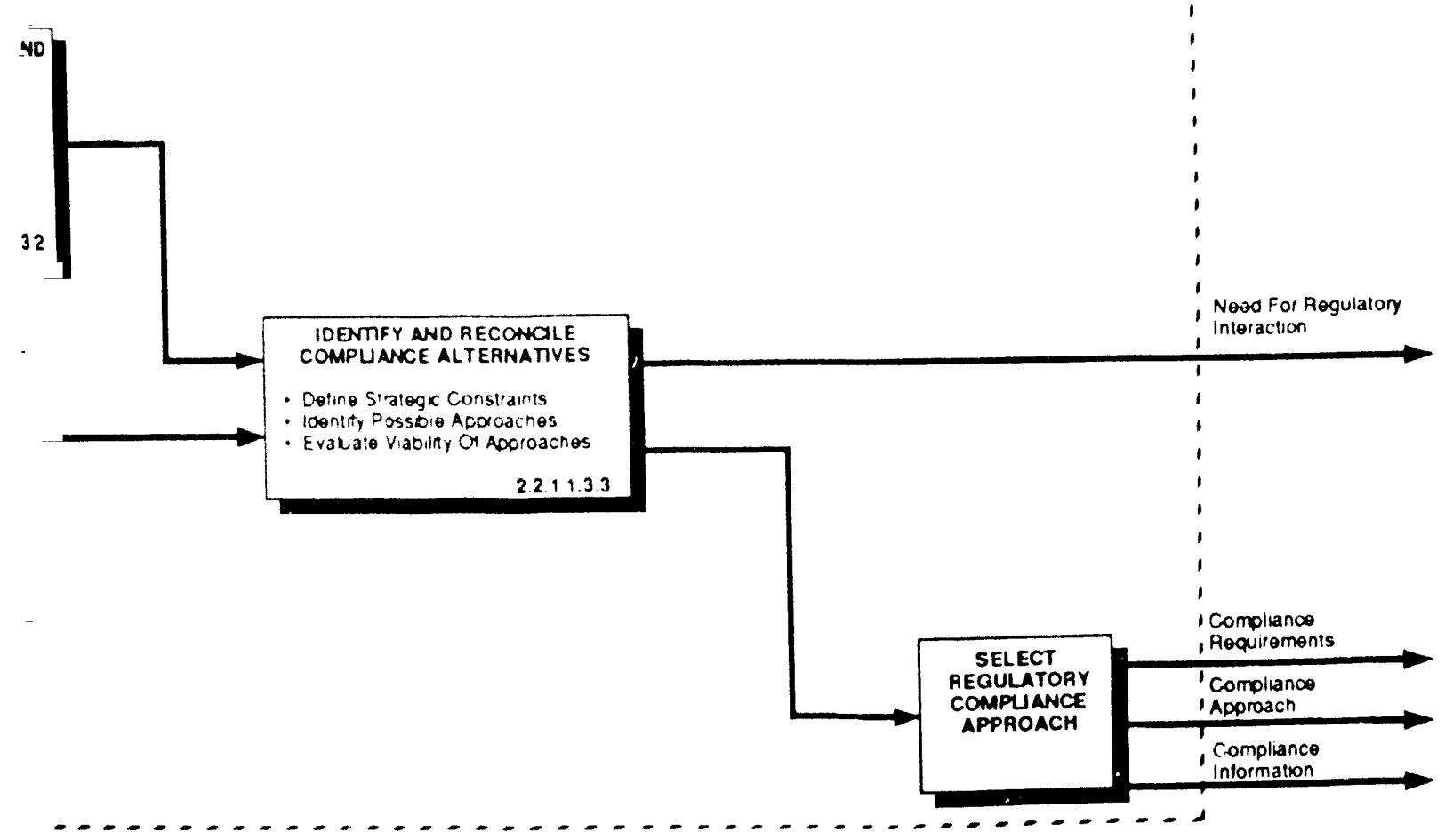


- A need for review of compliance criteria. which can occur if it is discovered that the criteria are inconsistent with current program or regulator positions on compliance, or if it is impossible to develop a viable alternative compliance approach under the existing criteria

- A need for review of regulatory screening guidance, which can occur if it is discovered the regulatory environment facing OCRWM must be expanded or contracted because of some assumption. finding, or strategy being incorporated into a compliance approach.

The latter two outputs are major feedback loops in this process which are discussed in the last section of this ERC discussion.

The primary product of this process is the compliance approach, which will be described in sufficient detail to enable approximate allocations of resources to be made to activities to assess compliance with individual requirements (for use by program control functions). and to provide guidance for the preparation of specific compliance plans (for use by implementing functions).

8.3.3.4 Significant Considerations. This function will operate after receiving a comprehensive set of compliance criteria and will proceed until an integrated compliance approach can be produced. It is subject to iteration by the imposition of significant changes in program strategy. the physical system, and programmatic activities. It is also subject to iteration if other ERC functions discover problems with the existing compliance approach and identify a need for review of compliance approach.

\subsubsection{Obtain Regulatory Approvals}

8.3.4.1 Mission/Objective. The objective is to conduct activities sufficient to obtain regulatory authorizations for the construction, operation, and decommissioning of the NWMS. A further objective is to conduct interactions with regulatory agencies and other concerned groups as mandated by statutes and regulations.

Regulatory approvals include permits, licenses, certificates, and other forms of permission. They may include permission to perform an action without formal approval after certain conditions are met. This later type of regulatory submission may simply be the publication of a report.

\subsubsection{Process Flows. This function is composed of the following three} subfunctions:

- Conduct Regulatory Interactions: Interact with individuals and organizations external to OCRWM that influence OCRWM's ability to obtain and/or maintain regulatory approvals.

- Submit Regulatory Documents: Prepare, produce, and submit regulatory documents to regulatory agencies and concerned parties.

- Transmit Regulatory Approvals: Receive regulatory approvals (such as 1 icenses, permits, certificates, and authorizations) and regulatory reports. Analyze any conditions that may form a part of regulatory approvals and reports to determine their impact on 
programmatically established requirements and activities. Determine any actions that need to be taken as a result of approval conditions, and inform program control functions that regulatory authorization to proceed exists as appropiriate.

This function operates in the following three modes (see figure 8-6):

- The process can be initiated to interact with regulatory agencies or concerned parties to obtain specific information. In this mode, the function only exercises the subfunction Conduct Reguiatory Interactions (2.2.1.1.4.1).

- The process can be initiated to obtain specific regulatory approvals by compiling and issuing the required applications or reports. In this mode, the subfunction Submit Regulatory Documents (2.2.1.1.4.2) will initiate the process, and needs for regulatory interaction will be issued to the Conduct Regulatory Interactions function as needed to support the process.

- The process can be initiated when regulatory approvals and authorizations are received or when regulatory reports are issued. In this mode, the subfunction Transmit Regulatory Approvals (2.2.1.1.4.3) will initiate the process to analyze any conditions contained in the approvals or reports and determine the regulatory impaci of those approvals on the program. Regulatory authorizations to proceed with the desired actions will be issued. if ajpropriate.

One ir.ternal feedback loop chat exists in this process occurs in the second mode of operation when a need for regulatory interaction is issued to support the procuction of a regulatory application. Such feedbacks can be integral parte of the process, such as the consultation and coordination necessary for Environmental Impact Statements: A second internal feedback $100 p$ exists in the third mode of operation. When regulatory approvals contain conditions that are ambiguous, a need for regulatory interaction will be issued so that the conditions can be clarified by the regulator.

8.3.4.3 Outputs. This process produces the following seven types of output:

- Applications, which are submitted to external regulatory agencies for approvals and authorizations

- Regulatory reports, which are mandated by regulations to be published before certain program activities can occur

- Interaction information. which occurs when some other function requires additional information from a regulator or concerned party to complete its mission

- A regulatory authorization to proceed, which is sent to PPC for implementation when all regulatory obstacles to a program activity have been removed

- A need for review of regulatory screening guidance. when conditions contained in regulatory approvals cause the regulatory environment facing OCRWM to change 


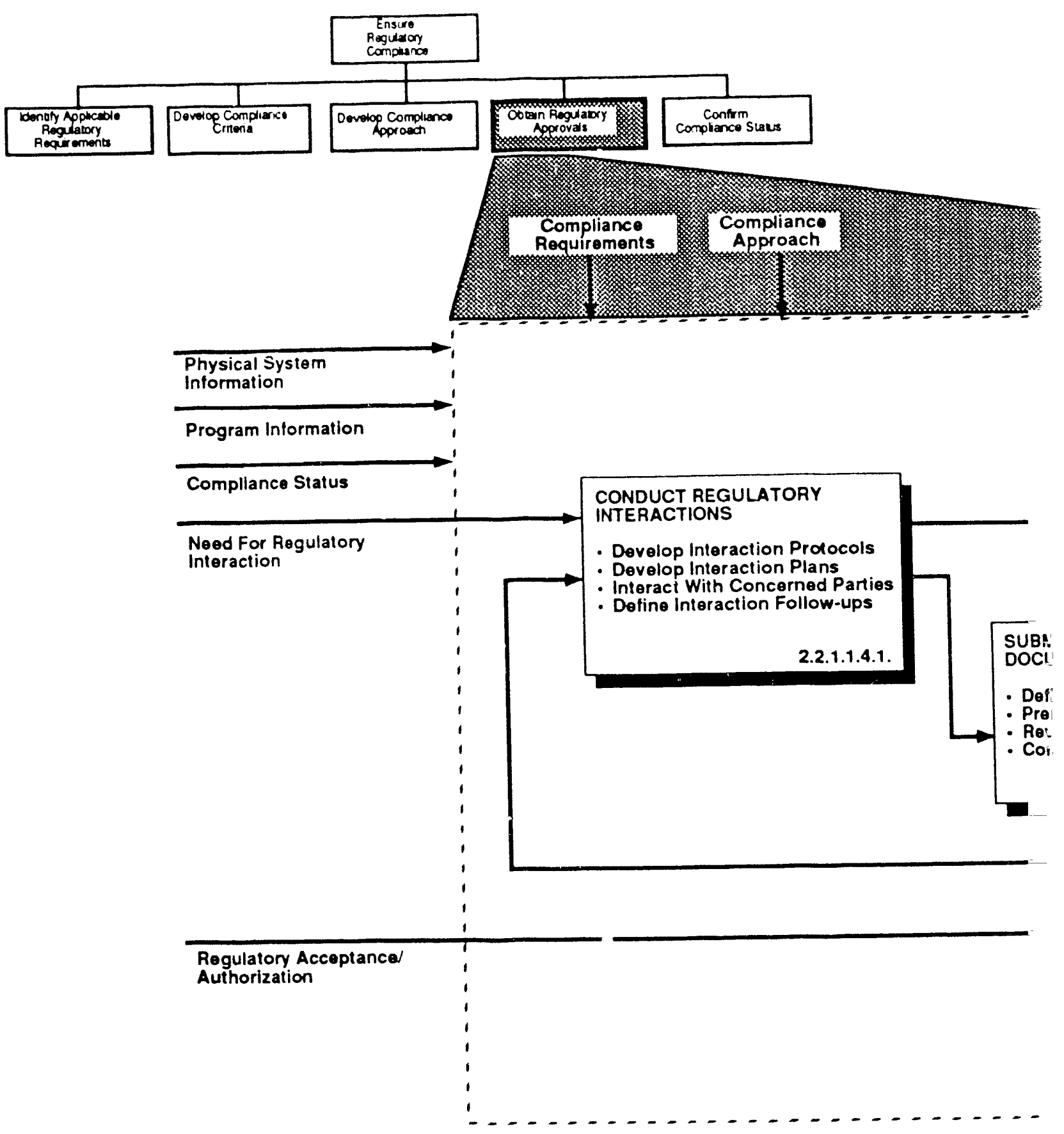


Fique 8-6. Process overview Obtain Regulatory Approvals.

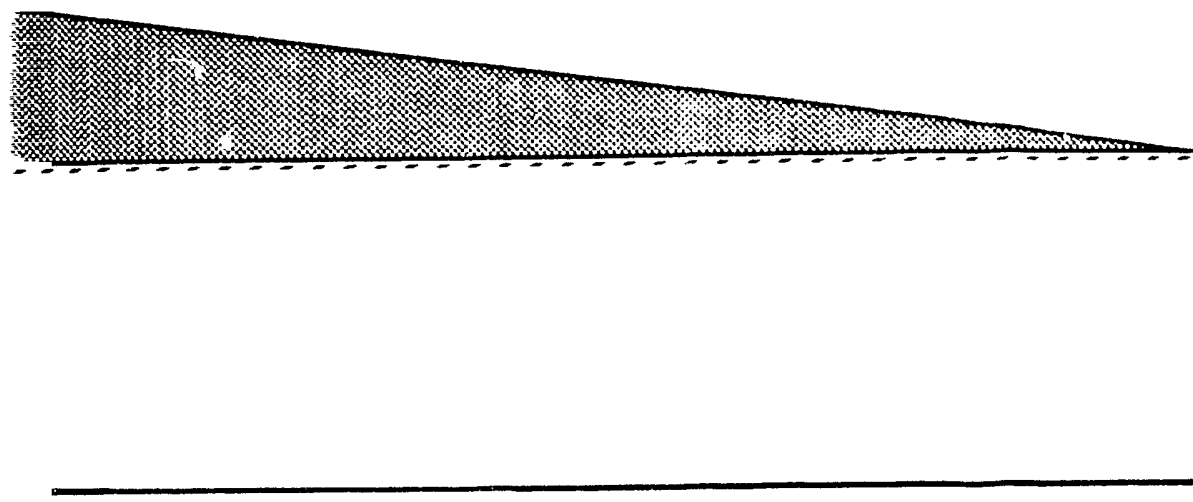

Interaction Information REGULATORY
ENTS

: Submittal Process re Regulatory Documents $\because$ Regulatory Documents lote Submittal

2.2.1.1.4.2

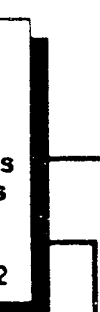

TRANSMIT REGULATORY APPROVALS

- Analyze Significance Of Approval

Conditions

- Determine Impacts On Requirements

And Activities

- Determine Actions To Be Taken

2.2 .1 .1 .4 .3
Applications :

Regulatory Reports

\section{Regulatory Authorization}

To Proceed

Need For Review Of Regulatory

Screoning Guldance

Need For Review of

Compliance Criteria

Need For Revier of

Compliance Approach 
- A need for review of compliance criteria, when conditions contained in regulatory approvals are inconsistent with the current set of compliance criteria

- A need for review of compliance approach, when conditions contained in regulatory approvals are inconsistent with the current compliance approach.

The latter three outputs of these seven types of outputs are major feedback loops in the process and are discussed in a subsequent section of the ERC discussion.

8.3.4.4 Significant Considerations. This process may be initiated under the following three conditions:

- A need for regulatory interaction : received (Mode 1 ).

- Compliance requirements are generated, consistent with program strategy. which require the generation and submission of specific regulatory applications or documents (Mode 2 ).

- Regulatory approvals/authorizations are received (Mode 3 ). follows:

Each mode of operation has a unique condition for termination as

- The desired interaction information is captured (Mode 1).

- The required application or regulatory report is submitted (Mode 2).

- A regulatory authorization to proceed can be issued (Mode 3 ).

This process can occur at any time during the life cycle of the program.

\subsubsection{Confirm Compliance Status}

8.3.5.1 Mission/Objective. The objective is to compare the results of internal and external reviews of program procedures, reports, and data generated during the siting, design, construction, operation, closure, and decommissioning against compliance requirements. The activities are as follows:

- Determine the degree to which compliance criteria and regulations have been met.

- Confirm or refute the conclusions of independent reviews performed to assure conformance with applicable compliance criteria and regulations.

Regulatory compliance is confirmed by assessing the results of independent reviews, such as QA management audits, system technical reviews. and by external reviews.

The function will produce compliance status information periodically using compliance requirements, the compliance approach, and DOE direction as 
the basis for scoping the range of verification results to review, and to establish the methodology and decision criteria for confirming regulatory compliance.

8.3.5.2 Process Flows. This function is composed of the following two subfunctions:

- Review Status of Verification Programs: Examine the programmatic implementation of verification programs within the program that relate to regulatory requirements. Determine if sufficient information is being acquired to enable the judgments to be made relative to conformance with regulatory requirements. Ensure that verification efforts are adequately implemented in other programs.

- Compare Review Results Against Requirements: Examine the results of system technical reviews. self-assessments, program status reviews, and independent reviews, such as $Q A$ management audits ana external reviews by regulators. Determine the degree of conformance with regulatory requirements by comparing review results with compliance requirements.

This function will occur periodically to assess compliance status (see figure 8-7). The two subfunctions in this process work sequentially. First, Review Status of Verification Programs, validates that the program's verification activities have been implemented according to requirements. Second, with that qualification established. the second function. Compare Review Results Against Requirements, can assess the results of 1 ine organization, independent, and external reviews to make the determination compliance has been achieved.

An internal feedback loop zan occur when, in comparing review results against requirements, a question arises regarding the adequacy of implementation of a verification activity within the program. In such a case. a need for review of program status will be issued so that the fundamental integrity of the verification effort in question can be established.

8.3.5.3 Significant Considerations. This function will operate periodically throughout the 1 ife cycle of the program. It is subject to iteration when reviews, both internal (system technical reviews and QA verification results) or external (reviews by regulators). conclude that the program is not complying with regulatory requirements.

\subsection{ENSURE REGULATORY COMPLIANCE INTERNAL INTERFACES}

The ERC process incorporates internal feedback loops to test for consistency of certain key ERC products with other programmatic and physical system information. A finding of inconsistency at key decision points will cause that finding to be driven back to a point in the process where that key variable is formulated. At that point, an analjsis can be conducted to determine what modifications, if any, are needed to remedy the inconsistency. products:

Major feedback loops have been constructed for the following three ERC

- Need for Review of Compliance Approach 


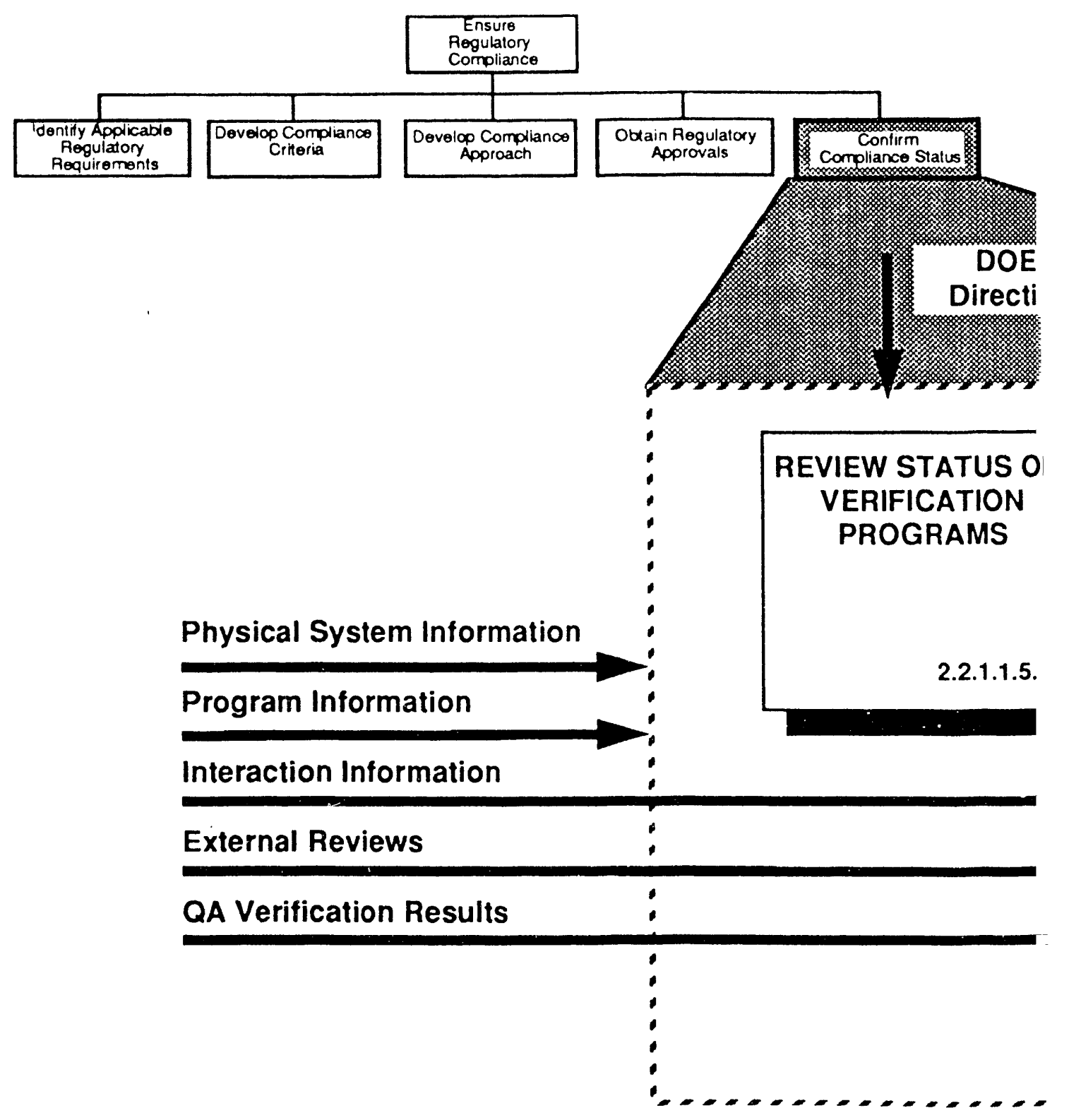


Figure 8-7. Process Overview

Confirm Compitance Status.

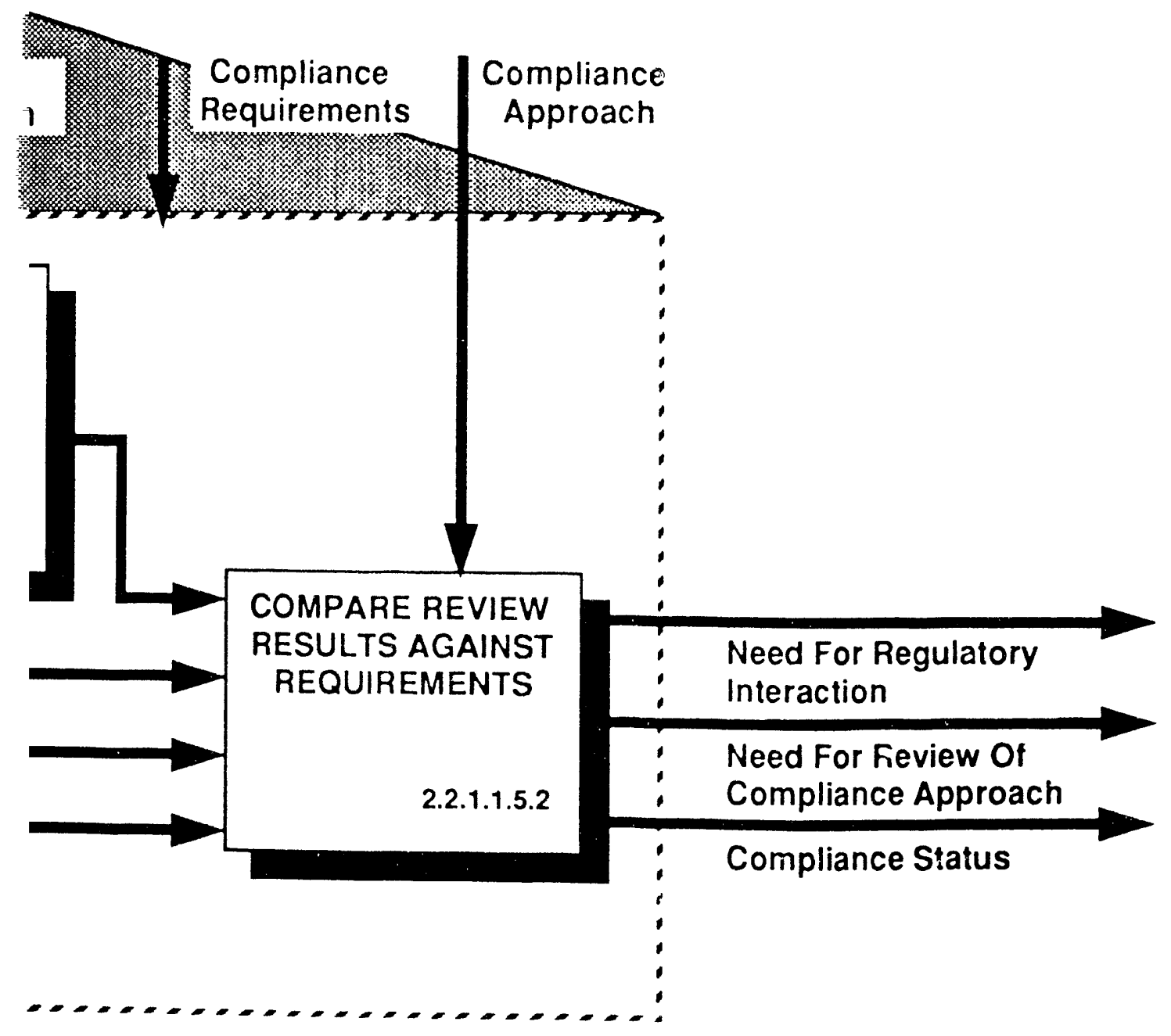


- Need for Review of Compliance Criteria

- Need for Review of Regulatory Screening Guidance.

Figure 8-8 displays these feedback loops within the three-level function hierarchy structure for ERC. The numerical identifiers in the figure correspond to the numerical identifiers of the ERC products in the list above.

Each major feedback loop is summarized as follows:

- Need for Review of. Compliance Approach

- Designed to identify problems in the compliance approach as that approach is being executed to obtain regulatory approvals and to confirm regulatory status

- Will occur when the compliance approach is shown to be incapable of achieving compliance. or when execution of the approach to leads noncompliance status

- Is the primary method to initiate the modification of ERC strategy

- Occurs only in response to a failure.

- Need for Review of Compliance Criteria

Designed to identify problems in the compliance criteria as those criteria are being implemented or conditions in regulatory approvals are analyzed

- Will occur when a compliance approach cannot be formulated with the existing criteria, or when conditions on regulatory approvals introduce new or conflicting criteria

- Initiates the fine tuning of compliance criteria

- Occurs both in a failure mode (failure to formulate a compliance approach) or in a restart mode (new criteria are imposed that conflict with the existing criteria).

- Need for Review of Regulatory Screening Guidance

Designed to identify problems in the regulatory screening guidance in evaluating requirements within source documents, in developing a compliance approach, or in analyzing conditions in regulatory approvals

- Will occur when new or obsolete regulatory requirements are encountered in evaluating candidate requirements, in developing a compliance approach, or in analyzing conditions in regulatory approvals

- Refines the definition of the regulatory environment facing OCRWM as the program evolves

- occurs in a restart mode as new or obsolete regulatory requirements are encountered. 
Fiqure 8-8. Ensure Requlatory Compliance - Major Feedback Loops.

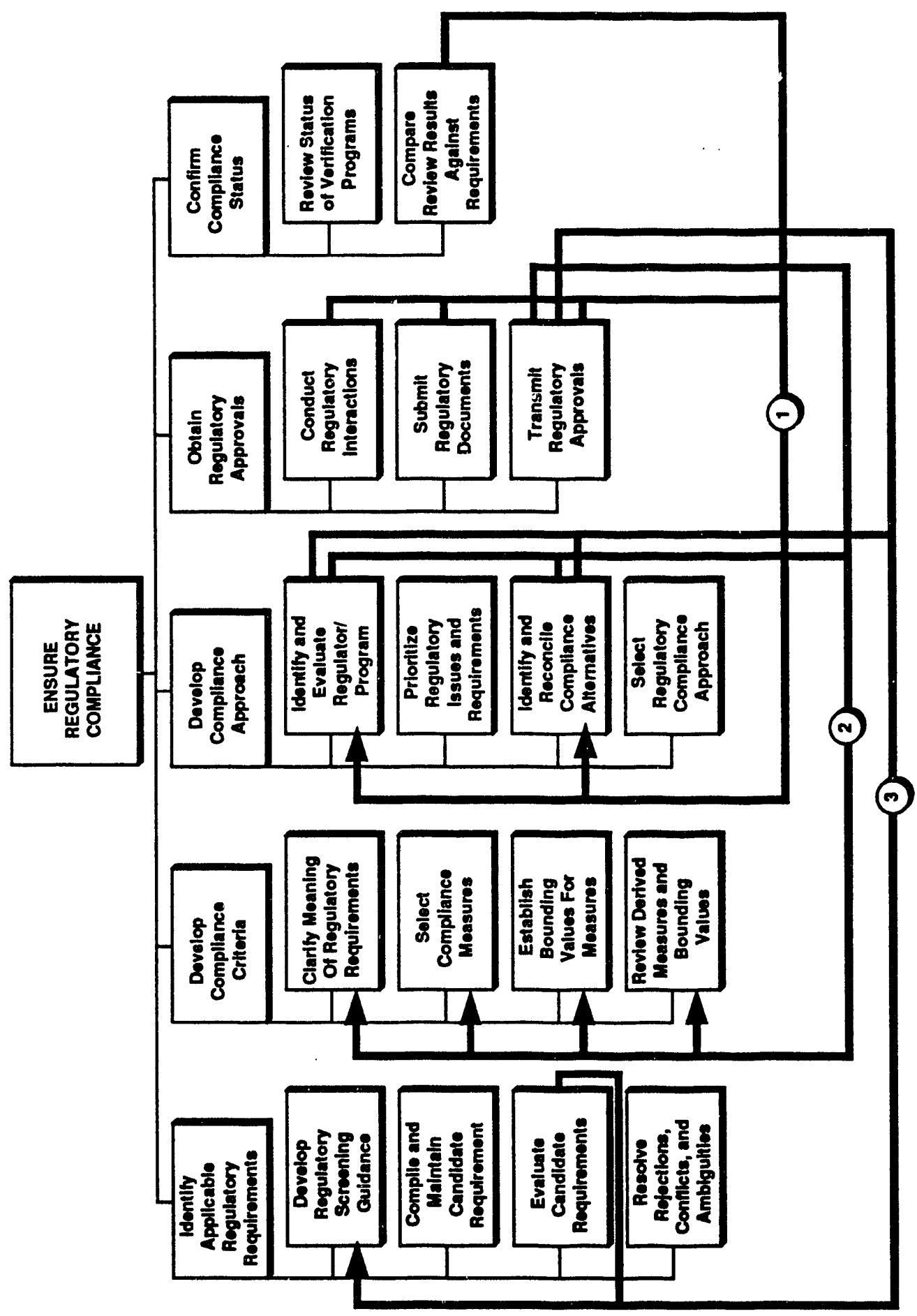


The feedback loops are linked in the sense that a need for review of compliance approach produced within Obtain Regulatory Compliance (2.2.1.1.4) or Confirm Compliance Status (2.2.1.1.5) can subsequently lead to the production of a need for review of regulatory screening guidance, or lead to a need for review of compliance criteria. When the original feedback is evaluated in Develop Compliance Approach (2.2.1.1.3). The generation of the subsequent feedbacks is received by Identify Applicable Regulatory Requirements (2.2.1.1.1) or Develop Compliance Criteria (2.2.1.1.2). This linkage of feedbacks occurs when significant, but indeterminate. problems are encountered in executing the compliance approach. In reevaluating the compliance approach, it is possible that the problem can be more specifically defined in the regulatory screening guidance or compliance criteria that underlie the compliance approach. 
WHC-EP-0482

This page intentionally left blank. 


\subsection{PROVIDE PROGRAM CONTROL PROCESS DESCRIPTION}

\subsection{PROVIDE PROGRAM CONTROL MISSION AND PROCESS OVERVIEW}

\subsubsection{Mission/Objective}

Control the NWMS program by organizing. planning monitoring, directing. and managing changes to workscope. schedule, cost, and technical baselines and to the standard practices.

\section{1 .2 Scope}

Figure 9-1 shows the hierarchical relationship among the first three levels of subfunctions that make up the Provide Program Control (PPC)

function. The extent of the functional scope defined by the hierarchy is described as follows:

- Define objectives for the entire NWMS program based on responsibilities under the Office of Civilian Radioactive Waste Management (OCRWM) NWPA.

- Define the constraints on implementing the program objectives by integrating the regulatory and nonregulatory requirements into the program implementation strategy.

- Based on the strategy and the integrated regulatory and nonregulatory requirements, specify and guide NWMS program implementation using direction, policy. plans, procedures. assumptions, and constraints as well as for technical. management. and administrative activities.

- Provide management and control of all programmatic baselines and processes.

- Provide an integrated function for the following:

- Generation of all programmatic requirements. These are the requirements for the physical system developed within Perform Systems Engineering (PSE) which uses the Program Direction (generated by $P P C$ ) information as the basis for all technical requirements.

- Developing work scopes, activity networks, resource needs.

- Balancing all resource needs and schedures and combining program plans.

- Requesting funds and other resources for the program. 
Figure 9-1. Provide Program Control Function.

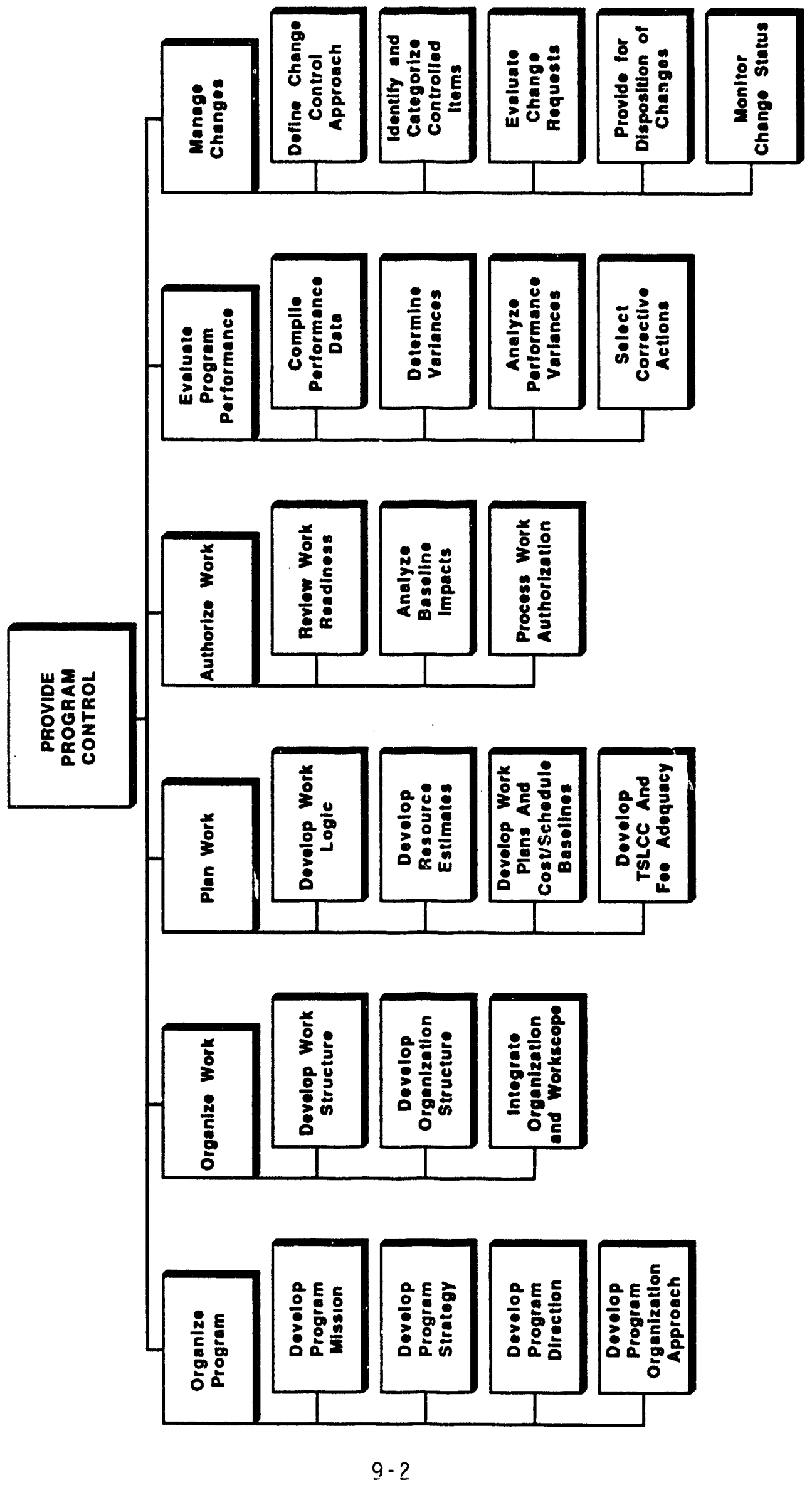


- Authorizing all work on the program.

- Evaluation of total integrated program performance relative to the requirements and plans as indicated by cost. schedule, and technical measures.

- Reviewing and approving or disapproving changes to all requirements (both programmatic and technical) and all other program items identified for change control.

\subsubsection{Process Flow}

Figure 9-2 shows the primary information flows through the PPC subfunctions. The small inset in the upper left corner of the figure shows the relationship of PPC to the other MSIS functions within the Provide Management Support function. The large dashed box in the figure represents the PPC functional boundary between the other MSIS functions outside the box and the subfunctions that make up PPC inside. Inside each subfunction. shown as shadowed boxes, are the titles of the next level subfunction as identified by black dots. All inputs to and outputs from PPC are shown as labeled lines ending or passing through the dashed-line box. To focus on the prillary PPC processes, the internal PPC paths shown inside the dashed-line box have been simplified. These internal information paths are simplified from the corresponding function diagram and show only the success-oriented paths [function diagrams are presented in Volume 2 of The Analys is of the Program to Develop the Nuclear Waste Management System (Woods 1991a)]. Additional discussion of the PPC-level information flows for feedback paths is presented in a subsequent subsection.

The PPC process flows are initiated by input and control information paths shown entering the left side of the dashed box in Figure 9-2. The processes culminate in the output information paths shown leaving the right side of the dashed box. Subsection 9.2 provides details on the contents of each information path including functional destinations for the inputs and controls and functional origins for the outputs.

The flows through the function can be viewed as groups of outputs from the dashed box in Figure 9-2, that is, outputs from PPC. The flows are as follows:

Outputs from both Organize Program and from Evaluate Program Performance go to all functions and provide control over what the functions must do. when they can do it, and the funding they are authorized to spend. The Program Direction output is generated by processing the information entering the Organize Program function. As Figure 9-2 shows, input information is a combination of mission (NWPA) information, requirements and constraints, and resource availability information. Processing this combination of inputs provides the initial Program Direction and. with additional processing, the initial Authorized Work. The other inputs to organize Program. the compliance and evaluation approaches and the strategic options are feedback types of inputs that result from other MSIS functions initial implementation of the program direction. Subsequent processing by the Or.ganize Program function. when these inputs are providing information. can result in updates to Program Direction and to Authorized work. 
WHC-EP-0482

This page intentionally left blank. 


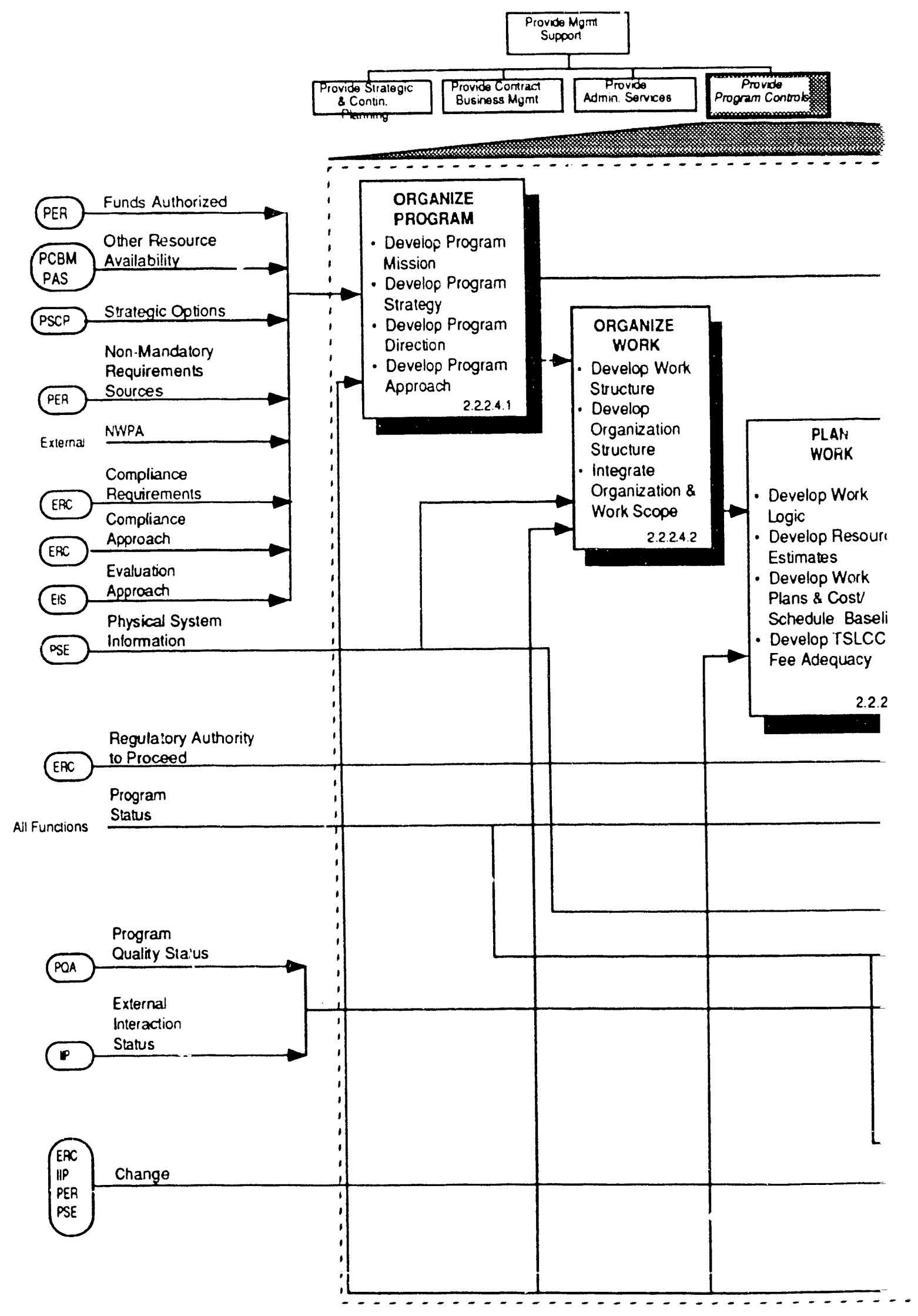


Figure 9-2. Process Overview

Provide Program control.

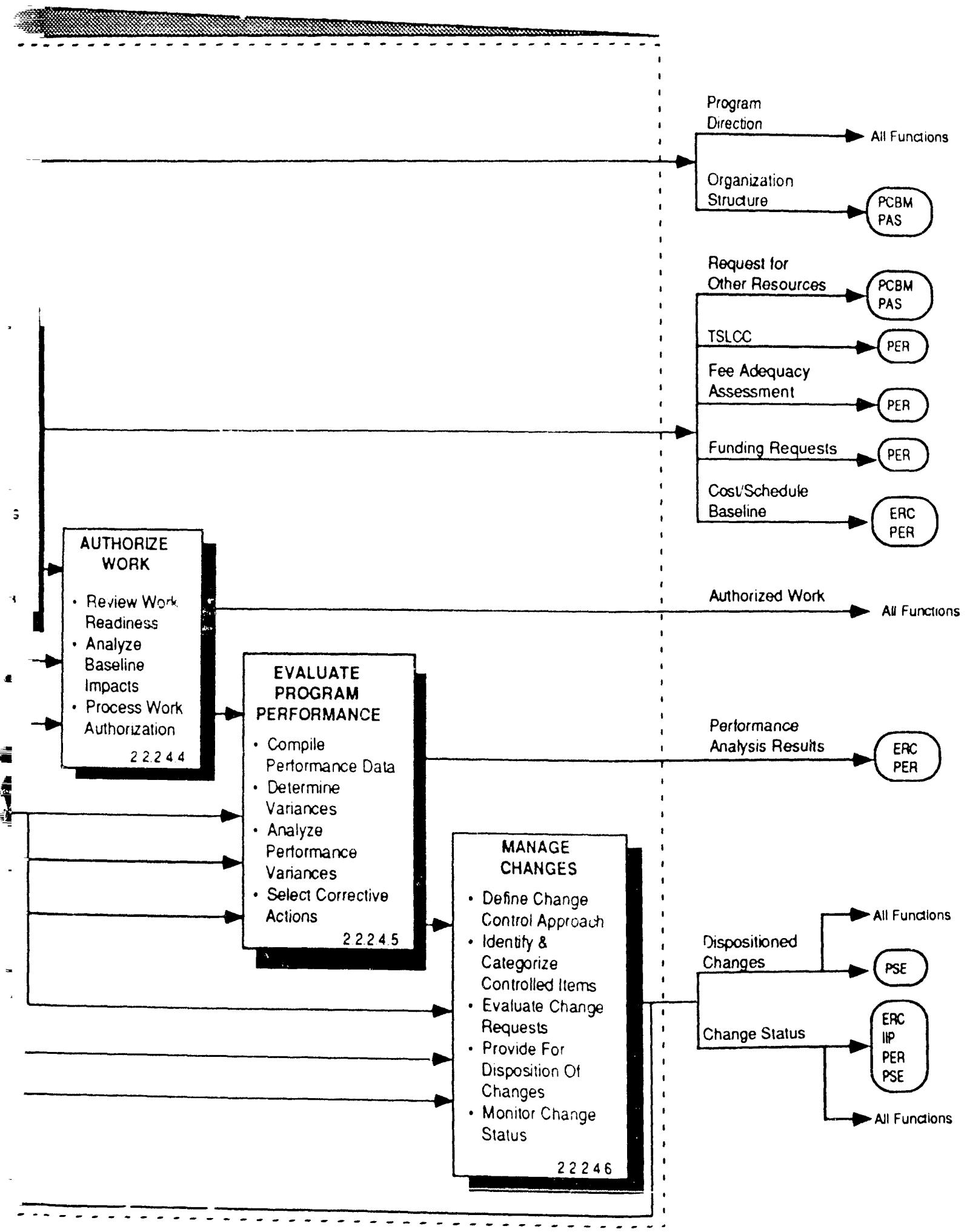


- The outputs leaving PPC from Plan Work can be viewed as primarily resource related. The Plan Work function uses Program Direction information and inputs from Organize Work co do the program planning, which results in developing the resource requests and information on current and projected funding. The Plan Work activities also result in program planning information which is passed on to Authorize Work.

- The two outputs from Manage Changes tell all the functions which request changes the status and disposition of those changes. This information is also provided to the PPC subfunction Organize Program as a feedback loop. The Organize Program feedback loop is a primary way ihat the other MSIS functions communicate back to $P P C$. In this 100p. the MSIS functions can generate change requests to get relief from Program Direction requirements. As the change requests are considered and disposition is determined in Manage Changes, the disposition is relayed to Organize Program which will change Program Direction, if that is the determination. Similarly, the loop from Manage Changes back to Organize Work and Plan Work can cause the work authorized to the other MSIS functions to be modified.

- The remaining output from PPC is Performance Analysis Results, which informs the Ensur'z Regulatory Compliance (ERC) and Provide External Relations functions concerning the state of the program based on evaluations of the planned work compared with the actually performed work. A loop through Evaluate Program Performance from all functions through to Manage Changes is another loop that communicates the other MSIS function activities back to PPC. The Evaluate Program Performance function, in addition to providing analysis results. can generate change requests and again the loops back to Organize Program. Organize Work, and Plan Work can result in modified program direction or authorized wo:k being sent back to the other MSIS functions.

- One other important information flow is related to the Plan Work function. The Plan Work function is a structure that all other MSIS functions use at the point planning and is required for them to implement their function. That is, it is a centralized function. Each MSIS function must do planning at some stage of their implementation. Rather than repeat all the function steps required to do planning in each MSIS function. the steps are shown once in the PPC functional analysis. Each individual function will do its planning as represented by the Plan Work function and the results are integrated at the total program level by the same process.

- Flow Summary

PPC provides overall management, direction, and integration of program activities.

PPC provides management and control of evaluations and changes to program baselines. 
- The processes in PPC are highly iterative. The initial program start activities begin with high-level strategy, program direction, and work plans. PPC authorizes work that directs the other program functions to expand the initial work plans and develop approaches. PPC receives these plans, approaches, and any new requirements, which it uses to update strategy, direction, and work plans and to authorize revised work.

- As the program progresses. PPC begins getting information on the physical system configuration. on program status. and receives change requests. It evaluates the program progress based on the configuration and status knowledge and communicates back to the other funztions either through change dispositions or new direction and work plans.

- During these same iterations. PPC communicates with the? functions responsible for obtaining funding in a similer manner by updating information based on the evolving program.

This iterative process continues throughout the program life continually adjusting to changing requirements and to the evolving configuration.

\subsection{PROVIDE PROGRAM CONTROL EXTERNAL INTERFACES}

This subsection provides details of the external PPC interfaces listed in Figure 9-2. The interface information is separated into three external interface categories: inputs, controls, and outputs. The distinction between inputs and controls is made in this subsection as an aid to the reader who will also read the function diagrams [see Volume 2 of The Analysis of the Program to Develop Nuclear Waste Management System (Woods 1991a)]. However. throughout the process descriptions. the figures that show interfaces to functions do not make the distinction between inputs and controls. The lack of this distinction is a simplification to help the reader focus on the processes.

The following three subsections each provide a figure listing and summarizing the particular interfaces to PPC. Discussions briefly highlight specific aspects of the information in the figures.

\subsubsection{External Inputs}

Tables 9-1, 9-2, and 9-3 list the inputs to the PPC function. In each table, the first column lists the inputs in the same order they appear on the left side of the flow diagram in figure 9-2. The second column provides a summary description of the type of information that PPC will be given as input. The third column lists the PPC subfunctions that directly process the input. The activities are as follows:

- Table 9-1 lists the inputs that enter the Organize Program function. 
Table 9-1. Provide Program Control External Inputs.

\begin{tabular}{|c|c|c|}
\hline Input Name & Input Definition & $\begin{array}{c}\text { Destination } \\
\text { Function }\end{array}$ \\
\hline $\begin{array}{l}\text { Strategic } \\
\text { Options }\end{array}$ & $\begin{array}{l}\text { Options, strategies and associated risks } \\
\text { that should be considered in development } \\
\text { of the overall NWMS program strategy. } \\
\text { These options and strategies reflect current } \\
\text { and forecasted socio-political } \\
\text { considerations in planning for the disposal } \\
\text { of high-level nuclear waste. }\end{array}$ & $\begin{array}{l}2.2 .2 .4 .1 .2- \\
\text { Develop } \\
\text { Program } \\
\text { Strategy }\end{array}$ \\
\hline $\begin{array}{l}\text { Non- } \\
\text { Mandatory } \\
\text { Requirements } \\
\text { Scurces }\end{array}$ & $\begin{array}{l}\text { Sources of program requirements } \\
\text { exclusive of the regulatory compliance } \\
\text { requirements (e.g., DOE orders, oversight } \\
\text { authorities, other applicable agencies, or } \\
\text { national standards). }\end{array}$ & $\begin{array}{l}\text { 2.2.2.4.1.3.1- } \\
\text { Define Internal } \\
\text { Program } \\
\text { Requirements }\end{array}$ \\
\hline N'WPA & $\begin{array}{l}\text { Nuclear Waste Policy Act and its } \\
\text { amendments. }\end{array}$ & $\begin{array}{l}2.2 .2 .4 .1 .1- \\
\text { Develop } \\
\text { Program } \\
\text { Mission }\end{array}$ \\
\hline $\begin{array}{l}\text { Compliance } \\
\text { Requirements }\end{array}$ & $\begin{array}{l}\text { The set of requirements derived from } \\
\text { applicable regulatory requirements and } \\
\text { translated into compliance criteria and } \\
\text { subsequently adopted, possibly with } \\
\text { additional translation, as constraints on a } \\
\text { compliance approach. These } \\
\text { requirements, in their final form, have been } \\
\text { integrated and reconciled with } \\
\text { requirements developed by other functions } \\
\text { and introduced into the compliance } \\
\text { approach selection function as a constraint } \\
\text { imposed by program strategy. }\end{array}$ & \begin{tabular}{|l} 
2.2.2.4.1.3- \\
Develop \\
Program \\
Strategy \\
2.2.2.4.1.3.1 - \\
Define Internal \\
Program \\
Requirements \\
2.2.2.4.1.3.2 - \\
Define \\
Comprehensive \\
Set of Program \\
Requirements
\end{tabular} \\
\hline $\begin{array}{l}\text { Compliance } \\
\text { Approach }\end{array}$ & $\begin{array}{l}\text { The strategic framework, consistent with } \\
\text { program strategy, by which compliance } \\
\text { with regulatory requirements will be } \\
\text { demonstrated. }\end{array}$ & $\begin{array}{l}\text { 2.2.2.4.1.2- } \\
\text { Develop } \\
\text { Program } \\
\text { Strategy }\end{array}$ \\
\hline $\begin{array}{l}\text { Evaluation } \\
\text { Approach }\end{array}$ & $\begin{array}{l}\text { A step-by-step procedure for performing } \\
\text { the integrated system evaluation including } \\
\text { (1) numerical procedures for evaluating } \\
\text { suitability measures, (2) programmatic } \\
\text { interfaces for evaluation data collection, } \\
\text { and (3) reporting methodologies for } \\
\text { suitability and impact assessments. }\end{array}$ & $\begin{array}{l}2.2 .2 .4 .1 .2- \\
\text { Develop } \\
\text { Program } \\
\text { Strategy }\end{array}$ \\
\hline
\end{tabular}


Table 9-2. Provide Program Control External Inputs.

\begin{tabular}{|c|c|c|}
\hline Input Name & Input Definition & $\begin{array}{l}\text { Destination } \\
\text { Function }\end{array}$ \\
\hline $\begin{array}{l}\text { Physical } \\
\text { System } \\
\text { Information }\end{array}$ & $\begin{array}{l}\text { A very broad range of information on the } \\
\text { system configuration. The information } \\
\text { includes the following: } \cdot \text { technical baseline } \\
\text { and PSE controlled information and data } \\
\text { not part of technical baseline, } \\
\text { configuration data on acquired/constructed } \\
\text { system components, } \cdot \text { system and } \\
\text { component test plans and site investigation } \\
\text { plans, - evaluation approach, } \\
\text { performance measures, evaluation data } \\
\text { needs, evaluation data collection } \\
\text { techniques to be used, } \cdot \text { results of } \\
\text { inspection, demonstration, test, and } \\
\text { analysis activities. In addition to technical } \\
\text { data, the information path also includes } \\
\text { requests for relief from or review of the } \\
\text { direction, constraints, or requirements } \\
\text { placed on the physical system. }\end{array}$ & $\begin{array}{l}\text { 2.2.2.4.2.1.1 - } \\
\text { Develop Work } \\
\text { Hierarchy } \\
\text { 2.2.2.4.5.2 - } \\
\text { Determine } \\
\text { Variances } \\
\text { 2.2.2.4.6.2 - } \\
\text { Identify and } \\
\text { Categorize } \\
\text { Controlled Items }\end{array}$ \\
\hline $\begin{array}{l}\text { Regulatory } \\
\text { Authorization } \\
\text { to Proceed }\end{array}$ & $\begin{array}{l}\text { Internal directives to implement compliance } \\
\text { direction. Signifies receipt of regulatory } \\
\text { acceptance/ authorization. }\end{array}$ & $\begin{array}{l}\text { 2.2.2.4.4.1- } \\
\text { Review Work } \\
\text { Readiness }\end{array}$ \\
\hline $\begin{array}{l}\text { Program } \\
\text { Status }\end{array}$ & $\begin{array}{l}\text { Cost, schedule, quality, and technical } \\
\text { status of the program. Cost status is } \\
\text { composed of actual expenditures and } \\
\text { actual and forecast funding conditions. } \\
\text { Schec'ste status is composed of actual } \\
\text { work progress measured by achievement } \\
\text { of events or other means of quantifying } \\
\text { progress. Quality status is incor-porated } \\
\text { as an included Program Quality Status } \\
\text { arrow from the Quality Assurance function. } \\
\text { All functions provide program status and, } \\
\text { therefore, the arrow is tunneled for } \\
\text { modeling purposes. }\end{array}$ & $\begin{array}{l}\text { 2.2.2.4.4.1 - } \\
\text { Review Work } \\
\text { Readiness } \\
\text { 2.2.2.4.5.1 - } \\
\text { Compile } \\
\text { Performance } \\
\text { Data } \\
\text { 2.2.2.4.6.3.2 - } \\
\text { Analyze } \\
\text { Change } \\
\text { Requests } \\
\text { 2.2.2.4.6.5 - } \\
\text { Monitor Change } \\
\text { Status }\end{array}$ \\
\hline $\begin{array}{l}\text { Program } \\
\text { Quality Status }\end{array}$ & $\begin{array}{l}\text { Compilation of surveillance, audit, and } \\
\text { inspection findings, records of adverse } \\
\text { incidents and observations, and results of } \\
\text { analyses of those findings and records. } \\
\text { Included are results of monitoring trends, } \\
\text { corrective action implementation, and root } \\
\text { cause analyses. }\end{array}$ & $\begin{array}{l}\text { 2.2.2.4.5.3.1 - } \\
\text { Identify } \\
\text { Variances } \\
\text { Subject to } \\
\text { Analysis }\end{array}$ \\
\hline
\end{tabular}


Table 9-3. Provide Program Control External Inputs.

\begin{tabular}{|l|l|l|}
\hline \multicolumn{1}{|l|}{ Input Name } & \multicolumn{1}{|c|}{ Input Definition } & \multicolumn{1}{c|}{$\begin{array}{c}\text { Destination } \\
\text { Function }\end{array}$} \\
\hline $\begin{array}{l}\text { External } \\
\text { Interactions } \\
\text { Status }\end{array}$ & $\begin{array}{l}\text { Status of program interactions where such } \\
\text { interactions may influence program cost, } \\
\text { schedule, or technical progress. }\end{array}$ & $\begin{array}{l}2.2 .2 .4 .5 .3 .1- \\
\text { IContify } \\
\text { Variances } \\
\text { Subject to } \\
\text { Analysis }\end{array}$ \\
\hline $\begin{array}{l}\text { Change } \\
\text { Requests }\end{array}$ & $\begin{array}{l}\text { Collective set of requested changes to the } \\
\text { NWMS system technical controlled items. } \\
\text { This information set consists of two } \\
\text { components, system technical information } \\
\text { change requests and system configuration } \\
\text { change requests. Technical information } \\
\text { change requests are generated to request } \\
\text { a change to controlled physical system } \\
\text { information that is not a part of the technical } \\
\text { baseline (system configuration). System } \\
\text { Requests }\end{array}$ & \\
& $\begin{array}{l}\text { Renfiguration change requests are } \\
\text { generated to request changes to the } \\
\text { current NWMS physical system technical } \\
\text { baseline. }\end{array}$ & \\
\hline
\end{tabular}


- Four of the inputs provide information to the Develop Program Strategy function. The input Compliance Requirements along with other mission objectives internal to PPC is used by Develop Program Strategy to develop the initial strategy for the entire program. The other three inputs. Strategic Options. Compliance Approach and Evaluation Approach return information later in the program for Develop Program Strategy to use to update the strategy.

- In addition to supporting the development of program strategy, the Compliance Requirements input is used by two $P P C$ functions to define program requirements. The two functions are Define Internal Program Requirements, and Define Comprehensive Set of Program Requirements.

- The Nonmandatory Requirements Sources input also supports program requirements definition. It is provided to the Define Internal Program Requirements function.

- The other input on Table 9-1 is NWPA, which provides the policy act information to the Develop Program Mission function. The information is used to structure the program strategy and to establish program objectives.

- Table 9-2 shows the following four inputs to PPC.

The contents and usage of the Physical System Information input evolves over the program life.

- - The input has a broad range of information on the current state of the system. The information includes configuration descriptions, plans, approaches, references on measures, needs for information, and responses to those needs.

- At the initiation of the program, the input would not have information available. As the program progresses. the information would be updated to reflect the changing state of the program.

-. The Develop Work Hierarchy function uses the input to extend the product-oriented Work Breakdown Structure to progressively more detailed levels as the program matures.

- The Determine Variances function uses system data including the current evaluation data from the input to determine the variances between the planned system performance and the actual system performance.

- The Identify and Categorize Controlled Items function uses the input to identify the specific hardware. software, and processes to be cortrolled.

The Regulatory Authorization to Proceed input is processed by the function Review Work Readiress as part of the work authorization process within PPC. 
- The Program Status input contains information on the cost. schedule, quality, and technical status of the program. The input is widely used within PPC to make decisions related to the following four areas:

-. Work readiness (Review Work Readiness)

- Preparation for evaluating the program performance (Compile Performance Data)

- Assessment of the overall impacts, risks, and benefits of proposed program changes (Analyze Change Requests)

- Monitoring of the evaluation and disposition of proposed changes (Monitor Change Status).

- Program Quality Status input is used by Identify Variances Subject to Analysis as part of the program evaluation process. The function selects the significant cost. schedule, technical, and quality variances that must be corrected.

- Table 9-3 lists the following two PPC inputs.

The External Interactions Status input is screened by the Identify Variances Subject to Analysis function for those items that present variances that are significant enough to be corrected.

- The Change Requests input is an information path from all activities requiring changes to controlled hardware. software, or processes in the program. These controlled items can include the program direction and the authorized work. The input is processed by the Screen Change Requests function.

\subsubsection{External Controls}

Table 9-4 presents the controls to the PPC function. The first column lists the two controls that appear on the upper left side of the flow diagram in Table 9-4. The second column provides a summary description of the type of information that PPC will be provided by the control. The third column lists the PPC subfunctions that recei e the control. The information in the controls provides the following:

- Both controls provide the Balance Resources and Schedules function, with coristraints related to resources available to the program.

- The Review Work Readiness function also is constrained by the Other Resource Availability control. The function determines if the available resources allow the work authorization process to continue.

- The Analyze Baseline Impacts function receives the Funds Authorized control to determine if the authorized funds differ from the baselined fund requests have impacts of the program. 
Table 9-4. Provide Program Control External Controls.

\begin{tabular}{|c|c|c|}
\hline Control Name & Control Definition & $\begin{array}{l}\text { Destination } \\
\text { Function }\end{array}$ \\
\hline $\begin{array}{l}\text { Other } \\
\text { Resource } \\
\text { Availability }\end{array}$ & $\begin{array}{l}\text { Amount of resources other than funding } \\
\text { (services, equipment, material, facilities, } \\
\text { personnel) available to execute planned } \\
\text { work. }\end{array}$ & $\begin{array}{l}\text { 2.2.2.4.3.3.1 - } \\
\text { Balance } \\
\text { Resources \& } \\
\text { Schedules } \\
\text { 2.2.2.4.4.1 - } \\
\text { Review Work } \\
\text { Readiness }\end{array}$ \\
\hline $\begin{array}{l}\text { Funds } \\
\text { Authorized }\end{array}$ & $\begin{array}{l}\text { Funds provided for expenuiture on } \\
\text { approved scopes of work. }\end{array}$ & \begin{tabular}{|l|} 
2.2.2.4.3.3.1 - \\
Balance \\
Resources \& \\
Schedules \\
2.2.2.4.4.2- \\
Analyze \\
Baseline \\
Impacts \\
\end{tabular} \\
\hline
\end{tabular}


WHC - EP- 0482

\subsubsection{External Outputs}

Table 9-5 shows the outputs from the PPC function. The format is the same as that presented in the descriptions of E:.ternal Inputs and External Controls. The information presented in Table 9-5 summarizes the Process flow discussion in section 9.1. which describes the function of all the PPC outputs.

\subsection{PROVIDE PROGRAM CONTROL EXECUTION DETAILS}

This section expands the process flow discussion of Section 9.1. Each of the six subfunctions shown in Figure 9-2 are individually discussed in the following six subsections. In each subsection, a figure similar to Figure 9-2, expands one of the PPC subfunctions into the next lower level of subfunctions from the functional analysis. As in Figure 9-2. the function (a first-level subfunction of PPC) is shown as a dashed box with the next level of subfunctions shown as shadowed boxes. Within the shadowed boxes are either another lower level of subfunctions indicated by black dots. or. if no lower level of subfunctions was developed. a phrase in parentheses listing the major elements of the subfunctions.

\subsubsection{Organize Program}

9.3.1.1 Mission/Objective. The objective has the following four parts:

Provide the program mission definition by establishing program strategy and objectives consistent with the NWPA.

- Initiate the program control process by establishing the guiding principles and requirements for the other PPC subfunctions and the other MSIS functions.

- Maintain the program focus through integration of the regulatory requirements and the other program-external constraints with the program strategy and objectives.

- Ensure a requirements-constrained program by developing program direction consistent with the integrated strategy. objectives and requirements.

9.3.1.2 Process Flows. Figure $9-3$ shows a simplified view of the subfunctional relationships within the Organize Program (2.2.2.4.1) function. The small inset in the upper left corner of the figure shows the relationship of Organize Program to the other functions that make up PPC. All of the information flows into anr out of the Organize Program function are shown in the figure next to the dashed box enclosing the Organize Program subfunctions. Within the dashed box. the primary information flows between the subfunctions are shown. The information paths shown in the figure are simplified representations of the information flow. Two types of path simplifications are made in the figure: First, the paths shown are the major information paths but are not all the paths: and second, feedback paths are not shown. Both of these simplificacions provide a focus on the process flows. The details of the flows are provided in the functional analyses corresponding to the Organize Program function [see Volume 2 of The Analysis of the Program to Develop the Nuclear Waste Management System (Woods 1991a)]. 
Table 9-5 Provide Program Control External Outputs. (sheet 1 of 2 )

\begin{tabular}{|c|c|c|}
\hline Output Name & Output Definition & $\begin{array}{l}\text { Originating } \\
\text { Function }\end{array}$ \\
\hline $\begin{array}{l}\text { Program } \\
\text { Direction }\end{array}$ & $\begin{array}{l}\text { Technical, management, and } \\
\text { administrative direction, policy, plans, } \\
\text { procedures, assumptions, and constraints } \\
\text { that specify and guide program } \\
\text { implementation.Program Direction }\end{array}$ & $\begin{array}{l}2.2 .2 .4 .1 .3 .5- \\
\text { Formulate } \\
\text { Program Direction }\end{array}$ \\
\hline $\begin{array}{l}\text { Organization } \\
\text { Structure }\end{array}$ & $\begin{array}{l}\text { An organizational hierarchy that identifies } \\
\text { functions, relation-ships, roles, and } \\
\text { authorities. }\end{array}$ & $\begin{array}{l}\text { 2.2.2.4.2.2 - } \\
\text { Develop } \\
\text { Organization } \\
\text { Strategy }\end{array}$ \\
\hline $\begin{array}{l}\text { Request for } \\
\text { Other } \\
\text { Resources }\end{array}$ & $\begin{array}{l}\text { Request for resources other than funding } \\
\text { (services, equip- ment, material, facilities, } \\
\text { personnel) to execute planned work. }\end{array}$ & $\begin{array}{l}\text { 2.2.2.4.3.3.3- } \\
\text { Formulate Funding } \\
\text { and Resource } \\
\text { Requests }\end{array}$ \\
\hline $\begin{array}{l}\text { Total System } \\
\text { Life Cycle Cost }\end{array}$ & $\begin{array}{l}\text { The total of the direct, indirect, recurring, } \\
\text { nonrecurring, and other related costs } \\
\text { incurred or estimated to be incurred in the } \\
\text { design, development, production, } \\
\text { operation, maintenance, support, and } \\
\text { final disposition of the NWMS over its } \\
\text { anticipated useful life span. }\end{array}$ & $\begin{array}{l}\text { 2.2.2.4.3.4- } \\
\text { Develop Total } \\
\text { System Life Cycle } \\
\text { Cost and Cee } \\
\text { Adequacy }\end{array}$ \\
\hline $\begin{array}{l}\text { Fee Adequacy } \\
\text { Assessment }\end{array}$ & $\begin{array}{l}\text { The assessment whether the Nuclear } \\
\text { Waste Fund contains, and will contain, } \\
\text { adequate funds to pay for the NWMS. }\end{array}$ & $\begin{array}{l}\text { 2.2.2.4.3.4- } \\
\text { Develop Total } \\
\text { System Life Cycle } \\
\text { Cost and Fee } \\
\text { Adequacy }\end{array}$ \\
\hline $\begin{array}{l}\text { Funding } \\
\text { Requests }\end{array}$ & $\begin{array}{l}\text { Requests for funds to execute planned } \\
\text { work. }\end{array}$ & $\begin{array}{l}\text { 2.2.2.4.3.3.3- } \\
\text { Formulate Funding } \\
\text { and Resource } \\
\text { Requests }\end{array}$ \\
\hline $\begin{array}{l}\text { Cost / } \\
\text { Schedule } \\
\text { Baseline }\end{array}$ & $\begin{array}{l}\text { Approved quantitative expression of } \\
\text { projected cost, other resources, and } \\
\text { schedule objectives to serve as a base or } \\
\text { standard for measurement of progress } \\
\text { during the performance of an effort. }\end{array}$ & $\begin{array}{l}\text { 2.2.2.4.3.3.2- } \\
\text { Establish Cost and } \\
\text { Schedule Baseline }\end{array}$ \\
\hline $\begin{array}{l}\text { Authorized } \\
\text { Work }\end{array}$ & Work approved for execution. & $\begin{array}{l}\text { 2.2.2.4.4.3- } \\
\text { Process Work } \\
\text { Authorization }\end{array}$ \\
\hline $\begin{array}{l}\text { Performance } \\
\text { Analysis } \\
\text { Results }\end{array}$ & $\begin{array}{l}\text { Assessment and compilation of variance } \\
\text { magnitudes, causes, and impacts of } \\
\text { those variances and alternative corrective } \\
\text { actions. Identification of potential } \\
\text { corrective action and alternatives and } \\
\text { identification. Assessment of risks } \\
\text { associated with each corrective action. }\end{array}$ & $\begin{array}{l}2.2 .2 .4 .5 .3 .4- \\
\text { Performance } \\
\text { Analysis Results }\end{array}$ \\
\hline
\end{tabular}


Table 9-5 Provide Program Control External Outputs. (sheet 2 of 2 )

\begin{tabular}{|c|c|c|}
\hline Output Name & Output Definition & $\begin{array}{r}\text { Originating } \\
\text { Function }\end{array}$ \\
\hline $\begin{array}{l}\text { Dispositioned } \\
\text { Changes }\end{array}$ & $\begin{array}{l}\text { The collective set of dispositions of } \\
\text { submitted change requests provided by } \\
\text { Provide Program Control. In most cases } \\
\text { these will be dispositions of change } \\
\text { requests submitted from the Systems } \\
\text { Engineering function, but may be } \\
\text { dispositions of requests initiated from } \\
\text { other NWMS programmatic functions } \\
\text { which will impact the NWMS physical } \\
\text { system configuration. Change requests } \\
\text { initiated by Systems Engineering will } \\
\text { either be requests to change system } \\
\text { configuration information or to change } \\
\text { controlled system technical information } \\
\text { that is not part of the system } \\
\text { configuration. Systems Engineering will } \\
\text { initiate change requests either as a result } \\
\text { of its own analyses and evaluations or as } \\
\text { a result of inputs received from the other } \\
\text { Configure System programmatic } \\
\text { functions. }\end{array}$ & $\begin{array}{l}\text { 2.2.2.4.6.3- } \\
\text { Evaluate } \\
\text { Change } \\
\text { Requests/Provid } \\
\text { e for Disposition } \\
\text { of Changes }\end{array}$ \\
\hline Change Status & $\begin{array}{l}\text { Information regarding the current status of } \\
\text { in-process change requests and } \\
\text { implementation of approved/disapproved } \\
\text { changes. }\end{array}$ & $\begin{array}{l}\text { 2.2.2.4.6.5- } \\
\text { Monitor Change } \\
\text { Status }\end{array}$ \\
\hline
\end{tabular}


Figure 9-3. Process Overview - Organize Program.

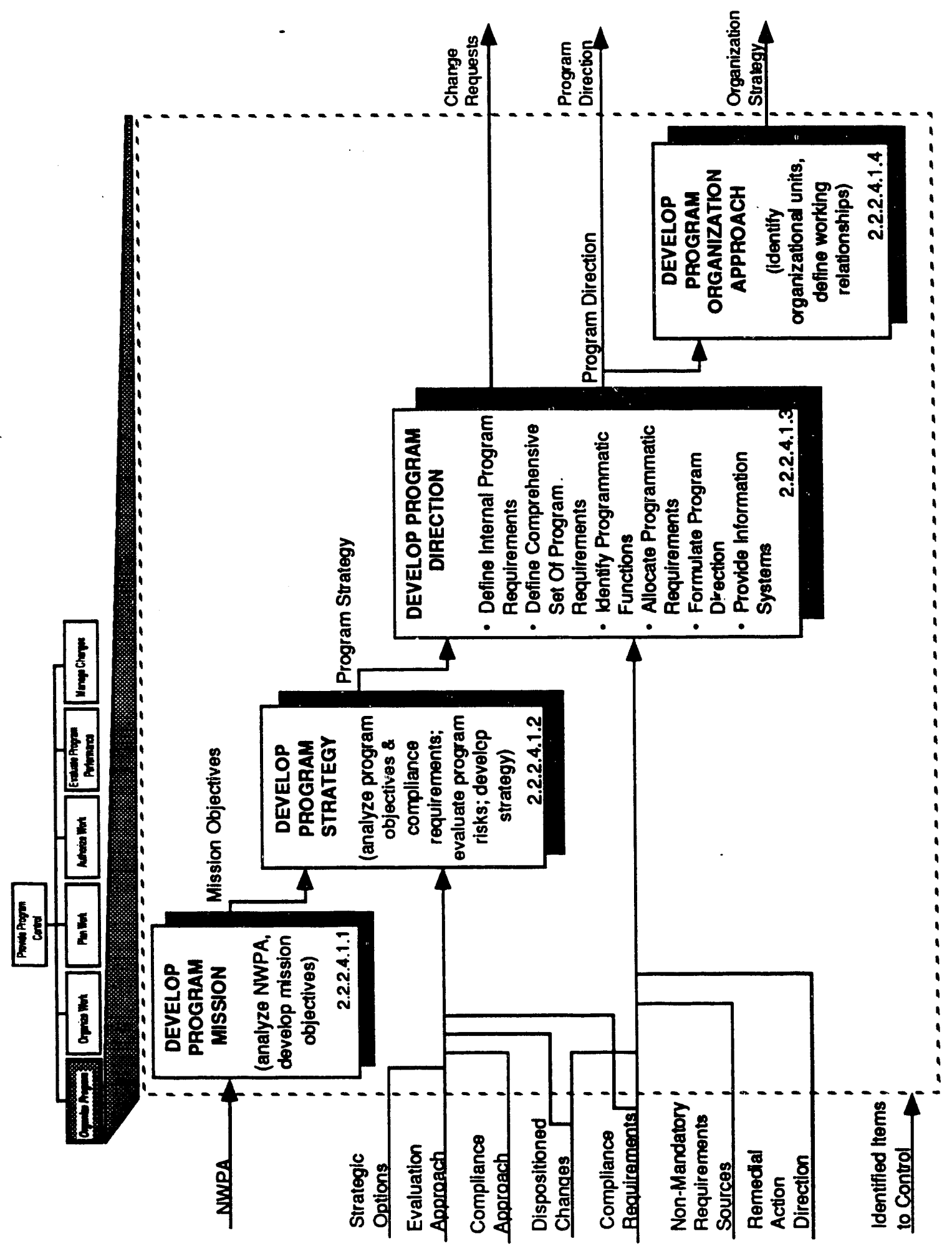


The Organize Program function is the primary PPC interface for inputs from other MSIS functions for the initial program start-up functions. These inputs provide the Organize Program subfunctions with the necessary information to develop a definition of the NWMS objectives, then translate these into an NWMS strategy that reflects the constraints imposed by the regulatory compliance requirements. In the following manner. the strategy is further translated into program direction and into a strategy for developing the organization necessary for implementing the program direction:

- Subfunction Develop Program Mission develops the primary NWMS mission objectives by translating and interpreting the contents of the NWPA. The objectives provide the purpose or focus for the NWMS activities providing the basis for determining the appropriate scope and applicability for all NWPA activities.

- Subfunction Deveiop Program Strategy is an iterative function that first combines the mission objectives with the compliance requirements to develop a high-level strategy for the program. As the succeeding functions (beginning with Develop Program Direction) direct the development of strategic options and evaluation and compliance approaches based on this initial strategy, a further refined strategy is developed within Develop Program Direction. Future changes in compliance requirements or any other program changes that impact the strategy are integrated in the Develop Program Strategy function and promulgated to the Develop Program Strategy subfunction that updates the program direction. Strategy development includes identifying and evaluating program risk so that the most acceptable strategy can be developed.

- Subfunction Develop Program Direction is the single focal point in the NWMS for integrating and maintaining all programmatic requirements ensuring that conflicting requirements are identified and resolution is provided. Develop Program Direction combines requirements and strategy into program direction for all NWMS requirements. It identifies those functions required to develop and maintain the programmatic aspects of the NWMS. The associated programmatic requirements are identified and allocated to these programmatic functions. The integrated information systems for the NWMS are identified and procured within Develop Program Direction.

- Subfunction Develop Program Organization Approach identifies the types of interprogram organizational units and intragovernmental agencies required to implement the program strategy and direction. It identifies the types of contractual support required to accomplish the strategy and direction. It defines the working relationships between the organizational units and the strategy for developing the roles, responsibilities, and authorities of the units.

9.3.1.3 Outputs. The primary Organize Program outputs are Program Direction and Organization Strategy. Program Direction provides the technical. management, and administrative direction, policy, plans, procedures. assumptions, and constraints that specify and guide program implementation. Organization Strategy provides the approach and constraints that govern the interaction and involvement of DOE units, contractors, and other participants in the NWMS program. 
The output, Change Requests, is used to provide information to the Manage Changes subfunction of PPC. This information path provides all the information necessary for the Manage Changes subfunction to evaluate the impact on the system of any changes in program direction or organization strategy. The disposition of the change requests is provided directiy and as input to the Develop Program Strategy subfunction on the Dispositioned Changes information path.

A second change related input titled Remedial Action Direction can be provided to the Develop Program Direction subfunction if specific changes are identified by the Manage Changes, but do not fall under the controlled changes process. Both Dispositioned Changes and the Remedial Action Direction can act as feedback paths from other MSIS functions.

9.3.1.4 Significant Considerations. The Organize Program function and the output Program Direction provide the centralized information path for keeping the actions of all program functions consistent with the NWMS mission and consistent with the regulatory compliance constrained strategy. Figure 9-4 provides a sampling of the type of information that is provided in the Program Direction path. As the figure shows. Program Direction consists of a broad range of directed implementing criteria, standards, and other requirements.

\subsubsection{Organize Work}

9.3.2.1 Mission/Objective. The Objective is to provide a centralized function for integrating a 11 work áctivity descriptions and the assignment of those activities to specific organizations, and to ensure the efficient. nonredundant allocation of all the work scopes necessary to implement the program direction to the responsible organizations.

9.3.2.2 Process Flows. Figure $9-5$ shows a simplified view of the subfunctional relationships within the Organize Work (2.2.2.4.2) function. The sma!l inset in the upper left corner of the figure shows the relationship of Organize Work to the other functions that make up PPC. All of the information flows into and out of the Organize Work function are shown in the figure next to the dashed box enclosing the Organize Work subfunctions. Within the dashed box the primary information flows between the subfunctions are shown. The information paths shown in the figure are simplified representations of the information flow. Two types of path simplifications are made in the figure: In the first, the paths shown are the major information paths but not all of the paths: and in the second. feedback paths are not shown. Both these simplifications provide a focus on the process flows. The details of the flows are provided in the functional analyses corresponding to the Organize Work function [see Volume 2 of The Analysis of the Program to Develop the Nuclear Waste Management System (Woods 1991a)].

This is an iterative function that initially, based on program direction, establishes a high-level structured work scope and organization structure with responsibility assignments. Succeeding iterations of the function use the physical system information to develop lower-level work scopes and organization structures.

Subfunction Develop Work Structure develops a product-oriented hierarchy of work scopes, provides sufficient definition of each work scope so that cost and schedule planning can be accomplished, and extends the depth of the hierarchy and definitions through iterations as the program implementation progresses. 
Figure 9-4. Program Direction Information Path Sample Contents.

PROGRAM DIRECTION: This arrow is used by all functions and contains many components. The broad definition is:

Technical, management, and administrative direction, policy, plans,procedures, assumptions, and constraints that specify and guide program implementation.

- DIRECTED POTENTIALLY ACCEPTABLE SITES: Sites that, by external direction, are as potential nominees; they are ranked, but not screened out, in the initial screening and ranking of potentially acceptable sites.

- DATA ACQUISITION SYSTEM (DAS) RECONCILIATION CRITERIA:The set of requirements that constrain the process by which data acquisition strategies are selected from the array of screened strategies.

- DATA ACQUISITION STRATEGY (DAS) SCREENING CRITERIA: The set of requirements that define characteristics of an acceptable data acquisition strategy and constrain the process by which strategies are screened from the array of feasible strategies.

- TEST AND ANALYSIS AVAILABILITY CRITERIA: Criteria by which testing methods potentially capable of acquiring needed information will be judged in terms of state-of-the-art, cost, operational constraints, physical limitations, or other constraints that affect actual "availability".

- FACILITIES REQUIREMENTS SELECTION CRITERIA: Programmatically driven criteria which constrain the development of requirements placed on facilities for tests and analyses.

- FACILITIES SELECTION CRITERIA: The set of requirements that constrain the process for reconciling needs and choosing facilities from among the total identified facilities.

- PROGRAM GOALS: Program direction incorporates the Mission Objectives formulated in the "Develop Program Mission" function. These objectives are defined as: The technical, cost, schedule, and programmatic goals of the NWMS as established by the NWPA.

- PROGRAM STRATEGY: Program direction incorporates the Program Strategy formulated in the "Develop Program Strategy" function. This strategy is defined as: Approach to achieving the program objectives.

* POLICIES AND STARNDARD PRACTICES: Policies and Standard Practices used to establish the accepted manner of doing business.

- NWMS DESIGN DIRECTION: External guidance, constraints, parameters that are used to develop the strategy for executing the NW'MS design. Contains the OCRWM program-level strategy for performing design as well as programmatic data describing methodologies, procedures, mechanisms that "Design Engineered System" should use in developing its design strategy and in organizing, structuring, presenting, or controlling the engineered system design development process.

- ORGANIZATION STRUCTURE: An organizational hierarchy that identifies function assignments to organizational entities, organizational entity relation-ships, roles, and authorities.

* SELECTED DESIGN: Design approach selected based upon technical recommendation and programmatic risks, life cycle costs, and other programmatic factors. 
Figure 9-5. Proress Overview - Organize Work.

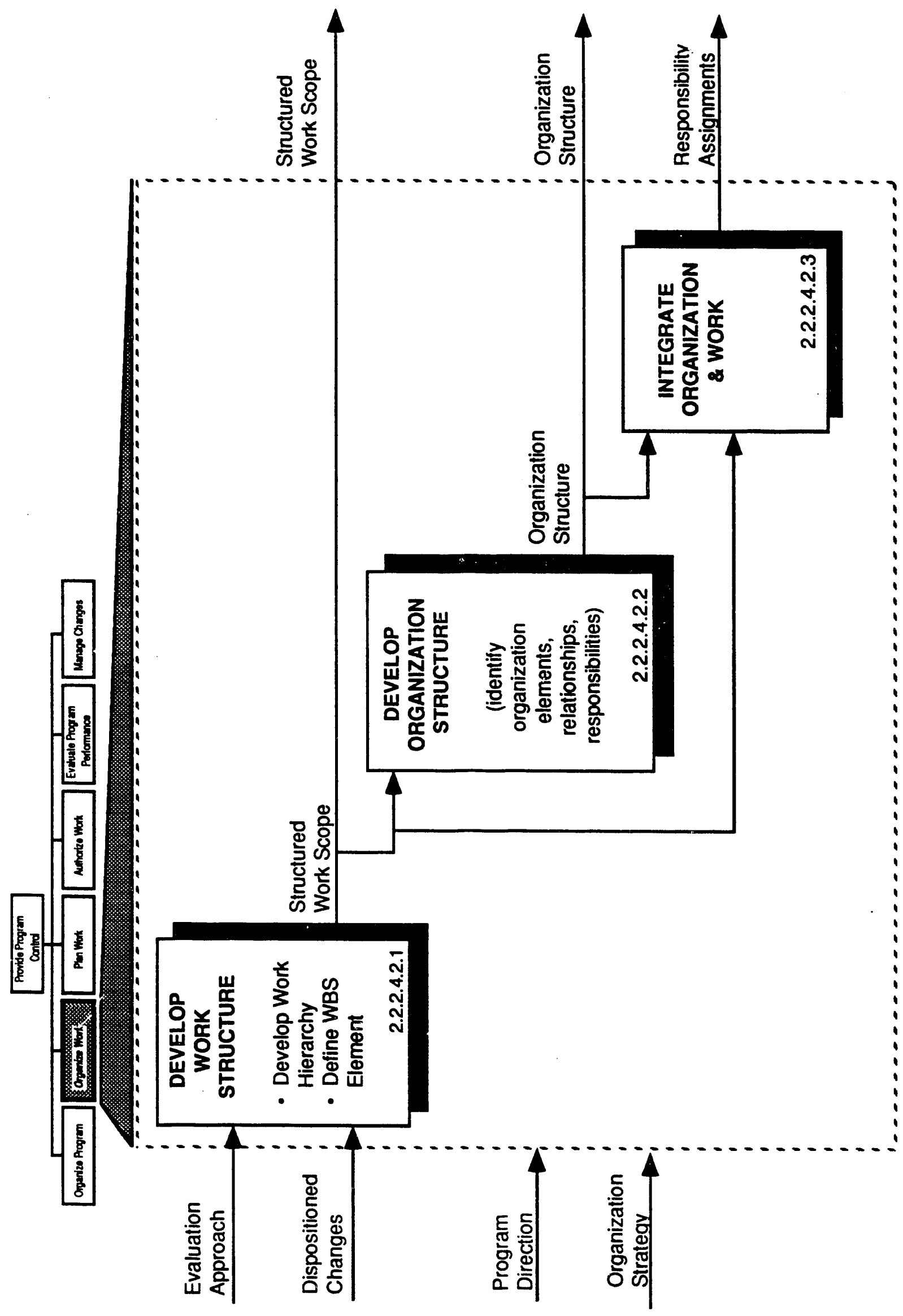


Subfunction Develop Organization Structure uses the previously developed organization strategy, and defines the organizational functions, entities. relationships, and responsibilities required to manage, administer, and perform program work. The organization structure includes al 1 aspects of implementing the NWMS program not just an organization responsible for program administration.

Subfunction Integrate Organization Structure, for each work scope in the hierarchy, assigns specific organizational responsibilities.

9.3.2.3 Outputs. Each of the three subfunctions provides a specific output as identified in the figure 9-5. The three outputs are as follows:

- Structured work scope: A product-oriented hierarchy with definitions of work elements. It includes a Work Breakdown Structure index and a Work Breakdown Structure dictionary. The dictionary is the composite of work scope descriptions for individual elements contained in the index.

- Organization structure: An organizational hierarchy that identifies functions, relationships, roles, and authorities.

- Responsibility assignments: Assignment of work scope to performing organizational entities.

9.3.2.4 Significant Considerations. The development of these elements for organizing the work is not conducted by a single organization. The implementation of these functional activities will involve personnel identified within each organization who are responsible for these planning and initial management activities. For example, the development of the initial Work Breakdown Structure, that is the implementation of the Organize Work subfunctions. could use personnel assigned to the organization responsibie for implementing system engineering activities. As the Work Breakdown Structure evolves to more detail, the Organize Work subfunctions could be implemented by personnel from the design and site characterization organizations.

\subsubsection{Plan Work}

9.3.3.1 Mission/Cbjective. The objective has the following three components:

- Provide a centralized understanding, awareness, and decision authority that balances the total program resource commitments in a way that i.s consistent with the priorities astablished by the program strategy and requirements.

- Provide a common definition of planning to be followed by all NWMS planning activities and combine these into integrated plans for accomplishing all NWMS work.

- Include in the plans the work logic, schedules, estimates, and budgets for all NWMS work.

9.3.3.2 Process Flow. Figure $9-6$ shows a simplified view of the subfunctional relationships within the Plan Work (2.2.2.4.3) function. The small inset in the upper left corner of the figure shows the relationship of Plan Work to the other functions that make up PPC. All of the information flows into and out of the Plan Work function are shown in the figure next to 
Figure 9-6. Process Overview - Plan Work.

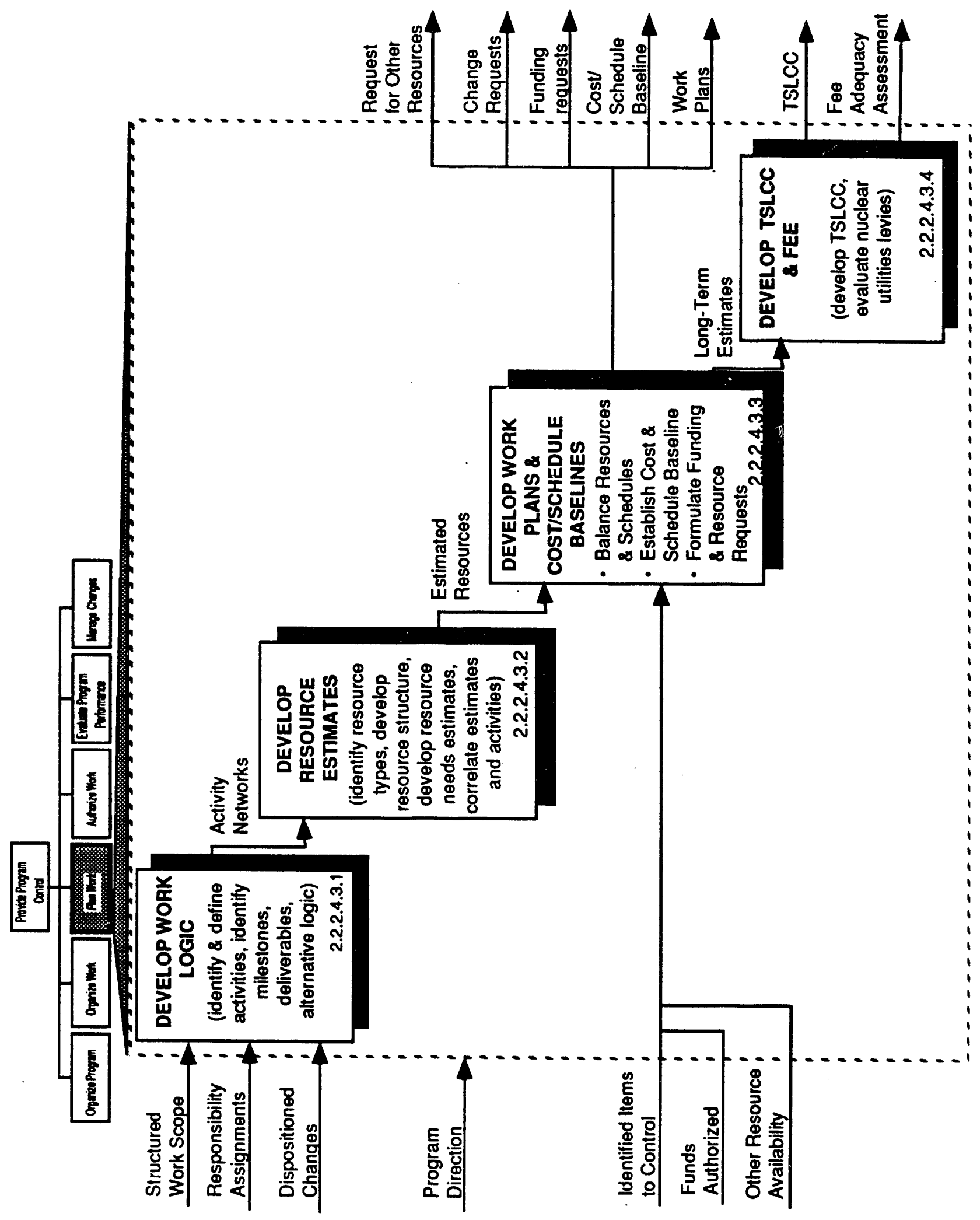


the dashed box enclosing the subfunctions. Within the dashed box the primary information flows between the Plan Work subfunctions are shown. The information paths shown in the figure are simplified representations of the information flow. Two types of path simplifications are made in the figure: In the first, the paths shown are the major information paths but are not all of the paths; and in the second, feedback paths are not shown. Both of these simplifications provide a focus on the process flows. The details of the flows are provided in the functional analyses corresponding to the Plan Work function [see Volume 2 of The Analysis of the Program to Develop the Nuclear Waste Management System (Woods 1991a)].

The first two subfunctions process the work scopes and responsibility assignments to identify the pieces of information required for planning. The third subfunction combines these pieces with information on the availability of funds and other resources to balance the schedules and budgets into an acceptable set of plans. The fuurth subfunction produces two specific products required by the nature of the NWMS, the total system 1 ife cycle costs and a fee adequacy assessment.

Subfunction Develop Work Logic translates the work scopes into specific activities, milestones, deliverable items, identifies external interfaces and constraints for the activities, and develops activity networks by identifying the logical interrelationships among the activities.

Subfunction Develop Resource Estimates identifies the types of resources required (e.g. manpower, facilities, equipment, computer time, etc.); develops a structure to organize the resource types and associated resource requirements; develops estimates for the resource requirements: provides estimates in various units such as work hours. person-days/months/years. amount of material. amount of equipment, etc.: establishes cost figures for each estimate; and ties the cost estimates back to the activity networks, that is, develops resource-loaded activity networks.

Subfunction Develop Work Plans and Cost/Schedule Baselines integrates and balances the resource-loaded activity networks with information on available funds and other resources and develops program plans from the balanced resource results and the work scope statements with the associated activities, milestones, and deliverables. The plans include all information needed to identify the time- and resource-phased expected progress of the program activities. The subfunction uses the information. Identified Items to Control provided by the Manage Changes function, to estabiish the cost and schedule baselines from the program plans, and then develops long-term estimates of resource expenditures.

Subfunction Develop TSLCC and Fee Adequacy translates the long-term resource expenditure estimates into the format required for a total system life cycle cost and evaluates the levels and timing of fees levied against the nuclear utilities to determine if adequate funds (fee adequacy) will be available when required.

\subsubsection{Outputs. The Plan Work function produces the following three types} of outputs:

- Request outputs: The Funding Requests and Requests for Other Resources go to MSIS functions outside the PPC function and receive responses back from the same functions. Both information paths make the requests based on integrated assessments of the program needs. The Change Request output is provided to another 
PPC function, Manage Changes, which determines the impact of work plan. baseline, or other changes on the total program. The Manage Changes response to the change request is received by plan Work on the Dispositioned Changes information path.

- The work plans and baseline outputs provide informatior chat is based on program-wide considerations: they are linked directly to the program mission and regulatory requirements.

- The two formal reporting outputs are the total system life cycle costs and the fee adequacy assessment information paths, which are used for relations external to the NWMS program.

9.3.3.4 Significant Considerations. The Plan Work functions define functions that all organizations in the NWMS program must implement. In a way similar to the Organizing Work efforts that define lower-level Work Breakdown Structure elements, no single organization will do all the planning for the program. The functions described here serve as a structure for each organization that does planning. The integration of all the aspects of the planning will be conducted in a way that is consistent with this distributed. but centrally defined. planning.

The integration and central control of this distributed planning activity is inherent in two aspects of the PPC functional hierarchy. First, the Organize Work function integrates work scopes, organization structures. and responsibility assignments, which inherentiy provides an integrated basis for all planning activities. Second, within the Develop Plans and Cost/Schedule Baselines function are subfunctions for balancing resources and schedules, which requires a programmatic implementation with a single organization integrating all other organizations' planning efforts.

\subsubsection{Authorize Work}

9.3.4.1 Mission/Objective. The objective is to control the program by assuring consistency among the work plans and all elements necessary to initiate those plans before authorization of any activities.

\subsubsection{Process Flows. Figure 9-7 shows a simplified view of the} subfunctional relationships within the Authorize Work (2.2.2.4.4) function. The small inset in the upper left corner of the figure shows the relationship of Authorize Work to the other functions that make up PPC. All of the information flows into and out of the Authorize Work function are shown in the figure next to the dashed box enclosing the subfunctions. Within the dashed box the primary information flows between the Authorize Work subfunctions are shown. The information paths shown in the figure are simplified representations of the information flow. Two types of path simplifications are made in the figure: In the first, the paths shown are the major information paths but are not all of the paths; and in second. feedback paths are not shown. Both of these simplifications provide a focus on the process flows. The details of the flows are provided in the functional analyses corresponding to the Authorize Work function [see Volume 2 of The Analysis of the Program to Develop the Nuclear Waste Management System (Woods 1991a)].

The subfunctions in Authorize Work check the work plans against available resources and funds, regulatory authorizations, and the current program status to determine if all the necessary prerequisites are ready for 
Figure 9-7. Process Overview - Authorize Work.

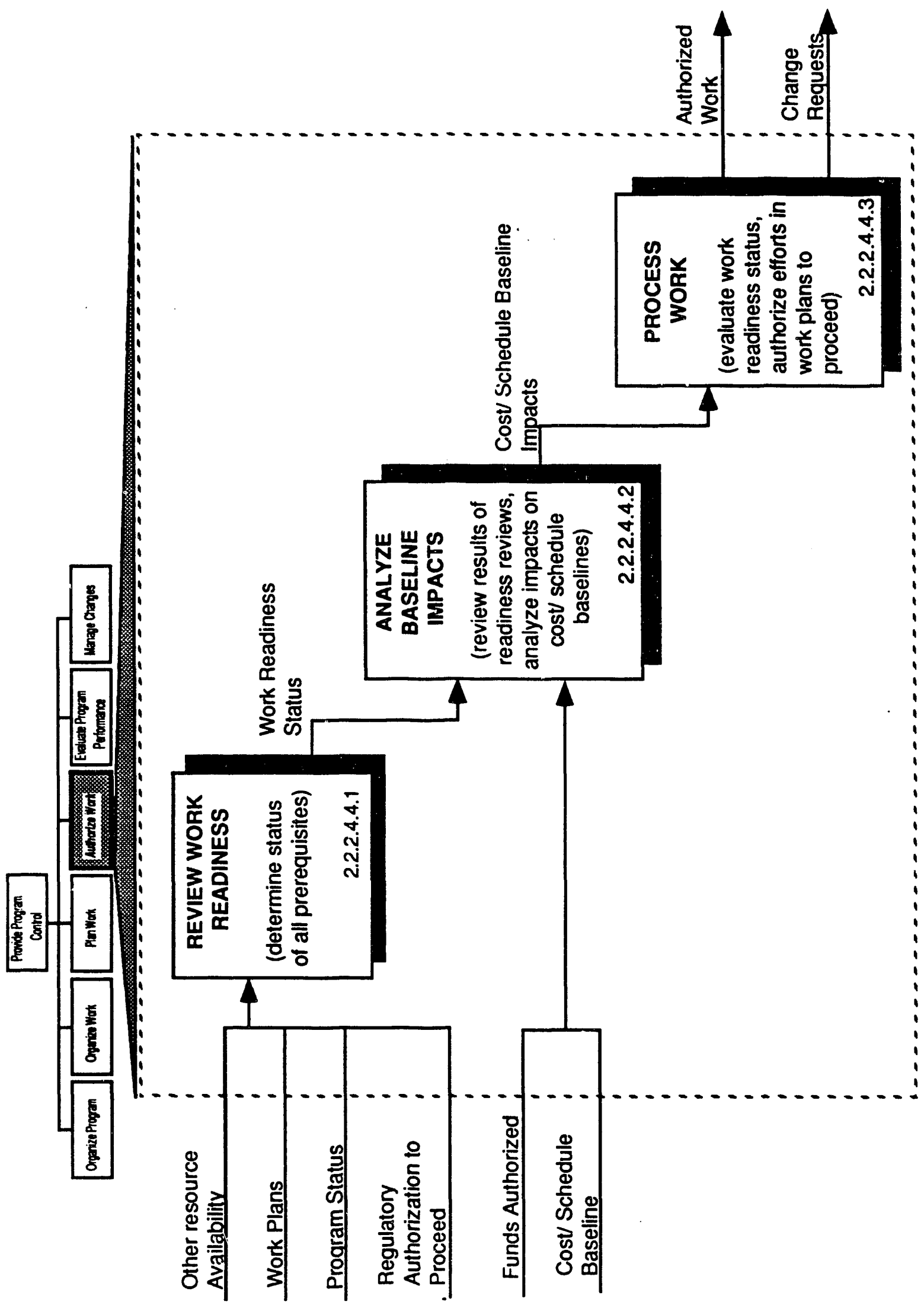


the work to begin. If the prerequisites are in order, and if the work to be authorized will not negatively impact the cost/schedule baseline, the work will be authorized.

Subfunction Review Work Readiness determines if the other resources (nonfunding resources) necessary to initiate the work plans are available. determines if any regulatory authorizations are necessary and if so that they have been obtained, and determines if the current program status and the planned work are consistent.

Subfunction Analyze Baseline Impacts determines if the work plans will adversely affect the cost/schedule baselines.

Subfunction Process Work Authorization generates the work authorization if readiness and impacts are acceptable and generates a change request if some aspect of readiness or baseline impacts prevent the existing work plan from being authorized.

9.3.4.3 Outputs. The Authorize Work function has two outputs. One is the authorized work. which is composed of the work plans that have been found to be acceptable. The other output is a change request indicating that the work plans could not be authorized and requesting that specific changes be made to work plans, resource requests, or other program elements that prevent the authorization.

\subsubsection{Evaluate Program Performance}

9.3.5.1 Mission/Objective. The objective is to ensure that the program objectives are met by determining the degree to which the program plans have been successfully implemented and by developing corrective actions for the aspects of the plans which have not been successfully met.

\subsubsection{Process Flows. Figure 9-8 shows a simplified view of the} subfunctional relationships within the Evaluate Program Performance (2.2.2.4.5) function. The small inset in the upper left corner of the figure shows the relationship of Evaluate Program Performance to the other functions that make up PPC. All of the information flows into and out of the Evaluate Program Performance function are shown in the figure next to the dashed box enclosing the subfunctions. Within the dashed box, the primary information flows between the Evaluate Program Performance subfunctions are shown. The information paths shown in the figure are simplified representations of the information flow. Two types of path simplifications are made in the figure: In the first. the paths shown are the major information paths but are not all of the paths; and in the second, feedback paths are not shown. Both of these simplifications provide a focus on the process flows. The details of the flows are provided in the functional analyses corresponding to the Evaluate Program Performance function [see Volume 2 of The Analysis of the Program to Develop the Nuclear Waste Management System (Woods 1991a)].

Within the Evaluate Program Performance subfunctions, the status of all program functions is compiled and compared with the planned performance. Any undesirable variances between actual and planned performance are analyzed to determine the causes and the impact on the total program. Any variances that 
Figure 9-8. Process Overview - Evaluate Program Performance.

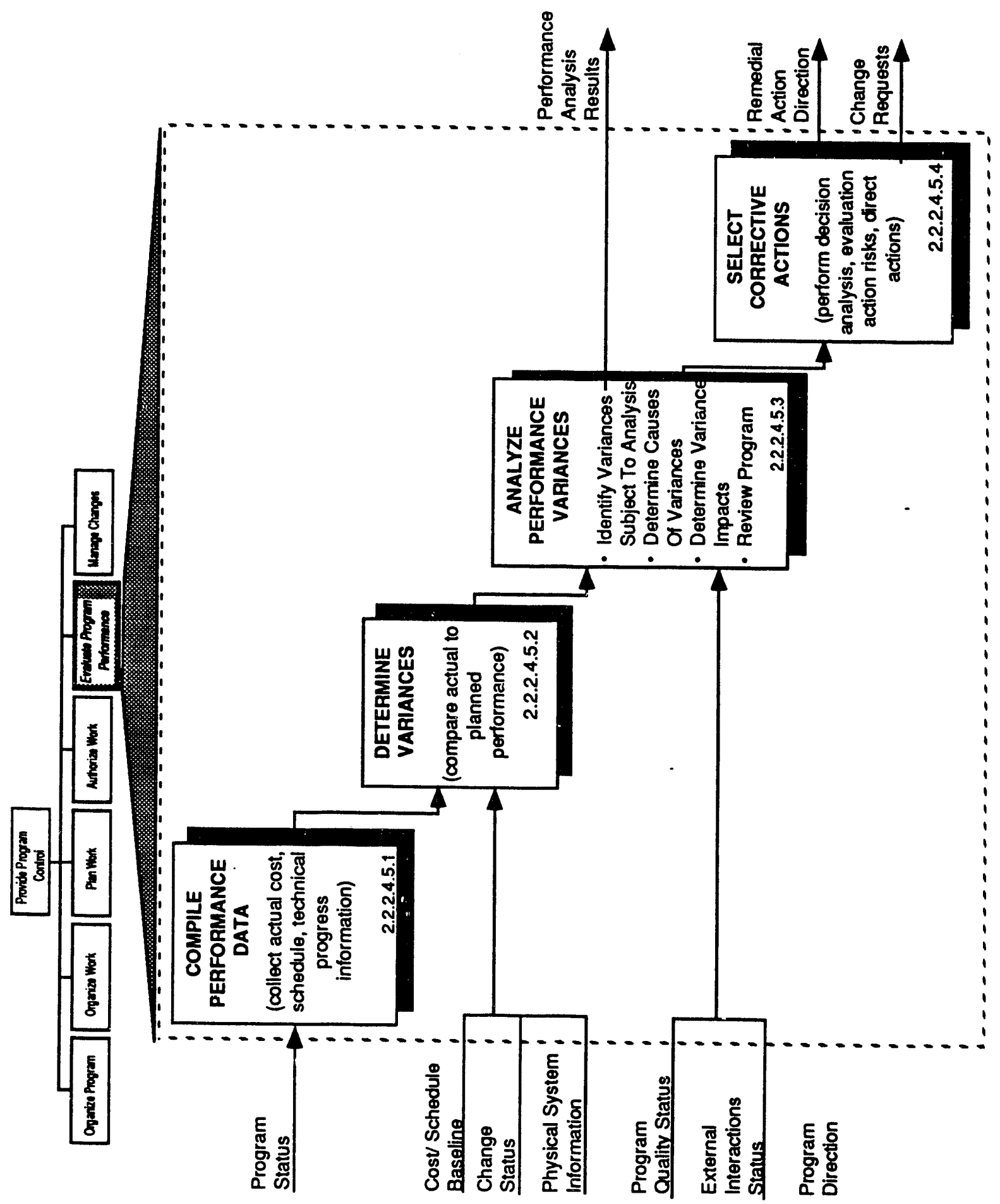


are found to have undesirable program impacts are analyzed further to determine appropriate corrective actions. The activities for each subfunction shown in Figure 9-8 are as follows:

- Subfunction Compile Performance Data

- From all other NWMS organizations conducting authorized work. collect the actual cost. schedule, and technical progress.

- Determine the extent of the work scope that has been completed.

- Subfunction Determine Variances

- Compare the actual cost. schedule, and technical progress with the planned performance.

- Identify differences between actual and planned performance.

- Subfunction Analyze Performance Variances

- Establish thresholds for acceptable variances from planned performance.

- Use values of identified variances to project future performance.

- For those variances whose projected future performance exceeds thresholds determine the root causes of the variance. The determination of these root causes is conducted by the organizations responsible for the performance item.

- Determine the total integrated program impact of the variances exceeding the thresholds including cost. schedule, technical, and programmatic impacts.

- Develop alternative actions to correct the root causes of the variances and to mitigate the integrated program impacts.

- Subfunction Select Corrective Actions

- Using decision analysis, compare the alternative corrective actions within the framework of the program mission. strategy, and requirements.

- Select the most acceptable corrective actions.

9.3.5.3 Outputs. The Evaluate Program Performance function has the following three outputs:

- The Performance Analysis Results are an assessment and compilation of variance magnitudes, causes, and impacts of those variances and alternative corrective actions. They also include identification 
of potential corrective action alternatives and identification and assessments of risks associated with each corrective action.

- The Remedial Action Direction output is a set of instructions and constraints describing actions required to recover or mitigate the effects of the identified program variance. The Remedial Action Direction is limited to actions that do not affect controlled items.

- The Change Request output is applied to remedial actions that affect controlled items in the program.

\begin{abstract}
9.3.5.4 Significant Considerations. The Organize Work and Plan Work functions both use the program direction requirements derived from program strategy and compliance requirements as the basis for an integrated program. The Evaluate Program Performance function closes the loop around the Organize Work and Plan Work established integrated program. It does this by evaluating all aspects of the NWMS program as an integrated whole against performance requirements, i.e.. work scopes and plans developed by organize Work and Plan Work. The result is that the functions enforce a program that is requirements-driven and is based on meeting the primary NWMS mission as constrained by the regulatory requirements.
\end{abstract}

\title{
9.3.6 Manage Changes
}

9.3.6.1 Mission/Objective. The objective is to control all changes to the program so that proposed changes to the program are evaluated for total system impact and approved changes are promulgated throughout the program and implementation is tracked.

\subsubsection{Process Flows. Figure $9-9$ shows a simplified view of the} subfunctional relationships within the Manage Changes function. The small inset in the upper left corner of the figure shows the relationship of Manage Changes to the other functions that make uP PPC. All of the information flows into and out of the Manage Changes function are shown in the figure next to the dashed box enclosing the subfunctions. Within the dashed box the primary information flows between the Manage Changes subfunctions are shown. Two types of path simplifications are made in the figure: In the first. the paths shown are the major information paths but are not all of the paths: and in the second, feedback paths are not shown. Both of these simplifications provide a focus on the process flows. The details of the flows are provided in the functional analyses corresponding to the Manage Changes function [see Volume 2 of The Analysis of the Program to Develop the Nuclear Waste Management system (Woods 1991a)].

The first two subfunctions in Manage Changes establish the structure for evaluating changes by identifying and categorizing by control level, the items in the program subject to control. Using this structure, the third subfunction receives and evaluates the change requests and the fourth subfunction determines the disposition of the change. The fifth subfunction monitors the status of changes. Descriptions of each subfunction shown in Figure $9-9$ are as follows:

- Subfunction Define Change Control Approach uses the program direction information to:

Develop criteria and methods for managing changes. 
WHC-EP-0482

This page intentionally left blank. 


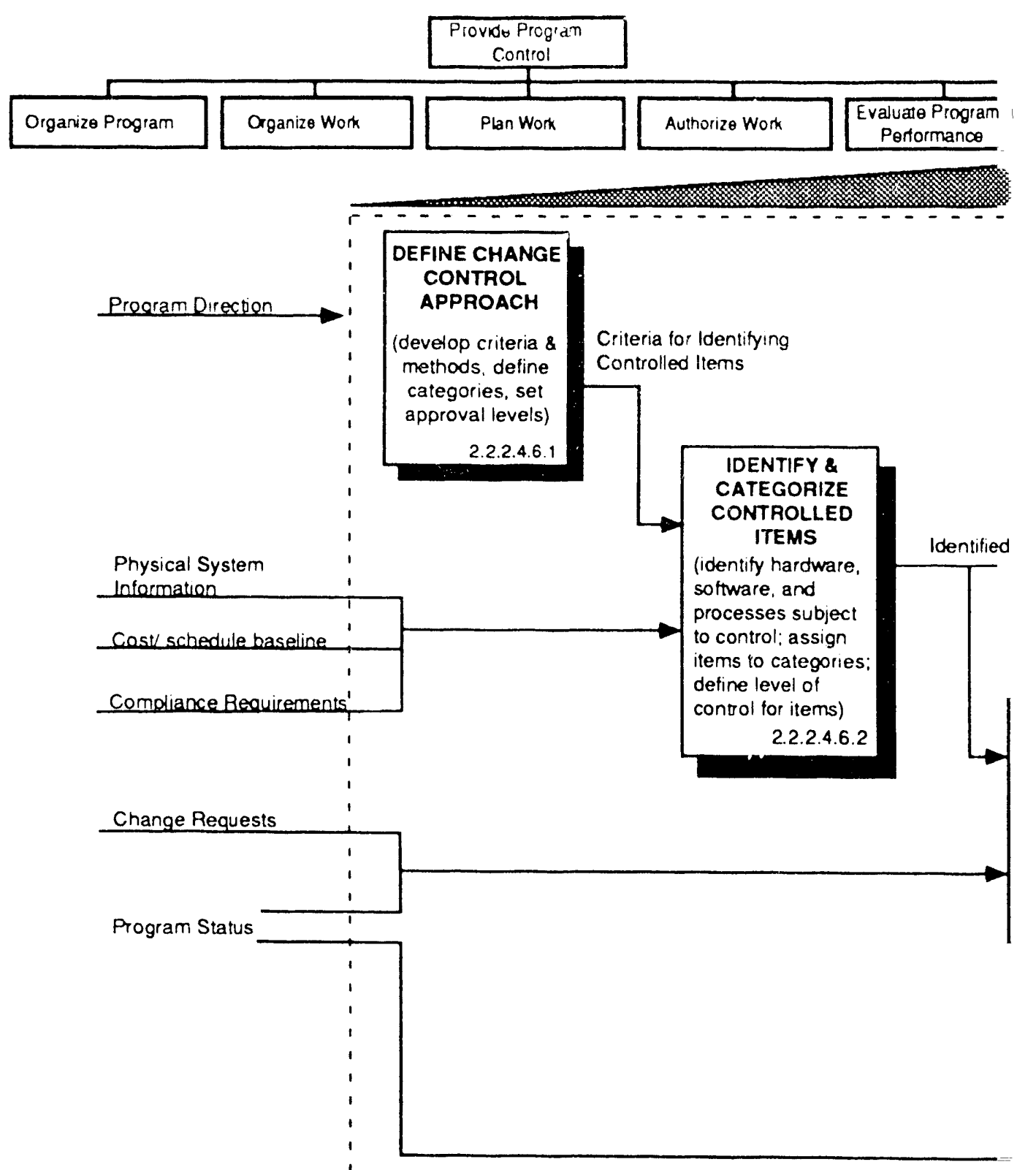


Figure $9-9$. Process overview Manage Changes.

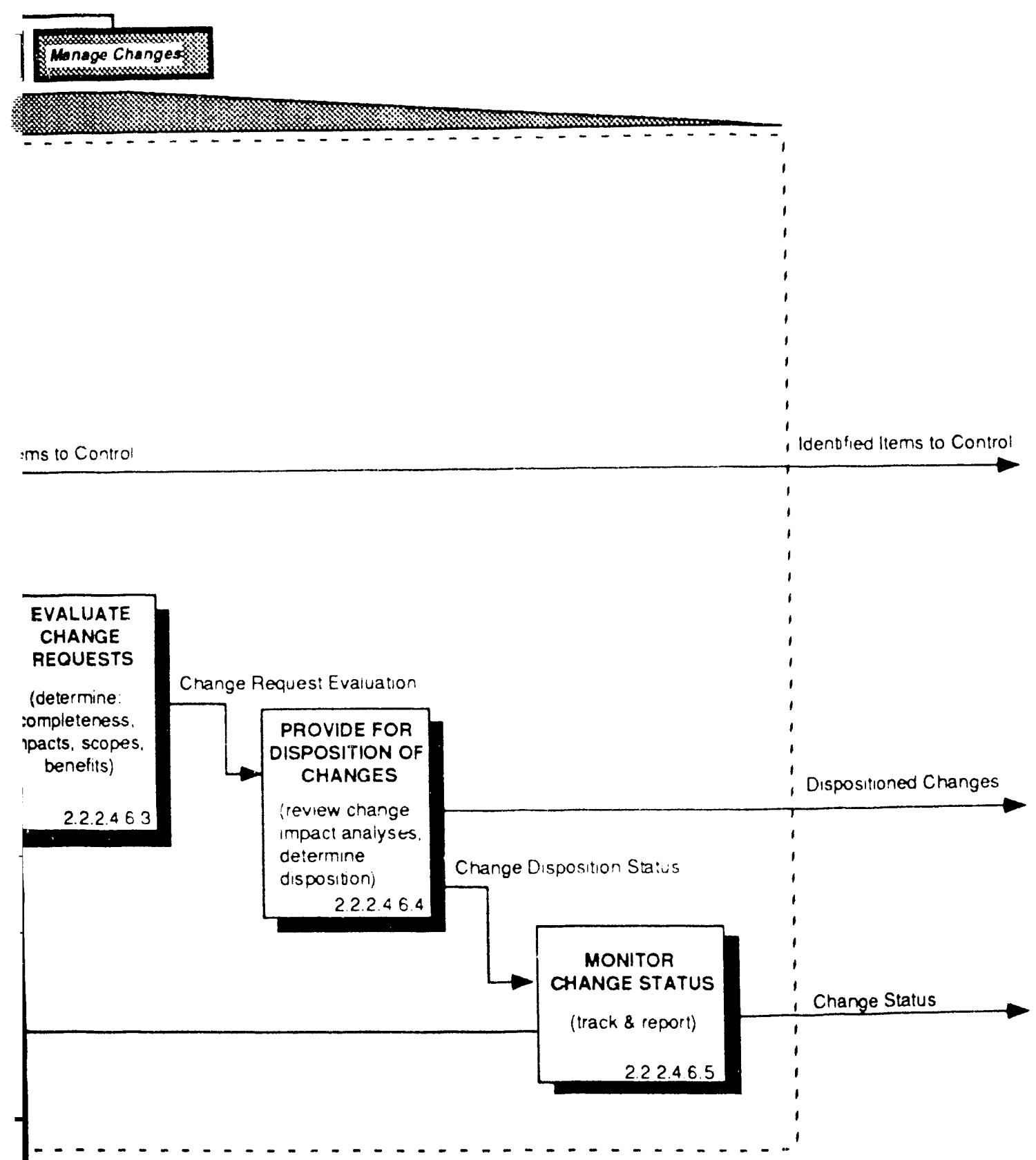


- Define control categories associated with the change management methods.

- Develop thresholds for approval levels.

- Establish change request package format.

- Develop the process to be followed in receiving. categorizing, evaluating, and dispositioning change requests and tracking changes.

- Subfunction Identify and Categorize Controlled Items follows the defined process using inputs from the cost/schedule baseline and the compliance requirements to review the physical system information to:

Identify hardware, software, and processes that are subject to change control.

- Assign the identified items to the change control categories defining the ievel of control to be applied.

- Select those items subject to change control.

Subfunction Evaluate Change Requests processes the received change requests using the defined process and the controlled items categorization to:

- Determine completeness of the change request package.

- Determine similarity to other in-process change requests and consolidate requests, where appropriate.

- Prioritize processing of change requests.

- Establish the level of analysis required to evaluate the requests based on the level of requirements, design, cost. schedule, or programmatic process affected.

- Analyze the requests to determine the impacts on cost. schedule, technical, and programmatic entities and then analyze program risks and determine the benefits.

- Subfunction Provide for Disposition of Changes processes the change request evaluation results to:

- Assess the results of the impact analyses to determine the most acceptable disposition of the change requests.

- Accept, reject, or request modifications to each request.

- Subfunction Monitor Change Status continually processes the program status information with the change evaluation status and the change disposition information to determine status of the change request from the point the change is identified until the change disposition is implemented. 
9.3.6.3 Outputs. Two of the three outputs from Manage Changes inform the requesting organizations of the status and disposition of the changes they requested. The third output Identified Items to Control is provided to the Plan Work subfunction of PPC to identify those items that are subject to control. Plan Work uses the information to develop the cost/schedule baselines.

9.3.6.4 Significant Considerations. Like many of the other PPC subfunctions. the Manage Changes function is iterative. Early in the program. the process used to control the change requests is developed and initial items to be controlled are identified. This information is provided to another PPC subfunction. Plan Work which creates the cost/schedule baselines. A later iteration of Manage Changes uses the newly created or updated cost/schedule baseline to refine the list of identified items to control.

The Change Request input serves as a primary information path from other MSIS functions back to PPC. All MSIS functions can generate a Change Request, which is a request to alter any of the controlled items in the program. Program requirements represent an important category of controlled items. For example. al1 MSIS functions receive Program Direction. which constrains and directs how that function can operate. A function generates a Change Request if the function determines that the Program Direction requirements cannot be met, or that if the requirements were changed, the function implementation could be improved. The Manage Changes function determines the disposition of the requested change with one possible change being a change in Program Direction. Figure 9-2 shows the Change Requests originating from four functions. All other functions request changes within the Plan work function. As described in the Plan Work discussion in Subsection 9.3.3, all functions and the implementing organizations use the planning functions described in Plan Work. As each function and organization develops or upuates work plans and cost/schedule baselines, the need for requesting changes, including relief from Program Direction, is identified. A Change Request will be generated within the Plan Work subfunction Develop Work Plans and Cost/Schedule Baseline by the function/organization conducting the plarning.

\subsubsection{Internal Feedback}

Figure 9-10 shows the top three hierarchy levels of PPC. Heavier. numbered lines on the figure show the feedback paths that occur within each hierarchy level. These paths indicate how the functions can request changes to information or direction they have received from preceding functions.

Feedback path (1) in the figure is a major loop that communicates from the Manage Changes function to four of the other five PCC functions. The feedback provides Organize Plan. Organize Work. and Plan Work with change disposition information. This new information can cause these three functions to change outputs with the results varying from new program strategy and direction to changes in the orsanizational responsibilities and work packages. With the exception of Organize Work, any of the functions preceding Manage Changes can access the change disposition loop and communicate with a function that precedes it by sending a Change Request to Manage Changes. Any feedback that Organize Work needs can be provided through Plan Work. which can generate a Change Request. 
WHC-EP-0482

Figure 9-10. Provide Program Control - Major Feedback.

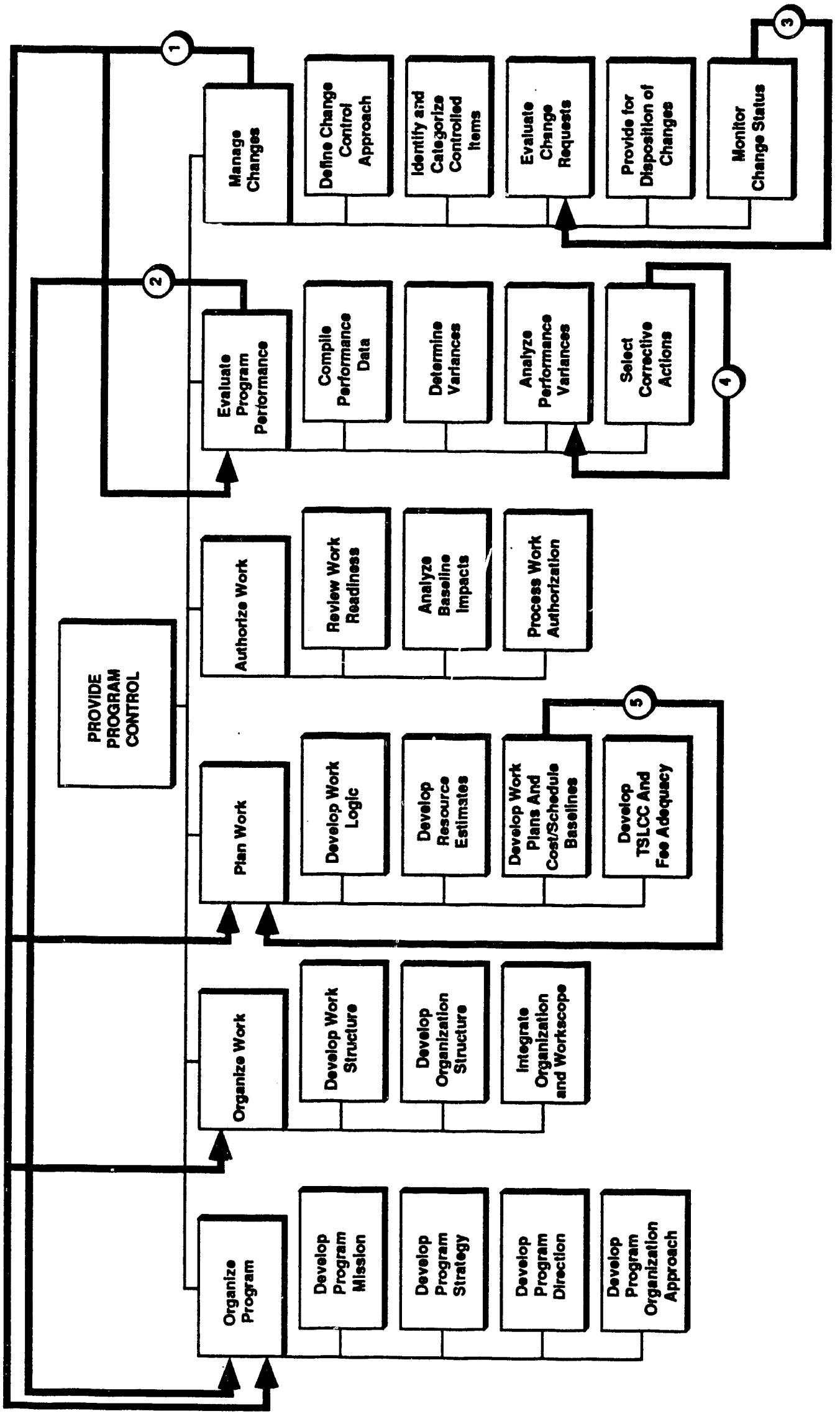


A second feedback is represented in loop (1) and provides change status information to Evaluate Program Performance which is used to evaluate the program at any point in time. A third feedback contains information on the program items to be controlled by the Manage Changes function. Organize Plan uses the information to update program direction. Plan Work uses this information to update work plans.

Feedback path (2) provides. Remedial Action Direction from Manage Changes to Organize Plan. This is another loop that can result in changes throughout PPC and the rest of the program functions. The Remedial Action Direction information results from the program evaluation process determining that some change in noncontrolled aspects of the program is required. The Organize Plan function can respond to the feedback with an update to program direction that can change the direction of other functions directly and can cause work packages and work authorizations to change through the organize Work. Plan Work. and Authorize Work functions.

The lower-level feedback paths of (3), (4), and (5) each provide slightly different types of feedback. Path (3) allows the change request evaluation process to stay apprised of the implementation of changes. Path (4)identifies the need for additional performance variance analyses in order for corrective actions to be selected. Path (5) allows for a request to modify the initial work logic to accommodate new needs identified by the work plan development processes. 
WHC-EP- 0482

\subsection{SPECIAL TOPICS}

During the conduct of the program functional analysis and the development of the process descriptions contained in this report. several significant themes were identified whose scope transcended the boundaries of the individual Management System Information Strategy (MSIS) functions and whose implementation required the coordination of multiple functions or linking of several process. These themes are presented in the following sections of this report as discussions of Special Topics. Each of the Special Topics represents an activity that was considered to have the potential for playing an important role in the success of the Nuclear Waste Management Strategy (NWMS) program. Therefore, a discussion of how the activity would be accomplished within the framework established by the program functional analysis is provided in the following subsections. These Special Topics are as follows:

- Design Control: This Special Topic discussion traces the elements of physical system design control through the MSIS functions and demonstrates that the control requirements of Quality Assurance Program Requirements for Nuclear Facilities (ANSI/ASME 1986) are reflected in the functions and in the processes identified in the functional analysis. This discussion also addresses the process of technical information management and control within the framework of the MSIS functions.

- System Test. Evaluation, and Verification: Test evaluation, and verification of a system as large as the NWMS is a complex process. This discussion traces the activities required to test. evaluate, and verify the performance of the physical system through the multiple MSIS functions that participate in these activities. The discussion includes the many functions that are involved in ensuring that the evolving design and construction of the physical system meet regulatory, performance, and compliance requirements.

- Scientific Risk and Uncertainty: The extent and heterogeneity of sites, as well as the required duration for waste containment within the engineered barriers and the controlled area, preclude acquisition of sufficient data to justify assertions of certainty to meet regulatory requirements: characterization will not eliminate all uncertainties. The discussion defines issues related to risk and uncertainty, identifies program functions in which these issues must be addressed. and proposes guidance for controlling the impact of uncertainties on acceptability of the physical system.

- Parallel Design Efforts: The design of the NWMS physical system. and its system elements. cannot be expected to occur as a single thread of activities, progressing from conceptual to as-built design. At any one time, there will be multiple design efforts underway, each at its own unique stage of development. This Special Topic focuses on the coordination and integration of multiple design activities. 
- Test Facility Design: This discussion describes the flow of events. from identification of the need for a test facility to the ultimate design and construction of such a facility, through the numerous MSIS functions involved. This Special Topic provides a basic example of how the MSIS functions and processes may be linked to satisfy a plansible program need. 
WHC -EP- 0482

\subsection{DESIGN CONTROL}

\subsubsection{Issue Overview}

Control of the system design and the design process is essential to the success of the Office of Civilian Radioactive Waste Managements (OCRWM) program and to the mission effectiveness of the Nuclear Waste Management System (NWMS) physical hardware.

- The design of the physical system must be licensed for waste acceptance, transportation, storage, and disposal.

- The licensing process submits the design, and the design process, to expert and public examination.

- The design process must produce a cost-effective and licensable design.

Regulatory agencies accept Quality Assurance Program Requirements for Nuclear Facilities (NOA-1) (ANSI/ASME NQA-1 1986) as a source document for Quality Assurance requirements. NOA-1 defines Design Control as follows:

"The design shall be defined, controlled, and verified. Applicable design inputs shall be appropriately specified on a timely bas is and correctly translated into design documents. Design interfaces shall be identified and controlled. Design adequacy shall be verified by persons other than those who designed them. Design changes, including field changes. shall be governed by control measures commensurate with those applied to the original design."

NQA-1 defines a set of topics that constitute an effective Design Control program. These topics are as follows:

- Design Process Control

- Design Input Control

- Design Verification

- Change Control

- Interface Control

- Documentation and Recordkeeping.

This section discusses each NOA-1 topic and explains how each is addressed in the functional analysis. In addition, the functional analysis considers the planning and control for design of the system as part of design control. The analysis is described in detail in The Analysis of the Program to Develop the Nuclear Waste Management System (Woods 1991a).

The functional analysis implements the NOA-1 requirements.

Because Design Control spans many MSIS functions, other sections of this report contain additional explanations relating to these topics.

- Section 2.0. "Overview of Integrated Functional Processes," describes the information interfaces between MSIS functions: the control mechanisms associated with the functional processes; and the relationship of the quality assurarice program to the analyzed functions. 
WHC-EP- 0482

- Section 3.0. "Perform Systems Engineering." and Section 8.0 "Ensure Regulatory Compliance," provide additional detail on requirements generation and traceability. the methods for interface management, and technical information documentation and control.

- Section 4.0. "Design Engineered Systems," and Section 6.0. "Evaluate Integrated System." provide details on specific steps in design generation, evaluation, and verification.

- Section 9.0, "Provide Program Control," describes methods for program evaluation and change management, program redirection, and replanning.

- Section 10.4. "Parallel Design Efforts." places the interface and design control methods in the program-wide context of parallel efforts addressing separate elements of the NWMS.

\subsubsection{Fundamental Approach}

The fundamental approach to design in the functional analysis implements Design Control across several MSIS functions. The following information provides a view of Design Control from the perspective of the NOA-1 topics. The definitions of the functions and the information flows among the functions reflect design control principles.

10.1.2.1 Design Process Control. NQA-1 defines the Design Process as the "Technical and management processes that commence with identification of design input and that lead to and include the issuance of design output documents." Figure 10.1-1 shows the major functions that participate in the design process and the general flow of information as Design Input evolves to Design output. The functional analysis implements the following design process principles:

- The design is mission-driven. The design process reflects the elements required to perform the required mission of waste acceptance, transportation. storage, and disposal. Design Control is implemented in the design process by top-down mission analysis.

- The design meets an integrated set of controlled requirements. Requirements constrain the design choices for fulfiliing the . mission. All requirements must be identified and traceable to the architectural elements that fulfill the requirements.

- The design is formally verified and performance must be demonstrated through technical reviews, inspections, analyses, and tests. Design is verified at all appropriate levels from the component level to total system.

- A Technical Performance Measurement (TPM) program and a System Evaluation program measure the technical capabilities of the evolving design. 
Figure 10.1-1. Information Flow in Controlling Design Process.

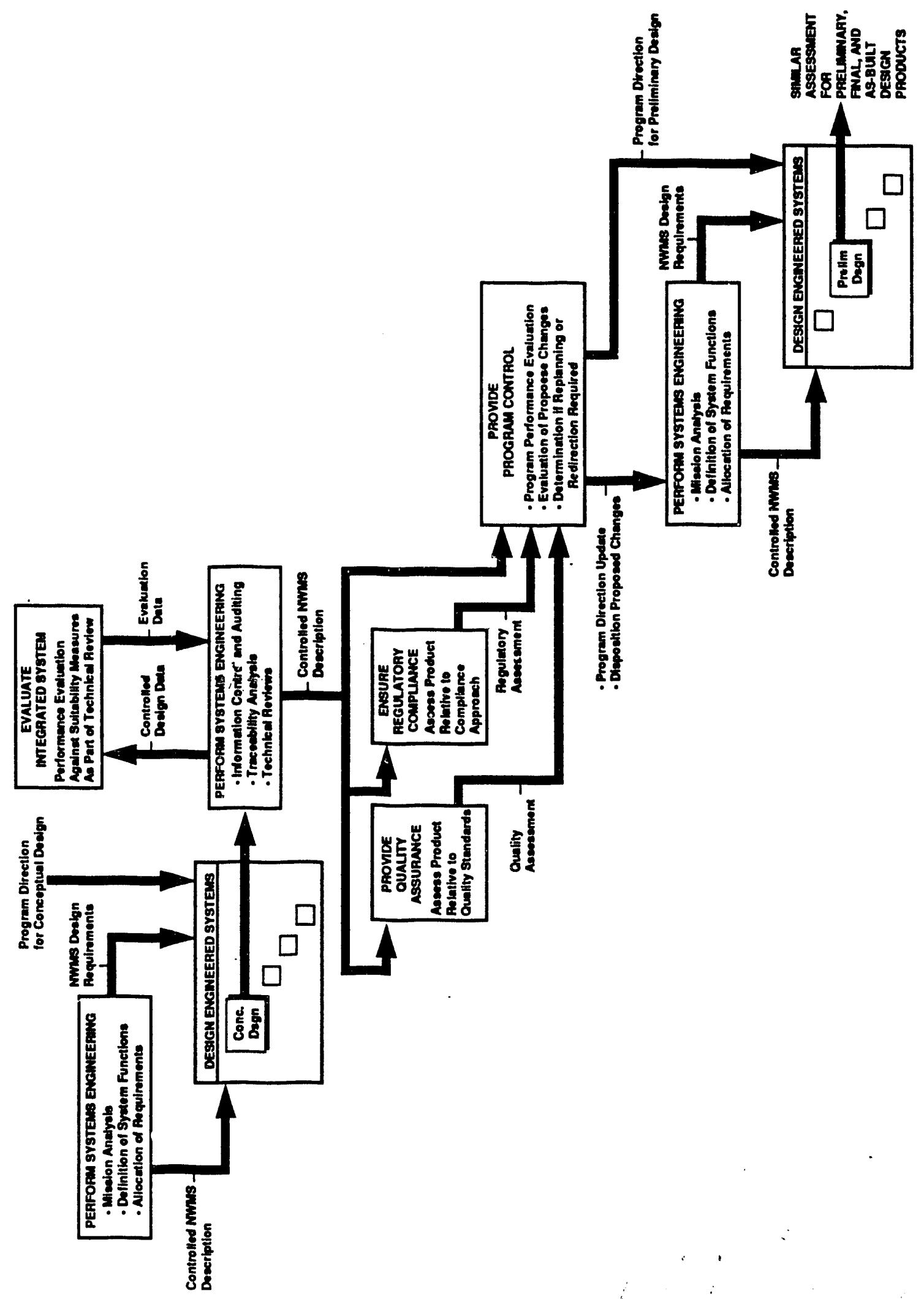


- The design process inherently imp?ements quality assurance standards. Good design practice and tre necessity to produce design products of acceptable and licensable quality guide the process in defining and executing the design engineering tasks. Periodic reviews of design processes determine if appropriate standard practices are being implemented.

- Design work is planned and controlled and ensures that the design activities are properly defined, structured, performed in proper sequence, performed with qualified resources. and use the appropriate procedures.

- Design avolves in steps to reduce program and design risk. The design evolves through three major steps - conceptual. preliminary, and final. Planned reviews evaluate the effectiveness of the design and the selected approach before committing resources to execute the next step.

- Design alternatives must be identified and compared to optimize design effectiveness, including cost and schedule considerations.

- Technical baseline management identifies, maintains, and controls the evolving functional and physical configuration. Results of eacll phase of design are approved and incorporated into the technical baseline.

10.1.2.2 Design Input Control. NQA-1 defines Design Input as "Those criteria, parameters, bases, or other design requirements upon which detailed final design is based." The functional analysis accepts this definition but extends design input to conceptual and preliminary design as well as final design. Design Input is also referred to as design requirements in the functional analysis. Figure 10.1-2 shows the MSIS functions and primary information flows relating to Design Input. As shown in Figure 10.1-2. the Provide Systems Engineering (PSE) function is the key cont. ol point for design input. This function receives design input information from several functions, consolidates and controls the input, and provides the design input directly to the Design Engineered System (DES) function.

The Ensure Regulatory Compliance (ERC) function performs the following:

- Derives regulatory requirements from statutory sources, resolves conflicts and ambiguities. provides regulatory interpretation, and establishes traceability of system mission requirements to laws and regulations.

- Develops an approach to compliance that may influence the design of the system.

- Maintains the regulatory requirements database and a qualified list of regulatory sources to ensure that changes to the externally imposed requirements are rapidly identified, evaluated, and incorporated into engineering planning and direction updates.

The Provide Program Control (PPC) function performs the following:

- Creates the overall NWMS development and acquisition strategy and implements the strategy in the form of design requirements where applicable. 
Figure 10.1-2. Design Input Control.

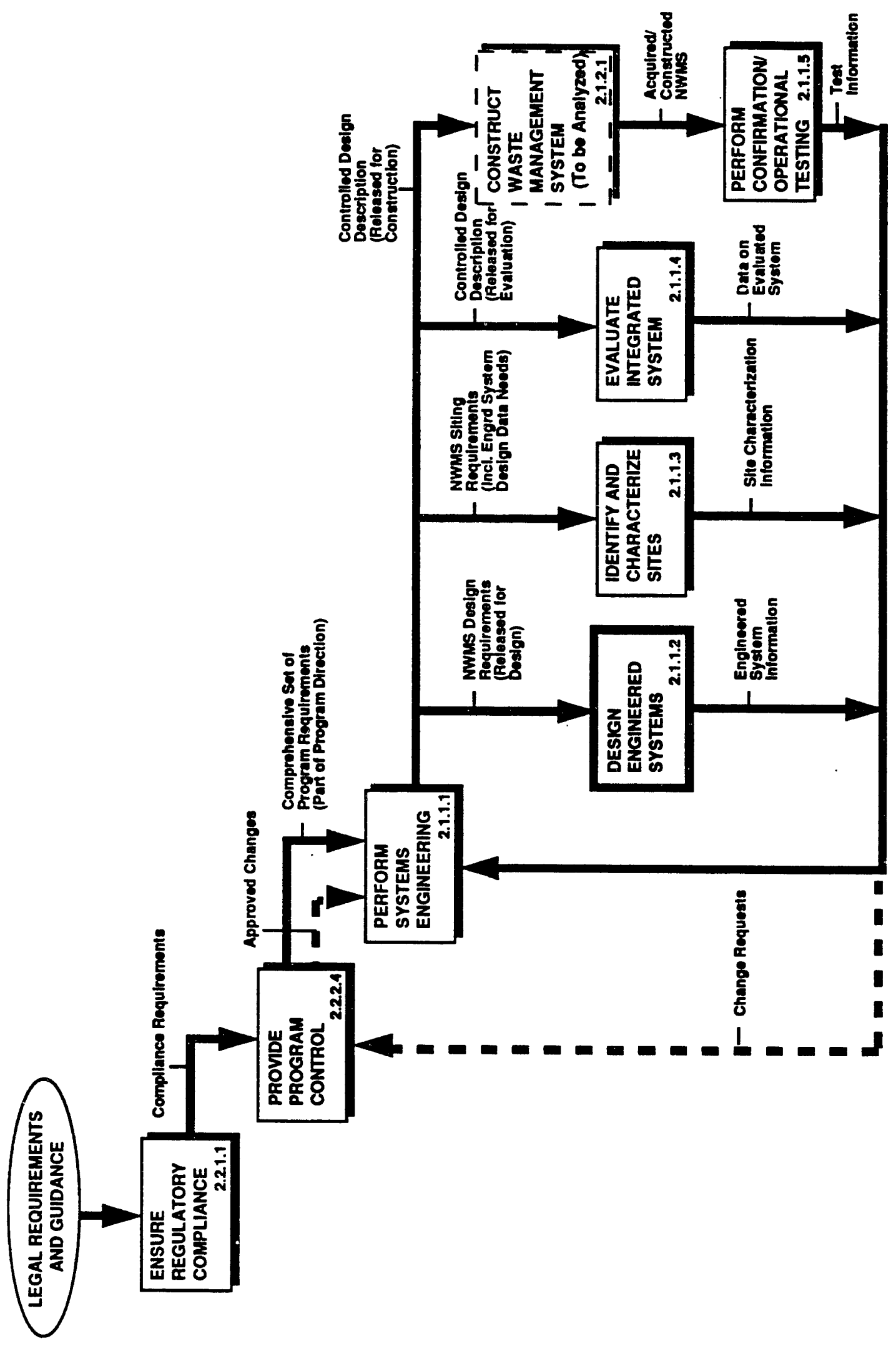


- Assembles compliance requirements and internally generated requirements (such as those requirements that evolve from the program strategy) into a comprehensive and cohesive set of requirements that will constrain and guide the program (a portion of which may be Design Input).

- Provides a focal point for change management where change requests are evaluated for total program impact. change disposition is determined, and design input (if affected) is controlled.

The PSE function performs the following:

- Converts technical system mission requirements into physical system performance requirements that can serve as the basis for design and thereby ensure-that the design is mission-driven.

- Controls the requirements that constrain the design, supports the traceability of externally imposed requirements to their sources. and maintains traceability and control of the requirements generated during the design process.

- Provides a focal point for all design input by evaluating potential design input from a total physical system viewpoint and controlling the release of design inputs.

- Maintains all requirements and the developing design architecture as. a controlled Design Reference in the form of technical baselines.

- Allocates functional requirements to each physical system function. which is then used to develop the design requirements for the architecture that will perform the function.

- Evaluates change requests for technical impact on requirements and design input, and provides the evaluations to Program Control for change management.

The Identify and Characterize sites (ICS) function performs the following:

- Maintains a design input loop wherein the engineered design requires information about the natural configuration of sites. The site characterization process provides that information. The PSE function integrates the natural and engineered attributes to develop the design inputs.

The Evaluate Integrated System (EIS) function performs the following:

- Evaluates the system design relating to achievement of system performance requirements and recommends changes to design features (and, thereby, design irputs) that may improve system performance.

10.1.2.3 Design Verification. NOA-1 defines Design Verification as "The act of reviewing, inspecting, testing, checking, auditing, or otherwise determining and documenting whether items. processes. services, or documents 
conform to specified requirements." The functional analysis implements Design verification by means of a TPM program. an independent system evaluation program, and a centralized compliance review program.

The TPM program encompasses the following:

- TPM is defined as "the portion of design assessment which estimates, through engineering analyses and tests, the values of essential performance parameters of current design of work breakdown struciure product elements" in the System Engineering Management Guide (Defense Systems Management College 1990).

- TPMS are defined in the PSE function and are provided to DES function as part of the NWMS design requirements.

- The TPMS provide early detection of potential design problems by monitoring. measuring, forecasting, and identifying system performance attributes that will not meet design requirements.

- Figure 10.1-3a shows the functional sequence in the TPM program as follows:

- The PSE function develops the system performance measures including the TPMs, verifies that these are consistent with the system structure definition, and establishes control over the definitions of the measures.

- The DES function and ICS function generate estimates of the TPM values. As the program evolves, the design and site characterization functions refine the TPM estimates to reflect the new knowledge about the design and the site.

- PSE receives the evolving TPM estimates, controls them, and provides them to the ERC and PPC functions.

- ERC monitors the TPMS to identify any issues related to the system's compliance ability. If issues are identified. ERC notifies the PPC function of the specific problem. The Program Control function evaluates the variances for total program impact and redirects the program where necessary.

The Independent System Evaluation program encompasses the following:

- The independent system evaluation program is the set of activities that independently and formally verifies that the NWMS complies with regulatory requirements. These evaluations are independent of the evaluations conducted within the DES function as part of the design process. The independent evaluation includes evaluating the performance of individual elements and subelements of the NWMS to develop assessments of the total system performance. This program is implemented in the EIS function and the ERC function.

- Several functions in the NWMS collect evaluation data that are used by the EIS function to perform the integrated evaluations and assessments. The assessments identify performance variances from the system requirements. Recommendations are made for correcting adverse variances. 
Figure 10.1-3a. Design Verification - Functional Sequence.

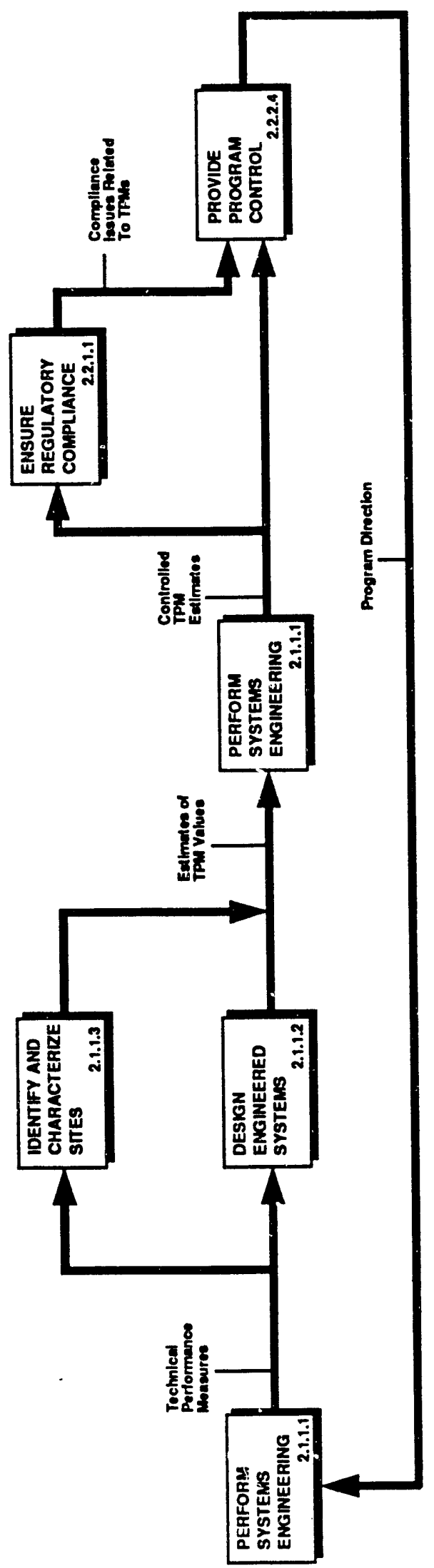


WHC - EP- 0482

- Figure 10.1-3b shows the functional sequence for the independent evaluation of design verification.

- The PSE function develops system performance and verification requirements.

- The EIS function performs a variety of processes uepending on the maturity of the system. Early in the program, the function develops an evaluation approach and defines references for the evaluation processes. These references include the following:

- Descriptions of the items, configurations, and interfaces to be evaluated

- Definitions of the mission scenarios and environments to be used in conducting the evaluations and analyzing the data

- Specific suitability measures and the associated data requirements for providing values of the suitability measures

-. Data needs for verifying the evaluation methods and for evaluating the system performance.

Later in the program, the EIS function receives, through the PSE function, the data collected by other MSIS functions. These other functions are DES, ICS, and Perform Confirmation/Operational Test (PCOT). The EIS function then does the following:

- EIS establishes the acceptability of the evaluation methods and analyzes and assesses the integrated system performance relative to the requirements.

- EIS identifies adverse variances in the integrated system performance and recommends corrective actions.

The PSE function controls the output from EIS and develops requirements for collecting data.

Initially, the DES and the ICS functions collect the required data. After submittal of the License Application, the PCOT functio: assumes the site data collection activities. After acceptance of the facilities and hardware at the operational locations, ti.e PCOT function assumes the engineered system data collection activities.

The data collection functions feed the data back to the PSE function and the PSE, in turn, sends controlled data to the following two places: One is the EIS function, which conducts the type of activities described above, and the other is the ERC function, which continues monitoring the evaluation processes.

The PPC function integrates and reviews the system cost, schedule, and technical evaluations. The results from the integrated review can generate direction to PSE to correct any technical problems. 
WHC-EP-0482

Figure 10.1-3b. Design Verification - Independent Evaluation Functional Sequence.

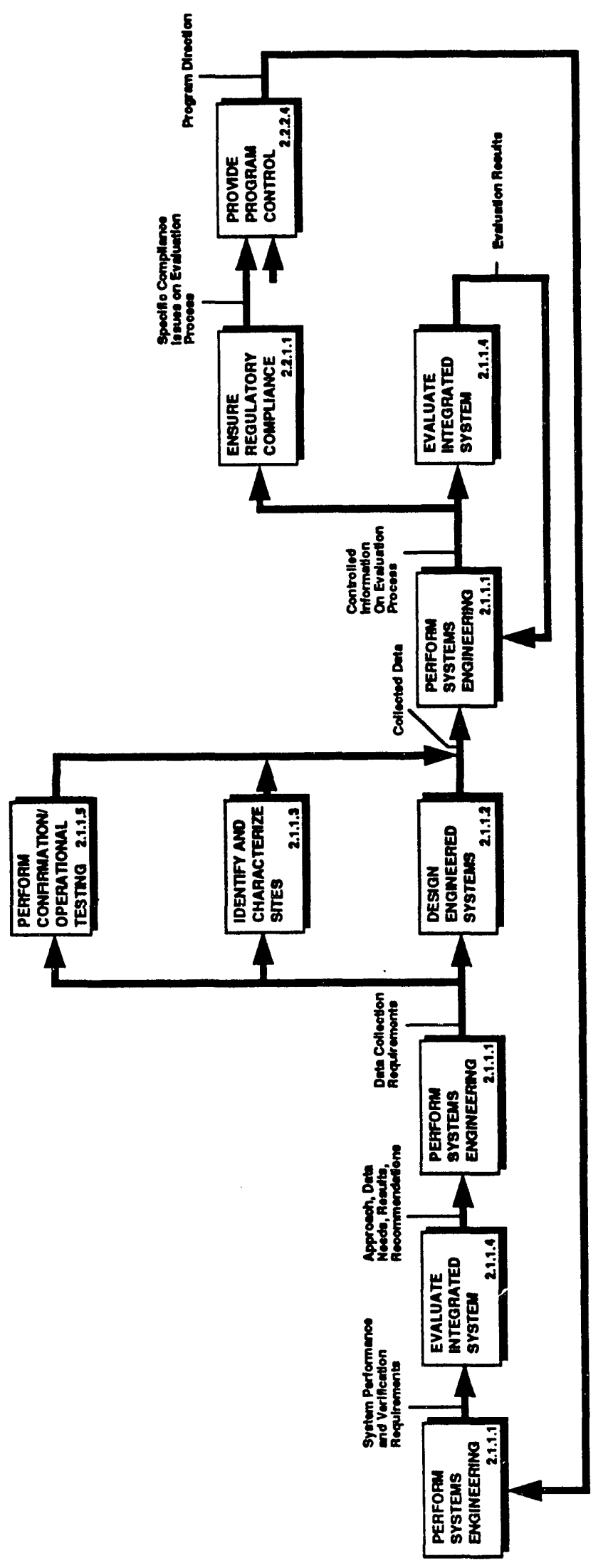


WHC -EP- 0482

The Centralized Compliance Review program monitors the activities of the independent evaluation program to determine if the independent evaluation will demonstrate program compliance with regulatory requirements.

The five significant design verification elements that are implemented in these programs are as follows:

- Technical information auditing and management identify all changes and evaluate technical data for completeness.

- Technical reviews ensure that the design is meeting current requirements in the most effective manner.

- Regularly scheduled technical reviews provide timely identification of issues. Design input and design tasks are adjusted accordingly to maintain technical focus.

- Ensure interface control by verifying that all elements of the system operate in concert.

- Audits verify that traceability is established and documented between each configuration item and the requirements that generated the item, and that design documentation is complete.

10.1.2.4 Change Control. Effective design change control requires defining and maintaining a technical baseline, critical examination of proposed changes to that baseline, and knowledgeable management decisions regarding the disposition and implementation of the changes.

Technical Baseline definition maintains a consistent representation (e.g.. descriptions, drawings, computer images, and analytic results) of all items that require configuration control. Technical Baseline definition includes the following three elements:

- Identifying and categorizing specific program items to be controlled. This includes identifying hardware, software, and processes that are subject to control and assigning those items to change control categories.

- Defining a change control approach that defines categories of change control. establishes thresholds governing approval levels. and develops change control evaluation criteria.

- Maintaining current, approved representations of controlled items.

All changes requested to controlled items must be critically evaluated to determine their impacts. risks, and benefits on the entire NWMS. The change evaluations include cost. schedule, and other applicable programmatic considerations as well as all technical considerations.

The change decision process assesses the system impacts, risks, and benefits of the change and determines the most appropriate disposition of the change. Technical changes are processed through the following two functions:

- The PSE function to evaluate technical impact on the NWMS. 
- The PPC function to incorporate evaluation of programmatic impacts (e.g... cost. schedule, and quality) with the technical impacts and provide the disposition of the change and implementing program direction and work authorization.

Figure 10.1-4 shows the flow of information relating to the change control topic within Design Control.

The PPC function, as part of its Manage Changes subfunction, develops definitions of the items that must be controlled within the NWMS program. Similarly, the PSE function develops recommendations for items to be controlled and provides these to the PPC.

When items have been placed under control by the PPC function. the PSE function maintains control of the physical system items. This effort includes the following three items:

- Identifying the physical system item recommendations for control and the procedures for implementing the control.

- Establishing an accounting and control system for maintaining the control.

- Auditing system configuration information to ensure that the items and their descriptions are complete, consistent, and current.

The current representations of the controlled items are maintained by the technical baseline process. For the design process, the PSE function maintains this information and provides it to the change control activities within the PPC function for use in evaluating change requests.

In the change evaluation and disposition process, control is exercised by ensuring that all changes are thoroughly justified and that proper and timely notification of changes is provided to all program organizations.

10.1.2.5 Interface Control. NQA-1 requires the identification and control of design interfaces. Technical requirements, design architecture, and the physical system operational processes all require interface control. Technical baseline management and effective change management implement control over requirements interfaces and design interfaces.

Requirements Interfaces. The PSE function performs a functional analysis that defines the interfaces among functions. The analysis allocates requirements to each function and uses the allocated requirements to define requirements on each interface. The functions interact to perform the mission according to the allocated requirements. The functional interactions, i.e.. the objects that are exchanged among functions, constitute the functional interfaces that must be controlled.

Design Interfaces. Interactions among the physical system functions initially define the Design Interfaces. The DES function receives all requirements and interface objects as design inputs. The design function converts these requirements and interfaces to a physical system architecture that will meet the requirements. The architectural interfaces are defined with regard to form, fit, and function. 
Figure 10.1-4. Tecinical Change Control.

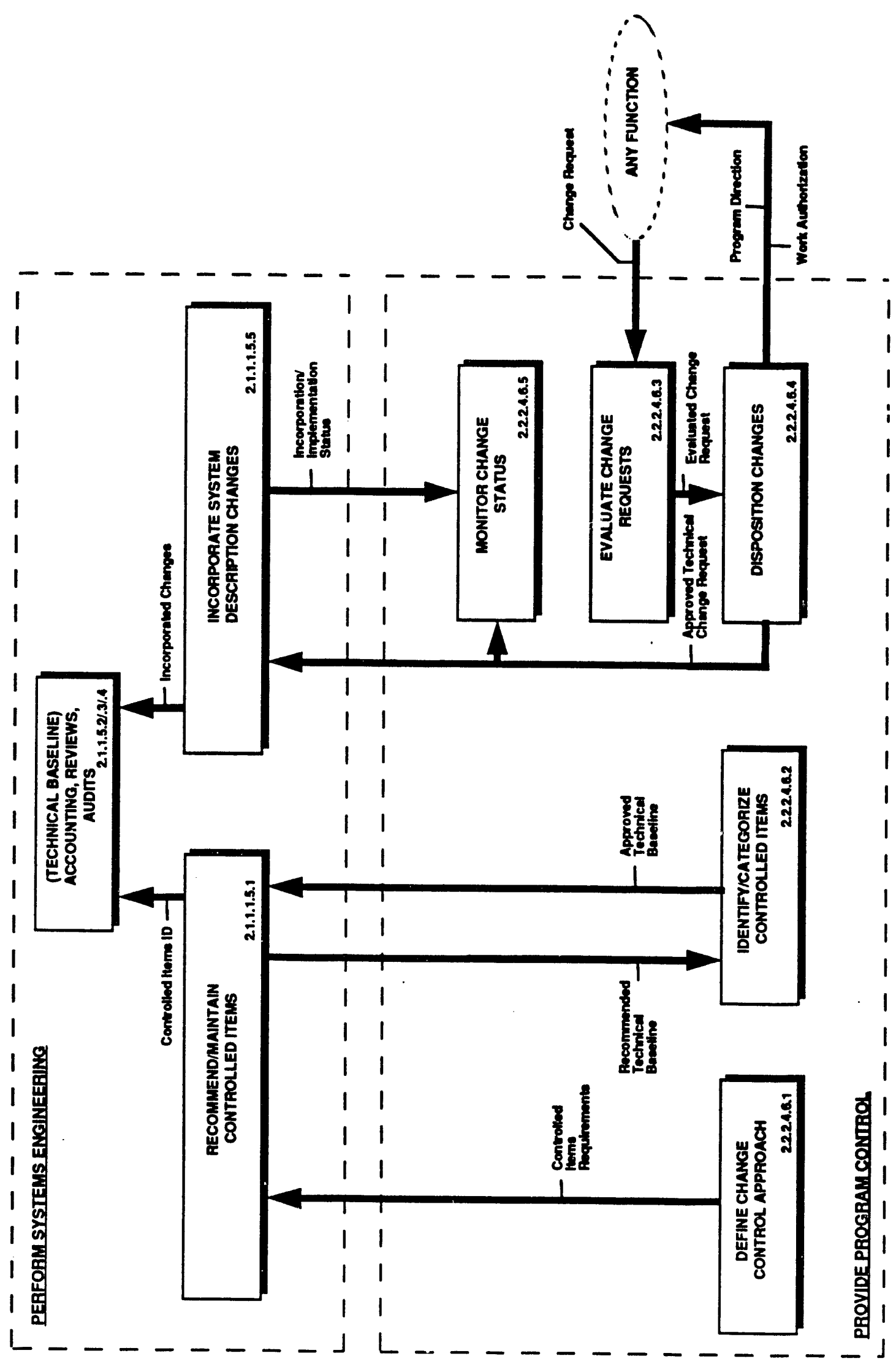


Because interfaces are part of the design and have form, fit, and function requirements levied on them, the physical mechanism selected for each interface becomes controlled and the next phase of design treats them as requirements.

For the case of independent design efforts, operating in parallel on different parts of the system. the interfaces between the two engineered systems requires additional mechanisms for coordination (see the parallel design effort discussion in Section 10.4).

The interfaces, being parts of the Technical Baseline, are subject to the Technical Baseline Change Control process.

Interface Design References are developed from the Controlled NWMS Technical Baseline and provide definitions for all form, fit, and function factors shared by the parallel design efforts. Interface Control Drawings are an example of an Interface Design Reference.

An Interface Design Reference formalizes the information exchange between parallel design efforts. It provides for common mission environment representations, bounds for excursions in analyses, and information that must be exchanged between the parallel efforts. The Interface Design References are generated from controlled information and become controlled information. This ensures that they use the most accurate information when that information is generated and that the same version is shared by all parallel efforts.

The design information flow developed in the functional analysis accomplishes three things, as follows:

- It defines and analyzes the design interfaces

- It provides information for technical review, and exchanges valid information between program efforts

- It evaluates proposed changes for both technical and program effects before change acceptance.

The PSE function checks interface control by performing configuration audits. If interface requirements are not addressed or if interface design is not traceable to requirements, the audit process generates findings for corrective action.

10.1.2.6 Documentation and Recordkeeping (Technical Information Control). The NOA-1 requirements for Documentation and Recordkeeping are expanded in the functional analysis to consider the entire spectrum of technical information. Therefore, in the functional analysis and in this section, documentation is not addressed separately. but is included as part of technical information.

Several functions produce and use technical information. Technical information systems capture. control. and protect the technical information. The scientific, engineering. physical system implementation, and operational processes must use timely and valid information. Appropriate and wellmaintained records demonstrate both design configuration and design process traceability. Proper management and control of this information are critical to the success of the program and to the accomplishment of the mission. 
Technical information relates to the physical system and describes the following four aspects of the physical system:

- Mission and requirements

- Functional and physical configuration

- Operating requirements and processes

- Maintenance requirements and processes.

Technical information also includes study, analysis, and test results that are used in the development of the technical information listed above. and performance results derived from the operation of the physical system.

Figure 10.1-5 illustrates the source and extent of technical information that must be controlled. The Provide Information Systems function develops. operates, and maintains the information systems that rocess and maintain the technical information.

Information paths flowing from each technical function contain technical information. As functions are decomposed in the functional analysis process. these information paths become more specific as the functions become more detailed. In this manner. the significant information that is subject to control is identified.

The information systems classify, protect, maintain security and integrity, facilitate traceability, and provide acquisition and distribution methods for the technical information.

10.1,2.7 Design Planning and Control. An effective Design Control program requires that design activities must be performed on time, in the proper logical sequence, and using qualified resources. The PPC function contains the subfunctions for design planning and controi and accomplishes the following:

- Describes the functions, flows, and constraints under which the design work is planned and controlled.

- Evaluates design progress from a total program perspective and generates recovery actions where necessary.

- Evaluates the quality and effectiveness of the design process through program review and audit results evaluation to determine if the design process is achieving the desired results.

\subsubsection{Significant Considerations}

Effective Design Control requires implemerting the processes described in this section. These processes should be implemented across all technical disciplines that are required to develop the NWMS. The four key advantages of using the results of the functional analysis are as follows:

- The functional analysis results define processes critical to implementing design control. 
WHC-EP-0482

Figure 10.1-5. Technical Information Management and Control.
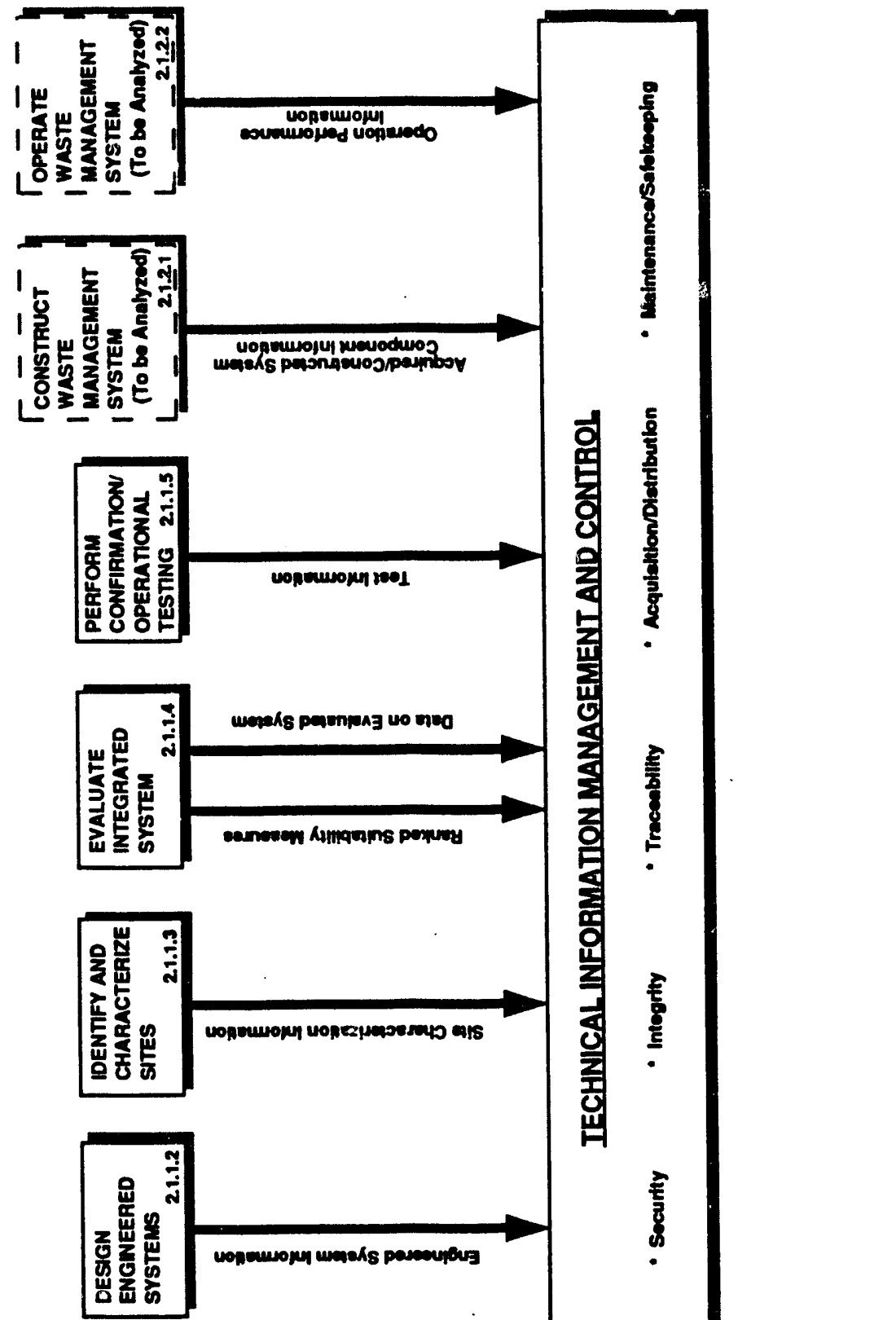

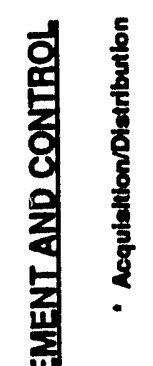

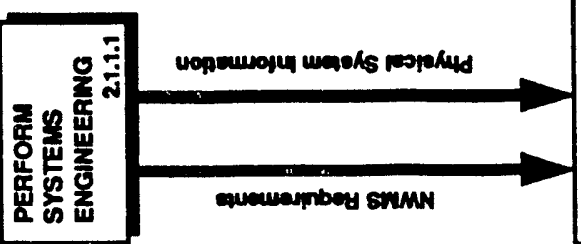

$\frac{8}{8}$

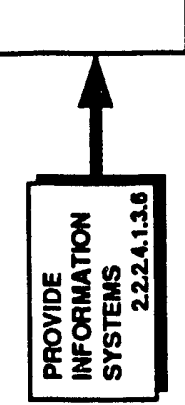


- The functional aralysis effort has examined all aspects of these processes to determine how they must be performed, how they relate to each other, and how they relate tc engineering design.

- The analysis results should form the basis for standard.practices for the design process and for the procedures for implementing design control.

- Existing or future standard practices that do not follow the principles discussed in this section may be internally inconsistent. 
WHC-EP-0482

This page intentionally left blank.

$10.1-18$ 
WHC-EP-0482

\subsection{SYSTEM TEST, EVALUATION. AND VERIFICATION}

\subsubsection{Description of Concept}

System test, evaluation, and verification are functions that collectively provide an assessment of the integrated system technical performance. The evaluation function provides a basis for establishing the test needs and for developing the assessment information required to verify that the program regulatory requirements can be met by the integrated system. This concept leads to a consistent set of information being established that can be used within the program efforts and throughout the program life to describe the system performance relative to the system requirements.

\subsubsection{General Approach Selected in Analysis}

The functional analysis draws on the integrated capabilities provided by several MSIS functions to define the system test, evaluation, and verification concept. The Ensure Regulatory Compliance (ERC) and Provide Program Control (PPC) functions develop the requirements for the system including directed evaluation requirements. The Perform Systems Engineering (PSE) function extends the system requirements to specific technical requirements. The Evaluate Integrated System (EIS) function further extends the system and technical requirements into specific measures that need to be evaluated to verify system performance meets the compliance requirements. The Design Engineered Systems (DES). Identify and Characterize Site (ICS), and Perform Confirmation/Operatiorlal Testing (PCOT) functions collect the needed data which EIS then uses to conduct the evaluations.

The functional analysis emphasizes an approach that establishes a common set of definitions, standards, and evaluation tools that will be used to demonstrate system compliance with the regulatory requirements. The commonality also provides a traceable history of the information used to make program decisions throughout the program life.

\subsubsection{Process and Information Flow}

Figure 10.2-1 shows the sequence of functions that process the information for the test, evaluate. and verify activities. Within the dotted box is a loop of functional activities that begins at the $A$ and then, at the end of the sequence, starts over again at the $A$. Outside the dotted box are activities that tend to occur at times that are not part of the $A-i O-A$ sequence.

The information flows depicted in the figure are annotated with numbers in circles. The following paragraphs describe each of these paths.

- 1 - ERC passes regulatory requirements to PPC.

- 2 - PPC develops program direction for a?l the other functions. which includes providing PSE with all the technical program requirements. The direction also includes specific regulatory requirements on EIS including constraints on how evaluations can be conducted and requirements to conduct specific evaluations. 
Figure 10.2-1. Test, Evaluation, and Verification Function Flow Sequence.

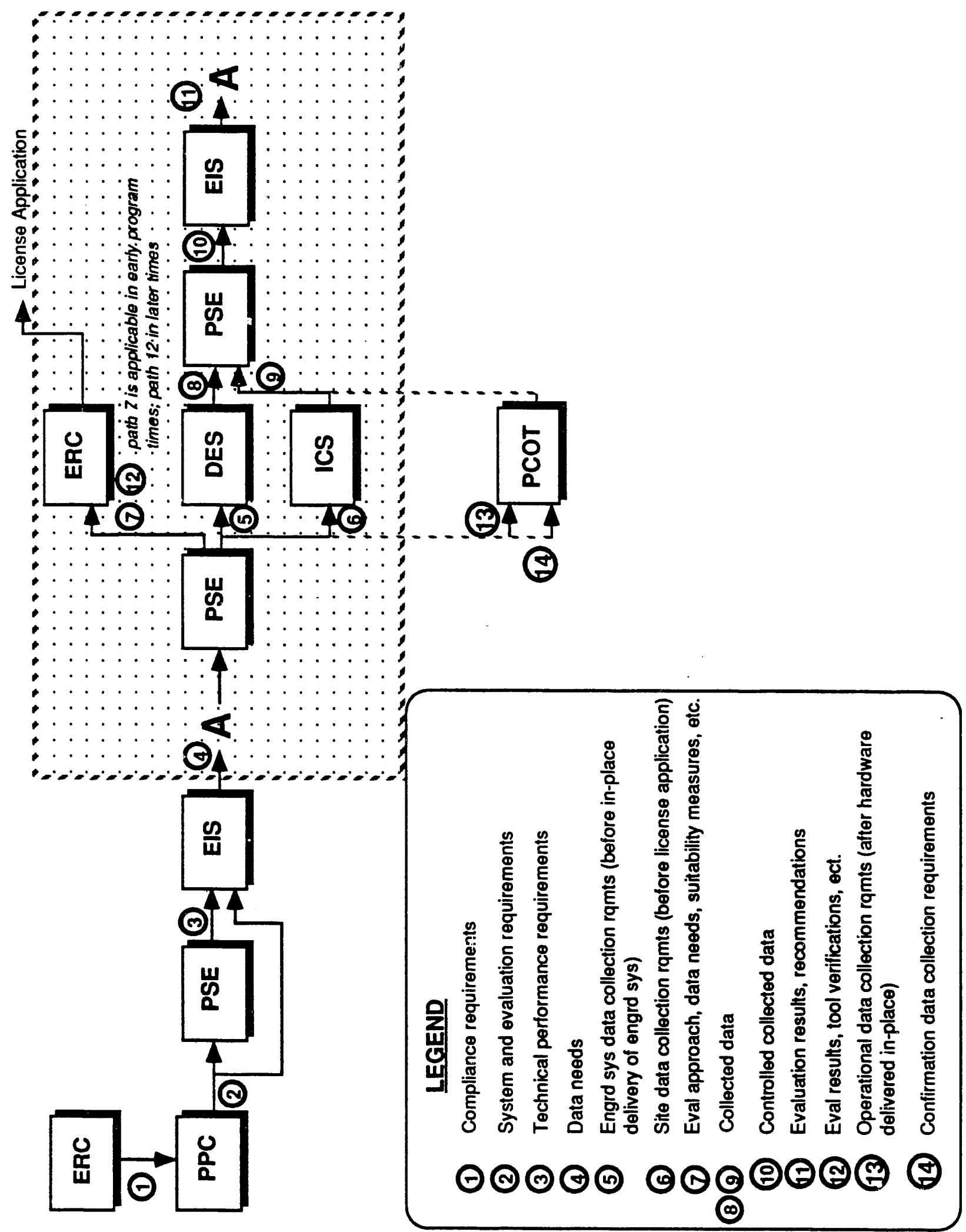


- 3 - The PSE function interprets the requirements from PPC and develops technical requirements for the system. In path 3 . PSE passes the technical requirements that the system must meet to EIS.

- 4 - The EIS function translates the PPC and PSE requirements into the following:

- Suitability measures

- An evaluation approach

- Evaluation tools

- References for the configurations to be tested, the mission scenarios to be considered in the evaluations, and the environments to be considered in the evaluations.

- The information on path 4 is comprised of the data needed to conduct the evaluations. The data identified are consistent with the suitability configurations, scenarios, environments. and evaluation tools. Early in the program. information on path 4 will be requests for data to be used to validate the evaluation tools. Later in the program. information on path 4 will be requests for data to be used in the integrated program evaluations.

- Path 4 is the beginning of the sequence of functions labeled as A. The specific activities performed by each function in the loop varies with the maturity of the program.

- 5 - PSE uses the data needs generated by EIS to develop test requirements for the design engineered system. Early in the program, while design activities are occurring, the DES functions receive these test requirements. These tests will be focused on the elements that make up the NWMS and will provide information on the elements as they go through the various aspects of development from a paper design to a constructed element ready for installation in the entire system.

Later in the program. when the design activities have produced a design and the engineered system components have been constructed and tested, the PCOT function receives the test requirements as indicated by path 13 .

- 6 - This path is similar to path 5, in that PSE develops test requirements for the site data coliection activities based on the EIS data needs. Early in the program, while site characterization activities are occurring. the ICS functions receive these test requirements. Later in the program. after the. license application has been made, the PCOT function receives the site test requirements as indicated by path 14 .

- 7 - ERC monitors the data requests and other information on the evaluation process including approach. suitability measures, and evaluation tools. The monitoring function ensures that the evaluation process is compliant with the regulations and will 
validate the system by showing that it is compliant with the performance requirements. If ERC determines that a compliance problem exists, it can request a change to program direction through path 1 . In this case, path 2 would be reused to correct the compliance problem and the sequence of functions depicted in the A-loop would then continue.

- 8 and 9 - Both the DES and ICS fulfill the test requirements sent from PSE and generate data either to validate the evaluation tools or to meel the evaluation data needs. Later in the program, as described in the discussion of paths 5 and 6 , the PCOT function would provide the test data related to the engineered system and the site.

- 10 - PSE archives and controls the data and provides them to EIS for evaluation.

- 11 - EIS, in reference again to $A$. either verifies the evaluation tools with the data or concucts the evaluations depending on which type of data is provided by PSE. EIS provides results and recommendations back to PSE on path $A$.

- 12 - ERC monitors the controlled assessment results from PSE. At the point the assessments indicate a license application can be made. ERC prepares the formal application.

- 13 and 14 . The testing within PCOT covers both the site and the engineered system.

In the case of the site testing in PCOT, the difference between the type of testing in ICS and PCOT is primarily orie of timing. Before license application. ICS functions conduct the site characterization testing. After i icense appiication. PCOT functions conduct the confirmation testing. In the case of engineered system testing. PCOT tests the in-place engineered system for a 17 the system integration and checkout tests, the system initiation tests, and operational tests. This serves to verify that the system can be operated by personnel trained in accordance with program training procedures and that they can follow the program operational procedures resulting in the desired system performance.

The result of this process flow is a requirements-driven process that is keyed to obtaining data and evaluating it in a manner capable of verifying that the NWMS meets the compliance requirements.

\subsubsection{Feedbacks and Control Paths in Process}

Figures 10.2-2a and 10.2-2b show the control and feedback paths in the test, evaluate, and verify activities. In Figure 10.2-2a. the control paths indicate that one function is directing, or constraining, the activities of other functions. As the figure shows, the PPC function exerts a centralized control over ali the functions involved in test, evaluation, and verification. PPC uses the information path entitled Program Direction to provide a consistent source of direction that is based on the Compliance Requirements from the ERC function in addition to other internal program requirements and program strategy developed by the PPC function. 
Figure 10.2-2a. Test, Evaluation, and Verification Control Paths.

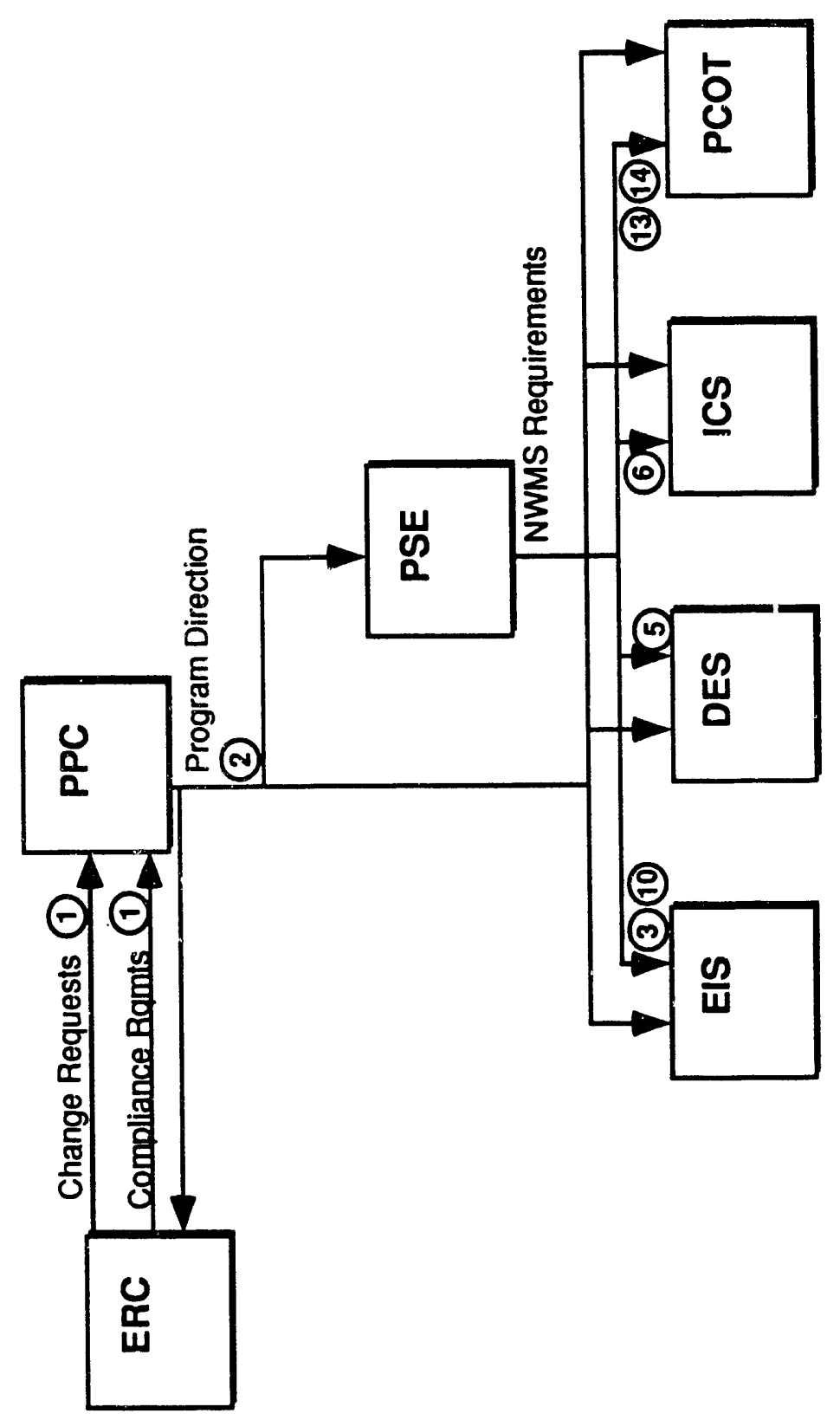


Figure 10.2-2b. Test. Evaluation, and Verification Feedback Paths.

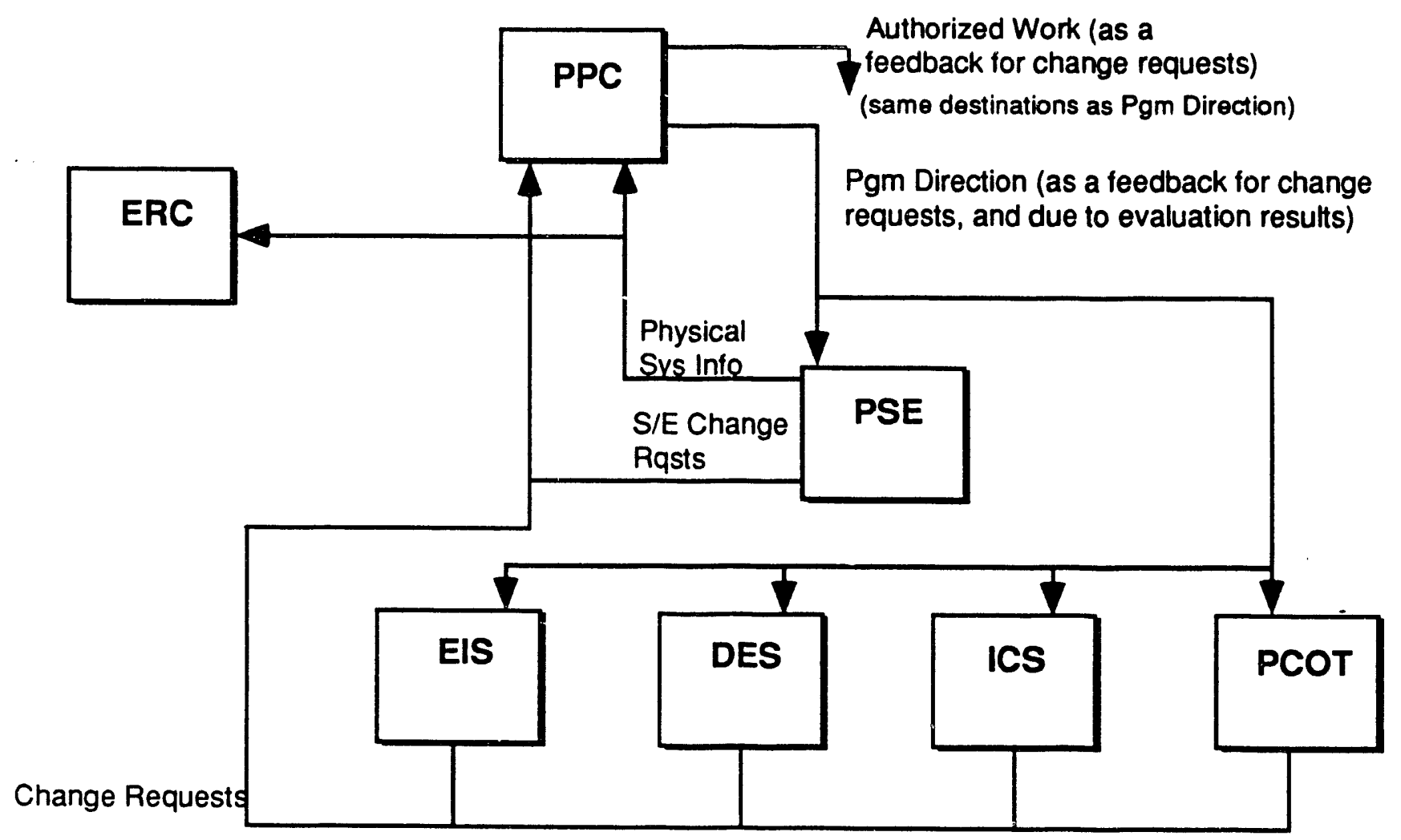


The Program Direction and NWMS Requirements paths shown in Figure 10.2-2a provide two different types of control exerted on the functions. The Program Direction requirements are requirements that describe how the program must operate (programmatic functions). That is, each specific function is provided with constraints and direction related to how it does its function. The NWMS Requirements from the PSE function define what the system must do. That is, each specific function is provided with constraints and direction related to what that function must do so that the system will meet its performance requirements.

The one exception to this separation of requirements types is the Program Direction provided to the PSE function. which includes both programmatic requirements and system requirements. PSE uses these requirements to develop the NWMS Requirements for the other functions.

Figure $10.2-2 a$ is annotated with the same number symbols used in functional sequences shown in Figure 10.2-1 to show how the sequence is controlled.

Figure 10.2-2b shows the feedback paths in the functional analys is that close the loop to show that the control is being implemented as planned. Because PPC develops the central Program Direction, it also receives the information that indicates how well that direction is being implemented. provides the information to PPC on the Physical System Information path. physical the information to ppe on the Physical system information path. The state of the physical system at any time and also includes technical performance measures to describe the projections of the performance of the system when it is completed. The PPC function uses this type of information to determine if the Program Direction is being followed and if new direction is required.

The ERC function also receives the Physical System Information including test and evaluation plans and results. ERC uses this feedback information to determine if the implementation selected by the system developers is consistent with the compliance requirements.

Some types of information from PPC provide feedback to the other program functions. Any of the other functions in the program can generate Change Requests. PPC evaluates the total system impacts of the requested changes and determines the disposition of the changes. If the changes are to be implemented, the other functions will receive new Program Direction, and new authorized work.

\subsubsection{Specific Products in the Flow of Information}

Table 10.2-1 describes the products that are generated in the test. evaluate, and verify process. Six of the seven major products identified in the table originate in the EIS function (indicated by the function number 2.1.1.4 in the Product Type column). The information includes the following:

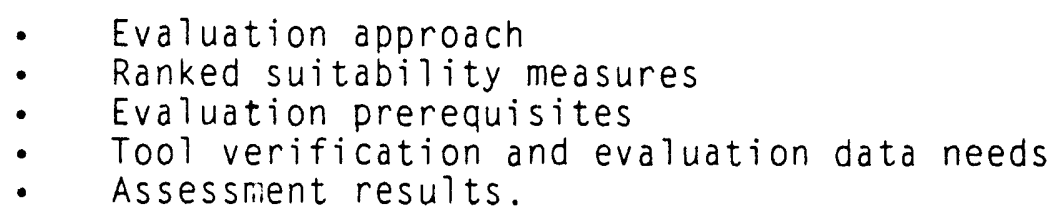


With a single function developing this interrelated information. a consistency is maintained in format and content. The consistency is tied to the performance requirements and is maintained in the associated suitability measures, the data items needed to quantify the suitability measures, and the evaluation tools that will be used to develop the system assessments from the data. The consistency provides traceability of the system evaluations back to the performance and verification requirements. The consistency also permits a comparison between evaluation results based on data from many different sources and data produced at different times during the program.

\begin{tabular}{|c|c|c|}
\hline \multicolumn{3}{|c|}{ Table 10.2-1 } \\
\hline Product Type & Product Description & Product Usage \\
\hline $\begin{array}{l}\text { Evaluation } \\
\text { approach (part } \\
\text { of Data on } \\
\text { eval sys and a } \\
\text { separate } \\
\text { information } \\
\text { path named } \\
\text { Eval appr: } \\
\text { both from } \\
2.1 .1 .4 \text { ) }\end{array}$ & $\begin{array}{l}\text { All information necessary to } \\
\text { develop the evaluation } \\
\text { tools, identify the specific } \\
\text { data needs, develop } \\
\text { procedures for conducting } \\
\text { evaluations. conduct } \\
\text { assessments of the } \\
\text { evaluations, and report on } \\
\text { the results. The } \\
\text { information includes } \\
\text { definitions of the } \\
\text { suitability measures and the } \\
\text { representations of the } \\
\text { scenarios and environments } \\
\text { that will be used in the } \\
\text { evaluations. }\end{array}$ & $\begin{array}{l}\text { Provided to PPC which uses } \\
\text { it to refine the program } \\
\text { strategy. } \\
\text { Provided (within Physical } \\
\text { System Information path) to } \\
\text { ERC which uses it to monitor } \\
\text { the program for regulatory } \\
\text { compliance. }\end{array}$ \\
\hline $\begin{array}{l}\text { Ranked } \\
\text { suitability } \\
\text { measures (the } \\
\text { information } \\
\text { path of the } \\
\text { same name from } \\
2.1 .1 .4 \text { ) }\end{array}$ & $\begin{array}{l}\text { A prioritized list of the } \\
\text { measures and data required } \\
\text { to evaluate the measures } \\
\text { that determine to what level } \\
\text { the system performance } \\
\text { requirements are met. }\end{array}$ & $\begin{array}{l}\text { Provided to PSE so that } \\
\text { decisions can be made } \\
\text { concerning the appropriate } \\
\text { level of effort to be } \\
\text { expended on collecting and } \\
\text { evaluating the data. }\end{array}$ \\
\hline $\begin{array}{l}\text { Prerequisites } \\
\text { (part of the } \\
\text { information } \\
\text { path Data on } \\
\text { eval sys from } \\
2.1 .1 .4 \text { ) }\end{array}$ & $\begin{array}{l}\text { The activities and products } \\
\text { that are required. by } \\
\text { regulation or other } \\
\text { programmatic requirements, } \\
\text { to be completed prior tc } \\
\text { conducting any evaluation } \\
\text { related data collection } \\
\text { activities. These } \\
\text { prerequisites are } \\
\text { specifically those that } \\
\text { require interorganizational } \\
\text { cooperation for developing } \\
\text { the data needs and cbtaining } \\
\text { the data. }\end{array}$ & $\begin{array}{l}\text { Provided to PSE for further } \\
\text { dissemination to the data } \\
\text { collection functions. DES. } \\
\text { ICS and PCOT. }\end{array}$ \\
\hline
\end{tabular}




\begin{tabular}{|c|c|c|}
\hline \multirow{2}{*}{\multicolumn{2}{|c|}{ Table 10.2-1. }} & \multirow{2}{*}{$\begin{array}{l}\text { Test, Evaluate, and Verify } \\
\text { et } 2 \text { of } 2 \text { ) } \\
\text { Product Usage }\end{array}$} \\
\hline & & \\
\hline $\begin{array}{l}\text { Verification } \\
\text { data needs } \\
\text { (part of Data } \\
\text { on eval sys } \\
\text { information } \\
\text { path from } \\
2.1 .1 .4 \text { ) }\end{array}$ & $\begin{array}{l}\text { The evaluation tools need a } \\
\text { reference set of data to } \\
\text { establish the tools } \\
\text { performance. This product } \\
\text { is a request for the data } \\
\text { collection functions to } \\
\text { gather specification data } \\
\text { related to establishing the } \\
\text { tools ability to show the } \\
\text { system performance relative } \\
\text { to the required performance. }\end{array}$ & $\begin{array}{l}\text { Provided to PSE for further } \\
\text { dissemination to the data } \\
\text { collection functions, DES. } \\
\text { ICS and PCOT. }\end{array}$ \\
\hline $\begin{array}{l}\text { Data needs } \\
\text { (part of Data } \\
\text { on eval system } \\
\text { information } \\
\text { path from } \\
2.1 .1 .4 \text { ) }\end{array}$ & $\begin{array}{l}\text { The specific data needed to } \\
\text { conduct an evaluation. The } \\
\text { data are defined and the } \\
\text { attributes of the data are } \\
\text { specified including the } \\
\text { accuracy. precision. } \\
\text { uncertainty. and any } \\
\text { restrictions on the data } \\
\text { collection methods. }\end{array}$ & $\begin{array}{l}\text { Provided to PSE for further } \\
\text { dissemination to the data } \\
\text { collection functions. DES. } \\
\text { ICS and PCOT. }\end{array}$ \\
\hline $\begin{array}{l}\text { Test results } \\
\text { (part of Engrd } \\
\text { sys info. Site } \\
\text { chrzn info. } \\
\text { and Test info. } \\
\text { information } \\
\text { paths from } \\
2.1 .1 .2 \text {. } \\
2.1 .1 .3 \text {, and } \\
2.1 .1 .5 \text {. } \\
\text { respectively) }\end{array}$ & $\begin{array}{l}\text { The data collected in } \\
\text { accordance with the defined } \\
\text { data needs. }\end{array}$ & $\begin{array}{l}\text { Provided through PSE to EIS } \\
\text { from the data collection } \\
\text { functions. PSE ensures that } \\
\text { the data is controlled. }\end{array}$ \\
\hline $\begin{array}{l}\text { Assessment } \\
\text { results (part } \\
\text { of Data on } \\
\text { Eval Sys } \\
\text { information } \\
\text { path, from } \\
2.1 .1 .4)\end{array}$ & $\begin{array}{l}\text { Information describing the } \\
\text { results of system } \\
\text { performance evaluations and } \\
\text { any impact assessments. The } \\
\text { information includes } \\
\text { comparisons of the results } \\
\text { with the requirements and } \\
\text { recommendations for } \\
\text { correcting any shortfalls. }\end{array}$ & $\begin{array}{l}\text { Provided to PSE for } \\
\text { decisions on the status of } \\
\text { the technical performance of } \\
\text { the system. } \\
\text { ERC also uses the } \\
\text { information to determine if } \\
\text { the progress on the system } \\
\text { development is leading to a } \\
\text { compliant NWMS. }\end{array}$ \\
\hline
\end{tabular}


WHC-EP-0482

This page intentionally left blank.

$10.2 \cdot 10$ 
WHC-EP-0482

\subsection{SCIENTIFIC RISK AND UNCERTAINTY}

This section describes how the functional processes identify, analyze. and resolve issues of scientific risk and uncertainty encountered in executing the Office of Civilian Radioactive Waste Management (OCRWM) mission. It specifically addresses risk and uncertainty as found in regulatory requirements. Other requirements identified or derived by the program may generate risk and uncertainty issues and would be handled in a manner similar to that described in this section.

\subsubsection{Description of Concept}

Scientific risk and uncertainty are encountered in executing the OCRWM mission because compliance with certain regulatory requirements relating to waste isolation cannot be verified by direct experiment. In addition, the natural setting is inherently uncertain and can only be characterized by probability statements. For example. 10CFR60.113. Disposal of High-Level Radioactive Wastes in Geologic Repositories (NRC 1990). specifies performance measures and bounding values that must be demonstrated to obtain a license from the Nuclear Regulatory Commission. One example is: "The release rate of any radionuclide from the engineered barrier system following the containment period shall not exceed one part in 100.000 per year of the inventory of that radionuclide calculated to be present at 1.000 years following permanent closure..."

The following three problems are involved in demonstrating compliance with such a requirement:

- Predictions of interactions between materials and environmental conditions are outside the range of human experience with those materials and conditions.

- The results of experiments must be extrapolated credibly to the durations of interest.

- The mechanisms for radionuclide release, as well as external processes and events that may impact release, are not fully understood and to the extent they are understood. can only be described stochastically.

Under these conditions, predictions of release rates from the engineered barrier system entail uncertainties in the models used for prediction. and in the parameter values used in the models. follows:

For the purpose of this analysis, risk and uncertainty are defined as

- Risk is the potential for a scenario to yield an unacceptable outcome, where potential includes both the probability of the scenario occurring and the consequences of the scenario, if it occurs.

- Uncertainty is the absence of knowledge about processes and events critical to their conceptualization or modeling. No basis exists for assigning probabilities to events. 
The use of the term uncertainty to characterize aspects of certain specialized quantitative analyses of design and performance parameters is recognized. but is not being applied in this discussion.

\subsubsection{General Approach Selected in Analysis}

The general approach used in the functional analysis to handle the issues of scientific risk and uncertainty was to treat risk as an attribute of system performance requirements and treat: uncertainty as an element of an evaluation approach associated with verification requirements.

Risk is initially identified from applicable regulatory requirements as an attribute of bounding values on performance measures, and thus, is an integral part of compliance criteria. The compliance criteria are translated into compliance requirements, which then become program mission requirements.

Risk eventually risk will be assessed as an element of the conceptual design, and the program will ultimately achieve a prescribed level of acceptable risks in the design by balancing cost. schedule, performance, and risk considerations.

Uncertainty is identified initially in formulating evaluation approaches to verify compliance with certain performance requirements. In these cases, insufficient knowledge exists to specify relationships among between the performance measures to be verified and their causal factors. Various efforts can then be initiated to reduce uncertainty, or adopt decision methods that accommodate uncertainty. These efforts are as follows:

- Initiate site investigations and performance testira to eliminate specific data gaps and produce credible background assumptions.

- Adopt an evaluation approach that accommodates all credible scenarios of processes and events.

- Work with the regulators to define specific acceptance criteria that include acceptable residual uncertainty, to avoid an openended evaluation scheme.

A comprehensive evaluation approach may involve any or all of the efforts described, but must eventually go forward with the uncertainties inherent in the current state of scientific knowledge and engineering expertise.

\subsubsection{Process and Information Flow}

The functional analysis has produced a set of processes that provide a structure of requirements definition, design, and evaluation that is capable cf accommodating the issues of risk and uncertainty.

As shown in Table 10.3-1, risks are initially identified in the function that establishes bounding values for compliance measures. These compliance measures are direct transiations of applicable regulatory requirements. Risk becomes an attribute of a bounding value and is sent to the Develop Compliance Approach function within a compliance criterion. A compliance approach for the criterion will be formulated that will identify any special problems associated with implementing the criterion as a design requirement. Risk 


\begin{tabular}{|c|c|}
\hline Function & Description of Activity Regarding Risk \\
\hline $\begin{array}{l}\text { Establish Bounding } \\
\text { Values For Measures } \\
2.2 .1 .1 .2 .3\end{array}$ & $\begin{array}{l}\text { Analyze applicable regulatory requirements to } \\
\text { determine if risk is an element of bounding } \\
\text { values for compliance measures. and } \\
\text { incorporate acceptable risk as an attribute of } \\
\text { the compliance criteria. }\end{array}$ \\
\hline $\begin{array}{l}\text { Develop Compliance } \\
\text { Approach } \\
2.2 .1 .1 .3\end{array}$ & $\begin{array}{l}\text { Analyze the compliance criteria to identify } \\
\text { potential differences in the program and } \\
\text { regulator's positions on risk. Establish } \\
\text { prioritized concerns relative to risk issues. } \\
\text { Define the strategic constraints involved in } \\
\text { implementing the requirements given that risk } \\
\text { exists. Synthesize a compliance approach. } \\
\text { based on compliance requirements, that } \\
\text { adequately addresses the regulatory } \\
\text { requirement under conditions of risk. }\end{array}$ \\
\hline $\begin{array}{l}\text { Develop Program } \\
\text { Strategy } \\
2.2 .2 .4 .1 .2\end{array}$ & $\begin{array}{l}\text { Integrate the compliance approach with other } \\
\text { program strategies. and produce a } \\
\text { comprehensive and consistent program straieygy } \\
\text { that recognizes all risk issues. }\end{array}$ \\
\hline $\begin{array}{l}\text { Develop Program } \\
\text { Direction } \\
2.2 .2 .4 .1 .3\end{array}$ & $\begin{array}{l}\text { Translate the program strategy into a } \\
\text { consistent set of physical system requirements } \\
\text { (program mission requirements as contained in } \\
\text { program direction) that will ensure that the } \\
\text { design of the NWMS will reduce risk to } \\
\text { acceptable levels. }\end{array}$ \\
\hline $\begin{array}{l}\text { Perform Systems } \\
\text { Engineering } \\
2.1 .1 .1\end{array}$ & $\begin{array}{l}\text { Transform program mission requirements into } \\
\text { NWMS design requirements, including both the } \\
\text { levels of acceptable risk and how the design } \\
\text { should be evaluated against those risk } \\
\text { requirements. }\end{array}$ \\
\hline $\begin{array}{l}\text { Evaluate Techriology } \\
\text { Drivers } \\
2.1 .1 .2 .2 .3\end{array}$ & $\begin{array}{l}\text { Identify and characterize technology concepts } \\
\text { that are responsive to the engineered system } \\
\text { conceptual design requirements (as derived } \\
\text { from NWMS design requirements). including, isk } \\
\text { considerations. This function includes } \\
\text { assessing accessible technologies. determining } \\
\text { options for functional drivers. performing } \\
\text { parametric analyses of concept options. and } \\
\text { performing concept assessment testing. Thus } \\
\text { risk is evaluated together with other } \\
\text { functional and technological design drivers. } \\
\text { The function produces characterized driver } \\
\text { technology options that acknowledge acceptable } \\
\text { residual levels of risk. }\end{array}$ \\
\hline
\end{tabular}




\begin{tabular}{|c|c|}
\hline Function & Description of Activity Regarding Risk \\
\hline $\begin{array}{l}\text { Compose Griving } \\
\text { Technology Options } \\
2.1 .1 .2 .2 .4\end{array}$ & $\begin{array}{l}\text { Select the most effective characterized driver } \\
\text { technology options for each system functional } \\
\text { driver and form a driver technology } \\
\text { (architecture) description. "Most effective" } \\
\text { will involve reducing risk to levels which are } \\
\text { as low as reasonably achievable. This } \\
\text { function includes determining discriminants } \\
\text { among the concepts, specifying a concept } \\
\text { selection process, and specifying the selected } \\
\text { driving technology concepts in terms of a } \\
\text { driver technology architecture. The driver } \\
\text { technology architecture. with its inherent } \\
\text { levels of residual risk. becomes the basis for } \\
\text { the engineered system conceptual design } \\
\text { information. which becomes engineered system } \\
\text { information. and eventually Nims information. } \\
\text { This information is sent to the Perform } \\
\text { systems Engineering function for further } \\
\text { action. }\end{array}$ \\
\hline $\begin{array}{l}\text { Perform System } \\
\text { Technical Reviews } \\
2.1 .1 .1 .5 .3\end{array}$ & $\begin{array}{l}\text { Review the conceptual design information, } \\
\text { including risk information, against } \\
\text { requirements. Provide recommendations and } \\
\text { transmit the conceptual design information } \\
\text { (review documentation and recommendations) to } \\
\text { the Provide Program (ontrol function as } \\
\text { physical system information for } \\
\text { implementation. }\end{array}$ \\
\hline $\begin{array}{l}\text { Provide Program } \\
\text { Control } \\
2.2 .2 .4\end{array}$ & $\begin{array}{l}\text { Analyze the technical review results contained } \\
\text { in the physical system information to } \\
\text { determine if performance variances are } \\
\text { evident. In this analysis. scientific risk } \\
\text { will be evaluated with all other aspects of } \\
\text { the conceptual design in terms of its cost. } \\
\text { schedule and performance impacts on the } \\
\text { program. If necessary. identify the necessary } \\
\text { corrective measures in terms of remedial } \\
\text { action direction. otherwise implement the } \\
\text { conceptual design jy making the necessary } \\
\text { changes to the cost/ schedule baseline: } \\
\text { issuing the required program direction: and } \\
\text { organizing, planning, and authorizing the work } \\
\text { necessary to proceed with the conceptual } \\
\text { design. }\end{array}$ \\
\hline
\end{tabular}


WHC-EP- 0482

considerations then become embodied in a compliance requirement, which in turn. becomes a program mission requirement, and finally a Nuclear Waste Management System (NWMS) design requirement. In producing the NWMS design requirements, risk parameters may be developed as analytically derived values in cases where the original regulatory requirements do not stipulate numerical requirements. Design efforts then proceed to balance risk with the other design drivers being considered in conceptual design. Finally. a conceptual design is produced with known risks implicitly accepted; it is reviewed for technical adequacy by the Perform System Engineering (PSE) function and provided to the Provide Program Control (PPC) function for integration with other cost and schedulc objectives anci implementation through program direction.

As shown in Table 10.3-2, uncertainty is identified initially in the function that identifies and selects the appropriate evaluation technique for each NWMS evaluation requirement (which originally was an externally imposed system performance requirement, and eventually was translated into a verification requirement). In evaluating the capability and feasibility of various techniques, the uncertainty inherent in demonstrating compliance with the requirement will be identified. An evaluation approach is then formulated that will set objectives and a plan of action for reducing uncertainty, or selecting decision methods that accommodate uncertainty. The evaluation approach must then be reconciled with existing compliance criteria. requirements, and approaches. A parallel integration is conducted by the PSE function to assure consistency with coher elements of the technical baseline. Finally, it must be integrated with uther program objectives (cost, schedule, performance, and risk) and the overall program strategy. Program direction can then be issued to implement the evaluation approach.

\subsubsection{Feedback and Control Points in Process}

As demonstrated in the previous section, both risk and uncertainty are integral elements of system requirements. Risk is explicitly incorporated in NWMS design requirements. Uncertainty considerations are incorporated as assumptions or findings in the strategy associated with implementing an evaluation approach. When the program controls or refines risk and uncertainty information, it must do so in the context of these requirements.

Risk and uncertainty are controlled in the same way all system requirements are controlied in the functional analysis. The PSE function assures that the requirements are consistent with other elements of the technical baseline, and the PPC function integrates those requirements with a 17 other program requirements to balance cost, schedule, and performance within the program.

As the risk considerations are addressed by the Design Engineered Systems (DES) function, and uncertainty considerations are addressed by Evaluate Integrated System (EIS). conflicts with other requirements may be encountered. In such cases, the respective functions will formulate change requests to the technical baseline, as is the case when problems are encountered in implementing any system requirement. Thus, the primary feedback loop to be exercised when problems are encountered in working risk and uncertainty is the basic change control process for the technical baseline. 


\begin{tabular}{|c|c|}
\hline Function & Description of Activity Regarding Uncertainty \\
\hline $\begin{array}{l}\text { Identify and Select } \\
\text { Evaluation Techniques } \\
2.1 .1 .4 .1 .3\end{array}$ & $\begin{array}{l}\text { Based on an analysis of ranked suitability } \\
\text { measures and (associated) data requirements. } \\
\text { select the evaluation techniques which will be } \\
\text { used to verify compliance with the system } \\
\text { requirements. This selection will focus on } \\
\text { the capability and feasibility of } \\
\text { demonstrating compliance by means of the } \\
\text { technique, and will consider all relevant } \\
\text { factors including uncertainty in } \\
\text { conceptualizing and modelling the processes } \\
\text { and events which impact the predicted values } \\
\text { of the suitability measures. This function } \\
\text { will produce the final technique } \\
\text { specifications, with residual levels of } \\
\text { uncertainty built into the technique. }\end{array}$ \\
\hline $\begin{array}{l}\text { Complete Evaluation } \\
\text { Approach Development } \\
2.1 .1 .4 .1 .4\end{array}$ & $\begin{array}{l}\text { Establish the steps necessary to conduct the } \\
\text { evaluations required under the NwMS evaluation } \\
\text { requirements consistent with the chosen } \\
\text { evaluation technique. In order to reduce } \\
\text { uncertainty. such steps may include specific } \\
\text { directions to the Identify and Characterize } \\
\text { sites and Perform Confirmation/ Operational } \\
\text { Testing functions to produce data that could } \\
\text { confirm certain hypotheses and allow } \\
\text { uncertainty associated with the technique to } \\
\text { be reduced. This function produces an } \\
\text { evaluation approach. Which eventually is sent } \\
\text { to the Perform Systems Engineering function } \\
\text { for further disposition. }\end{array}$ \\
\hline $\begin{array}{l}\text { Perform Systems } \\
\text { Engineering } \\
2.1 .1 .1\end{array}$ & $\begin{array}{l}\text { The evaluation approach is assessed and } \\
\text { integrated into the technical baseline with } \\
\text { other system requirements through the standard } \\
\text { PSE approach to developing the functions/ } \\
\text { requirements / architecture ( } F-R-A \text { approach) } \\
\text { for the program. With consistency } \\
\text { established, the requirements associated with } \\
\text { the evaluation approach (and the uncertainty } \\
\text { considerations inherent in that approach) are } \\
\text { made available to the program as physical } \\
\text { system information. }\end{array}$ \\
\hline $\begin{array}{l}\text { Review Derived } \\
\text { Measures and Bounding } \\
\text { Values } \\
2.2 .1 .1 .2 .4\end{array}$ & $\begin{array}{l}\text { The ERC monitors the technical baseline as } \\
\text { contained in physical system information and } \\
\text { identifies performance requirements that are } \\
\text { derived from compliance criteria. To the } \\
\text { extent that no apparent conflicts exist with } \\
\text { the existing criteria (which would necessitate } \\
\text { the generation of a change request). the } \\
\text { requirements are adopted as compliance } \\
\text { criteria and delivered to the Develop } \\
\text { Compliance Approach function. }\end{array}$ \\
\hline
\end{tabular}




\begin{tabular}{|l|l|}
\hline Table 10.3-2. Generalized Process Flow for Incorporating Uncertainty. \\
(sheet 2 of 2)
\end{tabular}




\subsubsection{Specific Products in the Flow of Information}

Risk considerations are captured in a number of major functional products, reflecting the evolution from performance measures and bounding values required to demonstrate compliance to NWMS requirements and Program Direction. These products are as follows and are listed with the functions that produce them:

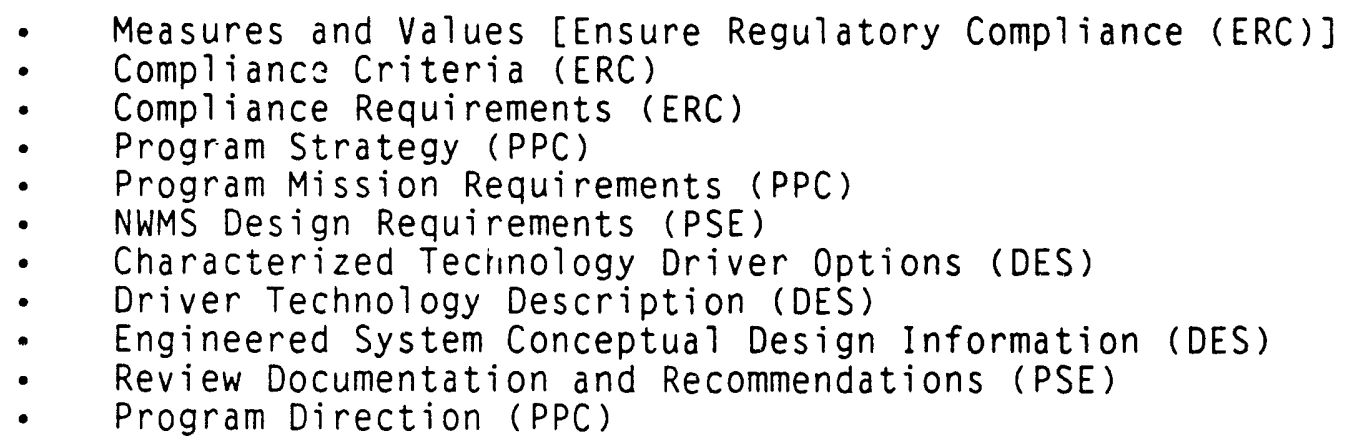

In implementing the final Program Direction. DES will work with EIS and Perform Confirmation/Operational Testing (PCOT) to assess rijk as preliminary design activities proceed.

In all cases, acceptable risk is embodied in the bounding values of pelformance measures that establish system acceptance criteria.

Uncertainty considerations are captured in a number of major functional products, reflecting the evolution from final (evaluation) technique specifications to Program Direction. These products are as follows and are with the functions that produce them:

- Final Technique Specifications (EIS)

- Evaluation Approach (EIS)

- Physical System Information (PSE)

- Compliance Criteria (ERC)

- Compliance Approach (ERC)

- Program Strategy (PPC)

- Program Direction (PPC)

In implementing the final Program Direction. EIS will quantify. as far as possible, the system level risk given the residual level of uncertainty in the approach.

At no point in the process is uncertainty explicitly stated as a requirement. but exists as a finding that shapes the evaluation requirements. i.e.. the manner in which verification processes are executed. 
WHC -EP- 0482

\subsubsection{Critical Considerations}

A critical consideration in accommodating risk and uncertainty is producing information that the regulators. concerned parties, and the public can use to assess the level of residual risk and uncertainty that the program is accepting when it proposes a particular design. This consideration is necessary because of the following:

- Risk and uncertainty cannot be reduced to zero. To be successful. any program must accept some reasonable level of risk.

- Residual risk and uncertainty can be described and compared to other societal risks and uncertainties (including those associated with the no-action, status quo alternative).

- Methods must be developed for calculating and displaying residual risk and uncertainty within the framework of other societal risks and uncertainties as an important element of program communication with regulators and the public.

The program must use these communication methods in an advocacy role to ensure that the public and Congress have the necessary information to resolve the fundamental implementation issues associated with executing the OCRWM mission.

The functional analysis describes a method in which communication with regulators and other concerned parties must be executed in accordance with an interaction plan, which in turn, must be consistent with the compliance approach and compliance requirements. As the compliance approach and compliance requirements are being formulated, issues associated with risk and uncertainty will necessarily involve the extent to which agreements with regulators and acceptance by the concerned parties must be pursued. These considerations will then be incorporated into an overall strategy that balances the cost. schedule, and performance objectives of the program. Thus, program strategy. which adopts specific design and evaluation requirements together with specific implementation approaches will address residual risk and uncertainty associated with implementing those requirements. 
WHC-EP-0482

This page intentionally left blank.

$10.3-10$ 
WHC - EP- 0482

\subsection{PARALLEL DESIGN EFFORTS}

\subsubsection{Issue Overview}

The Design Engineered System (DES) Management Systems Improvement Strategy (MSIS) function (2.1.1.2) defines how a single engineering effort would be performed to define a self-contained subset of the Nuclear Waste Management System (NWMS). However, the size and scope of the NWMS is so large, that its design is certain to be decomposed into multiple, parallel. design efforts. Parallel engineering efforts will arise naturaliy as part of the NWMS program; several of the pathways to such efforts are illustrated in Figure 10.4-1. At a minimum. NWMS design will consist of separate efforts for the waste acceptance system, the waste transport system, the retrievable storage system. and the geologic depository system. Each of these elements could also be further separated into additional parallel efforts for contractual reasons or because of the scope of the ultimate system and its subsystems. Large developmental items will require significant engineering efforts: these are likely to be managed as separate efforts.

Performing a useful functional analysis that easily accommodates parallel efforts requires a novel perspective on the functional analysis process. For functional analysis results to be useful to the engineer. they must incorporate the details of the engineering process. However, parallel design efforts emphasize the need to control system configuration evolution and the programmatic processes that develop that configuration. Thus, technical integration of the products of parallel of efforts brings in programmatic processes outside the standard scope of engineering. Such processes include work scoping and tasking, program planning and organizing. program management decisions and program direction, and requirements and technical information integration.

Controlling the interaction between these process and the engineering design process is essential to ensure effective physical system integration. to ensuring effective physical system interfacing, to ensuring effective data exchange, and to coordinating responses to external changes.

\subsubsection{Fundamental Approach}

The design of any subset of the NWMS engineered system requires the same steps of Conceptual. Preliminary. Final, and As-Built Design. Therefore, the functional analysis results show these as the basic processes of engineering design. In addition, the iterative information pathways and the interfaces to program control processes provide for performing the same set of engineering design steps on multiple topics simultaneously.

The functional analysis process achieves an integrated system and maintains an integrated program in the presence of multiple parallel design efforts using the following techniques:

- A centralized description of the engineering process is used to ensure uniformity of engineering efforts

- An integrated requirements set is maintained to ensure all technical products are compatible and traceable 
Figure 10.4-1. How Parallel Design Efforts Could Arise in the OCRWM Program.

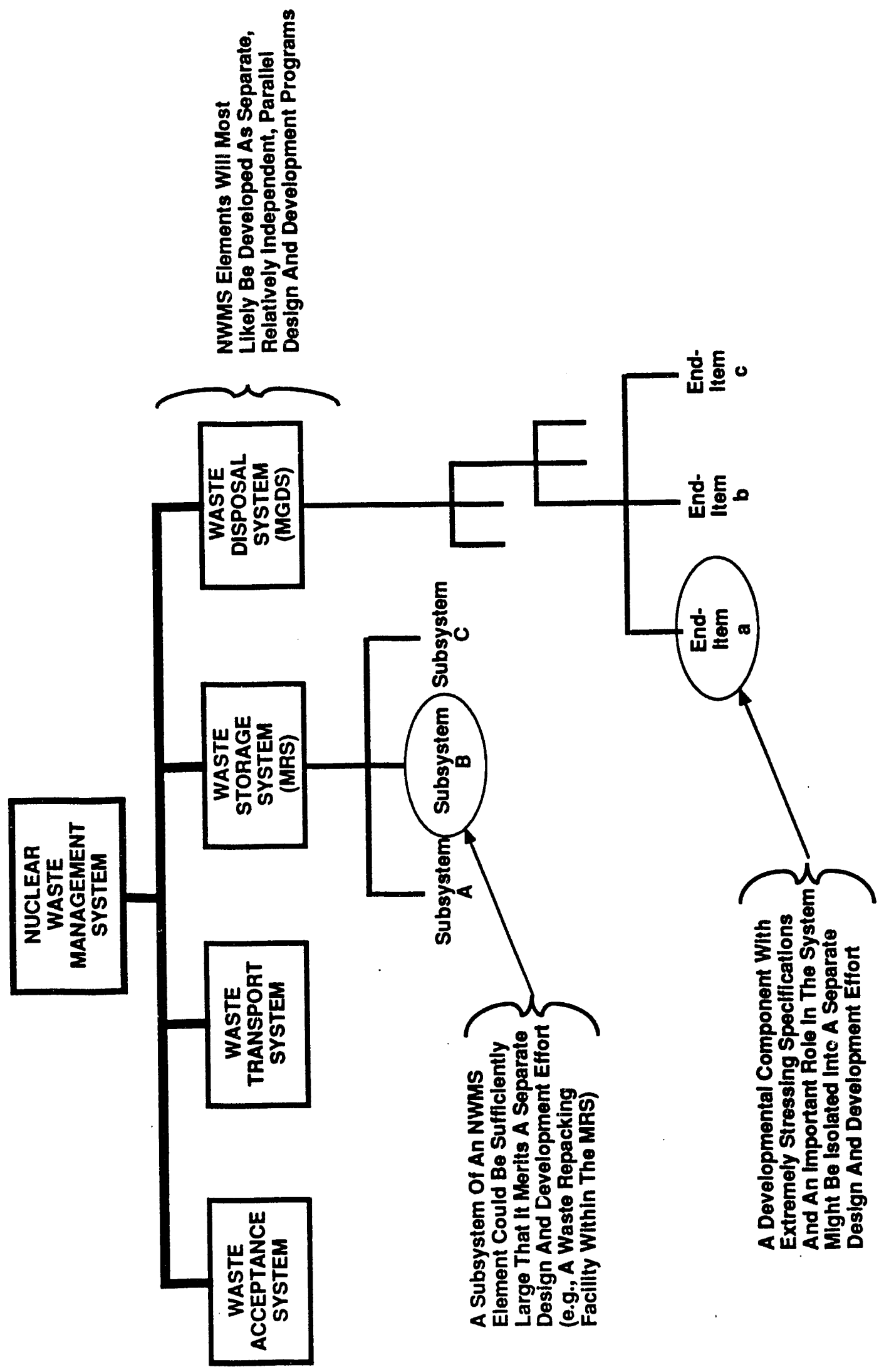


WHC-EP-0482

- A formalized Design Reference is established across all design efforts to control and facilitate information between parallel efforts concerning the interfaces that link the hardware of the two efforts.

- A centralized programmatic tasking and strategy development is used to control changes that impact multiple design efforts.

The general engineering functions defined in the DES functional analysis can be viewed as centralized functions. The functions are centralized in the sense that all engineering efforts perform these tasks. Having such centralized functions allows the functional analysis to work down to the details that apply to all engineering design efforts. This centralization yields a definition of an engineering process that can form a standard practice applied to all participating organizations.

The integrated NWMS requirements set is essential to ensuring that the total system achieves its mission and is in compliance. All requirements on individual pieces of the NWMS must be traceable to a requirement levied on the entire system. Establishing upward traceability to regulatory sources requires that a full set of all NWMS requirements be maintained so that requirements on pieces of NWMS can be followed upward through all system tiers to the regulatory source. Ensuring that all regulatory requirements are met requires that the allocation process consider all system tiers (i.e.. flowdown traceabiiity requires an integrated set of NWMS physical system functions and requirements to ensure each regulatory requirement is met). Requirements integration is intrinsic to the mission analysis, functional analysis, and requirements allocation processes in the Perform Systems Engineering (PSE) MSIS function (2.1.1.1). This process is initiated by input of the total NWMS program mission requirements. The analysis addresses the total NWMS mission and all system functions to complete the mission. Thus, the initial analysis sets the stage at the integrated NWMS level. Each design effort adds detail to the system functions already defined in initial analysis. The technical information control process reviews and audits these additions to ensure completeness and compatibilitv Thus, the requirements are integrated and the description of the total system to meet the requirements is integrated.

A Design Reference for system interfaces is shared in common by all parallel engineering efforts. The Design Reference is developed from the Controlled NWMS Information database (see PSE function). This Design Reference formalizes the information exchange between parallel efforts. It defines shared interface modeling techniques shared mission environment definitions, and common bounds for excursions relative to interfaces. It identifies and transfers the information each parallel design effort requires from the other efforts. The advantages of a formal Design Reference are that it ensures that all relevant organizations and programs participate. It ensures a controlled response to evolution among the parallel efforts and maintains traceability of interface design data and design bases.

Control of the parallel design effort is maintained through work scopes and the Design Strategy. All technical efforts are performed only under authorization of approved tasking from the program control processes [see Perform Program Control (PPC) MSIS function (2.2.2.4)]. The program evaluation processes (also part of the PPC function) is to make the decision whether a development effort should continue as a single program or as a set of parallel programs. The program evaluation process performs the trade-offs for resource efficiency, level of control, and technical justification. Work tasking and Program Direction define the existence of each parallel design 
WHC-EP-0482

effort, their scopes, their programmatic interfaces, the responsible organizations and organizational interfaces.

The existence of parallel design efforts places unique requirements on the testing and system evaluation processes to integrate across the parallel designs. This integration is an intrinsic part of both the EIS (2.1.1.4) and the PCOT (2.1.1.5) MSIS functions. The use of a reqdirements-driven testing program is key to successful testing of systems designed in parallel. The PCOT functional process responds to requirements from all sources including PSE (requirements allocation process). EIS (compliance suitability measures). DES (verification of design and requirements). and Identify and Characterize Site (ICS) (needs for confirming site performance). If requirements exist at multiple levels of the system, then the PCOT process responds by developing and executing a test at each level. Furthermore, the PCOT function incorporates an explicit integrating step composed of the following:

- Integration across requirements and across planned testing activities is a major part of test approach development and is shown as a separate subfunction in the PCOT functional analysis.

- The integration subfunction compares approaches, techniques, and support needs to address simultaneous needs and commonalities. It increases commonality where consistency in methods is required.

- The integration subfunction represents corporate memory so that late tests are equivalent to early tests. The subfunction examines procedures, techniques, and apparatus from development program for utility and need for consistency.

The EIS function is, by definition, an integrating process. This aspect is particularly important for parallel design efforts. Integrated system evaluation always develops evaluation results in terms of the total NWMS. Furthermore, it develops suitability measures for the complete NWMS and a complete compliance approach that flow down to elements of NWMS. The EIS process will generate testing requirements. If aspects of compliance cannot be met until the complete NWMS is integrated, then the EIS process will identify these and produce the appropriate testing requirements. Thus, NWMS level testing still occurs even when there are relatively independent programs for each NWMS element.

\subsubsection{Flow of Activities}

All parallel design efforts, including those for the four NWMS elements. would begin as a single design effort of the overall system. The design of the overall system would begin with a system level conceptual design. This would yield constraints for the conceptual design of any subelement that is broken out as a separate design effort. The Design Reference would then be used as a formal coordinating process among the several engineering development efforts. 
WHC-EP-0482

The initial step leading to parallel design efforts is the Conceptual Design of the overall system (see Figure 10.4-2). This starting point applies for the complete NWMS before forming separate efforts for Acceptance. Transport. Monitor Retrievable Storage (MRS), and Mined Geological Disposal System (MGDS). This starting point also applies to breaking out subsystems or even developmental end-items from one of these four NWMS elements. The relevance of conceptual design information to planning of parallel design efforts is as follows:

- The nature of the system must be understood to provide a proper definition of the scope and requirements of individual efforts and the relationships and interfaces among them. The conceptual design provides this technical understanding.

- The program structure for parallel engineering efforts must make technical sense or program activities will be difficult to integrate. The conceptual Design provides technical definitions needed to organize the program properly.

- Thus the conceptual design defines the structure of each of the parallel efforts and quantifies the driving relationships among them.

The Conceptual Design of the overall system expands the system definition prior to the decision to form parallel design efforts. The Conceptual Design is input to the requirements allocation and control in the the PSE function process. In this process the physical system functions set is expanded by the function decomposition in the Conceptual Design. Derived requirements are verified for traceability. allocated to the new functions, and placed under control. Definitions of interfaces are expanded and their requirements are verified for traceability and placed under control. This expanded system configuration definition is then input to the program control and design processes in PPC.

The program evaluation and planning processes in PPC compare program technical data to program strategy to determine the need for parallel design efforts. If a need is identified, technical information defining the need is input to the program structuring and work planning processes to define a new program structure. New program direction. strategy, and tasking is produced to initiate parallel design efforts. New tasks are authorized to form the parallel design efforts. New program direction defines the irganizational implementation of the parallel design efforts. The allocated requirements from the overall system conceptual design are used to form the design requirements for each of the separate, parallel design efforts.

As the parallel design efforts progress, the Design Reference process maintains integration between efforts (see Figure 10.4-3). Design Reference defines how the parallel efforts will relate to each other technically. It is formed from the Controlled NWMS Description provided by the technical information control process in the PSE function. To form the Design Reference, the individual design efforts first identify their information. needs from the other design efforts. Then, all design efforts jointly exchange needs and data and resolve interfacing issues. Finally. consolidated 
Figure 10.4-2. Information Flow in Establishing Parallel Design Efforts.

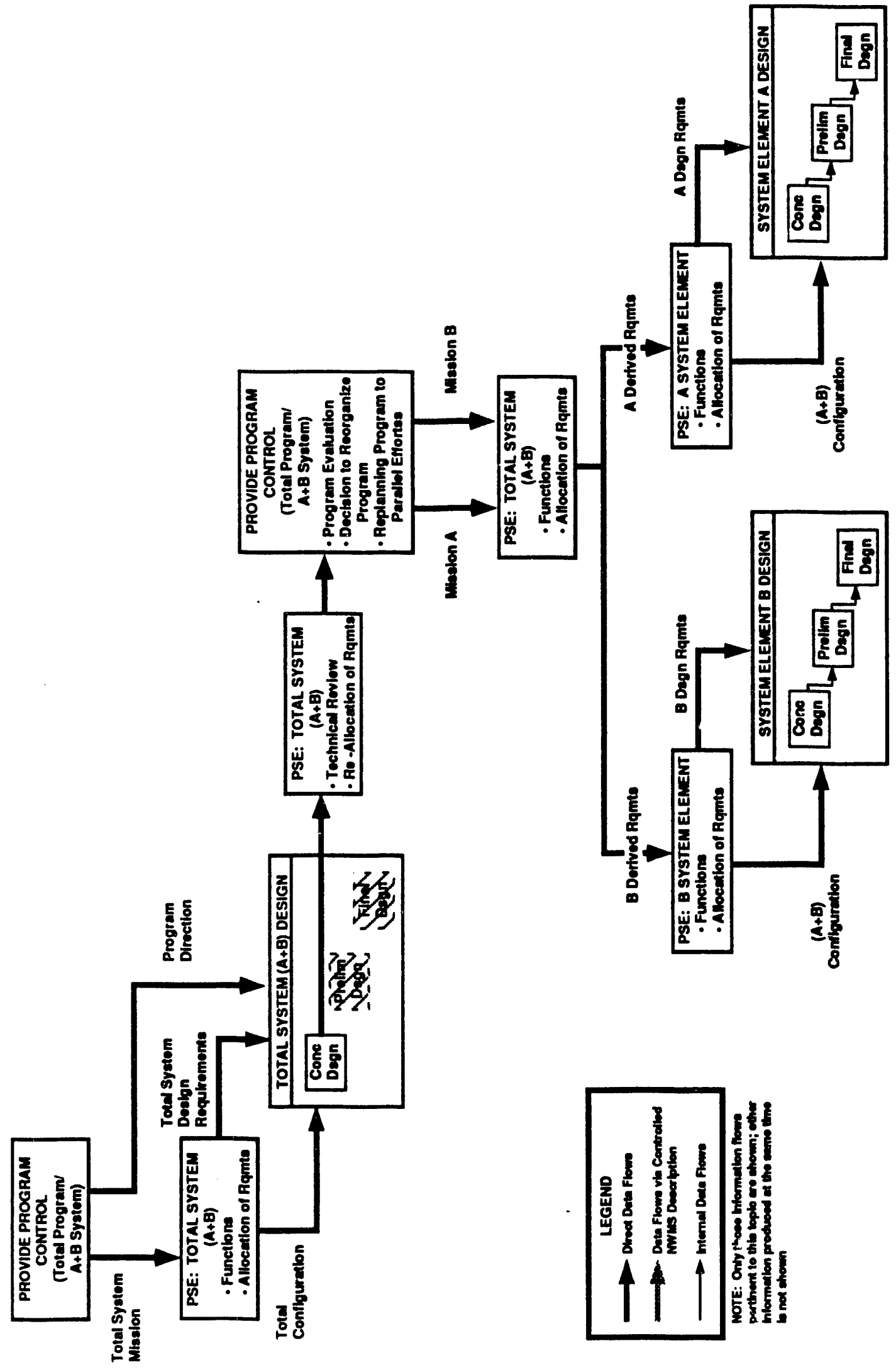


Figure 10.4-3. Data Flow Between Parallel Design Efforts.

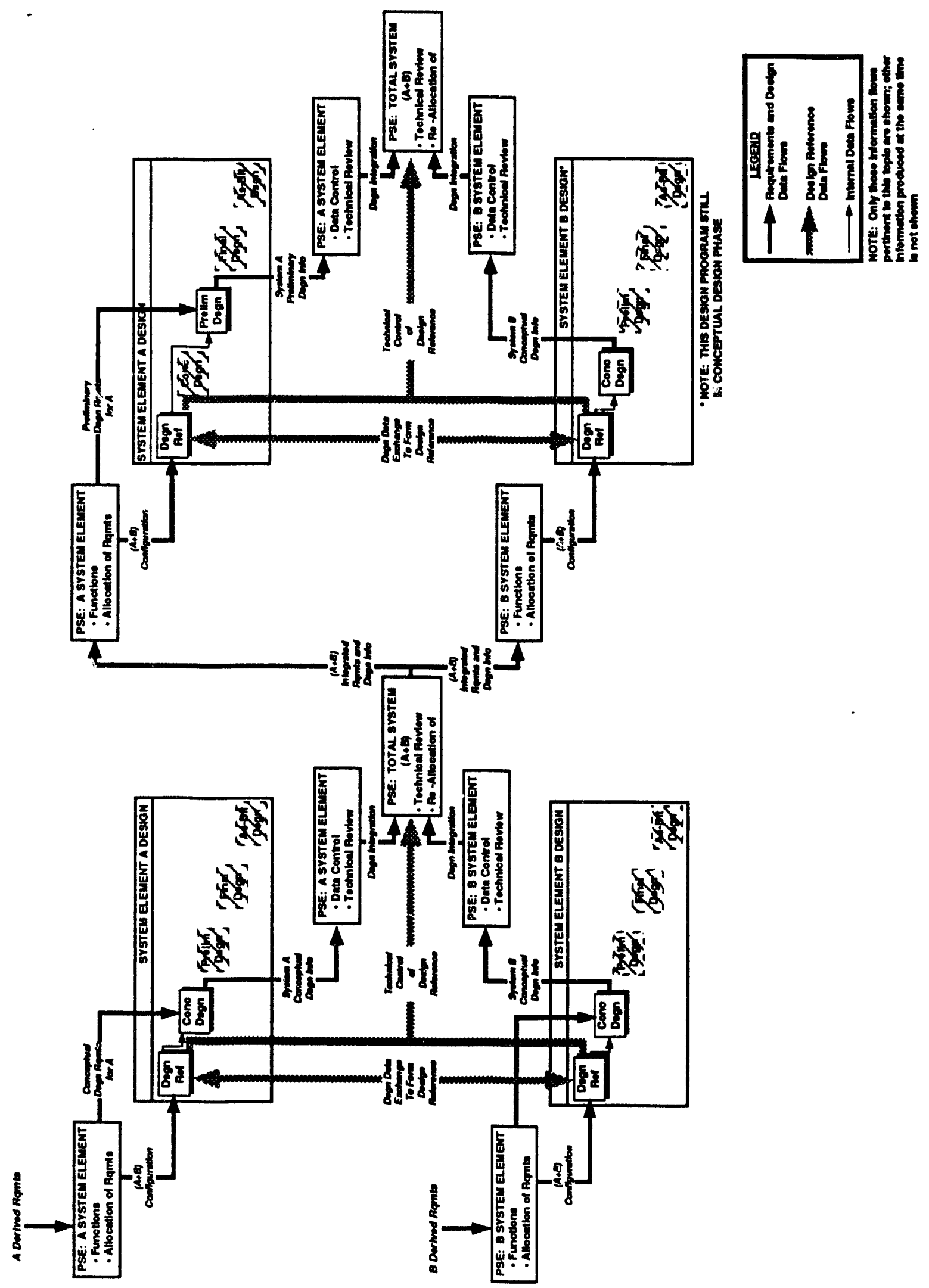


descriptions are produced that define how each design effort will technically treat the half of interfaces that are consistent in the parallel effort. As the designs progress, a new Design Reference is developed for each phase of each parallel design effort that has an interface. This ensures that the most current information is available. Thus the Design Reference provides the most detailed estimates of the mission execution environment to each design process.

The relationship of these parallel design efforts to the NWMS testing program and to tne NWMS integrated system evaluation is illustrated in Figure 10.4-4. Parallel design efforts are established as described above. Within each engineering program, individual system element testing needs are generated. Each developinent process provides design/description data and testing requirements to verify the individual system elements. The integrated system evaluation effort evaluates the individual elements and derives element suitability measures and corresponding testing requirements. It also determines the suitability measures that require integration of all system elements and defines testing requirements on the integrated NWMS. The PCOT process responds by developing a testing program for each class of requirements. Each program includes all three phases: develop approach. prepare. execute. Internal integration within the test program transfers information to ensure that corisistency. resource use optimization, etc.. are achieved.

\subsection{4 iritical Considerations}

The factors that determine the success of this approach are the thoroughness of the initial NWMS-level conceptual design and the level of data exchange mandated in the establishment of accurate design references. Conceptual design of the complete system always is the first step and occurs before the decision to run parallel design efforts. Without the system-level conciptual design, the nature. scope. responsibilities, and interfaces of the parallel efforts cannot be defined. This is especially true for decomposing NWMS into Acceptance. Transport. MRS, and MGDS elements. The NWMS-1evel conceptual design is needed to determine the requirements for designing any of these major elements. This also applies to developing a demonstration system (e.g.. Exploratory Studies Facilities). If there is no system conceptual design, then there is no way to specify the requirements on a demonstrator and no way to know what must be demonstrated.

Without formal and structured information exchange between design efforts, the development of the parallel configuration items cannot be controlied. Parallel efforts must share information to resolve interfacing issues and to determine how interface performance will be modeled during trend aralyses in each effort. Furthermore. parallel efforts must have common assumptions about mission execution environment, effects of excursions, range of excursions analyzed, etc.. or else analysis results will not be comparable. The formalized Design Reference places this information exchange under control so that consistency between efforts is always maintained. 
Figure 10.4-4. Testing and Integrated System Evaluation for Parallel Design Development Efforts.

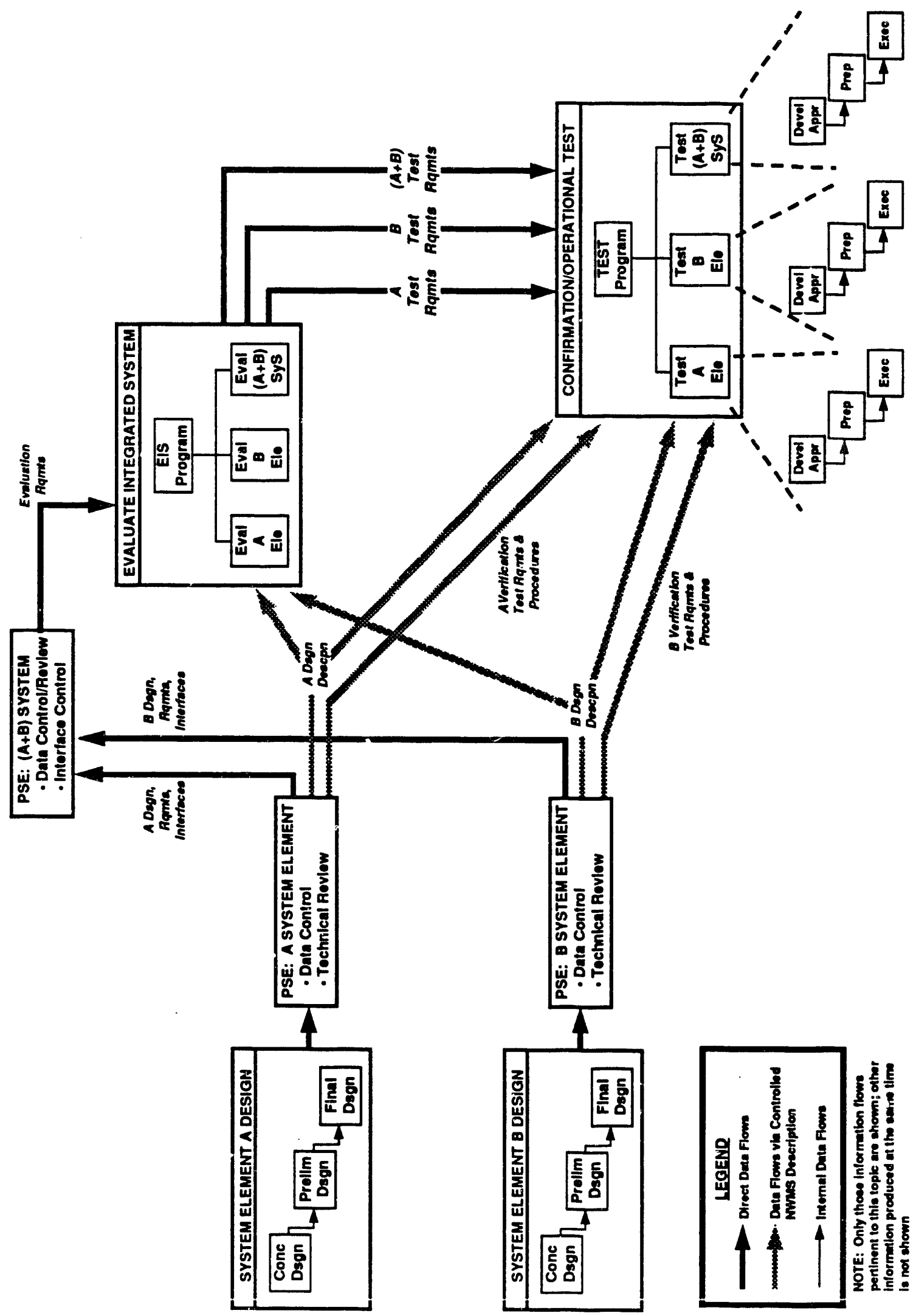


The integrating elements of testing and systems evaluation functions provide the feedback that forces control and integration of the products of parallel design programs. Testing at the integrated level proves that compatibility of interfaces and designs has been achieved. Test program integration ensures common test methodologies and techniques so that data across systems are consistent and comparable. Integrated system evaluation verifies that all parts of the NWMS and the NWMS as a whole are compliant with laws and regulations. 
WHC - EP- 0482

\subsection{TEST FACILITY DESIGN}

\subsubsection{Issue Overview}

Test facility development is a significant part of the overall office of Civilian Radioactive Waste Management (OCRWM) program. The facilities themselves will consume significant program resources and may become major pieces of the Nuclear Waste Management System (NWMS) physical system. Test facilities must accomplish their assigned task and those tasks are always in support of system development. Test facilities must meet program needs in an efficient and cost-effective manner, and must meet a regulatory approval process similar to that applied to the NWMS itself. The functional analysis results show how the test facility mission and requirements are established and met. The following discussion uses tie functional analysis results to show the methodology to identify needs. co formulate requirements, to ensure configuration development is tied to requirements, and to maintain control and integration during development.

\subsubsection{Fundamental Approach}

The functional analysis of the NWMS program incorporates a missiondriven test facility development process. The concept of a mission-driven test facility is that the test facility has requirements that must be met if it is to be successful. The mission of a test facility is to siovide data needed to complete NWMS configuration (engineered and natural systems) development. Data needs are identified by each of the MSIS functional processes. It is these data needs that determine there is a need for the test facility. The data needs and the need for fidelity to the NWMS mission execution environment, define the mission for the test facility.

The need for test facilities can be identified during the Design Engineered System (DES) (2.1.1.2). Identify and Characterize Sites (ICS) (2.1.1.3), and Perform Confirmation/Operational Testing (PCOT) (2.1.1.5) MSIS functional processes (see Figure 10.5-1).

The process of identifying a need for a test facility leads to the definition of the facility's mission and its technical requirements. Each test facility results from identification of information required to complete a functional process. The required characteristics of the needed data yield performance requirements on the facility. Additional requirements arise from the requirement for fidelity to overall NWMS mission environment. These requirements are subjected to the same mission and function analysis and requirements allocation processes used for all design efforts. The test facility configuration and hardware are then developed using the same requirements-driven design process used for developing NWMS elements and contained in the DES MSIS function. Using the DES functional process is a natural approach because test facility development has al 1 the characteristics of a major design effort. First, drivers must be identified to ensure a suitable design approach is identified (i.e.. a conceptual design is needed). Next, test facility design performance and adequacy must be proved to ensure that the design will meet the test facilities mission needs (i.e.. a preliminary design is needed). Finally, hardware must be selected and qualified to provide the procurement process with needed technical information (i.e., a final design is needed). 
Figure 10.5-1. MSIS Functions Where Test Facilities are Identified.

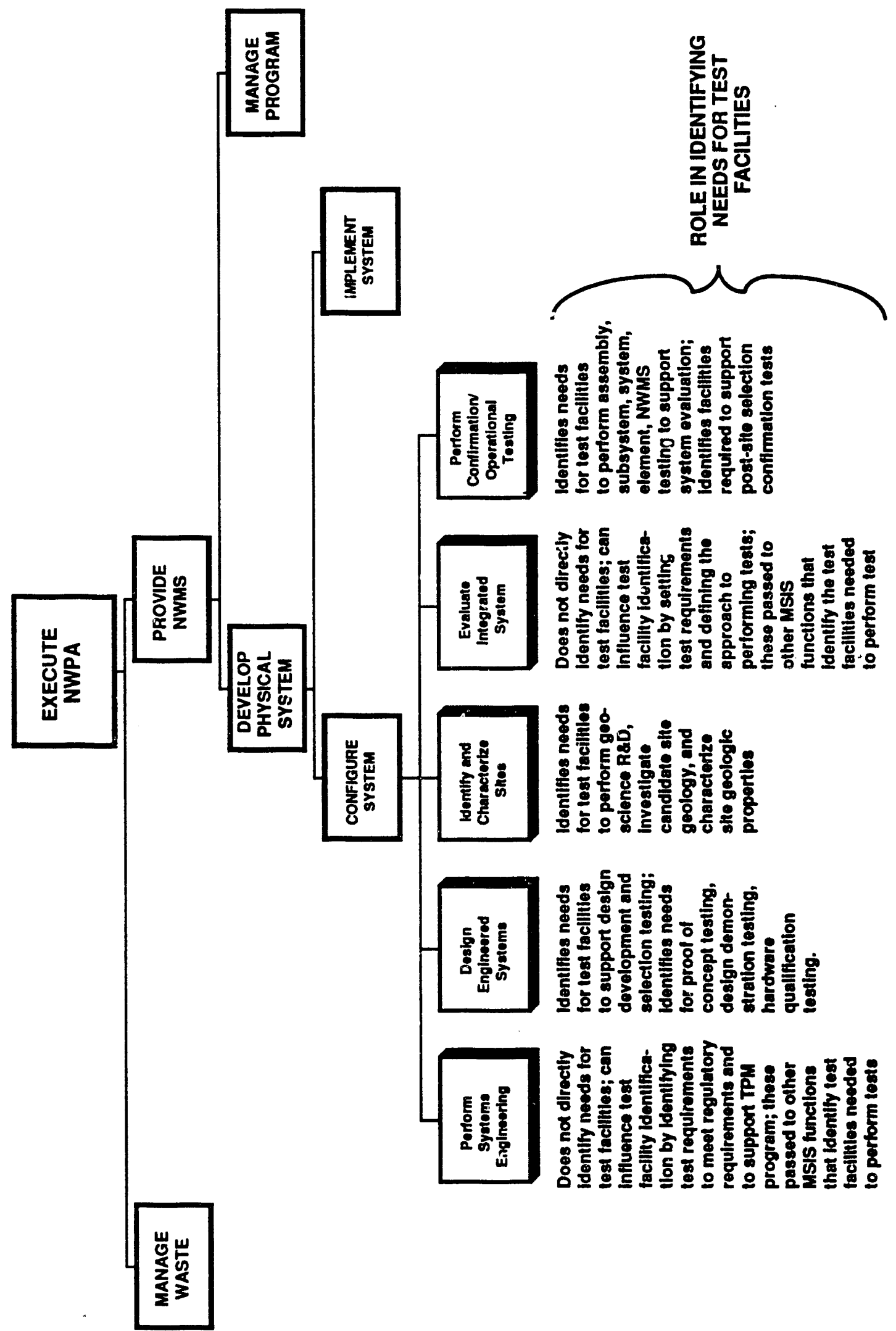


WHC -EP-0482

\subsubsection{Flow of Activities}

The design of test facilities begins during the conceptual design of the NWMS element that the test facility will support. The need for a test facility and the requirements that it must meet are produced as part of the MSIS functions (see Figure 10.5-2). The analyses of requirements in each of the MSIS functions yield information/data needs (from the DES function). investigation plans (from the ICS function), and test approaches (from the PCOT function). Each of these defines the facilities required to gather the data to satisfy the requirement. The Evaluate Integrated Systems (EIS) (2.1.1.4) function can strongly affect the development of test facility requirements. EIS receives requirements for system evaluation and defines an approach for verifying system suitability. System verifications during the configuration development stage yield requirements for DES and ICS processes to produce evaluation data. Verifications during system implementation yield requirements for the PCOT process to produce evaluation data. All of these evaluation support requirements can lead to requirements for testing and test facilities in the DES. ICS, and PCOT processes. The DES function may identify needs at several points in the design process (see Figure 10.5-3).

The information needs arid test facility needs are reviewed, audited, and controlled in the technical information control process in Provide Systems Engineering (PSE) (2.1.1.1). Needs that are within the scope of existing tasks and task plans are forwarded directly to the appropriate MSIS function via the technical baseline. All information is forwarded to the program review and program status evaluation in PPC function.

Initiating a test facility development program requires the development of program direction and the allocation of technical requirements. This process is illustrated in Figure 10.5-4. The review of program data in Provide Program Control (PPC) (2.2.2.4) identifies the program action for test facility development as part of continuing program evaluation. Application of program strategy yields a decision on a programmatic approach to satisfying the information and facility needs. If the approach selected is to develop a test facility, then the Organize Program functional process is reinitiated to develop the programmatic structure for test facility development. The resulting structure determines the number of facilities to be developed, how to combine facility requirements, etc. This centralized planning function is multidisciplinary and includes managers, engineers, systems analysts, etc.

The output of the Organize Program function initiates the rest of the centralized planning process and a new program direction and work scope are issued for test facility development. Program direction and work scope become inputs to PSE and DES to authorize technical work. The program direction includes the test facility mission requirements (i.e.. the data needs and data characteristics extracted from the physical system information examined during program evaluation). Also included are the regulatory requirements that apply to test facilities (extracted from the database of regulatory requirements provided by the ERC process to the PPC process). Program direction. work scope, and technical requirements are part of the program information reviewed by the ERC process to ensure that all regulatory requirements on test facilities are met. The technical requirements portion of program direction becomes input to the mission and functional analysis and requirements allocation processes (see PSE function) and these determine if the selected test facility/facilities can address all requirements given the selected 
Figure 10.5-2. Process Flow to Identify Test Facility Needs for Management Review and Program Planning.

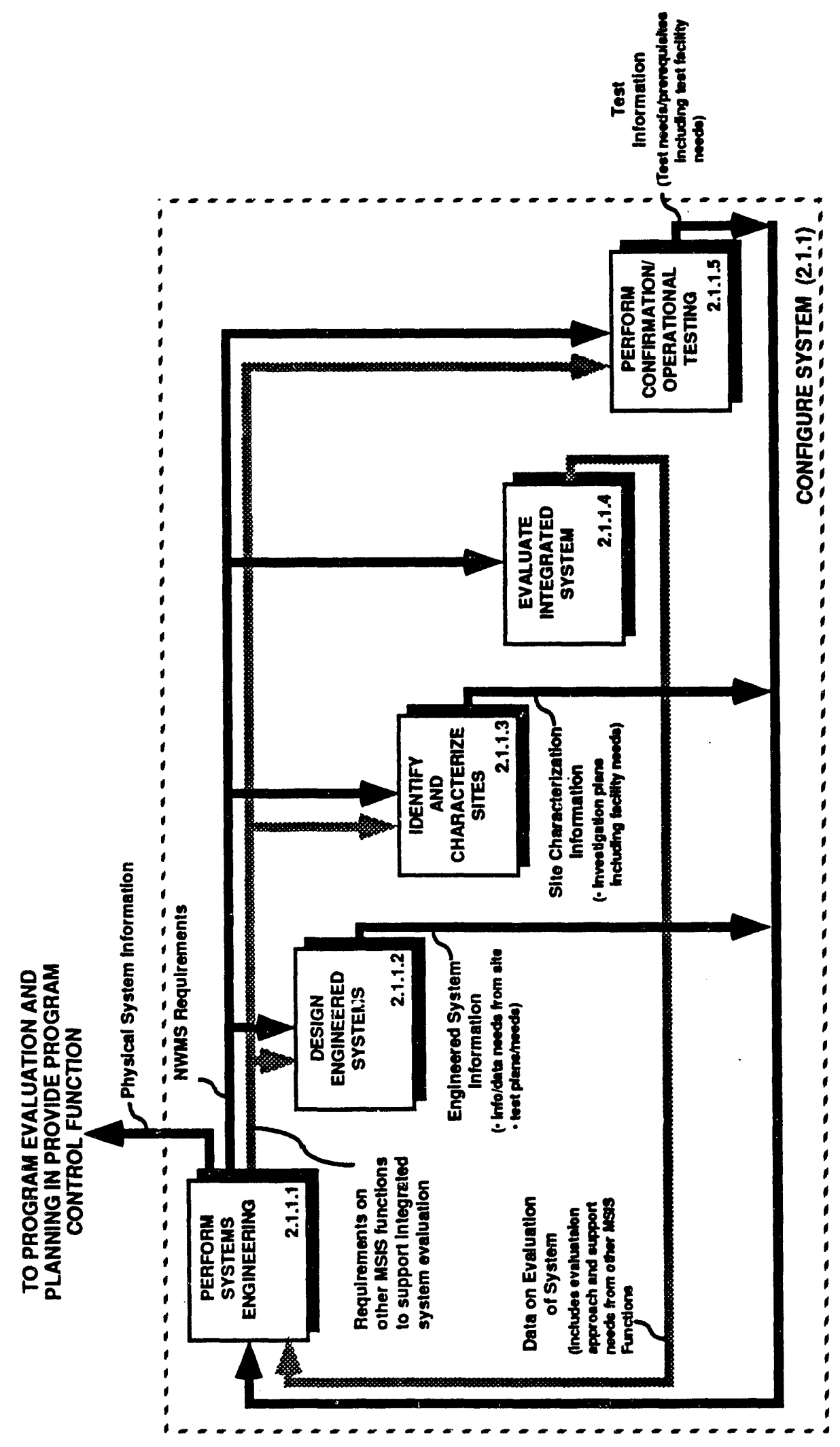


Figure 10.5-3. Test Facility Needs Generated During Engineering Design.

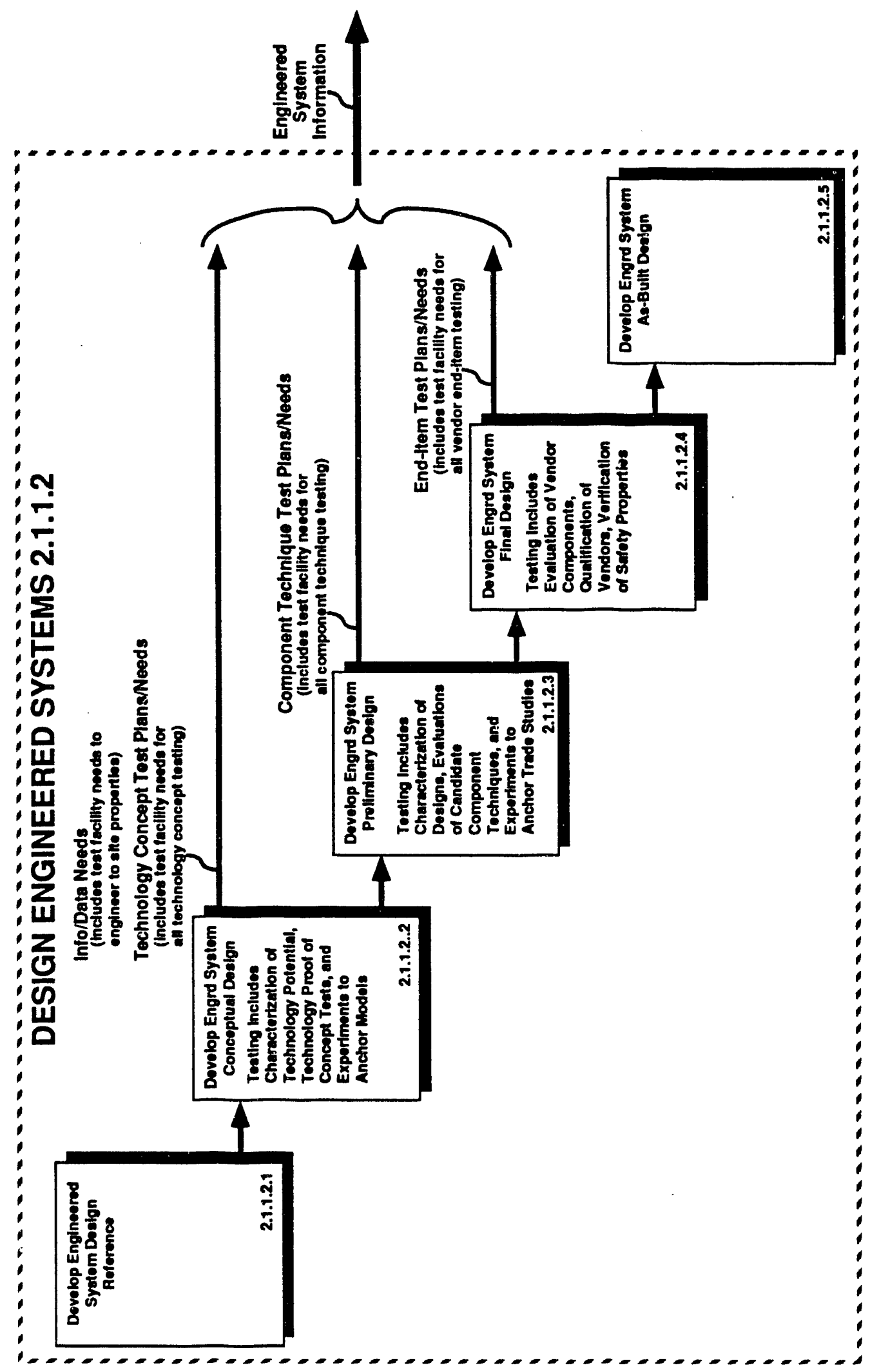


Figure 10.5-4. Process Flow Establishing Test Facility Development Program.

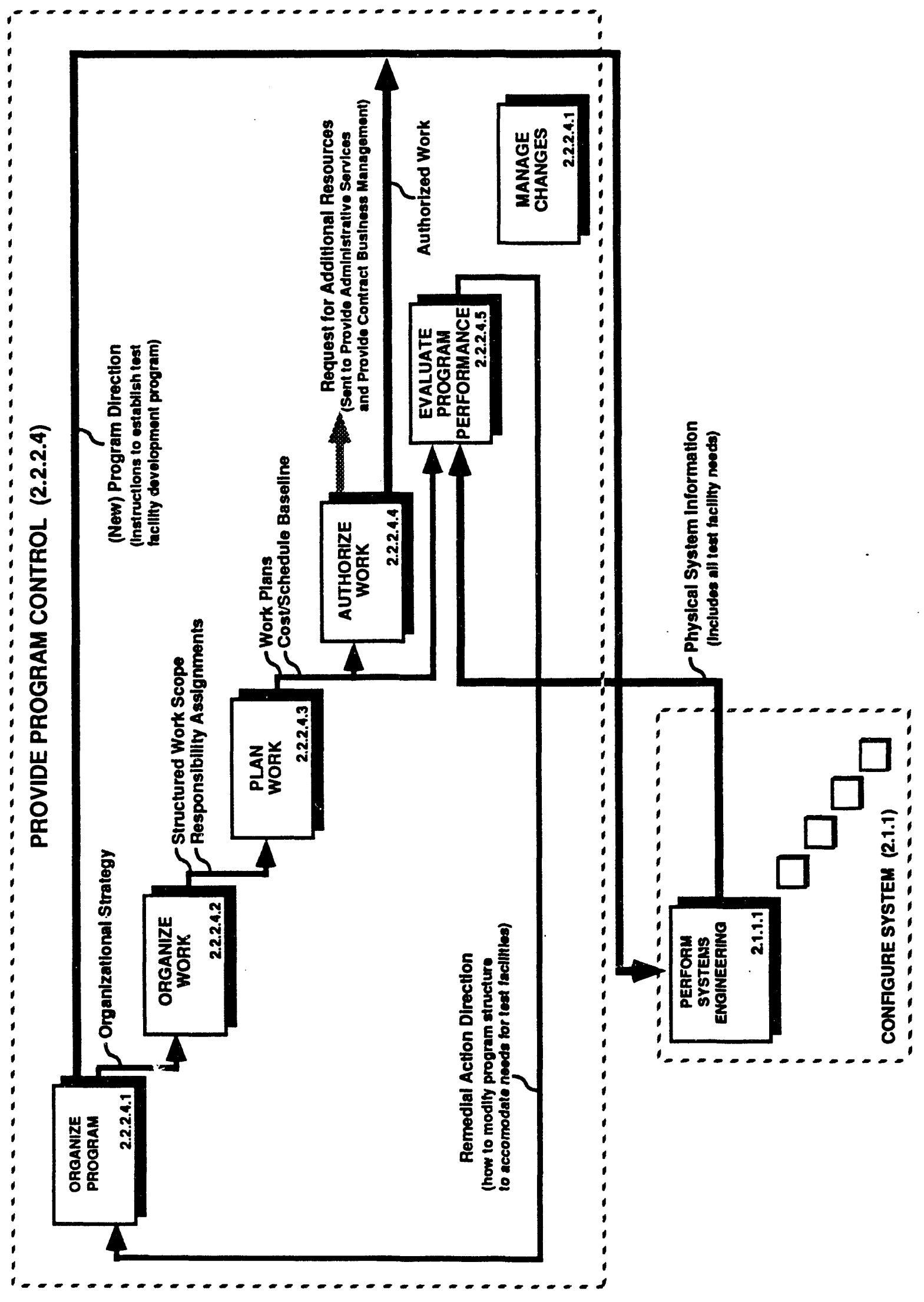

$10.5-6$ 
program strategy. Issues in meeting requirements become change requests to the change control process in the PPC function. Integration of test the facility functional analysis into program-wide functional analysis identifies redundancies in authorized test facility programs. Redundancy issues also become change requests to PPC.

The actual test facility design development follows the requirements driven process for engineering design described under the. DES function. The results of the mission analysis, and functional analysis, and requirements allocation for the test facility initiate the design process. The evolution of test facility design through conceptual. preliminary. and final design phases yields a progressive decomposition of requirements and a selection of the best design solution to meet the requirements. The design process, by the nature of the functions included, continuously maintains traceability of test facility design to the program needs and the requirements that initiated the design. The Design Reference process is used to maintain fidelity to the parts of the NWMS that the test facility addresses. The Design Reference provides the most current representation of the NWMS design that the test facility will support and provides the most detailed estimates of mission execution environment.

Once the engineering design process defines the test facility configuration, the remainder of the test facility's development proceeds in a fashion similar to that for any subsystem of the NWMS. The engineering design includes all procedures and information to build, operate and maintain the facility. It also includes procedures for any verifications required by statute or regulation (e.g.. when the test facility penetrates the natural barriers at proposed sites or when it uses nuclear waste as part of test operations). Once the final design is approved, the build-to procedures are provided to the system implementation functions and the end-item technical packages are provided to the procurement functions. The test facility hardware is acquired and installed and implementation information is returned to DES for compilation of the As-Built design. Compliance evaluations are performed by the EIS and PCOT functions as for any NWMS item. When the system is finally made compliant, the As-Built design package, the operating and maintenance procedures, and the evaluation data archive are provided to the test facility user organization.

\subsubsection{Critical Considerations}

The effectiveness of this approach to the test facility design depends upon the effectiveness of the individual MSIS functions in identifying and defining their needs and on the integrating subfunctions within the MSIS functions that integrate technical information and program control. Data and facility needs are identified by individual program processes for engineering design. site characterization and evaluation, and testing of systems. elements, and items. Test facilities are only developed when they are required to meet a program objective or program requirement and are designed to satisfy a clearly specified requirements set. Divergence from this rule leads to loss of control of the program and to ineffective use of resources. Data and facility needs are integrated technically and programmatically to define work scopes, task plans and technical requirements for each facility. Integration is important to ensure that a 11 program requirements are met. Integration is also important to ensure cost-effective resource utilization. 
Once the test facility performance, functional, and regulatory requirements are well-defined, then the requirements-driven design process of the DES MSIS function will ensure that test facility meets the program need. The engineering design process iterates on the design until the facility requirements have been met. It maintains traceability of derived requirements, specifications, and selected design solutions. The DES process interfaces to the technical information control and technical review processes to ensure control and credibility of the selected test facility design. This requirements-driven process, responsive to both performance and programmatic requirements. applies the same degree of design control and quality assurance practice to test facility development as applies to NWMS development, thus assuring compliance of the design and preparation of all licensing and regulatory design information. 


\subsection{REFERENCES}

ANSI/ASME, 1986. Quality Assurance Program Requirements for Nuclear Facilities. NOA-1-C-1986. American National Standards Institute and American Society of Mechanical Engineers. New York. New York.

DOE, 1991. OCRWM Systems Engineering Management Plan (SEMP), Rev. 2. U.S. Department of Energy. Office of Civilian Radioactive Waste Management. Washington. D.C.

DOE, 1987. Project Management System. DOE Order 4700.1. U.S. Department of Energy. Washington. D.C.

DSMC, 1990. Systems Engineering Management Guide. Defense Systems Management College. Fort Belvoir. Virginia.

Hoesse1. 1991. Office of Civilian Radioactive Waste Management Decision Methodology. WHC-EP-0492. Westinghouse Hanford Company, Richland. Washington.

Nuclear Waste Policy Act of 1982, Public Law 97-425, 96 Stat. 220. 42 USC 10101, et seq.

Woods. T. W.. 1991a. The Analysis of the Program to Develop the Nuclear Waste Management System. WHC-EP-0465. Westinghouse Hanford Company. Richland. Washington.

Woods, T. W.. 1991b. Program Information Architecturel Document Hierarchy, WHC-EP-0506. Westinghouse Hanford Company. Richland. Washington. 
WHC-EP-0482

This page intentionally left blank. 
WHC-EP-0482

GLOSSARY

\section{ABBREVIATIONS, ACRONYMS, AND INITIALISMS}

$\begin{array}{ll}\text { ANSI } & \text { American National Standards Institute } \\ \text { ASME } & \text { American Society of Mechanical Engineers } \\ \text { CFR } & \text { Code of Federal Regulations } \\ \text { DAS } & \text { Data ACquisition Strategy } \\ \text { DES } & \text { Design Engineered Systems } \\ \text { DOE } & \text { U.S Department of Energy } \\ \text { EIS } & \text { Evaluate Integrated Systems } \\ \text { ERC } & \text { Ensure Regulatory Compliance } \\ \text { ICS } & \text { Identify and Characterize Sites } \\ \text { MGDS } & \text { Mined Geological Disposal Facility } \\ \text { MRS } & \text { Monitored Retrievable Storage } \\ \text { MSIS } & \text { Management Systems Improvement Strategy } \\ \text { NRC } & \text { Nuclear Regulatory Commission } \\ \text { NWMS } & \text { Nuclear Waste Management System } \\ \text { NWPA } & \text { Nuclear Waste Policy Act (including } \\ & \text { Amendments) } \\ \text { OCRWM } & \text { Office of Civilian Radioactive Waste Management } \\ \text { PCOT } & \text { Perform Confirmation/Operational Testing } \\ \text { PER } & \text { Provide External Relations } \\ \text { PPC } & \text { Provide Program Control } \\ \text { POA } & \text { Provide Quality ASsurance } \\ \text { PSE } & \text { Perform Systems Engineering } \\ \text { OA } & \text { Quality Assurance } \\ \text { SEMP } & \text { Systems Engineering Management Plan } \\ \text { TPM } & \text { Technical Performance Measures }\end{array}$


WHC-EP-0482

This page intentionally ieft blank. 
DISTRIBUTION

Number of Copies

\section{OFFSITE}

7

U.S. Department of Energy - DOE-HO/OCRWM 1000 Independence Avenue S.W. Washington. D.C.

B. A. Cerny

S. E. Gomberg (5)

D. D. Shelor

$\mathrm{RW}-12$

$\mathrm{RW}-322$

$\mathrm{RW}-30$

1

Battelle Energy Systems Group 505 King Avenue

Columbus, $\mathrm{OH} 43201$

M. A. Duffy

5

Roy $F$. Weston. Inc.

955 L'Enfant Plaza, 8th Floor

Washington, D.C. 20024

R. E. Jackson (5)

10

IRW

10306 Eaton Place - Suite 300

Fairfax. VA 22030

Dr. A. Greenberg (10)

ONSITE

U.S. Department of Energy Field office. Richland

D. C. Langstaff (4)

J. J. Sutey

D. E. Trader

A5 - 90

Public Reading Room

A5 -90

A5 -90

A1 -65 


\section{DISTRIBUTION (cont.)}

Number of copies

QNSITE (Cont.)

1

Pacific Northwe:t Laboratory

Technical Files KI-11

54

Westinghouse Hanford Company

M. K. Korenko

B3-08

E. W. Gerber

L5 -62

J. J. Holmes

T. W. Woods (46)

L5- 55

Central files

LO -14

Document Processing and Distribution (2)

L8- 04

Information Release Administration

L8- 15

Publications Services

L8- 07

L8-07 

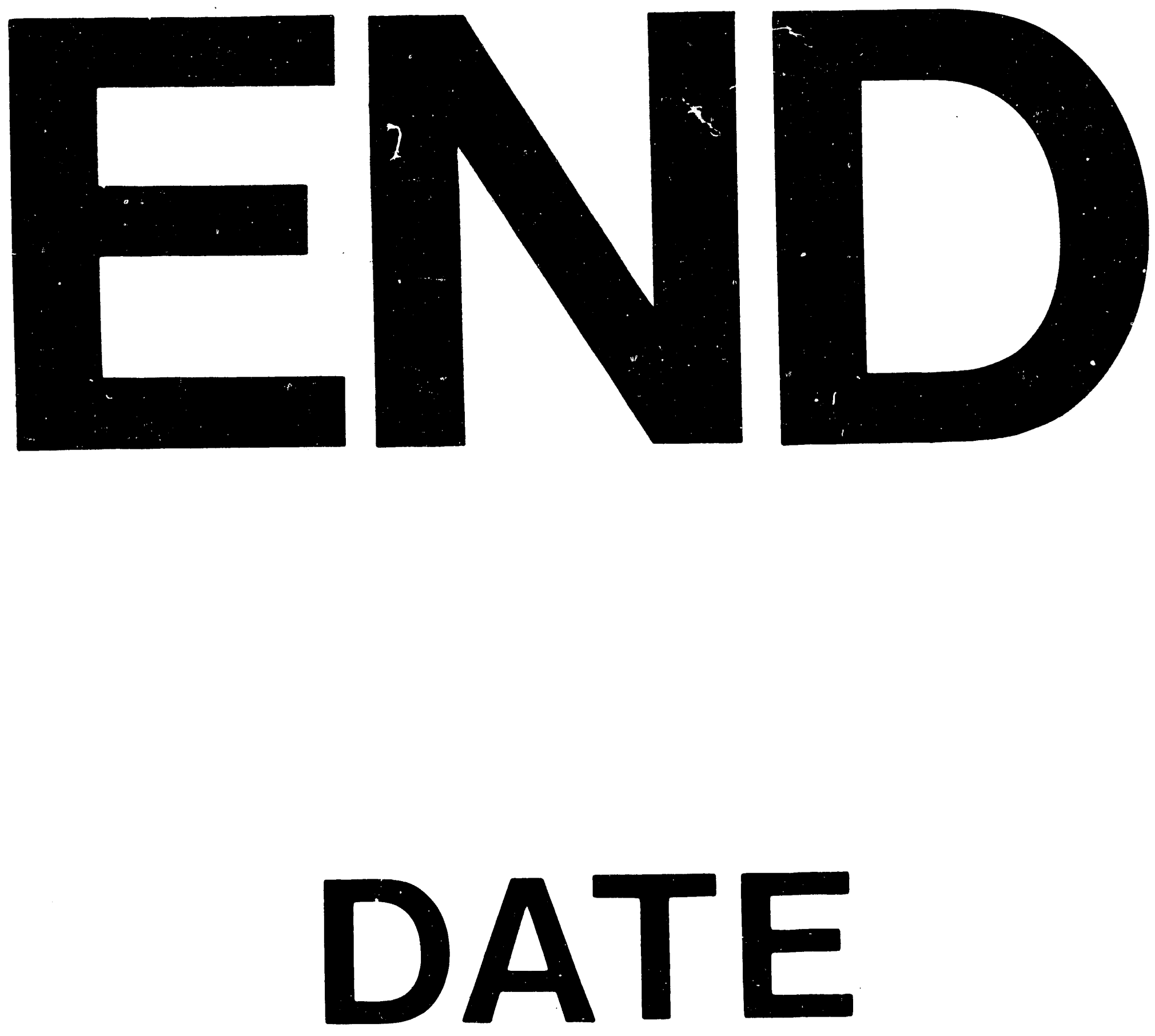

3
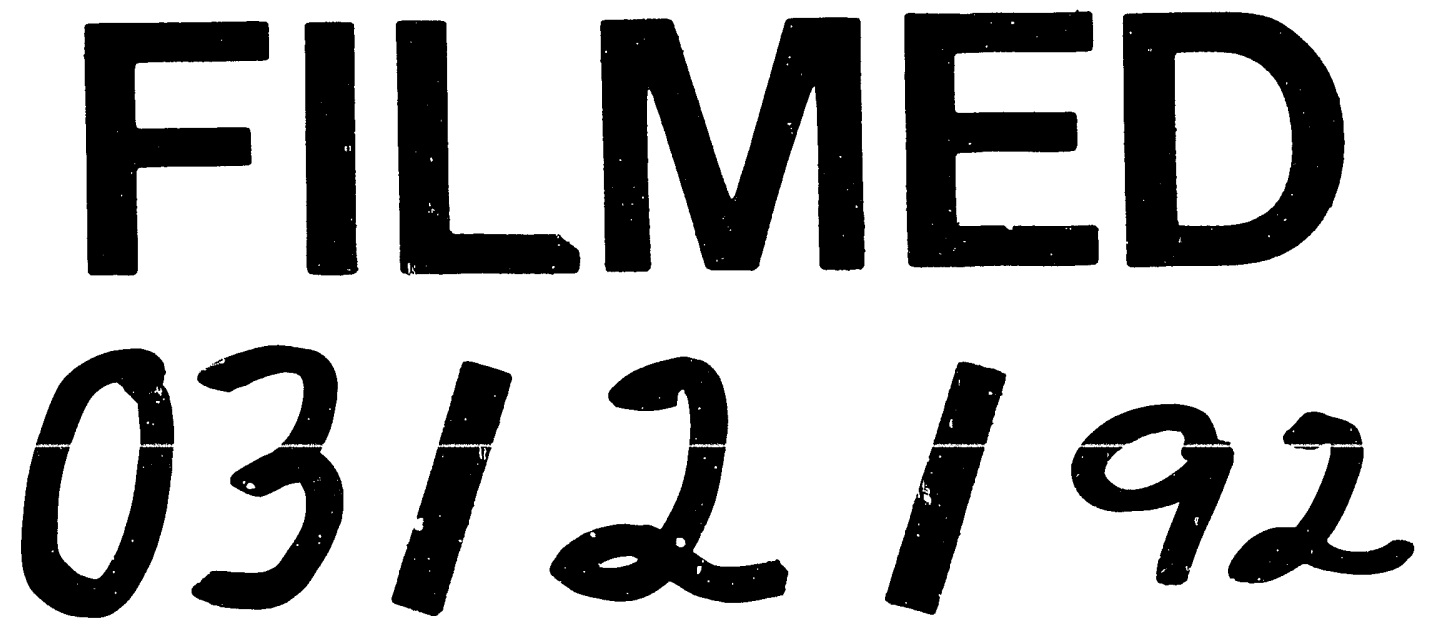
